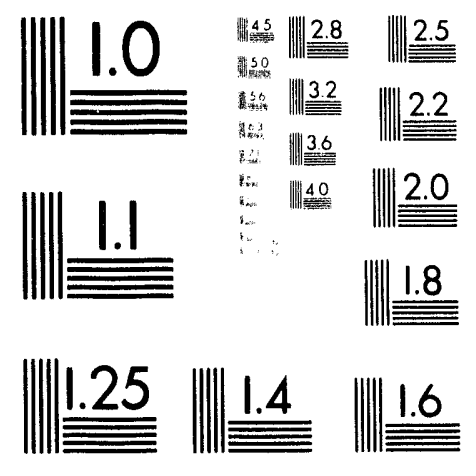



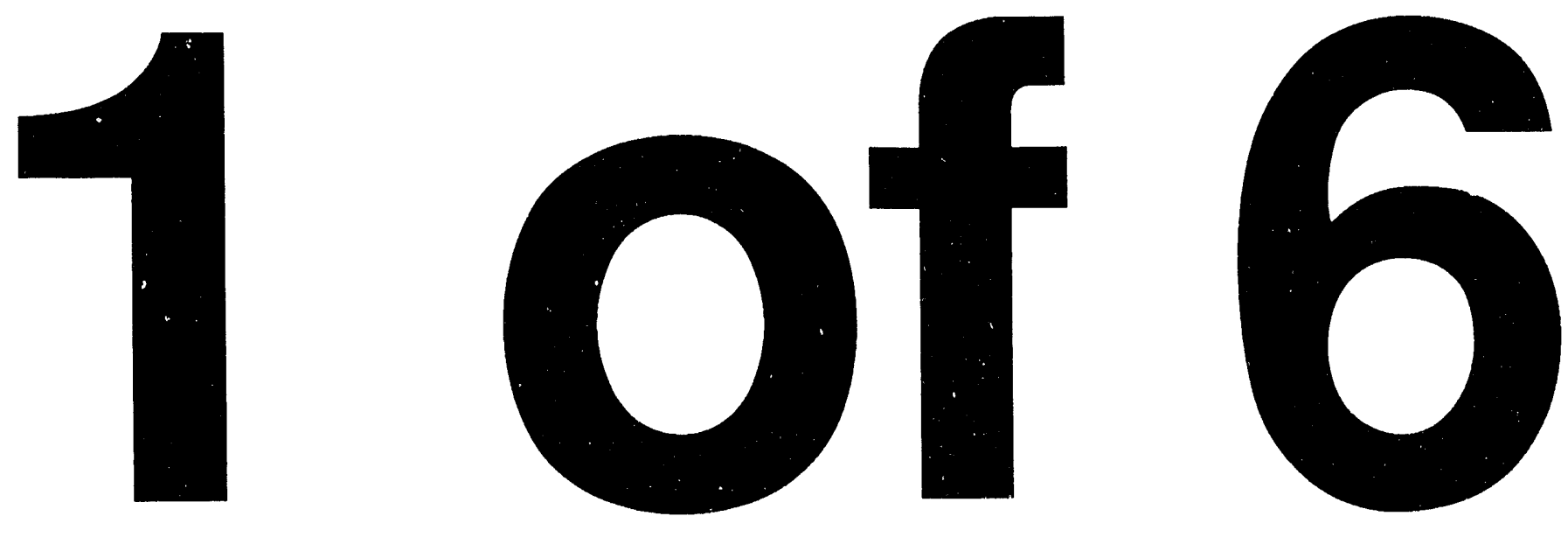


\section{Remedial Investigation Work Plan for Chestnut Ridge Operable Unit 1 (Chestnut Ridge Security Pits) at the Oak Ridge Y-12 Plant, Oak Ridge, Tennessee}

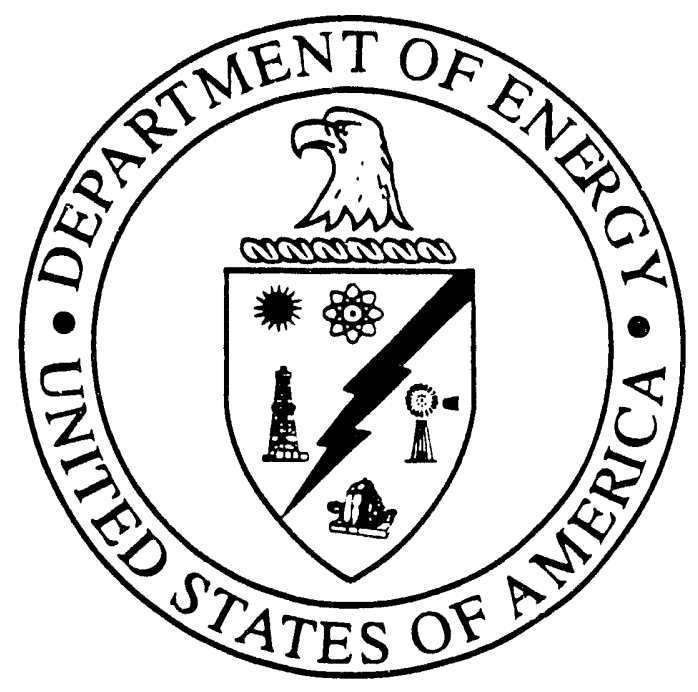

\section{DISCLAIMER}

This report was prepared as an account of work sponsored by an agency of the United States Government. Neither the United States Government nor any agency thereof, nor any of their employees, makes any warranty, expres. or implied, or assumes any legal liability or responsibility for the accuracy, completeness, or usefulness of any information, apparatus, product, or process disclosed, or represents that its use would not infringe privately owned rights. Reference herein to any specific commercial product, process, or service by trade name, trademark, manufacturer, or otherwise does not necessarily constitute or imply its endorsement, recommendation, or favoring by the United States Government or any agency thereof. The views and opinions of authors expressed herein do not necessarily state or reflect those of the United States Government or any agency thereof. 
This report has been reproduced directly from the best available copy.

Available to DOE and DOE contractors from the Office of Scientific and Technical Information, P.O. Box 62, Oak Ridge, TN 37831; prices available from 615-576-8401, FTS 626-8401.

Available to the sublic from the National Technical Information Service, U.S. Department of Commerce, 5285 Port Royal Rd., Springfield, VA 22161.

\section{CDM Federal Programs Corporation}

contributed to the preparation of this document and should not be considered an eligible contractor for its review. 
Energy Systems Environmental Restoration Program Y-12 Environmental Restoration Program

\title{
Remedial Investigation Work Plan for Chestnut Ridge Operable Unit 1 \\ (Chestnut Ridge Security Pits) at the Oak Ridge Y-12 Plant, Oak Ridge, Tennessee
}

Date Issued-September 1993

\author{
Prepared by \\ CDM Federal Programs Corporation \\ Oak Ridge, Tennessee \\ under contract 96B-99052 Y05
}

Prepared for U.S. Department of Energy

Office of Environmental Restoration and Waste Management under budget and reporting code EW 20

OAK RIDGE Y-12 PLANT

Oak Ridge, Tennessee 37831-8169 managed by MARTIN MARIETTA ENERGY SYSTEMS, INC.

$$
\text { for the }
$$

U.S. DEPARTMENT OF ENERGY under contract DE-AC05-84OR21400

$$
\text { MATER }
$$




\section{CONTENTS}

FIGURES $\ldots \ldots \ldots \ldots \ldots \ldots \ldots \ldots \ldots \ldots \ldots \ldots \ldots \ldots \ldots \ldots$ vii

TABLES $\ldots \ldots \ldots \ldots \ldots \ldots \ldots \ldots \ldots \ldots \ldots \ldots \ldots \ldots \ldots \ldots \ldots \ldots \ldots \ldots$

QAMS-005/80 LOCATOR PAGE $\ldots \ldots \ldots \ldots \ldots \ldots \ldots \ldots \ldots \ldots \ldots$

NQA-1 LOCATOR PAGE $\ldots \ldots \ldots \ldots \ldots \ldots \ldots \ldots \ldots \ldots \ldots \ldots \ldots$

ACRONYMS AND ABBREVIATIONS $\ldots \ldots \ldots \ldots \ldots \ldots \ldots \ldots \ldots \ldots$

EXECUTIVE SUMMARY $\ldots \ldots \ldots \ldots \ldots \ldots \ldots \ldots \ldots \ldots \ldots$

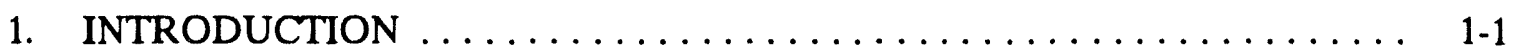

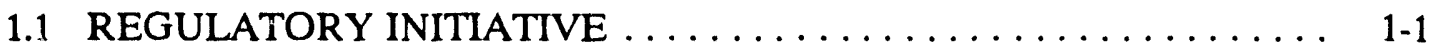

1.2 ORR ENVIRONMENTAL RESTORATION PROGRAM $\ldots \ldots \ldots \ldots .1-2$

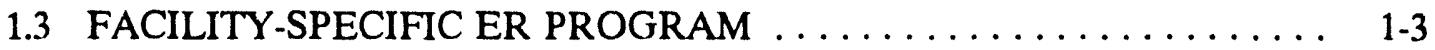

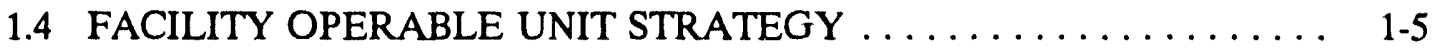

1.5 INTENT AND SCOPE OF THE RI WORK PLAN $\ldots \ldots \ldots \ldots \ldots \ldots \ldots$

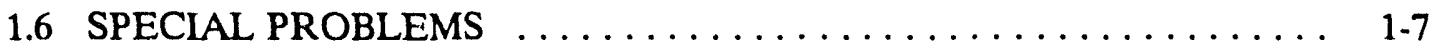

1.7 OVERALL PROJECT OBJECTIVES $\ldots \ldots \ldots \ldots \ldots \ldots \ldots \ldots \ldots$ 1-7

1.8 DATA QUALITY OBJECTIVES $\ldots \ldots \ldots \ldots \ldots \ldots \ldots \ldots \ldots \ldots \ldots \ldots$

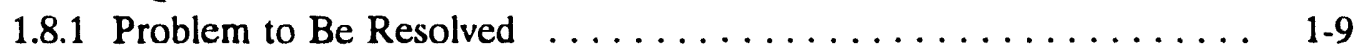

1.8.2 Decision to Be Made . . . . . . . . . . . . . . . . . . . 1-9

1.8.3 Identification of Inputs to the Decision . . . . . . . . . . 1-10

1.8.4 Definition of the Boundaries of the Study . . . . . . . . . 1-10

1.8.5 Development of a Decision Rule . . . . . . . . . . . . . 1-10

1.8.6 Development of Uncertainty Constraints . . . . . . . . . 1-10

1.8.7 Optimization of the Design for Obtaining Data . . . . . . . 1-11

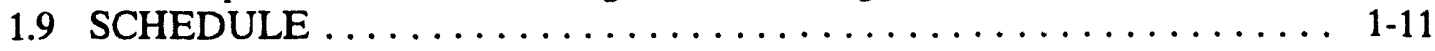

1.10 QUALITY ASSURANCE $\ldots \ldots \ldots \ldots \ldots \ldots \ldots \ldots \ldots \ldots \ldots \ldots \ldots \ldots$

2. HISTORY AND CURRENT CONDITIONS $\ldots \ldots \ldots \ldots \ldots \ldots \ldots \ldots \ldots . \ldots \ldots$

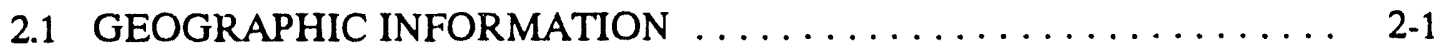

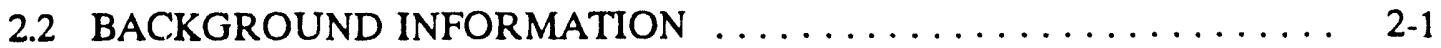

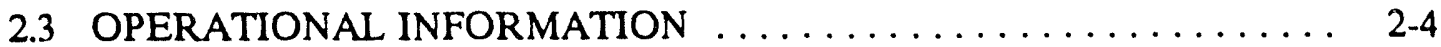

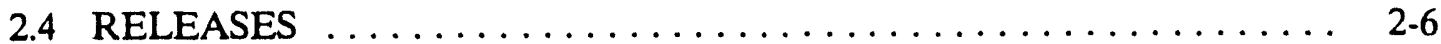

3. CHARACTERIZATION OF ENVIRONMENTAL SETTING
AND CONCEPTUAL SITE MODEL $\ldots \ldots \ldots \ldots \ldots \ldots \ldots \ldots \ldots \ldots \ldots \ldots$ 3-1

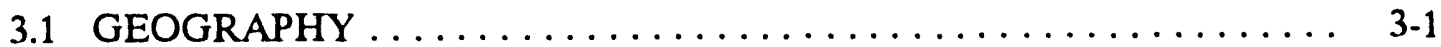

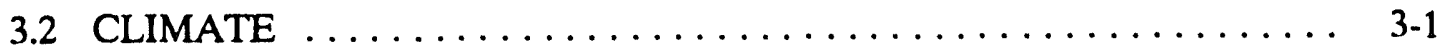

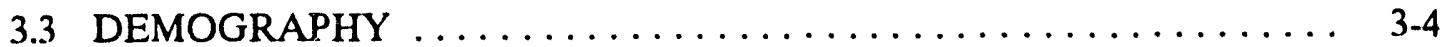

3.4 GEOLOGY AND SOILS $\ldots \ldots \ldots \ldots \ldots \ldots \ldots \ldots \ldots \ldots \ldots \ldots$

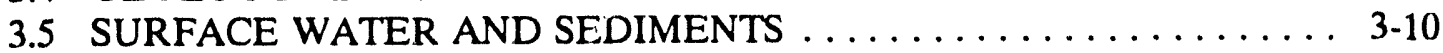




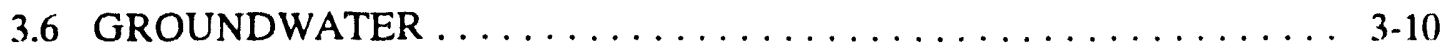

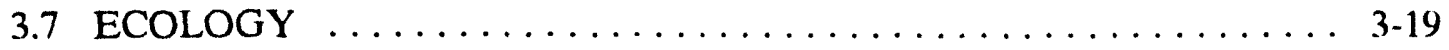

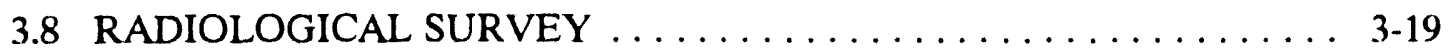

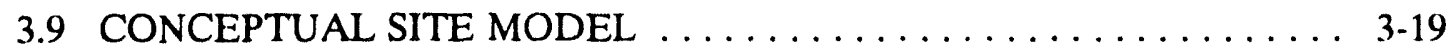

3.9.1 Conceptual Site Model for Exposure of Human Receptors . . . . . . 3-21

3.9.2 Conceptual Model for Exposure of Ecological Receptors . . . . . . . 3-24

4. POTENTIAL RECEPTORS AND EXPOSURE PATHWAYS $\ldots \ldots \ldots \ldots$ 4-1

4.1 HUMAN POPULATIONS AND EXPOSURE PATHWAYS . . . . . . . . 4-1

4.1.1 On-site Potential Human Receptors and Exposure Pathways ... . . 4-2

4.1.2 Off-site Potential Human Receptors and Exposure Pathways . . . . 4. 4-2

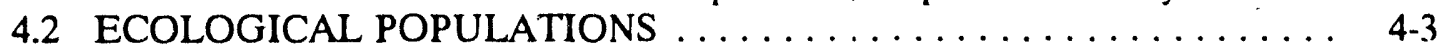

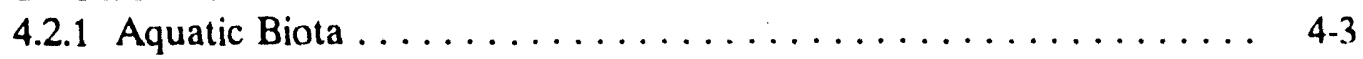

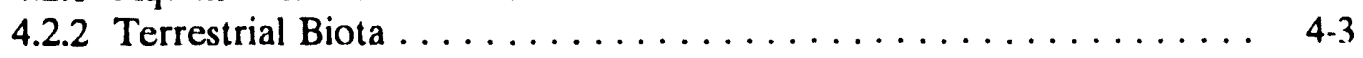

4.2.3 Threatened and Endangered Species $\ldots \ldots \ldots \ldots \ldots \ldots \ldots \ldots$ 4-3

4.2.4 Wetlands and Floodplains $\ldots \ldots \ldots \ldots \ldots \ldots \ldots \ldots \ldots \ldots$ 4-3

5. IDENTIFICATION OF INVESTIGATION REQUIREMENTS $\ldots \ldots \ldots \ldots$. . $5-1$

5.1 IDENTIFICATION OF ARARS $\ldots \ldots \ldots \ldots \ldots \ldots \ldots \ldots \ldots \ldots \ldots \ldots$

5.2 IDENTIFICATION OF PRELIMINARY REMEDIAL

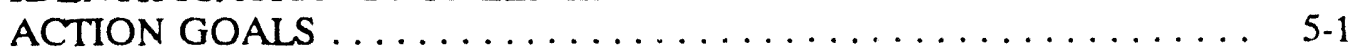

5.3 IDENTIFICATION OF POTENTIAL CLASSES

OF REMEDIAL TECHNOLOGIES $\ldots \ldots \ldots \ldots \ldots \ldots \ldots \ldots \ldots \ldots$

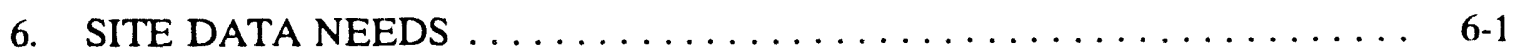

6.1 PHYYSICAL/CHEMICAL CHARACTERIZATION ........... $6-2$

6.2 SAMPLING AND ANALYTICAL REQUIREMENTS . . . . . . . . 6-3

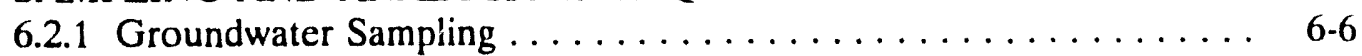

6.2 .2 Dye Tracer Study . . . . . . . . . . . . . . . . . . 6-8

6.2.3 Spring/Seep Surface Water/Sediment Sampiing . . . . . . . . . . 6. 6-8

6.2.4 Surface and Subsurface Soil Sampling . . . . . . . . . . . . 6- 6

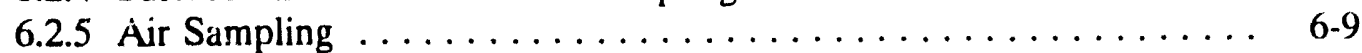

6.2 .6 Ecological Surveys . . . . . . . . . . . . . . . . 6-10

6.2.7 Biological Sampling . . . . . . . . . . . . . . . . 6-10

6.3 DATA EVALUATION AND INTERPRETATION . . . . . . . . 6 6-10

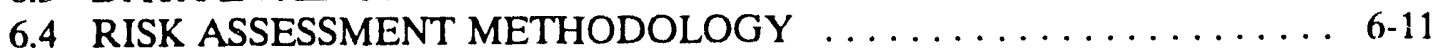

6.4.1 Baseline Human Health Risk Assessment . . . . . . . . . . . . 6-11

6.4.2 Ecological Risk Assessment Methodology . . . . . . . . . . . . . 6-12

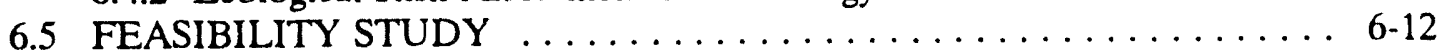

6.5.1 FS Contractor Responsibilities ................. 6-13

6.5.2 Scope and Assumptions ..................... 6-13

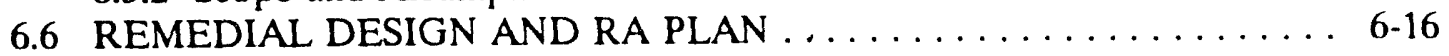

6.6.1 Remedial Design ......................... 6-16

6.6.2 Remedial Action ...................... 6-17

7. FIELD AND LABORATORY QUALITY ASSURANCE PROJECT PLAN . 7-1

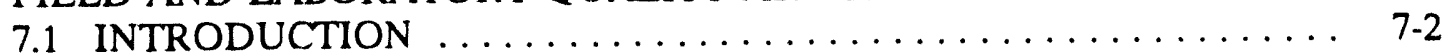

7.2 QUALITY ASSURANCE/PROJECT ORGANIZATION $\ldots \ldots \ldots \ldots .7-2$

7.2.1 Program Manager Roles and Responsibilities . . . . . . . . . . 7-2 
7.2.2 Project Manager Roles and Responsibilities ............ 7-4

7.2.3 CDM Federal Health and Safety Roles and Responsibilities ... . . . 7-5

7.2.4 Field Task Manager Roles and Responsibilities ... . . . . . . . . . 7-6

7.2.5 Quality Assurance Management Roles and Responsibilities ...... 77

7.2.6 Technical Review Committee . . . . . . . . . . . . . . . . . . . . 7 7-8

7.3 QUALITY ASSURANCE OBJECTIVES FOR

MEASUREMENT DATA $\ldots \ldots \ldots \ldots \ldots \ldots \ldots \ldots \ldots \ldots \ldots \ldots$

7.3.1 Data Quality Objectives .................... 7-8

7.3.2 Intended Uses of Acquired Data . . . . . . . . . . . . 7-9

7.3.3 Intended Users of Data .................... 7-9

7.3.4 Levels of Quality Control . . . . . . . . . . . . . . 7-10

7.3.5 Precision, Accuracy, Representativeness,

Completeness, and Comparability ............... 7.11

7.4 SAMPLE COLLECTION AND ANALYSIS PROCEDURES . . . . . 7.13

7.5 SAMPLE AND DOCUMENT CUSTODY PROCEDURES $\ldots \ldots \ldots \ldots$. $7-19$

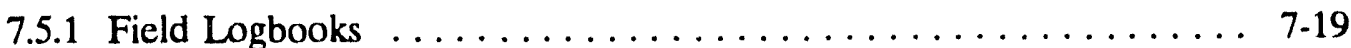

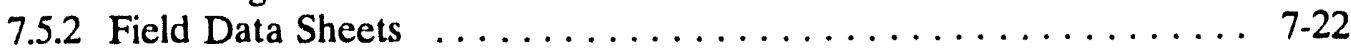

7.5.3 Sample Identification, Numbering, and Labeling . . . . . . . . 7.22

7.5.4 Sample Chain of Custody . . . . . . . . . . . . . . . . . 7-24

7.5.5 Sample Shipment ... . . . . . . . . . . . . . . . . 7.27

7.5.6 Document Control ... . . . . . . . . . . . . . . . . 7.27

7.6 EQUIPMENT CALIBRATION AND FREQUENCIES . . . . . . . . 7 7-27

7.6.1 Equipment Calibration Procedures and Frequencies . . . . . . 7.27

7.6.2 Calibration Records ... . . . . . . . . . . . . . . . . . 7 7-27

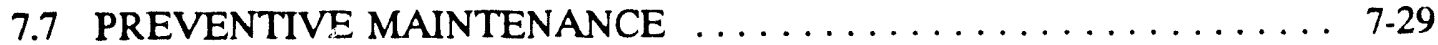

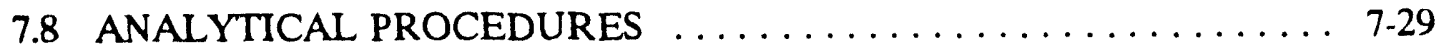

7.9 DATA REDUCTION AND REPORTING $\ldots \ldots \ldots \ldots \ldots \ldots \ldots \ldots \ldots$. 7.29

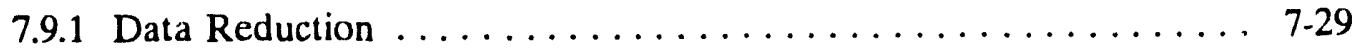

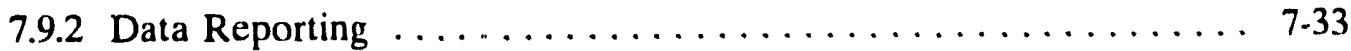

7.10 FIELD QUALITY CONTROL SAMPLES $\ldots \ldots \ldots \ldots \ldots \ldots \ldots \ldots 7.3 . \ldots \ldots$

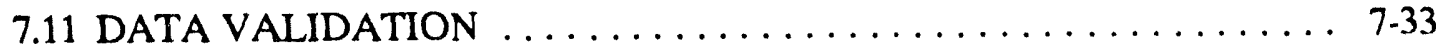

7.12 FIELD AUDITS, SURVEILLANCES, AND INSPECTIONS . . . . . . 7.37

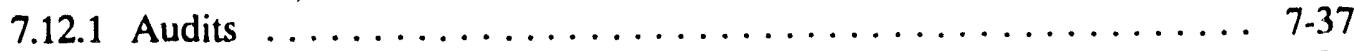

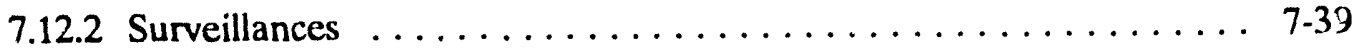

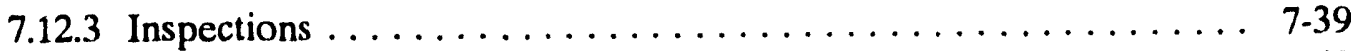

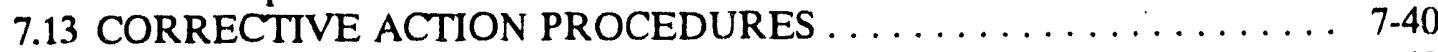

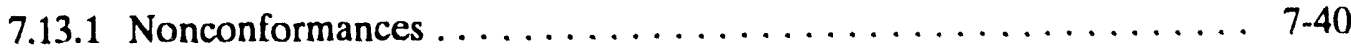

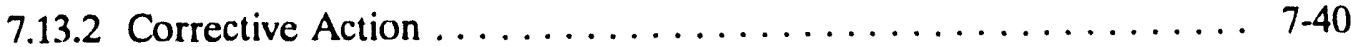

7.14 QUALITY ASSURANCE REPORTS $\ldots \ldots \ldots \ldots \ldots \ldots \ldots \ldots \ldots . \ldots \ldots$

7.15 QUALIFICATIONS AND TRAINING OF PERSONNEL . . . . . . . $7-43$

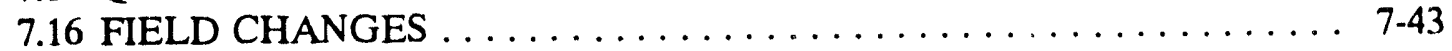

8. ENVIRONMENTAL RESTORATION PROGRAM HEALTH

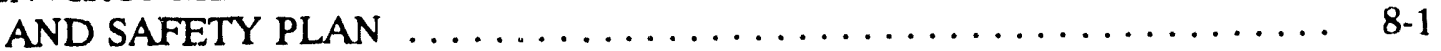

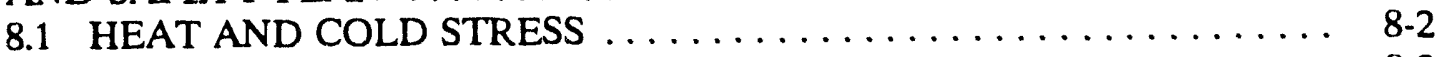

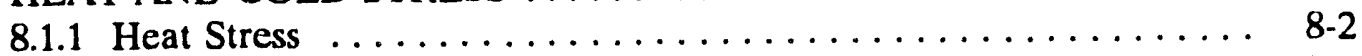

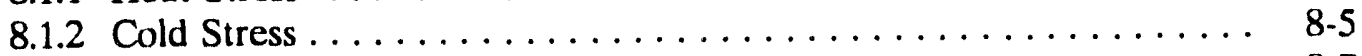

8.2 HEALTH AND SAFETY PLAN $\ldots \ldots \ldots \ldots \ldots \ldots \ldots \ldots \ldots \ldots .7$ 
9. ENVIRONMENTAL RESTORATION PROGRAM WASTE

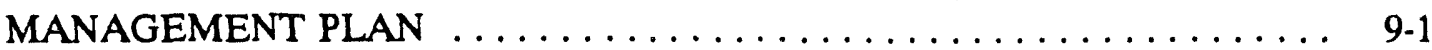

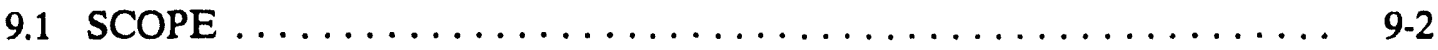

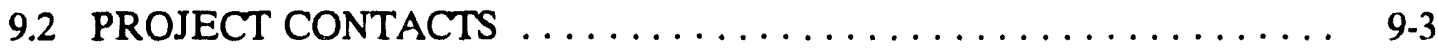

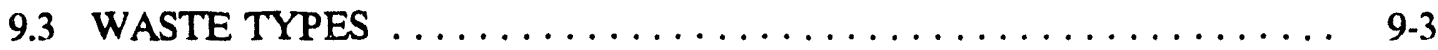

9.4 WASTE ESTIMATES $\ldots \ldots \ldots \ldots \ldots \ldots \ldots \ldots \ldots \ldots \ldots \ldots . \ldots \ldots$

9.5 WASTE STAGING AND STORAGE REQUIREMENTS . . . . . . . . 9-4

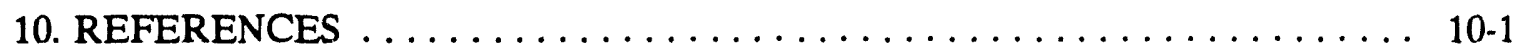

APPENDIX A GROUNDWATER QUALITY DATA $\ldots \ldots \ldots \ldots \ldots \ldots \ldots \ldots$ A-1

APFENDIX B APPLICABLE OR RELEVANT AND APPROPRIATE REQUIREMENTS FOR Y-12 CHESTNUT RIDGE OPERABLE UNIT ONE

B-1 APPENDIX C STANDARD OPERATING PROCEDURES FOR Y-12 CHESTNUT RIDGE OPERABLE UNIT ONE . . . . . . . . C-1 


\section{FIGURES}

1.1 DOE Facilities on the Oak Ridge Reservation . . . . . . . . . . . $1-4$

2.1 General Location of the Chestnut Ridge Security Pits $\ldots \ldots \ldots \ldots \ldots \ldots$ 2-2

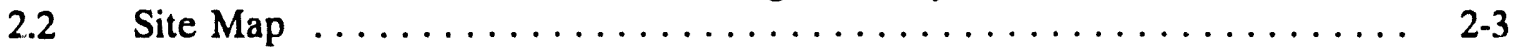

2.3 Components of Engineered Cap . . . . . . . . . . . . . . . 2-7

3.1 Location of ORR in Southern Appalachian Valley and Ridge Province .... 3-2

3.2 Site Map ...........................

3.3 Wind Rose for the Oak Ridge Reservation $\ldots \ldots \ldots \ldots \ldots \ldots \ldots \ldots \ldots$

3.4 Simplified Geologic Map of the Oak Ridge Reservation . . . . . . . . . . 3-7

3.5 Stratigraphic Section in the Vicinity of Chestnut Ridge OU1, ORR ..... 3-8

3.6 Distribution of Knox Aquifer \& Aquitards Across

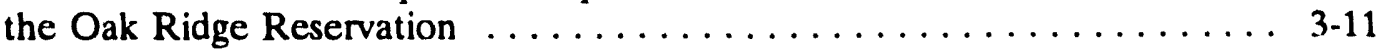

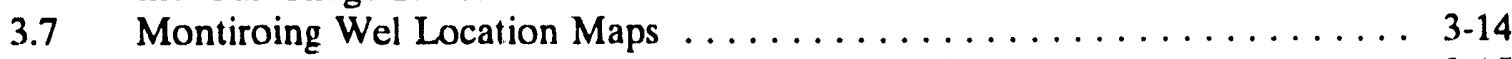

3.8 Cross-Section $A-A^{\prime}$ at Chestnut Ridge Security Pits $\ldots \ldots \ldots \ldots \ldots \ldots \ldots$. $\ldots \ldots \ldots$

3.9 Cross-Section B-B' at Chestnut Ridge Security Pits . . . . . . . . . . 3-16

3.10 Chestnut Ridge Security Pits Operable Unit 1 Conceptual Site Model . . . . 3-20

3.11 Chestnut Ridge Source OU1 Conceptual Site Model for Human Receptors - 3-22

3.12 Chestnut Ridge OU1 Ecological Conceptual Model Current Base State ... 3-25

3.13 Chestnut Ridge OU1 Ecological Conceptual Model

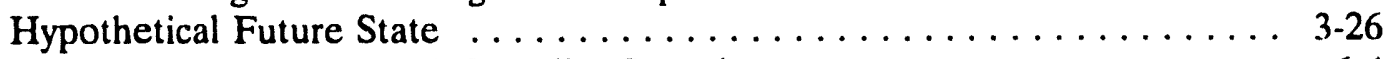

6.1 Proposed Monitoring Well Sampling Locations ................ 6-4

6.2 Proposed Locations for Surface and Subsurface Soil Sampling . . . . . . . . 6-5

7.1 Quality Assurance/Project Organization Chart ............... $7-3$

7.2 Examples of a Sample Label and Chain-of-Custody Seal . . . . . . . . . 7.23

7.3 Example of a Chain-of-Custody Record Form . . . . . . . . . . . . 7.25

7.4 Example of an Equipment Calibration Form . . . . . . . . . . . . $7-28$

7.5 Example of a Nonconformance Report Form . . . . . . . . . . . . $7-41$

7.6 Example of Field Change Request Form . . . . . . . . . . . . $7-45$ 


\section{TABLES}

1.1 Remedial Investigation/Remedial Action Schedule . . . . . . . . . . 1-12

2.1 Summary of waste disposal in Chestnut Ridge Security Pits . . . . . . . 2.5

3.1 Chestnut Ridge OU1 Monitoring Wells ................ 3-13

4.1 Federaly and state-listed threatened and/or endangered species and species designated In Need of Management by the state of Tennessee known or expected to occur on the Oak Ridge Reservation . . . . 4-4

5.1 Identification of preliminary remedial action goals, preliminary general response actions, and preliminary remedial technology types in specified media ...................... 5-3

6.1 Summary of sample numbers, media, and parameters for chemical analysis . 6 6-7

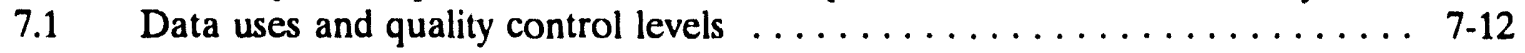

7.2 Quality assurance objectives for laboratory measurements . . . . . . . 7 74

7.3 Quality assurance objectives for field measurements $\ldots \ldots \ldots \ldots \ldots \ldots$ 7-15

7.4 Analytical methods and sample requirements $\ldots \ldots \ldots \ldots \ldots \ldots \ldots \ldots . \ldots \ldots$

7.5 Method detection limits for laboratory analysis $\ldots \ldots \ldots \ldots \ldots \ldots \ldots \ldots$

7.6 Summary of quality control sample requirements $\ldots \ldots \ldots \ldots \ldots \ldots$ 


\section{QAMS-005/80 LOCATOR PAGE}

The criteria listed below are outlined in the USEPA document Interim Guidelines and Specifications for Preparing Quality Assurance Project Plans (QAMS-005/80, 1983). OAMS-005/80 is the standard used for specific quality assurance/quality control activities to meet data quality objectives. All of the QAMS-005/80 criteria apply to site monitoring and measurement activities.

QAMS-005/80 Criterion

Title Page

Table of Coritents

Introduction

Project Description

Project Organization and Responsibility

QA Objectives

Sampling Procedures

Custody

Equipment Calibration Procedures

Analytical Procedures

Data Reduction, Validation, and Reporting

QC Checks

Performance and System Audits

Preventive Maintenance

Data Assessment Procedures

Corrective Action Procedures

Quality Assurance Reports
CDM Federal Reference (Section No.)

Title Page

Contents (p. ii)

Quality Assurance Project Plan

(QAPjP) (Sect. 7.1)

Work Plan (Sects. 1 and 2)

QAPjP (Sect. 7.2)

QAPjP (Sect. 7.3)

QAPjP (Sect. 7.4)

QAPjP (Sect. 7.5)

QAPjP (Sect. 7.6)

QAPjP (Sect. 7.8)

QAPjP (Sects. 7.9 and 7.11)

QAPjP (Sect. 7.10)

QAPjP (Sect. 7.12)

QAPjP (Sect. 7.7)

QAPjP (Sect. 7.3)

QAPjP (Sect. 7.13)

QAPjP (Sect. 7.14) 


\section{NQA-1 LOCATOR PAGE}

The following 18 elements are outlined in American Society of Mechanical Engineers (ASME) Nuclear Quality Assurance (NQA)-1 1989 edition, Quality Assurance Program Requirements for Nuclear Facilities (ASME 1989). NQA-1 is the primary DOE quality assurance (QA) program standard. Some of the 18 NQA-1 elements are not applicable to this investigation.

NOA-1 Element

QA Program

Organization

Design Control

Procurement Document Control

Instructions, Procedures, Drawings

Document Control

Control of Purchased Items and Services

Identification and Control of Items

Control of Processes

Inspection

Test Control

Control of Measuring and Test Equipment

Handling, Storage, and Shipping

Inspection, Test, and Operating Status

Control of Nonconforming Items

Corrective Action

Quality Assurance Records

Audits
CDM Federal Reference (Section No.)

CDM Federal QA Manual (Part I)

QAPjP (Sect. 7)

QAPjP (Sects. 7.1 through 7.16)

CDM Federal QA Manual (QP 8.0 and 9.0)

SOPs (ESH/Sub/87-21706/1)

QAPjP (Sect. 7.5)

CDM Federal QA Manual (QP 8.0 and 9.0)

QAPjP (Sect. 7.5)

CDM Federal QA Manual (QP 18.0)

QAPjP (Sect. 7.12)

CDM Federal QA Manual (QP 15.0)

SOPs (ESH/Sub/87-21706/1); Lab QA Plan/ Analytical Procedures

SOPs (ESH/Sub/87-21706/1)

SOPs (ESH/Sub/87-21706/1)

QAPjP (Sect. 7.13.1)

QAPjP (Sect. 7.13.2)

QAPjP (Sect. 7.14)

QAPjP (Sect. 7.12.1) 


\section{ACRONYMS AND ABBREVIATIONS}

\begin{tabular}{|c|c|}
\hline ARARs & applicable or relevant and appropriate requirements \\
\hline ASME & American Society of Mechanical Engineers \\
\hline bls & below land surface \\
\hline BOD & biological oxygen demand \\
\hline CDM Federal & CDM Federal Programs Corporation \\
\hline CERCLA & $\begin{array}{l}\text { Comprehensive Environmental Response, Compensation, and } \\
\text { Liability Act of } 1980\end{array}$ \\
\hline CLP & Contract Laboratory Program \\
\hline $\mathrm{COC}$ & contaminant of concern \\
\hline COD & chemical oxygen demand \\
\hline CRHR & Chestnut Ridge Hydrogeologic Regime \\
\hline CRSDB & Chestnut Ridge Sediment Disposal Basin \\
\hline CRSP & Chestnut Ridge Security Pits \\
\hline CSM & conceptual site model \\
\hline DOE & U.S. Department of Energy \\
\hline DOE-ORO & U.S. Department of Energy Oak Ridge Operations Office \\
\hline DOT & U.S. Department of Transportation \\
\hline DOO & data quality objective \\
\hline EFPC & East Fork Poplar Creek \\
\hline Energy Systems & Martin Marietta Energy Systems, Inc. \\
\hline ER & Environmental Restoration \\
\hline ERA & Ecological Risk Assessment \\
\hline ESD & Environmental Sciences Division \\
\hline ESP & Environmental Surveillance Procedure \\
\hline FCRF & Field Change Request Form \\
\hline FFA & Federal Facilities Agreement \\
\hline FS & Feasibility Study \\
\hline GC & gas chromatograph \\
\hline H\&S & health and safety \\
\hline HHRA & Human Health Risk Assessment \\
\hline HR & heart rate \\
\hline HWDU & Hazardous Waste Disposal Unit \\
\hline IDW & investigation-derived waste \\
\hline MCL & maximum contaminant limit \\
\hline MDL & method detection limit \\
\hline MLE & most likely exposure \\
\hline MS & matrix spike \\
\hline MSD & matrix spike duplicate \\
\hline MSL & mean sea level \\
\hline NEPA & National Environmental Policy Act \\
\hline NCP & National Contingency Plan \\
\hline NPL & National Priorities List \\
\hline NRDA & Natural Resource Damage Assessment \\
\hline ORNL & Oak Ridge National Laboratory \\
\hline
\end{tabular}




$\begin{array}{ll}\text { ORR } & \text { Oak Ridge Reservation } \\ \text { OU } & \text { operable unit } \\ \text { PA } & \text { Preliminary Assessment } \\ \text { PARCC } & \text { precision, accuracy, representativeness, completeness, and } \\ \text { comparability } \\ \text { PPE } & \text { personal protective equipment } \\ \text { PRG } & \text { preliminary remediation goal } \\ \text { QA } & \text { quality assurance } \\ \text { QAPjP } & \text { Quality Assurance Project Plan } \\ \text { QC } & \text { quality control } \\ \text { QPP } & \text { Quality Program Plan } \\ \text { RA } & \text { Remedial Action } \\ \text { RAO } & \text { remedial action objective } \\ \text { RCRA } & \text { Resource Conservation and Recovery Act of 1976 } \\ \text { RD } & \text { Remedial Design } \\ \text { RFI } & \text { RCRA Facility Investigation } \\ \text { RI } & \text { Remedial Investigation } \\ \text { RME } & \text { reasonable maximum exposure } \\ \text { ROD } & \text { record of decision } \\ \text { SI } & \text { Site Investigation } \\ \text { SOP } & \text { Standard Operating Procedure } \\ \text { SVOC } & \text { semivolatile organic compound } \\ \text { TAL } & \text { Target Analyte List } \\ \text { TCL } & \text { Target Compound List } \\ \text { TDEC } & \text { Tennessee Department of Environment and Conservation } \\ \text { TDS } & \text { total dissolved solids } \\ \text { TOC } & \text { total organic carbon } \\ \text { TRC } & \text { Technical Review Committee } \\ \text { USEPA } & \text { U.S. Environmental Protection Agency } \\ \text { USFWS } & \text { U.S. Fish and Wildlife Service } \\ \text { VOC } & \text { volatile organic compound } \\ \text { WAG } & \text { waste area grouping } \\ \text { WQP } & \text { water quality parameter } \\ & \end{array}$




\section{EXECUTIVE SUMMARY}

The Oak Ridge Y-12 Plant, located within the Oak Ridge Reservation (ORR), is owned by the U.S. Department of Energy (DOE) and managed by Martin Marietta Energy Systems, Inc. (Energy Systems). The ORR contains both hazardous and mixed waste sites that are subject to regulaticns promulgated under the Resource Conservation and Recovery Act of 1976 (RCRA) and the Comprehensive Environmental Response, Compensation, and Liability Act of 1980 (CERCLA), amended in 1986 by the Superfund Amendments and Reauthorization Act.

Under RCRA guidelines and requirements from the Tennessee Department of Environment and Conservation (TDEC), the Y-12 Plant initiated investigation and groundwater monitoring of various sites within its boundaries. The entire ORR was placed on the National Priorities List (NPL) of CERCLA sites on November 21, 1989. Following CERCLA guidelines, a site initially is investigated by a Preliminary Assessment/Site Investigation (PA/SI). If the PA/SI suggests that a Remedial Investigation (RI) is necessary, an RI is conducted to define the nature and extent of contamination, to evaluate the risks to the public health and the environment, and to determine the available alternatives for a Feasibility Study (FS) of potential remedial actions.

The Oak Ridge Y-12 Plant includes -800 acres near the northeast corner of the Reservation and adjacent to the City of Oak Ridge. The U.S. Army Corps of Engineers built the Y-12 Plant in 1943 as part of the Manhattan Project. The plant is a manufacturing and developmental engineering facility that produced components for various nuclear weapons systems and provides engineering support to other Energy Systems facilities. More than 200 contaminated sites created by past waste management practices have been identified at the Y-12 Plant. Many of the sites have been grouped into operable units (OUs) based on priority and on investigative and remediation requirements.

This RI Work Plan specifically addresses Chestnut Ridge OU1, which consists of the Chestnut Ridge Security Pits (CRSP).

The CRSP are located $\sim 800 \mathrm{ft}$ southeast of the central portion of the Y-12 Plant atop Chestnut Ridge, which is bounded to the northwest by Bear Creek Valley and to the southeast by Bethel Valley. Operated from 1973 to 1988, the CRSP consisted of a series of trenches used for the disposal of classified hazardous and nonhazardous waste materials. Disposal of hazardous waste materials was discontinued in December 1984, while nonhazardous waste disposal ended on November 8, 1988.

An RI is being conducted at this site in response to CERCLA regulations. The overall objectives of the RI are to collect data necessary to evaluate the nature and extent of contaminants of concern (COC), support an ecological risk assessment (ERA) and a human health risk assessment (HHRA), support the evaluation of remedial alternatives, and ultimately develop a Record of Decision for the site. 
The purpose of this Work Plan is to outline RI activities necessary to define the nature and extent of suspected contaminants at Chestnut Ridge OU1. Potential migration pathways also will be investigated. Data collected during the RI will be used to evaluate the overall risk posed to human health and the environment by OU1.

In order to fill data gaps and supplement and confirm existing data, additional site characterization data are needed in the following areas: site hydrogeology, groundwater quality, surface and subsurface soil contamination, and ecological characterization. The site investigation will specifically include

- collecting groundwater samples for chemical analyses (from 12 existing monitoring wells surrounding the CRSP and 1 existing monitoring well from a background location in the same geologic group) twice during the investigation as representative of wet and dry weather periods,

- screening for subsurface soil volatile organic compound (vOC) contamination using a Geoprobe and field gas chromatograph,

- collecting subsurface soil samples using the Geoprobe for chemical analyses from horizons where VOCs are found and $10 \%$ of the samples without detectable VOCs,

- conducting wetlands and endangered species habitat suiveys,

- collecting surface soil samples for chemical and grain size analyses,

- conducting a spring and seep survey to identify potential monitoring locations for design of the dye tracer study,

- designing and conducting a dye tracer study to elucidate the hydrology of Chestnut Ridge,

- collecting spring/seep and sediment samples from locations identified by the dye tracer study as hydrologically associated with the CRSP,

- collecting time-integrated air samples for VOC analysis,

- collecting earthworm samples for chemical analyses if areas of surface soil contamination are found adjacent to the pits,

- conducting plant and earthworm toxicity testing if areas of surface soil contamination are found adjacent to the pits, and

- conducting aquatic toxicity testing with daphnids and fathead minnow larvae at spring and/or seep locations if contaminants are found there.

The groundwater characterization data will be used to establish $\mathrm{COC}$ for the groundwater pathway. The soil characterization data will be used to identify $\mathrm{COC}$ in on-site (near-site) soils and to provide information on the nature and extent of soil contamination. The spring and seep survey/sampling and the dye tracer study will be used to estimate groundwater flow characteristics and to determine if contaminated groundwater is discharging to surface waters 
or at ground surface within the watershed. The air VOC data are needed to determine if VOCs are currently present at measurable concentrations at the site. The biological/ecological data will specifically be used to evaluate aquatic and terrestrial risk pathways for biota and man. Existing data on the volume and types of waste in the pits available in the waste inventory will be used for source characterization; the cap on the pits will not be sampled or breached in any way during this investigation. All of these data are needed to determine exposure points and pathways for the ERA and HHRA, to establish locations/extent of contamination for development of remedial alternatives in the FS, and to evaluate potential treatment/process alternatives. 


\section{INTRODUCTION}

This document outlines the activities necessary to conduct a Remedial Investigation (RI) of the Chestnut Ridge Security Pits (CRSP) at the Oak Ridge Y-12 Plant. The CRSP, also designated Chestnut Ridge Operable Unit (OU) 1, is one of four OUs along Chestnut Ridge on the Oak Ridge Reservation (ORR). The purpose of the RI is to collect data to

- evaluate the nature and extent of known and suspected contaminants,

- support an Ecological Risk Assessment (ERA) and a Human Health Risk Assessment (HHRA),

- support the feasibility study in the development and analysis of remedial alternatives, and, ultimately,

- develop a Record of Decision (ROD) for the site.

This section summarizes the regulatory background of environmental investigation on the ORR and the approach currently being followed and provides an overview of the RI to be conducted at the CRSP. Subsequent sections of the document provide details on site history, sampling activities, procedures and methods, quality assurance, health and safety, and waste management related to the RI.

\subsection{REGULATORY INITIATTVE}

The Oak Ridge Y-12 Plant, located within the ORR, is owned by the U.S. Department of Energy (DOE) and managed by Martin Marietta Energy Systems, Inc. (Energy Systems). The ORR contains both hazardous and mixed waste sites that are subject to regulations promulgated under the Resource Conservation and Recovery Act of 1976 (RCRA) and the Comprehensive Environmental Response, Compensation, and Liability Act of 1980 (CERCLA), amended in 1986 by the Superfund Amendments and Reauthorization Act.

Under RCRA guidelines and requirements from the Tennessee Department of Environment and Conservation (TDEC), the Y-12 Plant initiated investigation and groundwater monitoring of various sites within its boundaries. The entire ORR was placed on the National Priorities List (NPL) of CERCLA sites on November 21, 1989. Following CERCLA guidelines, initially, a site is investigated by a Preliminary Assessment/Site Investigatioin (PA/SI). If the PA/SI suggests that an RI is necessary, an RI is conducted to define the nature and extent of contamination, to evaluate the risks to the public health and the environment, and to determine the available alternatives for a Feasibility Study (FS) of potential remedial actions.

DOE, the U.S. Environmental Protection Agency (USEPA), and TDEC negotiated a Federal Facilities Agreement (FFA) in response to the NPL placement of the ORR. The FFA was developed for compliance pursuant to CERCLA, RCRA, the National Environmental Policy Act (NEPA), and the National Contingency Plan. A common goal of the parties 
that entered into the FFA is to ensure that past releases from operations and waste management at ORR are thoroughly investigated and that appropriate remedial action is taken for the protection of human health and the environment.

The general purposes of the FFA are to establish a framework and schedule for development, implementation, and monitoring of response actions on the ORR in accordance with applicable guidance and policy; to coordinate responses under CERCLA and RCRA to maximize flexibility and preclude redundant activity; to minimize duplication of analytical and investigative work; to ensure quality of data management; and to expedite response actions with minimal delay.

\subsection{ORR ENVIRONMENTAL RESTORATION PROGRAM}

DOE established the Environmental Restoration (ER) Program to plan and implement the investigation and remediation of the ORR (and other DOE facilities) in cooperation with the parties to the FFA. A fundamental goal in the implementation of the program is that remedial action be emphasized. The goal acknowledges that no investigatory process can resolve all uncertainties and that remedial actions must be able to accommodate deviation from original hypotheses after they are initiated. This approach to the process of investigation and remediation promotes early remedy selection, flexibility for the remedial action, and contingencies to account for new data obtained during investigation of the sites. Removal actions will be implemented, as necessary, to protect human health and the environment from an imminent short-term threat. Interim remedial actions may also be implemented if the site warrants quick stabilization or risk reduction.

The parties to the FFA divided the ORR into waste area groupings (WAGs)/OUs that are prioritized to obtain effective and rapid investigation and cleanup. Characterization of WAGs and OUs are planned on the basis of optimizing field sampling and maximizing the use of existing data. Using the framework of WAGs and OUs, the ER Program is following some guidelines that shape the overall approach for the remediation of the ORR. First, emphasis is placed on the integration of ongoing activities and historical information concerning the sites. Second, activities of other major programs on the ORR are to be coordinated and integrated with the ER Program to ensure that adequate resources are available, that data are provided in a consistent format, and that technical issues and remediation technologies are communicated throughout the ER Program. Third, remedial action schedules for OUs can be revised by consent of the FFA parties. Fourth, as the investigations proceed, OUs may be redefined or reprioritized with the consent of the FFA parties. Finally, waste minimization and the prevention of recontamination will be emphasized in all investigations.

The lead agency for the investigations and remedial actions on the ORR is the DOE Oak Ridge Operations Office (DOE-ORO). The duties of the lead agency include overseeing and managing ORR remedial actions pursuant to the FFA, serving as the primary contact and coordinator with regulators for implementing the FFA, and ensuring the availability of resources required to implement the site management plan. The USEPA and TDEC are working together within the terms of the FFA to initiate remedial action work and to provide regulatory oversight. 
The ER Division of Energy Systems is the integrating contractor for the DOE ER Program. The primary function of the integrating contractor is to ensure technical and operational consistency among all participants involved in the Oak Ridge ER Program. The ER Division will conduct meetings; collect information; assemble total packages on ER Program activities; and prepare monthly status reports on budget, cost, schedule, and progress for use by DOE-ORO. Technical consistency in such areas as risk assessment, NEPA compliance, waste management, and others are monitored and ensured by the ER Division.

In addition to these primary responsibilities, the ER Division has a variety of other responsibilities in its role as integrating contractor, including the following:

- evaluation of other DOE prime contractor, subcontractor, and prospective contractor ER programs, policies, and procedures;

- coordination with plant operations for any fieldwork;

- evaluation of design, strategies, and sequencing of work;

- preparation of ER Program technical and administrative policy and procedures;

- coordination of technical reviews of all products and documents prepared by all ER Program participants;

- provision of treatment, storage, and disposal services for management of ER-originated wastes;

- conduct of a rigorous self-assessment program to evaluate regulatory compliance and procedure adherence during ER activities;

- development and operation of the Oak Ridge Environmental Information System (OREIS) to manage environmental data on the ORR; and

- coordination and evaluation of priorities for ongoing and proposed activities for the DOEORO ER Program.

DOE-ORO has delegated remediation activities at each WAG or OU to three primary contractors in addition to Energy Systems. Radian Corporation is responsible for the FS, Environmental Assessments, Proposed Plans, RODs for interim actions, and RODs. EBASCO Services is responsible for Remedial Designs. MK-Ferguson is responsible for Remedial Actions. Additional information on the ER Program is available in the ORR Site Management Plan, DOE/OR-1001/R2 (Energy Systems 1992b).

\subsection{FACILITY-SPECIFIC ER PROGRAM}

The Oak Ridge Y-12 Plant, one of three major DOE facilities on the ORR, includes approximately 800 acres near the northeast corner of the reservation and adjacent to the city of Oak Ridge (Fig. 1.1). The U.S. Army Corps of Engineers built the Y-12 Plant in 1943 as 


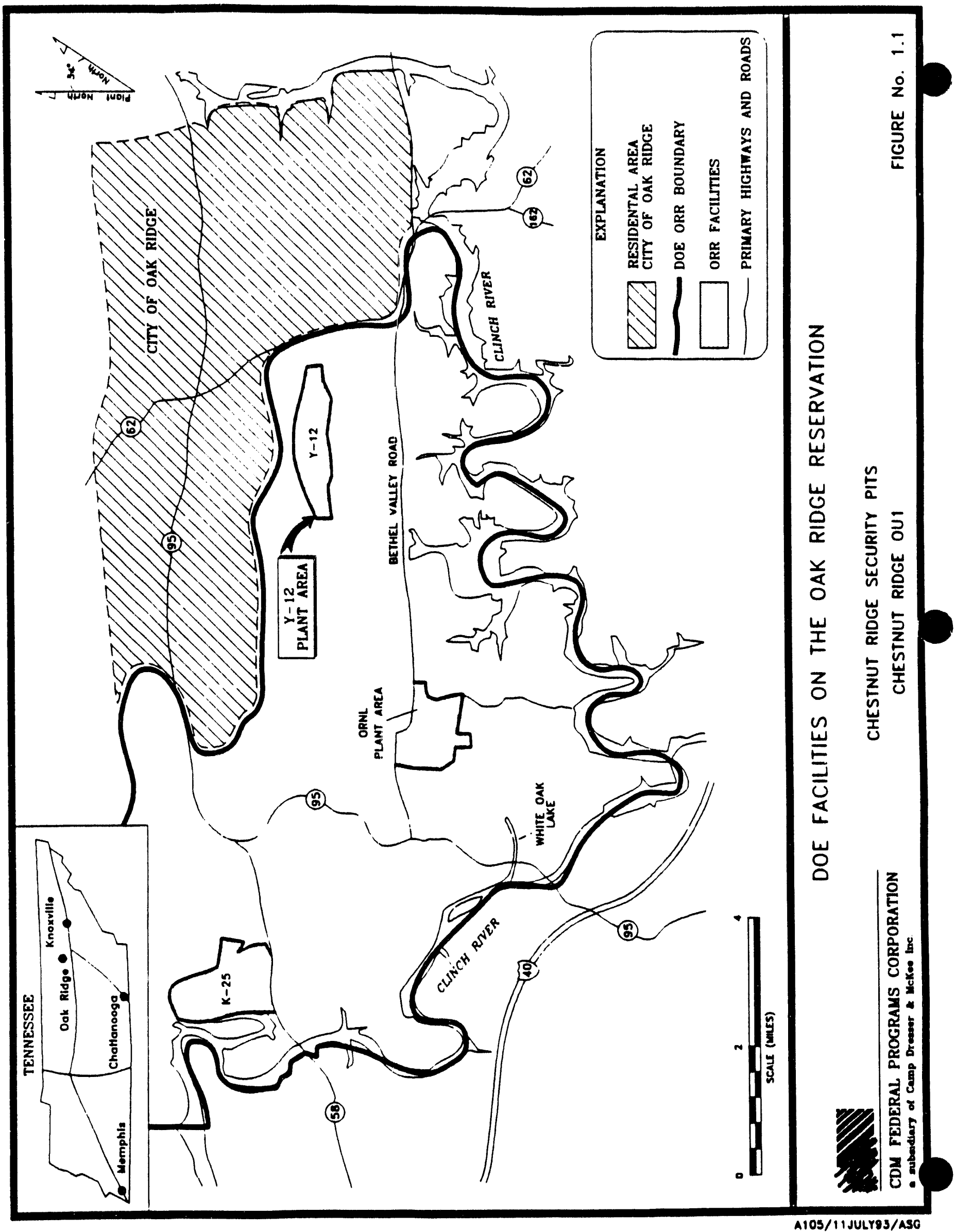

CR socurity Pits WP 
part of the Manhattan Project. The plant is a manufacturing and developmental engineering facility that produced components for various nuclear weapons systems and provides engineering support to other Energy Systems facilities. More than 200 contaminated sites created by past waste management practices have been identified at the Y-12 Plant. Many of the sites have been grouped into OUs based on priority and on investigative and remediation requirements. Specific information on the OUs at the Y.12 Plant is provided in Sect. 1.4.

A major component of the investigative and remedial strategy to be applied to the Y-12 Plant, and the entire ORR, is a structured approach. This approach is based on separate studies of groundwater, surface water, and contaminant sources. The hydrogeologic regime at the Y-12 Plant is complex and includes surface-water drainage, groundwater flow through a dominantly fractured system, and groundwater flow through a karst system. Numerous sources may have contributed to groundwater and surface water contamination; for example, sources contributing to groundwater that is part of one OU often contribute to groundwater contamination that is part of another $O U$.

Given these circumstances, the parties to the FFA concluded that the most timely and cost-efficient investigations would result if sources of contamination were studied separately from the groundwater and surface water. This conclusion led to the designation of source control and integrator OUs. Source control OUs focus on the nature and extent of contaminant contributions from a specific source or group of sources. Integrator OUs, on the other hand, focus on the nature and extent of contamination in a particular medium such as surface water or groundwater independent of the specific source or sources. Some OUs on the ORR combine both source control and integrator aspects.

Source control OUs will be addressed initially in interim action RODs. When all proposed source control $O U$ interim actions are complete, there should be an adequate amount of monitoring data from integrator OUs to determine if the interim actions have been effective, and, if not, additional remediation will be undertaken in the integrator OU final ROD. OUs designated as both source control and integrator are anticipated to reach a final ROD.

\subsection{FACILITY OPERABLE UNIT STRATEGY}

The OUs established for the Y-12 Plant include source control units, groundwater integration units, surface water integration units, and combined units. The plant area includes two groundwater integrator units: Bear Creek and Upper East Fork Poplar Creek (EFPC). Chestnut Ridge is a distinct hydrologic regime and is handled as a combined source control and groundwater OU. The ultimate integrator unit of all surface water and groundwater contamination from the ORR is the Clinch River/Melton Hill Lake/Watts Bar Lake.

Eleven OUs have been established at the Y-12 Plant and include 31 of the contaminated sites within the plant boundaries and surrounding areas. Sites at the Y-12 Plant not included in an OU have been grouped collectively into the "Y-12 Study Area." These lower priority sites will be investigated as Preliminary Assessments (PAs)/Site Investigations (SIs). Sites will be grouped into new OUs or added to existing OUs if the PAs/SIs suggest that an RI/FS is necessary. The sites generally were grouped on the basis of proximity and by common physical and hydrogeological characteristics. Bear Creek and Upper EFPC hydrologic regimes each 
are associated with an integrated surface water and groundwater OU. The Lower EFPC watershed constitutes both a source control and groundwater OU. The remaining eight OUs are source control OUs within the Bear Creek, Upper EFPC, and Chestnut Ridge hydrologic regimes. Groundwater contamination in the Chestnut Ridge hydrologic regime is associated with each source control OU.

Four OUs have been established for the Chestnut Ridge hydrologic regime: Chestnut Ridge OU1, the CRSP; Chestnut Ridge OU2, the Filled Coal Ash Pond/Upper McCoy Branch; Chestnut Ridge OU3, the United Nuclear Corporation Disposal Sitc; and Chestnut Ridge OU4, Rogers Quarry/Lower McCoy Branch. All OUs located in Chestnut Ridge are combined units that include source control and groundwater rather than addressing groundwater as a separate integrator unit. Media to be addressed in the investigations at these OUs include soil, groundwater, surface water, sediments, and air.

The ER Program prioritized the OUs established for the ORR and surrounding areas. Evaluation of the OUs was based on five weighted categories: human health risk, environmental impacts, regulatory obligations and other commitments, program impacts, and negative socioe:onomic impacts. Chestnut Ridge OU1 currently is ranked third in priority of the 11 OUs established at the Y.12 Plant. Additional information on the prioritization process is available in the ORR Site Management Plan (Energy Systems 1992b).

\subsection{INTENT AND SCOPE OF THE RI WORK PLAN}

An $\mathrm{RI}$ is being conducted at the CRSP in response to CERCLA regulations. The observational approach will be used in compiling and analyzing currently available data and new data to be collected under this RI. The purpose of this Work Plan is to outline RI activities necessary to define the nature and extent of known and suspected contaminants at Chestnut Ridge OU1. Potential migration pathways will be investigated as well. Data collected during the RI will be used to evaluate the risk posed to human health and the environment by the CRSP.

Samples to be collected during the RI include surface and subsurface soil from borings around the perimeter of the pits; groundwater samples from 13 monitoring wells, 12 on-site and 1 off-site; air samples from the site; and sediment and water samples from springs or seeps in the vicinity of the site. Soil samples will be analyzed for volatile organic compounds (VOCs) by gas chromatography with a portable or "field" gas chromatograph (GC). The field $\mathrm{GC}$ analysis will focus on VOCs because previous data from the site indicate that these are the primary contaminants of concern (COCs). All soil samples with measurable VOC concentrations and $10 \%$ of soil samples with nondetectable VOC concentrations will be submitted to a fixed base laboratory for Target Compound List/Target Analyte List (TCL/TAL) analysis. The samples will be analyzed for the full TCL/TAL because available waste inventories suggest that a variety of compounds were disposed of in the pits; in addition, no data on soils at the site have been obtained from previous investigations, so the nature and extent of contaminants must be verified. Groundwater, surface water, and sediment samples will also be analyzed for the TCLTAL analytes. Air samples will be analyzed for VOCs; the purpose of these samples will be to investigate the volatilization pathway for the risk assessment. Finally, a variety of ecological sampling and testing 
procedures will be used at the site to evaluate ecological impacts if the results of soil and spring/seep sampling show contaminants are present at levels of concern.

No monitoring wells will be installed during this RI. Nineteen wells exist in and around the CRSP, as does a substantial amount of data from previous well sampling, with which to characterize the groundwater at the site and to evaluate the potential contaminant contribution from the CRSP. Additional wells probably would not add any significant new information because previous studies (e.g., Haase et al. 1987) have included well installation and a discussion of hydrogeologic conditions at the site. Data from the ORR Groundwater Monitoring Program also define hydrologic characteristics of the site.

In addition to sampling activities, a spring and scep survey will be conducted along Chestnut Ridge; the survey will provide data for an accurate and comprehensive data base that will help clarify the groundwater network in bedrock. A well-developed karst system underlies Chestnut Ridge, and a clear understanding of the distribution of springs and seeps is particularly significant because of their connection with this system. A dye tracer test will be designed and conducted after the survey is completer. Two dye tracer tests have been conducted previously at Chestnut Ridge OU1; one of the tests provided some data clarifying hydrologic relationships, while the other test was inconclusive.

Source characterization will be accomplished by review of available inventory records, which are relatively comprehensive and complete. The multilayered engineered RCRA cap on the CRSP will not be breached during the RI.

\subsection{SPECIAL PROBLEMS}

Access to the CRSP is controlled, and the area is patrolled regularly by security personnel; therefore, all subcontract personnel performing the sampling must be badged and escorted by $\mathrm{L}$ - or Q-cleared escorts. In addition, the complete inventory of the materiais disposed of at the site is not available for inclusion in the RI report because many of the items are classified. Finally, some of the samples taken during the RI may be considered classified, given the controlled status of the site; this determination will be made by Energy Systems security personnel. If any samples are deemed classified, they will have to be analyzed at a laboratory at one of the facilities on the ORR, and access to the results of analyses will be controlled.

\subsection{OVERALL PROJECT OBJECTIVES}

The overall objectives of the RI are to collect data necessary to evaluate the nature and extent of COCs, support an ERA and an HHRA, support the evaluation of remedial alternatives, and ultimately develop a ROD for the site. The ROD for the CRSP will be consistent with the strategy outlined in the ORR Site Management Plan (Energy Systems 1992b).

The observational approach will be used to address the uncertainties inherent at hazardous waste sites such as this. The observational approach involves several steps to identify the most probable model of the site and reasonable deviations from that model that must be accounted 
for during design and implementation. The observational approach recognizes that complete site characterization is not possible, and an attempt to fully define the nature and extent of contamination is generally not achievable.

Initially, existing information on general site conditions is gathered, and remedial objectives and general responses are set. Next, additional information is gathered to refine knowledge of general site conditions and the nature and extent of contamination, receptors, pathways, remedial objectives, and so forth. Then, the most probable site conditions and reasonable deviations are identified. From this information, a conceptual design incorporating both a base action and a contingent action can be developed and a ROD signed. Achieving an understanding of the processes involved in the fate and transport of hazardous contaminants and their exposure and the effects on human health and the environment is a necessary addition to the observational approach to ensure that a reasonable model of the site can be developed.

The remedial action is designed from the most probable conditions and reasonable deviations expected. Key indicators (chemical, physical, and others) are selected for observation during remediation to detect deviations during construction and operation. The purpose of this step is to identify where actual site conditions do not match estimated or expected site conditions and to determine the level of deviation that will trigger a response. The observational approach is not appropriate if a model of the most probable conditions and reasonable deviations cannot be established or if key indicators cannot be defined. Finally, the remedial alternative is implemented, and selected parameters are measured during remediation to identify necessary modifications.

Potential migration pathways for contaminants from the CRSP include surface runoff, groundwater, transport, and air emission. Surface water is not present at the site, but surface runoff could carry contaminants to nearby surface water outlets or to groundwater via infiltration. Groundwater pathways include fractures and karst conduits in bedrock. To date, 22 wells that monitor a range of depths in the bedrock have been installed in and around the perimeter of the CRSPs; three of these wells have been plugged and abandoned, leaving 19 functional monitoring wells.

A review of historical records and existing data from sampling of groundwater around the CRSP indicates that the primary COCs are VOCs; metals and radionuclides are also present in groundwater, but rarely at significant concentrations [i.e., exceeding maximum contaminants limits (MCLs)]. Samples to be collected during the investigation will include surface and subsurface soil samples from the site, groundwater samples from monitoring wells in and around the site and from one background or control well, surface water/sediment samples from springs and seeps in the vicinity of the site, and air samples from the site. Section 6 provides detailed information on sampling locations and rationale.

\subsection{DATA QUALTTY OBJECTIVES}

Data quality objectives (DQOs) are qualitative and quantitative statements that specify the required quality of sample collection and analysis based on the intended uses of the data. The purpose of DQOs is to ensure that the data collected in a given study are of appropriate 
quality to support activities, such as site characterization, risk assessment, evaluation of remedial alternatives, or development of design criteria, required by that study. DQOs are project-specific and applicable to all data collection activities. This section describes the DQO process as applied to Chestnut Ridge OU1. A detailed presentation of the project DQOs is provided in Sect. 7, the Quality Assurance Project Plan (QAPjP).

\subsubsection{Problem to Be Resolved}

The CRSP site was used by the Y-12 Plant from 1973 to 1988 for the disposal of classified hazardous and nonhazardous waste materials. Previous studies of the CRSP indicated the presence of contaminants in groundwater. Therefore, the overall problem to be resolved during this $\mathrm{RI}$ is the determination of the nature and extent of contamination and the degree to which the CRSP poses a threat to human health and the environment. To meet this end, an adequate amount of data will be collected to support contaminant characierization, to conduct both an ERA and an HHRA, and to evaluate and select remedial alternatives.

The observational approach has been used in the development of RI activities described in this work plan. Historical data from previous studies at the site provided the information necessary to identify data gaps and to narrow the scope of the investigation. Media to be sampled include soil, groundwater, surface water, sediments, and air. Surface and subsurface soil will be sampled from borings located on transects across the site. Samples will be analyzed for VOCs with a field GC; samples with positive hits and a percentage of samples with nondetectable concentrations will be submitted to a fixed base laboratory for TCL/TAL and radionuclide analyses. Groundwater will be sampled from existing wells at the CRSP for TCL/TAL and radionuclide analytes. Air will be sampled at the site and analyzed for VOCs. Surface water and sediments both will be collected from locations in the vicinity of the site identified in the spring and seep survey and will also be submitted for TCL/TAL and radionuclide analyses. Finally, various activities to collect data necessary to support an ERA wili be included in the RI. Details of the sampling and analytical requirements are provided in Sect. 6.2.

\subsubsection{Decision to Be Made}

Decisions to be made in RIs on the ORR are defined by the FFA. Sites on the ORR identified as requiring an $\mathrm{RI}$ are designated on the basis of existing data indicating the presence of contamination. Decisions to be made after the RI include a determination of whether the site will require remediation and, if so, what type will be necessary. An FS follows the RI. The decision on whether to remediate will be based on National Environmental Po!:cy Act criteria, National Resources Damage Assessment criteria, and the nine criteria of CERCLA: overall protection of human health and the environment; compliance with applicable or relevant and appropriate requirements (ARARs); long-term effectiveness and permanence; reduction of toxicity, mobility, or volume through treatment; short-term effectiveness; implementability; cost; state acceptance; and community acceptance. Chestnut Ridge OU1 is a combined source control and integrator unit and is therefore projected to reach a firial ROD at the conclusion of the FS. 


\subsubsection{Identification of Inputs to the Decision}

Input for decisions to be made based on data collected from the CRSP will consider both intended data users and uses. Primary data users include personnel who collect the data, who evaluate and manipulate the raw data, and who make recommendations or draw conclusions from it. Examples of primary users include field personnel, the multidisciplinary project team that prepares the RI report, the FS subcontractor, and other subcontractors performing a specific task. Secondary data users include upper-level Energy Systems management, DOE, and the regulator agencies (USEPA and TDEC) who approve recommendations and support conclusions prepared by the primary users.

Intended data uses for the CRSP include defining the nature and extent of contamination, supporting both an HHRA and an ERA, addressing the requirements for evaluation of probable remedial alternatives, and preparing a ROD. The intended uses of data collected during health and safety monitoring and field screening include determining appropriate personnel protection levels, measuring indicator parameters, and screening samples for radiation before off-site shipment.

\subsubsection{Definition of the Boundaries of the Study}

The boundaries of an RI are narrowed by application of a site conceptual model. The model is based on the history and current condition of the site and its environmental setting. Examples of factors that ultimately determine the boundaries of an RI include the existence of wetlands or floodplain, known or assumed groundwater flow direction, the relationship between the surface water drainage system and groundwater, potential migration and exposure pathways, and potential receptors.

A conceptual model for Chestnut Ridge OU1 that considers the environmental setting and illustrates potentially contaminated media and potential migration and exposure pathways is presented in Sect. 3. Section 3 also includes three specific models that consider the potential human health and ecological risks associated with the site.

\subsubsection{Development of a Decision Rule}

Decision rule requirements for RIs on the ORR are specified in its FFA. The primary basis for the decision rule are documents prepared from the RI fieldwork and subsequent activities (e.g., risk assessments, FS, etc.) The RI report thai summarizes site history, investigatory activities, data collected, and conclusions based on the study will be prepared. The FS that follows the RI will include a report summarizing the evaluation of alternatives and will be followed by a prc posed plan and then a ROD. After completion and approval of the ROD, the final stage of the process, remedial design/remedial action, will be implemented.

\subsubsection{Development of Uncertainty Constraints}

All data pertinent to the investigation, not just laboratory data, will be of defensible quality. Nonlaboratory data, such as field observations and field screening readings, will be recorded in a manner consistent with applicable Standard Operating Procedures (SOPs) and quality control $(\mathrm{QC})$ procedures. Field personnel will be trained before initiation of fieldwork, 
and all fieldwork is subject to audits by regulatory agencies, Energy Systems, and subcontract personnel. Historical data or records included in the RI report will be used in a manner consistent with the level of scrutiny and review previously applied; known or potential uncertainties will be specified in the report. Additional details concerning the collection and evaluation of these data are in Sects. 6.3 and 7.

QC requirements for the laboratory will be specified in the quality assurance (QA) plan prepared by the contracted laboratory. The plan will identify intı i nal $\mathrm{QC}$ at the laboratory including calibration frequency, method blank frequency, and cor. sctive measures. This QA plan will be subject to review and approval by DOE, Energy Systems, and the subcontractor. Additionally, the laboratory must successfully complete an audit conducted by the Analytical Project Office of Energy Systems. CDM Federal Programs Corporation (CDM Federal) and Energy Systems may conduct additional audits or surveillances during the performance of the work. The latoratory data will meet both Level C (90\% of the total) and Level D (10\% of the total) QC and deliverable requirements and will include the entire Contract Laboratory Program (CLP) package of documentation. Additional details concerning the laboratory data are in Sect. 7.

\subsection{Optimization of the Design for Obtaining Data}

Data design optimization for Chestnut Ridge OU1 is based on a review of historical records, existing data, site visits, and discussion with Energy Systems personnel familiar with the site. The sampling locations identified in this Work Plan will provide representative samples of the potentially contaminated media at the site. A statistical analysis of the data may be necessary during the preparation of the RI report. The extent to which a statistical treatment is appropriate will be determined based on the results of the fieldwork. A statistical analysis combining existing data and newly collected data may be attempted; however, the variable quality of existing data may preclude this type of treatment.

\subsection{SCHEDULE}

Table 1.1 is the schedule for completion of the RI Work Plan, the RI itself, and subsequent remedial actions for the CRSP. If all schedule deadlines are met by all parties involved, the Final RI Work Plan should be submitted by March 1994. It is anticipated that field activities for this RI, including the spring and seep survey and the dye tracer studies, will take approximately 33 months. The ROD is scheduled for September 2000, and final remedial actions are to be completed by January 2011.

\subsection{QUALTTY ASSURANCE}

All QA and QC activities of this project will be governed by the Energy Systems Environmental Restoration Quality Program Plan, ES/ER/TM-4/R2 (1992a), which addresses the guidance in USEPA's Interim Guidelines and Specifications for Preparing Quality Assurance Project Plans, QAMS-005/80 (1983); the specifications of the Energy Systems Policies, Standards, and Procedures, Vol. 4, Quality Procedures Manual (1993); the American Society of Mechanical Engineers (ASME) document Quality Assurance 'rogram Requirements for 
Table 1.1. Remedial investigation/remedial action schedule for Chestnut Ridge Security Pits (Chestnut Ridge OU1)

\begin{tabular}{lcc}
\hline \multicolumn{1}{c}{ Task name } & Start date & End date \\
\hline Notice to Proceed & 26 Apr. 93 & 26 Apr. 93 \\
Submit Draft Work Plan & 14 July 93 & 14 July 93 \\
Receive DOE/Energy Systems Comments & 27 Aug. 93 & 27 Aug. 93 \\
Submit Final Draft & 17 Sept. 93 & 17 Sept. 93 \\
Energy Systems Submit Final Draft to Reg. & 30 Sept. 93 & 30 Sept. 93 \\
Receive Regulatory Comments & 05 Jan. 94 & 05 Jan. 94 \\
Submit Final Remedial Investigation Work Plan & 09 Mar. 94 & 09 Mar. 94 \\
Remedial Investigation Work Plan Approved & 06 Apr. 94 & 06 Apr. 94 \\
Remedial Investigation Site Preparation & 01 Apr. 94 & 30 June 94 \\
Field Activities & 01 Apr. 94 & 27 Dec. 96 \\
Remedial Investigation Report & 06 Jan. 97 & 28 Aug. 98 \\
Feasibility Study/Environmental Assessment Report & 05 Jan. 98 & 04 Jan. 99 \\
Feasibility Study-Proposed Plan & 08 Mar. 99 & 01 Sept. 00 \\
Feasibility Study-Record of Decision & 05 Sept. 00 & 14 Dec. 01 \\
Remedial Design & 01 May 00 & 14 June 02 \\
Remedial Action-Integration & 01 May 00 & 23 Mar. 07 \\
Remedial Action & 17 June 02 & 14 Jan. 11 \\
\hline
\end{tabular}


Nuclear Facilities, ASME NQA-1 (1989); and applicable DOE Orders. When appropriate, existing CDM Federal Programs Corporation (CDM Federal) quality procedures will be used to implement ES/ER/TM-4/R2 requirements. The QAPjP for this project is provided in Sect. 7. The QAPjP addresses QAMS-005/80 and applicable ES/ER/TM-4/R2 requirements. The QAPjP locator page identifies the requirements and the location of the text that addresses each requirement. 


\section{HISTORY AND CURRENT CONDITIONS}

\section{GEOGRAPHIC INFORMATION}

The CRSP Hazardous Waste Disposal Unit (as it is referred to in the historical RCRA documentation) is located $\sim 800 \mathrm{ft}$ southeast of the central portion of the DOE Y-12 Plant (Fig. 2.1) atop Chestnut Ridge, which is bounded to the northwest by Bear Creek Valley and to the southeast by Bethel Valley. Operated from 1973 to 1988, the CRSP consisted of a series of trenches used for the disposal of classified hazardous and nonhazardous waste materials. Disposal of hazardous waste materials was discontinued in December 1984 (Energy Systems 1988), while nonhazardous waste disposal ended November 8, 1988.

The CRSP occupy an area that extends from approximately plant grid coordinate $E 57,000$ to E59,500 along the crest of the ridge and from N24,300 to N24,700 across the ridge. Local relief is $\sim 70 \mathrm{ft}$, with elevations ranging from $1080 \mathrm{ft}$ above mean sea level (MSL) at the eastern end of the site to $1150 \mathrm{ft}$ above MSL at the western end of the site.

The 100-year floodplain of Upper EFPC occurs within the Y-12 Plant boundary but is confined by Chestnut Ridge to the southeast and does not extend above an elevation of $910 \mathrm{ft}$. The CRSP are situated $\sim 200 \mathrm{ft}$ above the highest elevation of the floodplain and, therefore, are not influenced by flooding from EFPC. Perennial streams on the southeast flank of Chestnut Ridge (e.g., McCoy Branch) have a relatively steep gradient and have not developed a discernible floodplain. During heavy storm events, any overbank flow from these streams would accumulate in Bethel Valley, where the base elevation is $\sim 200 \mathrm{ft}$ below the elevation of the CRSP.

A number of waste management sites are situated along Chestnut Ridge. The closest sites to the CRSP are the Filled Coal Ash Pond, $\sim 1 / 4$ mile to the southwest; the East Chestnut Ridge Waste Pile and Landfill III, $\sim 1 / 2$ mile to the northeast; and the United Nuclear Corporation Site, $\sim 3 / 4$ mile to the southeast along Chestnut Ridge. Existing data from the CRSP (discussed in sections that follow) do not suggest that these nearby sites are potential contaminant sources to the CRSP.

\subsection{BACKGROUND INFORMATION}

The CRSP disposal trenches are in two individual areas that have been designated the eastern trench area and the western trench area (Fig. 2.2), both of which are now capped and covered with grass. The individual trenches were about 8 to $10 \mathrm{ft}$ wide and 10 to $18 \mathrm{ft}$ deep and were excavated in sections and filled, as needed, for waste disposal activities. Sections of various trenches typically were open simultaneously to allow for the segregation of waste into separate cells. When a trench was nearly filled, it was covered with 3 to $6 \mathrm{ft}$ of fill dirt (Energy Systems 1984).

The eastern trench area consists of three trenches (Nos. 1, 2, and 3). Trench No. 1 is $\sim 700 \mathrm{ft}$ long and was active from February 1973 through December 1977. Trench No. 2 


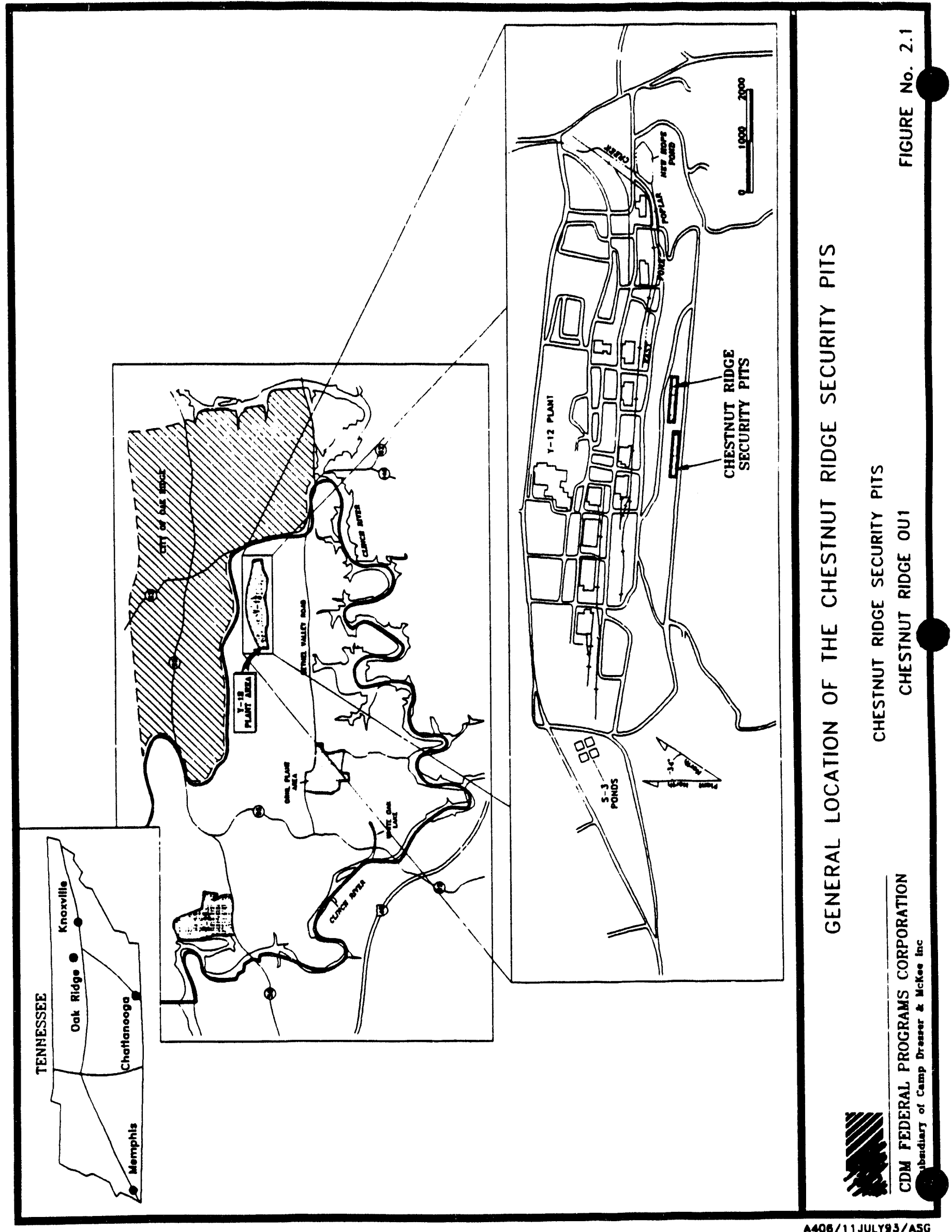




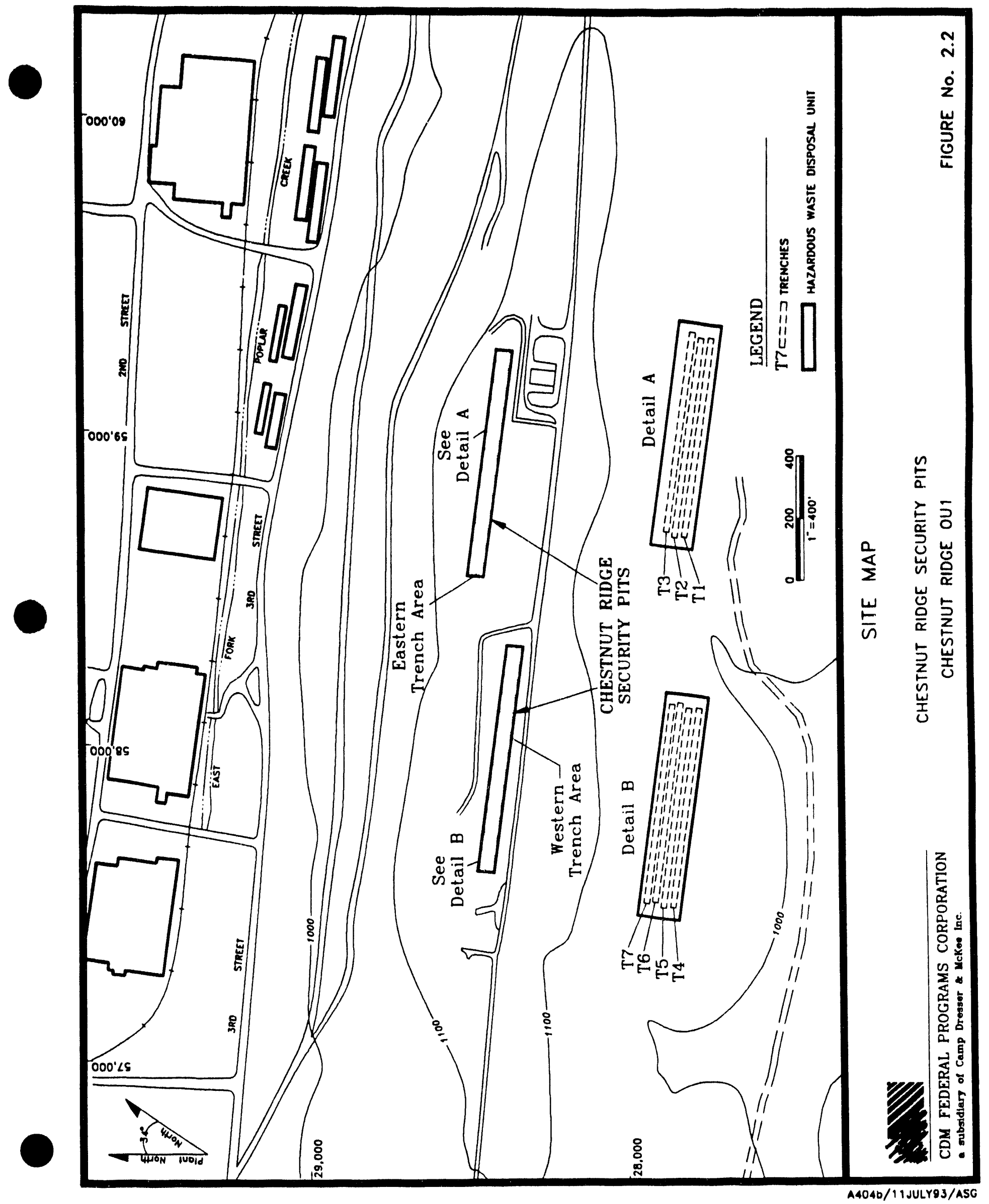


is $\sim 720 \mathrm{ft}$ long and was active from December 1977 through January 1981. Trench No. 3 is about $690 \mathrm{ft}$ long and was active from January 1981 through December 1982. Each trench is discontinuous in length by $\sim 18 \mathrm{ft}$ because of underground cables lying transverse to the trenches. Reactive materials were disposed of in six auger holes, located east of the eastern trench area. Each hole was $-2 \mathrm{ft}$ in diameter and $10 \mathrm{ft}$ deep. A temporary storage area was established adjacent to the eastern trench area on the south side of the trenches in the mid1980s. The storage area receives dismantled roof debris from a building at the Y-12 Plant. The debris was characterized as containing asbestos, mercury, and uranium.

The western trench area included four trenches (Nos. 4 through 7) that ranged in length from $\sim 720$ to $780 \mathrm{ft}$. Two trenches in this area were operated from December 1982 until 1985 (Energy Systems 1984). The other two trenches received non-RCRA waste from 1985 through 1988.

\subsection{OPERATIONAL INFORMATION}

The CRSP began receiving classified hazardous and nonhazardous waste in 1973. Detailed inventories of the waste placed in the CRSP are classified due to the secure nature of the waste. An unclassified inventory of materials disposed of in the pits includes ten major categories of waste: acids, fiberglass, beryllium, biological materials, debris, heavy metals, inorganics, organics, thorium, and uranium (Radian 1992). Table 2.1 lists the hazardous and nonhazardous materials disposed of at the CRSP and their known quantities and relative percentages as of October 1985.

Most of the classified waste disposal in the CRSP consisted of solid metal components such as machined weapons parts, gages, and shipping containers; other debris included gloves, bottles, bags, badges, and computer tapes (Energy Systems 1984). Powders such as lithium oxide and beryllium oxide and liquids such as dilute hydrochloric acid, mineral oil, and alcohol have been disposed of but constitute a small quantity of the total inventory (Energy Systems 1984).

Records are adequate to determine that materials were not indiscriminately dumped and buried in the trenches. The trenches were segregated such that similar materials were generally buried in the same location over a long period. For example, in trenches $6 \mathrm{E}$ and 4 , depleted uranium items were buried in $6 \mathrm{E}$, and materials such as steel and aluminum, which may be contaminated with uranium, were buried in 4 . At least 16 distinct areas, each for a specific material category, were used in trenches 1,2 , and 3.

The CRSP were closed as interim status hazardous waste landfills under RCRA because the classified nature of the hazardous wastes disposed of there precluded disposa!, treatment, or removal by other means. The CRSP were granted interim status by USEPA under RCRA in November 1985. A RCRA Closure/Post-Closure Plan for the CRSP was prepared and submitted to TDEC for review and approval in June 1987 (Energy Systems 1987). Subsequently, TDEC deleted the postclosure aspects of the plan and approved it on September 30, 1987. Later, a Revised RCRA Closure Plan (Y/TS-391, Energy Systems 1988) dated February 29, 1988, containing TDEC's recommended revisions, was prepared and 
Table 21. Summary of waste disposal in Chestnut Ridge Security Pits (through October 1985)

\begin{tabular}{lcc}
\hline \multicolumn{1}{c}{ Waste } & $\begin{array}{c}\text { Quantity } \\
(\text { lb })\end{array}$ & $\begin{array}{c}\text { Percentage of } \\
\text { total }\end{array}$ \\
\hline Uranium and uranium alloys & $4,072,910$ & 47.8 \\
$\begin{array}{l}\text { Steel, aluminum, stainless steel, copper, brass, and } \\
\text { titanium }\end{array}$ & $2,872,521$ & 33.7 \\
$\begin{array}{l}\text { Wood, cardboard, foam, steel, paper, plastic, } \\
\text { fiberglass, glass, and computer disks }\end{array}$ & 863,185 & 10.1 \\
$\begin{array}{l}\text { Beryllium, beryllium oxide, magnesium, and } \\
\text { carbon }\end{array}$ & 316,794 & 3.7 \\
Machine dust & & \\
Thorium & 193,341 & 2.3 \\
Water & 105,951 & 1.2 \\
Nonspecified metals & 65,034 & 0.8 \\
Acid & 33,508 & 0.37 \\
Other & 1863 & 0.02 \\
$\quad$ Total & 1174 & 0.01 \\
\hline
\end{tabular}

${ }^{a}$ Martin Marietta Energy Systems, Inc. 1988. Revised RCRA Closure Plan for the Chestmut Ridge Security Piss, Y/TS-391. 
submitted for approval. That document was approved by TDEC on May 24, 1988, and subsequently modified by approval changes.

Closure construction began in October 1988 and was completed on June 24, 1989. Closure consisted of construction of an engineered multilayered cap as shown in Fig. 2.3. Field testing was performed as appropriate to ensure compliance with the Closure/PostClosure Plan and closure performance standards. Closure certification was documented in a Closure Certification Report issued on June 29, 1989 (Dames \& Moore 1989).

During closure construction, three exceptions were approved by TDEC and are found under "Summary of Closure Under Riles Governing Hazardous Waste Management in Tennessee" (Energy Systems 1988). A Post-Closure permit application was prepared in March 1989; however, it was never submitted to TDEC due to a controversy over regulator compliance status/compliance issues. This plan is currently under revision and will be submitted in the fall of 1993.

Groundwater quality monitoring at the waste management sites along Chestnut Ridge has been in progress since the early 1980s. Between 1986 and 1988, groundwater monitoring under RCRA was initiated at three Chestnut Ridge sites, including the CRSP. Monitoring at these sites was conducted in accordance with RCRA regulations for interim status hazardous waste treatment, storage, and disposal facilities.

Since the initial groundwater monitoring, the assessment program at the CRSP has been modified in response to the analytical results. Each modification was proposed in the annual Groundwater Quality Assessment Report and implemented during the next year of the program. Examples of modifications include the installation of additional monitoring wells and the refinement of the list of assessment parameters. Monitoring well installation subsequent to the installations for interim status compliance has been for assessment monitoring to determine the extent of groundwater contamination.

\section{RELEASES}

Available information on the CRSP does not indicate that catastrophic releases or spills have occurred at the site. Rather, gradual infiltration of contaminants through the soil and residuum to groundwater has occurred. In January 1986, interim status detection monitoring was initiated at the CRSP as required under Part 1200-1-11-.05(6)(c) of the Tennessee Department of Health and the Environment (TDHE) regulations. (Note: The TDHE is the former name of the TDEC.) Background groundwater quality in each monitoring well at the site was established through quarterly monitoring during 1986 and semiannual monitoring for indicator parameters beginning in 1987. As required under Part 1200-1-11-.05(6)(d)2, analytical results from the first semiannual monitoring event were statistically compared to their corresponding background values.

The results of the statistical comparisons suggested that a contaminant release may have occurred at the site, as indicated by a significant increase in the level of some indicator parameters over their respective background values (Mercier and Kimbrough 1988). Followup sampling to confirm the statistical increase was not performed, however, because data 


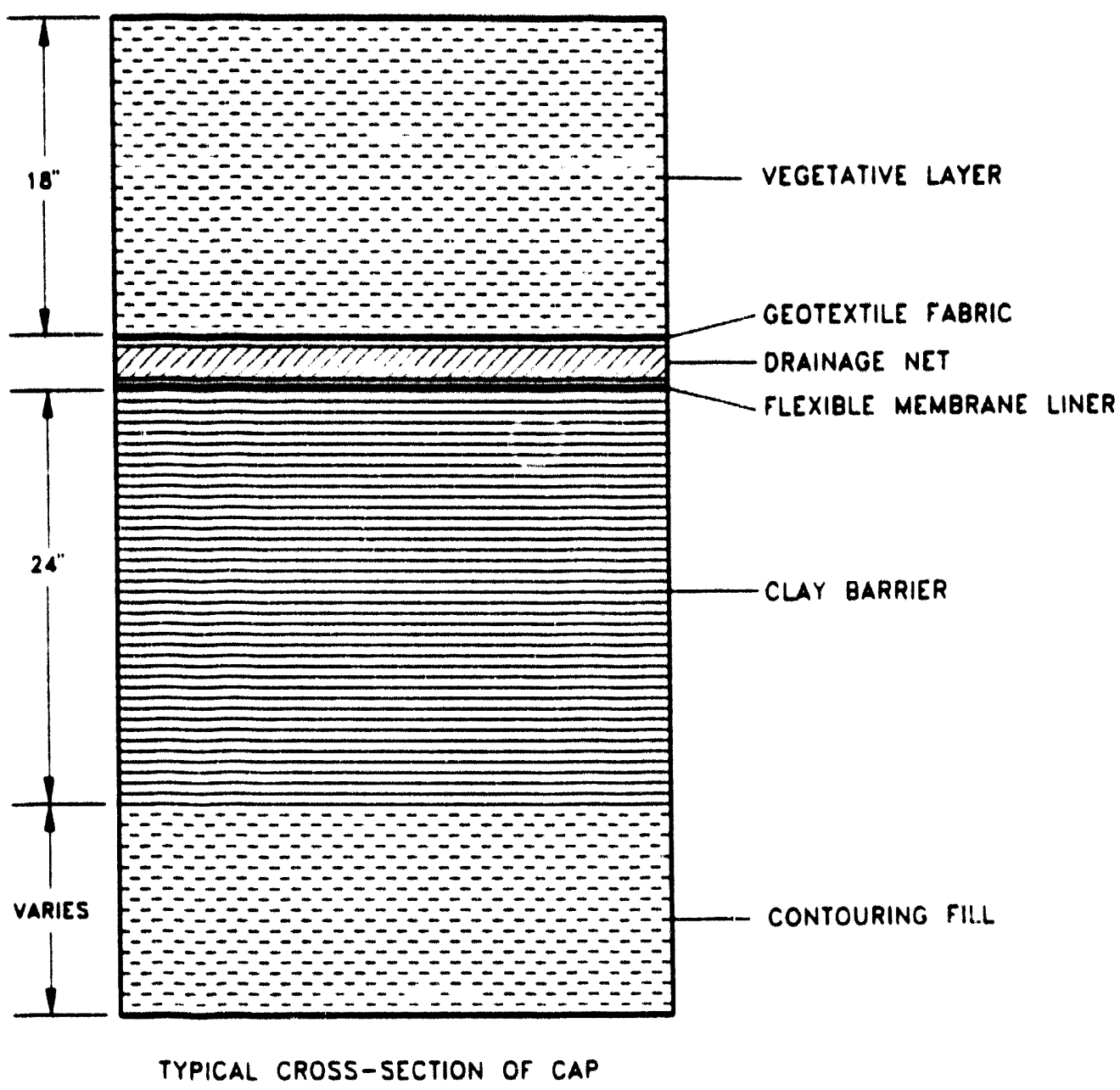

GEOTEXTILE FABRIC: MIRAFI I 40 N OR EOUAL

ORAINAGE NET: NATIONAL SEAL PN 3000 OR EOUAL

MEMBRANE LINER: 30 MIL PVC LINER

Modified From Energy Systems 19880 
obtained during a concurrent DOE monitoring program (charactcrization monitoring) indicated that the site had released contaminants to the groundwater system. Continued monitoring since 1986 has shown that the characteristics of groundwater contamination at the CRSP have not changed significantly.

The primary contaminants in groundwater at the CRSP are VOCs. The most prevalent VOCs are 1,1,1-trichloroethane; tetrachloroethene; 1,1,-dichloroethane; and 1,1-dichloroethene. In addition, metals and radionuclides have also been detected in groundwater samples. Concentration of these parameters have not typically exceeded their respective MCLs. Continued monitoring at the CRSP since 1986 has shown that the characteristics of groundwater quality have not changed significantly. Section 3.6 provides details on the hydrologic system at the CRSP and on groundwater chemistry and quality. 


\section{CHARACTERIZATION OF ENVIRONMENTAL SETTING AND CONCEPTUAL SITE MODEL}

\subsection{GEOGRAPHY}

The ORR includes $-58,000$ acres of federally owned land 20 miles west of Knoxville, Tennessee, bounded on the north and east by the city of Oak Ridge, Tennessee, and on the south and west by the Clinch River. The reservation is near the western margin of the Valley and Ridge physiographic province, a major subdivision of the Appalachians that stretches from Pennsylvania to Alabama. In the southern Appalachians, the Valley and Ridge province is bounded by the Blue Ridge province to the southeast and the Cumberland Plateau province to the northwest (Fig. 3.1). Characteristic features of the province include parallel valleys and ridges, typically trending northeast-southwest; topography controlled by alternating weak and strong rock units that have been folded and faulted and are now exposed by erosion; a trellis drainage pattern; abundant water gaps through resistant ridges; and many ridges with accordant summit levels that suggest former erosion surfaces.

The CRSP site is located atop Chestnut Ridge $-800 \mathrm{ft}$ southeast of the Y-12 Plant area (Fig. 3.2) and is bounded to the north by Bear Creek Valley and the Y-12 Plant area and to the south by the South Patrol Road. Chestnut Ridge OU2 (Filled Coal Ash Pond) and the new Steam Plant Ash Disposal landfill facility (currently under construction) are $\sim 1 / 4$ mile south and southeast, respectively, of the CRSP. The elevation of the CRSP ranges from $\sim 1080 \mathrm{ft}$ above MSL at the eastern end of the site to $\sim 1150 \mathrm{ft}$ above MSL at the western end of the site (Geraghty \& Miller 1989b.)

\subsection{CLMMATE}

Climate in the Valley and Ridge province in the vicinity of the ORR is strongly influenced by the presence of the Great Smoky Mountains to the southeast and the Cumberland Mountains to the northwest. The mountains exert a moderating influence on the climate, which results in warm, humid summers and cool winters. Noticeable extremes in precipitation, temperature, and winds rarely occur. The Cumberland Mountains retard and weaken the force of cold winter air that commonly reaches south to these latitudes. The mountains also modify the hot summer winds that are common in the plains to the west. The Great Smoky Mountains act as an inclined plane, which lifts warm, moist air flowing northward from the Gulf of Mexico, thereby increasing the frequency of afternoon thunderstorms during summer months.

The mean annual temperature in the Oak Ridge area is $58^{\circ} \mathrm{F}$ (Webster and Bradley 1988). January is generally the coldest month; temperatures average $\sim 38^{\circ} \mathrm{F}$, but occasionally dip to $0^{\circ} \mathrm{F}$ or below. July is generally the warmest month, although average temperatures exhibit little variation between June and August. The average daily temperature in July is $77^{\circ} \mathrm{F}$, with highs occasionally exceeding $100^{\circ} \mathrm{F}$. 


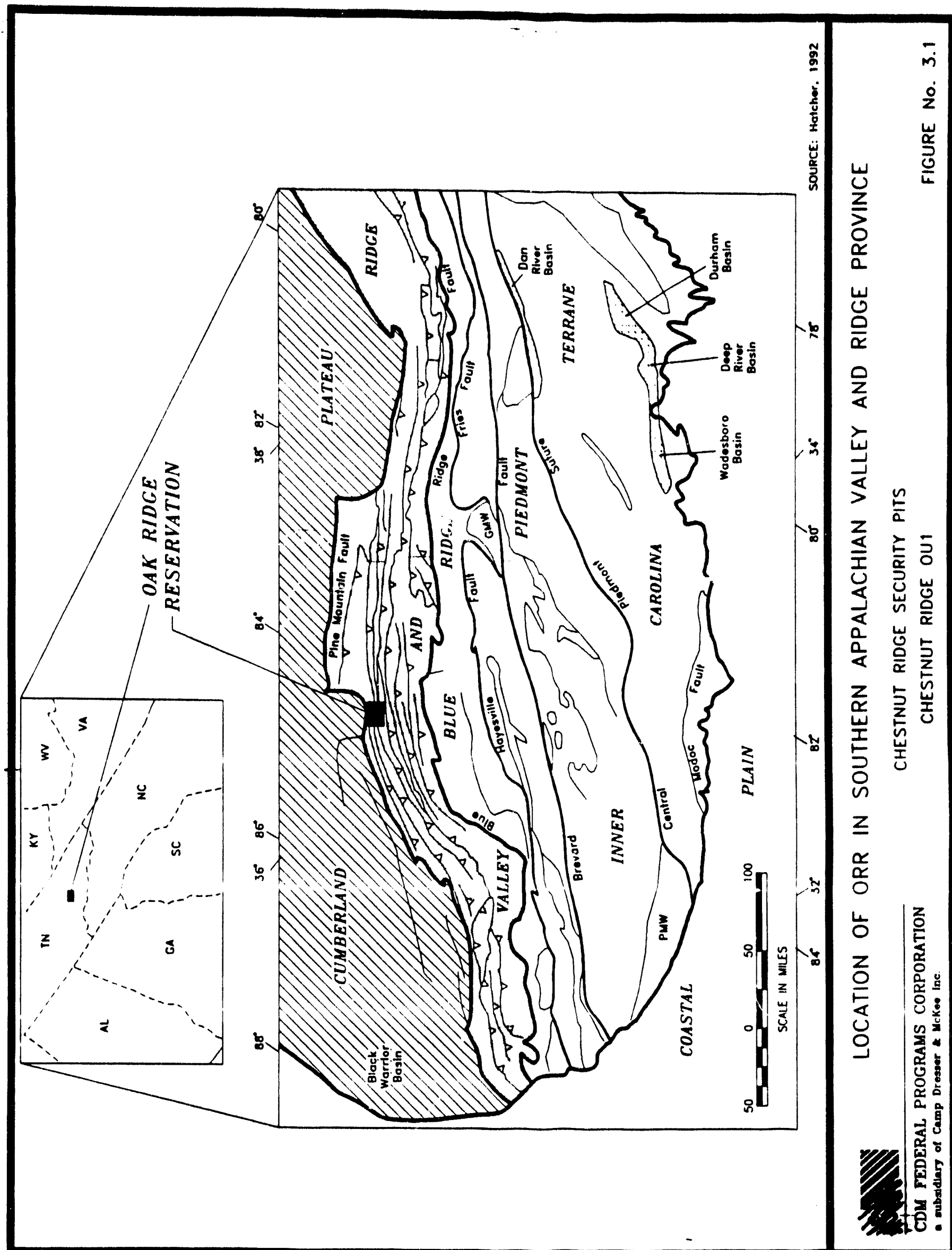




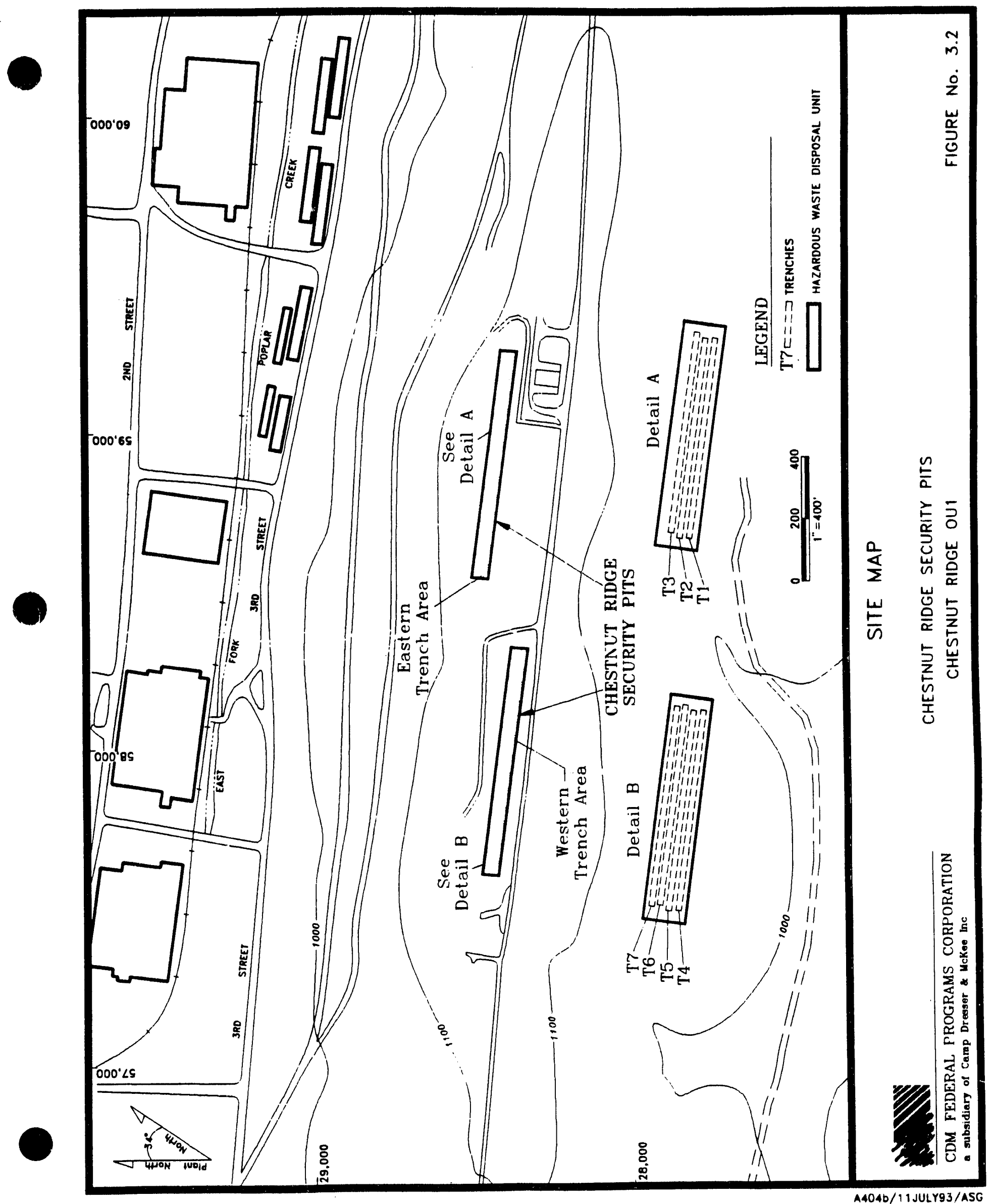


Data from the National Oceanic and Atmospheric Administration indicate that the mean annual precipitation in the Oak Ridge area is 55 in. The climate in the area is typically humid with frequent rain, and periods of 5 days or more without precipitation occur on average only four to five times per year (Boegly et al. 1984). Maximum monthly precipitation generally occurs between December and March and is associated with winter storms that are commonly of low intensity but long duration. Approximately $40 \%$ of the yearly precipitation falls during this interval. Snows occur between November and March, for the most part, and are usually light and accumulate only a trace. The mean annual snowfall between 1951 and 1988 was 9.8 in. (Energy Systems 1989). A second precipitation maximum occurs in July, when short, heavy rainfalls associated with thunderstorms are common (Davis et al. 1984). The driest period of the year normally occurs in September and October when slow-moving highpressure cells suppress rain and provide clear and dry weather.

Winds in the Oak Ridge area are controlled to some extent by the valley and ridge topography. The prevailing winds are either up-valley (northeasterly) or down-valley (southwesterly). Daytime winds generally blow up-valley, while nighttime winds usually blow down-valley (Davis et al. 1984). Figure 3.3 is a wind rose that shows the relative frequency (by percentage) of occurrence of winds by compass orientation and wind speed. High-velocity winds and tornadoes are rare. Wind speeds are $<7.4 \mathrm{mph} 75 \%$ of the time, and wind speeds exceeding $18.5 \mathrm{mph}$ are rare.

\subsection{DEMOGRAPHY}

The CRSP site is entirely within the ORR on federally owned land. The site is currently inactive; it was closed under RCRA as an interim status hazardous waste landfill in 1988. Few Energy Systems employees use or visit the CRSP, and the site is in a controlled access area that is patrolled regularly by security personnel. Energy Systems personnel also visit the site several times each year to obtain samples for the ongoing groundwater protection program monitoring.

As of April 1993, the Y-12 Plant employs 6200 regular employees. Within $1 / 2$ mile of the OU1 boundaries, there are no residents. The South Patrol Road, a paved two-lane road that runs along the crest of Chestnut Ridge adjacent to the main Y-12 Plant area, borders the site. Access to this road is controlled. Several businesses are located along Bethel Valley Road, $\sim 1-1 / 4$ miles southwest of the site and 1-1/2 miles southeast of the site at the Scarboro facility. Clark Recreational Park, which has a boat ramp with access to Melton Hill Lake, is $\sim 1-1 / 2$ miles south-southwest of OU1. Melton Hill Lake is open to recreational uses, including fishing, boating, and hunting, as sanctioned by the state of Tennessee.

There are no residents within 1 mile of OU1 to the east, south, and west. The closest residents are $-3 / 4$ mile north of OU1 in a residential neighborhood north of the ORR boundary. The closest major population center is Oak Ridge, $\sim 3 / 4$ to 1 mile north-northeast of OU1. The 1990 population of Oak Ridge was 27,310; the 1990 population of Anderson County was 68,250 . Knoxville is the largest local population center, with a 1990 population of 165,121 ; the population of Knox County was 355,749 . 


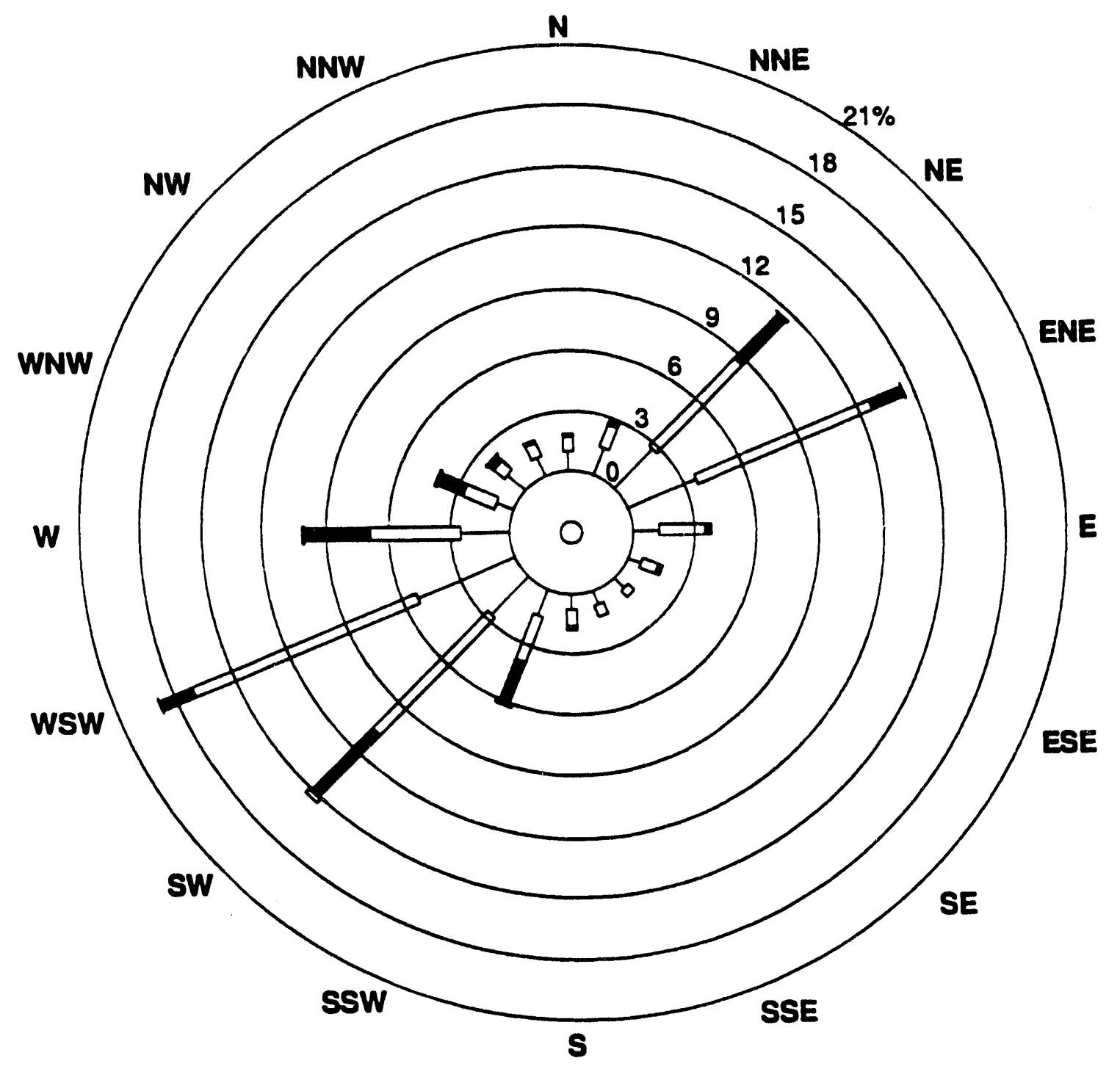

$m / s$

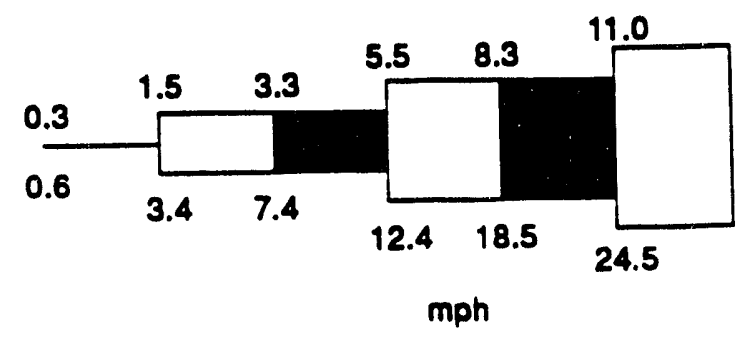

SOURCE: ORNL/ER/SUB-87/99053/5/VI WAG 6 RFI ROPOH, SOPI. 1991 


\subsection{GEOLOGY AND SOILS}

The Valley and Ridge province of Tennessee, in which the ORR is located, is a belt of southeast-dipping thrust faults and accompanying folds. Two regionally extensive thrust faults, the Copper Creek and Whiteoak Mountain, are exposed across the ORR along with folds and small-scale subsidiary structures (Fig. 3.4). The stratigraphic section exposed on the ORR includes rocks that range in age from Early Cambrian to Early Mississippian. The stratigraphic section exposed in the vicinity of OU1 has been abbreviated by faulting and includes beds ranging in age from Early Cambrian to Late Ordovician (Fig. 3.5). The units comprise a complex assemblage of lithologies, including shale, sandstone, siltstone, dolostone, and limestone; total thickness is -2.0 to $2.5 \mathrm{~km}$ (Hatcher et al. 1992).

OU1 is located atop Chestnut Ridge within the Whiteoak Mountain thrust sheet. The $\mathrm{OU}$ is underlain entirely by the Late Cambrian-Early Ordovician Knox Group, a sequence of dolostone with interbedded limestones that ranges from $\sim 2000$ to $3000 \mathrm{ft}$ (700 to $1000 \mathrm{~m}$ ) in thickness in East Tennessee. Safford (1869) named the Knox Group for exposures in Knoxville, and a succession of subsequent workers variously described and subdivided the group (e.g., Ulrich 1911; Oder 1934; Rodgers 1953; Bridge 1956; Harris 1969; Milici 1973). The Knox Group is found throughout the Valley and Ridge province of the Southern Appalachians; stratigraphic and petrographic studies suggest that the group was deposited in peritidal environments on a broad continental shelf setting (Churnet, Misra, and Walker 1982). The mechanism for widespread dolomitization is not clearly understood (Hatcher et al. 1992).

The Knox Group is a prominent stratigraphic sequence on the ORR and is one of the principal ridge-forming units; it underlies Copper Ridge, Chestnut Ridge, Blackoak Ridge, and McKinney Ridge. The thickness of the Knox Group on the ORR is believed to be $-2360 \mathrm{ft}$ $(720 \mathrm{~m})$, based on a nearly complete exposure near the Bull Run Steam Plant, just northeast of the ORR (Hatcher et al. 1992). The Knox Group is divisible into five formations across the ORR (and throughout much of East Tennessee). The formations are, in ascending stratigraphic order, the Copper Ridge Dolomite, the Chepultepec Dolomite, the Longview Dolomite, the Kingsport Formation, and the Mascot Dolomite.

Chestnut Ridge OU1 is underlain by the Copper Ridge Dolomite. The Copper Ridge is a massively bedded cherty dolomite, with beds ranging from 65 to $230 \mathrm{ft}$ (20 to $70 \mathrm{~m}$ ) in thickness. The lower two-thirds of the Copper Ridge is medium to coarsely crystalline, thickbedded, dark brownish-gray saccharoidal dolomite (Hatcher et al. 1992). Toward the top of the formation, medium to light gray, fine-grained, medium- to thick-bedded dolomite, typical of the entire Knox Group, is more common. Nodular chert, often oolitic and bedded, is a common feature of the Copper Ridge Dolomite, especially in the upper portions of the formation. Quartz sandstone beds also occur in the formation, particularly in the upper part.

Haase et al. (1987) briefly summarize the geology of Chestnut Ridge OU1, based upon corehole description; no bedrock is exposed at the site, and exposures of the Copper Ridge Dolomite are rare along Chestnut Ridge. Beds in the subsurface strike northeast-southwest and dip 40-50 50 southeast. Data from outcrops of the Copper Ridge east of the site are consistent with these corehole observations (Hatcher et al. 1992). 


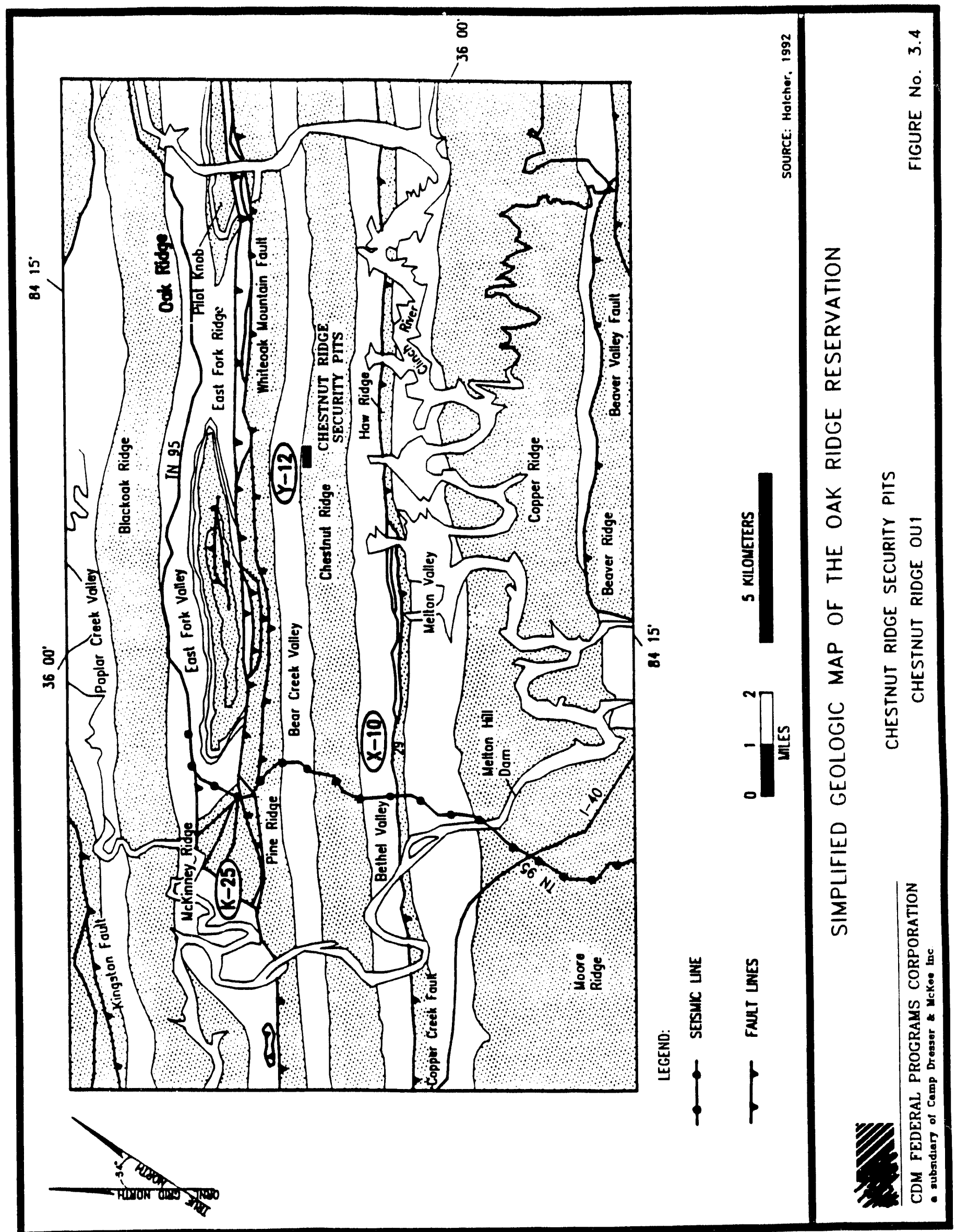




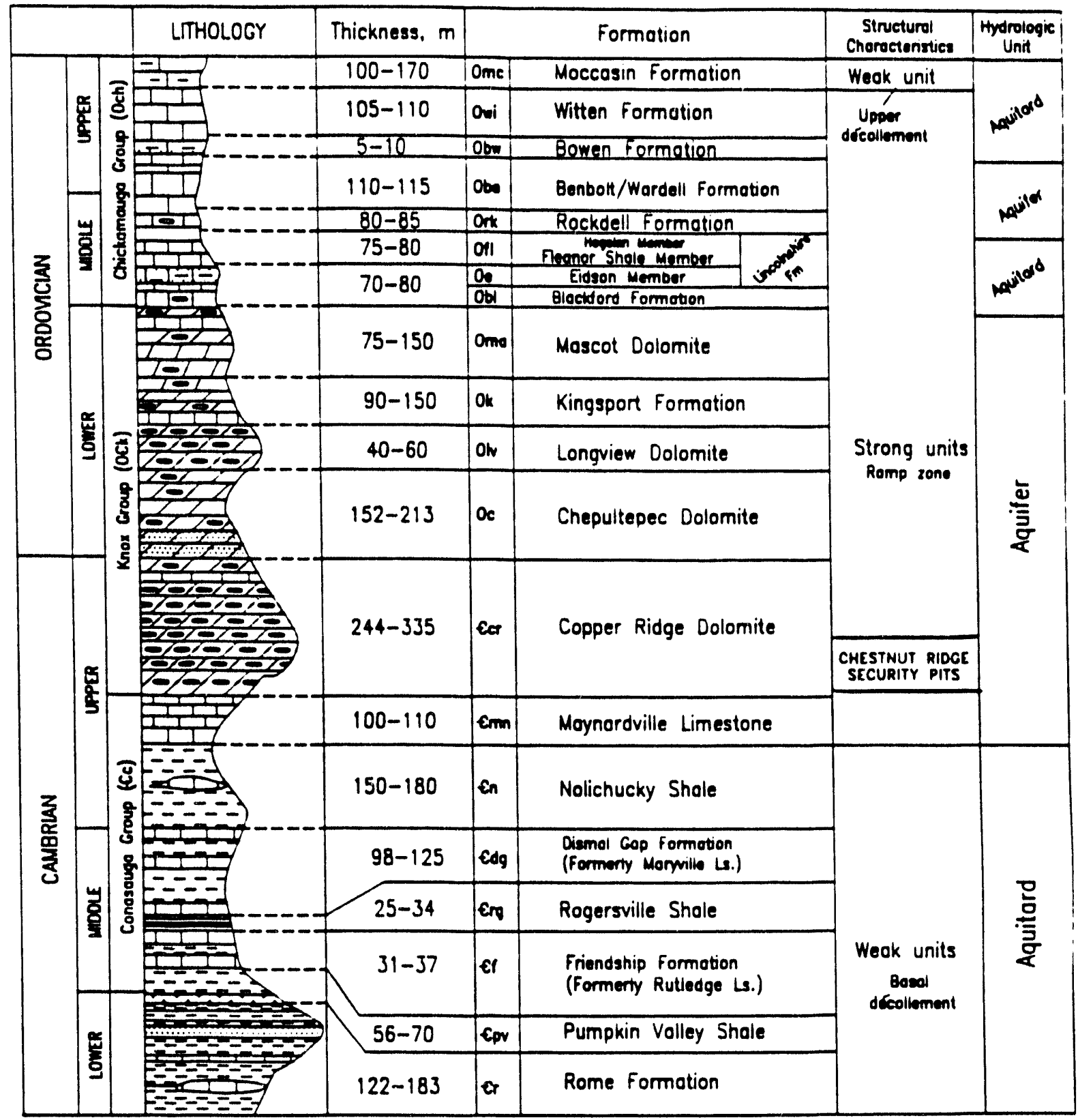


Fractures are well developed in all stratigraphic units on the ORR and are the most pervasive mesoscopic structure (Hatcher et al. 1992). Both systematic and nonsystematic fractures that formed at various times during the tectonic history of the Southern Appalachians are present. The fractures form a network of discontinuities and intersections that provide pathways for groundwater flow. Although there is some scatter in the orientation of the fractures, most of them tend to develop systematic orientations over a particular area, allowing patterns to be interpreted (Solomon et al. 1992).

Hatcher et al. (1992) studied the fracture system developed in bedrock across the ORR. Measurements of fractures in the Knox Group in the Whiteoak Mountain thrust sheet indicated the presence of two dominant fracture sets, one striking $N 68^{\circ} \mathrm{E}$ and dipping $56^{\circ}$ $\mathrm{NW}$ and the other striking $\mathrm{N} 39^{\circ} \mathrm{W}$ and dipping $87^{\circ} \mathrm{SW}$. A third set is also present, and previous workers have described four fracture sets (Geraghty \& Miller 1989b). Nonsystematic fractures of varying orientation are also developed.

Fracture density is highly variable and is noted to decrease with depth; reported values on the ORR range from 5 to 200 per meter (Solomon et al. 1992). Fracture lengths generally range from several centimeters up to $1 \mathrm{~m}$. Hatcher et al. (1992) discuss fracture spacing in strata on the ORR and note that dolomite has the greatest variation in fracture spacing versus bed thickness of the lithologies present; no clear trend was observed. Fracture spacing data from the Knox Group show considerable variation, with values ranging from a few inches to a nearly a foot.

Haase et al. (1987) described localized solutional widening of fractures and other karst features from the core of the Knox Group underlying OU1. Indeed, karst development is widespread in the Knox Group across the ORR (Ketelle and Huff 1984) and is responsible for features such as sinkholes, dolines, and an extensive network of subsurface cavities. Individual subsurface cavities develop independently but enlarge through solutional processes driven by groundwater and eventually coalesce into dominant flow channels somewhat analogous to a surface drainage system (Solomon et al. 1992).

The soil and residuum mantling the Knox Group in Chestnut Ridge OU1 is of variable thickness because of the irregular bedrock surface along Chestnut Ridge; reported depth to bedrock values range from 38 to $100 \mathrm{ft}$ below land surface (bls) (Geraghty \& Miller 1989b; Hatcher et al. 1992). In general, the soil or residuum is a reddish-brown to yellow-orange plastic to very plastic clay with locally abundant chert. A rubble-rich zone with large blocks of bedrock in a matrix of the clay is commonly encountered just above the top of the bedrock (Geraghty \& Miller 1989b). Hatcher et al. (1992) point out that the Knox Group soils are typically either Paleudults or Hapludults, both of which are within the Ultisol order. Ultisols have a clay-erriched subsoil but are mostly highly weathered and have $<35 \%$ base saturation at a depth of 1.8 to $2.0 \mathrm{~m}$.

A number of investigators have studied the permeability of the soil and residuum underlying the Knox Group along Chestnut Ridge (Mishu 1982; Ketelle and Huff 1984; Woodward-Clyde 1984). The permeability has been evaluated both in the field and in the laboratory, and results indicate widely variable values. For example, falling head permeability tests in the field resulted in values ranging from $7.05 \times 10^{-10}$ to $6.35 \times 10^{-8} \mathrm{ft} /$ day at varying depths (Mishu 1982; Woodward-Clyde 1984). Laboratory values range from $2.11 \times 10^{-11}$ to 
$1.41 \times 10^{-9} \mathrm{ft} /$ day at one site, with permeability decreasing with depth (Woodward-Clyde 1984).

Energy Systems personnel conducted a soil gas survey at OU1 in October 1991 (Wilson 1991). The survey included measurements of soil gas for VOCs at 45 locations in and around the trenches. The VOC concentrations were determined by photoionization and flame ionization measurements in each hole and by gas chromatographic head space analysis on samples collected from the bottom of each hole. Maximum photoionization and flame ionization measurements were 4.8 and $5.3 \mathrm{ppm}$, respectively; maximum depth was 33 in. below the surface.

Gas chromatographic analysis on soil samples used retention time for identification and tentatively identified the presence of acetone; trichloroethylene; 1,1,1-trichloroethane; and tetrachloroethylene. The analysis also identified benzene at two locations, but the identification was deemed "suspect." Concentrations were not provided from the gas chromatographic analyses, but samples were ranked "low," "medium," or "high"; criteria used to rank the samples were not provided (Wilson 1991). VOCs were not detected in $\sim 44 \%$ of the samples, and another $35 \%$ of the samples had a "low" ranking.

\subsection{SURFACE WATER AND SEDIMENTS}

Chestnut Ridge OU1 is located atop Chestnut Ridge, which forms a topographic divide between the EFPC watershed to the northwest and the watersheds of McCoy Branch and several numbered tributaries to the southeast (Geraghty \& Miller 1989b). OU1 is covered with grass, and there is no surface water; however, surface runoff from the site may potentially intercept either EFPC or the watersheds to the southeast. Detailed information on the characteristics of these watersheds and the surface water system on the ORR can be found in numerous documents (e.g., Geraghty \& Miller 1989b; Solomon et al. 1992).

Numerous springs and seeps along Chestnut Ridge feed the various watersheds described above. The karst hydrologic system underlying OU1 is connected with at least some of the springs and seeps. Previous dye tracer tests at OU1 have shown some hydrologic connection between groundwater and the springs and seeps, but the results have not been entirely conclusive (Geraghty \& Miller 1990b; SAIC 1992).

\subsection{GROUNDWATER}

The characteristics and movement of groundwater on the ORR are a function of the varying hydrologic properties of the underlying geologic units. Two broad groupings can be distinguished: the Knox aquifer, consisting of the Knox Group and the Maynardville Limestone of the Conasauga Group, and the ORR aquitards, consistirg of the remaining geologic units on the ORR (Solomon et al. 1992; refer to Fig. 3.5 for the stratigraphic succession on the ORR). Groundwater flow in the Knox aquifer is dominated by conduit flow through solution features that resulted from karst processes. Flow in the ORR aquitards, on the other hand, is dominated by flow through fractures. Figure 3.6 shows the distribution of the Knox aquifer and the aquitards across the ORR. 


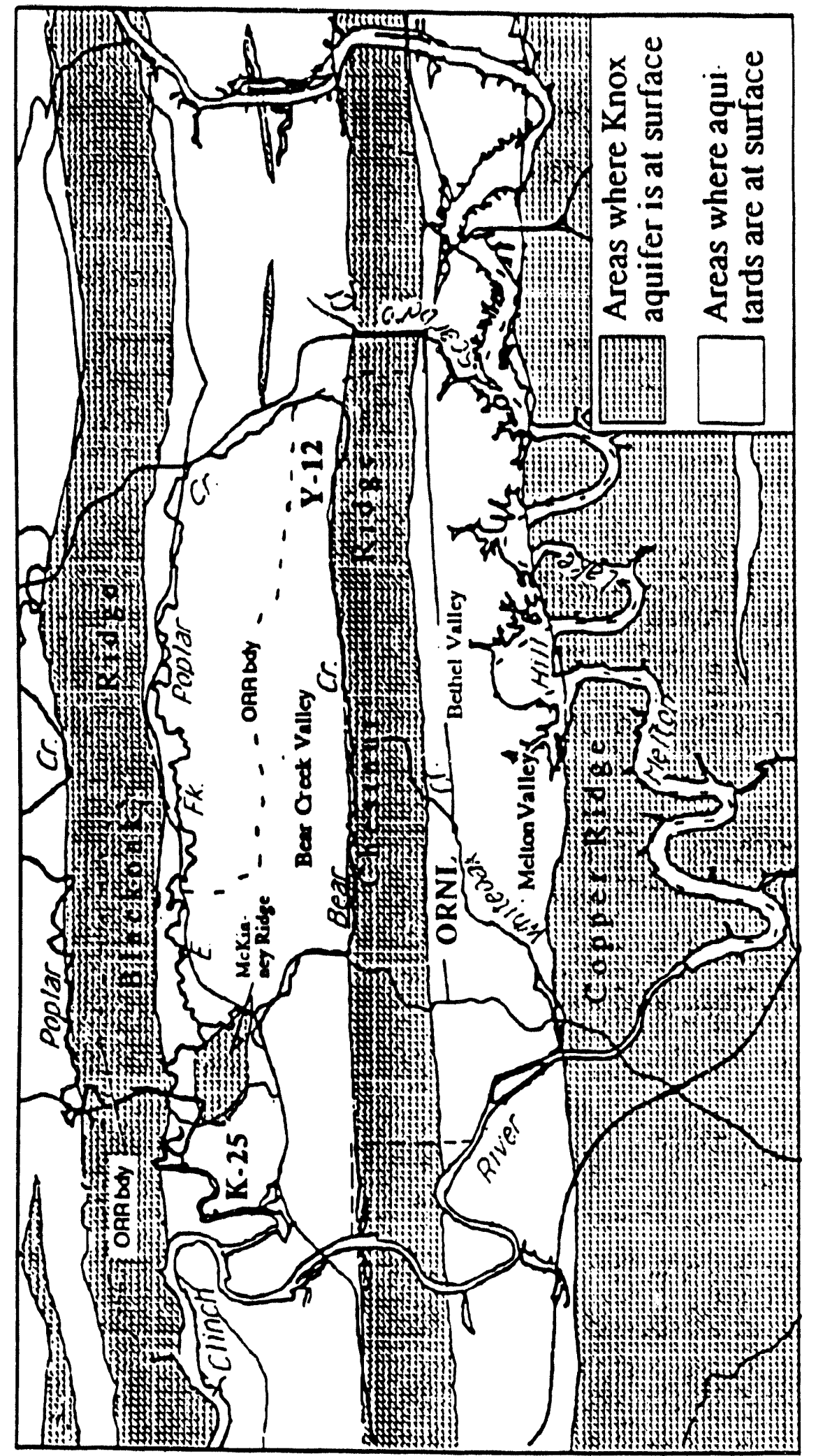


The flow system in both the Knox aquifer and ORR aquitards has been divided into four zones: storm flow, vadose, groundwater, and aquiclude (Solomon et al. 1992). The storm flow zone is a relatively thin interval at the surface. The zone includes precipitation-generated flow that constitutes nearly all of the water moving through the subsurface. It is a pathway for the transportation of contaminants to the subsurface. The vadose zone is an unsaturated zone above the water table. The groundwater zone is continuously saturated and is the region in which the remainder of subsurface water (exclusive of the storm now zone) occurs. The aquiclude is a zone in which any water movement occurs on a geologic time scale.

The Copper Ridge Dolomite (described in Sect. 3.4), which is part of the Knox aquifer, underlies Chestnut Ridge OU1. The Knox aquifer is the cnly true aquifer on the ORR; it is the source of sustained natural flow in many perennial streams (Solomon et al. 1992). The aquifer can supply large quantities of water to wells, and flow volumes are significantly larger than in the ORR aquitards. Flow paths are also deeper than in the aquitards.

Solomon et al. (1992) point out that flow in the Knox aquifer is dominated by a few cavity systems. Two wells in the Knox aquifer have produced large quantities of water ( $>60 \mathrm{~L} / \mathrm{s}$ ), but most wells yield relatively small quantities of water $(<1 \mathrm{~L} / \mathrm{min}$ ). King and Haase (1988) investigated hydraulic conductivity in the Knox aquifer along Chestnut Ridge. Their study employed straddle packer tests in 21 intervals selected from three core holes. All intervals were in the Copper Ridge Dolomite, and depths ranged from 120 to $615 \mathrm{ft}$ below surface. Hydraulic conductivity values from the King and Haase study ranged from $2.59 \times 10^{-11}$ to $3.98 \times 10^{-7} \mathrm{ft} /$ day.

Transmissivity values for the Knox aquifer suggest that the bulk permeability of the Knox is ten times greater than the ORR aquitards; however, the Knox is very permeable locally due to the presence of cavities and conduits and is therefore capable of transmitting large quantities of water. The potential groundwater flow path length in the Knox aquifer is much greater than in the ORR aquitards, with path lengths on the order of kilometers versus tens of, or a few hundred, meters in the aquitards (Solomon et al. 1992).

Groundwater investigations conducted by Energy Systems in the 1980 s and 1990 s included the installation of 22 monitoring wells in and around the perimeter of OU1; three of these wells have been plugged and abandoned (1080, GW-607, and GW-608A). The existing 19 monitoring wells at the site all monitor bedrock and include both screened and open-hole construction. Groundwater has not been found in the overburden above bedrock at OU1. Numerous fracture zones and cavities were encountered during the installation of many of the monitoring wells (Jones, Harrington, and Field 1992). Total depths of the wells range from 117 to $420 \mathrm{ft}$ bls, providing extensive vertical coverage of the aquifer. Table 3.1 summarizes some pertinent information about the monitoring wells, including elevations, total depths, screened or open-hole intervals, construction materials, and completion date. Figure 3.7 shows the location of OU1 monitoring wells, and Figs. 3.8 and 3.9 provide crosssectional interpretations of the site hydrogeology.

Haase et al. (1987) conducted one of the first studies of OU1. Included in the study was the installation of five monitoring wells (GW-173, $-174,-176,-177$, and -179 ), weekly waterlevel measurements, and quarterly collection of groundwater samples. Analysis of groundwater samples included parameters to evaluate both water chemistry and quality. 
Tuble 3.1. Chestnut Ridge OU1 monitoring wells

\begin{tabular}{|c|c|c|c|c|c|}
\hline Well & TOC & $\mathrm{TD}^{\mathrm{C}}$ & Screened/interval & $\begin{array}{l}\text { Construction } \\
\text { matcrial }\end{array}$ & $\begin{array}{l}\text { Completion } \\
\text { date }\end{array}$ \\
\hline GW-173 & 1115.00 & 165.0 & $155.0-165.0$ & $\mathbf{S S}^{d}$ & $8 / 15 / 85$ \\
\hline OW.174 & 1116.52 & 145.0 & $135.0-145.0$ & SS & $8 / 15 / 85$ \\
\hline GW.175 & 1084.00 & 166.7 & $150.6-i 66.4$ & SS & $6 / 22 / 88$ \\
\hline GW-176 & 1125.27 & 145.0 & $135.0-145.0$ & SS & $8 / 27 / 85$ \\
\hline OW.177 & 1157.95 & 145.0 & $133.0-143.0$ & SS & $10 / 25 / 85$ \\
\hline GW-178 & 1143.49 & 133.0 & $122.0-132.0$ & SS & $8 / 20 / 87$ \\
\hline GW.179 & 1128.00 & 117.0 & $107.0-117.0$ & SS & $12 / 3 / 85$ \\
\hline GW-180 & 1103.97 & 144.0 & $132.2-143.0$ & SS & $8 / 11 / 87$ \\
\hline GW-181 & 1093.03 & 168.0 & $\begin{array}{l}\text { Casing to } 155.0 \text {; } \\
\text { open to } 168.0\end{array}$ & Steel & $7 / 13 / 88$ \\
\hline$G W-182$ & 1147.35 & 402.1 & $\begin{array}{l}\text { Casing to 126.6; } \\
\text { open to } 402.1\end{array}$ & Steel & $5 / 27 / 88$ \\
\hline GW.322 & 1134.25 & 193.0 & $\begin{array}{l}\text { Casing to } 128.0 \\
\text { open to } 193.0\end{array}$ & Stcel & $9 / 2 / 87$ \\
\hline GW-511 & 1093.21 & 153.7 & $143.3-153.3$ & SS & $4 / 19 / 88$ \\
\hline GW-608 & 1073.95 & 220.0 & $\begin{array}{l}\text { Casing to } 148.0 \text {; } \\
\text { open to } 220.0\end{array}$ & Steel & $10 / 5 / 89$ \\
\hline GW.609 & 1112.11 & $26 \% .0$ & $258.7-269.0$ & SS & $10 / 18 / 90$ \\
\hline GW-610 & 1059.44 & 117.4 & $107.1-117.4$ & SS & $1 / 2 / 90$ \\
\hline GW.611 & 1048.38 & 121.6 & $107.0-117.0$ & SS & $1 / 19 / 90$ \\
\hline GW.612 & 1131.03 & 254.0 & $\begin{array}{l}\text { Casing to } 230.6 \\
\text { open to } 254.0\end{array}$ & Stacl & $11 / 1 / 89$ \\
\hline GW-742 & 1100.97 & 420.0 & $\begin{array}{l}\text { Casing to } 350.0 \text {; } \\
\text { open to } 420.0\end{array}$ & Stecl & $12 / 5 / 91$ \\
\hline GW-743 & 1100.36 & 161.1 & $150.1-161.1$ & SS & $12 / 13 / 91$ \\
\hline
\end{tabular}

Notes:

1. Elevations of TOC are in feet above sea level.

2. TD is in feet below TOC.

3. Screened interval is in feet below TOC.

Top of casing.

Total depth.

${ }^{d}$ Stainless steel. 


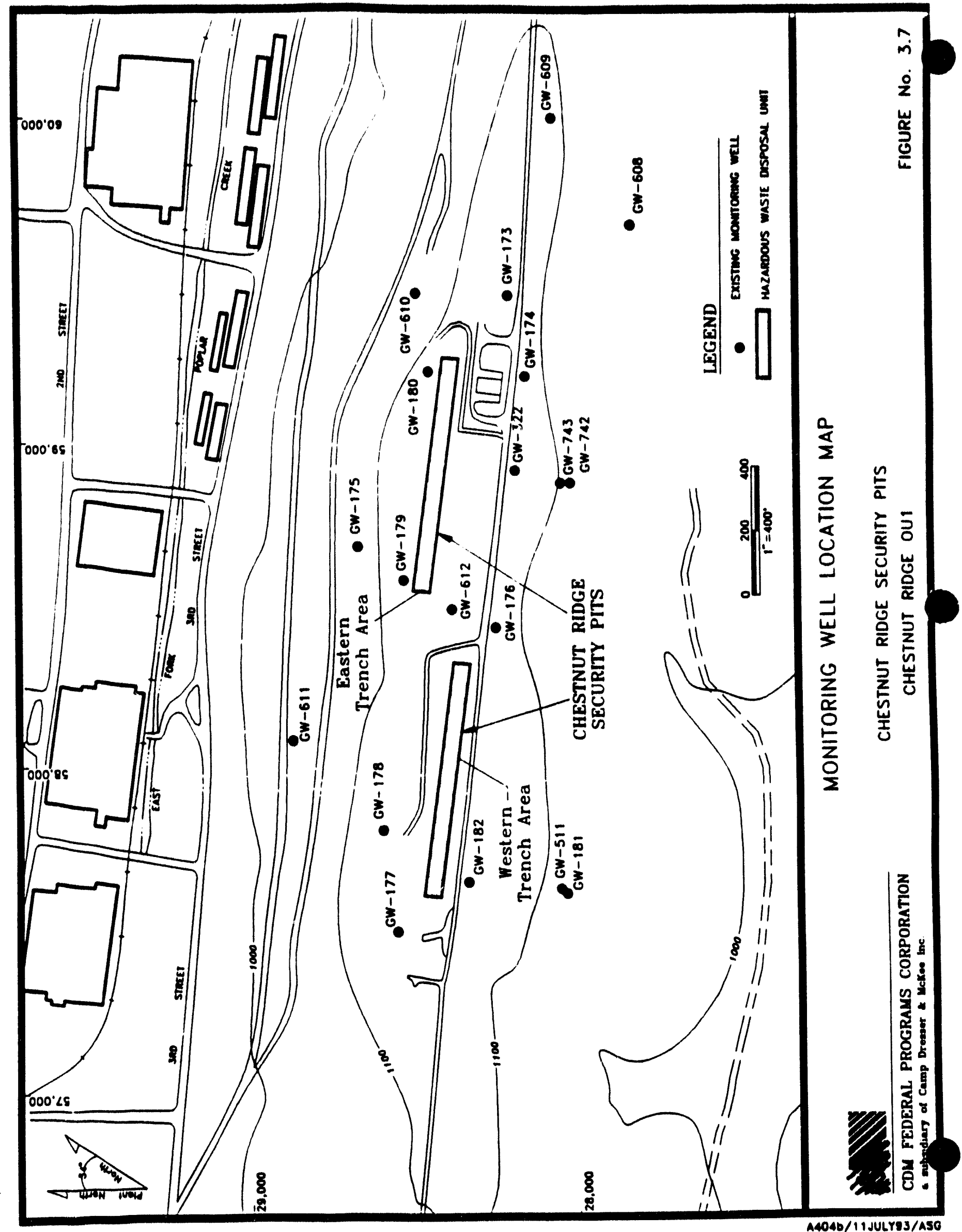




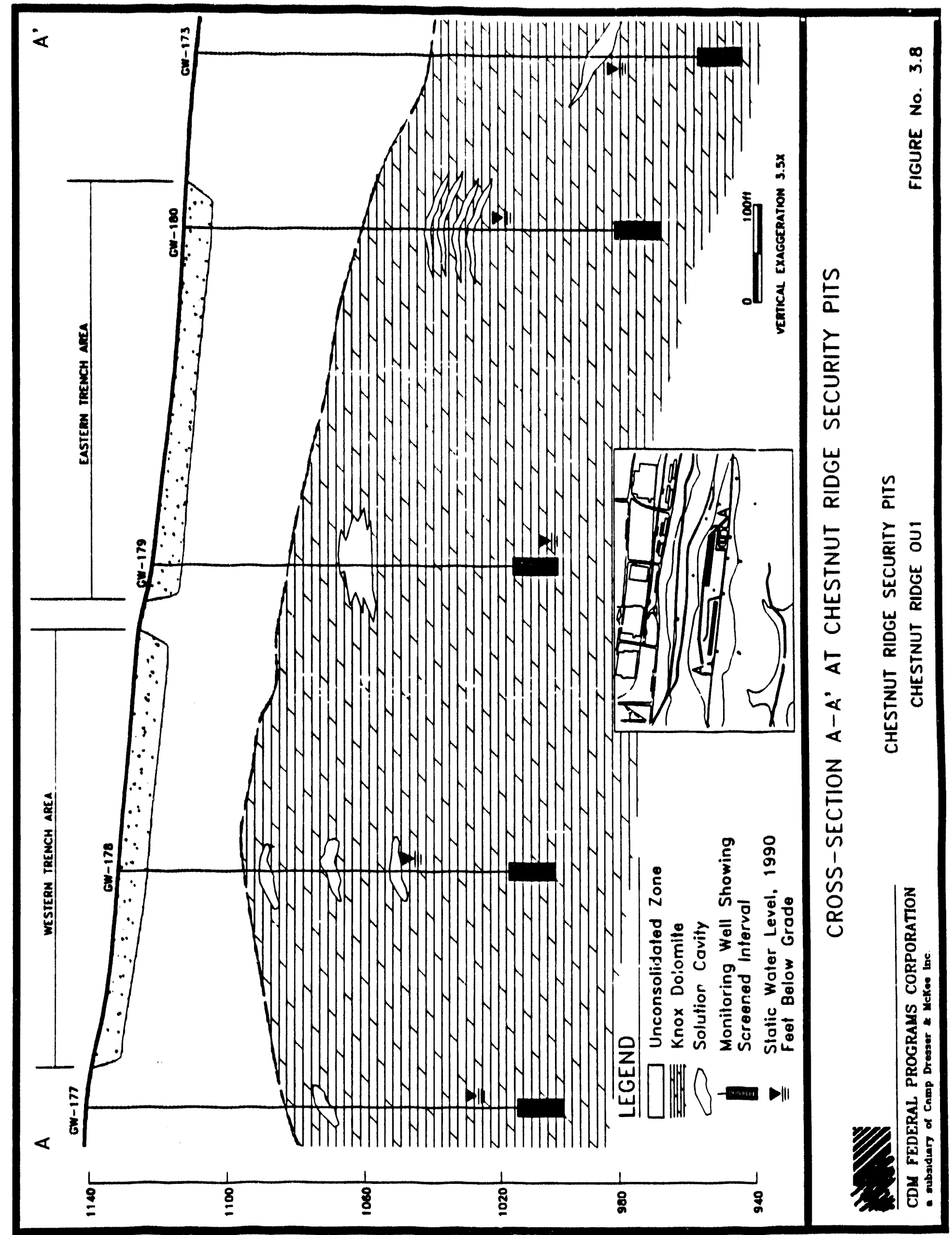




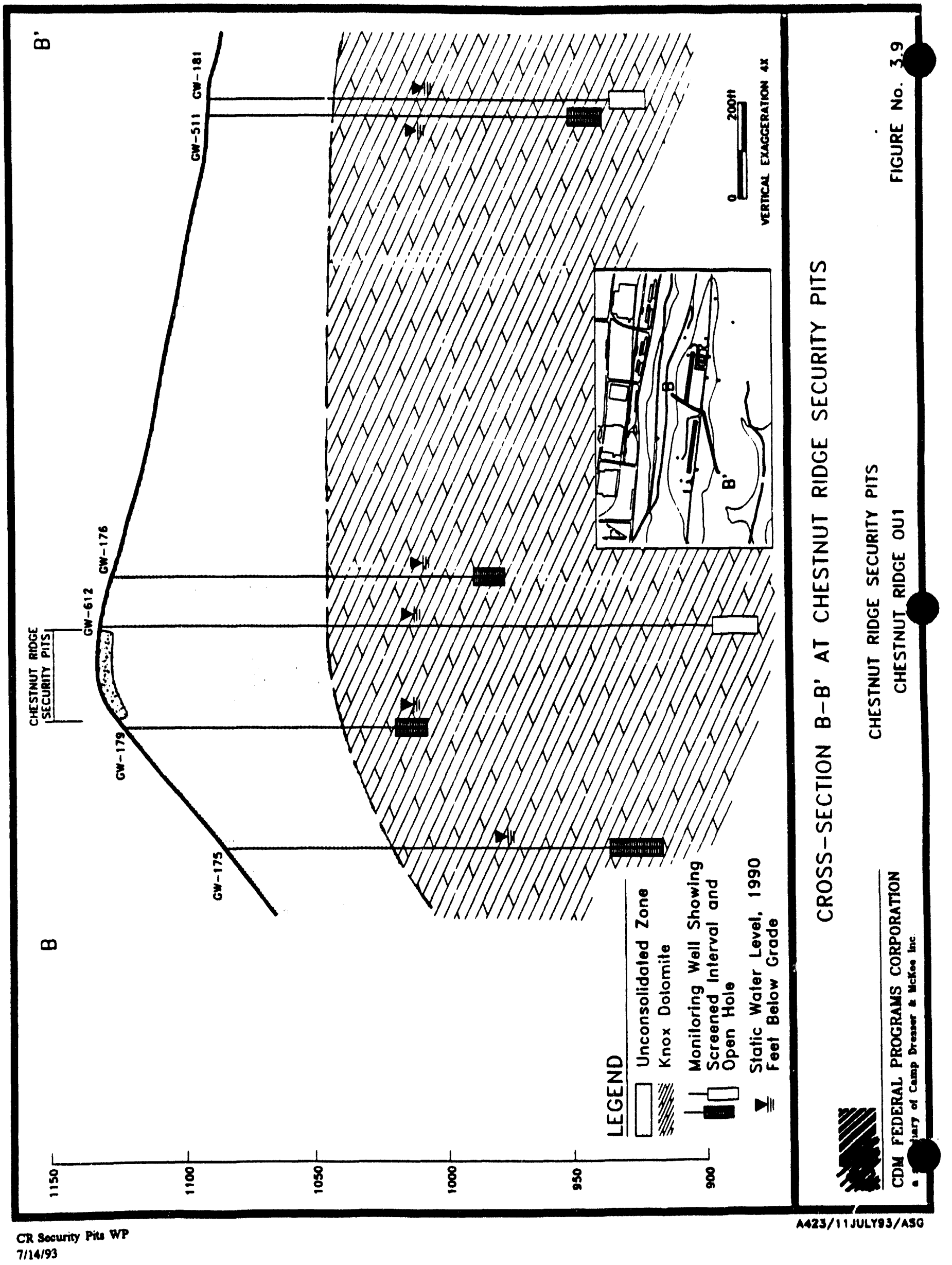


The Haase et al. (1987) study was the first systematic one of the hydrology of OU1. Their data indicated that hydrostatic head decreased in elevation to the northeast (parallel to Chestnut Ridge) with the highest elevation in GW-177 at the west end of the site and the lowest elevation in GW-173 at the east end of the site. Subsequent water-level monitoring at the site generally has been consistent with the Haase et al. data (HSW Environmental Consultants 1991 and 1992; Fig. 3.8). The potentiometric surface generally reflects surface topography, and a groundwater divide underlies the vicinity of the CRSP. The potentiometric surface appears to have a steep gradient north of the CRSP, reflecting the slope of Chestnut Ridge (Fig. 3.9). The direction of the groundwater gradient across the site is likely related to the development of channels or conduits in the bedrock by karst processes, which typically follow the orientation of fractures and/or bedding planes.

Two dye tracer studies have been performed at Chestnut Ridge OU1 to clarify the hydrologic system and groundwater gradient. The first test was during the driest part of 1990 . Before the test was started, a survey of potential discharge points was conducted. Forty monitoring points were established in both Bethel Valley and Bear Creek Valley, including streams, springs, and monitoring wells. Charcoal dye detectors were placed at each monitoring point. For three weeks before dye introduction, the points were monitored to collect background fluorescence data.

Ten kilograms of fluoriscein dye mixed with potable water was introduced into well GW-178 on July 11, 1990. Detectors at the monitoring points were sampled over a 6-month period. Dye was positively recovered from five springs, one monitoring well, and six surface water sites. Several other monitoring points were identified as having a "possible" connection. The study concluded that flow is dominantly along strike (i.e., northeast-southwest) coincident with Chestnut Ridge itself, with a potential component of flow toward the east and southeast (Geraghty \& Miller 1990b).

On the basis of results from the first study, Energy Systems recommended that a second test be conducted. The purpose of the second test was twofold. First, the study was undertaken to verify the hydraulic continuity between the source well and groundwater discharge points identified in the first test as containing dye (SAIC 1992). Second, it was undertaken to conduct a test during the wet season to identify any potential differences in flow characteristics between wet and dry portions of the year.

The second test started in February 1992 with a 4-week baseline monitoring period of background fluorescence. GW-178 again was selected for dye injection; 34 potential discharge points, including springs, streams, and wells, were monitored with charcoal detectors. Dyes included $255 \mathrm{lb}$ of Rhodamine WT and $246 \mathrm{lb}$ of Burco Fluor AR solution, and an optical brightener equivalent to Fluorescent Brightener 28. Dye injection commenced on March 13, 1992 , and monitoring was to continue for 12 weeks; the monitoring period was subsequently extended to 18 weeks because no definitive results were obtained. The test results were inconclusive. No results could be characterized on a qualitative basis as positively indicating the detection of dyes at monitoring locations (SAIC 1992). The investigators concluded that GW-178 may not be well integrated with the karst system and that the dye might not be available for transport even after several months (SAilC 1992). 
Water chemistry data from OU1 (Haase et al. 1987) show that the major cations are calcium and magnesium; the calcium-magnesium ratio was typically 0.45 to 0.55 . Major anions are carbonate-bicarbonate. Trace amounts of sulfate are present, along with a small but relatively constant silicon concentration. Specific conductance values range from 300 to 500 $\mu \mathrm{mho} / \mathrm{cm}$, and $\mathrm{pH}$ values range from 6.9 to 8.3, typical of Knox Group groundwater on the ORR.

Solomon et al. (1992) discuss chemical characteristics of the Knox aquifer and note that a calcium-magnesium-bicarbonate type of water exists to depths of nearly $984 \mathrm{ft}(300 \mathrm{~m})$ and that a transition to sodium-bicarbonate or sodium-chlorine water, observed with depth in the ORR aquitards, is not present. The difference in major ion chemistry of the Knox aquifer as compared to the aquitards may result from differences in residence times and dominant geochemical processes (Solomon et al. 1992).

Water quality data from the OU1 study of Haase et al. (1987) included analysis for metals, phenols, pesticides/herbicides, VOCs, semivolatile organic compounds (SVOCs), and radionuclides. The data showed that the primary COCs were VOCs, specifically 1,1-dichloroethene, 1,1-dichloroethane, and 1,1,1-trichloroethane. Summed concentrations of VOCs ranged from 20 to $945 \mathrm{ppb}$, with the highest concentrations in wells 1080 (now plugged and abandoned), GW-176, and GW-179. Metal concentrations showed considerable scatter and few exceedences of any water quality standards; Haase et al. attributed several of the exceedences to high turbidity generated by poor sampling techniques. Concentrations of pesticides/herbicides and SVOCs were all minimal or below detection limits. Radionuclide concentrations were widely variable and typically below any water quality standards.

Groundwater quality at OU1 has received considerable attention since the study of Haase et al. (1987) and has resulted in the installation of numerous wells and subsequent monitoring. Appendix A includes groundwater quality data from OU1 monitoring wells from 1986 (the Haase et al. data) and 1988 through 1992. Energy Systems conducted an Appendix IX sampling program in 1987, but these data were not available for inclusion in this document. The results of that sampling are summarized below.

The Appendix IX sampling program included over 100 monitoring wells at the Y-12 Plant, including seven wells at OU1 (GW-173, -174, -176, -177, -178, -180, and -322). The results of analysis from this program showed that VOCs were again the primary COCs in groundwater. VOCs most commonly detected and present at relatively high concentrations were carbon tetrachloride; 1,1-dichloroethane; 1,1-dichloroethene; trans-1,2-dichloroethene; tetrachlorethene; and 1,1,1-trichloroethane. The data showed that the dominant VOC contaminant in the western portion of the site was 1,1,1-trichloroethane, while the dominant VOC contaminant in the eastern portion of the site was tetrachloroethene (Geraghty \& Miller 1989b).

Metals (arsenic, barium, beryllium, chromium, copper, lead, mercury, uranium, and zinc) were also detected, but the data did not indicate substantial groundwater contamination. Several metals exceeded USEPA primary drinking water standards in a few samples, but the exceedences were not corroborated by historical monitoring results and were considered anomalous. Analyses for radionuclides did not show significant contamination; concentrations 
of uranium, gross alpha, and gross beta were typically below USEPA primary drinking water standards, although a few slight exceedences were observed.

Subsequent monitoring of wells at OU1 has shown that VOCs continue to be the primary COCs at the site and that concentrations of VOCs and other parameters (i.e., metals and radionuclides) remain consistent with no significant changes (Geraghty \& Miller 1989a; Geraghty \& Miller 1990a; HSW Environmental Consultants 1991; HSW Environmental Consultants 1992). The Y-12 Plant Groundwater Protection Program continues to monitor groundwater at OU1. Ten wells (GW-175, -177, -181, -511, -608, -609, -610, -611, -742, and -743) are currently included in the program's sampling sequence. Monitoring wells not currently included in the program have been dropped because their historical data show that they are clean or have been replaced by other wells that are deeper and/or farther away from the source of contaminants.

\subsection{ECOLOGY}

Chestnut Ridge OU1 consists of an upland artificial grassland (mowed fescue) surrounded by second-growth oak-hickory woodland. The ecological composition of the site is discussed in more detail in Sect. 4.2.

\subsection{RADIOLOGICAL SURVEY}

Available information indicates that uranium and uranium alloys constitute $\sim 48 \%$ of the total waste inventory at OU1, while thorium constitutes 1\% (Radian 1992). As discussed above, analytical data from groundwater sampling show that radionuclides, principally uranium, gross alpha, and gross beta, are present but generally below applicable standards. A number of exceedences of USEPA primary drinking water standards for radionuclides have been observed, but the exceedences generally are small and do not occur consistently. A reservation-wide geophysical survey was conductcd during January 1993 from an elevation of $150 \mathrm{ft}$. The survey included radiological parameters, magnetics, and electromagnetics. Results from the survey were expected in late spring 1993 but were not available for inclusion in this document.

\subsection{CONCEPTUAL SITE MODEL}

A generalized conceptual site model (CSM) for Chestnut Ridge OU1 is presented in Fig. 3.10. This model depicts potential exposure pathways and sources of contaminants. The primary sources of contaminations at the CRSP site are materials/wastes buried in the pits. These wastes are leaking into the groundwater as evidenced by the presence of VOCs in groundwater samples. Contaminated groundwater may be discharging at remote locations within the Chestnut Ridge hydrologic regime, thereby creating surface water/sediment contamination and presenting a mechanism for further off-site transport of contaminants. Because the pits are covered by a multilayered engineered cap, there is currently no surface contamination at the site. The extent of surface soil contamination in adjacent areas, potentially contaminated by surface runoff during operation of the pits, and subsurface soil 


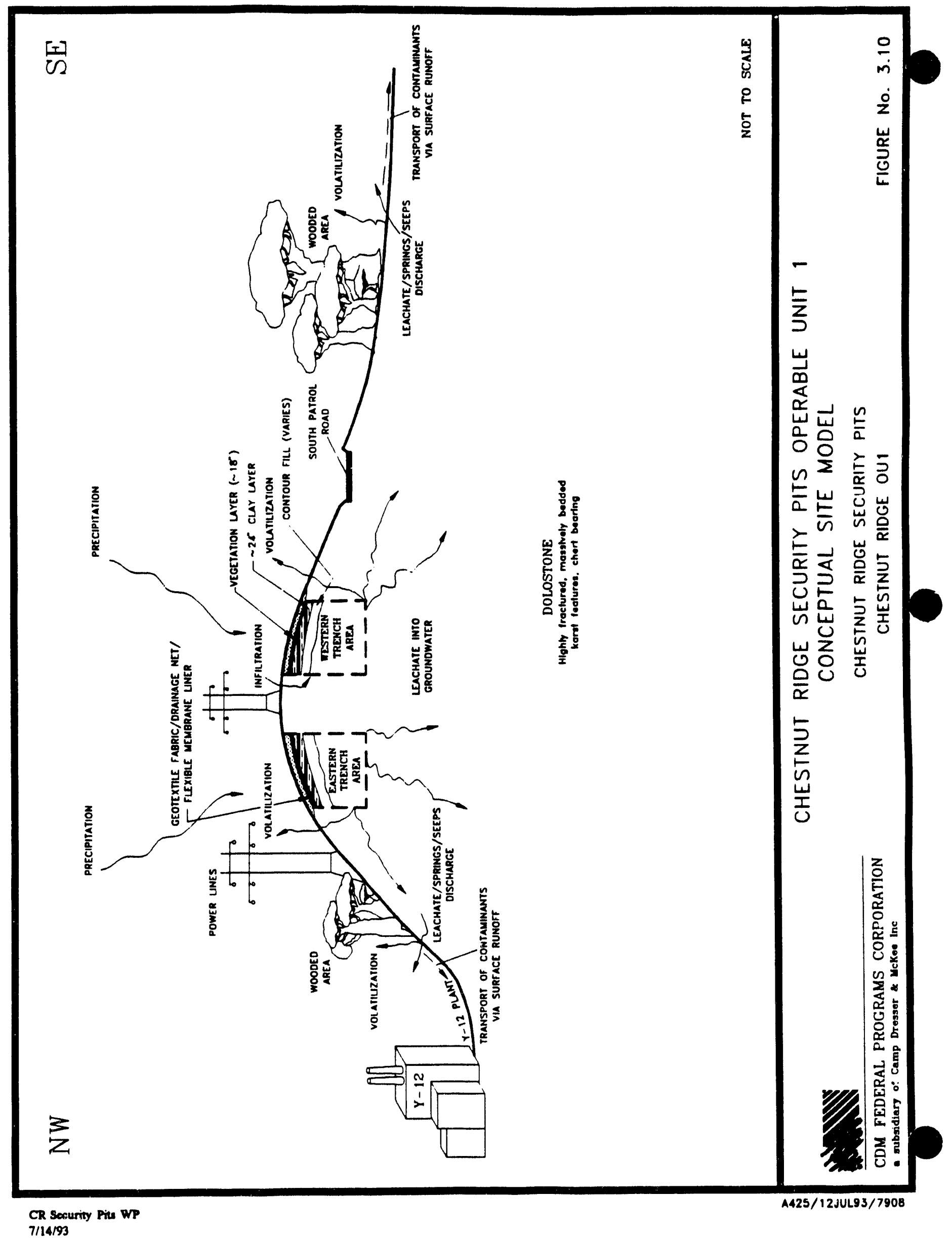


contamination beneath and surrounding the pits is unknown. Subsurface soil contamination can act as a source of groundwater contamination in the event that source control is achieved. The presence of contaminated surface soils adjacent to the site could potentially be impacting terrestrial flora and fauna in the wooded areas adjacent to the site. Because the site itself is mowed regularly, it has extremely low habitat value.

There are no surface water features directly associated with the CRSP, nor are there defined, intermittent surface drainage features or wetland areas. Some of the springs and seeps along Chestnut Ridge and in the adjacent valleys are likely connected with the karst hydrologic system underlying the CRSP.

In subsequent sections the CSM will be expanded to describe specific potential exposure media and pathways for both human and nonhuman receptors. Identification of these media and pathways forms the basis for the development of the RI sampling approach described in detail in Sect. 6.

\subsubsection{Conceptual Site Model for Exposure of Human Receptors}

The CSM flow diagram for human receptors is illustrated in Fig. 3.11 and considers five potentially contaminated media: (1) soil, (2) surface water, (3) groundwater, (4) air, and (5) biota. The primary source of contamination to these media is hazardous and nonhazardous wastes disposed of in the CRSP. Primary and secondary release mechanisms include (1) chemical releases to soil, (2) infiltration/percolation to groundwater, (3) groundwater discharge to surface water, (4) wind-generated dust, (5) volatilization from soil and water, and (6) plant and animal uptake.

\subsubsection{Soil}

The soil is a potential pathway of migration for the contaminants at Chestnut Ridge OU1 via percolation/infiltration into groundwater, volatilization of contaminants into the air, resuspensions of particles (wind-generated dust) into the air, and plant and animal uptake. This exposure medium will be evaluated in terms of human health risk using the hypothetical future on source-OU residential scenario assessment (baseline risk assessment) [i.e., a reasonable maximum exposure (RME) assessment using residential exposure parameters as discussed in Sect. 6.4]. Exposure pathways/routes that will be evaluated include ingestion of soil, inhalation of resuspended soil (dust), dermal contact with soil, inhalation of volatiles from the soil, ingestion of biota (meat, milk, and vegetables), and external exposure to radionuclides in the soil.

\subsubsection{Surface water}

Although Chestnut Ridge OU1 does not contain any surface water, contamination (to off source-OU surface water) may result from contaminated groundwater discharge to surface water. If identification of such discharge points (seeps and/or springs) is possible, the offsource surface water exposure medium will be evaluated in terms of human health risk. An RME assessment of the identified surface water contaminants (using the hypothetical industrial scenario) will be performed to identify and prioritize springs/seeps that are the primary contributors to off source-OU migration of contaminants. A hypothetical residential 


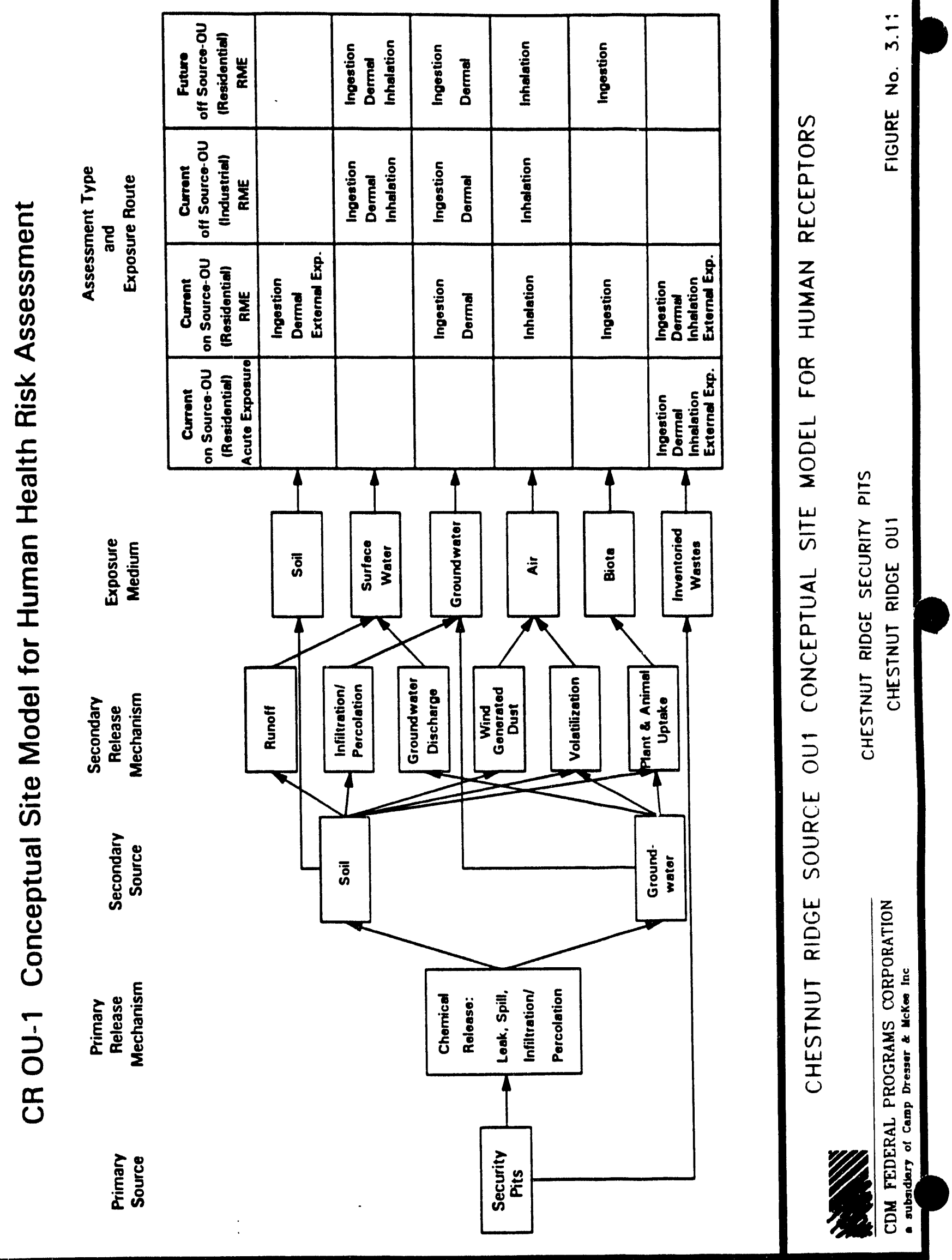


scenario RME assessment (baseline risk assessment) will be performed to support final action RODs for any off source-OU surface water attributed to CRSP groundwater discharge. Exposure pathways/routes that will be evaluated include ingestion of and dermal contact with the surface water and inhalation of volatiles in surface water.

\subsubsection{Groundwater}

The groundwater system is an on source-OU exposure medium and is also identified as a mechanism for contaminant transport (off source-OU) via groundwater movement and groundwater discharge to surface water. The on source-OU groundwater will be evaluated to support a final action ROD using the RME assessment with residential exposure parameters (baseline risk assessment). In addition, off source-OU groundwater identified as transporting CRSP contaminants will be evaluated using an industrial RME assessment to prioritize areas of significant contamination; remedial action prioritization may be influenced by this assessment. Furthermore, a residential scenario in an RME assessment will support a final action ROD for groundwater remediation. Exposure pathways/routes that will be evaluated include ingestion of and dermal contact with groundwater and inhalation of volatiles in groundwater.

\subsubsection{Air}

Contaminant release into the air may occur as a result of resuspension of dust (from soil) and volatilization of contaminants from surface water and directly from the source $O U$ (soil); some residential uses of groundwater can also result in volatilization of contaminants. Inhalation is the primary exposure route for contaminants in air.

\subsubsection{Biota}

Plants and animals may accumulate contaminants that are present in the soil and irrigation water. On source-OU groundwater (and associated off source-OU groundwater and surface water, if identified) would be the irrigation source. This exposure medium (i.e., the food chain) will be evaluated using the hypothetical residential scenarios in an RME assessment (i.e., a baseline risk assessment) for the ingestion pathway.

\subsubsection{Direct exposure}

Human receptors could be at risk from direct exposure to the contaminants (inorganics, organics, and radionuclides) placed in the CRSP; classified and unclassified inventory lists are available for the CRSP. A cap was placed on the CRSP in 1989, and no soil samples were taken at that time; therefore, a conservative estimate of the risk to a human receptor will be determined using the inventory list of the wastes deposited in the pits. (Best estimates for the total volume of each contaminant deposited in the pits will be used.) Exposure pathways to be considered include ingestion, dermal contact, inhalation, and external exposure. A bounded estimate will be determined in which the lower bound will be determined using a residential RME assessment, and an upper bound will be determined by evaluating risk from acute exposure to contaminants of potential concern listed in the CRSP inventory. 


\subsubsection{Conceptual Model for Exposure of Ecological Receptors}

A conceptual exposure model for ecological (nonhuman) receptors in the current baseline state is shown in Fig. 3.12. A conceptual model for ecological receptors in a hypothetical future state where the site is unmaintained is shown in Fig. 3.13.

\subsubsection{Problem definition}

The standard paradigm for an ERA will be followed in the baseline assessment (Suter 1992; USEPA 1992). The contaminant source of concern was identified as the mixed wastes buried in the CRSP. Concern is for the ecological risk associated with the waste site itself through (1) incidental soil contamination that occurred at the time of dumping (contaminated soil not covered by the three-layer RCRA cap) and (2) surface runoff water. The purpose of this ERA is to characterize the nature and extent of contaminant contributions from the source OU (Chestnut Ridge OU1) to adjacent aquatic (Chestnut Ridge OU2 or OU4, or Upper EFPC) or terrestrial (ORR sitewide ecosystem) integrator OUs. The spatial extent of Chestnut Ridge OU1 is limited to the mown grassland area. However, if contaminants originating from the CRSP are detected in downslope spring/seeps, these areas will be included in Chestnut Ridge OU1. A 20\% reduction in the abundance or production of any population of wildlife or vascular plant was chosen as the assessment endpoint. These endpoints were selected based on an analysis of USEPA guidance and regulatory practice and on the feasibility of detecting effects (Suter et al. 1992).

The conceptual exposure model for the current baseline state (refer to Fig. 3.12) shows how contaminants move from the source through the physical components of the site to the various biotic components. While surface runoff water is believed to be the primary source of contamination (because the site is capped), spring-seeps downslope from Chestnut Ridge OU1 will be monitored for contaminants.

Chestnut Ridge OU1 is believed to drain primarily to the northeast. Contaminants may therefore move in surface runoff water into Upper EFPC. In addition, surface runoff water may flow south-southwest into the McCoy Branch watershed or southeast into the sludge disposal ponds. These sites will be monitored to determine if Chestnut Ridge OU1 is making a significant contribution to their current contaminant load. As a result of observed drainage patterns and the absence of aquatic habitat at Chestnut Ridge OU1, Chestnut Ridge OU2 and OU4 and Upper EFPC have been identified as the integrator OUs for aquatic effects from Chestnut Ridge OU1. Risks to aquatic biota for Chestnut Ridge OU2 and OU4 and Upper EFPC should be assessed in the RIs.

Surface soils may be exposed to contaminants through incidental contamination (at time of dumping) and surface runoff water and by cycling of plants previously exposed to contaminants via surface runoff water. Soil invertebrates may be exposed to contaminants through surface soil contact. While there may be some use of the site by large mobile wildlife species such as whitetail deer and wild turkeys, these organisms cannot be clearly associated with the site, so they are not included. (Most of their diet comes from off Chestnut Ridge 


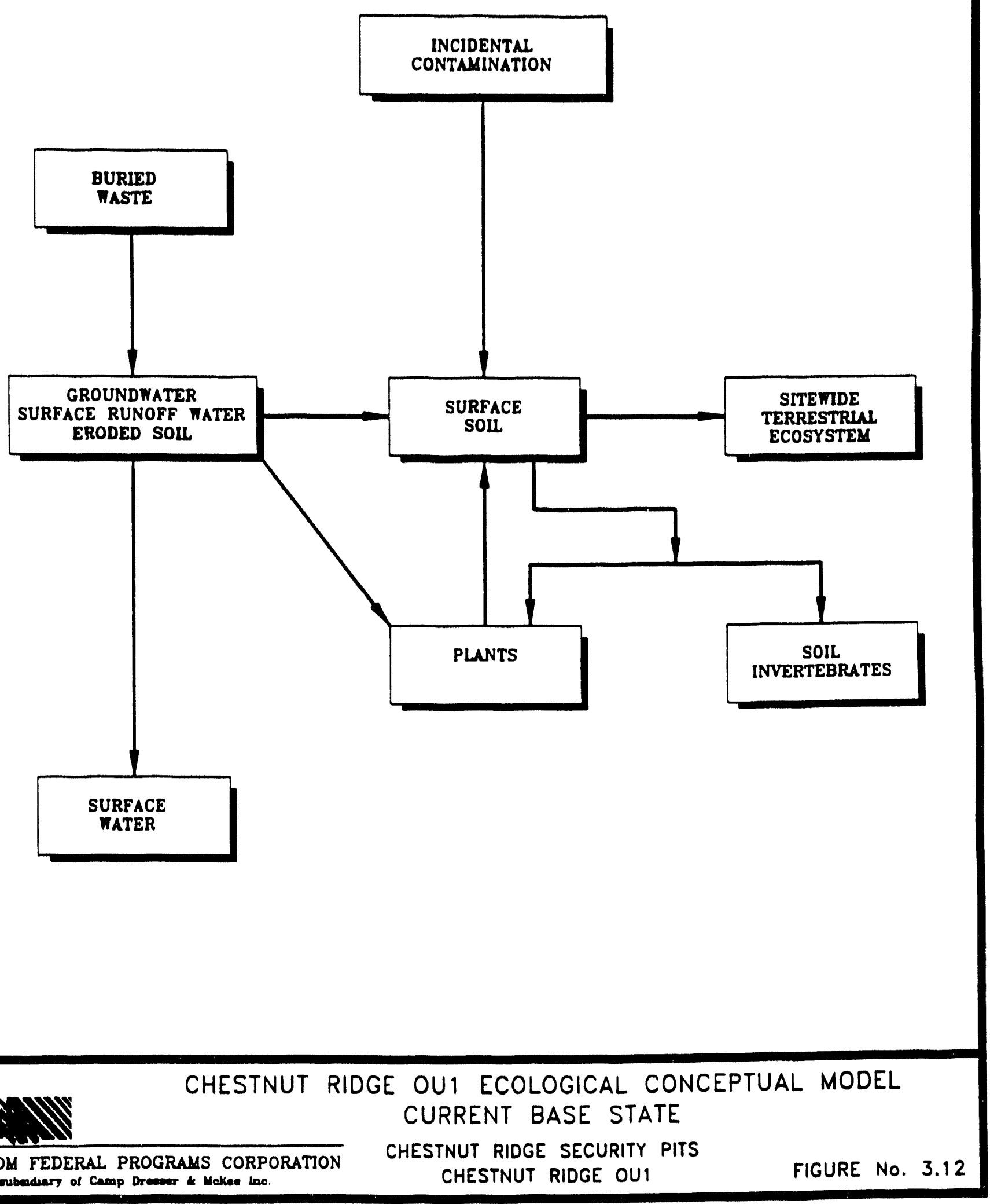

CR Security Pits WP 


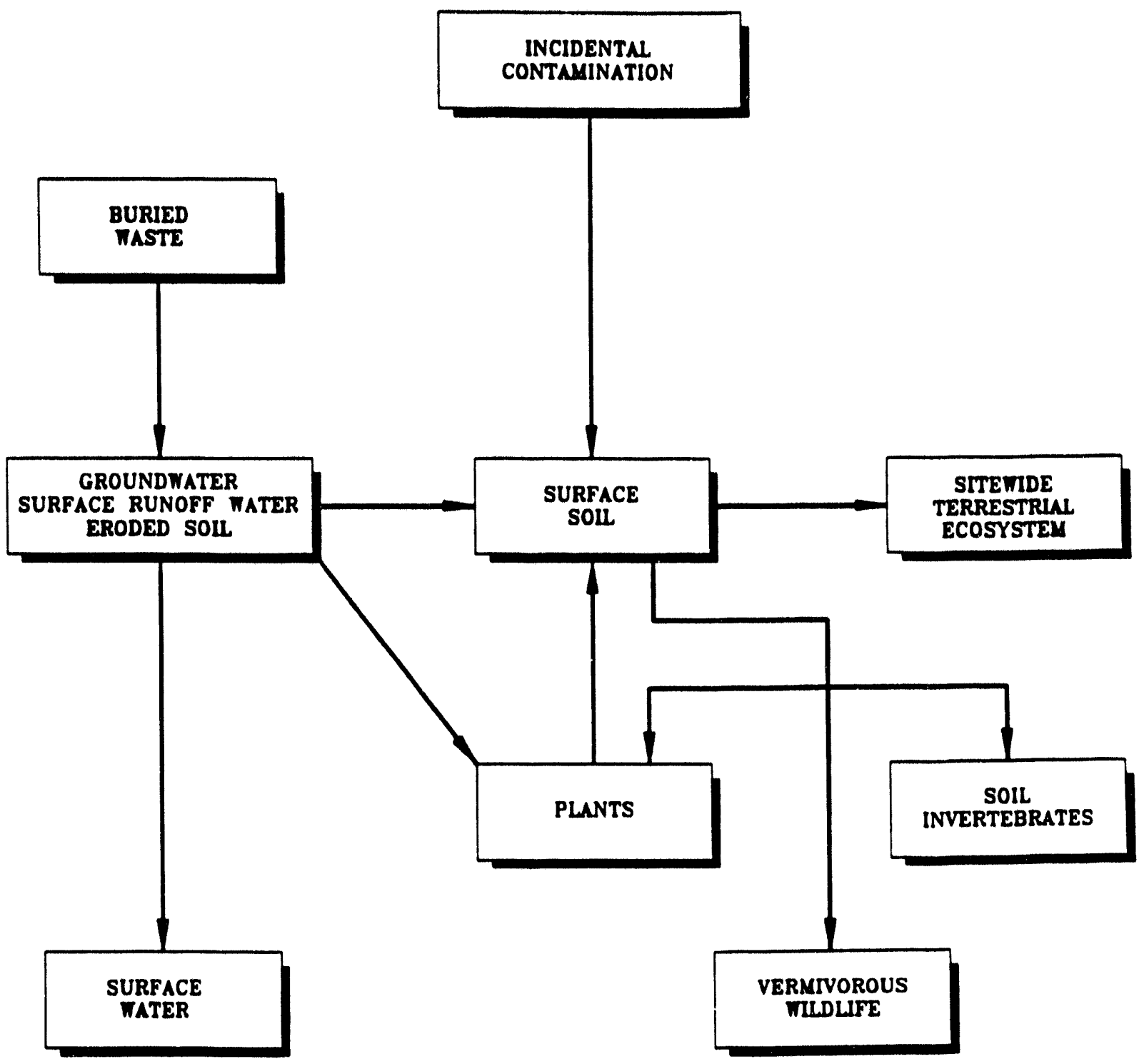


OU1.) Because they are exposed to multiple WAGs, risks to such species should be assessed in a reservation-wide assessment.

Small mammal abundance in the contaminated grasslands is expected to be low because mowed fescue lawns provide poor habitat. Talmage and Walton (1991) were able to trap significant numbers of small mammals in the wooded and brushy areas surrounding WAG 4 (a site similar to and near Chestnut Ridge OU1) but not on the lawns of the hurial ground. Because small mammals could not be sampled in sufficient numbers to characterize the distribution of exposure on the site, and because they are not ecologically important to the energy and nutrient dynamics of the grassland or the larger terrestrial ecosystem, they are not included. Similarly, small birds are believed to make relatively little use of the site. Therefore, the terrestrial portion of the ecological conceptual model focuses on the proximate receptors that can be associated with the site-plants and soil invertebrates. To assess risks to these receptors, earthworms will be sampled and analyeed from any significantly contaminated surface soils; plant and earthworm toxicity tests will be performed on soil from the same areas. In addition, contamirant concentrations in soils will be compared to concentrations reported to be toxic to piants or soil invertebrates.

If the U.S. government ceased to exist or abrogated responsibility for the ORR; if no other governmental entity assumed responsibility; and if no agricultural, residential, or industrial development occurred on the site, Chestnut Ridge OU1 would revert to mixed deciduous forest. This is the hypothetical future baseline case (refer to Fig. 3.13) for the ecological risk assessment.

The conceptual model for this case is complex because the habitat quality of the site would be greatly improved relative (i) the current case. All of the routes in the current case would continue to operate, and the route to the aquatic communities (OU4, EFPC, McCoy Branch, and sludge disposal ponds) would be substantially unchanged. (Greater transpiration would decrease aqueous flow.) However, in addition to uptake of contaminants from surface soil, deep-rooted trees could take up contaminants from shallow groundwater. Contaminants taken up in this manner and translocated to the aboveground parts would enter the litter layer and surface soil, thereby creating a route from groundwater to surface soil. In addition, the site would be occupied by shrews and ground-feeding birds that would consume soil and litter invertebrates. Although these species are not demonstrably ecologically important, they are highly exposed to contaminants in soil that bioaccumulate through food. They are likely to be the most susceptible wildlife species and are included for that reason. In forests, herbivores (predominantly insects) are not ecologically important in terms of either energy or nutrient dynamics. (Most energy and nutrients in these forests pass from the primary producers to the decomposers.) In addition, herbivores would have lower contaminant exposures than soil/litter invertebrates.

In East Tennessee forests, most vertebrate consumers of herbivorous insects are birds. These birds would have lower exposures than litter foragers because their food would be less contaminated and they would experience less incidental consumption of soil, so they should not be particularly susceptible. Similarly, omnivores such as Peromyscus are not exceptionally susceptible or ecologically important. Vertebrate forest predators such as bobcats and broadwinged hawks could not be particularly associated with the site because they have large home ranges, would not be particularly susceptible, and are not demonstrably ecologically 
important (i.e., are not keystone species and are not important to energy or nutrient dynamics). Exposure and effects on plants, soil invertebrates, and vermivorous wildlife will be estimated based on current concentrations and on estimates of additional exposure due to deep-rooted vegetation.

\subsubsection{Data needs for ecological risk assessment}

Surveys will be conducted for endangered, threatened, or in-need-of-management species and their habitats. Because Chestnut Ridge OU1 is an upland site, surveys for wetlands and floodplains at the waste disposal site are unnecessary. However, if hydrologic studies indicate that contaminated water from this site is reaching the surface, the exposed areas will be surveyed for wetlands and floodplains as well as threatened and endangered species.

Data are needed on the presence and nature of contaminants in the soil. If contaminants are found at potentially hazardous concentrations, soil toxicity tests should be performed using earthworms and cabbage seedlings in accordance with demonstrated procedures (Green et al. 1988; Roberts and Dorough 1985; Wentsel and Guelta 1987 and 1988).

Additionally, if monitoring of springs/seeps indici!es contamination originating from the CRSP, then ambient toxicity tests should be performed. These tests will be the USEPA's seven-day fathead minnow larval and Ceriodaphnia dubia tests. 


\section{POTENTIAL RECEPTORS AND EXPOSURE PATHWAYS}

In this section, characterization of the human and ecological populations on or near the CRSP site is considered. The receptor assessment aims to identify those individuals or populations with a current or future potential for exposure to CRSP site contaminants. The exposure pathway assessment identifies the routes by which a receptor might be exposed.

\subsection{HUMAN POPULATIONS AND EXPOSURE PATHWAYS}

The CRSP are located within the Y-12 Plant site ( $\sim 800$ acres) and are part of the ORR, which covers $\sim 58,000$ acres. The CRSP site is located along the crest of Chestnut Ridge south of the main Y-12 Plant facility. The Y-12 Plant is located along the northeastern boundary of the entire ORR /which includes the Y-12 Plant, the Oak Ridge National Laboratory (ORNL) and the K-25 Site), adjacent to the city of Oak Ridge. The presence of unauthorized persons at the Y-12 Plant is controlled. Security precautions currently limit admittance to this controlled area; consequently, the potential for human exposure to contaminants is limited at the present time.

A conceptual site model for human health risk assessment is discussed in Sect. 3.9.1 and illustrated in Fig. 3.11. Inhalation, ingestion, dermal contact, and external exposure pathways (for both water and soil) were selected as potential pathways of concern at Chestnut Ridge OU1 through use of the available knowledge of the site conditions. In addition, direct exposure to the inventoried wastes via ingestion, inhalation, dermal contact, and external exposure are potential pathways of concern.

An exposure pathway is the means by which contamination from any contaminated medium is transported from a source to a receptor. The components necessary to complete the pathway are (1) a contaminated source and a mechanism for release, (2) a transport medium, (3) an exposure point, (4) potential receptors, and (5) an exposure route. Exposure can occur if contaminants migrate from the CRSP to a receptor or if a receptor comes into direct contact with the contaminated media. Identification of exposure pathways for this $\mathrm{OU}$ include descriptions of both primary and secondary sources.

For the CRSP site, both primary and secondary media are identified (refer to Fig. 3.11 in Sect. 3.9.1). The primary source of contamination for this $O U$ is from contaminants disposed of in the security pits. Contaminants from this primary source are released, through primary mechanisms (e.g., leaks, spills, and infiltration/ percolation), to secondary sources. Two potential secondary sources (those that contribute contaminants through their exposure media) have been identified; they are soil and groundwater. Contaminants in these secondary sources are released to exposure media through secondary release mechanisms that include infiltration/percolation, groundwater discharge, wind-generated dust, volatilization, and plant/animal uptake. The exposure media identified for the CRSP are on source-OU soil, groundwater, air, and biota; off source-OU exposure media are surface water, groundwater, air, and biota.

A potential exists for the ingestion of contaminants via surface water and groundwater consumption as well as soil and biota intake. Exposure via ingestion of surface water or 
groundwater could occur if one or the other is used as a drinking water source by future residential receptors. On source-OU surface water has not been identified at the present time. There is, however, groundwater attributed to this OU, and the potential exists for contamination of this water through infiltration. The groundwater associated with the CRSP site is currently not a source for domestic or industrial use. Potential exposure to the contaminants in groundwater moving off of the source-OU to an off source-OU receptor must also be consijered here. In addition, exposure to the off source-OU receptor via contaminated surface water (i.e., groundwater discharged to surface water) must also be considered. The potential also exists for exposure to contaminants through ingestion of soil by the hypothetical on source-OU resident living on or near the CRSP. If soil sampling does not identify contamination, exposure from soil pathways is not expected and will not be evaluated in terms of risk to human health. Potential exposure via ingestion of biota, both on and off sourcc-OU, must also be considered.

Exposure of receptors to contaminants through dermal contact with soil and water is also a potential route. For the future hypothetical resident, dermal exposure to groundwater might occur through showering. Dermal contact with soil is another means of exposure. The potential for a receptor to be externally exposed to radionuclides (gamma radiation) in the CRSP soils also exists. There is a potential for exposure to volatile contaminants through inhalation of wind-generated dust and/or through contact with water (e.g., through showering). Furthermore, direct exposure to the contaminants disposed of in the CRSP (identified on the CRSP inventory lists) may also be a potential pathway of concern, especially for the remediation worker.

\subsubsection{On-site Potential Human Receptors and Exposure Pathways}

Employment at the Y-12 Plant (as of April 1993) consisted of $~ 6200$ full-time on-site personnel, the majority of whom work in the main Y-12 Plant complex in the northeastern part of the ORR. The CRSP site is south of the main Y-12 Plant on the crest of Chestnut Ridge. Employees do not frequent this area, although on-site workers do have the greatest risk of exposure to contaminants from the CRSP. Because this source OU has been closed and capped, activities are limited at this OU, and potential exposure of the on-site worker is limited to a small group of maintenance workers and future sampling and remediation workers. Exposure to a trespasser must also be considered here. A baseline risk assessment (residential RME assessment) will, however, be performed to support a final action ROD for Chestnut Ridge OU1.

Sensitive subpopulations identified as being of specific concern in this report (both off source-OU and on source-OU) are children who are potential receptors. Children 0 to 6 years of age will be evaluated separately to ensure protection of this population.

\subsubsection{Off-site Potential Human Receptors and Exposure Pathways}

The greatest potential for off source-OU human exposure is from groundwater migration of contaminants. Contributions to off source-OU surface water via groundwater discharge (seeps and springs) are also potential exposure pathways to an off source-OU receptor. If off source-OU surface water or groundwater is identified as being contaminated from the CRSP, 
exposure to receptors at those points will be evaluated in an RME assessment to support a final action ROD for Chestnut Ridge OU1.

\subsection{ECOLOGICAL POPULATIONS}

This ecological assessment is concerned with upland terrestrial communities (grasslands and woodlands) associated with Chestnut Ridge OU1. The sources for this information include the ORR Resource Management Plan (Parr 1984; Kroodsma 1987; Cunningham and Pounds 1991; Parr and Evans 1992) and the RFI Plan for the Y-12 Plant (Welch 1989).

\subsubsection{Aquatic Biota}

As an upland site, no aquatic biota are present at the CRSP site. Risks to aquatic biota will be addressed in Bear Creek OU4.

\subsection{Terrestrial Biota}

Because the CRSP site consists of a lawn of mown fescue, only incidental and peripheral use by wildlife is expected. Species that may make occasional use of the actual disposal site include small mammals (shrews and mice), rabbits, skunks, and foxes. Greater wildlife diversity and abundance are expected in the woodland habitat surrounding the CRSP.

\subsubsection{Threatened and Endangered Species}

No federally or state-listed threatened or endangered species or other specially designated species is known to occur on the CRSP site. However, no survey specific to this OU has been conducted. Specially designated species that may occur are listed in Table 4.1.

\subsubsection{Wetlands and Floodplains}

Chestnut Ridge OU1 is a ridgetop, upland site. Therefore, no wetlands or floodplains are present. 
Table 4.1. Federally and state-listed threatened and/or endangered species and species designated In Need of Management by the state of Tennessee known or expected to occur on the Oak Ridge Reservation

\begin{tabular}{|c|c|c|}
\hline Common name & Scientific name & $\begin{array}{l}\text { Administrative } \\
\text { status }\end{array}$ \\
\hline \multicolumn{3}{|l|}{ Fah } \\
\hline Tennessee dace & Phonizaus oreas & INM \\
\hline \multicolumn{3}{|l|}{ Birde } \\
\hline Black-crowned night heron & Nycticorax nyeticorax & INM \\
\hline Black vulture & Coragyps atratus & INM \\
\hline Common barn owl & Tyro alba & INM \\
\hline Cooper's hawk & Accipiter cooperii & ST \\
\hline Grasshopper sparrow & Ammodramus savannarum & ST \\
\hline Osprey & Pandion halioetus & SE \\
\hline Red-shouldered hawk & Buteo lineatus & ST \\
\hline Sharp-shinned hawk & Accipter striatus & ST \\
\hline \multicolumn{3}{|l|}{ Mammales } \\
\hline Indiana bat & Myotis sodalis & FE, SE \\
\hline \multicolumn{3}{|l|}{ Plants } \\
\hline Spreading false foxglove & Aureolaria pacula & ST \\
\hline Appalachian bugbane & Cimicifuga rubifolia & ST \\
\hline Pink lady's slipper & Cypripedium acaule & SE \\
\hline Tall larkspur & Delphinium exaliasum & SE \\
\hline Northern bush honeysuckle & Dienvilla lonicera & ST \\
\hline Nutall waterweed & Elodea nutrallii & SS \\
\hline Mountain witch-alder & Fothergilla major & ST \\
\hline Golden seal & Hydrastis canadensis & ST \\
\hline Butternut & Juglans cinerea & ST \\
\hline Canada lity & Lilium canadense & ST \\
\hline Michigan lily & Lilium michiganense & ST \\
\hline Fen orchid & Liparis loeselii & SE \\
\hline Ginseng & Panax quinquefolium & ST \\
\hline Tubercled rein orchid & Platanthera flava var herbiola & ST \\
\hline Purple fringeless orchid & Platanthera peranoena & ST \\
\hline Carey saxifrage & Saxifraga careyana & SS \\
\hline Lesser ladies' tresses & Spiranthes ovalis & SS \\
\hline
\end{tabular}

"FE-Fevierally Endangered; FT-Federally Threatened; INM-In Need of Management according to the State of Tennessee; SE-State Endangered; SS-State Special Concern; and ST-State Threatened. 


\section{IDENTIFICATION OF INVESTIGATION REQUIREMENTS}

\subsection{IDENTIFICATION OF ARARS}

CERCLA guidelines specify that remedial actions for cleanup of hazardous substances must comply with requirements or standards under federal or more stringent state environmental laws that are ARARs for a site. The following is a preliminary list of federal and state chemical- and location-specific ARARs for Chestnut Ridge OU1:

- National Contingency Plan (NCP);

- NEPA;

- CERCLA;

- RCRA;

- Safe Drinking Water Act;

- Clean Water Act;

- Clean Air Act;

- TDEC, Chapter 1200-4-6-.05(2);

- TDEC, Chapter 1200-5-1.12;

- TDEC, Chapter 1200-1-13-.08(4) (proposed);

- TDEC, Chapters 1200-4-3 and 1200-4-4;

- TDEC, Chapter 1200-1-13 (proposed);

- TDEC, Chapters 4-7 et seq.; and

- Toxic Substances Control Act.

The relevance of each of these federal or state laws or regulations is presented and discussed in Appendix B.

\subsection{IDENTIFICATION OF PRELIMINARY REMEDIAL ACTION GOALS}

The first step in the FS scoping process is the development of preliminary remedial action objectives (RAOs) for protecting human health and the environment. These objectives should specify contaminants and media of concern, potential exposure pathways, and preliminary remediation goals (PRGs). PRGs are chemical-specific concentrations in media based on readily available environmental or health-based ARARs or risk-based values calculated with default assumptions. As new information and data are collected and additional ARARs are identified during the RI, the PRGs may be modified, and RAOs will be established. These goals are used throughout the RI/FS process for screening purposes after the first phase of sampling. They identify general response actions and help to identify, screen, and develop remedial action alternatives.

Chestnut Ridge OU 1 will be addressed in a ROD consistent with the strategy outlined in the ORR Site Management Plan (Energy Systems 1992b). The general goal for the Chestnut Ridge OU 1 remedial action is to protect human health and the environment from the contaminant sources within the OU. For each contaminant source, the PRGs will be set for each $\mathrm{COC}$ and for each medium of concern at whichever of the following values is lowest and most technically feasible: (1) health-based criteria for carcinogenic effects or for systemic 
toxic effects, (2) the lowest chemical-specific ARARs, (3) ecologically based criteria, or (4) background concentrations.

\subsection{IDENTIFICATION OF POTENTIAL CLASSES OF REMEDIAL TECHNOLOGIES}

USEPA-established requirements pertaining to the remediation of CERCLA sites are listed in Sect. 300.430(a)(1)(iii) of the NCP. These requirements have been considered in developing the PRGs, which serve to focus the consideration of remedial action alternatives. The classes of remedial technologies are summarized below.

- Institutional controls such as fences and deed restrictions may be used alone or as a supplement to engineering controls, as appropriate, to prevent exposure to hazardous substances.

- Containment technologies such as capping, vertical barriers, horizontal barriers, and dust suppression may be used, as appropriate, to control contaminated areas that pose a relatively low long-term threat and for sites where treatment is impractical (e.g., in a pyrophoric setting).

- Removal technologies such as excavation may be used, as appropriate, alone or in combination with treatment to remove contamination or to abate the further migration of contaminants.

- Treatment technologies such as physicochemical, biological, or thermal ex situ or in situ may be used, as appropriate, alone or in combination with any of the other listed technologies to (1) abate principal threats such as highly mobile or toxic substances, (2) prevent further migration of contaminants, or (3) remove contamination. Where possible, treated material that no longer poses a threat to human health or the environment will be returned to the excavation site, or treatment will occur in situ.

- Innovative technologies may be considered when they offer the potential for superior treatment performance or lower costs for performance similar to that of demonstrated technologies.

As the RAOs are revised throughout the RI/FS process, the development and evaluation of the remedial action alternatives will reflect the scope and complexity of the site problems being addressed. During the FS, alternatives will be developed to protect human health and the environment by eliminating, reducing, and/or controlling risks posed through each exposure pathway.

The media of concern at Chestnut Ridge OU1 are soil, sediment, surface water, and groundwater. RAOs for this OU are described in Table 5.1. Soil and sediment are grouped together only because they have similar treatments.

Table 5.1 also presents a preliminary range of remedial action alternatives and associated technologies for Chestnut Ridge OU1. This table is not meant to present a detailed 


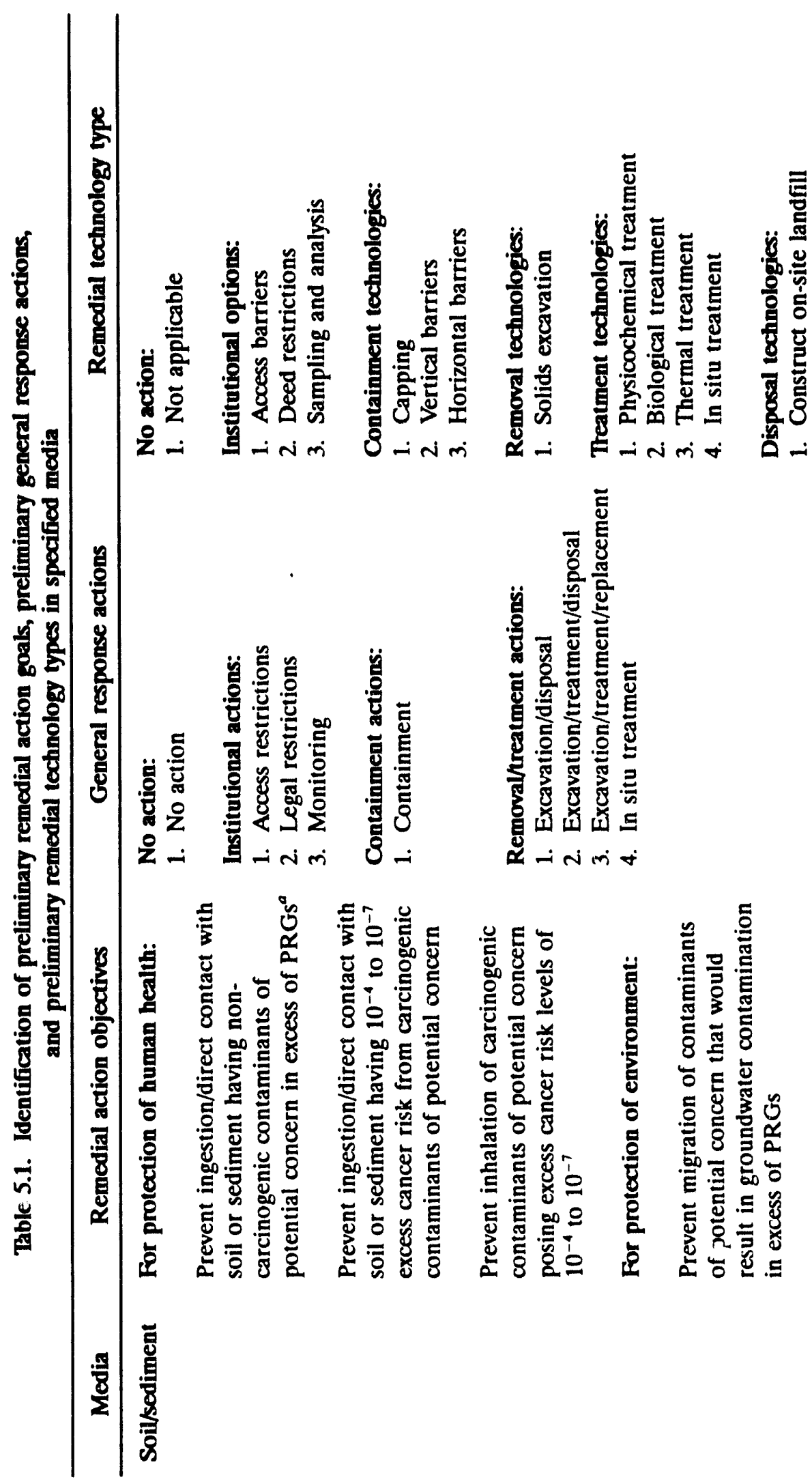




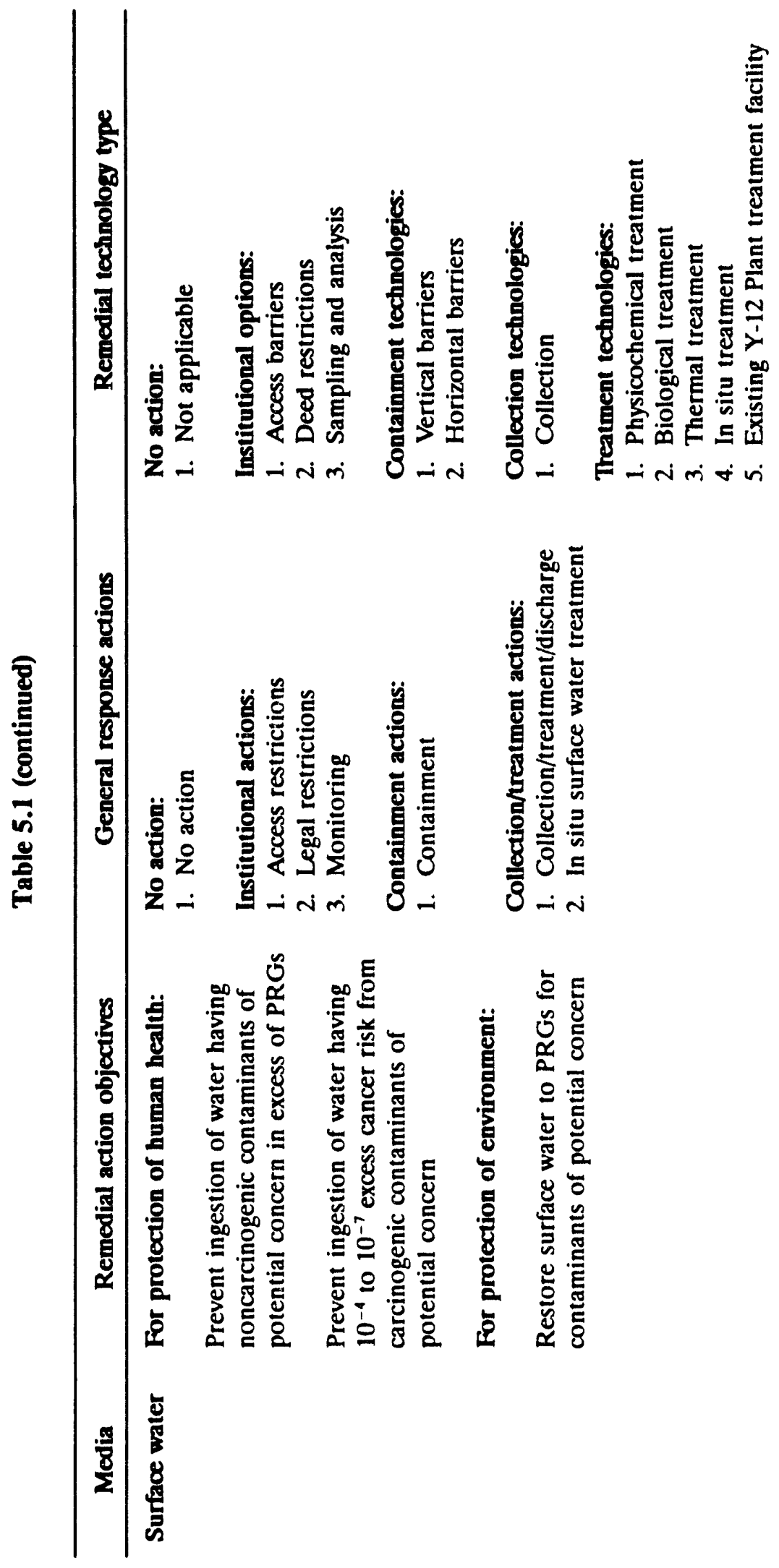


5-5

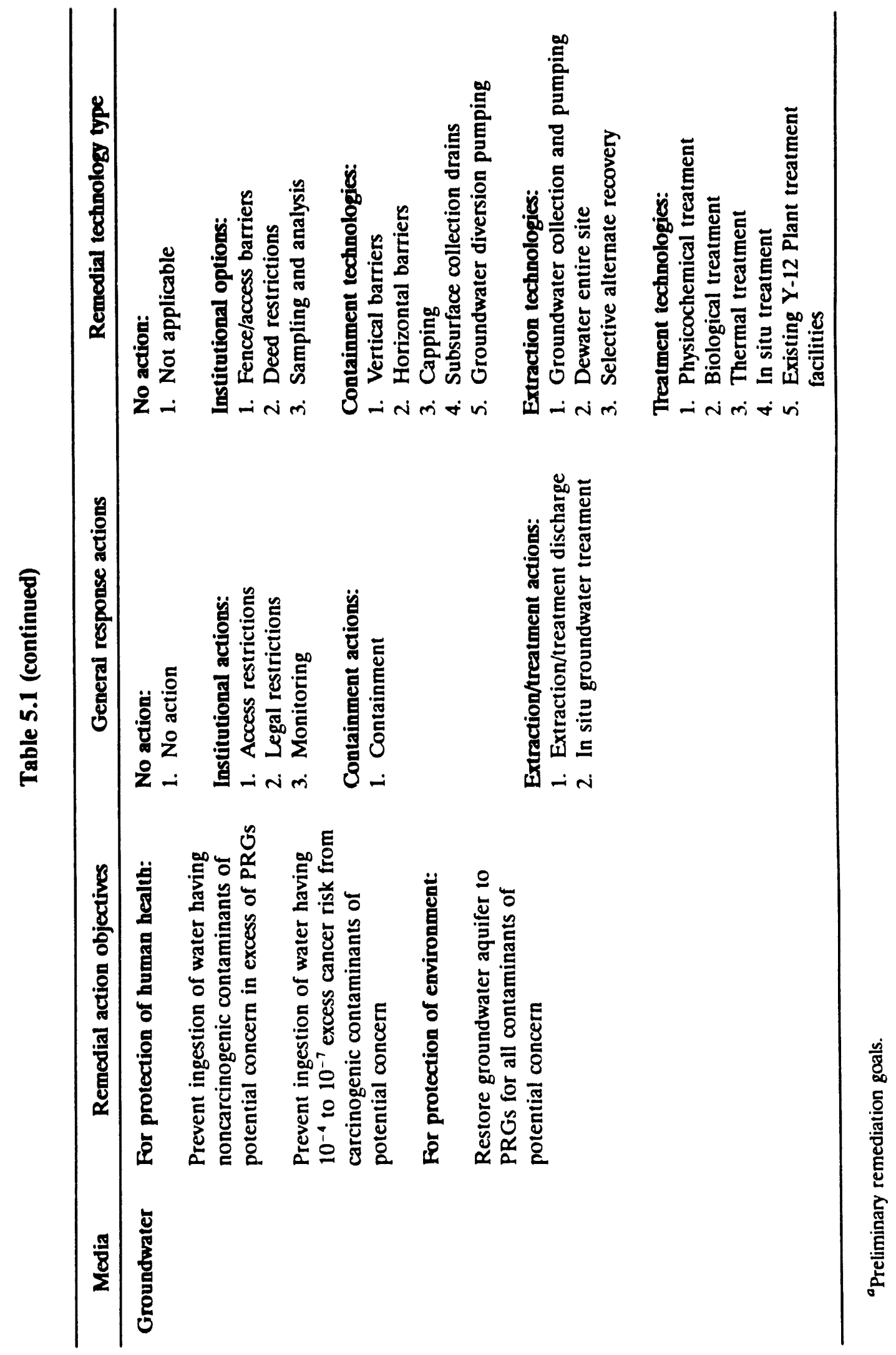


compilation of alternatives but to make an initial determination as to which general response actions might be applied to the sites alone or in combination with one another. This will be used later during the FS process to screen technologies and assemble alternatives. Identifying potential technologies at this stage will help ensure that data needed to evaluate them can be collected as early as possible. Early identification of technologies will also determine whether treatability studies are needed.

The general response actions are (1) no action, (2) institutional actions, (3) source containment, and (4) removal/treatment technologies. The "no-action" response required by CERCLA serves as a baseline comparison against which the other actions can be measured. The potential principal contaminants of interest affecting the specified media are primarily VOCs (see Sect. 3). As additional information becomes available, the list of contaminants may be revised. 


\section{SITE DATA NEEDS}

As described in previous sections, there have been a number of earlier investigations and monitoring activities conducted in and around the CRSP. Despite the resulting body of knowledge, additional site characterization data are needed to perform the HHRA, the ERA, and the FS, and to prepare the ROD describing the most appropriate remedial action, if any.

The overall sampling strategy is based on the following five premises.

1. Source characterization will be achieved using existing waste inventories, as-built drawings, and professional judgment regarding contaminant concentrations and exposure levels.

2. Existing groundwater quality data are generally adequate to define the extent of groundwater contamination at the site for VOCs, metals, and radionuclides. Additional samples will be collected for analysis of all TCL organics (plus TAL metals and radionuclides) to confirm the presence or absence of these analyzes. In addition, a study (dye tracer study, spring/seep survey, and/or spring/seep sampling) will be performed to identify and investigate/characterize the potential for exposure to contaminated groundwater discharged off-site.

3. There are no existing data on surface and subsurface soil contaminant levels other than the soil-gas survey results. These data will be collected using an on-site screening strategy (GC) that, based on existing knowledge of site conditions (i.e., groundwater contamination), should allow for determination of the nature and extent of soil contamination, if present. If the full extent of soil contamination is not characterized by direct measurenients, the data base should be adequate to apply predictive models to simulate the possible extent of contamination and potential exposure levels.

4. The site is located in an upland area. Therefore, migration of contaminants is likely from gravity drainage of leachate, and discharge of contaminants into adjacent areas is possible. There is minimal habitat value associated with the site in its current condition. There are wooded areas on either side of the CRSP that provide habitat for indigenous flora and fauna; however, at this time there are no indications that the wooded areas have been impacted by operation of the CRSP. Various biological test and/or chemical analyses are proposed if the results of surface soil sampling suggest that shallow soils in the wooded areas are contaminated. Similarly, if the dye tracer study and spring/seep sampling show that contaminants are present at these locations, then aquatic toxicity testing will be performed to assess potential ecological impacts.

5. The presence of VOCs at the site as indicated by previous groundwater analyses suggests that there is a potential for the presence of air contamination as well. The presence of the multilayered engineered cap should mitigate surface release of VOCs; however, there are no quantitative air quality data to verify VOC contaminant concentration or exposure levels at the site under current conditions. Time integrated air samples will be collected for VOC analyses. If spring/seep samples are found to be contaminated, exposures from volatilization of contaminants will be estimated or modeled; direct measurements will not be 
performed at these locations, because discrete data on the source at these locations will be available for modeling purposes.

Subsequent sections will describe the detailed approach for data collection for each of the media/pathways/receptors of concern at the CRSP.

\subsection{PHYSICAL/CHEMICAL CHARACTERIZATION}

Some of the physical characteristics of the CRSP have been well defined; surface and geological characteristics were presented and discussed in Sect. 3.4. Previous investigations associated with RCRA compliance activities conducted by Y-12 Plant personnel have generated chemical data that will be used in this RI. To fill data gaps and supplement and confirm existing data, additional site characterization data are needed in the following areas: site hydrogeology, groundwater quality, surface and subsurface soil contamination, and ecological characterization. The sitc investigation will specifically include

- collecting groundwater samples for chemical analyses (from 12 existing monitoring wells surrounding the CRSP and 1 existing monitoring well from a background location in the same geologic group) twice during the investigation as representative of wet and dry weather periods,

- screening for subsurface soil VOC contamination using a Geoprobe and field GC,

- collecting subsurface soil samples using the Geoprobe for chemical analyses from horizons where VOCs are found and $10 \%$ of the samples without detectable VOCs,

- conducting wetlands and endangered species habitat surveys,

- collecting surface soil samples for chemical and grain size analyses,

- conducting a spring and seep survey to identify potential monitoring locations for design of the dye tracer study,

- designing and conducting a dye tracer study to elucidate the hydrology of Chestnut Ridge,

- collecting spring/seep and sediment samples from locations identified by the dye tracer study as hydrologically associated with the CRSP,

- collecting time integrated air samples for VOC analysis,

- collecting earthworm samples for chemical analyses if areas of surface soil contamination are found adjacent to the pits,

- conducting plant and earthworm toxicity testing if areas of surface soil contamination are found adjacent to the pits, and 
- conducting aquatic toxicity testing with daphnids and fathead minnow larvae at spring and/or seep locations if contaminants are found there.

The groundwater characterization data will be used to establish COCs for the groundwater pathway. The soil characterization data will be used to identify COCs in on-site (near-site) soils and to provide information on the nature and extent of soil contamination. The spring and seep survey/sampling and the dye tracer study will be used to estimate groundwater flow characteristics and to determine if contaminated groundwater is discharging to surface waters or at ground surface within the watershed. The air VOC data are needed to determine if VOCs are currently present at measurable concentrations at the site. The biological/ecological data will specifically be used to evaluate aquatic and terrestrial risk path'vays for biota and man. Existing data on the volume and types of waste in the pits available in the waste inventory will be used for source characterization; the cap on the pits will not be sampled or breached in any way during this investigation. All of these data are needed to determine exposure points and pathways for the ERA and HHRA and to establish locations and extent of contamination for development of remedial alternatives in the FS; the data will also be used to evaluate potential treatment/process alternatives.

Background soil samples will not be collected. Results from the ORR-wide background soil study will be used in lieu of sampling. The scope of collection of background spring/seep data cannot be fully evaluated at this time. If warranted, these data will be collected. All locations where samples are collected will be surveyed for horizontal and vertical control and referenced to the Y-12 Plant grid system and state planar coordinates.

\subsection{SAMPLING AND ANALYTICAL REQUIREMENTS}

Proposed groundwater sampling locations for the CRSP RI are shown in Fig. 6.1. Proposed surface and subsurface soil sampling locations are shown in Fig. 6.2. The primary COCs for all matrices are VOCs; secondary COCs include metals and radionuclides.

Although SVOCs and the other TCL organics are not considered COCs at this site, they will be included in the list of analyzes for all media to provide definitive data concerning the presence or absence of these parameters. Radionuclides will be evaluated by analysis of gross alpha, gross beta, isotopic thorium, and isotopic uranium. These parameters were selected based on review of the disposal inventory and previous data collected at the site. Gross alpha and gross beta analyses will be performed on all aqueous samples; isotopic thorium and uranium analyses will be performed on all aqueous and soil/sediment samples. All groundwater and surface water samples will be analyzed for total and dissolved TAL metals; total TAL metals analyses only will be performed on soil/sediment samples. Additional parameters have been included in the list of analyzes for groundwater samples (on a limited basis) to provide data for analysis of treatment technologies and alternatives. These parameters include total organic carbon (TOC), nitrates, oil and grease, biological oxygen demand (BOD), chemical oxygen demand (COD), total dissolved solids (TDS), alkalinity, and cyanides. This list will be referred to as the water quality parameters (WQP) list. A limited number of subsurface soil samples will be analyzed for TOC, moisture content, and grain size and also to provide data needed for analysis of treatment technologies/alternatives. In the event that earthworm samples are collected for chemical analysis, the list of parameters will 


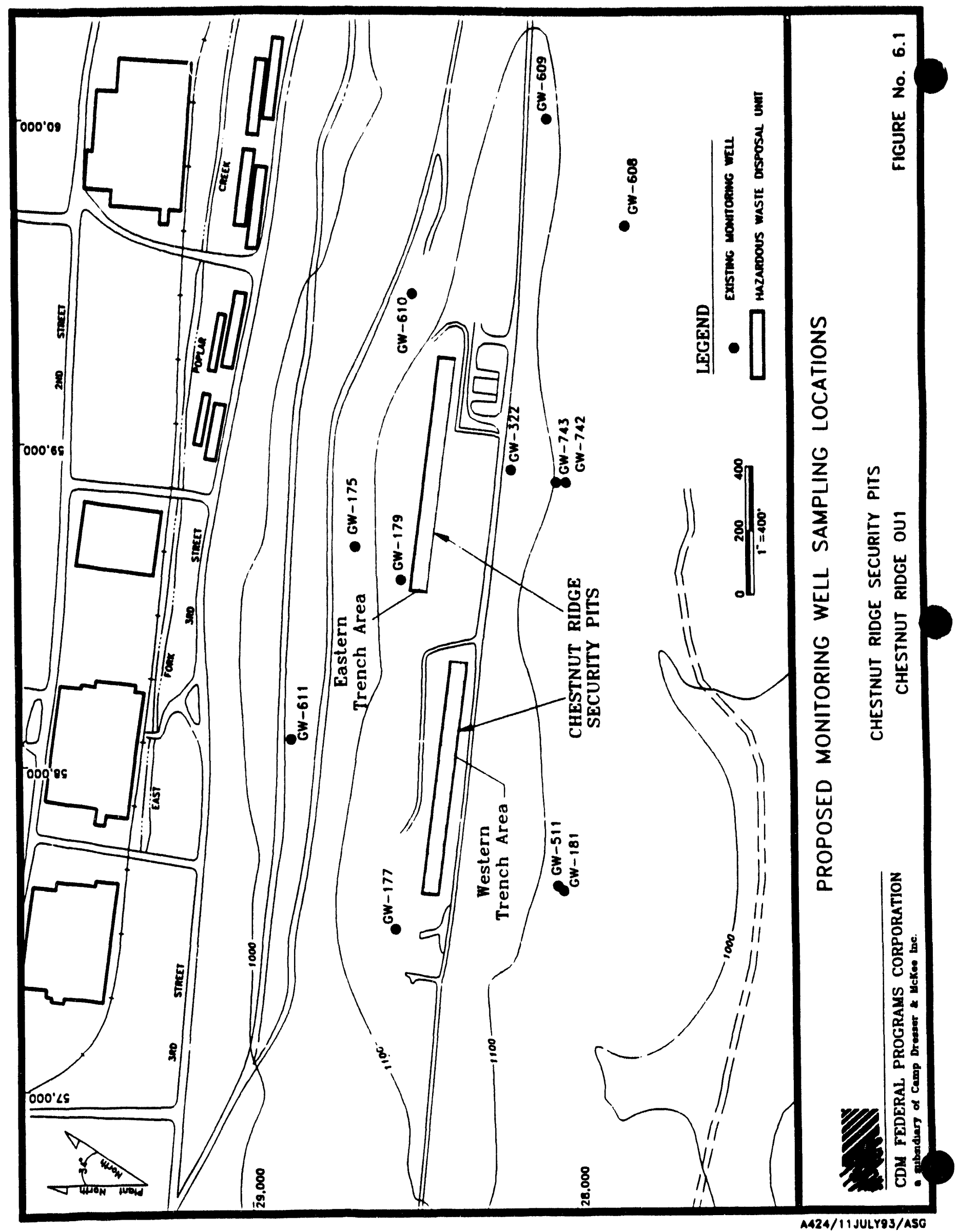

CR Security Pits WP 


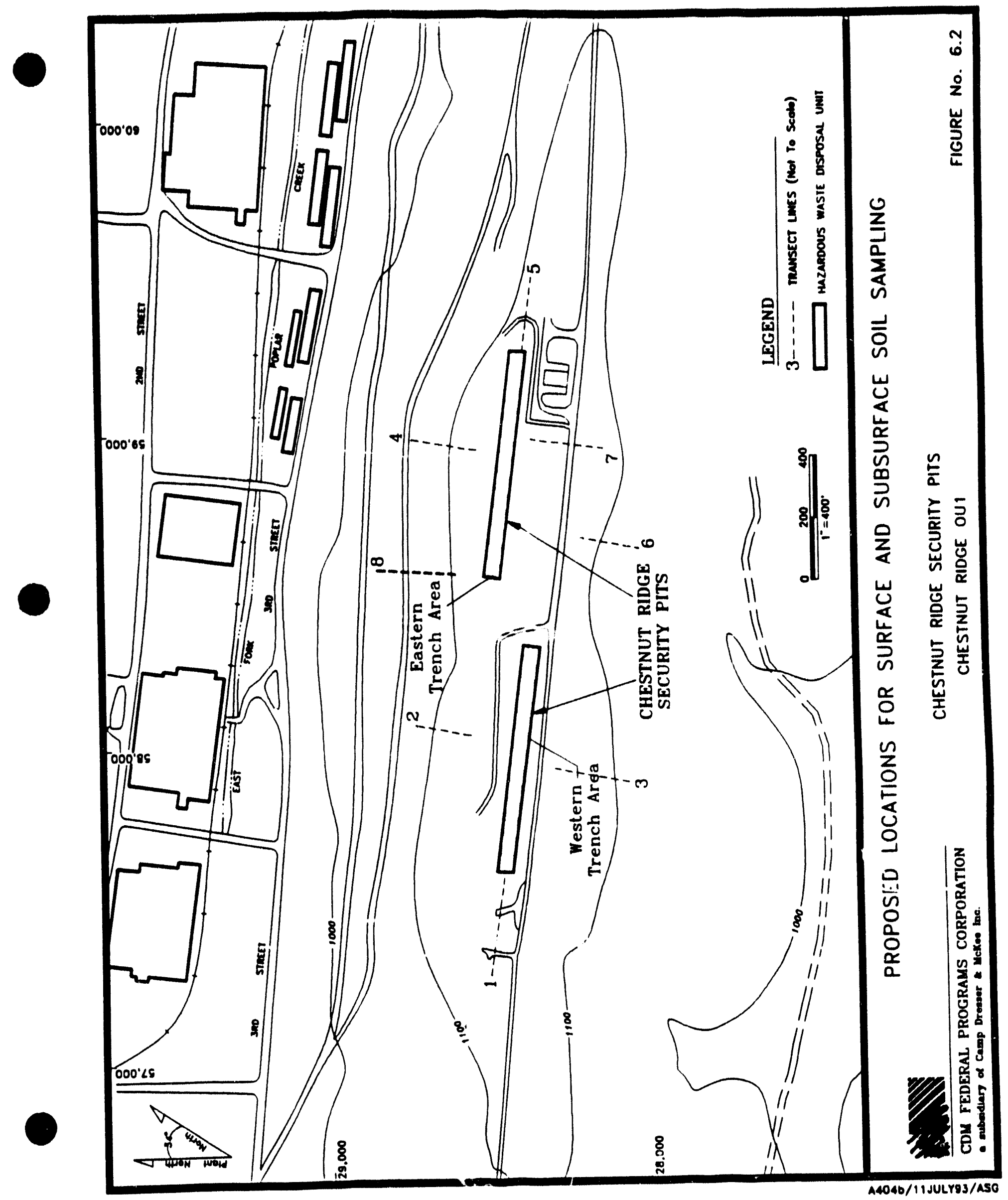


be selected based on the results of analyses of soil samples and information in the literature concerning parameters known to bioaccumulate in this species.

Table 6.1 summarizes the maximum number of samples to be collected and the analytical requirements, excluding the QC samples. A detailed discussion of the number and type of QC samples is presented in the QAPjP.

\subsubsection{Groundwater Sampling}

Two rounds of groundwater sampling will be conducted, one following the dry season and one following the wet season. The purposes of conducting two sampling rounds are to determine if there is seasonal variation in groundwater quality and to ciarify the hydrology in the vicinity of the CRSP. Section 3.6 provides additional information on the existing monitoring wells; Appendix A summarizes results of analyses from previous sampling rounds.

Thirteen monitoring wells will be sampled; two wells are immediately adjacent to the CRSP (GW-179 and -322), ten wells are located within a quarter-mile radius of the site (GW-175, -177, -181, -511,-608, -609, -610,-611,-742, and -743) and one well (GW-521) will be used for background data. Monitoring well GW-521 was chusen tor background control because there is an extensive data base of analytical results from this well that has been statistically analyzed to establish parameter concentrations at unimpacted levels. GW-521 is -7000 to $8000 \mathrm{ft}$ west-southwest of the CRSP.

Monitoring wells GW-179 and -322 were selected for sampling because they have consistently shown the highest levels of VOC contamination. They were also included to provide conclusive information on the presence or absence of the other TCL organics not routinely measured at the site. These two wells are no longer being sampled under the groundwater assessment/monitoring program because they are within the contaminant plume and, therefore, are not suitable for point-of-compliance monitoring.

The remaining ten wells in the vicinity of the site are part of the quarterly groundwater assessment/monitoring program at the CRSP. They are included for their spatial coverage of the site (known contaminant plume) and for data comparison purposes. All of the wells are placed in and monitor the bedrock aquifer. The locations of all proposed monitoring well sampling locations are shown in Fig. 6.2.

All groundwater samples will be analyzed for total and dissolved TAL metals, gross alpha and gross beta, isotopic uranium, isotopic thorium, and TCL organics. Samples for dissolved metals will be filtered at the time of collection, using a $0.45-\mu \mathrm{m}$ in-line filter or equivalent. Samples will be collected from three wells (GW-609, -179, and -177) for analysis of the WQP list. Thase wells were selected based on spatial coverage of the site. All wells will be purged and sampled using a bladder pump operated at a low flow rate to minimize groundwater turbidity and maximize analytical accuracy. Puls and Powell (1992) discuss the advantages of this approach to monitoring well sampling. Groundwater samples will be subject to field measurements of dissolved oxygen, specific conductance, $\mathrm{pH}$, and temperature. 


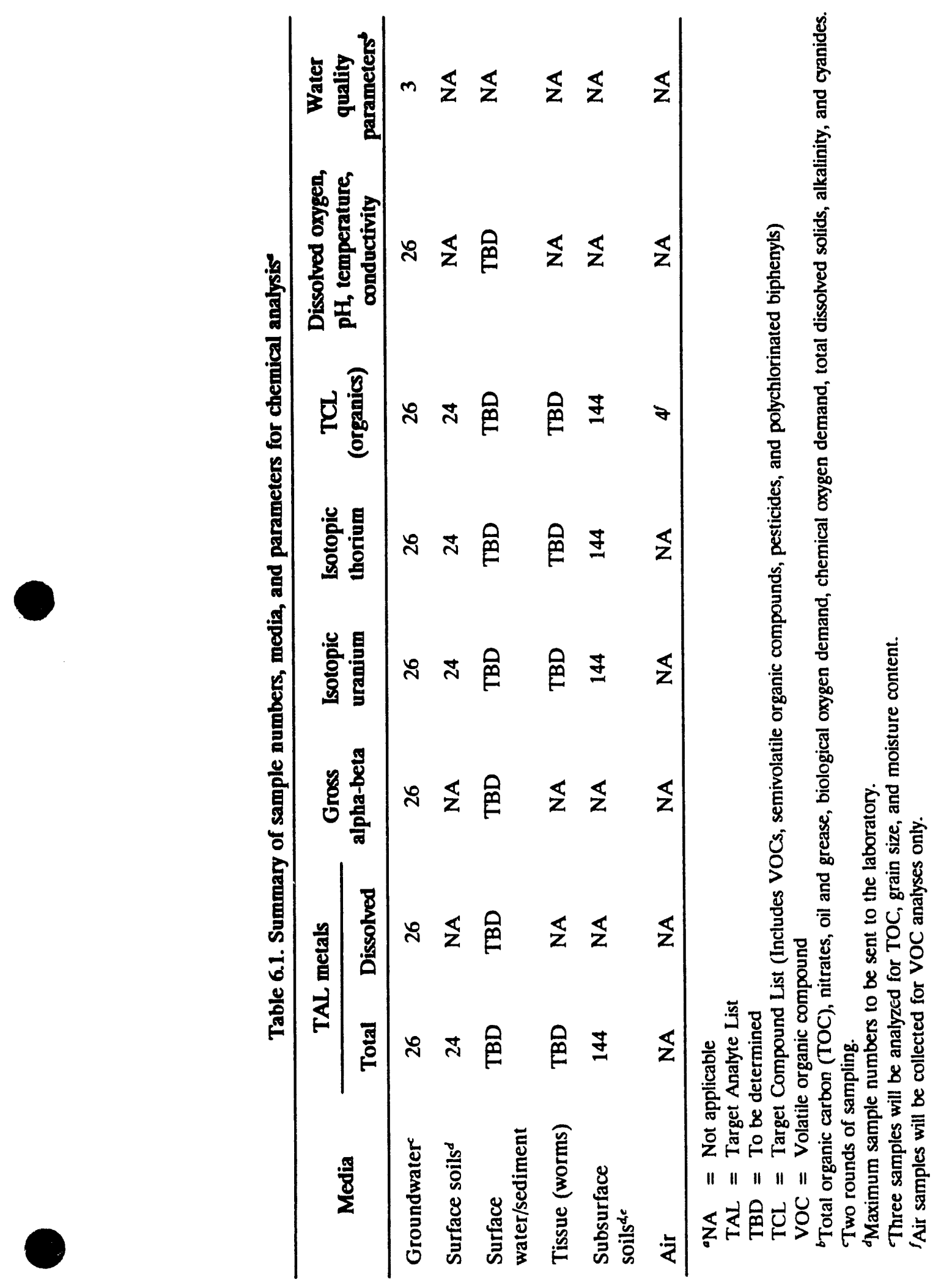




\subsubsection{Dye Tracer Study}

Due to the karst hydrologic system underlying the CRSP, it is difficult to determine the direction(s) of groundwater flow and, therefore, to determine exposure points for risk analysis. Dye tracer studies provide a mechanism for determining flow paths in karst systems. Two dye tracer studies have been conducted within the Chestnut Ridge hydrologic regime and are described in Sect. 3.6. The results of these two studies were inconclusive; therefore, a third study will be designed and performed in conjunction with this investigation. Development of the design of the dye tracer study is included in the tasks to be performed. The two previous studies will be reviewed and scrutinized, and the spring and seep survey will be conducted before the study design becomes definite. Study parameters to be determined include the dye to be used, monitoring locations, the frequency and duration of monitoring, and the dye injection points. During design of the dye tracer study, a meeting will be convened with the regulators to review the approach. An addendum to the Work Plan and QAPjP will be prepared once the final details of the dye tracer study and sampling program have been defined. The dye tracer study will be conducted under wet weather conditions.

\subsubsection{Spring/Seep Surface Water/Sediment Sampling}

The CRSP site is an upland area and not directly connected to surface waters. However, based on the hydrogeological characteristics of the site, there may be nearby locations where groundwater discharges as a spring or seep and becomes surface water. A spring and seep survey will be conducted within the Chestnut Ridge hydrologic regime to identify locations for monitoring during the proposed dye tracer study. Following the dye tracer study, springs and seeps believed to be hydrologically associated with the CRSP will be subject to sampling. A surface water and a sediment sample will be collected from each location. Surface water samples will be analyzed for the same list of parameters as the groundwater samples (listed above). The sediment samples will be analyzed for the same list, except that dissolved metals, gross alpha, and gross beta will not be measured. Surface water samples will be subject to field measurement of dissolved oxygen, specific conductance, $\mathrm{pH}$, and temperature, if possible.

At this time there is no way to accurately project the number of spring and seep surface water and sediment samples to be collected. Results of the dye tracer study and selection of spring/seep sampling locations will be discussed with the regulators before initiation of the spring/seep sampling campaign. This information will also be described in the Work Plan addendum.

\subsubsection{Surface and Subsurface Soil Sampling}

Surface and subsurface soil sampling adjacent to the CRSP will be conducted at eight transect locations that surround the site (Fig. 6.2). There are no existing surface or subsurface soil data for the CRSP. Six of the eight transects were situated to provide spatial coverage around the pits in all directions (Transects 1-6). Transects 7 and 8 are situated over areas of known groundwater contamination. The transects will be $-150 \mathrm{ft}$ in length. Three sampling locations will be identified along each transect at $-50-\mathrm{ft}$ intervals. There are numerous obstructions and other constraining site features that must be accommodated in the field. The precise locations of the transects and individual sampling locations will be determined in the field. 


\subsubsection{Surface soil sampling}

A total of 24 surface soil samples will be collected, three from each transect. Each surface soil sample will be a composite of three aliquots, except for samples for VOC analyses, which will be grab samples. Surface soil samples will be analyzed for TAL metals, TCL organics, isotopic uranium and thorium, and particle size. Surface soil samples will be collected to characterize the risk from direct contact (ingestion and inhalation of dust) with surface soils under the no-action scenario.

\subsubsection{Subsurface soil sampling}

A total of 24 borings will be drilled at the same three locations along each transect as the surface soil samples. The strategy for collecting subsurface soil samples includes the use of a Geoprobe soil sampling device and an on-site GC for screening samples for VOCs. The Geoprobe will be used to collect samples at 5 -ft intervals to $25 \mathrm{ft}$ bls from each of the 24 sampling locations. The $25-\mathrm{ft}$ bls depth is well below the bottom of the pits and addresses a zone adjacent to the pits where a future homesteader might excavate to construct a basement or other potential construction activities could occur.

All samples $(5,10,15,20$, and $25 \mathrm{ft})$ from each borehole will be collected and screened with the on-site GC. For all locations and depths where VOCs are present above the detection limit, another sample will be collected using the Geoprobe and sent to the laboratory for CLP analysis. The second Geoprobe location will be immediately adjacent to the screening location. If VOCs are not found in a particular borehole, a sample from the 25 - $\mathrm{ft}$ depth will be collected and sent to the laboratory for verification. In addition, based on screening results, $10 \%$ of the samples without detectable VOCs will be sent to the laboratory for analysis. If the sample collected from the 25-ft depth shows VOC contamination, a sample will be collected from $35 \mathrm{ft}$ and sent to the laboratory. For practical purpose, the $35-\mathrm{ft}$ depth is considered the maximum depth for collection of samples via Geoprobe at this site. The data collected from the 5- to 35 - $\mathrm{ft}$ horizon should be adequate to describe the extent of contamination and/or provide data that can be used for exposure modeling to greater depths.

All subsurface soils sent to the laboratory will be analyzed for TAL metals, TCL organics, isotopic uranium, and isotopic thorium. In addition, samples will be collected from the $25-\mathrm{ft}$ depth from three locations for analysis of TOC, grain size, and moisture content to support exposure modeling and treatment technology screening in the FS.

\subsubsection{Air Sampling}

Quantitative air sampling is required to evaluate the no-action alternative. Air sampling is proposed for the CRSP due to the known presence of VOC contamination. A total of four 24-h time-integrated ambient air samples will be collected and analyzed for TCL VOCs. Site-specific meteorological data (primarily wind direction) will be collected at the time of sampling to locate one upwind and three downwind locations for sampling. The sampling devices will be located adjacent to the CRSP within a few feet of the cap. Sampling will be conducted during the summer months and specifically over a 24-h dry period, if possible. Concentrations of VOCs in subsurface soils can be used to predict exposure concentrations associated with excavation of these materials. If significant levels of VOCs are found at a 
spring/seep location, additional air samples may be warranted; however, these are not planned at this time. The dust inhalation pathway will be evaluated using surface soil contaminant levels and soil particle size data.

\subsubsection{Ecological Surveys}

Because the CRSP constitute an upland site, there are no wetlands on-site; therefore, a wetland survey is not required. If, however, specific springs and seeps are found to be hydrologically associated with the site, wetland surveys of these areas will be performed as appropriate. An endangered species habitat survey will be conducted in the wooded areas adjacent to the CRSP. These areas could be impacted during site remediation. Similarly, endangered species habitat surveys will be performed at spring/seep locations hydrologically associated with the CRSP.

\subsubsection{Biological Sampling}

As discussed in Sect. 3.9.2, Conceptual Model for Exposure of Ecological Receptors, plant (cabbage seedlings) and earthworm testing/contaminant analyses are included as contingencies for use if contaminants are found at significant concentrations in surface soil samples collected adjacent to the CRSP. The need for and the numbers and locations of these test and analyses to be performed will be determined following receipt of the analytical results from the laboratory and data validation of surface soil samples.

Similarly, aquatic toxicity tests using fathead minnow larvae and Ceriodaphnia dubia will be performed at selected spring/seep locations where contaminants are present. Testing locations will be selected based on review of validated data from the spring/seep sampling campaign.

The biological sampling program described herein is essentially a Phase II investigation that will be fully determined following receipt of validated data on surface soils and spring/seep samples. The regulators will be involved in the data review process and contribute to the decision of the numbers and locations of tests/analyses to be performed. The details of the investigation will be included in the Work Plan Addendum.

\subsection{DATA EVALUATION AND INTERPRETATION}

Data collected during this RI will be used to evaluate the nature and extent of contamination at the CRSP, to support an HHRA and ERA, and evaluate the remedial alternatives for the FS. An RI report will be prepared that discusses the OU (i.e., site history, geology, hydrology, etc.); the work conducted during the investigation; an interpretation of the data; conclusions; and, as appropriate, recommendations. The report will follow the format specified by Energy Systems and will be subject to review by Energy Systems, DOE, and regulatory agencies (i.e., USEPA and TDEC).

To accomplish the objectives of the RI, the data will be assessed and interpreted in a variety of ways. Before any interpretation or assessment are made, all analytical data from the contract laboratory will be verified and validated. Data will meet appropriate precision, 
accuracy, representativeness, comparability, and completeness (PARCC) parameters. The QAPjP (Sect. 7) discusses data assessment and validation parameters applicable to this RI.

All sampling locations will be surveyed and clearly shown on a base map of OU1. Water level data will be presented in tabular form and also plotted on a map to evaluate any patterns in hydrostatic head for the groundwater. Cross sections may be prepared to depict the water table and/or potentiometric surface. Similarly, validated laboratory data from the monitoring wells will be tabulated. Contaminant concentrations and contours also may be prepared on maps, as appropriate, to depict relevant trends. If the data suggest vertical variation in contaminant levels, cross sections also may be prepared. Validated surface water and sediment data will be presented in a tabular format and, if appropriate, plotted on a map. Validated surface and subsurface soil data will be presented in a similar manner. As previously discussed, the results of surface soil and spring/seep sampling will be reviewed and evaluated to define the numbers and locations of biological tests/analyses to be performed.

Analytical data obtained from the RI will also be compared to existing data from OU1. Every attempt will be made to determine the statistical significance and associated confidence represented by the entire body of data. Because the observational method/approach was used in design of the sampling program, nonrandom, nonparametric statistical tests, such as the Mann-Whitney U-Test, will be used for comparison of site data to background data.

The HHRA and ERA will use the data described above as well as data from the ecological/biological studies. The baseline ERA will follow the standard paradigm for an ERA, as described in Sect. 3. The baseline HHRA will be conducted following established USEPA guidelines. In addition, recommendations from the ER Risk Assessment Council and other supporting documentation will be followed.

\subsection{RISK ASSESSMENT METHODOLOGY}

\subsubsection{Baseline Human Health Risk Assessment}

The scope of this RI Work Plan entails using the data collected in the RI to evaluate the potential risk to human health from exposure to the potentially contaminated media related to the CRSP; refer to the conceptual site model for human health risk assessment in Fig. 3.11 of Sect. 3.9.1. The objective will be accomplished by evaluating on source-OU and off source-OU human exposure to media using the residential scenario RME risk assessment (i.e., BRA).

Source OUs are defined as on-site (property owned/managed by DOE-ORO) waste areas that are currently releasing or have the potential to release contaminants into the environment. For final action RODs, the future land use scenario will be used. [This land use (i.e., industrial or residential) will be agreed upon by the regulators.] The baseline risk assessment (an RME assessment), under the current default parameters, describes a future residential land use.

The methodology employed to conduct the RME risk assessment (i.e., BRA) will follow guidelines established in the Risk Assessment Guidance for Superfund, Volume I: Human 
Health Evaluation Manual (Part A) (EPA 1989). In addition, recommendations from the Risk Assessment Council and other supporting documentation, including the results from the Phase I and II Background Soil Characterization Project (BSCP) for the ORR, will be followed. A method will be used that includes upper (acute exposure) and lower (RME assessment) bounds to evaluate the risk posed to human health via direct exposure to all COPC in the Security Pits (i.e., those reported in the inventory list).

\subsubsection{Ecological Risk Assessment Methodology}

A baseline ERA will be performed for the CRSP because of possible soil contamination and because the site is a potential source of contaminants for EFPC, McCoy Branch, and the sludge disposal ponds. Risk assessments for the CRSP will serve to characterize its contribution to these other sites.

An ERA for waste sites differs from an HHRA in that the consequences of the risks can be measured. Biological surveys provide a direct measure of the state of the biotic communities that constitute the ecological assessment endpoints. Hence, ecological epidemiology will be employed (Suter 1990; Suter 1992; Suter and Loar 1992). In ecological epidemiology, the primary data are the field survey data that indicate the actual state of the system relative to the expected uncontaminated state. Other data are used to support inferences concerning the causes of any deviations from this expected state. This approach is consistent with the Risk Assessment Guidance for Superfund, Volume II: Environmental Evaluation Manual (USEPA 1989b).

The goals of the baseline risk assessment will be to determine (1) whether significant ecological effects are occurring in the OU, (2) the cause of any such effects, (3) the source of the causal agent, and (4) the consequences of leaving the system unremediated. These goals call for an epidemiological approach based on the weight of evidence. New and historical biological survey data will be compared to data from reference sites to determine the nature and magnitude of effects. Alternative causal factors such as habitat quality will be considered.

A phased approach will be applied to the ERA for the CRSP. In the initial phase, potential routes of exposure of the biotic community by contaminants will be identified. These routes are outlined in the baseline conceptual model (Sect. 3.9.2). Contaminant levels and contaminant transport routes in abiotic substrates will be quantified and identified in the second phase (Sect. 3.4, 3.5, and 3.6). In the final phase, actual exposure of the biota to contaminants will be determined and toxicity testing performed if appropriate (Sect. 3.9.2.2).

\subsection{FEASIBILTY STUDY}

The following sections describe the tasks necessary to conduct and produce the FS report. The report will follow the format outlined in USEPA's Guidance for Conducting Remedial Investigations and Feasibility Studies Under CERCLA (EPA/540/G-88/004) and the annotated outline developed by the DOE-ORO Document Content and Response Committee. The FS report will be prepared to integrate Natural Resource Damage Assessment (NRDA) and NEPA requirements. When USEPA and TDEC approve the FS, 
a proposed plan will be submitted that presents the preferred alternative for a remedial action, followed by a ROD.

\subsubsection{FS Contractor Responsibilities}

The FS contractor will prepare the FS within project quality, cost, and scheduling goals. The FS contractor will also provide engineering and technical resources to support QC efforts, provide project management, and coordinate project activities to ensure that established goals are achieved. Monthly progress reports on the FS process will be issued to DOE. FS contractor activities for Chestnut Ridge OU1 include scoping activities and technical support of the RI and will be completed upon final approval of the ROD prepared for this OU.

\subsubsection{Scope and Assumptions}

As stated in Sect. 5.2, the general goal for Chestnut Ridge OU1 remedial action is to protect human health and the environment from the contaminant sources within the OU. To meet this goal, the CERCLA process will be followed. The process will include characterization of this source control OU to the extent necessary to (1) identify, screen, and develop remedial action alternatives; (2) select a preferred remedial alterative or a set of alternatives; and (3) prepare the required decision documents.

The FS contractor will be responsible for completing the FS process for Chestnut Ridge OU1. This process will require preparing the following milestone documents: (1) the FS Report, which documents the process used to examine the remedial technologies and select the preferred remedial alternative(s) and which incorporates the requirements under NRDA and NEPA; (2) the Proposed Plan, which is a summary plan for presenting the selected remedial alternative; and (3) the $R O D$, which is the legal document that confirms that selected remediation methods met statuiory and regulatory requirements. The FS/Proposed Plan/ROD process may include the principal Work Breakdown Structure elements listed below.

- FS Scoping Activities

- Treatability Studies

- FS Development

- NEPA Activities
- NRDA Activities

- FS OU Coordination/Oversight

- Proposed Plan Development

- ROD Development

\subsubsection{FS scoping activities}

Preliminary remedial alternatives have been selected to address the response actions for Chestnut Ridge OU1. The response actions are listed in Sect. 5.3 and in Table 5.1. These or similar alternatives will be screened as part of the FS process to eliminate those judged too difficult to implement based on unproved technologies, those judged insufficient to remediate the site within a reasonable time period, or those judged to have limited application for the specific contaminant or site conditions. Those technologies judged to have a reasonable chance of success for remediation will be carried forward for more detailed development and analysis. 
The following issues must be addressed before the technologies can undergo detailed development and analysis. This list may change as additional information becomes available.

- Results of the HHRA

- Results of ERA

- Groundwater characteristics

- Groundwater quality

- Air quality
- Quality of any affected surface water or sediment

- Presence of classified material

- Possible treatability studies

- Surface and subsurface soil quality

- Level of NEPA documentation required

\section{5 .22 Treatability studies}

If necessary, treatability studies will be conducted to provide data to allow treatment alternatives to be fully developed and evaluated during the detailed analysis and to support the remedial design of a selected alternative.

\subsubsection{FS development}

The FS contractor will use the format presented in the CERCLA RI/FS guidance document and the DOE-ORO Document Content and Response Committee FS annotated outline to develop the FS. As required, exceptions and modifications to the format will be made for site-specific conditions in Chestnut Ridge OU1. On the basis of the data obtained during the RI, selected alternatives will be analyzed and compared using the following 11 criteria:

- overall protection of human health and the environment;

- compliance with ARARs;

- short-term effectiveness;

- long-term effectiveness;

- reduction of contaminant toxicity, mobility, and volume;

- implementability;

- cost;

- state acceptance;

- community acceptance;

- compliance with NEPA requirements; and

- compliance with NRDA requirements.

NEPA and NRDA requirements are discussed in more detail in the following subsections.

The FS will be developed in sufficient detail to allow the preferred alternative(s) to be selected in the Proposed Plan. Criteria will be developed to assess the ability of the alternatives to meet the cleanup goals and to comply with administrative and regulatory requirements. The draft FS report will be issued to USEPA and TDEC for review. Submittal of the draft FS report to USEPA is an FFA milestone.

\subsubsection{NEPA activities}

To comply with the federal facility requirements under NEPA, the remedial alternatives will be evaluated for their impact on the environment. NEPA establishes public policies and 
goals for protecting environmental quality and mandates procedural requirements to be considered when implementing decisions that may impact the environment. DOE Order 5400.4 requires that NEPA and CERCLA be integrated to the maximum extent possible to avoid duplication of efforts that might slow the process. NEPA issues to be addressed include rare and endangered species, archeological studies, wetlands, and floodplains. The environmental impacts of the alternatives will be integral to the evaluation and selection process.

\subsubsection{NRDA activities}

To comply with NRDA, the Natural Resource Trustees may assess damages or injuries to natural resources resulting from release of hazardous substances. The first step in the NRDA process is to perform a preassessment screen. If the screening indicates that NRDA is inappropriate, no further assessment actions will be taken. However, if the preassessment screen indicates that NRDA is appropriate, a type $B$ assessment will begin, requiring an Injury Determination phase, a Quantification phase, and a Damage Determination phase (April 29, 1991, Federal Register).

\subsubsection{FS OU coordination/oversight}

The objective of FS oversight activities is to provide review and technical input during the FS. The results ensure that the data and information obtained during the RI are incorporated properly into the FS report and that they are adequate for preparation of a proposed plan and support of the development of the ROD.

\subsubsection{Proposed plan development}

The preferred alternatives for a site are presented to the public in a Proposed Plan. The Proposed Plan provides a brief summary of all the alternatives studied in the detailed analysis phase of the RI/FS, highlighting the key factors that led to the identification of the preferred alternative(s). The Proposed Plan is made available for public comment, in addition to the $\mathrm{RI} / \mathrm{FS}$ and the other information, in the administrative record.

\subsubsection{ROD development}

The final step in the decision process for any remedial action for Chestnut Ridge OU1 will be preparation of the ROD. This legal document formally describes the preferred remediation alternative and establishes the remediation schedule and monitoring plan for the site. The Chestnut Ridge OU1 ROD will be written in accordance with the statutory requirements of CERCLA and applicable federal and state requirements. It will contain a decision summary outlining the nature and extent of the contamination and associated risks at Chestnut Ridge OU1, the evaluation and analysis of the Remedial Action (RA) alternatives considered, and an explanation of how the selected alternative(s) will meet statutory requirements. The ROD will also contain a responsiveness summary addressing the public comments obtained during public review of the Proposed Plan and public examination of the administrative record. The ROD is a primary FFA milestone. 


\subsection{REMEDIAL DESIGN AND RA PLAN}

\subsubsection{Remedial Design}

This section presents the scope of the Remedial Design (RD) effort required to prepare an RD Work Plan; perform any required engineering studies; prepare a Title I 30\% design package; and prepare Title II 50, 90, and 100\% final design reports for Chestnut Ridge OU1 remediation.

\subsubsection{Scope and assumptions}

The scope of the RD Work Plan for the remediation of Chestnut Ridge OU1 is to provide necessary supporting documents for implementation of each RA activity. These documents require approval from TDEC and USEPA. The following sections present details of the scope of work and assumptions associated with remediation of Chestnut Ridge OU1.

\subsubsection{RD Work Plan}

The RD Work Plan will provide the technical and managemental approaches for the RD work. The RD contractor will prepare a draft RD Work Plan based on the scope and design criteria specified in the Proposed Plan and the ROD. The RD Work Plan will include the detailed design process and schedule for the design effort and will be prepared in accordance with CERCLA/NEPA regulations. The RD contractor will incorporate comments from USEPA and TDEC and submit the final RD Work Plan for approval.

\subsubsection{RD Work Plan oversight activities}

During the preparation of the RD Work Plan, DOE will provide review and technical input to ensure that the scope of work is adequately defined in accordance with the criteria specified in the ROD. Review of the draft RD Work Plan will also ensure that the selected technologies do not violate the intent of the ROD and that the Work Plan meets all regulatory and administrative requirements.

\subsubsection{RD report Title I design}

Based on the engineering studies and other information available from the RI/FS, the RD contractor will prepare Title I (30\%) design/construction drawings for remedial activities that will show the extent of remedial activities, site plan, details, and outline of specifications for the work involved.

\subsubsection{RD report Title II design}

Upon approval of the Title I design document, the RD contractor will prepare Title II engineering designs, analyses, and calculations required for all civil, structural, mechanical, and electrical construction; construction drawings; technical specifications; and cost estimates.

All documents will be submitted to Energy Systems for comment at $60 \%$ completion. Upon resolution of comments, the $90 \%$ design package will be submitted to Energy Systems 
and DOE for review and comment. Upon resolution of $90 \%$ of the comments, the final design report (100\%) for remedial activities will be submitted to USEPA and TDEC for review and approval. Agency comments will then be incorporated during preparation of the design documents certified for construction.

\subsubsection{RD oversight activities}

During the review of the Title I design documents at $30 \%$ and the Title II design documents at 60 and $90 \%$, all participants will provide their review and technical input to ensure submission of the final design document to TDEC and USEPA in the given time frame.

\subsubsection{Remedial Action}

This section presents the scope of the RA activities required for preparation of an RA Work Plan and implementation of the remediation of Chestnut Ridge OU1. The risk, uncertainties, and communication issues for the remedial activities are also identified in this section.

\subsubsection{Scope and assumptions}

The scope of the RA includes the RA Work Plan, construction management, Title III construction services, construction of one remediation design package, construction support, independent certification, and verification.

\subsubsection{RA Work Plan}

The RA Work Plan will (1) define the scope and objectives of the RA based on the ROD and final RD; (2) document the specific construction components of the RA; and (3) present the RA schedule, subcontracting strategy, QA plan, health and safety plan, and $\mathrm{RA}$ monitoring plan.

After comments from USEPA and TDEC are incorporated, the final RA Work Plan will be prepared for approval and implementation.

\subsubsection{RA Work Plan oversight activities}

The purpose of this activity is to provide technical input and review during the preparation of the RA Work Plan. During this time, all of the DOE prime contractors will review the work plan. This will ensure that the proposed construction efforts implement the selected remedial action consistent with the ROD and the final RD report. This oversight activity will also ensure that the bid process and implementation plans comply with administrative and regulatory requirements.

\subsubsection{RA integration}

The objective of this element is to provide construction management, independent certification, Title III services, and construction support as required. 
RA integration for Chestnut Ridge OU1 remedial activities includes the following tasks:

- Ensure that subcontracted work is performed on schedule, in accordance with all technical requirements and in compliance with the Environmental Safety and Health Program, the QA Program, the Waste Management Program, and the Security Program.

- Perform field inspections, provide as-built drawings, approve Design Change Notices and Field Change Requests as applicable, and ensure that construction is accomplished according to final design requirements. 


\section{FIELD AND LABORATORY QUALITY ASSURANCE PROJECT PLAN}

$\begin{array}{ll}\text { Project Title: } & \text { REMEDIAL INVESTIGATION WORK PLAN FOR CHESTNUT } \\ & \text { RIDGE OPERABLE UNIT 1 (CHESTNUT RIDGE SECURITY } \\ & \text { PITS) AT THE OAK RIDGE Y-12 PLANT }\end{array}$

Prepared By: CDM Federal Programs Corporation

Technical Support Contractor

Date:

Program Manager

Approved By:

Technical Support Contractor

Date:

Quality Assurance/Quality Control

Officer Concurrence

Approved By:

DOE-ER Division Site Program Manager

Date:

Approved By:

DOE-ER Division QA. Program Manager

Date:

Approved By:

Energy Systems ER Site Program Manager

Date:

Approved By:

Energy Systems ER Site Project Manager

Date:

Approved By:

Energy Systems ER Site

Date:

Quality Assurance Specialist 


\subsection{INTRODUCTION}

Work on this assignment will be performed in accordance with the Energy Systems document, Environmental Restoration Quality Program Plan (ES/ER/TM-4/R2), and the CDM Federal Quality Assurance Manual (1593). This QAPjP has been prepared in accordance with USEPA Interim Guidelines and Specifications for Preparing Quality Assurance Project Plans (QAMS-005/80), revised 1983; USEPA Region IV Standard Operating Procedures and Quality Assurance Manual, revised February 1991; the Environmental Restoration Quality Program Plan (ES/ER/TM-4/R2); and Environmental Surveillance Procedures, Quality Control Program (ES/ESH/INT-14). This QAPjP has been reviewed for QA/QC requirements by the CDM Federal QA staff, who will maintain QA oversight for the duration of this project. Energy Systems will also maintain oversight during this project to ensure compliance with all applicable QA requirements. In addition, all deliverables will be subject to technical review by CDM Federal technical specialists, and all deliverables presenting measurement data will also be reviewed by the CDM Federal QA staff. A description of the project can be found in Sects. 1 through 3 of this RI Work Plan.

\subsection{QUALITY ASSURANCE/PROJECT ORGANIZATION}

The principal CDM Federal personnel assigned to prepare and review the Work Plan are Richard C. Johnson, P.E., P.G. (Program Manager); Mary Leslie (Y-12 Program Coordinator); Charles T. Lutz, Ph.D. (Project Manager); Charles Meyers (Health and Safety Manager); the Site Health and Safety Coordinator; the Field Task Manager; RoseMary Ellersick (Corporate QA Director); and David O. Johnson (Contract QA Specialist). Figure 7.1 shows the project organization, reporting relationships, and lines of authority for this project. General responsibilities of key individuals are discussed in this section. Other personnel will be assigned as necessary.

\subsubsection{Program Manager Roles and Responsibilities}

\subsubsection{CDM Federal Program Manager}

The CDM Federal Program Manager, Richard C. Johnson, has responsibility for the successful preparation of this project plan and for ensuring that adequate resources are available as needed. He also has overall responsibility for implementing the CDM Federal QA Program and for ensuring that effective corrective action is taken to address quality problems should they occur.

\subsubsection{CDM Federal Y-12 Program Coordinator}

The Y-12 Program Coordinator, Mary Leslie, is responsible for oversight and coordination of all active task orders with the Y-12 Plant ER Division. Ms. Leslie assists Project Managers in scoping meetings, preparing and reviewing documents, and resolving problems. The Program Coordinator performs an overview function that ensures consistency of approach among Y-12 Plant ER projects performed by CDM Federal and a mechanism for actively benefiting from lessons learned from projects. Ms. Leslie is also responsible for ensuring that 


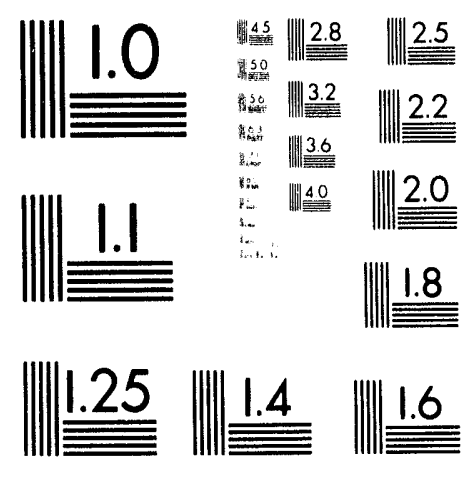



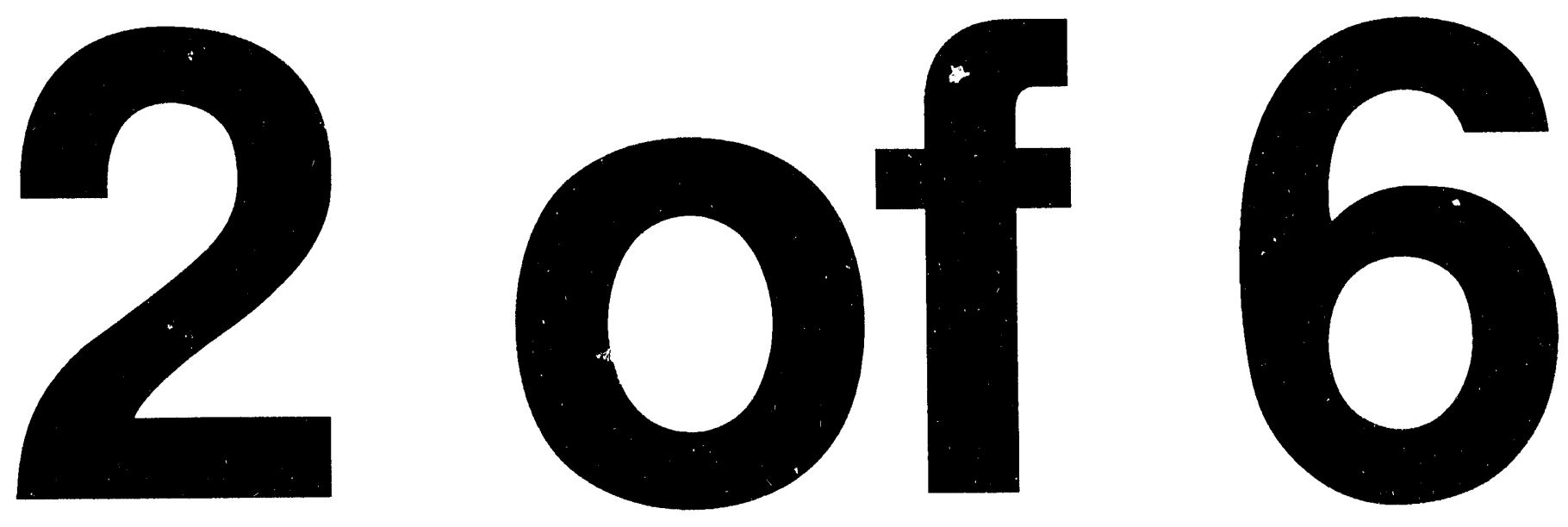
Dato: July 1993

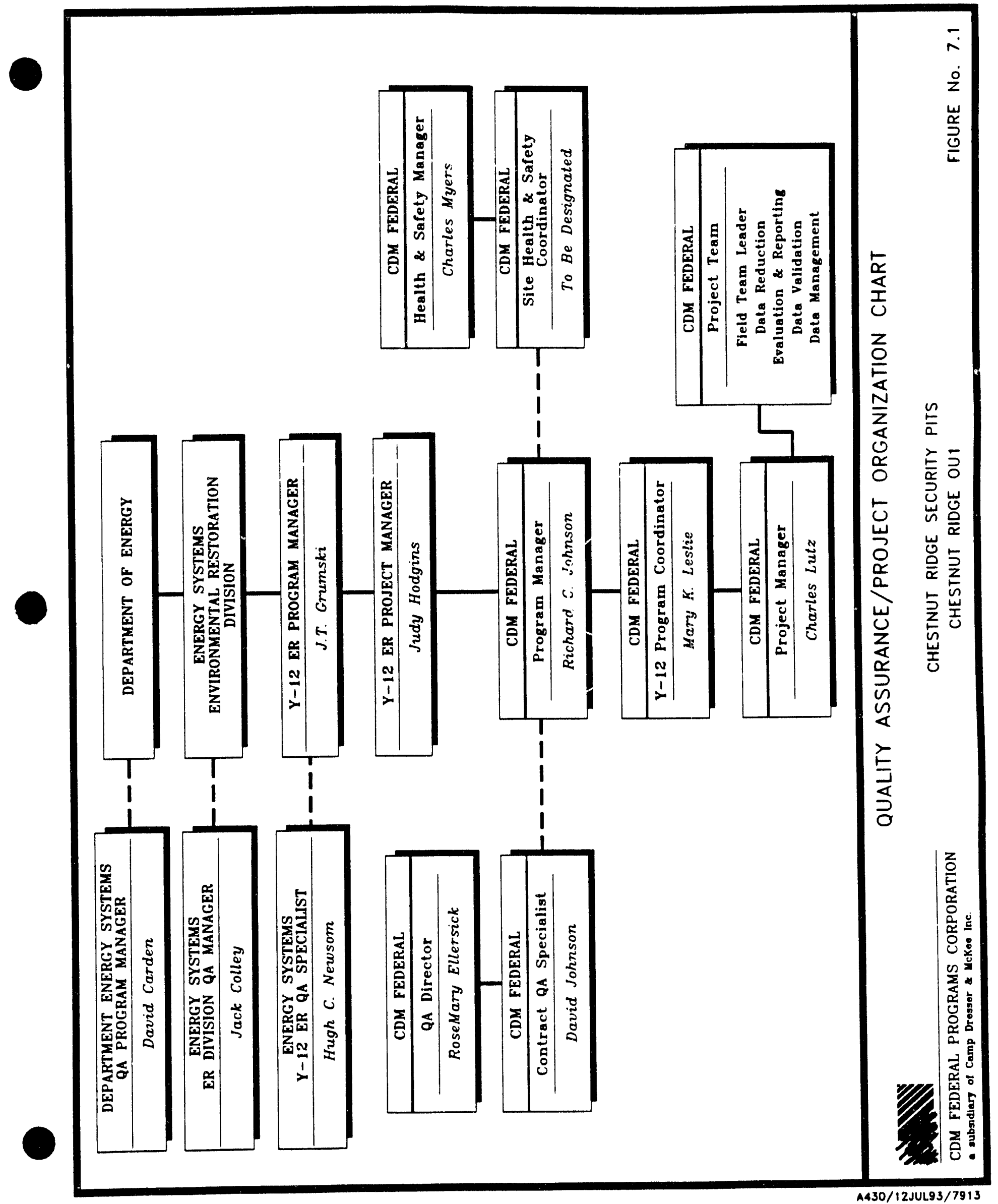


adequate resources are available for Y-12 Plant projects and that completion of task orders is accomplished on budget and schedule.

\subsubsection{Energy Systems Y-12 ER Program Manager}

The Energy Systems Y-12 ER Program Manager, J. T. Grumski, is responsible for ensuring that the quality requirements of this project are met and that operating procedures are effectively implemented. He is also responsible for interfacing with and directing the activities of the assigned ER QA $S_{\mathfrak{I}}$ ecialist on all quality-related matters and for stopping work when the severity of conditions adverse to quality warrants such actions.

\subsubsection{Project Manager Roles and Responsibilities}

\subsubsection{CDM Federal Project Manager}

The Project Manager, Charles T. Lutz, will be the prime point of contact with Energy Systems and will have primary responsibility for technical, financial, and scheduling matters. His duties will include the following:

- implementing the CDM Federal QA program;

- preparing, reviewing, and approving all project documents;

- assigning duties to the project staff and orienting the staff to the needs and requirements of the project;

- obtaining the approval or guidance from Energy Systems for proposed major changes to the QAPjP and Field Sampling Plan;

- supervising the performance of project team members;

- evaluating training needs for the project staff;

- providing budget and schedule control;

- reviewing subcontractor work and approving subcontractor invoices;

- establishing a project record system;

- ensuring that major project deliverables are reviewed for technical accuracy and completeness before their release;

- ensuring that the requirements of the RI Work Plan are satisfied; and

- regularly communicating project status, progress, and any problems to the Energy Systems Project Manager. 


\subsubsection{Energy Systems Y-12 ER Project Manager}

The Energy Systems ER Project Manager, Judy Hodgins, will be the prime point of contact between Energy Systems ER and CDM Federal and will have primary responsibility for technical, financial, and scheduling matters and coordinating with the various Energy Systems divisions and organizations participating in this project. Duties will include the following:

- implementing the Energy Systems ER Quality Program Plan (QPP);

- preparing, reviewing, and approving all project documents generated by Energy Systems personnel;

- reviewing and approving all deliverables prepared by CDM Federal;

- assigning duties to the Energy Systems project staff and orienting the staff to the needs and requirements of the project;

- providing review and approvals or guidance for proposed changes to the QAPjP and Field Sampling Plan;

- supervising the performance of Energy Systems project team members;

- evaluating training for the Energy Systems project staff;

- providing overall budget tracking and schedule control;

- establishing a project record system that meets the ER QPP record requirements;

- ensuring that major project deliverables are reviewed for technical accuracy and completeness before their release to DOE and regulatory agencies;

- ensuring that all project requirements are satisfied;

- regularly communicating project status, progress, and any problems with Y-12 Plant ER management staff; and

- initiating stop-work actions when the severity of conditions adverse to quality warrants immediate action.

\subsection{CDM Federal Health and Safety Roles and Responsibilities}

\subsubsection{CDM Federal Health and Safety Manager}

CDM Federal Health and Safety Manager, Charles Myers, is responsible for all health and safety (H\&S) issues and will be available $24 \mathrm{~h}$ a day for consultation on such issues. His responsibilities include the following: 
- ensuring that the corporate H\&S Manual is followed,

- reviewing H\&S plans,

- maintaining all $\mathrm{H} \& S$ records and files, and

- conducting safety training.

\subsubsection{Site Health and Safety Coordinator}

The Site H\&S Coordinator is responsible for implementation of the H\&S Plan at the site. The responsibilities are as follows:

- ensuring that the H\&S of personnel are maintained,

- conducting site safety training,

- conducting daily H\&S briefings,

- ensuring that all monitoring equipment is operating properly,

- reporting any H\&S issues to the H\&S Manager, and

- stopping work if safety issues arise.

\subsubsection{Field Task Manager Roles and Responsibilities}

The CDM Federal Field Task Manager will be responsible for execution of all field activities by CDM Federal personnel and will have authority to direct activities of subcontractors including stopping work and/or taking appropriate emergency actions. The Field Task Manager's duties and responsibilities are as follows:

- reviewing and implementing the Field Sampling Plan and QAPjP;

- notifying the Project Manager and QA staff of problems encountered in the field and implementing corrective action;

- providing orientation and any necessary training to field personnel (including subcontractors) on the requirements of the RI Work Plan and the QAPjP before the start of work;

- providing direction and supervision to CDM Federal and subcontract personnel to ensure that all on-site sampling and activities adhere to the QAPjP and the RI Work Plan;

- ensuring the use of calibrated measurement and test equipment;

- establishing and maintaining a field records management system;

- coordinating activities with the Project Manager;

- overseeing field data documentation;

- reviewing reports for compliance with applicable requirements; and

- assigning the duties of the Site H\&S Coordinator to a qualified on-site individual, if necessary. 


\subsection{Quality Assurance Management Roles and Responsibilities}

The Corporate QA Director, RoseMary Ellersick, is responsible for ensuring and assessing the implementation of the CDM Federal QA program. The CDM Federal Corporate QA Director is independent of the technical staff and reports to the CDM Federal Office of the President. The Corporate QA Director thus has the authority to review and identify problems and to bring corporate resources to bear in solving problems, if necessary. The Corporate QA Director is assisted by the Contract QA Specialist and other QA staff, who report directly to the Corporate QA Director on quality matters.

\subsubsection{CDM Federal Corporate QA Director}

The CDM Federal Corporate QA Director, RoseMary Ellersick, is responsible for the following:

- actively identifying and responding to QA/QC needs, resolving problerns, and answering requests for guidance or assistance;

- preparing and submitting QAVQC reports to CDM Federal senior management;

- conducting an annual trend analysis to identify potential problem areas;

- verifying that appropriate corrective actions are taken for all nonconformances; and

- scheduling, on a quarterly basis, appropriate QA audits or surveillances for significant activities to ensure compliance with requirements and procedures.

\subsubsection{CDM Federal Contract QA Specialist}

The CDM Federal Contract QA Specialist, David Johnson, is responsible for the following:

- reviewing and approving the Field Sampling Plan and QAPjP and all subsequent changes to these documents,

- actively tracking the progress of QA requirements in this plan and consulting periodically with the Project Manager,

- arranging or conducting training of project personnel,

- preparing a monthly QA status report for submittal to the Corporate QA Director,

- arranging or performing audits or surveillances, and

- participating in field planning sessions for field activities. 


\subsubsection{Energy Systems ER QA Manager}

The ER Division QA Manager, James Colley, is responsible for directing and verifying the implemertation of the ER Quality Program. Specific responsibilities are given in the ER QPP (ES/ER/TM-4/R2), Sect. 1.5.3.

\subsubsection{Energy Systems Y-12 ER QA Specialist}

The ER QA Specialists, Hugh Newson and Don White, are responsible for supporting the development and implementation of the ER Quality Program. Specific responsibilities are given in the ER QPP, Sect. 1.5.4.

\subsubsection{DOE QA Program Manager}

The DOE QA Program Manager, David Carden, is responsible for oversight of QA Program implementation including:

- reviewing and approving QAPjPs;

- reviewing summary reports;

- performing audits, surveillances, and appraisals;

- following up on corrective action; and

- informing the DOE Program Manager of QA Program status.

\subsubsection{Technical Review Committee}

The Technical Review Committee (TRC) is a forum for peer review that is composed of individuals with fields of expertise appropriate to the project. The TRC for this project includes Robert Kasper, Fletcher Armstrong, and James Wedekind. The TRC has reviewed the entire RI Work Plan (including this QAPjP) and will review future major deliverables. Compliance with internal TRC requirements is checked in audits or surveillances.

\subsection{QUALITY ASSURANCE OBJECTIVES FOR MEASUREMENT DATA}

\subsubsection{Data Quality Objectives}

Data Quality Objectives (DQOs) are qualitative and quantitative statements developed by data users to specify the quality of data from field and laboratory data collection activities to support specific decisions or regulatory actions. The DQOs describe what data are needed, why the data are needed, and how the data will be used to address the problem being investigated. DQOs also establish numeric limits for the data to allow the data user (or reviewers) to determine whether data collected are of sufficient quality for use in their intended application. Some of the tests to be performed in support of the ERA and 
ecological characterization of the site do not have applicable QC levels for measurement data (e.g., toxicity testing and the various surveys to be performed). Although QC levels do not apply, DQOs do. For toxicity testing, DQOs are frequently defined by the method in terms of percent survival in the control samples and percenı error among replicates. For field surveys, DQOs are tangible in terms of the time of year of the survey, the minimum number of species encountered, the expertise level of the surveyor, and so on. Although more subjective, these DQOs are real and in many cases, such as toxicity testing, are formalized in the SOPs.

\subsubsection{Intended Uses of Acquired Data}

The intended uses of the acquired data are to

- characterize the nature and extent of contamination in soil and groundwater at the CRSP;

- characterize the hydrologic system at the site based on results of a dye tracer study;

- characterize the nature of contaminated media (the source) at the site to drive the alternatives assessment and FS;

- characterize soil, surface water, sediment, and air contaminant concentrations to determine if huinan and environmental receptors are at risk from exposure to contaminants; and

- characterize the ecological communities at the site and perform tests and collect data on the levels of contaminants in flora and fauna to support an ERA.

Data objectives to accomplish this are as follows:

- Scientific data generated will be of sufficient quality to withstand technical and scientific scrutiny. QC levels $C$ and $D$ are designated for analytical data.

- Data will be gathered or developed in accordance with procedures appropriate for their intended use. All field and laboratory methods/procedures specified for this project comply with or exceed the USEPA requirement for CERCLA investigations.

- Data will be of known PARCC within the limits of the project. Specific criteria for PARCC parameters have been established, as appropriate, and are presented in Sect. 7.3.5.

\subsubsection{Intended Users of Data}

The primary users of data acquired during this investigation will be the following:

- the Field Task Manager, who will use field data for well purging and health and safety monitoring;

- the Project Team, which will use the data to determine the nature, extent, transport, and fate of contaminants and present these results in an KI Report; 
- the risk assessor(s), who will use the data to complete the risk assessment data base and to conduct an HHRA and an ERA; and

- the engineers/scientists, who are involved in development of alternatives and conducting the FS.

\subsubsection{Levels of Quality Control}

Five general levels of analytical options to support data collection are specified by the USEPA as QC levels (Levels I, II, III, IV, and V). Energy Systems has defined QC Levels in Requirements for Quality Control of Analytical Data (ES/ER/TM-16, Sect. 3) as Levels A, $\mathrm{B}, \mathrm{C}, \mathrm{D}$, and $\mathrm{E}$; these are generally analogous to the USEPA levels. These levels are based on the type of site to be investigated, the level of accuracy and precision required, and the intended use of the data.

Level A QC is designated for field screening. The objective of Level A analysis is to generate data that are generally used to refine sampling plans and monitor health and safety. Level $A$ is also used for screening samples that will be subject to further analysis. No data quality criteria are specified for Level $\mathrm{A}$, because this level is characterized by the use of hand-held instrumentation that is not conducive to the generation of quantitative data. An organic vapor meter or photoionization detector is an example of such instrumentation. However, a calibration or performance check of the instrument is required.

Level B QC is designed to provide real-time data for ongoing field activities or to provide initial data that will be the basis for seeking laboratory analytical support. Level B QC data typically are confirmed by submission of some duplicate samples to a fixed-base laboratory. Level B analysis is used for on-site, real-time screening; baseline data development; extent of contamination determination; and on-site remedial activities. Field analysis involves the use of portable or transportable instruments that are based at or near a sampling site and can provide data from the analysis of air, soil, and water samples for organic and inorganic compounds. Examples of those instruments include portable GCs, $\mathrm{pH}$ meters, and conductivity meters. Because Level B analyses are performed in the field, the amount and type of documentation available will vary with the type of analysis and SOPs used. Field and analysis logbooks also would be a source of additional documentation.

Level C QC applies to data produced by a laboratory meeting Energy Systems QA/QC requirements. Level $C \mathrm{QC}$ includes review and approval of the laboratory QA Plan, Field Sampling Plan, and the field QA Plan. Level C allows the use of non-CLP methods but requires that the methods be USEPA-approved or USEPA-equivalent ones. The laboratory is required to provide the summary CLP package with the analytical results (not the full CLP package). Level C QC results in technically defensible data, which can be used for risk assessment purposes.

Level D QC field and laboratory requirements are similar to Level $C$ for the basic laboratory QA/QC, Field Sampling Plan, and QAPjP development and approvals. However, for Level $D Q C$, the laboratory is required to submit the full CLP data package (or 
equivalent) with analytical results. This QC level typically applies to sites on the NPL and results in very defensible data.

Level E QC requires the use of USEPA or USEPA-equivalent analytical methods. It generally is method-specific and applies to unique materials such as pure waste, biota, explosives, etc.

QC Levels A, B, C, and D will apply to data collected during this investigation. Table 7.1 identifies the intended use, intended users, and QC level for various field activities or types of data.

\subsubsection{Precision, Accuracy, Representativeness, Completeness, and Comparability}

The PARCC parameters are tools by which data sets can be evaluated. PARCC parameters can help ensure that DQOs are met. Definitions of the parameters and procedures for assessing them are provided below.

Precision refers to the level of agreement among repeated measurements of the same characteristic, usually under a given set of conditions. To determine the precision of the laboratory analysis, a routine program of replicate analyses in accordance with the analytical method requirements is performed by the laboratory. The results of replicate analyses are used to calculate the relative percent difference, which is used to assess laboratory precision. For replicate results $C_{1}$ and $C_{2}$,

$$
\text { Relative percent difference }=\frac{\left|C_{1}-C_{2}\right|}{\frac{C_{1}+C_{2}}{2}} \times 100 \text {. }
$$

Precision of the total sampling and analytical measurement process will be assessed from field duplicates. Although a quantitative goal cannot be set due to field variability, CDM Federal will review field duplicate relative percent difference values to estimate precision.

Accuracy refers to the nearness of a measurement to an accepted reference or true value. To determine the accuracy of an analytical method and/or the laboratory analysis, a periodic program of sample spiking is conducted (minimum 1 spike and 1 spike duplicate per 20 samples). The results of sample spiking are used to calculate the QC parameter for accuracy evaluation, the percent recovery (\% R). For surrogate spikes and QC samples,

$$
\% R=\frac{C_{s}}{C_{1}} \times 100
$$

where

$\mathrm{C}_{\mathrm{s}}=$ measured spiked sample concentration (or amount),

$C_{1}=$ true spiked concentration (or amount). 
$7-12$

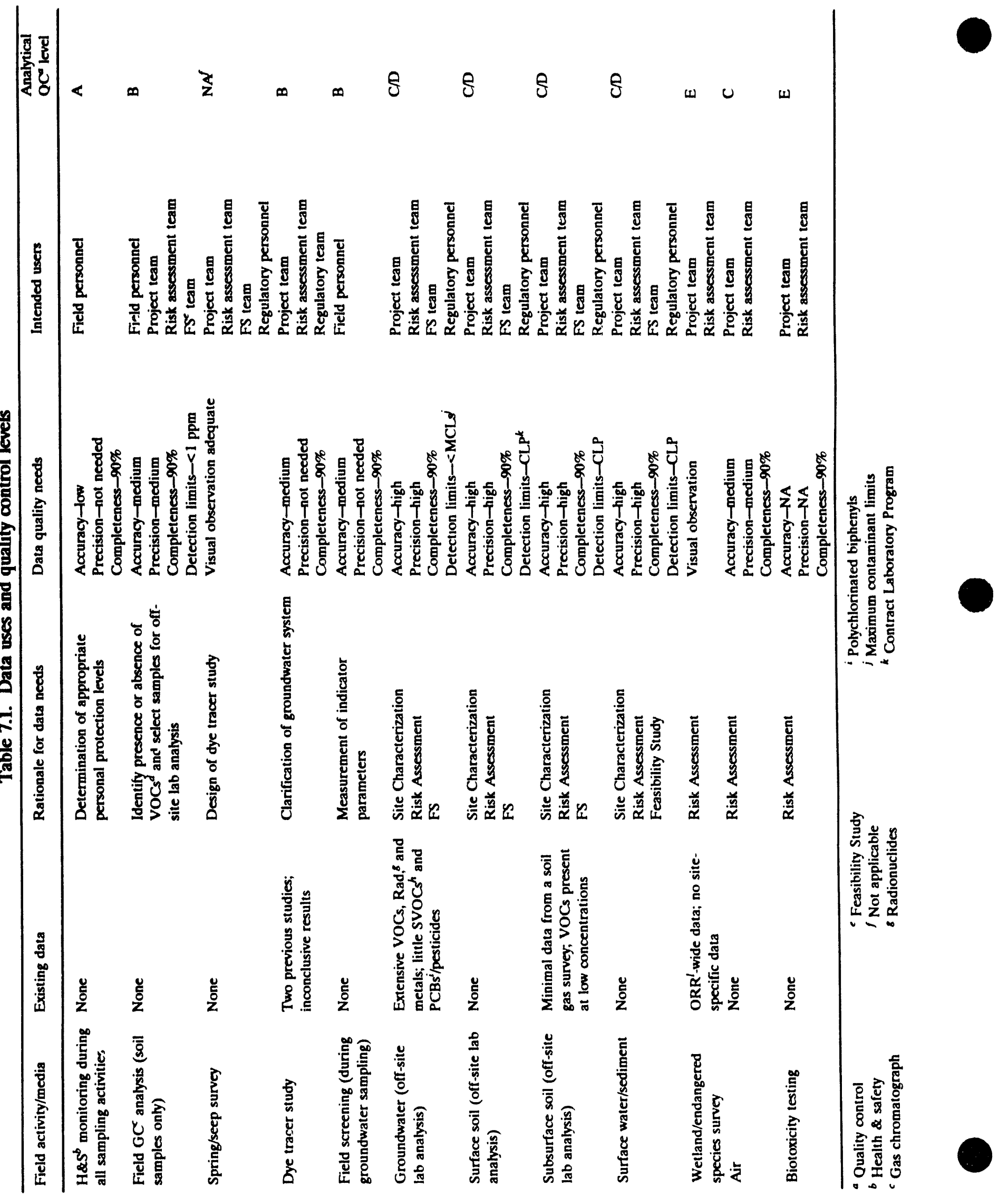


For matrix spikes,

$$
\% R=\frac{\left|C_{s}-C_{0}\right|}{C_{t}} \times 100
$$

where

$\mathrm{C}_{\mathbf{s}}=$ measured spiked sample concentration,

$\mathrm{C}_{0}=$ sample concentration (not spiked),

$C_{1}=$ true concentration of the spike.

Objectives for accuracy and precision for this project are shown in Tables 7.2 and 7.3.

Accuracy of the total sampling and analytical measurement process will not be determined. This would require the addition of chemical spiking compounds to the samples in the field.

Representativeness is the degree to which discrete samples accurately and precisely reflect a characteristic of a population, variations at a sampling location, or an environmental condition. Representativeness is a qualitative parameter and will be achieved through careful, informed selection of sampling sites and analytical parameters and through the proper collection and handling of samples to avoid interferences and to minimize contamination and sample loss.

Completeness is a measure of the percentage of valid, viable data obtained from a measurement system compared to the amount expected under normal conditions. The goal of completeness is to generate a sufficient amount of valid data to satisfy project needs. For this project, the completeness objective, 90\%, is shown in Tables 7.2 and 7.3.

Comparability is the extent to which comparisons among different measurements of the same quantity or quality will yield valid conclusions. Comparability will be achieved through the use of SOPs, analytical methods, QC, and data reporting. In addition, data validation evaluates processes employed by the laboratory that affect data comparability.

\subsection{SAMPLE COLLECTION AND ANALYSIS PROCEDURES}

Sampling locations and rationales are discussed in Sect. 6 (Site Data Needs) of this Work Plan. The Energy Systems document Environmental Surveillance Procedures, Quality Control Program, ESH/ESH/INT-14 (1990a), will be followed where applicable. Environmental Surveillance Procedures (ESPs) from this document that are applicable to this investigation include those listed below.

- Water Sampling Using a Dipper: ESP-301-1

- Grab Sampling with Kemm Bottles: ESP-301-4

- Sediment Sampling Procedures: Stream Bed: ESP-304-1 
Table 7.2. Quality assurance objectives for laboratory measurements

\begin{tabular}{|c|c|c|c|c|c|}
\hline Parameter & Method & Matrix & Precision $^{a}$ & Accuracy ${ }^{b}$ & Completeness \\
\hline \multirow[t]{3}{*}{$\mathrm{TCL}^{c}$ volatiles } & CLP method ${ }^{d}$ & Soil/sediment & CLP & CLP & $90 \%$ \\
\hline & & Water & 524.1 & 524.1 & $90 \%$ \\
\hline & & Air & TO-14 & TO-14 & $90 \%$ \\
\hline \multirow[t]{2}{*}{ TCL semivolatiles } & CLP method & Soil/sediment & CLP & CLP & $90 \%$ \\
\hline & & Water & CLP & CLP & $90 \%$ \\
\hline \multirow[t]{2}{*}{ TAL' metals } & CLP method & Soil/sediment & CLP & CLP & $90 \%$ \\
\hline & & Water & CLP & CLP & $90 \%$ \\
\hline $\begin{array}{l}\text { Chromium - } \\
\text { hexavalent }\end{array}$ & $\begin{array}{l}\text { SW- } 846^{\prime} \\
7196\end{array}$ & Water & $20 \%$ & $75-125 \%$ & $90 \%$ \\
\hline \multirow[t]{2}{*}{ Gross alpha } & SW-846 & Soil/sediment & $30 \%$ & $80-120 \%$ & $90 \%$ \\
\hline & 9310 & Water & $20 \%$ & $80-120 \%$ & $90 \%$ \\
\hline \multirow[t]{2}{*}{ Gross beta } & SW-846 & Soil/sediment & $30 \%$ & $80-120 \%$ & $90 \%$ \\
\hline & 9310 & Water & $20 \%$ & $80-120 \%$ & $90 \%$ \\
\hline \multirow[t]{2}{*}{ Isotopic thorium } & USEPA $907.0^{d}$ & Soil/sediment & $30 \%$ & $85-115 \%$ & $90 \%$ \\
\hline & & Water & $20 \%$ & $85-115 \%$ & $90 \%$ \\
\hline \multirow[t]{2}{*}{ Isotopic uranium } & USEPA $908.0^{d}$ & Soil/sediment & $30 \%$ & $85-115 \%$ & $90 \%$ \\
\hline & & Water & $20 \%$ & $85-115 \%$ & $90 \%$ \\
\hline \multirow[t]{2}{*}{ Pesticides/PCB } & CLP & Soil/sediment & CLP & CLP & $90 \%$ \\
\hline & & Water & CLP & CLP & $90 \%$ \\
\hline \multirow[t]{2}{*}{ TOCh } & USEPA 415.1 & Water & $30 \%$ & $80-120 \%$ & $90 \%$ \\
\hline & $\begin{array}{c}\text { ASA-SSSA } \\
\text { Monograph No. } 9\end{array}$ & Soil & $40 \%$ & $60-140 \%$ & $90 \%$ \\
\hline TSS ${ }^{i}$, TDS & USEPA $160.1 / 160.2$ & Water & $N A^{k}$ & NA & $90 \%$ \\
\hline Alkalinity & USEPA 310.1 & Water & $15 \%$ & NA & $90 \%$ \\
\hline BOD & USEPA 405.1 & Water & NA & NA & $90 \%$ \\
\hline $\mathrm{COD}^{m}$ & USEPA 410.2 & Water & $30 \%$ & $80-120 \%$ & $90 \%$ \\
\hline \multirow[t]{2}{*}{ Oil and grease } & USEPA 413.1 & Water & $30 \%$ & $80-120 \%$ & $90 \%$ \\
\hline & SW846-9071 & Soil & $40 \%$ & $60-140 \%$ & $90 \%$ \\
\hline
\end{tabular}

Note: Precision and accuracy values shown for radionuclides represent levels of $5 \mathrm{pCi} / \mathrm{L}$ and $5 \mathrm{pCi} / \mathrm{g}$ and above. Lower levels will have substantially greater precision and accuracy limits. Precision given as a relative percent difference based on laboratory replicates.

aprecision for Contract Laboratory Program (CLP) methods based on matrix spike/matrix spike duplicate (organics) or laboratory duplicate (inorganics); objectives are as given in the most recent CLP Statement of Work.

${ }^{b}$ Accuracy given as Percent Recovery based on laboratory spikes. For CLP methods, accuracy is based on matrix spikes; objectives are as given in the most recent CLP Statement of Work. In addition, accuracy will be dependent on matrix effects from the site.

Target Compound List.

dUSEPA CLP, Statement of Work for Inonganics Analysis, current revision; Statement of Work for Organics Anahysis, current revision.

Target Analyte List.

fUSEPA Ter Methods for Evaluating Solid Wast, Physical/Chemical Methods, 3rd Ed., SW-846, November 1986.

solychlorinated biphenyl.

hTotal organic carbon.

'Total suspended solids.

Total dissolved solids.

kNot applicable.

'Biological axygen demand.

"Chemical axygen demand. 
Table 7.3. Quality assurance objectives for field measurements

\begin{tabular}{llccc}
\hline \multicolumn{1}{c}{ Parameter } & Matrix & Precision & Accuracy & $\begin{array}{c}\text { Completeness } \\
(\%)\end{array}$ \\
\hline $\mathrm{pH}$ & Aqueous & $\mathrm{ND}^{\circ}$ & $\pm 0.05 \mathrm{unit}$ & 90 \\
Conductivity & Aqueous & ND & \pm 50 units & 90 \\
Temperature & Aqueous & ND & ${ }^{\circ} 1^{\circ} \mathrm{C}$ & 90 \\
Dissolved oxygen & Aqueous & ND & $\pm 0.1 \mathrm{ppm}$ & 90 \\
Total organic vapors & Gas & ND & $\pm 10 \mathrm{ppm}$ & 90 \\
Water level & Aqueous & ND & ${ }_{ \pm 0.01 \mathrm{ft}}$ & 90 \\
\hline
\end{tabular}

aPrecision, as assessed by replicate measurements, will not be performed in the field. 
- Groundwater Sampling Procedures: Water Level Measurements Using Water Level Indicator: ESP-302-1

- Groundwater Sampling Procedures: Guidelines for Well Purging: ESP-302-2

- Groundwater Sampling: Energy Systems SOP No. 8102.R2

- Groundwater Sampling Procedures: Using a Bailer: ESP-302-3

- Groundwater Sampling Procedures: Using a Gas Driven Piston Pump: ESP-302-4

- Groundwater Sampling Procedures: Using a Bladder Pump: ESP-302-5

- Field Measurements Procedures: Temperature: ESP-307-1

- Field Measurements Procedures: pH (Hydrogen Ion Concentration): ESP-307-2

- Field Measurements Procedures: Oxidation/Reduction Potential of Water: ESP-307-5

- Field Measurements Procedures: Specific Conductance (IAD): ESP-307-8

- Field Sampling and Analytical Processes Within Environmental Restoration: ER/C-S2301

- Sample Classifying, Packaging, Marking, Labeling, and Shipping for Analysis Through the K-25 and Y-12 Environmental Restoration Programs: ER/C-P2302(IAD), Rev. 0

- Cleaning and Decontaminating Sample Containers and Sampling Devices: ESP-900

- Equipment Decontamination: ESP-901

- Waste Management: ESP-1000

- Waste Removal and Disposition through the Y-12 ER Program: ER/Y-P2102

Any modification of or deviation from these procedures will be documented and approved by the Energy Systems Project Manager. Soil sampling with a Geoprobe is not included in the environmental surveillance SOPs. A procedure for this method of sampling, entitled "Geoprobe Soil Sampling Survey" (SOP 3-1), is provided in Appendix C.

A PhotoVac $10 S 55$ portable GC (or equivalent) will be used to perform headspace gas analyses on collected soil samples. These collected soil samples will be analyzed according to the guidelines described below.

- A small amount of relatively undisturbed soil will be extruded into a labeled $40-\mathrm{mL}$ vial.

- Aluminum foil will immediately be placed tightly over the jar opening. 
- Sufficient time $(-10 \mathrm{~min})$ will be allowed for the jar to reach ambient temperature to permit vapor release from the soil matrix. The sample vial will be gently shaken prior to analysis.

- The aluminum foil will be perforated by Teflon tubing, and headspace gas will be introduced directly into the GC. The headspace gas will be analyzed for carbon tetrachloride; 1,1,1-trichloroethane; 1,1,2,2-tetrachloroethane; and 1,1-dichloroethane. Specific procedures for sample analysis are given in the SOP for the PhotoVac Portable GC, entitled "Standard Measurement Procedure for: PhotoVac Portable Gas Chromatograph," located in Appendix C.

- The expected analysis time for the target volatiles is $\sim 15 \mathrm{~min}$.

The PhotoVac GC will be calibrated at the beginning of the day and after every 10 samples as stated in the SOP in Appendix C. A certified calibration gas containing the analytes of interest at concentrations of $\sim 0.5$ to $1.0 \mathrm{ppm}$ will be used for calibration. The calibration gas cylinder will be hardpiped to the $\mathrm{SC}$ to facilitate calibration.

An analytical zero check will be performed each day before sample analysis as outlined in the SOP. An analytical zero check will also be performed after highly contaminated samples to determine if contamination carryover has occurred. If contamination has occurred, the GC column will be flushed as described in the SOP. Preventive maintenance for the PhotoVac is also discussed in the SOP.

A single logbook will be dedicated to the PhotoVac GC operation. At a minimum, the following documentation will be recorded in the logbook:

- manufacturer, lot number, and expiration date of standards, carrier gas, and other materials;

- list of all samples submitted for headspace analysis;

- log of all analyses including calibration standards, blanks, and routine samples; and

- preventive maintenance and repair information.

Instrument printouts and chromatograms will also be retained.

A Summa Stainless Steel Canister (or equivalent) will be used to conduct air samples for VOC analysis. A summary of sampling procedures and a description of the method for analysis (USEPA Method TO-14) are in Appendix C.

For a majority of the biological/ecological samples to be collected, there are no environmental surveillance SOPs. In cases where they are available, they are referenced accordingly. If SOPs are not available, methods are described or specific methods and procedures are provided in Appendix C. These methods are also described below.

Threatened and Endangered Species and Wetlands Surveys. Although there are no standard methods for conducting these surveys, but rather conventions by which biologists/ecologists approach the work, compliance with federal legislation concerning 
threatened and endangered species on the ORR has been formally addressed, and the program has been reviewed with both the U.S. Fish and Wildlife Service (USFWS) and the appropriate state of Tennessee agencies (Kroodsma 1987), none are known to occur at the CRSP. Several state-listed species do occur on the ORR and may be present in the study area. Wooded areas adjacent to the site will be surveyed to determine whether the federally and/or state-listed species are present or likely to be present. The surveys will be conducted by biologists familiar with the species that may be expected to live in habitats similar to the site and will be conducted when species that are expected to occur on the ORR are likely to be most readily observed. For plants, the surveys will be scheduled to coincide with the flowering season. Because there are no federally listed threatened or endangered wildlife species known to occur on the ORR, the animal survey will be limited to identifying suitable habitat. The surveys may provide only evidince of the presence or absence of the species; quantitative information on population status will not be obtained. In addition, wetlands areas will be delineated, and wetlands plant species will be identified based on nationally accepted standards (Federal Interagency Committee for Wetland Delineation 1989; Reed 1988; and USFWS 1979).

Aquatic Toxicity Tests. Water samples for aquatic toxicity testing will be collected using ESP-301-1, which describes a method for collecting grab samples with dippers. At the time of sample collection, field measurements for $\mathrm{pH}$ (ESP-307-2), temperature (ESP-307-1), conductivity (ESP-308-1), and dissolved oxygen (USEPA 1991) will be performed. A copy of the USEPA SOP is included in Appendix C. Field measurements will be repeated at the beginning and end of the toxicity tests in conjunction with sample collection. In addition, daily measurements are performed in the laboratory. The toxicity test procedure for Ceridaphnia will be an ORNL Environmental Sciences Division (ESD) Toxicology Laboratory procedure that originated as a USEPA method but is slightly more detailed than that given in USEPA's Cladoceran, Ceriodaphnia dubia, Survival and Reproduction Test (Method 1002.0; Weber et al. 1989). Ceriodaphnia tests are typically conducted with water collected fresh daily. Holding times are $<24 \mathrm{~h}$ in all instances and usually $<1 \mathrm{~h}$. Similarly, toxicity testing with fathead minnow larvae will be conducted according to ESD SOP-1 (Method 1000.0). A copy of the ESD Toxicology Laboratory Quality Assurance Program Plan, including the testing method to be used is included in Appendix $C$. This document discusses the specific QA procedures applicable to the toxicity testing to be performed.

Soil Toxicity Testing Using Earthworms and Seedlings. Soil samples for toxicity testing will be collected using ESP-303-1 (spade or scoop) and ESP-303-2 (hand auger) methods. Approximately $8 \mathrm{~L}$ of soil are needed from each site for toxicity testing. Grab samples will be collected from the surface down through the root zone to ensure an adequate volume for testing. Earthworms, Eisenis foetida, and cabbage seedlings will be tested using the methods described in EPA/600/3-88/029. This method describes the use of lettuce seedlings; however, in this study cabbage seedlings will be used. The holding time for soil for toxicity testing is less than $24 \mathrm{~h}$. Toxicity tests will be run on natural soil and on soil that has been autoclaved under an inert atmosphere to destroy all pathogens. A copy of the test method is included in Appendix C.

Bioaccumlation Testing. Soil invertebrate samples will be collected from each sampling area (sampling locations and number to be determined) by establishing 1- by $1-\mathrm{m}$ quadrants, excavating soil from the root zone (top 12 in.) using a shovel or trowel, and sieving for invertebrates using a standard No. 30 sieve. The sample size will be $\sim 1 \mathrm{~g}$ of tissue. 
Table 6.1 in the Site Data Needs section of this Work Plan lists sample totals for all media. Analytical methods, sample preservation requirements, and sample container requirements are summarized in Table 7.4.

\subsection{SAMPLE AND DOCUMENT CUSTODY PROCEDURES}

Field documentation will be maintained throughout this project in various formats, including field logbooks, sample tags, chain-of-custody forms, field data sheets, and field calibration and maintenance data. Records of all field activities, including sampling locations, site conditions, types of samples taken, and analyses requested, will be documented in appropriate field logbooks and on field data sheets. The laboratory will be responsible for maintaining chain-of-custody samples received for analysis. Laboratory custody procedures will be discussed in detail in the laboratory QA Plan, prepared by the contract laboratory, and reviewed and approved by Energy Systems.

Documentation will follow requirements outlined in procedure ESP-500 in the Energy Systems document ES/ESH/INT-14 (1990a). The following general guidelines for maintaining field documentation will be followed.

- Documentation will be completed in permanent black ink.

- All entries will be legible.

- Errors will be crossed out with a single line, dated, and initialed.

- Unused space on a page will be marked through with a diagonal line, dated, and initialed.

- None of the documents will be altered, destroyed, or discarded, even if they are illegible or contain inaccuracies that require correction. They will be maintained on-site and referenced in the site logbook.

\subsubsection{Field Logbooks}

Field team personnel will use bound field logbooks with sequentially numbered pages for the maintenance of field records and for documenting any information pertinent to field activities. Information identified in the field logbook will be obtained from site exploration, observation, and sampling activities and will be recorded by the Field Task Manager or his/her designee.

The front cover of the logbook will list the contract name and number, the task order number, the site name, the names of subcontractors, the name of the client, the name of the Field Task Manager, the start date, and, when complete, the finish date. The logbooks will be sequentially numbered, and if a logbook is dedicated to a particular task or site, that information will be noted on the cover.

The field logbook will be included as an appendix to the appropriate site investigation report. Specific information to be recorded in field logbooks is provided in procedure ESP-500 of ES/ESH/NNT-14 (Energy Systems 1990a). 


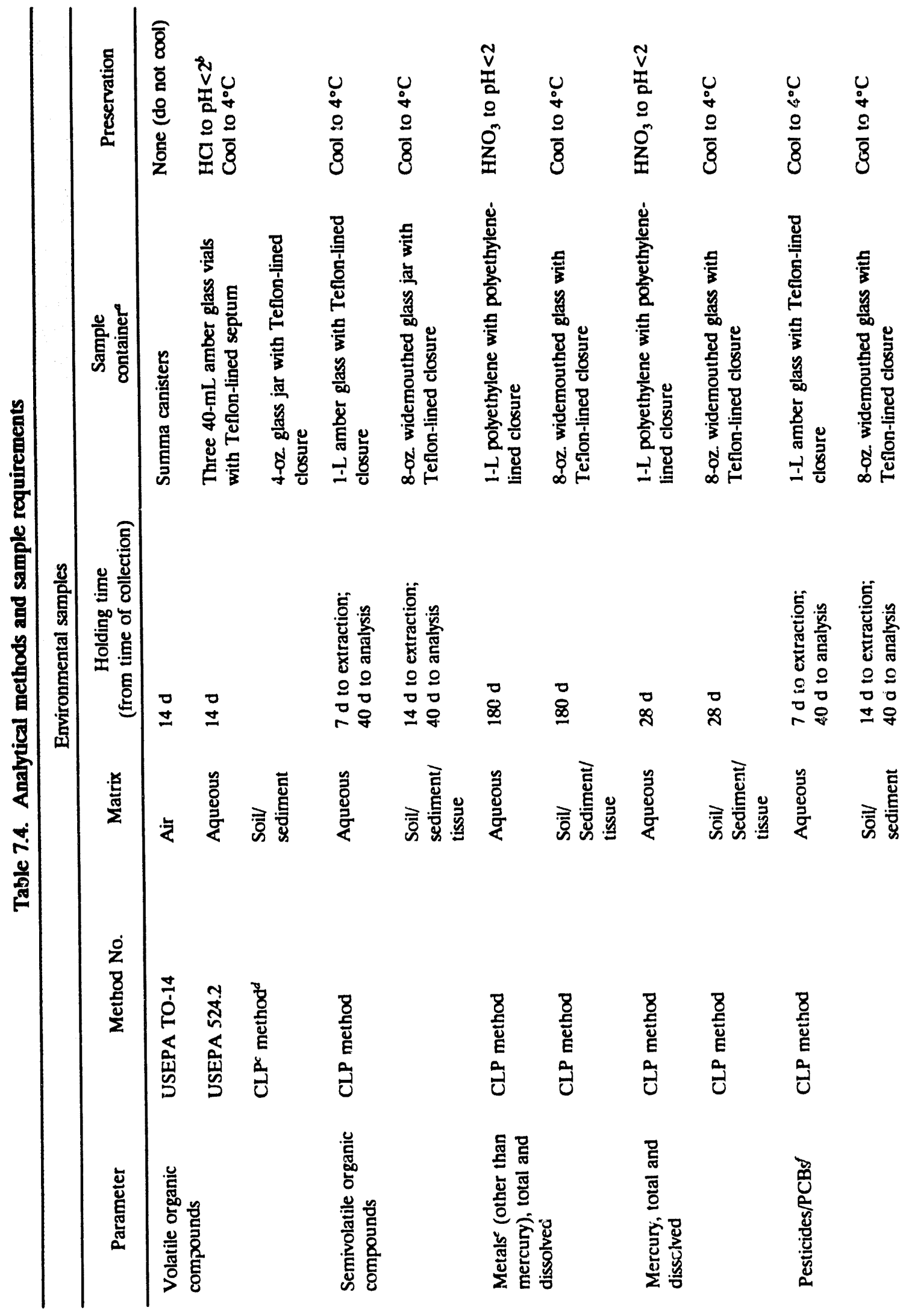




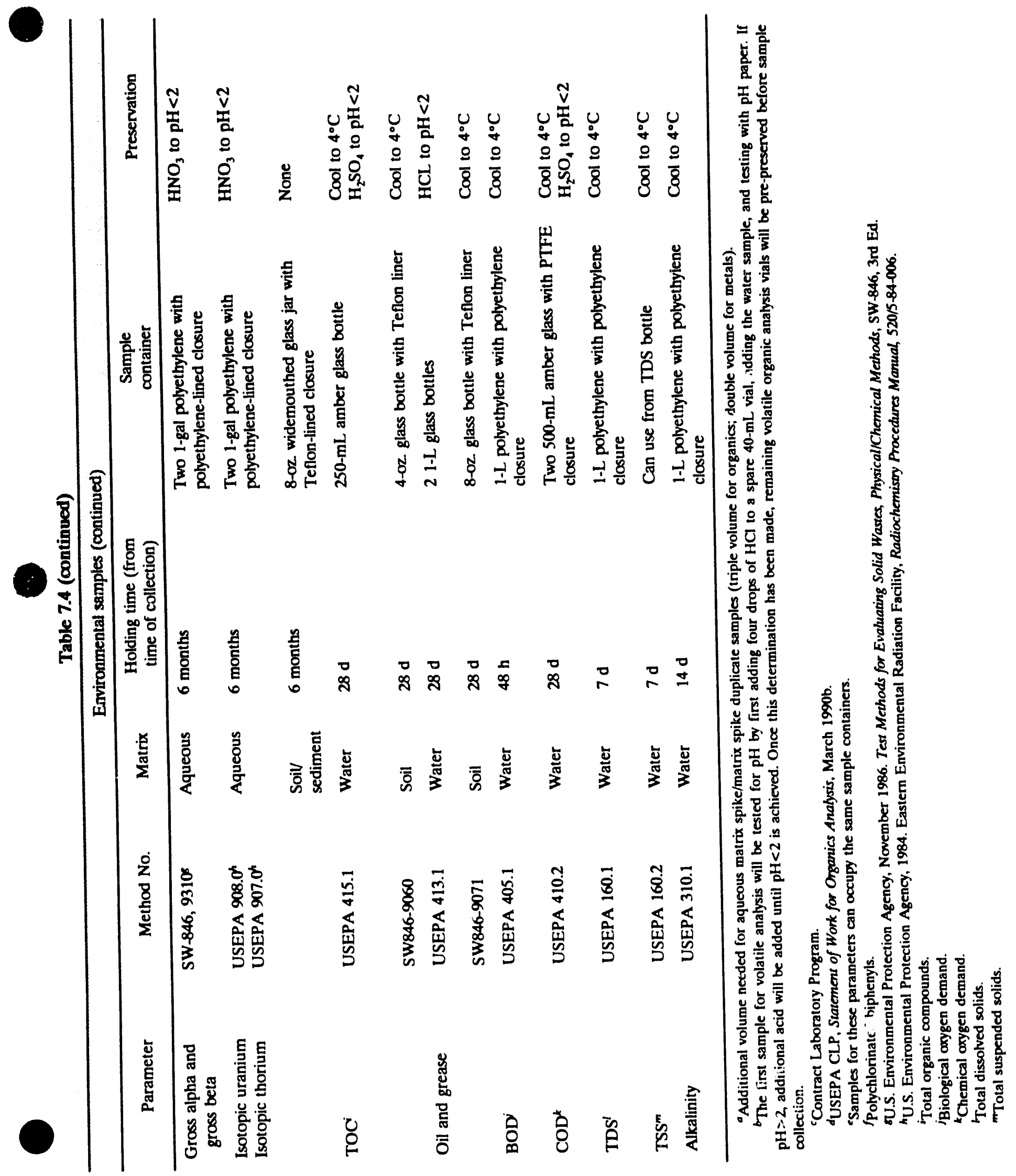




\subsubsection{Field Data Sheets}

Field data sheets will be maintained as appropriate and will include the following logs and forms:

- water-level measurement log,

- environmental survey forms,

- surface water/sediment sampling log,

- well-purging log,

- groundwater sampling log,

- chain-of-custody form, and

- instrument calibration log.

Data to be recorded will include such information as the sample location (e.g., depth, sampling station, elevation, and field coordinates) and applicable sample analysis to be conducted. If necessary, field-generated data forms will be prepared based on the appropriate requirements. The same information may be included in the field logbook.

\subsubsection{Sample Identification, Numbering, and Labeling}

In addition to field logbooks and field data sheets, the sampling team will use labels to track sample holding times, to ensure sample traceability, and to initiate the chain-of-custody record on the environmental samples. Custody seals will also be used to ensure traceability and to prevent tampering. Figure 7.2 is an example of a sample label and chain-of-custody seal. A completed label will be secured to each sample container, including duplicates and trip or field blanks, at or before the completion of collection of that sample. Sample labels will be waterproof or will be sealed to the sample container with clear acetate tape after all information has been written on the label. Labels will include the project code number; the station number and location for the sampling site; the type of sample, the analyses required, and date and time of sampling; and the signature of the sampler. The person who physically collects each sample is the sampler and will sign the sample label. Information to be included on sample labels and seals is provided in ESP-500 (Energy Systems 1990a).

The sample numbers will be recorded in the field logbook along with the time of collection and descriptive information of the sampling conditions.

Samples will be identified and numbered according to the following system:

SP-BB-XX-ZZ,

where

SP identifies the site as the Y-12 Plant, CRSP.

BB identifies the media using these codes:

$\begin{array}{llll}\text { GW } & \text { Groundwater } & \text { SO } & \text { Soil } \\ \text { SW } & \text { Surface water } & \text { SD } & \text { Sediments } \\ \text { TB } & \text { Trip blank } & \text { BW } & \text { Bioaccumulation-worms } \\ \text { FB } & \text { Field blank } & \text { EB } & \text { Equipment blank }\end{array}$



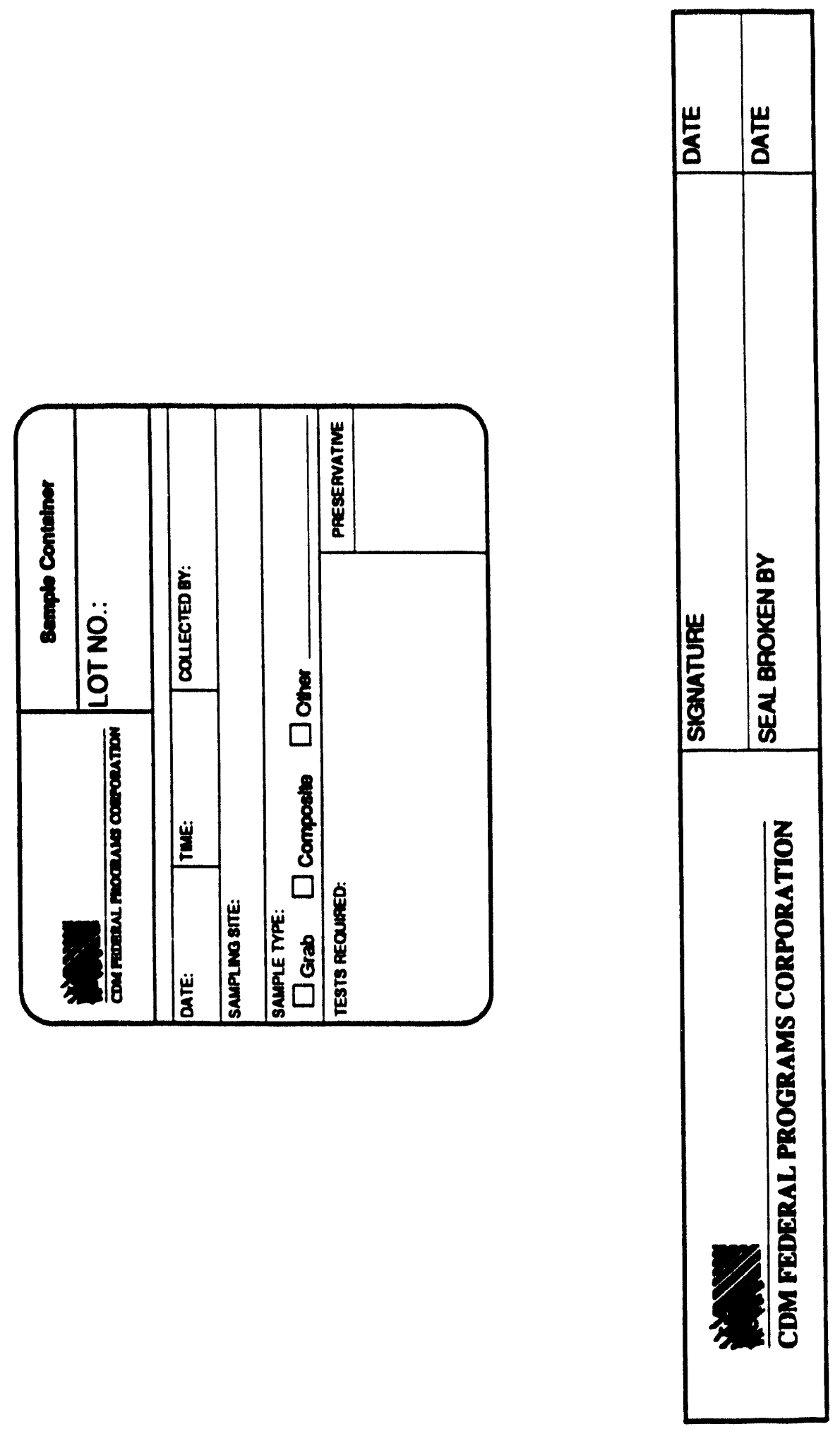
$\mathrm{XX}$ identifies the location of the sample, which will be consistent with the Y-12 Plant identification system.

$\mathrm{ZZ}$ is the sample number at that location.

Therefore, the sample number "SP-GW-10-01" designates a groundwater sample from monitoring well 10. The "01" at the end of the sample number indicates that it is the first sample taken at this location. The actual location where this sample was collected is specified in the field logbook along with a complete description of the sample.

QC samples are numbered in the same manner as the other samples using the above symbols. Duplicate samples, however, will be assigned a unique sample number by the sampling team, and this number will be recorded in the field logbook along with sample information such as the time of collection, matrix type, analysis requested, and corresponding sample. This procedure ensures that subsequent tracking of the QC sample results is facilitated. The data validators and users will be told which of the samples were duplicates, spikes, or blanks. A list of analyzed samnles, including QC samples, and their locations will also be included in the draft RI report.

\subsubsection{Sample Chain of Custody}

Chain-of-custody procedures will document sample possession from the time of collection through all transfers of custody to receipt at the laboratory and subsequent analysis. Chain-ofcustody records will accompany each packaged lot of samples; the laboratory will not analyze samples without a correctly prepared chain-of-custody record form. Internal laboratory records will document the custody of the sample through its final disposition. The QC level for individual samples also will be communicated to the laboratory on the chain-of-custody record.

Custody records following the National Enforcement Investigation Center format will be used for this project. The multipart carbonless copy forms will be correlated with the sample collection tags; requested information will have the same heading on both. Figure 7.3 presents an example of a chain-of-custody record form. One similar to this will be used by CDM Federal throughout this field effort. ESD personnel will use their existing chain-ofcustody records, which may vary from the one shown in Fig. 7.3. The sampler or sample custodian will complete a chain-of-custody record form to accompany each sample shipment from the field to the laboratory.

The custody records will be used for a packaged lot of samples; more than one sample will usually be recorded on one form. More than one custody record sheet may be used for one package, if necessary. The purpose of the sheets is to document the transfer of a group of samples traveling together; when the group of samples change, a new custody record is initiated. The original custody record travels with the samples; the initiator of the record keeps a copy. When custody of the same group of samples changes hand, several people will not have a copy of the custody record. This is acceptable as long as the original custody record shows that each person who received custody has properly relinquished it.

The sampling event will have a designated sample custodian with overall responsibility for sample custody and for field document control. The custodian will ensure that the sampling teams have used the appropriate identification and custody records, resolved custody 


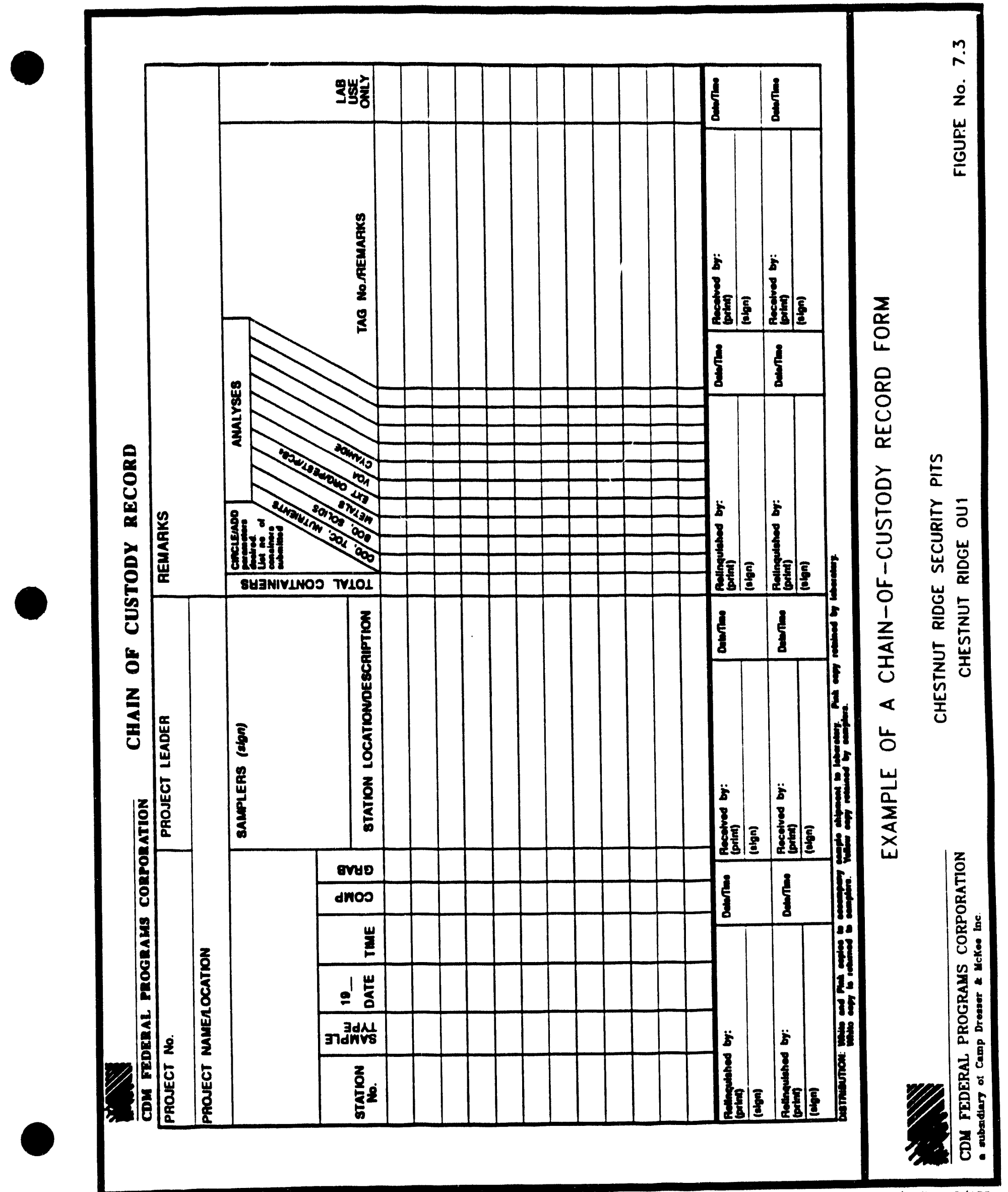


problems in the field, and handled the shipment of samples to the analytical laboratories. The analytical laboratory will have an identified sample custodian and document control officer.

The following procedures are used to complete the chain-of-custody form.

1. The originator (e.g., sample custodian) fills in all requested information from the sample label. The bill-of-lading number obtained from the overnight carrier is recorded in the comments section of the form, and it also is recorded in the field logbook. Unused space on the form will be marked through with a diagonal line, dated, and initialed.

2. The originator signs in the top left "Relinquished by" box and keeps a copy.

3. The original record sheet and remaining copies travel with the samples.

4. The laboratory sample custodian receiving the samples checks the sample label information against the custody record. He/she also checks the sample condition and notes anything unusual under "Comments" on the custody form. The laboratory custodian receiving custody signs in the adjacent "Received by" box and keeps a copy. The original and the additional copy are returned to the originator.

5. The date/time will be the same for both signatures because custody must be transferred to another person. When samples are shipped via common carrier (e.g., Federal Express), the date/time will not be the same for both signatures. Common carriers are not required to sign the form. The original form travels with the samples, and the shipper (e.g., field sample custodian) keeps the copy. The shipper also keeps all shipping papers, bills of lading, and so forth.

In all cases, it must be apparent that the same person who received custody has relinquished it to the next custodian. If samples are left unattended or if a person refuses to sign, this occurrence must be documented and explained on the custody record.

To enable tracking of the shipment of samples from the field to the laboratory, the field sample custodian will promptly telephone the laboratory following shipment and provide the following information:

- the exact number and types of samples collected and the sample identification numbers;

- air carrier and airbill number(s);

- estimated date and time of arrival at each designated laboratory; and

- other pertinent information including special handling instructions, changes in scheduled sampling activity, or deviations from established sampling procedures.

Internal laboratory cu.iody procedures will be specified in the laboratory QA plan.

Custody seals are narrow strips of adhesive paper that are used to demonstrate that no tampering has occurred (see Fig. 7.2). Custody seals will be placed on coolers used for sample shipment. Seals will not be placed on individual sample containers. The sampler must sign and date each custody seal. 


\subsubsection{Sample Shipment}

Each sample shipped will be packed in accordance with the SOP, "Sample Classifying, Packaging, Marking, Labeling, and Shipping for Analysis through the K-25 and Y-12 Environmental Restoration Programs," ER/C-P2302(IAD), Rev. 0. All shipping procedures will comply with Department of Transportation (DOT) regulations. In addition, each sample will be identified with a sample identification label and will be listed on the chain-of-custody record completed for each sample shipping container. The field sample custodian will notify the laboratory sample custodian of sample shipment.

\subsubsection{Document Control}

Document control is the act of ensuring that documents, including revisions, are reviewed for adequacy, approved for release by authorized personnel, and distributed to and used at the locations where the prescribed activities are performed. CDM Federal's document control procedure is given in the CDM Federal Quality Assurance Manual, QP 3. The Project Manager will develop distribution lists for the various types of documents to be issued during this project.

Procedures have been established for the inventory, control, filing, storage, and retrieval of data collected and of reports/documents generated under this program. CDM Federal's record control procedures are given in the CDM Federal Quality Assurance Manual. The Field Task Manager will forward field documentation to the CDM Federal document control center for processing as QA records. The project files will be maintained in the Oak Ridge office.

\subsection{EQUIPMENT CALIBRATION AND FREQUENCIES}

\subsubsection{Equipment Calibration Procedures and Frequencies}

All field equipment, including $\mathrm{pH}$, conductivity, dissolved oxygen, radiation, and organic vapor (or equivalent) meters will be calibrated daily (or more frequently, if necessary) by the user according to the manufacturer's specifications. The off-site laboratory(ies) will use written, standard procedures for equipment calibration and frequency. These procedures are based on USEPA guidance or manufacturer's recommendations and are given in the laboratory QA Plan or in the USEPA-approved analytical methods. The laboratory QA Plan will then be reviewed and accepted by CDM Federal and Energy Systems as part of the laboratory review process. The appropriate references for all analyses are included in the reference section of this document. All standards used for calibration will be National Institute of Standards and Technology-traceable. Procedures for improperly functioning equipment will be addressed in the laboratory QA Plan and in factory manuals for equipment.

\subsubsection{Calibration Records}

Calibration records (Fig. 7.4) will be maintained for each piece of field measuring and test equipment and each piece of reference equipment. The records will indicate that established calibration procedures have been followed. The frequency of calibration against a traceable standard will be specified on the calibration record form. The lot number of all calibration gases will be recorded on the calibration record form. Records of equipment use 


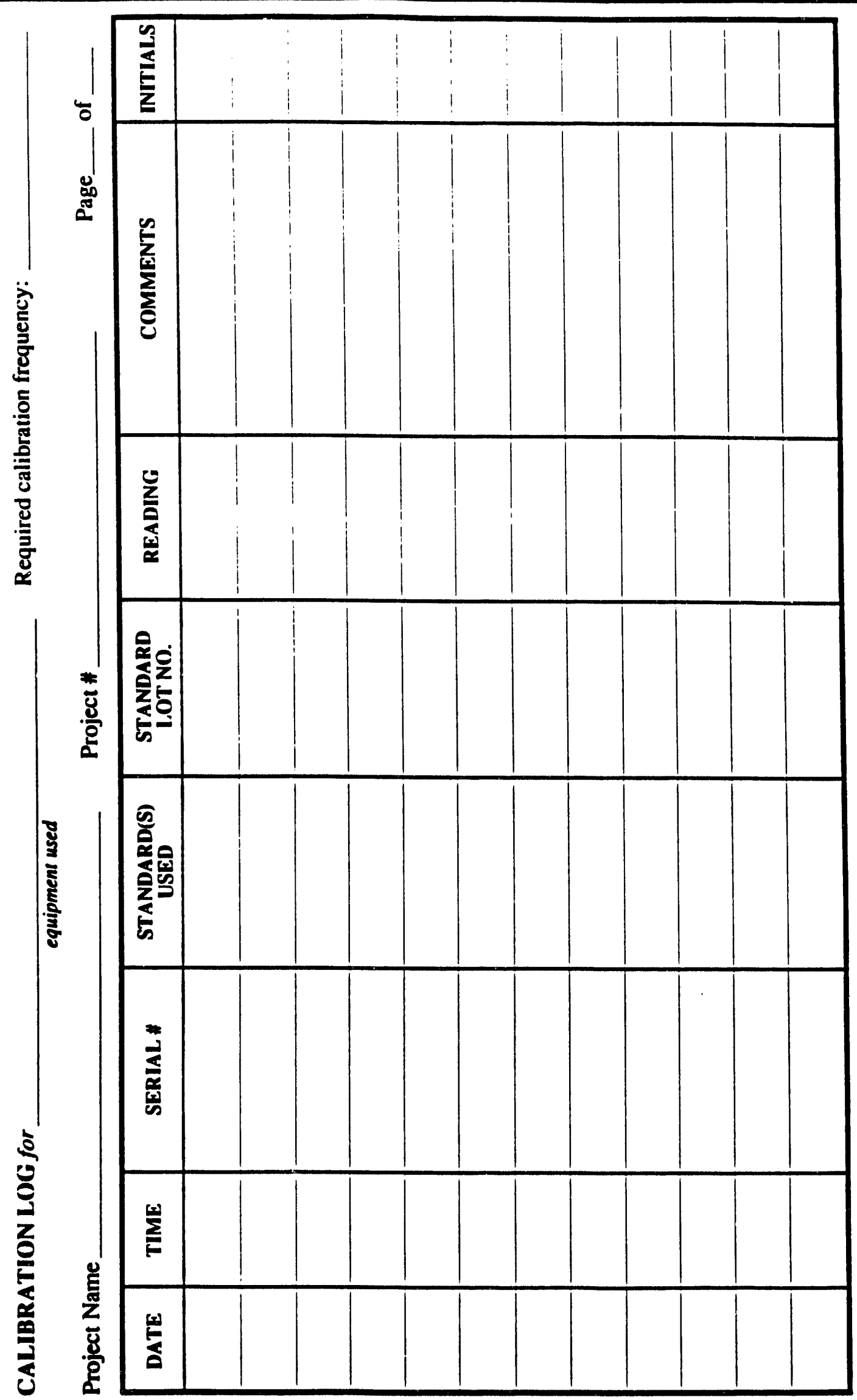

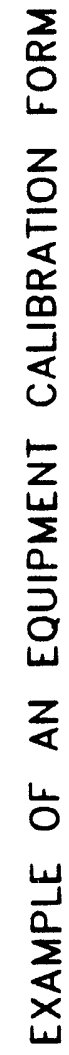


will be kept in the project files. The off-site laboratory(ies) will use written, standard procedures for calibration records. These procedures are based on USEPA guidance and are given in the laboratory QA Plan. The laboratory QA Plan will be reviewed and accepted by CDM Federal and Energy Systems as part of the laboratory review process.

\subsection{PREVENTIVE MAINTENANCE}

Periodic preventive maintenance is required for all equipment. CDM Federal will keep a maintenance $\log$ for each piece of field equipment. Appendix $C$ contains forms that will be used to log the maintenance record of each field instrument. Specific preventive maintenance practices, frequency, and spare parts are described in the factory manual for each instrument. The troubleshooting section of factory manuals will be used to assist personnel in performing maintenance tasks. CDM Federal keeps on hand critical spare parts to minimize equipment downtime.

Preventive maintenance procedures for laboratory equipment and instruments are provided in laboratory QA Plans. All maintenance activities will be recorded in maintenance logs. Laboratories will be required to maintain an adequate inventory of spare parts and consumables to prevent downtime as a result of minor problems.

\subsection{ANALYTICAL PROCEDURES}

Table 7.4 summarized the analytical methods, sample container requirements, and sample preservation requirements for sampling required during this investigation. A discussion of method detection limits follows.

Method detection limits (MDLs) describe the extent to which the equipment or analytical process can provide accurate, minimum data measurements of a reliable quality for specific constituents in replicate field samples. The MDL is defined as the minimum concentration of a substance that can be measured and reported with $99 \%$ confidence that the value is above zero. The actual quantitation limit for a given analysis will vary depending on instrument sensitivity and matrix effects. MDLs for this project are shown in Table 7.5. The MDLs for aqueous media are equal to or lower than the established MCLs used to evaluate potential risks to human health and the environment. Detection limits will not be established for analyses performed using field instruments. The detection limits established by the manufacturer will be used as guidelines.

\subsection{DATA REDUCTION AND REPORTING}

To ensure that data management activities provide an accurate and controlled flow of data generated by the laboratory, it is important that the following data reduction and reporting steps be defined and implemented. Data management procedures applicable to field-generated data are discussed in the Field Sampling Plan.

\subsubsection{Data Reduction}

Field program data will be produced through visual observation, direct-reading instrumentation, measuring devices, and laboratory chemical analyses. All field activities, direct-reading instruments, and measuring devices will occur or be used in accordance with 
Table 7.5. Method detection limits for laboratory analysis

\begin{tabular}{|c|c|c|c|c|c|}
\hline $\begin{array}{l}\text { Water } \\
(4 \& / L)\end{array}$ & $\begin{array}{l}\text { Soilsediment } \\
\text { (Mg/kg) }\end{array}$ & $\begin{array}{l}\text { Air } \\
(\mathrm{ppb}) \\
(\mathrm{v} / \mathrm{N})\end{array}$ & \multicolumn{3}{|c|}{$\begin{array}{l}\text { Volatile organic compounds } \\
\text { CLLP method }\end{array}$} \\
\hline 10 & 10 & 1 & $\begin{array}{l}\text { Acetone } \\
\text { Benzene } \\
\text { Bromodichloromethane } \\
\text { Bromolorm } \\
\text { Bromomethane } \\
\text { 2-Butanone } \\
\text { Carbon disulfide } \\
\text { Carbon tetrachloride } \\
\text { Chlorobenzene } \\
\text { Chloroethane } \\
\text { 2-Chloroethyl vinyl ether } \\
\text { Chloroform } \\
\text { Chloromethane } \\
\text { Dibromochloromethane }\end{array}$ & $\begin{array}{l}\text { 1,1-Dichloroethane } \\
\text { 1,2-Dichloroethane } \\
\text { 1,1-Dichloroethene } \\
\text { 1,2-Dichloroethene } \\
\text { (Total) } \\
\text { 1,2-Dichloropropane } \\
\text { Cis-1,3- } \\
\text { dichloropropene } \\
\text { Trans-1,2- } \\
\text { dichloropropene } \\
\text { Ethyl benzene } \\
\text { 2-Hexanone } \\
\text { Methylene chloride } \\
\text { 4-Methyl-2-pentanone } \\
\text { Styrene }\end{array}$ & $\begin{array}{l}1,1,2,2- \\
\text { Tetrachloroethane } \\
\text { Tetrachloroethene } \\
\text { Toluene } \\
\text { 1,1,1-Trichloroethane } \\
\text { 1,1,2-Trichloroethane } \\
\text { Trichloroethene } \\
\text { Vinyl acetate } \\
\text { Vinyl chloride } \\
\text { Xylenes (Total) }\end{array}$ \\
\hline $\begin{array}{l}\text { Water } \\
(\mu g / L)\end{array}$ & \multicolumn{2}{|c|}{$\begin{array}{l}\text { Soil/sediment } \\
\quad(\mu g / k g)\end{array}$} & \multicolumn{3}{|c|}{$\begin{array}{c}\text { Semivolatile organic compounds }{ }^{c} \\
\text { (including polynuclear aromatic hydrocarbons) } \\
\text { CLP method }\end{array}$} \\
\hline 10 & \multicolumn{2}{|l|}{330} & \multicolumn{3}{|l|}{ Acenaphthene } \\
\hline 10 & \multicolumn{2}{|l|}{330} & \multicolumn{3}{|l|}{ Acenaphthylene } \\
\hline 10 & \multicolumn{2}{|l|}{330} & \multicolumn{3}{|l|}{ Anthracene } \\
\hline 10 & \multicolumn{2}{|l|}{330} & \multicolumn{3}{|l|}{ Benzo(a)anthracene } \\
\hline 10 & \multicolumn{2}{|l|}{330} & \multicolumn{3}{|l|}{ Benzo(a)pyrene } \\
\hline 10 & \multicolumn{2}{|l|}{330} & \multicolumn{3}{|l|}{ Benzo(b)fluoranthene } \\
\hline 10 & \multicolumn{2}{|l|}{330} & \multicolumn{3}{|l|}{ Benzo(g,h,i)perylene } \\
\hline 10 & \multicolumn{2}{|l|}{330} & \multicolumn{3}{|l|}{ Benzo(k)fluoranthene } \\
\hline 10 & \multicolumn{2}{|l|}{330} & \multicolumn{3}{|l|}{ Carbazole } \\
\hline 10 & \multicolumn{2}{|l|}{330} & \multicolumn{3}{|l|}{ 2-Chloronaphthalene } \\
\hline 10 & \multicolumn{2}{|l|}{330} & \multicolumn{3}{|l|}{ Chrysene } \\
\hline 10 & \multicolumn{2}{|l|}{330} & \multicolumn{3}{|l|}{ Dibenzo(a,h)anthracene } \\
\hline 10 & \multicolumn{2}{|l|}{330} & \multicolumn{3}{|l|}{ Dibenzofuran } \\
\hline 10 & \multicolumn{2}{|l|}{330} & \multicolumn{3}{|l|}{ Fluoranthene } \\
\hline 10 & \multicolumn{2}{|l|}{330} & \multicolumn{3}{|l|}{ Fluorene } \\
\hline 10 & \multicolumn{2}{|l|}{330} & Indeno(1,2,3-cd)pyrene & & \\
\hline 10 & 330 & & 2-Methylnaphthalene & & \\
\hline 10 & 330 & & Naphthalene & & \\
\hline 10 & 330 & & Phenanthrene & & \\
\hline 10 & 330 & & Pyrene & & \\
\hline CLP & CLP & & Other target compound & semivolatiles & \\
\hline
\end{tabular}


Table 7.5 (continued)

\begin{tabular}{|c|c|c|}
\hline $\begin{array}{l}\text { Water } \\
(\mu g / L)\end{array}$ & $\begin{array}{c}\text { Sediment } \\
(\mathbf{m g} / \mathbf{k g})\end{array}$ & $\begin{array}{c}\text { Metals } \\
\text { CLP method }\end{array}$ \\
\hline 200 & 40 & Aluminum \\
\hline 60 & 12 & Antimony \\
\hline 10 & 2 & Arsenic \\
\hline 200 & 40 & Barium \\
\hline 5 & 1 & Beryllium \\
\hline 5 & 1 & Cadmium \\
\hline 5000 & 1000 & Calcium \\
\hline 10 & 2 & Chromium \\
\hline 50 & 10 & Cobalt \\
\hline 25 & 5 & Copper \\
\hline 100 & 20 & Iron \\
\hline 3 & 0.6 & Lead \\
\hline 5000 & 1000 & Magnesium \\
\hline 15 & 3 & Manganese \\
\hline 0.2 & 0.04 & Mercury \\
\hline 40 & 8 & Nickel \\
\hline 5000 & 1000 & Potassium \\
\hline 5 & 1 & Selenium \\
\hline 10 & 2 & Sitver \\
\hline 5000 & 1000 & Sodium \\
\hline 10 & 2 & Thallium \\
\hline 50 & 10 & Vanadium \\
\hline 20 & 4 & Zinc \\
\hline
\end{tabular}


Table 7.5 (continued)

\begin{tabular}{|c|c|c|c|c|}
\hline Water $(\mu g / L)$ & Soil $(\mu \mathrm{g} / \mathrm{kg})$ & \multicolumn{3}{|c|}{ Pesticides and PCBs CLP } \\
\hline 0.10 & 3.3 & Dieldrin & & \\
\hline 0.05 & 1.7 & Alpha-BHC & Beta-BHC & $\begin{array}{l}\text { Delta-BHC } \\
\text { Gamma-BHC }\end{array}$ \\
\hline 0.05 & 1.7 & Aldrin & & \\
\hline 0.10 & 3.3 & 4,4'-DDD & 4,4'-DDE & 4,4'-DDT \\
\hline 0.05 & 1.7 & Alpha-chlordane & Gamma-chlordane & \\
\hline 0.10 & 3.3 & Endrin & Endrin Ketone & Endrin aldehyde \\
\hline 0.05 & 1.7 & Endosulfan I & & \\
\hline Not analyzed & 44.2 & Endosulfan sulfate & Endosulfan II & \\
\hline 0.05 & 1.7 & Heptachlor & Heptachlor epoxide & \\
\hline 0.5 & 17.0 & Methaxychlor & & \\
\hline 5.0 & 170.0 & Toxaphene & & \\
\hline 2.0 & 67.0 & Aroclor 1221 & & \\
\hline Nol anałyzed & $\mathrm{ND}^{d}$ & $\begin{array}{l}\text { Aroclor } 1016 \\
\text { Aroclor } 1232\end{array}$ & $\begin{array}{l}\text { Aroclor } 1242 \\
\text { Aroclor } 1248 \\
\text { Aroclor } 1254\end{array}$ & Arocior 1260 \\
\hline
\end{tabular}

\begin{tabular}{|c|c|c|c|}
\hline \multicolumn{4}{|c|}{ Radionuclides } \\
\hline Water (pCi/L) & Sediment (pCi/g) & Analytes & Method \\
\hline 3 & 10 & Gross alpha and beta & SW-846, Method $9310^{\circ}$ \\
\hline 1.0 & 0.5 & Isotopic thorium & USEPA $907.0^{\circ}$ \\
\hline 2.0 & 0.5 & Isotopic uranium & USEPA $908.0^{\circ}$ \\
\hline \multicolumn{4}{|c|}{ Wet chemistry } \\
\hline Water (mg/L) & Soil (mg/kg) & Anatytes & Method \\
\hline $\mathrm{ND}^{d}$ & $\mathrm{NA}^{\mathrm{B}}$ & BOD ${ }^{h}$ & USEPA 405.1 \\
\hline ND & NA & $\mathrm{COD}^{i}$ & USEPA 410.2 \\
\hline ND & NA & TDS & USEPA 160.1 \\
\hline ND & NA & $\mathrm{TSS}^{k}$ & USEPA 160.2 \\
\hline ND & 5 & Oil and grease & $\begin{array}{l}\text { SE846-9071 (soil) } \\
\text { USEPA } 413.1 \text { (water) }\end{array}$ \\
\hline ND & 5 & TOC & $\begin{array}{l}\text { ASA/SSSA Monograph No. } 8 \\
\text { USEPA } 415.1 \text { (water) }\end{array}$ \\
\hline
\end{tabular}

${ }^{\circ}$ Contract Laboratory Program (CLP)

bU.S. Environmental Protection Agency (USEPA) CLP, Statement of Work for Organics Analysis, March 1990, and Statement of Work for Inorganics Analysis, March 1990.

'All Target Compound List semivolatiles will be analyzed and reported. Only polynuclear aromatic hydrocarbons are listed here; detection limits for other semivolatiles will be the CLP contract required detection limits.

${ }^{d} \mathrm{ND}=$ Not determined.

'USEPA Test Methods for Evaluating Solid Waste, Physical/Chemical Methods, SW-846. 3rd Ed., November 1986.

fUSEPA Radiochemisry Procedures Manual, 520/5-84.006.

${ }^{8} \mathrm{NA}=$ Not applicable.

hBiological oxygen demand.

iChemical axygen demand.

Total dissolved solids.

kTotal suspended solids.

Total organic compounds. 
the procedures in Energy Systems' document ES/ESH/INT-14 and the specifications in the manufacturers' operations and maintenance manuals, as appropriate.

To present field data in a report, the data recorded in data books and forms will need to be summarized and transferred to tables, figures, maps, or logs. To analyze data, some data will need to be entered into computer data bases or onto spreadsheets. The Field Task Manager and other team members are responsible for data transfer activities pertinent to their roles on the project. The data manager will be responsible for ensuring that data transfers are performed accurately and will perform spot checks of the transfer activities.

Data generated by laboratories will be reduced using the format specified by the USEPA or other standard analytical methods. The analytical data packages will be checked by CDM Federal for completeness (i.e., all deliverables required for data validation must be in the package) and reasonableness. CDM Federal will contact the laboratory if deliverables are absent from the data packages or if discrepancies are noted. Laboratory data will be reconciled with field records before data validation.

It will be the responsibility of the data manager to ensure that all data transferred to tables, spreadsheets, logs, maps, figures, or into computerized data bases are transferred correctly. All data transferred, both hard copy and electronic copy, will be checked at least once for completeness and accuracy of transfer. Checking will be performed by comparing the raw data with the transferred data. All computer programs used for calculation or analysis will be checked at least once with a data set of known results before the program is used to process data for any site.

\subsubsection{Data Reporting}

For data produced following Level D QC, the laboratory is required to report data in accordance with ES/ER/TM-16.

The appropriate CLP forms are presented in the latest revision of the USEPA CLP Statement of Work for Inorganics Analysis (1990a) and the Statement of Work for Organics Analysis (1990b). The other Level C parameters will be reported in CLP-type format. The laboratory also is required to submit control charts for the blank spike analyses for each method and matrix and, if requested, calculations used to obtain results. Two copies of each data package will be required. Equivalent information, in accordance with ES/ER/TM-16, will be reported for radionuclides and other parameters.

\subsection{FIELD QUALTTY CONTROL SAMPLES}

QC sampling will be conducted to check sampling and analytical accuracy and precision for both laboratory and field analyses of the original samples. If contaminants are found in the blanks, attempts will be made to identify the source of contamination, and corrective action will be initiated in accordance with Sect. 7.13. The laboratory analyzing the samples will also include QC samples. These samples will be discussed in the laboratory QA Plan. The QC samples and frequency specified in ES/ER/TM-11 (Energy Systems 1991) will be used for this task. All QC samples will be shipped according to the chain-of-custody procedures specified in the Field Sampling Plan and in ESP-500 (ES/ESH/INT-14). 
QC samples will have sample numbers as described in the Field Sampling Plan. Duplicates will be submitted as "blind" to the laboratories. These samples will be analyzed for the parameters of interest. Results of these samples will be included in the analytical report. Table 7.6 summarizes QC samples necessary for this investigation.

- A trip blank consists of a sealed container of American Society for Testing and Materials (ASTM) Type II water that travels from the field to the laboratory with the samples to be analyzed for VOCs. The trip blank identifies contamination that may have been contributed to the field samples during transport (receives same treatment as sample containers). One trip blank will be placed in each cooler containing samples to be analyzed for VOCs.

- An equipment rinseate is collected in the field from a final ASTM Type II organic-free water rinse of decontaminated field sampling equipment. The field rinseate determines if the decontamination procedure is adequate to avoid carryover of contamination from one sampling location to another. One field rinseate will be collected for every ten samples (per matrix) for each equipment type during each sampling event (sampling period without a 48 -h interruption).

- A field blank consists of water used for rinse during field decontamination. One field blank will be collected from each source of rinse water (ASTM Type II and tap water) at the beginning of the sampling program and at the end.

- The field duplicate samples are collected from the composited sample matrix in a separate set of containers and labeled with a different sample numbers. They indicate whether the field sampling and measurcment technique is reproducible and are collected at a frequency of one for every ten samples.

- Matrix spike (MS)/matrix spike duplicate (MSD) samples may require the collection of additional sample volume and are often collected at the same location as duplicates. Samples are split into duplicates. The laboratory adds predetermined quantities of spiking solutions to the samples before preparation and analysis. The relative percent difference between samples is used to evaluate analytical precision. Percent recoveries are used to evaluate accuracy. MS/MSD samples will be collected at a minimum frequency of 1 for every 20 samples. For inorganics, a laboratory duplicate will be analyzed instead of the MSD.

\subsection{DATA VALIDATION}

Data validation is the process of screening data and accepting, rejecting, or qualifying them on the basis of sound criteria. Data validation will be performed in accordance with USEPA procedures and ES/ER/TM-16, Requirements for Quality Control of Analytical Data. Data will be validated, as appropriate, based on holding times, initial calibration, continuing calibration, blank results, and other QC sample results.

The Field Task Manager will review all field documentation, and the CDM Federal data validation staff will review all laboratory documentation for completeness, legibility, consistency, and reasonable agreement with expected or typical results. Field measurements and observations will be checked against the field log and records and discussed with the 
Table 7.6. Summary of quality control sample requirements

\begin{tabular}{lccccc}
\hline & $\begin{array}{c}\text { Trip } \\
\text { blanks }\end{array}$ & Duplicates & $\begin{array}{c}\text { Matrix spike/ } \\
\text { matrix spike } \\
\text { duplicate }\end{array}$ & $\begin{array}{c}\text { Equipment } \\
\text { rinseates }\end{array}$ & Total $^{\circ}$ \\
\hline Groundwater & 10 & 3 & 2 & 3 & 18 \\
$\begin{array}{l}\text { Surface } \\
\text { water/sediment }\end{array}$ & TBD $^{6}$ & TBD & TBD & TBD & TBD \\
Subsurface soil & 10 & 15 & 8 & 15 & 48 \\
Surface soil & 10 & 3 & 2 & 3 & 18 \\
Air & 1 & 1 & 1 & 1 & 4 \\
Tissue & & TBD & TBD & & TBD \\
\hline
\end{tabular}

'Field blanks will also be taken, two each from two anticipated samples.

TBD $=$ To be determined. 
individuals who collected the data to determine the possibility of error. However, checking of field instrument data is largely performed in the field at the time of analysis, based on equipment calibration and professional judgment.

All data packages received from the analytical laboratory will be reviewed and verified by CDM Federal project personnel to determine whether they are in compliance with all contractual requirements. Specific activities include checking for the following:

- invalid or missing key fields (Sample ID, Sample Delivery Group No.);

- missing forms;

- invalid reporting and analysis times;

- correct reporting units;

- cross-reference to field sample records; and

- valid method and analysis codes.

The data packages then will be validated by CDM Federal project personnel using ES/ER/TM-16 guidelines to determine whether the data can be used for th ir intended purpose as specified in the DQOs. Specific validation guidelines will be kept on file by CDM Federal. Results will be reviewed by a project chemist and reported to the Project Manager. Examples of $\mathrm{QC}$ information reviewed during data validation include

- holding times,

- calibrations,

- blanks,

- surrogates,

- internal standards,

- matrix spikes,

- duplicate analyses, and

- control charts.

The procedures used to assess the data from field measurements for PARCC are given in procedures specific to field measurements (ESP-307 series) in Energy Systems' ES/ESH/INT-14 and, more generally, in ESP-1100, Statistical Sampling Design.

The output from both the data verification and validation processes will be used by the data validators to assign data usability flags (e.g., $\mathrm{U}=$ not detected, $\mathrm{J}=$ estimated value, $\mathrm{R}=$ rejected) to each result as needed. A summary for each data package will be prepared, documenting the results that are not within the $\mathrm{QC}$ acceptance criteria and any other laboratory or field occurrences that affect the data quality. This report will explain the resulting data qualifiers applied to the data.

Deliverables to be supplied to the Energy Systems Project Manager on completion of the project include the following:

- completed and signed data compliance checklists,

- completed and signed data validation summary reports,

- completed and signed validation definitions and narrative, and

- copy of the Form I CLP report or equivalent with accompanying data flags. 
Analytical data outliers, as defined in the laboratory QA Plan, will be discussed with the data validators, and possibly the analytical laboratory, to determine if the outlier is a result of laboratory error. If necessary and possible, additional samples or measurements may be performed to confirm or disprove the outlier. If the outlier cannot be confirmed, it will be flagged as such and not used for decision purposes until subsequent analyses/measurements allow confirmation.

\subsection{FIELD AUDIS, SURVEILLANCES, AND INSPECTIONS}

Audits, surveillances, and inspections are conducted regularly by the CDM Federal QA staff to

- check on adherence to the QAVQC requirements specified in the project documents;

- evaluate the procedures used for data collection, data handling, and project management;

- verify that the QA program developed for this project is being implemented according to the specified requirements;

- assess the effectiveness of the QA program; and

- verify that identified deficiencies are corrected.

CDM Federal's policies and procedures are given in the CDM Federal Quality Assurance Manual. Specific procedures for scheduling and performing audits are given in QP 6 (Audits) of the CDM Federal Quality Assurance Manual. Specific procedures for scheduling and performing surveillances (QP 19) and inspections (QP 17) also are presented in the Quality Assurance Manual.

The Corporate QA Director is responsible for scheduling audits, surveillances, and inspections and will prepare a quarterly schedule planned to coincide with appropriate activities on the project schedule and sampling plans. The Contract QA Specialist is responsible for conducting or arranging audits, surveillances, and inspections. Scheduled audits, surveillances, and inspections may be supplemented by additional audits, surveillances, and inspections for one or more of the following reasons:

- significant changes are made in the QAPjP,

- significant personnel changes occur,

- it is necessary to verify that corrective action has been taken on a deficiency reported in a previous audit, or

- the additions are requested by the Corporate QA Director.

\subsubsection{Audits}

Audits are qualitative reviews of project activity to check that the overall CDM Federal QA program is functioning. Audits are conducted for projects that involve significant effort 
and have a long duration (several quarters). Audits should be conducted early in the project so that problems can be corrected quickly. An audit involves the review of all available and relevant project and contract documents and includes an evaluation of QC measures for field, laboratory, and office work.

Office audits evaluate the following:

- record keeping, including appropriate available field documentation, training, problem prevention, corrective action, change control, monthly reports, and other documentation of project work and QA measures;

- preparation of deliverables specified in the Work Plan;

- proper technical and QA review of documents; and

- filing, storage, and completeness of documents in the central files.

For this project, one office audit will be conducted by the Contract QA Specialist (D. Johnson) when approximately 30 to $50 \%$ of the work has been completed.

Field audits examine the following:

- cleaning/decontamination and storage of sampling equipment and containers;

- sample collection, preservation, custody, and shipping procedures;

- preparation and frequency of collection of QC samples;

- calibration, operation, and maintenance procedures; and

- documentation of field activities in the field logbook or appropriate data forms.

A field audit will not be performed because the field effort is of relatively short duration. However, a field surveillance will be conducted as discussed below.

Laboratory audits are conducted to verify that QA/QC measures specified in the QAPJP, lahoratory QA Plan or other project documents are followed in the laboratory. The following items are reviewed during the laboratory audit:

- documentation of training, nonconformance reporting, and corrective action;

- frequency of QC checks, such as blanks and spikes;

- calibration and preventive maintenance records;

- chain-of-custody forms; and

- data review and filing procedures. 
All laboratories used for this project will have been audited by Energy Systems and/or CDM Federal before initiation of fieldwork. Additional laboratory audits may be conducted during the performance of work.

\subsubsection{Surveillances}

Surveillances follow the same general format as an audit, but they are less detailed and require a less formal report. A surveillance is designed to provide rapid feedback to the project staff concerning QA compliance and to facilitate corrective action. Further discussion of surveillances is found in QP 19 of the CDM Federal Quality Assurance Manual.

Office surveillances may be performed as scheduled by the CDM Federal QA Director. For this project, one field surveillance is planned and will take place shortly after mobilization. Additional field surveillances will be conducted at $-4-$ to 6 -week intervals or at critical milestones. The following activities and documentation will be subject to surveillance:

- soil sampling;

- groundwater sampling;

- surface water and sediment sampling;

- air sampling;

- equipment and supplies related to sampling, measurements, and calibration;

- chain-of-custody documentation;

- field documentation;

- field training records; and

- field QC procedures.

\subsubsection{Inspections}

An inspection is defined as an examination or measurement to verify whether an item or activity conforms to specified requirements. Inspections focus on field procedures, equipment, and supplies and are conducted early in the field effort to identify and resolve problems quickly. No stand-alone inspections are planned for this project because the field surveillance discussed in Sect. 7.12.2 will include a review of procedures, equipment, and supplies. However, field inspections may be conducted if deemed necessary by the Corporate QA Director. 


\subsection{CORRECTIVE ACTION PROCEDURES}

\subsubsection{Nonconformances}

Nonconforming equipment, items, activities, and conditions and unusual incidents that could affect compliance with project requirements will be identified, controlled, and reported in a timely manner. The Field Task Manager or Project Manager initiates the nonconformance reporting and corrective action process by completing a Nonconformance Report. The Y-12 ER Product Manager will be notified of any nonconformances and will be provided with a copy of the Nonconformance Report. An example of a Nonconformance Report is shown in Fig. 7.5. Nonconforming equipment will be immediately labeled or tagged and segregated, if possible. Specific procedures for controlling nonconforming items are described in the CDM Federal Quality Assurance Manual (QP 4, Control of Nonconforming Items). All work performed by ORNL ESD, which will include ecological risk assessment activities: will conform with requirements described in appropriate Energy Systems QA proceúures.

\subsubsection{Corrective Action}

CDM Federal's corrective action system is described in the CDM Federal Quality Assurance Manual (QP 13, Corrective Action). This procedure requires that conditions adverse to quality be identified and documented and that corrective action be taken and verified. Specific procedures for controlling nonconforming items and the corrective action systems of the subcontract laboratories are contained in the respective laboratory QA Plans. Other team subcontractors (drilling and surveying) are required to follow equivalent corrective action procedures.

Each CDM Federal Team staff member is responsible for notifying the Field Task Manager, the Project Manager, the QA staff, or other responsible persons when he/she discovers a condition that may affect the quality of the work being performed. The staff and their specific corrective action responsibilities are the following:

- CDM Federal Program Manager has overall responsibility for implementing corrective actions.

- CDM Federal Corporate QA Director has overall responsibility for tracking and accepting corrective actions.

- CDM Federal Project Manager is responsible for implementing task-specific corrective actions.

- CDM Federal Field Task Manager is responsible for identifying and implementing corrective actions during field activities and for notifying the Project Manager and QA Director of conditions not immediately corrected.

- Subcontractor Laboratory Supervisor is responsible for identifying and implementing corrective action during analysis and for notifying the CDM Federal Project Manager and QA Director when applicable acceptance criteria or DQOs are not satisfied. 


\section{NONCONTORMANCE REPORT}

Job/Task Order No./Site location:

Name/D No. of nonconforming item:

Nature of nonconformance:

Requiremenu/Specification not met:

Identified by: Daic:

[Fonward to property manager; copy to QA manager]

[Below for use by property manager]

Method of identification of nonconforming item (label, tag, etc.):

Storage or hold location:

Disposition: (circle) Use-2s-is Repair Rewortk Reject Justification:

Approved by: (Tech. Spec.) Dare:

Approved by: (Propery Mgr.) Dale:

If item was repaired or reworked:

Reinspected and accepted by:

Dare:

Information copies w: 
Immediate corrective actions will be noted in task notebooks. Deficiencies or nonconformances not immediately corrected will require formal corrective action as described in QP 13 (Corrective Action) in the CDM Federal Quality Assurance Manual. Deficiencies or nonconformances will be submitted to the ER Division for review.

\subsection{QUALTTY ASSURANCE REPORTS}

As described in the CDM Federal Quality Assurance Manual, all levels of the CDM Federal Team QA staff are responsible for preparing QA reports. These reports include those described below.

- Weekly Quality Status Reports-The Project Manager is responsible for reporting quality problems to the Program Manager and QA Director on a weekly basis.

- Monthly QA Staff Reports-The Contract QA Specialist (David O. Johnson) will submit a monthly activity report to the CDM Federal Corporate QA Director.

- Laboratory Monthly Progress Report-The subcontract laboratory will submit a report in accordance with ES/ER/TM-16 to the CDM Federal Project Manager by the 15th of the month following each month in which work is performed. This report will be forwarded to the Energy Systems Project Manager and the Energy Systems Analytical Project Office.

- Audit, Surveillance, and Inspection Reports-The results of each QA audit, surveillance, or inspection will be documented in a report that is distributed within 30 working days of the audit, surveillance, or inspection.

- QA Sections in Project Reports-All reports that present measurement data generated during the work assignment require a QA section addressing the quality of the data and its limitations. Each QA section will address, at a minimum:

- precision, accuracy, and completeness achieved for reported measurement data in relation to goals for these indicators;

- results of performance and system audits of the measurement work;

- quality problems found and corrective actions taken; and

- deviations from Field Sampling Plan and QAPjP.

All reviews and document checks will be documented. All deliverables produced for this project will be subject to at least the three QC reviews described below.

- The technical review will be performed by senior professionals who have not been involved in project management or data collection activities. This technical review will focus on technical statements, conclusions, and recommendations to ensure that they are justifiable and defensible.

- The QA review will be conducted by the QA staff to ensure that QA/QC requirements have been addressed.

- The final review will be performed by the Project Manager. This review will be conducted to ensure that the document addresses all contractual requirements. 


\subsection{QUALIFICATIONS AND TRAINING OF PERSONNEL}

Personnel assigned to the project, including field personnel and subcontractors, will be qualified to perform the tasks to which they are assigned. In addition to education and experience, specific training may be required to qualify individuals to perform certain activities. Training will be documented on appropriate forms and placed in the project file as a record. At a minimum, the following records will be maintained in the project file:

- required reading reports;

- attendance lists; and

- certificates of qualification, as appropriate.

Project personnel will receive an orientation to the Work Plan, QAPjP, relevant ESPs, H\&S Plan, and their roles and responsibilities before participation in project activities. The field planning meeting will be the forum for the orientation. All field personnel will be required to read and familiarize themselves with the Work Plan, QAPjP, and H\&S Plan before completing any work at the site. A copy of the following documents will be available to all field personnel while in the field:

- CDM Federal Quality Assurance Program Plan for Environmental Restoration Activities at the Y-12 Plant, Oak Ridge, Tennessee;

- CDM Federal Health and Safety Assurance Manual - Hazardous Waste Projects;

- CDM Federal Field Equipment Operation, Calibration, and Maintenance Manual;

- this Work Plan;

- this RI Work Plan, which includes

- Site Data Needs (Sect. 6),

- QAPjP (Sect. 7),

- H\&S Plan (Sect. 8), and

- Waste Management Plan (Sect. 9); and

- relevant Energy Systems ESPs.

In addition, during the field planning meeting the ESPs and other SOPs to be followed during field activities will be reviewed and/or demonstrated to serve as a methods refresher session. At a minimum, the records to be maintained include required reading reports, attendance lists, and Certificates of qualification.

\subsection{FIELD CHANGES}

The CDM Federal Quality Assurance Manual requires that field changes be governed by control measures commensurate with those applied to the documentation of the original design. The procedures for control of field changes are the following: 
- Major changes from approved field operating procedures, project scope, cost, or schedule will be documented on a Field Change Request Form (FCRF). An example FCRF is shown in Fig. 7.6. The Field Task Manager will initiate and maintain the FCRFs.

- Each FCRF requires the approval of the Energy Systems Project Manager before work proceeds. Approval by the Energy Systems Project Manager can be initiated on a verbal basis via telephone with follow-up sign-off. In no case will a subcontractor initiate a field change. If a field change is proposed by the client, it will be so recorded. Copies of the FCRFs will be kept on-site until the fieldwork is complete and then will be sent to the project files. Weekly reports prepared by the CDM Federal Project Manager serve as the mechanism for notifying the QA staff of field changes.

- Variances or minor changes to field operating procedures will be documented in the field logbook and reported on a weekly basis.

- If deemed necessary, the Field Sampling Plan, QAPjP, H\&S Plan, or other relevant documents will be revised, reviewed, approved, and reissued in accordance with CDM Federal's document control procedures. The Energy Systems Project Manager must approve each FCRF before work proceeds.

- For the ecological risk assessment tasks to be conducted by ORNL ESD, field changes will be recorded directly in the registered field notebooks. These are controlled documents. 


\section{FIELD CHANGE REQUEST FORM}

Project No.

Field Change No.

Page_of

Project:

Applicable Document:

Description:

Reason for change:

Recommended disposition:

Impact on present and completed work:

Requested by:

(Field/Project Manager)

Approval:

(Energy Systems Project Manager)

NOTE: the Energy Systems Project manager is notified of the need for change in project cost, schedule direction, or scope. This form does NOT satisfy Section 3, "Changes", of contract Terms and Conditions.

\section{EXAMPLE OF FIELD CHANGE REQUEST FORM}




\section{ENVIRONMENTAL RESTORATION PROGRAM HEALTH AND SAFETY PLAN}

Revision No. 0

Project Title: REMEDIAL INVESTIGATION WORK PLAN FOR CHESTNUT RIDGE OPERABLE UNIT 1 (CHESTNUT RIDGE SECURITY PITS) AT THE Y-12 PLANT, OAK RIDGE, TENNESSEE

Prepared By: CDM Federal Programs Corporation

Technical Support Contractor

Date:

Program Manager

Approved By:

Technical Support Contractor

Date:

Quality Assurance/Quality Control Officer

Approved By:

DOE-ER Division

Date:

Program Manager

Approved By:

DOE-ER Division

Date:

QA Program Manager

Approved By:

Energy Systems

Date:

ER Site Program Manager

Approved By:

Energy Systems

ER Site Project Manager

Date:

Date:

Approved By:

Energy Systems

ER Site Quality Assurance Specialist

Approved By:

DOE-ER Division

Health and Safety Manager

Date:

Approved By:

Energy Systems-ER Division

Date:

Health and Safety Manager 


\subsection{HEAT AND COLD STRESS}

Stress can contribute significantly to accidents or harm workers in other ways. The term stress denotes the physical (gravity, mechanical force, heat, cold, pathogen, injury) and psychological (fear, anxiety, crisis, joy) forces that are experienced by individuals. The body's response to stress occurs in the following three stages:

- alarm reaction, in which the body recognizes the stressor and the pituitary-adreno-cortical system responds by increasing the heart rate and blood sugar level, decreasing digestive activity, and dilating the pupils;

- adaptive stage, in which the body repairs the effects of stimulation and the stress symptoms disappear; and

- exhaustion stage, in which the body can no longer adapt to stress and the individual may develop emotional disturbances and cardiovascular and renal diseases.

The most common types of stress that affect field personnel are heat and cold stress. Current thinking is that heat and cold stress may be the most serious hazards to workers at waste sites.

\subsubsection{Heat Stress}

For field workers, heat stress usually is a result of protective clothing decreasing natural body ventilation, although it may occur at any time work is being performed at elevated temperatures.

If the body's physiological processes fail to maintain a normal body temperature because of excessive heat, a number of physical reactions can occur, ranging from mild (such as fatigue, irritability, anxiety, and decreased concentration, dexterity, or movement) to fatal. Because heat stress is one of the most common and potentially serious illnesses at hazardous waste sites, regular monitoring and other preventive measures are vital.

Site workers must learn to recognize and treat the various forms of heat stress. The best approach is preventive heat stress management. In general, the following steps should be undertaken.

- Have workers drink $16 \mathrm{oz}$ of water before beginning work, such as in the morning or after lunch. Provide disposable, 4-oz. cups and water that is maintained at 50 to $60^{\circ} \mathrm{F}$. Urge workers to drink 1 to 2 cups of water every $20 \mathrm{~min}$, for a total of 1 to $2 \mathrm{gal} / \mathrm{d}$. Provide a cool, shaded area for rest breaks. Discourage the use of alcohol in nonwork hours and discourage the intake of coffee during work hours. Monitor for signs of heat stress.

- Acclimate workers to site work conditions by slowly increasing workloads; that is, do not begin site work with extremely demanding activities. 
- Provide cooling devices to aid natural body ventilation. These devices, however, add weight, and their use should be balanced against worker efficiency. An example of a cooling aid is Iong cotton underwear, which acts as a wick to help absorb moisture and protect the skin from direct contact with heat-absorbing protective clothing.

- Install mobile showers and/or hose-down facilities to reduce body temperature and cool protective clothing.

- In hot weather, conduct field activitics in the early morning or evening.

- Ensure that adequate shelter is available to protect personnel against heat, as well as cold, rain, snow, and so forth, which can decrease physical efficiency and increase the probability of both heat and cold stress. If possible, set up the command post in the shade.

- In hot weather, rotate shifts of workers wearing impervious clothing.

- Good hygienic standards must be maintained by frequent changes of clothing and showers. Clothing should be permitted to dry during rest periods. Persons who notice skin problems should immediately consult medical personnel.

\subsubsection{Heat stroke}

Heat stroke is an acute and dangerous reaction to heat stress caused by a failure of the heat regulating mechanisms of the body-the individual's temperature control system that causes sweating stops working correctly. Body temperature rises so high that brain damage and death will result if the person is not cooled quickly.

- Symptoms: Red, hot, dry skin, although person may have been sweating earlier; nausea; dizziness; confusion; extremely high body temperature; rapid respiratory and pulse rates; unconsciousness or coma.

- Treatment: Cool the victim quickly. If the body temperature is not brought down fast, permanent brain damage or death will result. Soak the victim in cool but not cold water, sponge the body with cool water, or pour water on the body to reduce the temperature to a safe level $\left(102^{\circ} \mathrm{F}\right)$. Observe the victim and obtain medical help. Do not give coffee, tea, or alcoholic beverages.

\subsubsection{Heat exhaustion}

Heat exhaustion is a state of very definite weakness or exhaustion caused by the loss of fluids from the body. This condition is much less dangerous than heat stroke, but it nonetheless must be treated.

- Symptoms: Pale, clammy, moist skin, profuse perspiration, and extreme weakness. Body temperature is normal, pulse is weak and rapid, and breathing is shallow. The person may have a headache, may vornit, and may be dizzy. 
- Treatment: Remove the person to a cool, air-conditioned place; loosen clothing; place in a head-low position; and provide bed rest. Consult a physician, especially in severe cases. The normal thirst mechanism is not sensitive enough to ensure body fluid replacement. Have patient drink 1 to 2 cups of water immediately, and every $20 \mathrm{~min}$ thereafter, until symptoms subside. Total water consumption should be about 1 to $2 \mathrm{gal} / \mathrm{d}$.

\subsubsection{Heat cramps}

Heat cramps are caused by perspiration that is not balanced by adequate fluid intake. Heat cramps are often the first sign of a condition that can lead to a heat stroke.

- Symptoms: Acute painful spasms of voluntary muscles (e.g., abdomen and extremities).

- Treatment: Remove victim to a cool area and lonsen clothing. Have patient drink 1 to 2 cups of water immediately, and every $20 \mathrm{~min}$ thereafter, until symptoms subside. Total watei consumption should be 1 to $2 \mathrm{gal} / \mathrm{d}$. Consult a physician.

\subsubsection{Heat rash}

Heat rash is caused by continuous exposure to heat and humid air and is aggravated by chafing clothes. The condition decreases the ability to tolerate heat.

- Symptoms: Mild red rash, especially in areas of the body in contact with protective gear.

- Treatment: Decrease amount of time in protective gear and provide powder to help absorb moisture and decrease chafing.

\subsubsection{Heat stress monitoring and work cycle management}

For strenuous field activities that are part of on-going site work activities in hot weather, the following procedures will be used to monitor the body's physiological response to heat and to manage the work cycle, even if workers are not wearing impervious clothing.

These procedures are to be instituted when the temperature exceeds $70^{\circ} \mathrm{F}$.

- Measure Heart Rate (HR). Heart rate should be measured by the radial pulse for $30 \mathrm{~s}$ as early as possible in the resting period. The HR at the beginning of the rest period should not exceed 110 beats/min. If the HR is higher, the next work period should be shortened by $33 \%$, while the length of the rest period stays the same. If the pulse rate still exceeds 110 beats/min at the beginning of the next rest period, the following work cycle should be further shortened by $33 \%$. The procedure is continued until the rate is maintained below 110 beats/min.

- Measure Body Temperature. Body temperature should be measured orally with a clinical thermometer as early as possible in the resting period. Oral temperature at the beginning of the rest period should not exceed $99.6^{\circ} \mathrm{F}$. If it does, the next work period should be shortened by $33 \%$, while the length of the rest period stays the same. If the temperature 
exceeds $99.6^{\circ} \mathrm{F}$ at the beginning of the next period, the following work cycle should be further shortened by $33 \%$. The procedure is continued until the body temperature is maintained below $99.6^{\circ} \mathrm{F}$.

- Manage a Work/Rest Schedule. The following work/rest schedule shall be used as a guideline:

Adjusted temperature

$\left({ }^{\circ} \mathrm{F}\right)$

75 or less

80

85

90

95

100

\section{Active work time $(\mathrm{min} / \mathrm{h})$ using}

Level $B / C$ protective gear

Calculate the adjusted temperature:

$$
\mathrm{T}(\text { adjusted })=\mathrm{T} \text { (actual })+(13 \times \text { fraction sunshine }) .
$$

Measure the air temperature with a standard thermometer. Estimate fraction of sunshine by judging what percent the sun is out:

$100 \%$ sunshine $=$ no cloud cover $=1.0$

$50 \%$ sunshine $=50 \%$ cloud cover $=0.5$

$0 \%$ sunshine $=$ full cloud cover $=0.0$.

Reduce or increase the work cycle according to the guidelines under the heart rate and body temperature sections.

\subsubsection{Cold Stress}

Persons working outdoors in low temperatures, especially at or below freezing, are subject to cold stress. Exposure to extreme cold for a short time may cause severe injury to the surface of the body or result in profound generalized cooling, causing death. Areas of the body that have high surface area-to-volume ratios, such as fingers, toes, and ears, are the most susceptible.

Protective clothing generally does not afford protection against cold stress. In many instances, it increases susceptibility.

Two factors influence the development of a cold injury: ambient temperature and the velocity of the wind. The term wind chill is used to describe the chilling effect of moving air in combination with low temperature. 
As a general rule, the greatest incremental increase in wind chill occurs when a wind of $5 \mathrm{mph}$ increases to $10 \mathrm{mph}$. Additionally, water conducts heat 240 times faster than air. Thus, the body cools suddenly when chemical-protective equipment is removed if the clothing underneath is soaked with perspiration.

\subsubsection{Frostbite}

Local injury resulting from cold is included in the generic term frostbite. Frostbite of the extremities can be categorized into the categories described helow.

- Frost nip or incipient frostbite is characterized by sudden blanching or whitening of skin.

- Superficial frostbite is characterized by skin with a waxy or white appearance that is firm to the touch, but the tissue beneath is resilient.

- Deep frostbite is characterized by tissues that are cold, pale, and solid.

To administer first aid for frostbite: Take the victim indoors and rewarm the affected areas quickly in water that is between 39 and $41^{\circ} \mathrm{C}\left(102\right.$ and $\left.105^{\circ} \mathrm{F}\right)$. Give a warm drink-not coffee, tea, or alcohol. The victim must not smoke. Keep the frozen parts in warm water or covered with warm clothes for $\mathbf{3 0}$ min even though the tissue will be very painful as it thaws. Then elevate the injured area and protect it from injury. Do not allow blisters to be broken. Use sterile, soft material to cover the injured areas. Keep victim warm and get immediate medical care.

After thawing, the victim should try to move the injured areas a little, but no more than can be done alone, without help.

- Do not rub the frostbitten part (this may cause gangrene).

- Do not use ice, snow, gasoline, or anything cold on the frostbitten area.

- Do not use heat lamps or hot water bottles to rewarm the part.

- Do not place the part near a hot stove.

\subsection{Hypothermia}

Systemic hypothermia is caused by exposure to freezing or rapidly dropping temperature. Its symptoms are usually exhibited in five stages:

- shivering;

- apathy, listlessness, sleepiness, and (sometimes) rapid cooling of the body to $<95^{\circ} \mathrm{F}$;

- unconsciousness, glassy stare, slow pulse, and slow respiratory ratc;

- freezing of the extremities; and

- death.

As a general rule, field activities shall be curtailed if equivalent chill temperature $\left({ }^{\circ} \mathrm{F}\right)$, as defined by the U.S. Army Research Institute of Environmental Medicine, is below $0^{\circ} \mathrm{F}$ unless the activity is of an emergency nature. 


\subsection{HEALTH AND SAFETY PLAN}

The Health and Safety Plan for the CRSP project is given on the following pages. 


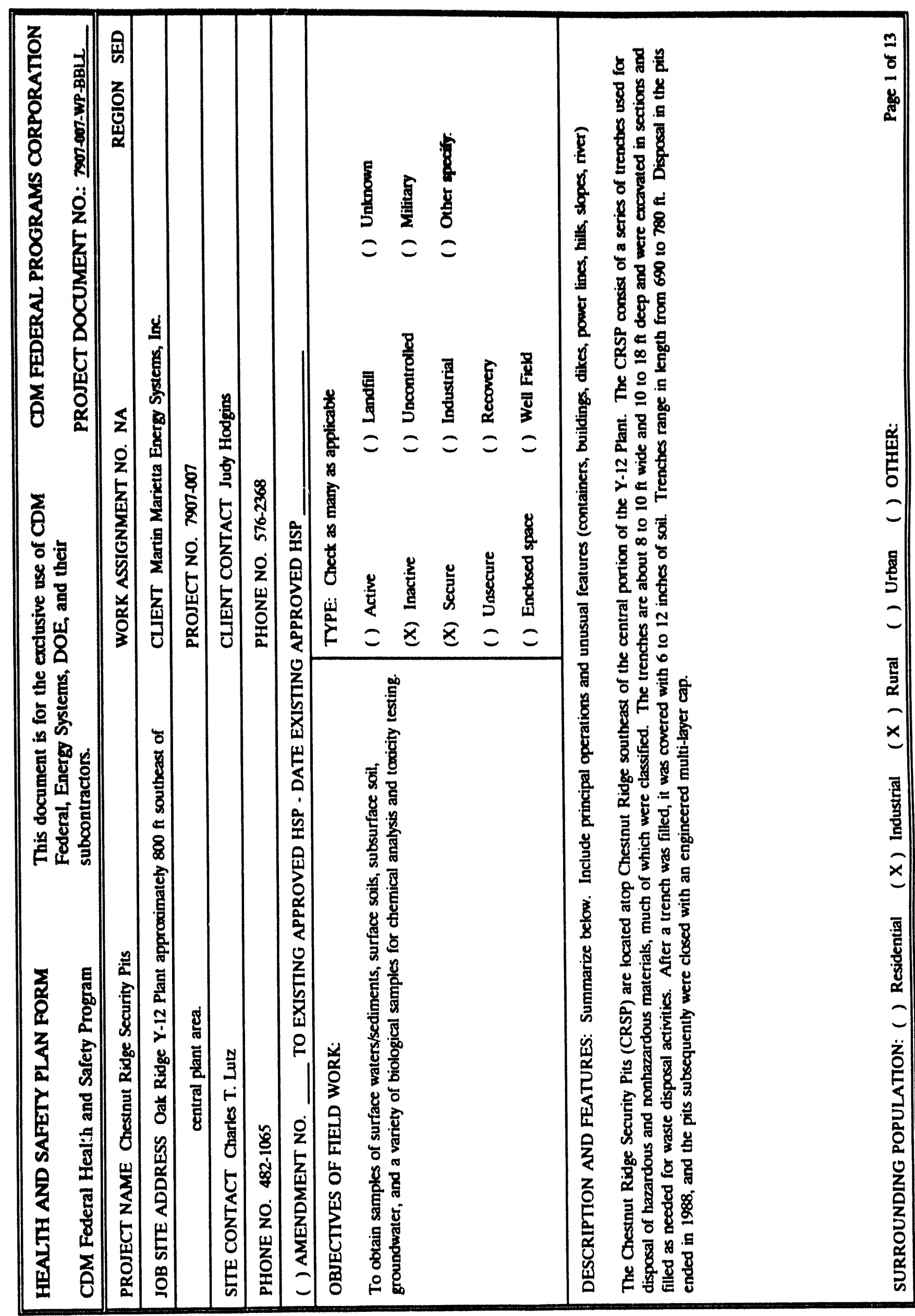




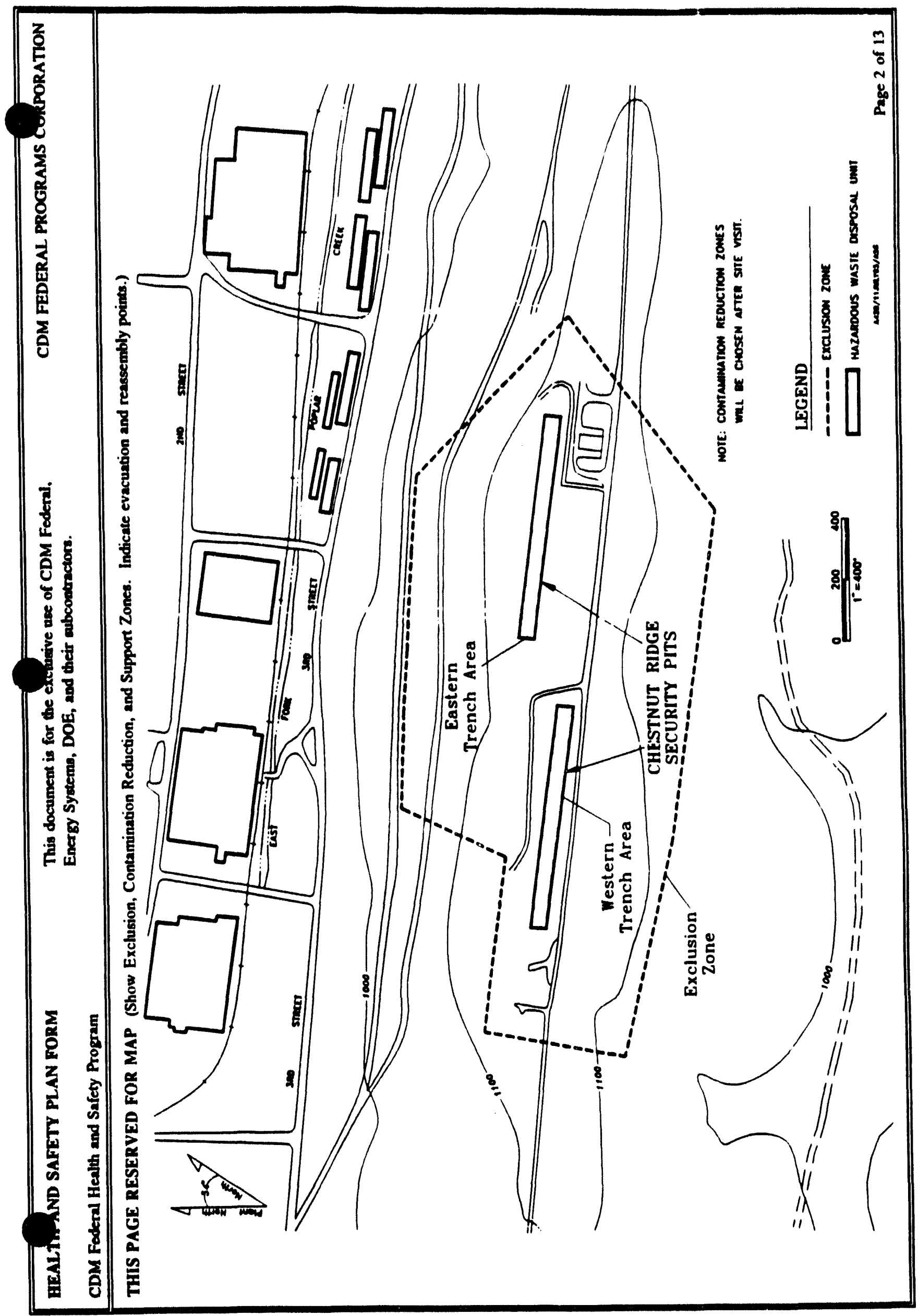




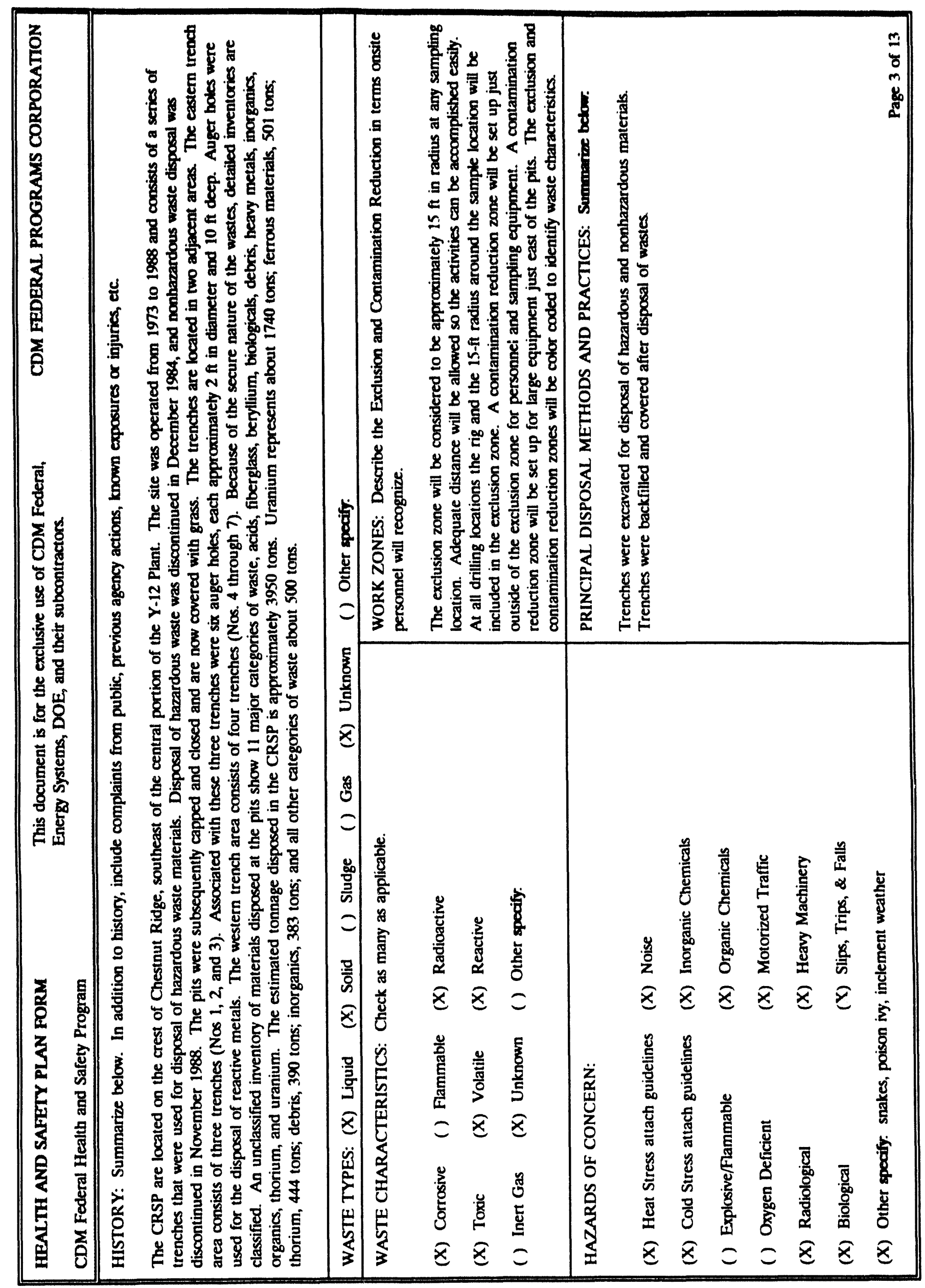




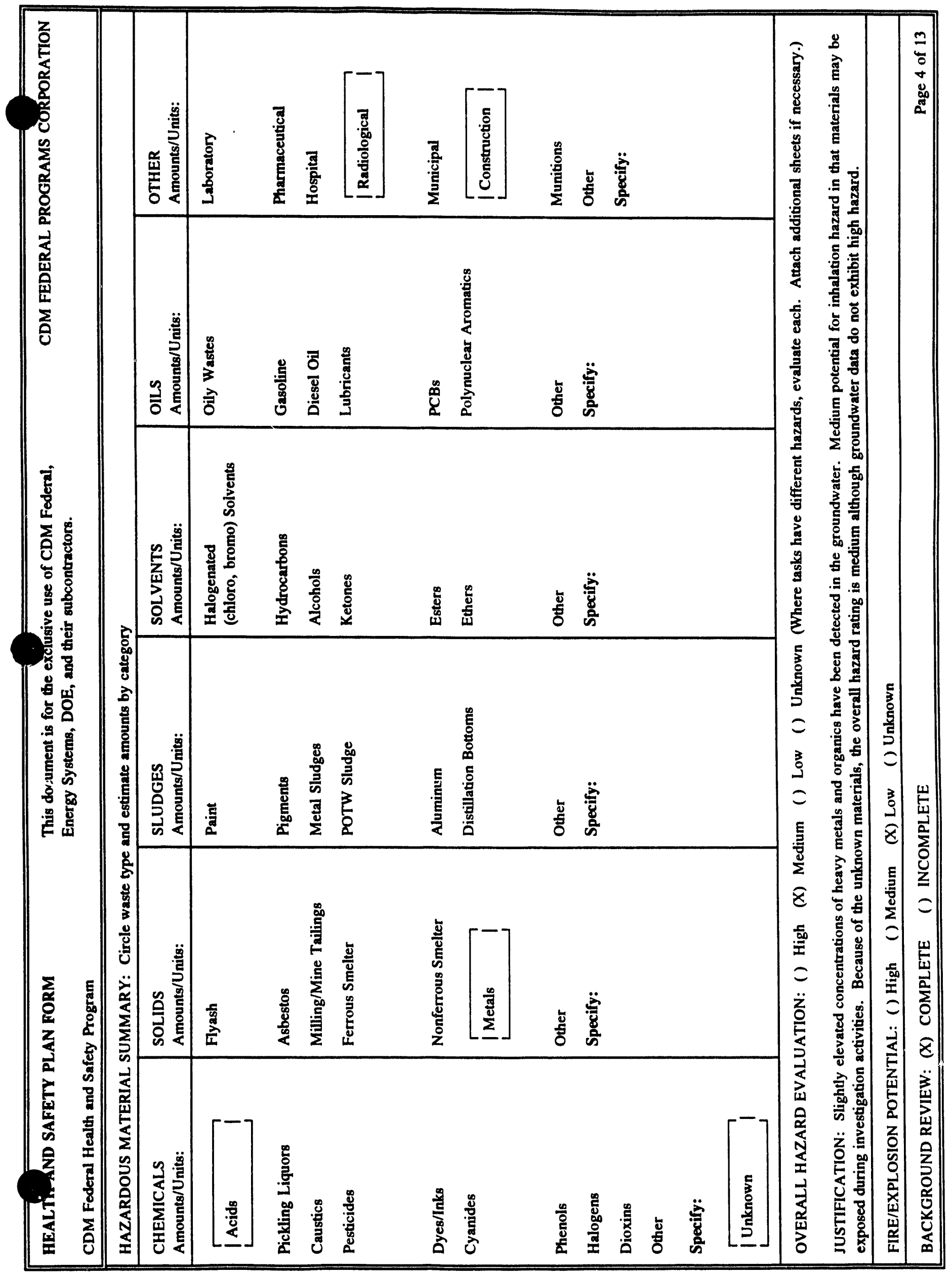




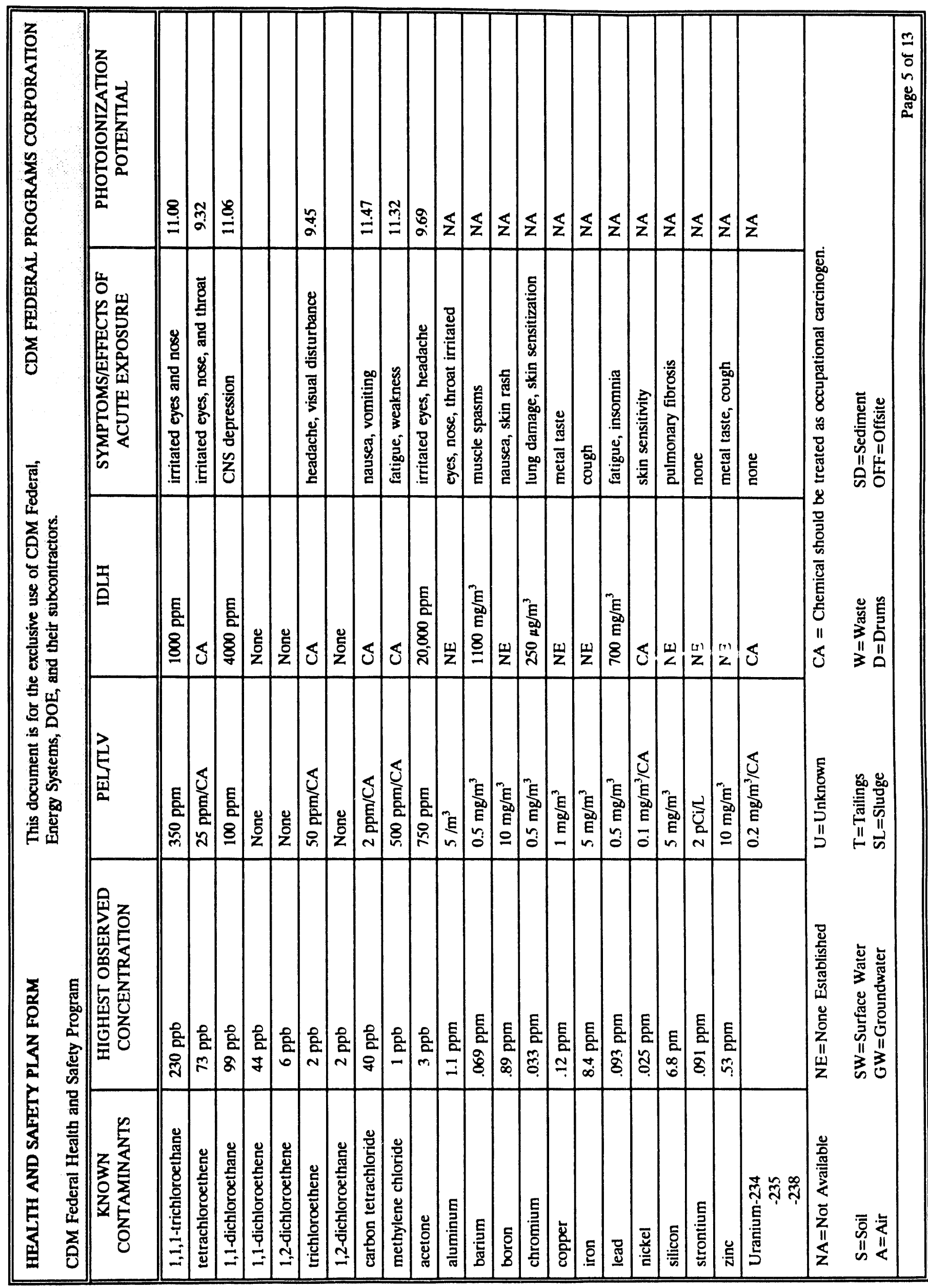




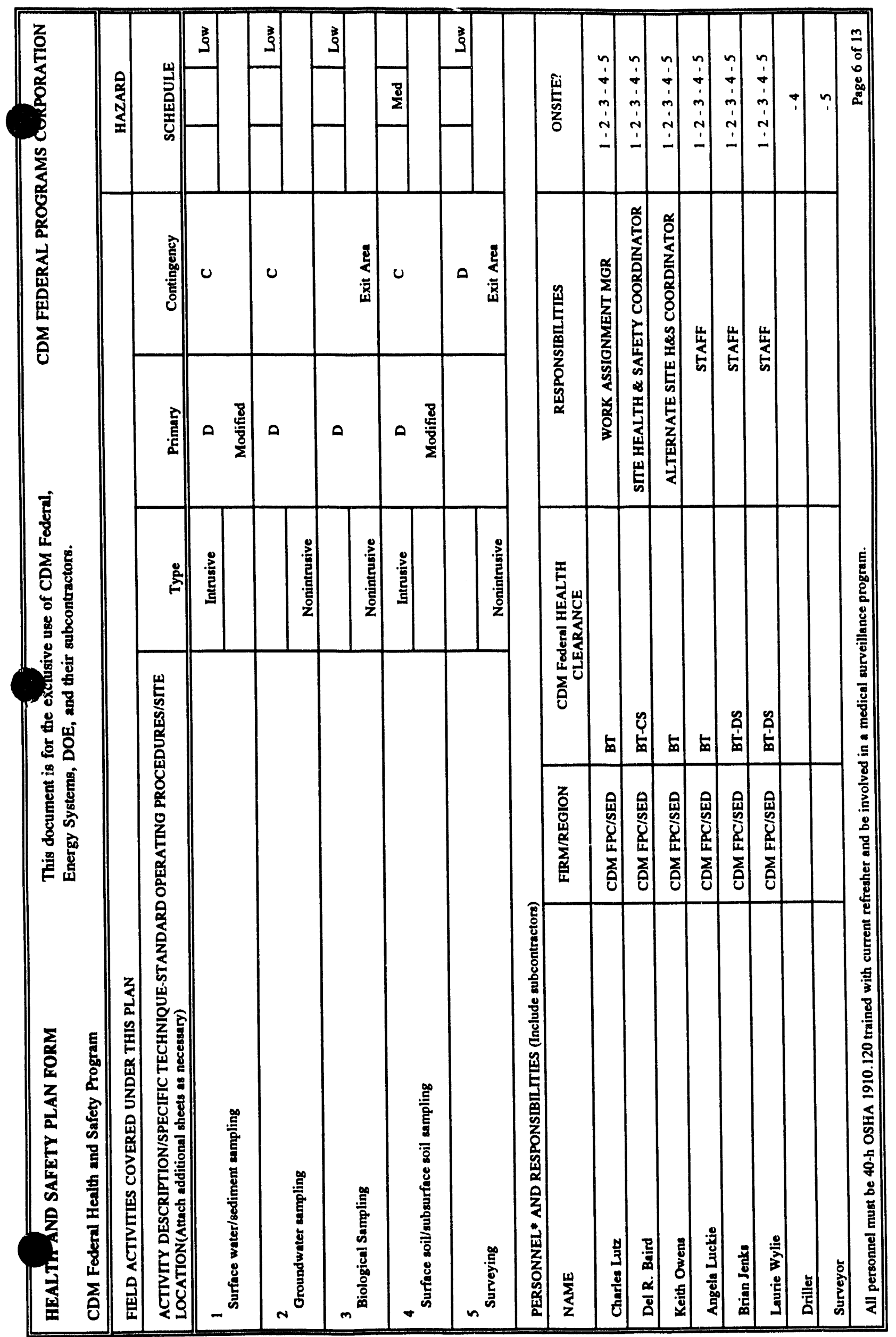




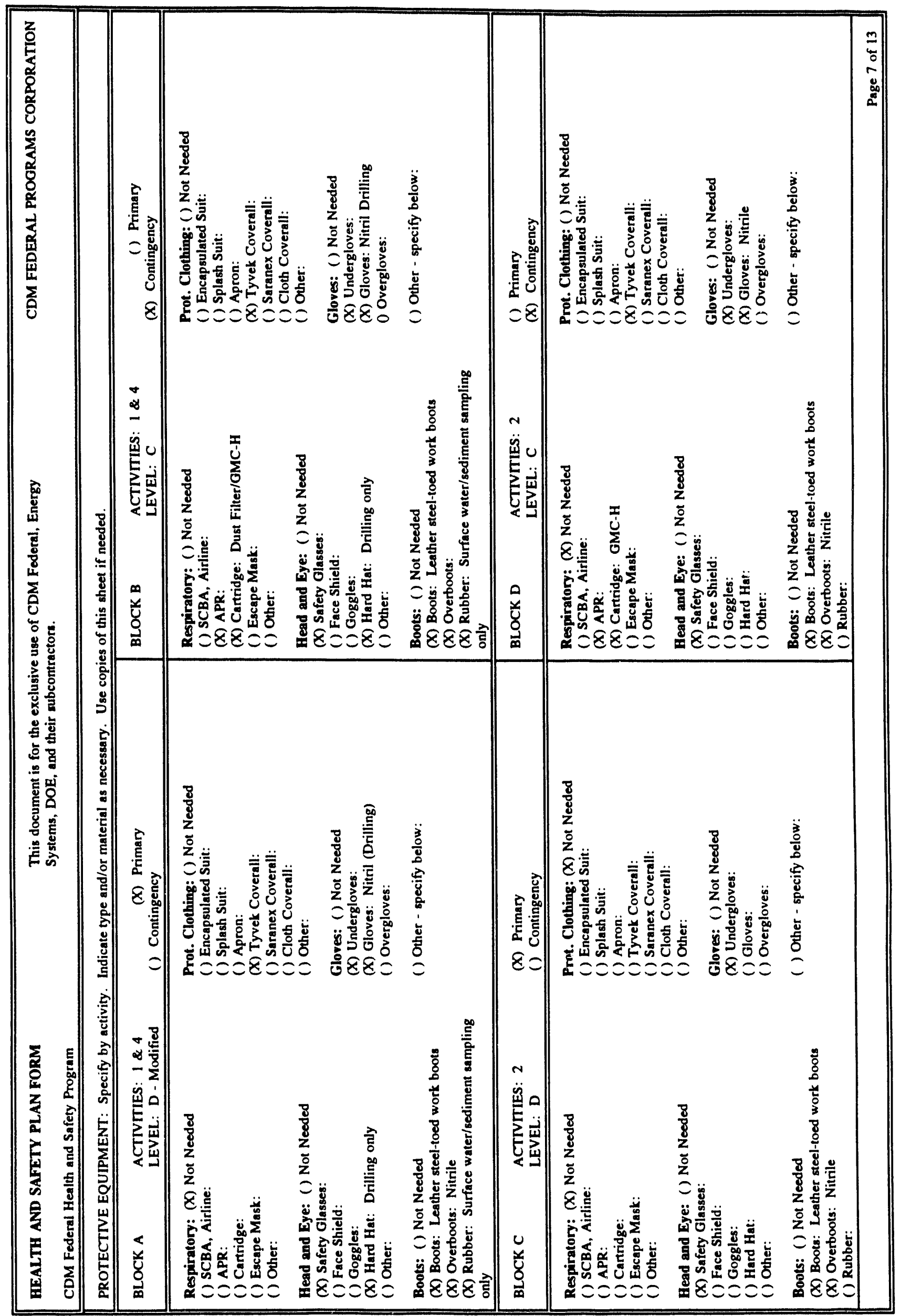




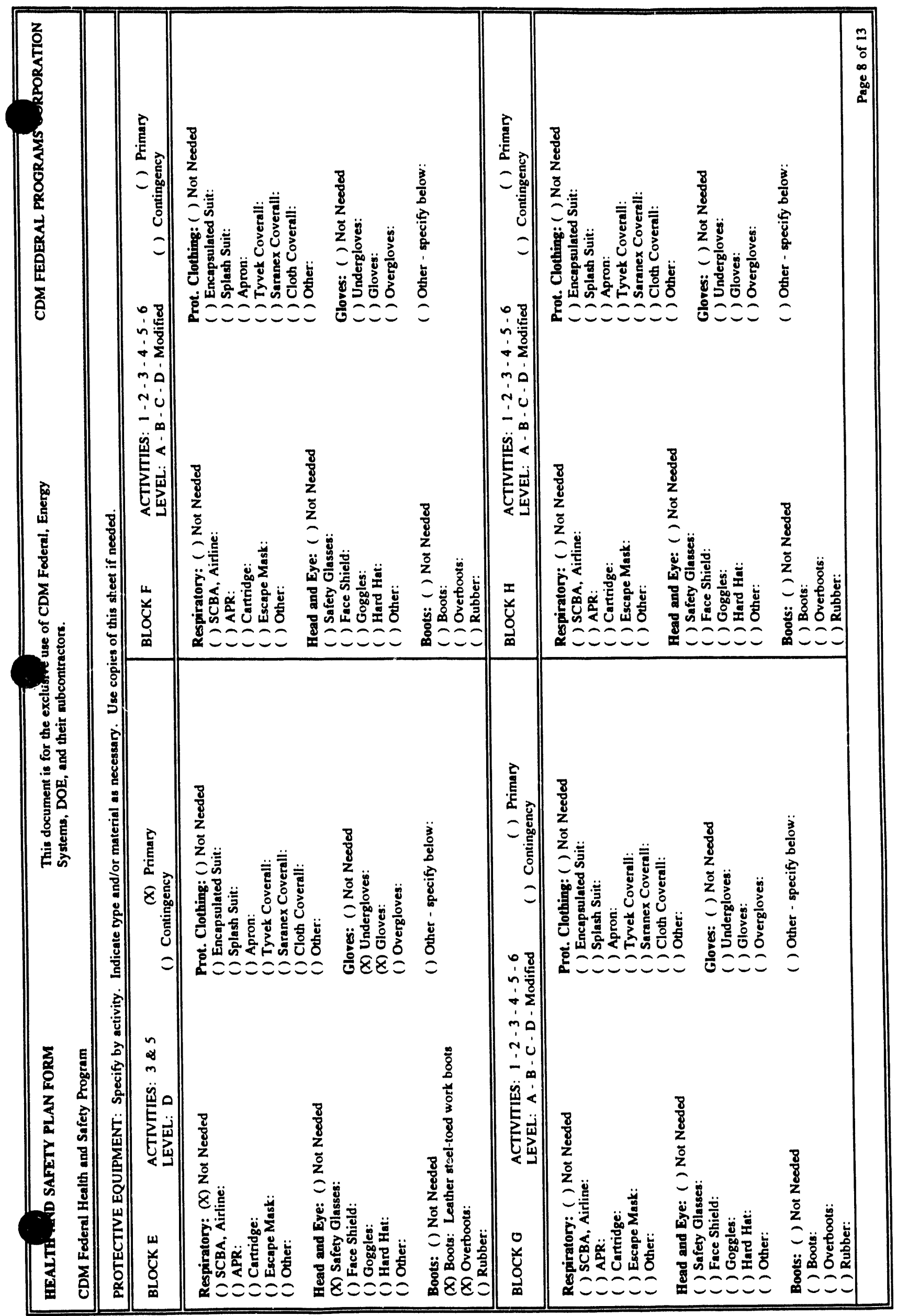




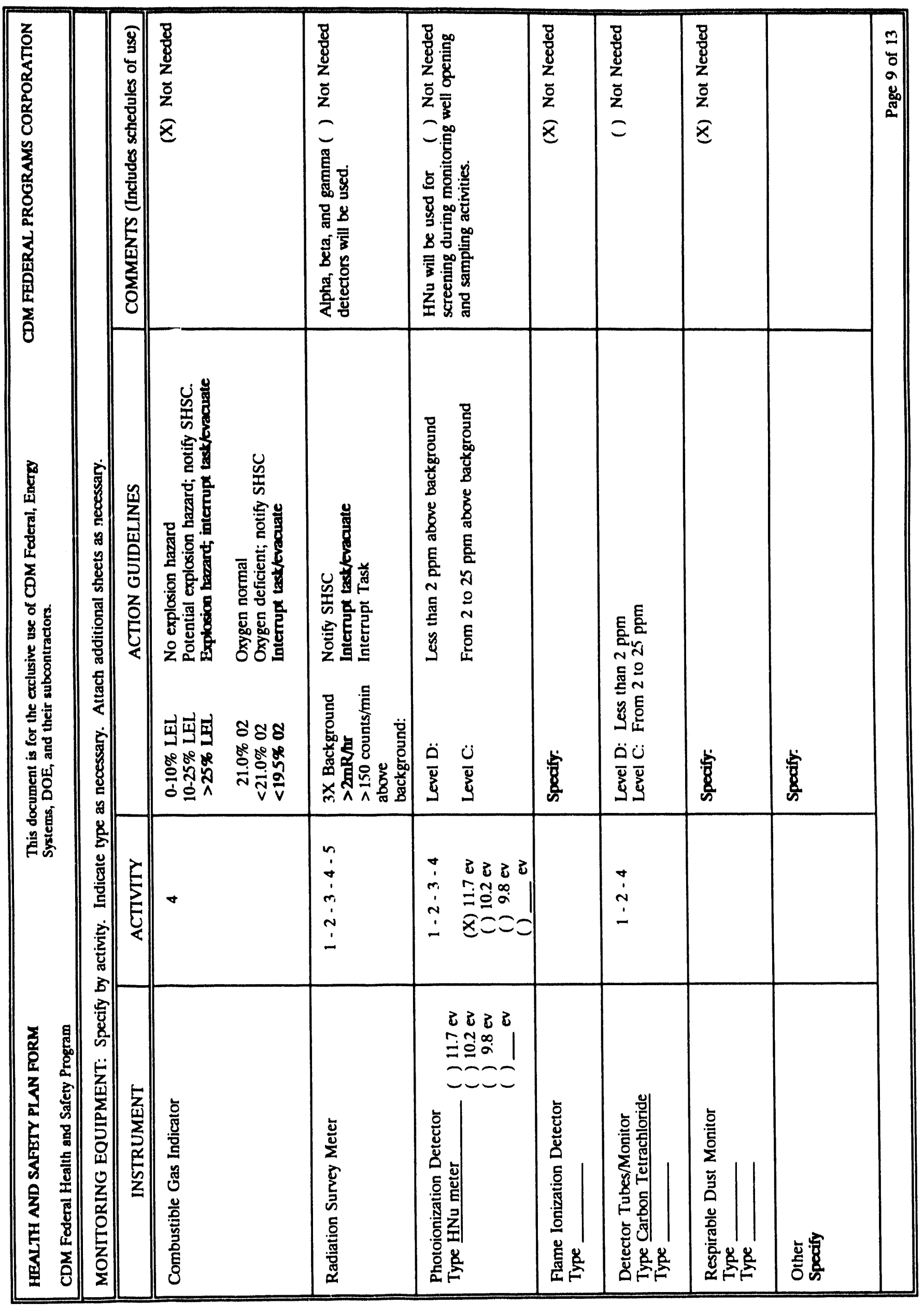




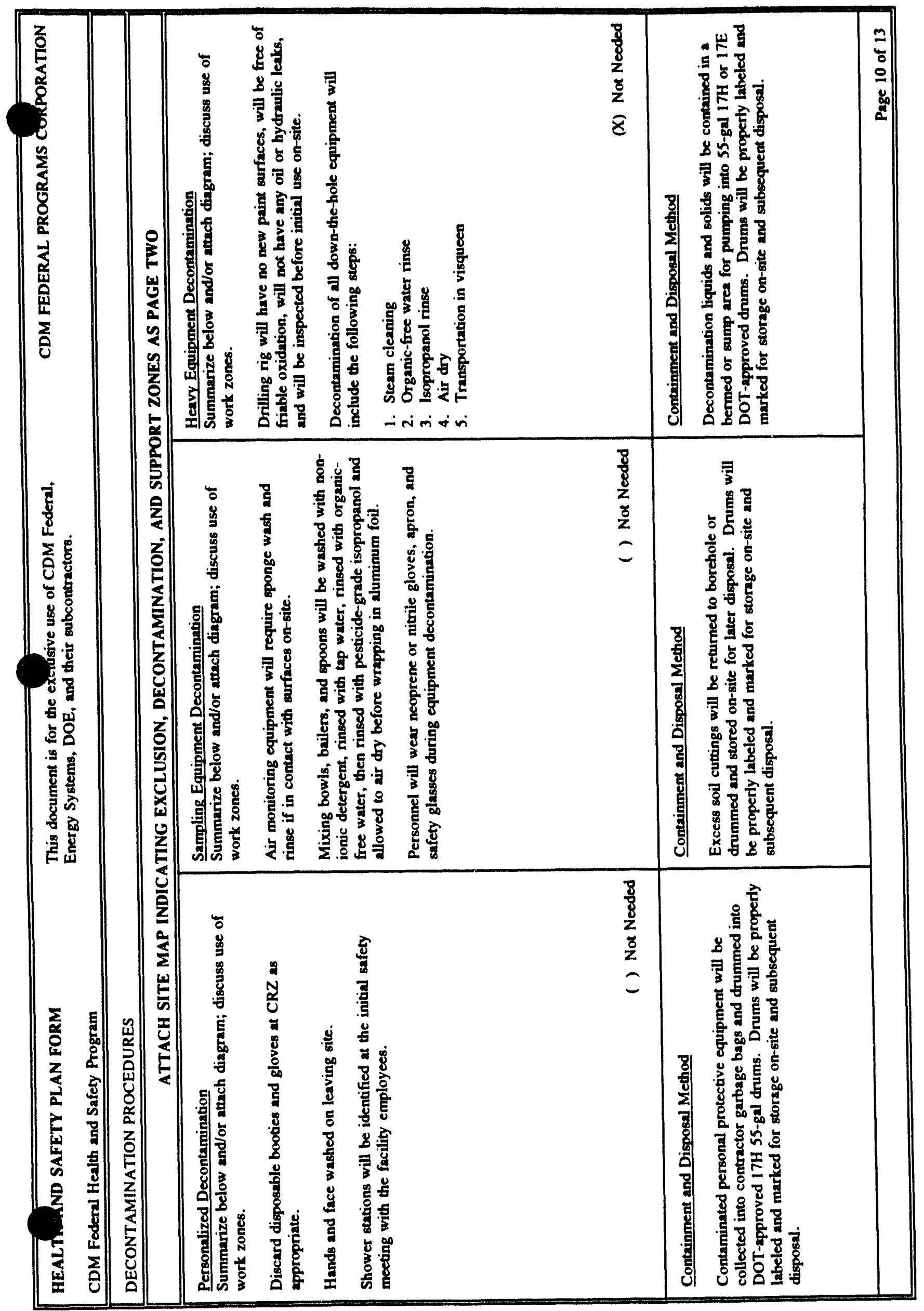




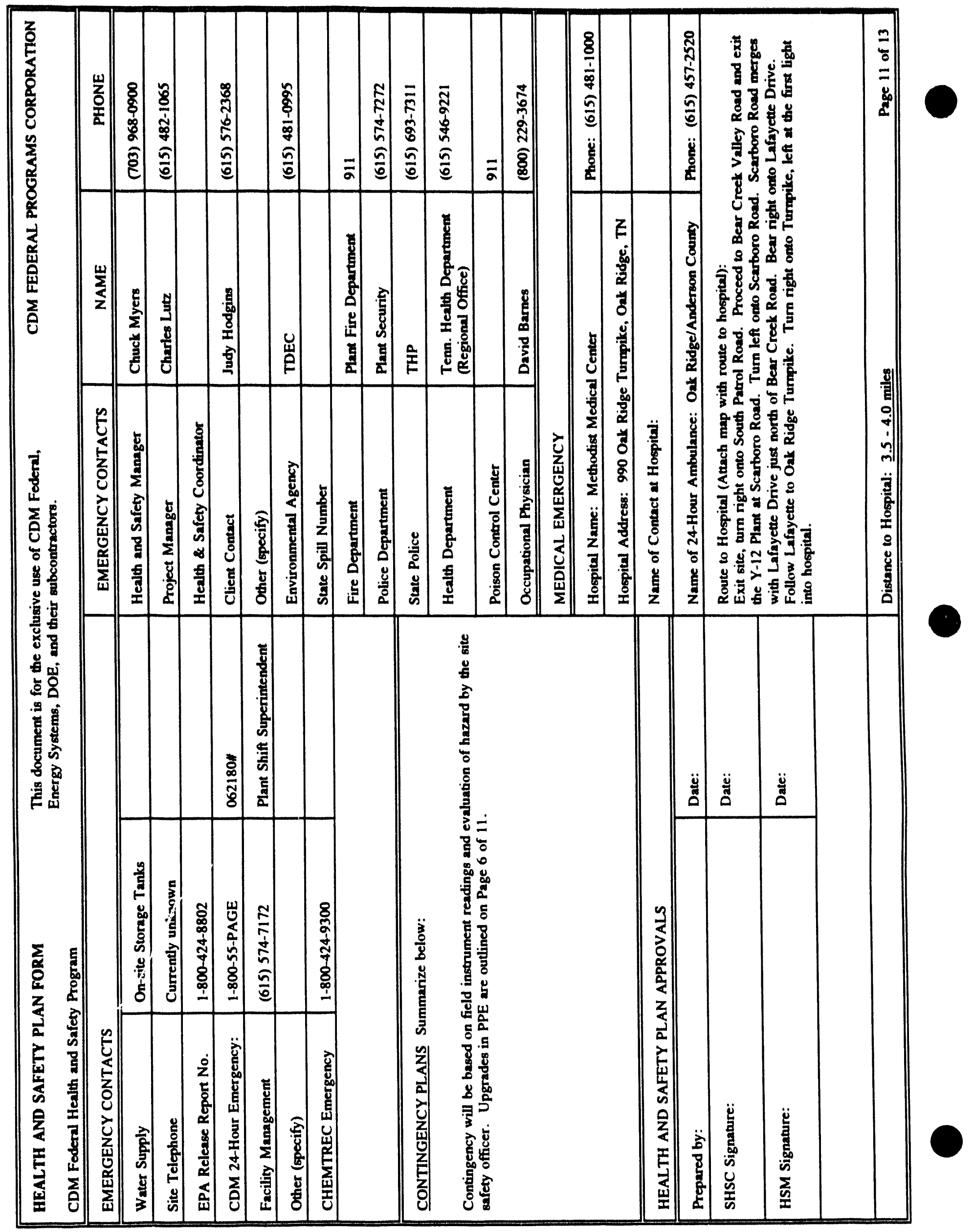




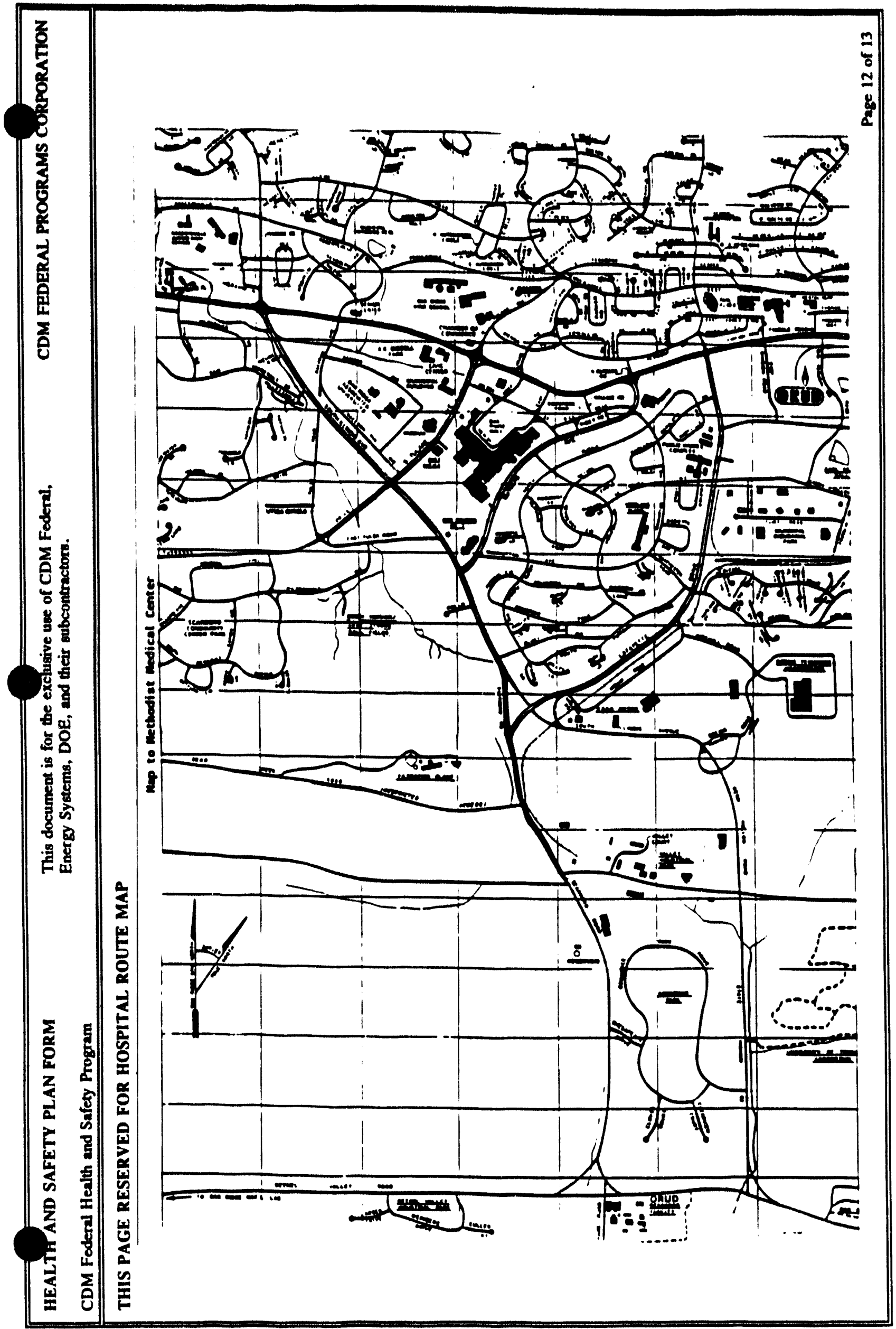




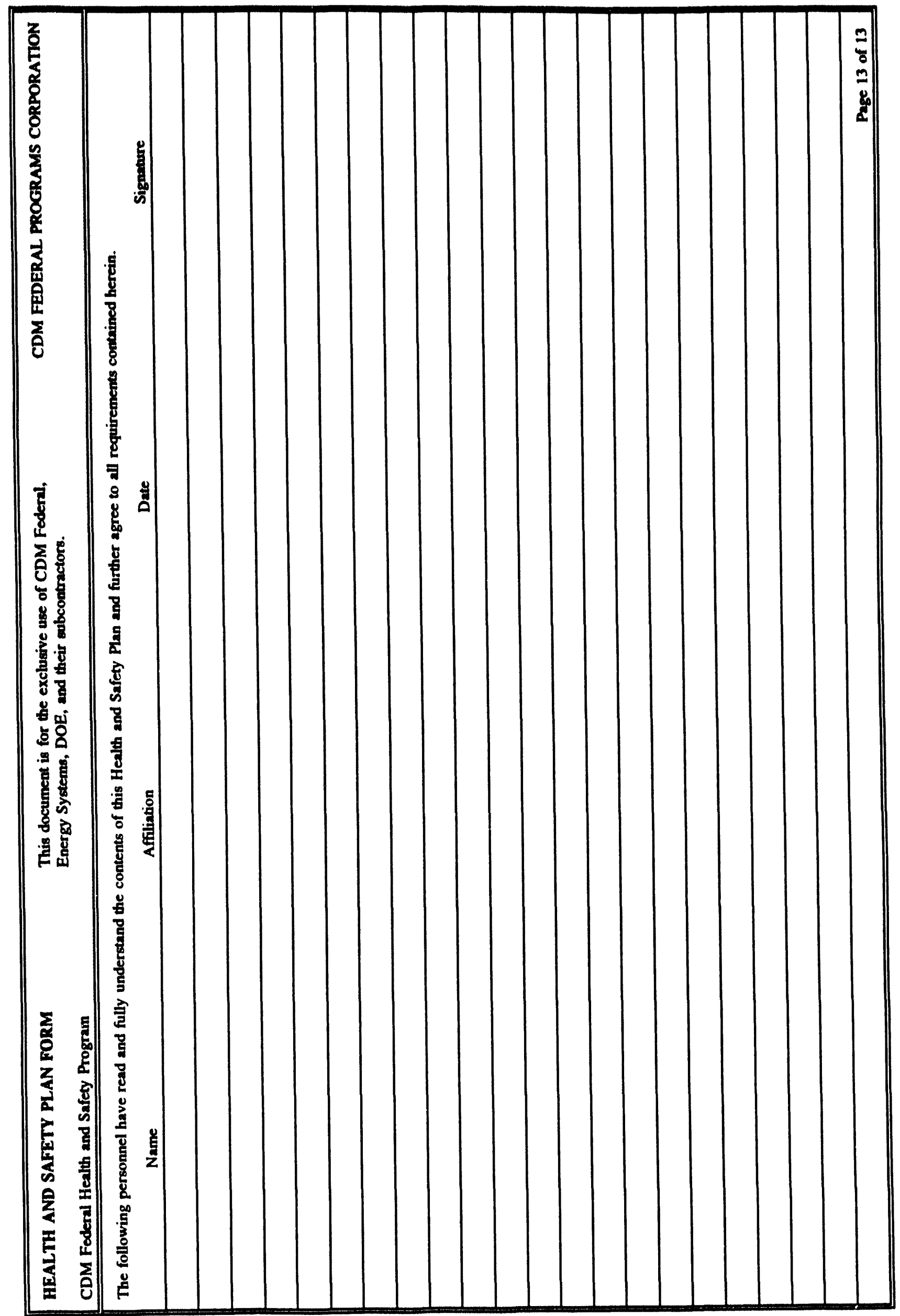




\section{ENVIRONMENTAL RESTORATION PROGRAM WASTE MANAGEMENT PLAN}

Project Title: REMEDIAL INVESTIGATION WORK PLAN FOR CHESTNUT RIDGE OPERABLE UNIT 1 (CHESTNUT RIDGE SECURITY PITS) AT THE Y-12 PLANT, OAK RIDGE, TENNESSEE

Prepared By: CDM Federal Programs Corporation

Technical Support Contractor

Date:

Program Manager

Approved By:

Technical Support Contractor

Quality Assurance/

Quality Control Officer

Approved By:

DOE-ER Division

Date:

Program Manager

Approved By:

DOE-ER Division

Date:

QA Program Manager

Approved By:

Energy Systems

Date:

ER Site Program Manager

Approved By:

Energy Systems

ER Site Project Manager

Approved By:

Energy Systems

ER Site Quality Assurance Specialist

Date:

Date:

Date: 


\subsection{SCOPE}

This Waste Management Plan outlines the procedures to be followed for the handling and management of investigation-derived waste (IDW) generated during the implementation of the RI Work Plan at Chestnut Ridge OU1. Waste minimization will be practiced during both the generation and disposal of waste. Every attempt will be made to minimize the amount of waste generated during field sampling activities. Plastic sheeting will be reused as long as sample integrity is not compromised. Use of Tyvek coveralls will be limited to those activities presenting a threat of external contamination to the participant. While coveralls are not to be worn longer than a single work shift, every attempt will be made to minimize changes during the shift. Sediments and surface water not used for samples will be returned to the original collection location. Liquid wastes will be minimized by a combination of evaporation and sparing usage. Other waste minimization and reduction techniques will include segregation, decontamination, compaction, selection of personal protective equipment (PPE), material recycling, and selection of equipment. Every attempt will be made to keep waste types (low-level wastes, hazardous, etc.) segregated so that no mixed wastes arc generated.

Waste minimization techniques will be documented in project logs and records. All waste streams will be assessed to implement minimization/prevention activities. Audits of the project waste minimization will be conducted to ensure adequacy and effective implementation. A waste generator evaluation scoresheet for numerical evaluation of this project's waste minimization program will be completed and submitted to ER Central Waste Management.

Practices included in waste management will comply with procedures for the ER Program at the Y-12 Plant, Waste Removal and Disposition through the Y-12 ER Program, ER/Y-P2102 (IAD), Rev. 0, and with procedures outlined in the Energy Systems document Environmental Surveillance Procedures, Quality Control Program, ESH/Sub/87-21706/1, Rev. 1 (1990a), Method ESP-1000, Waste Management. In addition, a waste management planning checklist will be prepared in coordination with ER Waste Management.

Previous work at the site indicated that the primary COCs are VOCs. These contaminants have exceeded background levels in several monitoring wells at the CRSP; MCL exceedences have also occurred. The VOCs of greatest concern are 1,1,1-trichloroethane; tetrachloroethene; 1,1-dichloroethane; and 1,1-dichloroethene. Metals and radionuclides have also been detected in groundwater at the CRSP, although the concentrations were not excessively high. Exceedences of MCLs by metals and radionuclides have been reported only occasionally. Neither SVOCs (except for presumed laboratory contaminants) nor pesticides/polychlorinated biphenyls have been detected at the site. The generation of listed waste during this investigation is not anticipated. 


\subsection{PROJECT CONTACTS}

The project contacts for this site are as follows:

\begin{tabular}{lc} 
& Phone No. \\
\cline { 2 - 2 } Judy Hodgins, Energy Systems Project Manager & $576-2368$ \\
Chris Smith, Y-12 ER Waste Management & $576-6526$ \\
Charles Lutz, CDM Federal Project Manager & $482-1065$
\end{tabular}

\subsection{WASTE TYPES}

A variety of IDW will be generated during the investigation. All IDW will be handled in accordance with Energy Systems Procedure ER/C-2101. An identification of each type of waste and activities responsible for its generation follow.

Soil Cuttings. All soil cuttings from all sampling locations, including those sampled with the Geoprobe, will be returned to the borehole. It is anticipated that no waste will be generated from the borings. If cuttings remain after the borehole is filled, they will be containerized.

Purge Water. Each monitoring well will be purged of three to five well volumes before sampling to ensure that samples taken for analysis are representative of formation water. Water generated during purging will be discharged to the ground surface in accordance with the Y-12 Plant policy. Field personnel will maintain continuous monitoring for VOCs and radionuclides during purging using an organic vapor analyzer; $\mathrm{HNu}$; and an alpha, beta, gamma detector.

Decontamination Water. Decontamination water will be generated each time the sampling equipment is cleaned. This water will contain any solvents used for decontamination and may contain contaminants present at the site. Decontamination water will be placed in drums on-site in accordance with procedures outlined in Energy Systems Y-12 Procedure 70-903, Transfer, Storage, and Disposal of Waste. Steel, 55-gal, 17E DOT-approved drums will be used to store the decontamination water on-site. Filled drums will be taken to the West End Treatment Facility, where the contents will be emptied and treated.

Personal Protective Equipment. Although the suspected hazards at Chestnut Ridge OU1 are low, on-site personnel will be required to wear PPE. Types of disposable PPE include Tyvek coveralls, gloves, plastic sheeting, and tape. These items will be bagged on-site and subsequently taken to a trash dumpster designated by ER personnel. The contents of the dumpster will ultimately be taken to the sanitary landfill at the Y-12 Plant.

During the field activities, additional Energy Systems and DOE requirements may be identified. Necessary revisions to the Waste Management Plan will ensure the inclusion of these additional requirements in the daily activities performed by each of the waste management personnel. 
Analytical Waste. Analyses of samples taken during the RI will generate two types of waste: laboratory extracts and digestates and excess sample material. The contract laboratory will dispose of extracts, digestates, and excess sample material. Energy Systems has ultimate determination of the disposal of analytical wastes.

\subsection{WASTE ESTMMATES}

Only PPE is expected to be generated under this investigation. It will be disposed of in a designated dumpster then be disposed of at the Y-12 Plant Landfill.

\subsection{WASTE STAGING AND STORAGE REQUIREMENTS}

No wastes will be stored permanently at the site. All wastes will be transported to a storage area within the ORR. No public roads will be used for transportation of the wastes from the site. 


\section{REFERENCES}

American Society of Mechanical Engineers (ASME) 1989. Quality Assurance Program Requirements for Nuclear Facilities, ASME NQA-1, New York.

Boegly, W. J., Jr., et al. 1984. Site Characterization Data for Solid Waste Storage Area 6, ORNL/TM-9442.

Bridge, J. 1956. Stratigraphy of the Mascot-Jefferson City Zinc District, Tennessee, U.S. Geological Survey Professional Paper 277.

CDM Federal Programs Corporation. 1993. Quality Assurance Manual.

Churnet, H. G., Misra, K. C., and Walker, K. R. 1982. "Deposition and dolomitization of upper Knox carbonate sediments, Copper Ridge district, East Tennessee," Geological Society of America Bulletin.

Cunningham, M., and Pounds, L. 1991. Resource Management Plan for the Oak Ridge Reservation: Volume 28: Wetlands on the Oak Ridge Reservation, ORNL/NERP-5, Oak Ridge Natl. Lab.

Dames \& Moore, A Professional Limited Partnership 1989. Closure Certification Report for Chestnut Ridge Security Pits (D-023).

Davis, E. C. et al., 1984. Site Characterization Techniques Used at a Low-level Waste Shallow Land Burial Field Demonstration Facility, ORNL/TM-9146, Oak Ridge Natl. Lab.

Federal Interagency Committee for Wetland Delineation 1989. Federal Manual for Identifying and Delineating Jurisdictional Wetlands, U.S. Army Corps of Engineers, U.S. Environmental Protection Agency, U.S. Fish and Wildlife Service, and U.S.D.A. Soil Conservation Service, Washington D.C. Cooperative Technical Publication.

Geraghty \& Miller, Inc. 1988. Proposed Groundwater Quality Assessment Plan for Chestnut Ridge Security Hazardous Waste Disposal Unit at the Y-12 Plant, Y/Sub/87-00206C/19, Y-12 Plant, Oak Ridge.

Geraghty \& Miller, Inc. 1989a. Groundwater Quality Assessment for the Chestnut Ridge Security Pits Hazardous Waste Disposal Unit at the Y-12 Plant, Y/Sub/89-00206C/6, Y-12 Plant, Oak Ridge.

Geraghty \& Miller, Inc. 1989b. Post-Closure Permit Application for the Chestnut Ridge Security Pits Hazardous Waste Disposal Unit at the Y-12 Plant, Y/Sub/89-00206C/10, Y-12 Plant, Oak Ridge. 
Geraghty \& Miller, Inc. 1990a. Groundwater Quality Assessment for the Chestnut Ridge Security Pits Hazardous Waste Disposal at the Y-12 Plant, 1989, Y/Sub/90-00206C/3, Y-12 Plant, Oak Ridge.

Geraghty \& Miller, Inc. 1990b. A Study of Ground-water Flow from Chestnut Ridge Security Pits Using a Flourescent Dye Tracer: Preliminary Results, Y/Sub/90-00206C/6, Y-12 Plant, Oak Ridge.

Green, J. C. et al. 1988. Protocols for Short-term Toxicity Screening of Hazardous Waste Sites, Environmental Research Laboratory, U.S. Environmental Protection Agency, Corvallis.

Haase, C. S. et al. 1987. Preliminary Analysis of Groundwater Data for the Chestnut Ridge Security Pit Site at the Y-12 Plant, Oak Ridge, Tennessee, Y/TS-281, Y-12 Plant, Oak Ridge.

Harris, L. D. 1969. "Kingsport Formation and Mascot Dolomite (Lower Ordovician) of East Tennessee," Tennessee Division Geology Rep. Invest. 23, 1-39.

Hatcher, R. D., Jr. et al. 1992. Status Report on the Geology of Oak Ridge Reservation, ORNL/TM-12074, Oak Ridge Natl. Lab.

HSW Environmental Consultants, Inc. 1991. Groundwater Qualtiy Assessment for the Chestnut Ridge Security Pits Hazardous Waste Disposal at the Y-12 Plant, 1990, Y/Sub/91-YP507C/3.

HSW Environmental Consultants, Inc. 1992. Groundwater Quality Assessment for the Chestnut Ridge Hydrogeologic Regime at the Y-12 Plant, Y/Sub/92-YP507C/3/P1.

Jones, Steven B., Harrington, Brenda K., and Field, Stephen M. 1992. Updated Subsurface Date Base for Bear Creek Valley, Chestnut Ridge, and Parts of Bethel Valley on the U.S. Department of Energy Oak Ridge Reservation, Y/TS-881, Y-12 Plant, Oak Ridge.

Ketelle, R. H. and Huff, D. D. 1984. Site Characterization of the West Chestnut Ridge Site, ORNL/TM-9229, Oak Ridge Natl. Lab.

King, H. L. and Haase, C. S. 1988. Summary of Results and Preliminary Interpretation of Hydrogeologic Packer Testing in Core Holes GW-131 through GW-135 and CH-157, Y/TS-495, Y-12 Plant, Oak Ridge.

Kroodsma, R. L. 1987. Resource Management Plan for the Oak Ridge Reservation, Volume 24: Threatened or Endangered Animal Species, ORNL/ESH-1/24, Oak Ridge Natl. Lab.

Martin Marietta Energy Systems, Inc. 1984. Inventory of Disposals Conducted in the Chestnut Ridge Security Pits February 1973 through March 1984, Y/DS-191, Y-12 Plant, Oak Ridge. 
Martin Marietta Energy Systems, Inc. 1987. RCRA Closure/Post Closure Plan for the Chestnut Ridge Security Pits (D-023), Y/TS-286, Y-12 Plant, Oak Ridge.

Martin Marietta Energy Systems, Inc. 1988. Revised RCRA Closure Plan for the Chestnut Ridge Security Pits, Y/TS-391, Y-12 Plant, Oak Ridge.

Martin Marietta Energy Systems, Inc. 1989. Oak Ridge Reservation Environmental Report for 1988, ES/ESH-8/V1.

Martin Marietta Energy Systems, Inc. January 1990a. Environmental Surveillance Procedures, Quality Control Program, ESH/Sub/87-21706/1, Rev. 1.

Martin Marietta Energy Systems, Inc. 1990b. Requirements for Quality Control of Analytical Data, ES/ER/TM-16.

Martin Marietta Energy Systems, Inc. 1991. Requirements for Quality Control of Field Methods, ES/ER/TM-11.

Martin Marietta Energy Systems, Inc. August 1992a. Environmental Restoration Quality Program Plan, ES/ER/TM-4/R2.

Martin Marietta Energy Systems, Inc. 1992b. Oak Ridge Reservation Site Management Plan for the Environmental Restoration Program, DOE/OR-1001/R2.

Mercier, T. and Kimbrough, C. 1988. Annual Report of 1987 Groundwater Monitoring Data for Treatment, Storage, or Disposal Facilities at the Y-12 Plant: Reporting and Statistical Evaluation of the Subsequent (Second Yard) Year Data, Y/TS-388, P2, Y-12 Plant, Oak Ridge.

Milici, R. C. 1973. "The Stratigraphy of Knox County, Tennessee," Tennessee Division Geology Bulletin 70, 9-24.

Mishu, L. 1982. Subsurface Analysis of Waste Disposal Facilities at the Y-12 Plant, 81-1020P, Y/Sub/82-24700/2, Geotek Engineering Company, Knoxville.

Oder, C. R. L. 1934. "Preliminary subdivision of the Knox dolomite in East Tennessee," J. Geology 42, 469-97.

Parr, P. D. 1984. Resource Management Plan for the Oak Ridge Reservation, Volume 4: Endangered and Threatened Plant Species, ORNL-6026/V4, Oak Ridge Natl. Lab.

Parr, P. D. 1992. Oak Ridge National Laboratory, Environmental Sciences Division, personal communication to E. P. McDonald, March 19.

Parr, P. D., and Evans, J. W. 1992. Resource Management Plan for the Oak Ridge Reservation: Volume 27: Wildlife Management Plan, ORNL/NERP-6/V27, Oak Ridge Natl. Lab. 
Puls, R. W., and Powell, R. B. 1992. "Acquisition of Representative Groundwater Quality Samples for Metals," Groundwater Monitoring Review, 167-176.

Radian Corporation 1992. Y-12 Plant: Chestnut Ridge Security Pits Remedial Investigation Data Adequacy Summary, DOE/OR-1000\&D2.

Reed, P. B. 1988. National List of Plant Species That Occur in Wetlands: Tennessee, Published report NERC-88/18.42 for the National Wetlands Inventory, U.S. Fish and Wildlife Service.

Roberts, B. and Dorough, H. 1985. "Hazards of Chemicals to Earthworms," Environ. Toxical. Chem. 4, 307-23.

Rodgers, J. 1953. "Geologic map of East Tennessee with explanatory text, scale 1:125,000," Tennessee Division Geology Bulletin 58.

Safford, J. M. 1869. Geology of Tennessee, Mercer, Nashville.

Science Applications International Corporation 1992. Final Report of the Second Dye-Tracer Test at the Chestnut Ridge Security Pits, Y.12 Plant, Oak Ridge, Tennessee, Y/Sub/93-99928c/Y10/1, Y-12 Plant, Oak Ridge.

Solomon, D. K. et al. 1992. Status Report: A Hydrologic Framework for the Oak Ridge Reservation, ORNL/TM-12026, Oak Ridge Natl. Lab.

Suter, G. W., II 1990. "Use of Biomarkers in Ecological Risk Assessment," pp. 419-426. In J. F. McCarthy and L. L. Shugart (eds.) Biomarkers of Environmental Contamination, Lewis Publishers, Ann Arbor.

Suter, G. W., II 1992. Ecological Risk Assessment, Lewis Publishers, Chelsea, Mich.

Suter, G. W., II, et al. 1992. Approach and Strategy for Performing Ecological Risk Assessments for the Department of Energy Oak Ridge Field Office Environmental Restoration Program, ES/ER/TM-33, Oak Ridge Natl. Lab.

Suter, G. W., II, and Loar, J. M. 1992. "Weighing the Ecological Risks of Hazardous Waste Sites: The Oak Ridge Case," Environmental Science Technology 26, 432-438.

Talmage, S. S. and Walton, B. T. 1991. "Small Mammals as Monitors of Environmental Contaminants," Rev. Environ. Contam. Toxicol. 119, 47-145.

Ulrich, E. O. 1911. "Revision of the Paleozoic systems," Geological Society of America Bulletin 22, 281-680.

U.S. Environmental Protection Agency February 1983. Interim Guidelines and Specifications for Preparing Quality Assurance Project Plans, QAMS-005/80, EPA-600/4-83/004. 
U.S. Environmental Protection Agency 1984. Radiochemistry Procedures Manual, EPA/520/5-84/006.

U.S. Environmental Protection Agency 1986. Test Methods for Evaluating Solid Waste, Physical/Chemical Methods, SW-846, third Ed.

U.S. Environmental Protection Agency 1988. Guidance for Conducting Remedial Invesigations and Feasibility Studies Under CERCLA, EPA/540/G-88/004.

U.S. Environmental Protection Agency 1989a. Risk Assessment Guidance for Superfund, Volume I: Human Health Evaluation Manual (Part A).

U.S. Environmental Protection Agency March 1989b. Risk Assessment Guidance for Superfund, Volume II: Environmental Evaluation Manual, EPA/540/1-89/001, Office of Emergency and Remedial Response, Washington, D.C.

U.S. Environmental Protection Agency, Contract Laboratory Program 1990a. Statement of Work for Inorganics Analysis, Doc. No. ILM01.0.

U.S. Environmental Protection Agency, Contract Laboratory Program 1990b. Statement of Work for Organics Analysis, Doc. No. OLM01.0.

U.S. Environmental Protection Agency 1991. Standard Operating Procedures and Quality Assurance Manual.

U.S. Environmental Protection Agency 1992. A Framework for Ecological Risk Assessment, EPA/630/R-92/001, Risk Assessment Forum, Washington, D.C.

U.S. Fish and Wildlife Service 1979. Classification of Wetlands and Deep Water Habitats of the United States, Biological Services Program, FWS-OBS 79/31.

Webster, D. A. and Bradley, M. W. 1988. Hydrology of the Melton Valley Radioactive Waste Burial Ground at Oak Ridge National Laboratory, USGS Open-File Report 87-686, Knoxville, Tenn.

Welch, S.H. 1989. RCRA Facility Investigation Plan, General Document, Y-12 Plant, Oak Ridge, Tennessee, Y/TS-352, Vol. 1, Rev. 1, Y-12 Plant, Oak Ridge.

Wentsel, R. S. and Guelta, M. A. 1987. "Toxicity of Brass Powder in Soil to Earthworm Lumbricus terrestris," Environ. Toxicol. Chem. 6, 741-745.

Wentsel, R. S. and Guelta, M. A. 1988. "Avoidance of Brass Powder-Contaminated Soil by the Earthworm Lumbricus terrestris," Environ. Taxicol. Chem. 7, 241-243.

Wilson, David L. October 11, 1991. Letter to Helen L. King. 
Woodward-Clyde Consultants 1984. Subsurface Characterization and Geohydrologic Site Evaluation West Chestnut Ridge Site, Vol. I, ORNL/Sub/83-64764/1, Oak Ridge Natl. Lab. 


$$
-
$$

○$$
\text { APPENDIX A }
$$ \\ GROUNDWATER QUALITY DATA \\ APPENDIX A}




\section{CONTENTS}

Results of 1986 K-25 Groundwater Sampling . . . . . . . . . . . . . A-5

Water Quality Data for Monitoring Wells, 1986 and $1987 \ldots \ldots$. . . . . . A A-61

Assessment Data for Monitoring Wells, $1988 \ldots \ldots \ldots \ldots \ldots$. . . . . . . . . . .

1989 Assessment Data for Monitoring Wells . . . . . . . . . . . . . . . A A-93

Water Quality, $1990 \ldots \ldots \ldots \ldots \ldots$. . . . . . . . . . . . . . . . . A-109

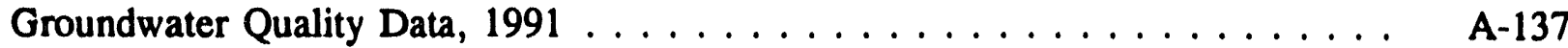

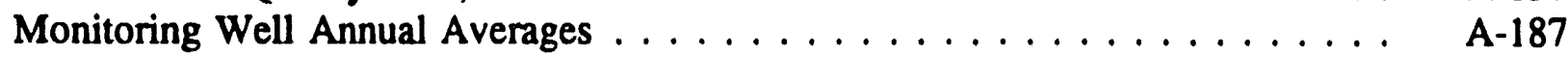


Key 10 Water Quality Data for Chestnut Ridge Security Pits

\begin{tabular}{|c|c|}
\hline Organic Compounds & $\begin{array}{l}G=5 \mathrm{ug} / \mathrm{L} \\
N=10 \mathrm{ug} / \mathrm{h} \\
V=20 \mathrm{ug} / \mathrm{h} \\
M=50 \mathrm{ug} / \mathrm{L} \\
X \cdot 80 \mathrm{ug} / \mathrm{L}\end{array}$ \\
\hline Turbidity & G. Greater than 200 NTU \\
\hline Coliform & $\mathrm{N}$ - None Found \\
\hline All Parameters & $<\#$ - Not Detected, \# = Detection Limit \\
\hline Analytical Methods & $\begin{array}{l}\text { ICP - Inductively Coupled Plasma Alomic } \\
\text { Emission Spectroscopy } \\
\text { AAS - Alomic Absorption Spectroscopy } \\
\text { FL - Fluorimetry }\end{array}$ \\
\hline
\end{tabular}


A-4

THIS PAGE INTENTIONALLY LEFT BLANK 
RESOLTS OF 1986 K25 GROONDHATER SAMPLIMG CHESTHUT RIDGZ SECURITY PITS

TOTAL HETALS-RADIOACTIVITY-RADIOH UNIT IS MG/L - URLISS OTHERUISE STITED

MELL

DATE SABPLED

TI HE SAMPLBD

METROD

AL OnI wo:

AHTIBONY

BARIOH

BERYZLIOH

BO ROH

CA DKIOK

CA ICIU⿺

CHROAIUn

COBALT

COPPER

IROR

LITHI OH

MA GNISIUA

MA HGA YESE

HOLTBDENOH

AICKEI

RIOBIUA

PH OSP HOROOS

POTASSIOA

SIIICOH

SILVIR

SODIOA

STRONTIOA

TH ORI OH

TITAMIOA

VARADIUA

ZI NC

RI RCOAIOH

METHOD

ARSERIC

LEAD

SELEXIUA

THALITOH

MERCURT

ALPHA ACTIVITI (PCI/L)

BETA ACTIVITI (PCI/L)

URAUIOA

RADIOE $(B Q / L)$
68- 173

rota2

$02 / 04 / 86$

15:00:00

ICAP

5. 1

$0.02 i$

$<0.0003$

0.041

$<0.003$

39

0.032

$<0.005$

0.13

43

$<0.004$

28

0.13

$<0.01$

0.098

$<0.007$

0.35

1.8

15

$<0.006$

2.4

0.0088

$<0.2$

0.11

0.0054

0.069

$<0.005$

AnS

$$
\begin{array}{r}
0.006 \\
0.073 \\
<0.005 \\
<0.01
\end{array}
$$

4. $08-04$

73

135

0.015

$<0.8$

$$
\begin{array}{r}
64-173 \\
\text { TOTAL }
\end{array}
$$

$04 / 15 / 86$

11:05:00

ICAP

0.36

0.017

$<0.0003$

0.11

$<0.003$

38

$<0.01$

$<0.005$

$<0.004$

1.3

$<0.004$

23

0.015

$<0.01$

$<0.01$

$<0.007$

$<0.2$

2.9

4.2

$<0.006$

1.4

$5.0 E-04$

$<0.2$

0.0036

$<0.005$

$<0.001$

$<0.005$

Aas

$<0.005$

0.016

$<0.005$

$<0.01$

$<0.0002$

$<1$

2.93

$1.0 \mathrm{E}-03$

<0. 1
$68-173$

TOTIL

64- 173

TOTAL

$07 / 29 / 86 \quad 10 / 17 / 86$

16:15:00 11:45:00

ICAP

ICAP

0.86

0.61

$<0.05$

$<0.05$

0.0069
$<0.0003$

0.062

$<0.003$

39

0.013

$<0.005$

0.042

4.7

$<0.004$

23

0.031

$<0.01$

0.026

$<0.007$

$<0.2$

2.1

4.8

$<0.006$

1.6

$<0.0004$

$<0.2$

0.019

$<0.005$

$<0.001$

$<0.005$

AAS

0.0074

$<0.0003$

0.044

$<0.003$

41

$<0.01$

$<0.005$

0.053

7.5

$<0.004$

24

0.033

$<0.01$

0.027

$<0.007$

$<0.2$

1.3

5.1

$<0.006$

1.6

0.018

$<0.2$

0.0055

$<0.005$

0.025

$<0.005$

$<0.005$

$<0.005$

$<0.01$

AAS

$<0.005$

0.019

$<0.005$

$<0.01$

$<0.0002$

0.003
$<0.0002$

$<2$

0.002 
RESOLTS OF 1986 K25 GROUNDAATER SAMPIIMG CAESTNOT RIDGE SZCTRITY PITS

DISSOLVED MEIALS-RADIOACTIVITY-RADIOH UNIT IS HG/L - UNLESS OTHEQHISE STATED

NELL.

DATE SAMBLED

TIME SAHPLEO

HETIIOD

ALOHINOH

AMTI HONY

BARIUK

BBRY LLIก!

BORON

CADHIOH

CARCIUH

CHROMIOH

COBA LT

COPPER

IRON

LITH IUM

MA GH ES IOA

MA NG ANESE

AOLI BDEX

HICK EL

MIOBIOA

IHOS PHOAOUS

POTL SSIOH

SIIICOK

SILVER

SODI UA

STRO KT IOE

TrOR 50:

TITA NIUA

VAMA DIUA

ZINC

ZIRCONIOH

ตETH on

ARSENIC

LEAD

SEIENIUA

THALLIUH

MERC ORY

ILPIIA ACTIVITI (PCI/L)

BETA ACIIVITY (PCI/L)

URAN IUG

RADIOH $(B Q / 2)$
64- 173

DISSOLVED

$02 / 04 / 86$

15:00:00

ICAP

0.064

$<0.05$

0.0048

$<0.0003$

0.027

$<0.003$

32

$<0.01$

$<0.005$

$<0.004$

0.051

$<0.004$

25

0.033

$<0.01$

0.023

$<0.007$

$<0.2$

3.6

$<0.006$

2.5

0.0025

$<0.2$

0.0074

$<0.005$

$<0.001$

0.0073

IAS

$<0.005$

$<0.004$

$<0.005$

$<0.01$

$<0.0002$

$<0.0002$

0.002
64- 173 DISSRLVEO

$04 / 15 / 86$

$11: 05: 00$

ICAP

$<0.02$

0.013

$<0.0003$

$<0.004$

$<0.003$

$<0.01$

$<0.005$

$<0.004$

$<0.004$

$<0.004$

0. 015

$<0.01$

$<0.01$

$<0.007$

$<0.2$

1.9

3. 6

0.14

$<0.0004$

$<0.2$

$<0.003$

$<0.005$

$<0.001$

$<0.005$

AAS

$<0.005$

$<0.004$

$<0.005$

$<0.01$

\section{DISSOrVED}

$07 / 29 / A 6$

$16: 15: 00$

ICAP

40.02

$<0.05$

0.0041

$<0.0003$

0.026

$<0.003$

$<0.01$

$<0.005$

0.014

$<0.004$

$<0.004$

0.0045

$<0.01$

$<0.01$

$<0.007$

$<0.2$

1.7

3.6

$<0.006$

1.5

$<0.0004$

$<0.2$

$<0.003$

$<0.005$

$<0.001$

$<0.005$

ANS

$<0.005$

$<0.004$

$<0.005$

$<0.01$

$<0.0002$

0.002
$6 x-173$

DIS3 OLVED

$10 / 17 / 86$

$11: 45: 00$

ICAP

0.038

$<0.05$

0.0044

$<0.0003$

0.031

$<0.003$

38

$<0.005$

$<0.004$

0.027

$<0.004$

0.0025

$<0.01$

$<0.01$

$<0.007$ $<0.2$ 1. 8 3.7

$<0.006$ 1.7

0.016

$<0.2$

$<0.003$

$<0.005$

$<0.001$

$<0.005$

AAS

$<0.005$

0.009

$<0.005$

$<0.01$

$<0.0002$

0.002 
RESULTS OF $1986 \times 25$ GROUNDNATER SAMPLIHG

CHESTYUT RIDGE SECURITY PITS

HISCELLANZOOS CONVEATIONAL AND WON-COYYENTIONAL POLLOTINTS AND RELATED PABAMETER ONIT IS MG/L - ORLESS OTHEBRISE STATED

HELL

DATE SAAPLED

TIHE SABPLED

HATER LEVEL (PT $/-$ GRADE)

hater temp (DEG. CENT.)

DISSOLVED OXIGEN

CONEUCTIVITY (IN OHHOS/CH)

PH (IN PH UNITS)

REDOX (IN HV)

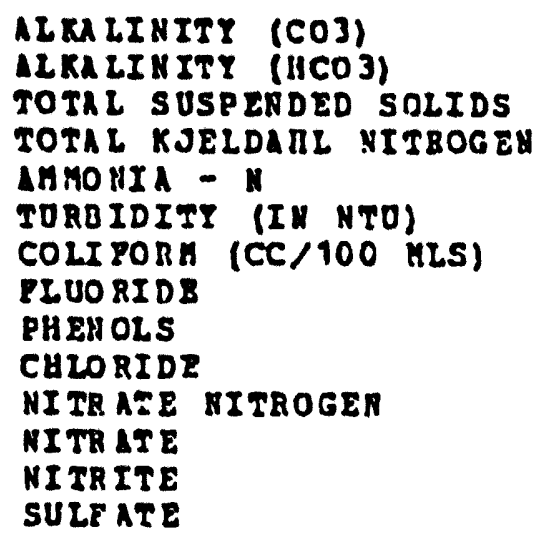

$$
\text { 6w-173 }
$$

$$
\text { 6D- } 173
$$

$68-173$

$64-173$

$02 / 04 / 86$

15:00:00

$04 / 15 / 86$

11:05:00

15.3
4
270
8.3
72

$-144.9$

72

:

0.18

0.003

$<1$

3. 4

9.3
19.7

11.2

330

7.5

197

$07 / 29 / 86$

16:15:00

$-158$

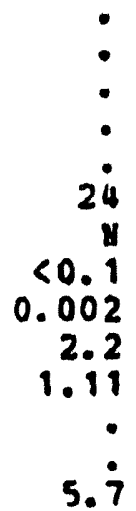

22.8

9.5

360

8.2

175

$10 / 17 / 86$

11:45:00

$-155$

20.2

7.4

340

8.4

192

007

3.1

1.06

5.

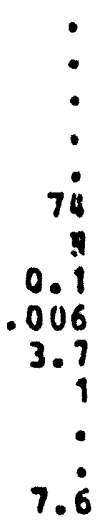




\section{RESOLTS OF 1986 R25 GROONDHATER SAMPLING \\ CHESTNOT RIDGE SECORITY PITS}

VOLATILE NRGANIC PRIORITY IND NON-PRIORITY POLLOTANTS ONIT IS UG/L

HELL

DATE SAKPIED

IIME SAGPLED

$$
\text { 61-173 }
$$

$02 / 04 / 86$ 15:00:00

$04 / 15 / 86$
$11: 05=00$

$64-173$

$68-173$

$07 / 29 / 86$ $16: 15: 00$

$10 / 17 / 86$ $11: 45: 00$

CIILOROHETHAUE

BROHOHETHA ME

VIUY 2 CHLORIDE

CALOROETRAME

GETHYIENE CHLORIDE

ACETONE

CABBON DISOLPIDE

1, 1-DICULOROETHENE

1. 1-DICALOROTTRARE

TRAN S-1.2- DI CULOR OETEEHE

CHLOROYORK

1.2- DTCHLOROETHANE

2-BUTAYON

1, 1, 1-TRICHLOROETHANE

CARBON TETRLCULORIDE

PINYL ACETATE

BROM OD I CHLOROUETUANE

1, 1,2,2-TETR A CHLOROETHAHE

1, 2-DICHLOROPROPANE

TRANS-1,3-DICALCRORROPEHE

TR ICHLOROETHENE

CELO ROD IBROH OHETH AME

1, 1, 2-TRICHL ROETRAHE

BEAZ ENE

CIS-1,3-NICAL OROP ROPENE

2-CHLOROET UIIVIRYL ETHER

BRONOPO RE

2- IIP XAKONE

4- BETHY 2-2-P RATANONE

TETR ACH LOROET HENE

TOLIENE

CALO ROBERZ ENE

ET AY LBENZENE

ST TRENE

XYLENES

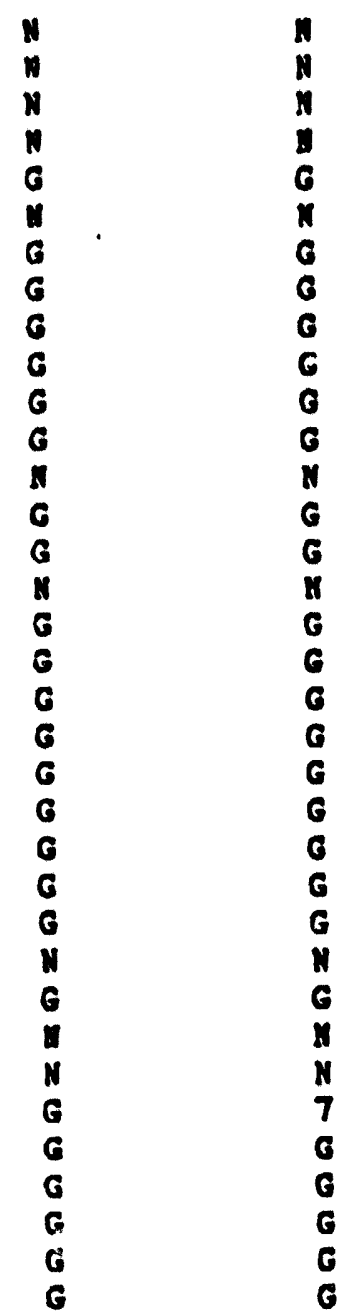




\section{RESULTS OF 1986 K25 GROONDHATER SAMPIIMG \\ CHESTNUT RIDGE SECURITI PITS \\ HERBICIDES AND PESTICIDES \\ ONIT IS $O G / L$}

\begin{tabular}{|c|c|c|c|c|}
\hline MELL & $G W-173$ & $G H-173$ & Gin-173 & $6 N-173$ \\
\hline $\begin{array}{l}\text { DATE SAAPLED } \\
\text { TIBE SAMPLED }\end{array}$ & $\begin{array}{l}02 / 04 / 86 \\
15: 00: 00\end{array}$ & $\begin{array}{l}04 / 15 / 86 \\
11: 05: 00\end{array}$ & $\begin{array}{l}07 / 29 / 86 \\
16: 15: 00\end{array}$ & $\begin{array}{l}10 / 17 / 86 \\
11: 45: 00\end{array}$ \\
\hline $\begin{array}{l}\text { 2.4-D } \\
\text { ENDRIN } \\
\text { IIRDANE } \\
\text { METHOXICALOR } \\
\text { SILVEX } \\
\text { TOX IPBENE }\end{array}$ & $\begin{array}{r}<1 \\
<0.05 \\
<0.01 \\
<0.04 \\
<0.1 \\
<1\end{array}$ & $\begin{array}{r}<2 \\
<0.1 \\
<0.02 \\
<0.08 \\
<0.2 \\
<2\end{array}$ & $\begin{array}{r}<2 \\
<0.1 \\
<0.02 \\
<0.08 \\
<0.2 \\
<2\end{array}$ & $\begin{array}{r}<1 \\
<0.1 \\
<0.02 \\
<0.08 \\
<0.1 \\
<2\end{array}$ \\
\hline
\end{tabular}


ACID 6 BASE-FEOTRAL EXTBACTABLE ORGANIC PRIORITI AND NON-PRIORITI POLIUTARTS-I ONIT IS UG/L

HELL

DATE SA MPLED

TIHE SAHPLED

$$
\text { G }-173
$$

$02 / 04 / 86$ $15: 00: 00$

$04 / 15 / 86$ 11:05:00

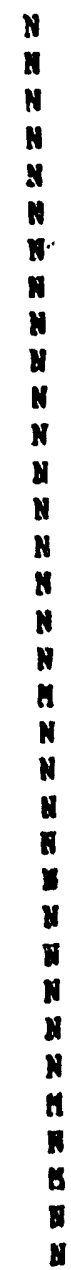

6x-173 $64-173$

$07 / 29 / 86$ $16: 15: 00$

$10 / 17 / 86$ $11: 45: 00$

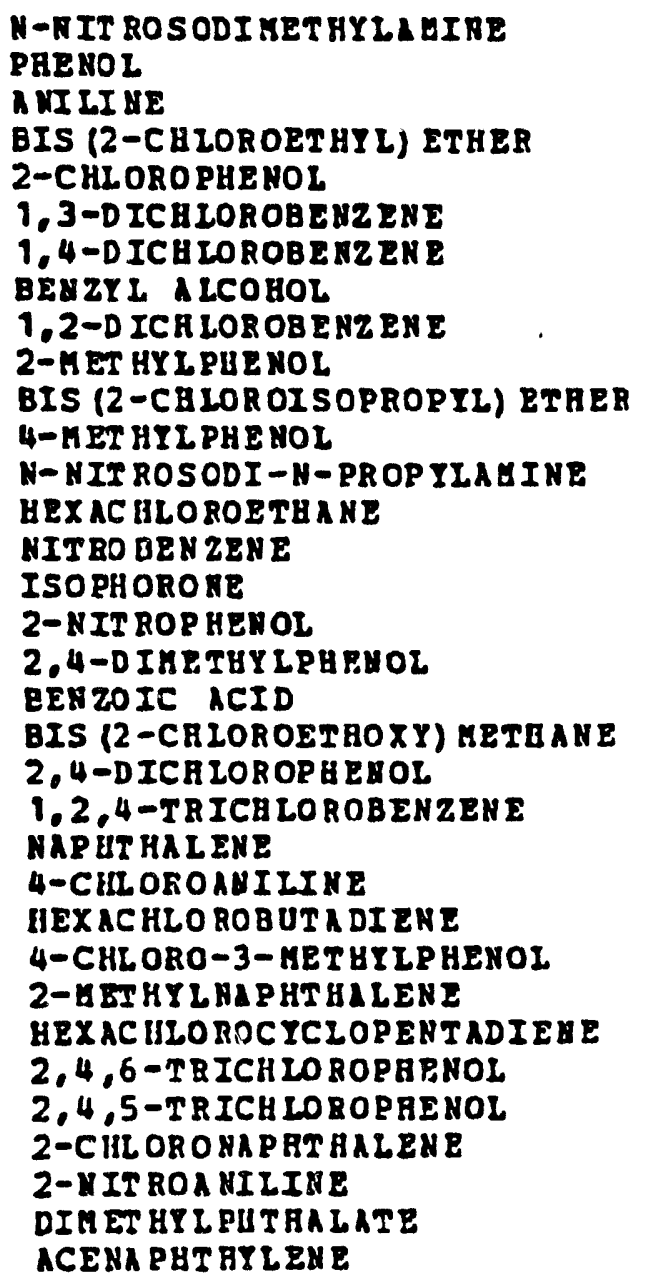


RESOLIS OF 1986 K25 GROUHDHATER SAMPLING

CHESTNOT RIDGE SECURITY PITS

ACID \&, BASE-NEOTRAL EXTRACTABLE

ORGANIC RRIORITI AND NON-PBIORITY ROLLOTRATS-II ONIT IS UG/L

HELI

DATE SAMPLED

TIME SAMELED

3-N IT ROANILINE

ACEMA PHT GENE

2.4-D IHITROPHENOL

4-NIT BOP HENOL.

DIB EN COF ORAH

2.4-D IRITROTOLOEKE

2.6-D INITROTOLOENE

DIETH YLPUTHALATE

4-CHLOROPHENIL PHESTL ETHEB

FLUOR ENE

4-NIT ROA

4,6-DINITKO-2-METH ILPAENOI

N-NIT RCSODIPH ENILA WIE

4-BRO TOPHENTL PHENTI ETHEB

BEXAC HLOROBEN ZENE

PENTACILOROPBEROL

PIIENA KTH RENE

ANTHR ICENE

DI-N- BUTILPHTHALATE

ELUOR A TTHENE

BENZI DINE

PYBEN $:$

BOTYL BEHZII PGTHALATE

3.3 - DICHLOROBEAZIDINE

ESAZO (A) ANTEB ICENE

BIS (2-EI BYLHEXIL) PRTHILATE

CHR YS FNE

CI-N-OCT YLPHTH ILTE

BENZO (B) FLOORA NTAEYE

BENZO (K) FIUORA NTHERE

BENZO (A) PYRENE

INDENO $(1,2,3-C D)$ PYBENE

CIBEN $20(A, H)$ INTHBACEAE

BPINO (G, A. I) PERTLEHE

$$
\text { GR-173 }
$$

GW- 173

GN-173

GH-173

$02 / 04 / 86$

$15: 00=00$

$04 / 15 / 86$

11:05:00

$07 / 29 / 86$

$16: 15: 00$

$10 / 17 / 86$

$11: 45: 00$

בע




\section{RESOLTS OF 1986 R25 GROUNDHATER SAMPIIKG CBESTHOT RIDGE SECURITY PITS}

LAB REPIICATES

UNIT IS UG/L $F O R$ TOX - MG/L FOR TOC

DELL

DATE SAMPLED

TIME SAMPLED

CONDUCTIVITY (IN OHHOS/CM)

PU (IN PE ONIIS)

TOTAL OBGARIC CABBOH

TOTAL ORGAHIC CHLORIDE

$$
\text { GW-173 GH-173 GT-173 GH-173 }
$$

$02 / 04 / 86 \quad 04 / 15 / 86 \quad 07 / 29 / 86 \quad 10 / 17 / 86$

15:00:00 11:05:00 16:15:00 11:45:00

$322 \quad 324$

$316 \quad 332$

$326 \quad 333$

325

334

7.8

7.7

7.7

7.7

7.7

7.7

7.9

389

386

384

385

7.8

7.8

7.8

7.8

58

57

55

47

377

375

374

379

8.3

8.2

8.2

8.2

56

57

55

59

24

26

24

26

83

$<10$

$<10$

$<10$

$<10$ 


\section{RESULTS OP 1986 K25 GROUADHATER SA MPLING CHESTNDT RIDGE SECDRITY PITS}

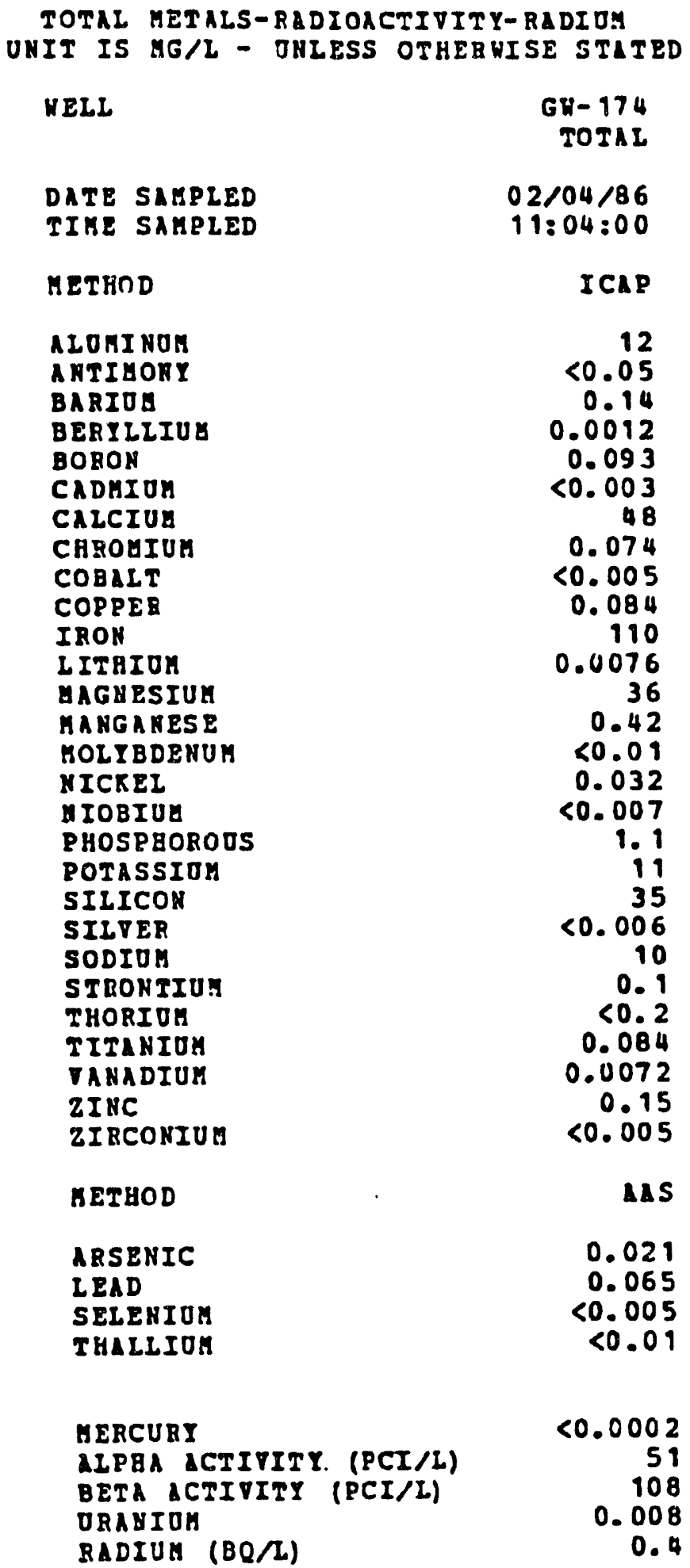




\section{RESULTS OP 1986 K25 GROUNDHATER SA HPIING CHESTNUT RIDGE SECURITY PITS \\ DISSOIVED KETALS-RADIOACTIVITI-RADIOH UNIT IS HG/L - INLRSS OTHPRHISE STATED}

NELI

DATE SAMPLED

TIME SAGPLED

METHOD

AIOBINUA

ARTIHONY

BARIOH

BERXIIIUA

BOROU

CADEIUA

CALCIUH

CHROHIUH

COBAIT

COPPER

IROR

LITRIOK

GAGRESIUK

MAYGLEESE

MOLYBDBNUA

KICKEI

MIOBIOH

PHOSPROROOS

POTASSIU日

SIIICON

SIIVER

SODIOH

STROAIIOK

THORIOH

TITAKIOH

YAAXDIOH

ZIRC

ZIRCONIOH

EETHOD

ARSERIC

LEAD

SELEFIOH

TBALIIOH

MERCORY

ALPRA $\triangle C T I Y I T Y$ (PCI/L)

BETA ACTIVITI (PCI/L)

ORANIOH

RADIUE (BQ/L)
GR-174

DISSOL VED

$02 / 04 / 86$

$11: 04: 00$

ICAP

$$
0.08
$$$$
<0.05
$$

0.0098

$<0.0003$

0.021

$<0.003$

24

$<0.01$

$<0.005$

$<0.004$

0.015

$<0.004$

19

0.05

$<0.01$

$<0.01$

$<0.007$

$<0.2$

10

3.8

$<0.006$

9.9

0.039

$<0.2$

0.006

$<0.005$

$<0.001$

0.007

AAS

$<0.005$

$<0.004$

$<0.005$

$<0.01$

$<0.0002$

0.004 


\section{RESULTS OF 1986 K25 GROUHDHATER SLMPLING CHESTNOT RIDGE SECURITY PITS}

YISCELLANEOUS CONPENYIONAL AND NON-CONVENTIONAL POLZUTANTS AND RELATED PABAKETER ONIT IS HG/L - ONLESS OTHERHISE STATED

WELL

$$
\text { DATE SAMPLED }
$$$$
\text { TIRE SAMPIED }
$$

WRTER LEVEL (PT + /- GBADE)

WATER TEMP (DEG. CENT.) DISSOLVBD OXYGEN CONDUCTIVITY (IN UNHOS/CM) PU (IN PH UNITS) RBDDX (IN HV)

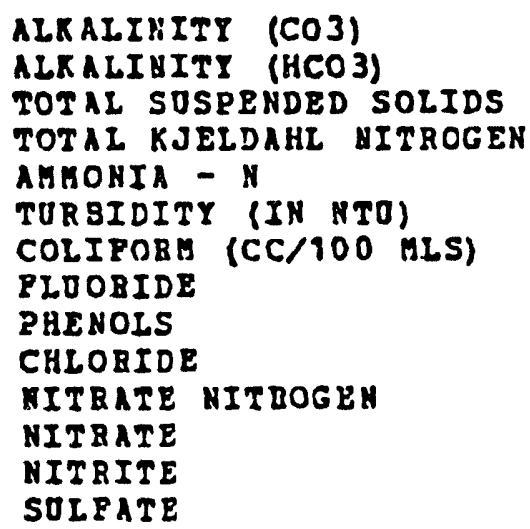

$$
6 x-174
$$

$02 / 04 / 86$ 11:04:00

$-3$ 17 3.2 270 7.9

110

$i$
$i$
$i$
$G$
$\pi$
0.14
0.01
$<1$
0.16
9.8


VOLATILE ORGANIC PRIORITI ARD NON-PRIORITY POLIOTAKTS UNIT IS UG/L

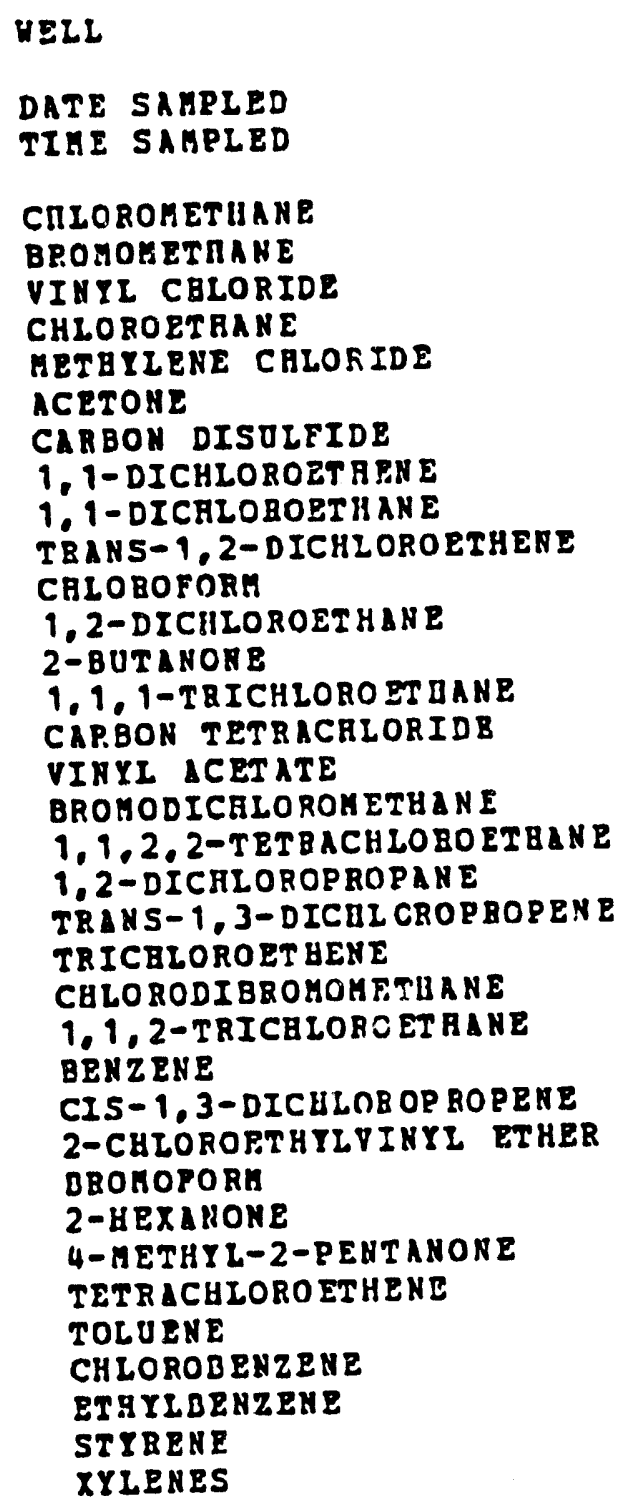

$G H-174$
$02 / 04 / 86$
$11: 04: 00$
$H$
$H$
$H$
$H$
$G$
$H$
$G$
$G$
$G$
$G$
$G$
$G$
$N$
$G$
$G$
$H$
$G$
$G$
$G$
$G$
$G$
$G$
$G$
$G$
$G$
$H$
$G$
$H$
$N$
20
$G$
$G$
$G$
$G$
$G$
$G$
$G$


RESULTS OP 1986 K25 GROONDHATER SAMPLING

CBESTMUT RIDGE SECORITY PITS

\begin{tabular}{|c|c|}
\hline RELL & $G H-17$ \\
\hline $\begin{array}{l}\text { DATE SLAPLED } \\
\text { TIME SAMPLED }\end{array}$ & $\begin{array}{l}02 / 04 / 86 \\
11: 04: 00\end{array}$ \\
\hline $\begin{array}{l}2,4-D \\
\text { EMDRIM } \\
\text { IIRDAKE } \\
\text { METHOXICRLOR } \\
\text { SILVEX } \\
\text { TOX PUEYR }\end{array}$ & $\begin{array}{l}<0.05 \\
<0.01 \\
<0.04 \\
<0.1\end{array}$ \\
\hline
\end{tabular}


RESOLTS OP 1986 R25 GROUNDHATER SAMPLING

CHESTROT RIDGF. SRCURITY PITS

ACID E BASE-NEOTRAL EXTRACTABLE ORGANIC PRIORITY AND MON-PRIORITY POLLOTANTS-I ONIT IS UG/L

WELL

$$
\text { GN- } 174
$$

DATE SAMPLED

$02 / 04 / 86$

TIKE SAMPLED

$11: 04: 00$

H-NITROSODINETHYLABINE

PHENOL

ANIIINE

BIS (2-CKLOROETATL) ETHER

2-CHLOROPHENOL

1,3-DICRLOROBENZENE

1,4-DICALOROBENZ ENE

BENZIL $\triangle I C O H O L$

1,2-DICALOBOBERZENE

2-HETBYIPBETOL

BIS (2-CHLOROISOPROPIL) ETHER

4- KETHYLPHEHOL

N-NITROSODI - N-PBOPY LAMINE

HEY $\triangle$ CALO 8 ETHANE

UITROBENZENE

ISOR GORONE

2-NITBOPBRHOL

2. 4-DIEETEYIPHENOL

BENZOIC ACID

BIS (2-CHLOROETHOXY) METHANE

2.4-DICALORORHEROL

1,2, 4-TRICHLOROBEHZENE

RAFETRALENE

4-CHLOROANILIVE

HEXACELOROBOTADIERE

4-CBLORO-3-METHILPHEXOL

2-HETHYLУLPATHALENE

IIEXACALOROCYCLOP ENTADIENE

2.4,6-TRICBLOROP QENOL

$2,4,5-T R I C H L O B O P$ BE NOL

2-CHLOBONAPHTHALENE

2-HITROANIIINE

DIMETBYLPBTUALATE

ACENAPGTHILEME

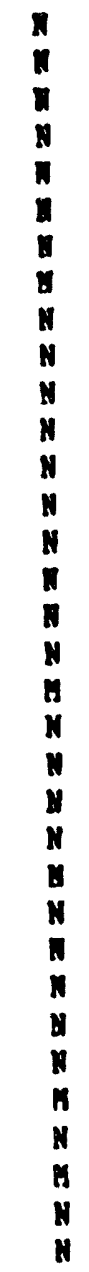




\section{A-19}

RESOLTS OP 1986 K25 GROUNDWATER SA UPLING

CHESTNOT RIDGE SECURITY PITS

ORGANIC PRIORITI AND NON-PRIORITT POLLOIANES-II ONIT IS UG/L

MELI

DATE SAMPLED
TIME SAMPLED

3-NITROA NILINE ACENA PHTHEUE

2,4-DIUITROP GEHOI

4- MITROPHEROL

DIBENZOPORAN

2,4-DINITROTOLOEVE

2,6-DINITROTOLOENE

DIETHTLPHTHALATE

4-CHLOROPRENYL PHENYL ETHER

FLUORENE

4-RITROARILINE

4,6-DIUITBO-2-HETHYLPRENOL

$N$-NITROSODIR BENY IAUINB

4-BROMOPRENYL PEENYL ETHER

HEXACALOROBEAZENE

PENTACHLOROR HEEOL

PHEMAMTHREHE

ANTHRACENE

DI-N-BDT ILPATEALATE

FINORANTHEAE

BENZIDINE

PTBENE

BOTIL BENZYL PRTHALITE

3,3 -DICELOROBENTI DIUE

BENZO (A) ANTURACENE

BIS (2-ETHILHEXYL) PBTRALATE

CRRYSENE

DI-N-OCT ILPHTHALATE

BENZO (B) PLOOBANTHEKE

BENZO (X) FLOOBANTRENE

BENZO (d) PYRENE

INDENO $(1,2,3-C D)$ PYRENE

OIBENZO $(\mathrm{A}, \mathrm{H})$ ANTHBACENE

BENZO (G, B, I) PEQILENE

$$
68-174
$$

$02 / 04 / 86$

$11: 04: 00$ 
BESULTS OP 1986 K25 GROOHDHATER SAHPLIMG

CHESTNUT RIDGE SECDRITY PITS

LAB REPLICATES

OHIT IS UG/L FOB TOL - HG/L FOB TOC

กะI

$6 x-174$

DATE SAMPLED

$02 / 04 / 86$

TIEE SLARLED $11: 04: 00$

CONDUCTIVITY (IV OHBOS/CH) 320

PH (IN PH URITS)

7.9

7.8

7.9

7.8

TOTAL OBGALIC CARBOA

35

37

38

38

TOTAL ORGANIC CRLORIDE 


\section{BESDLTS OT 1986 K25 GROUNDHATER SAMPLINO CHESTNUT RIDGE SLCOBITY PITS}

TOTAL METILS-RADIOACTIVITI-RADIUM UXIT IS MO/L - UALESS OTHERHISE STATED

WELL

DETE SAMPLED

TIME SAMPLED

MET\&OD

ALOSIMUN

ATTINONY

BARIOH

EERTLLIUA

BORON

CADHIn

CALCIOH

CIIRONIOH

COBALT

COPPER

IRON

LITIIU

MAGRESTOK

GARGA 252

MOLTBDENOE

MICKRI

HIOBIUH

PHOSRAOROOS

POIRSSIOH

SILICOA

SILVER

SODIUA

STRONTIUH

THORIOH

TITANIOH

VAN ADI UM

2IXC

ZIRCONTOH

METIIOD

ARSEAIC

LEAD

SRLENIOA

THAIIIOH

HEBCURY

ALPHA ACTIVITI (PCIR) BETA ACTIVITI (PCI/L) URARIUH

RADIOA (BQ/L)

$$
\begin{array}{rr}
69-176 & \text { GR-176 } \\
\text { TOLAL } & \text { TOTLL }
\end{array}
$$

\section{$02 / 04 / 86$} $10: 10: 00$

ICNP

$$
\begin{array}{r}
38 \\
<0.05
\end{array}
$$

0.11

0.014

2.6

60.003

120

0.036

0.029

0.14

97

0. 15

69

2.7

$<0.01$

0.17

$<0.007$

1.7

5.1

56

$<0.006$

0.65

$<0.0004$

$<0.2$

0.58

0.17

1.2

0.017

MAS

$$
\begin{array}{r}
0.108 \\
0.219 \\
<0.005 \\
<0.01
\end{array}
$$
6. 0z-04
76
83
0.01
0.24

$04 / 14 / 86$

14: 15:00

ICAP

0.013

$<0.0003$

1.6

$<0.003$

$<0.0$

$<0.005$

$<0.004$

1.6

0.071

30

0.074

$<0.01$

$<0.01$

$<0.007$

$<0.2$

1.4

5.8

$<0.006$ 0.5

$<0.0004$

$<0.2$

0.024

$<0.005$

0.0074

$<0.005$

A LS

$<0.005$

0.013

$<0.005$

$<0.01$

$<0.0002$

14.05

22.52

0.003

$<0.1$

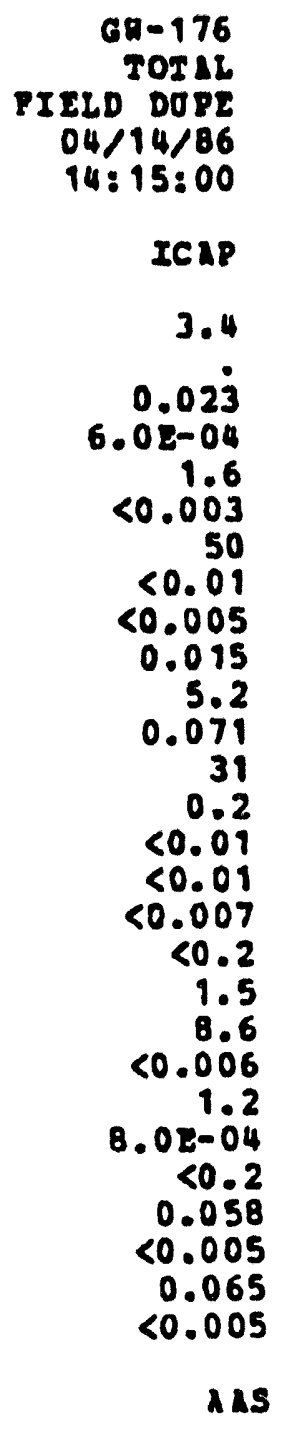

$<0.005$

0.011

$<0.005$

$<0.01$

$<0.0002$

20.89

27.12

0.005

$<0.1$ 
BESOLTS OP 1986 R25 GROUNDHATER SAUPLING CHESTNUT RIDGE SECHRITY PITS

TOTAL METALS-RADIOACTIVITI-AADIUH UNIT IS MG/L - UNLESS OTIERNISE STATED

URLL

DATE SAMPLED

TIEL SAMPLID

METHOD

ALOKIROH AMTIHOKY BAR IO:

BEB TLITUM

BOR ON

CADRIOK

CALCIOH

CHRORIOH

COBALT

COPPPB

IPON

IITHIOM

MAGNESTOE

MA NGA M ESB

HOL YBD ENOE

NICREL

NIOBIOH

PHOSPROROOS

BOTASSIOn

SIIICON

SIIVER

SODIOH

STRONTIOH

THORIUM

TIT BNIOE

VANADIUK

ZINC

ZIRCONIOH

HETHOD

ARS HAIC

LEAD

SELENION

THAILIOH

MERCURY

ALPHS ACTIVITY (RCI/L)

9ETA ACIIVITI (PCI/L)

ORANIOS

RADIOH (BQ $/ \mathrm{C})$

$\begin{array}{rr}6 H-176 & \text { GH-176 } \\ \text { TOTAL } & \text { TOTAL }\end{array}$

$07 / 29 / 86 \quad 10 / 15 / 86$

$14: 15: 00 \quad 12800=00$

ICAP

ICAP

0.095

$<0.05$

$<0.05$

0.011

$<0.0003$

0.84

$<0.003$

47

$<0.01$

$<0.005$

0.03

1.2

0.039

30

0.055

$<0.01$

0.012

$<0.007$

$<0.2$

1.2

5.8

$<0.006$

0.62

$<0.0004$

$<0.2$

0.024

$<0.005$

$<0.001$

$<0.005$

IAS

$<0.005$

0.006

$<0.005$

$<0.01$

$$
0.012
$$

$<0.0003$

0.2

$<0.003$

39

0.013

$<0.005$

$<0.004$

0.064

0.0069

23

0.0049

$<0.01$

$<0.01$

$<0.007$

$<0.2$

$<0.6$

4.6

$<0.006$

0.75

0.022

$<0.2$

$<0.003$

$<0.005$

0.0077

$<0.005$

I 15

$<0.005$

0.005

$<0.005$

$<0.01$

$\begin{array}{rr}<0.0002 & <0.0002 \\ 2 & <3 \\ 3 & 5 \\ <0.001 & 1.08-03 \\ <0.1 & <0.1\end{array}$
$68-176$

TOTAL

TIELD DUPE

$10 / 15 / 86$

12:00:00

ICAP

0.091

$<0.05$

0.012

$<0.0003$

0.2

$<0.003$

39

0.012

$<0.005$

$<0.004$

0.063

0.0073

23

0.0052

$<0.01$

$<0.01$

$<0.007$

$<0.2$

$<0.6$

4.6

$<0.006$

0.75

0.022

$<0.2$

$<0.003$

$<0.005$

0.0075

$<0.005$

145

$<0.005$

0.006

$<0.005$

<0. 01

$<0.0002$

63
5

$<0.001$

$<0.1$ 


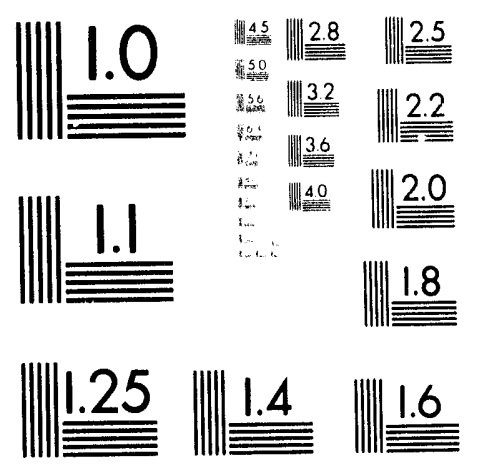



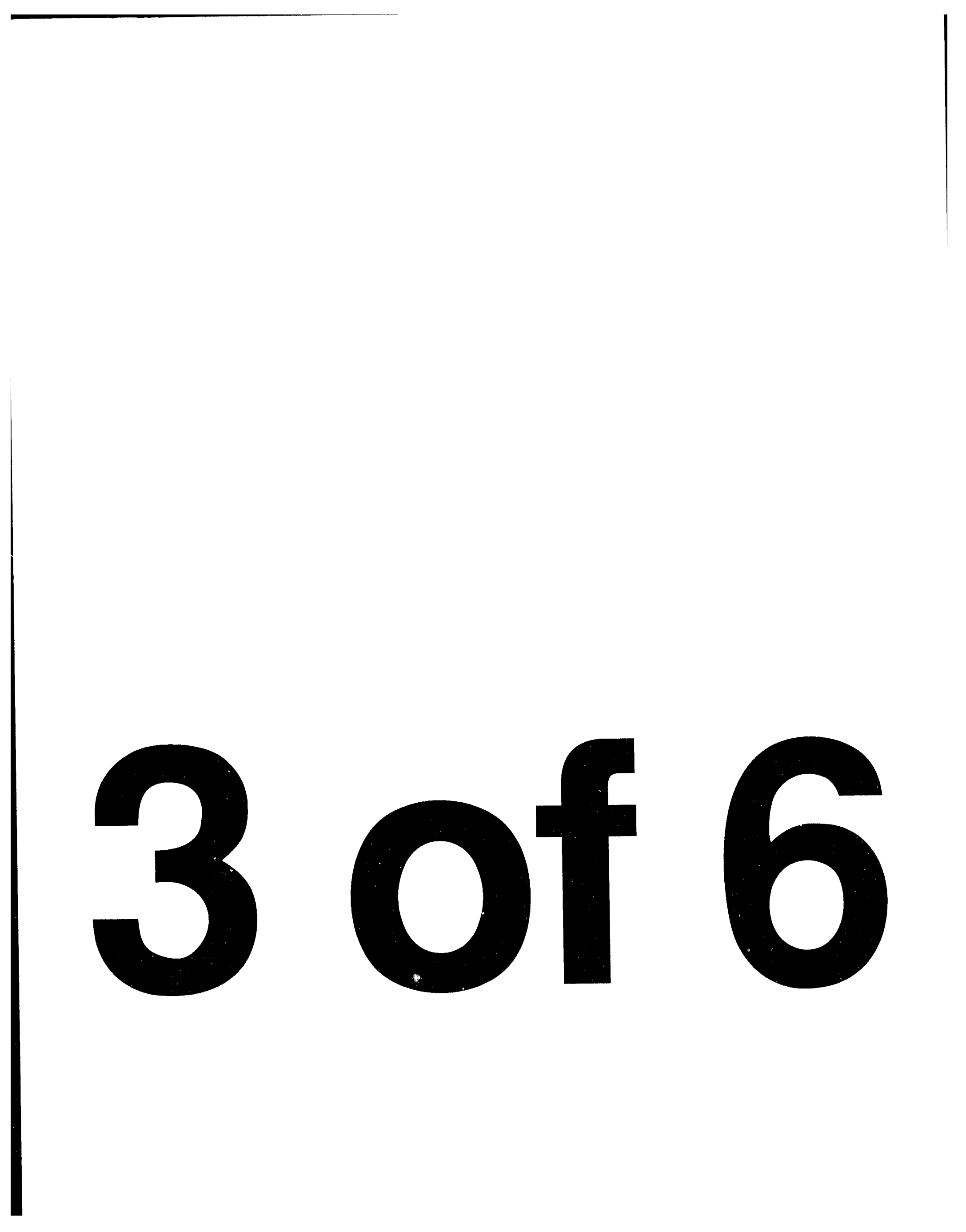
BESULTS OF 1986 K25 GROUNDWATER SARPLIRG CHESTNOT RIDGE SECURITY PITS

DISSOLVED METALS-RADIOACTIVITY-RADIOH UNIT IS HG/L - ONLESS OTHERUISE STLTED

WELL

DATE SAHPLED

MIRE SA MPLED

METROD

AIOIINUM

ANTI MONT

BRRIUR

BERIILIII

BORON

CADHIOY

CALCIUA

C. HลूOIIOA

COBAIT

COPPER

I RON

LITHIOA

MAGRESIOH

BAHGANESE

MOLY BDENOH

NICKEL

NIOBIOH

PHOS EHOROUS

BOTASSIUH

SIIICON

SILVER

SODIUA

STROATIOK

THORIOB

TITA HIUA

VANADIOH

ZINC

2IPCONIUH

МรTHOD

A RSEHIC

IEID

SRLPIION

TEALIIUN

MERCURY

AIPRA ICIIVITI (PCI/L)

BETA ACTIUITY (PCI/L)

OBANIOH

RADIUU $(B Q / L)$

\begin{abstract}
GN-176
DISSOLVED

GH- 176

DISSOLVED
\end{abstract}

$02 / 04 / 86$

$10: 10=00$

ICAP

0.051

$<0.05$

0.0084

$<0.0003$

2.5

$<0.003$

46

$<0.01$

$<0.005$

$<0.004$

0.014

0.11

32

0.0041

$<0.01$

$<0.09$

$<0.007$

$<0.2$

1.3

5.7

0.006

0.59

$<0.0004$

$<0.2$

0.0053

$<0.005$

$<0.001$

0.0051

ALS

$<0.005$

0.004

$<0.005$

$<0.01$

$<0.0002$

$$
0.00 \dot{2}
$$

$04 / 14 / 86$

$14: 15: 00$

$$
\begin{array}{r}
I C A P \\
<0.02 \\
0.01 \\
<0.0003 \\
1.6 \\
<0.003 \\
499 \\
<0.01 \\
<0.005 \\
<0.004 \\
0.01 \\
0.069 \\
30 \\
0.016 \\
<0.01 \\
<0.01 \\
<0.007 \\
<0.2 \\
0.87 \\
<0.006 \\
00.65 \\
<0.0004 \\
<0.22 \\
<0.003 \\
<0.005 \\
<0.001 \\
<0.005
\end{array}
$$

ALS

$<0.005$

0.004

$<0.005$

$<0.01$

$<0.0002$

0.002
GR- 176

DISSOL VED

FIELD DUPE

$04 / 14 / 86$

14: $15: 00$

\section{ICAP}

$<0.02$

0.017

$<0.0003$

1.5

$<0.003$

47

$<0.01$

$<0.005$

$<0.004$

$<0.004$

0.065

29

0.05

$<0.01$

$<0.01$

$<0.007$

$<0.2$

1.3

$$
4.4
$$

$<0.006$

0.59

0.0013

$<0.2$

$<0.003$

$<0.005$

$<0.001$

$<0.005$

ALS

$<0.005$

0.004

$<0.005$

$<0.01$

$<0.0002$

0.004 


\section{RESOITS OP 1986 K25 GROUNDAATER SAMPIIRG CEESTRUT RIDGE SECORITY RITS}

DISSOLVED METALS-RADIONCTIVITY-RADIUH UNIT IS MG/I - UNLESS OTHERRISE STITED

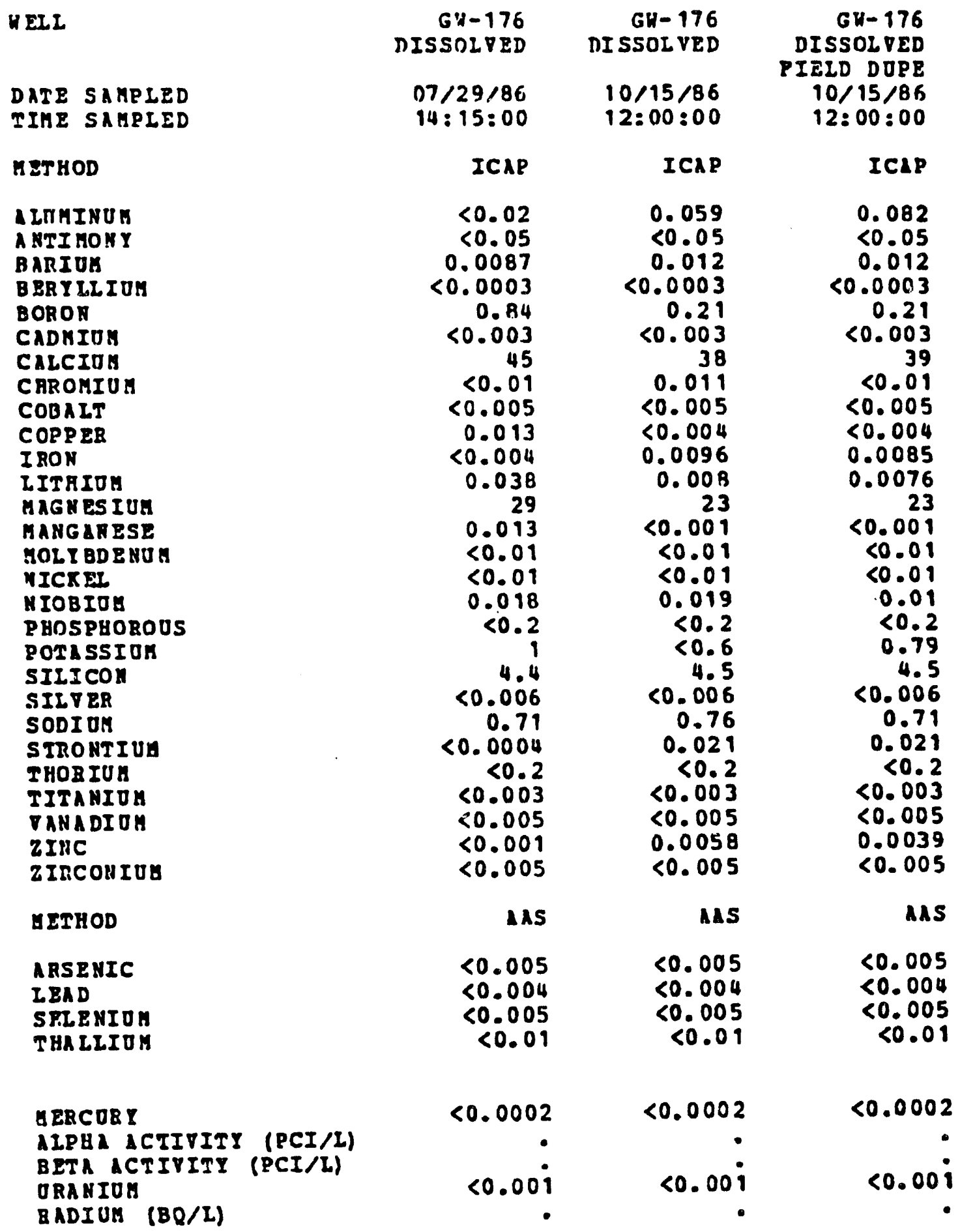


MISCELLANEOUS CONPRHTIONIL AND NON-CONVENTIONAI POLLOTANTS AND RELATED PARAGETER OHIT IS HG/L - URLESS OTHERHISE STATED

DELL

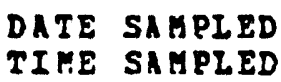

\begin{tabular}{|c|c|c|}
\hline $\begin{array}{l}G K-176 \\
02 / 04 / 86 \\
10: 10: 00\end{array}$ & $\begin{array}{l}G H-176 \\
04 / 14 / 86 \\
14: 15: 00\end{array}$ & $\begin{array}{r}\text { GE-176 } \\
\text { PIELD DOPE } \\
04 / 14 / 86 \\
14: 15: 00\end{array}$ \\
\hline $\begin{array}{r}-118.1 \\
14 \\
5.8 \\
400 \\
7.42 \\
153\end{array}$ & $\begin{array}{r}-113.2 \\
27.6 \\
8.6 \\
440 \\
7.4 \\
155\end{array}$ & $\begin{array}{l}\bullet \\
: \\
\bullet\end{array}$ \\
\hline$\bullet$ & - & - \\
\hline - & - & - \\
\hline$\bullet$ & - & - \\
\hline$\bullet$ & • & \\
\hline G & 4,5 & 118 \\
\hline N & n & $\pi$ \\
\hline $\begin{array}{r}0.1 \\
0.004 \\
<1 \\
0.27\end{array}$ & $\begin{array}{r}<0.1 \\
<0.001 \\
1.7 \\
0.41\end{array}$ & $\begin{array}{r}<0.1 \\
1.08-03 \\
1.8 \\
0.43\end{array}$ \\
\hline$\bullet$ & $\bullet$ & - \\
\hline$i$ & $<i$ & \\
\hline
\end{tabular}


RESTLTS OP 1996 K25 GROUNDWATER SAMPIING

CAESTNOT RIDGE SBCCRITY PITS

YISCELLANEOUS CONVENTIONAI AND RCN-CORVENTIONAL POLLOTANTS AND UNIT IS MG/L - ONIESS OTHERUISE STATED

WEIL

DATE SAMPLED

WLTER LEVEL (FY +/- GRADE)

WAIER TEVP (DEG. CENT.) DISSOLVED OXIGEN

CONDUCIIVITY (IA UABOS/CA)

PH (IN PA ONITS)

REDOX (IN HV)

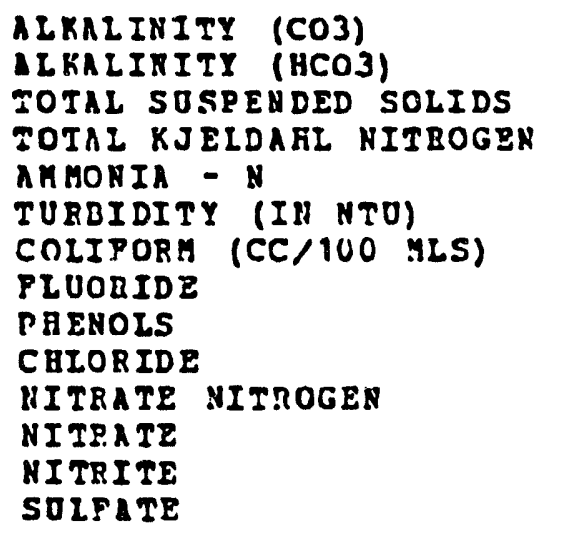

\begin{tabular}{|c|c|c|}
\hline $\begin{array}{r}69-176 \\
07: 29 / 86 \\
14: 15: 00\end{array}$ & $\begin{array}{r}G 1-176 \\
10 / 15 / 86 \\
12: 00: 00\end{array}$ & $\begin{array}{r}\text { GH-176 } \\
\text { PIELD DOPE } \\
10 / 15 / 86 \\
12: 00: 00\end{array}$ \\
\hline $\begin{array}{r}-115.3 \\
26.6 \\
8.9 \\
390 \\
7.6 \\
230\end{array}$ & $\begin{array}{r}-116.2 \\
15.6 \\
7.2 \\
330 \\
6.9 \\
256\end{array}$ & $\begin{array}{l}\bullet \\
\bullet \\
\bullet \\
\bullet \\
\bullet \\
\bullet\end{array}$ \\
\hline • & • & - \\
\hline - & $\bullet$ & $\bullet$ \\
\hline$\bullet$ & • & - \\
\hline • & $\bullet$ & : \\
\hline 27 & 1 & 1 \\
\hline N & 1 & 1 \\
\hline $\begin{array}{r}0.1 \\
0.005 \\
1.5 \\
0.43\end{array}$ & $\begin{array}{r}<0.1 \\
0.016 \\
1.8 \\
1.7\end{array}$ & $\begin{array}{r}<0.1 \\
0.005 \\
1.8 \\
1.8\end{array}$ \\
\hline$\bullet$ & $\bullet$ & - \\
\hline $1 . \dot{3}$ & $<i$ & $<1$ \\
\hline
\end{tabular}




\section{RESOLTS OF 1986 K25 GROUNDHATER SAMPLING \\ CHESTHUT RIDGE SECURITY PITS}

VOLATILE ORGANIC PRIORITY AND NON-PRIORITI POLLUTANTS

ONIT IS UG/L

WELL

$\begin{array}{rr}\text { GN-176 } & \text { GH-176 } \\ 02 / 04 / 86 & 04 / 14 / 86 \\ 10: 10: 00 & 14: 15: 00\end{array}$

GH- 176

DATE SAGPLED

TIME SAMPLED

$10: 10: 00$

$14: 15: 00$

RIELD DOPE

$04 / 14 / 86$

$14: 15: 00$

CHLOROMETHANE

BROMOHETHANE

VIMYL CULORIDE

CULOROETRAME

METHYLENE CHLORIDE

ACETONE

CARBON DISULEIDE

- 1. 1-DICALOROETHENE

-1,1-DICHLOROETHANE

TRIHS-1, 2-DICHLOROETHENE

CHLOBOTORH

1, 2-DICHLOROETAANE

2-BOTANONE

-1, 1, 1-TRICHLOROETHANE

CARBON TETRACULORIDE

VINYL ACETATE

BRCMODICALORORETHANE

1, 1,2,2-TETRACHLOROETHAME

1.2-DICHLOROPROPARE

TRANS-1, 3-DICELOROPROPEEE

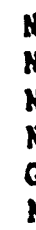

y

N

I

(

G

92

G

12

31

22

6

G

N

260

TRICHLOROETHERE

CHIOR OD I BROMOKETHANE

1, 1,2-TR ICALOROETHANE BENZENL

CIS-1,3-DICHI OROP ROPEKE 2-CHLOROETHYIVIRYI ETEER BRCAOFORH

2- HEX AHONE

4- METHYL-2-PENTA HOHE

TETR ACHLOROETHENE

TOLUERE

CHLOROBENZENE

ETUYLBENZENE

STTRENE

XILEIES 
VOLATILE ORGANIC PRIORITY ARD NON-PRIORITY POLIUTARTS

ONIT IS UG/L

\begin{tabular}{|c|c|c|c|}
\hline $\begin{array}{l}\text { UELL } \\
\text { DATE SAMPLED } \\
\text { TIME SAMPLED }\end{array}$ & $\begin{array}{r}G H-176 \\
07 / 29 / 86 \\
14: 15: 00\end{array}$ & $\begin{array}{r}G W-176 \\
10 / 15 / 86 \\
12: 00: 00\end{array}$ & $\begin{array}{r}G H-176 \\
\text { PIELD DOPE } \\
10 / 15 / 86 \\
12: 00: 00\end{array}$ \\
\hline 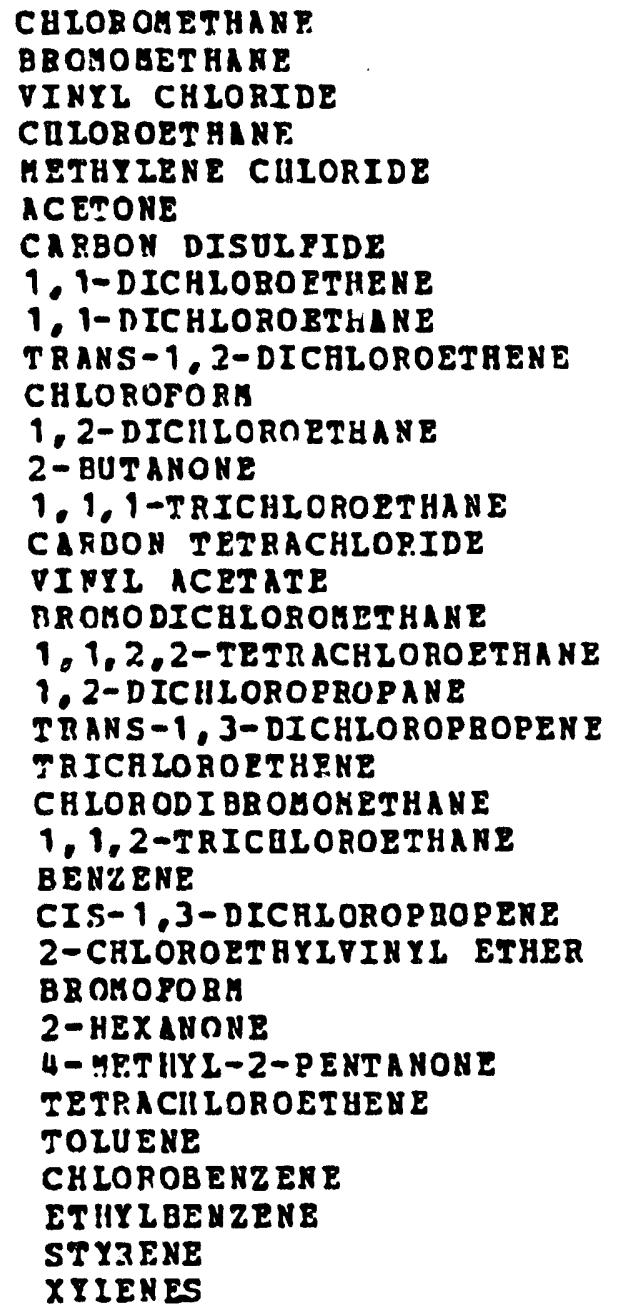 & $\begin{array}{r}\mathbf{N} \\
\mathbf{H} \\
\mathbf{H} \\
\mathbf{G} \\
\mathbf{N} \\
\mathbf{G} \\
\mathbf{1 0} \\
\mathbf{1 6} \\
\mathbf{G} \\
\mathbf{3} \\
\mathbf{G} \\
\mathbf{N} \\
200 \\
22 \\
\mathbf{W} \\
\mathbf{G} \\
\mathbf{G} \\
\mathbf{G} \\
\mathbf{G} \\
\mathbf{G} \\
\mathbf{G} \\
\mathbf{G} \\
\mathbf{G} \\
\mathbf{G} \\
\mathbf{H} \\
\mathbf{G} \\
\mathbf{H} \\
\mathbf{N} \\
\mathbf{7} \\
\mathbf{G} \\
\mathbf{G} \\
\mathbf{G} \\
\mathbf{G} \\
\mathbf{G}\end{array}$ & 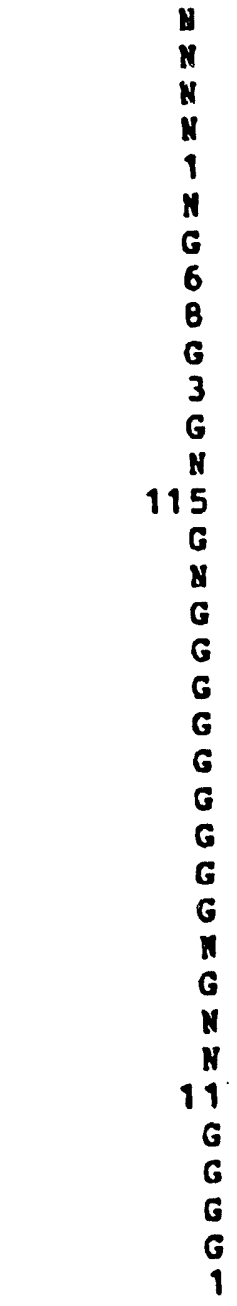 & 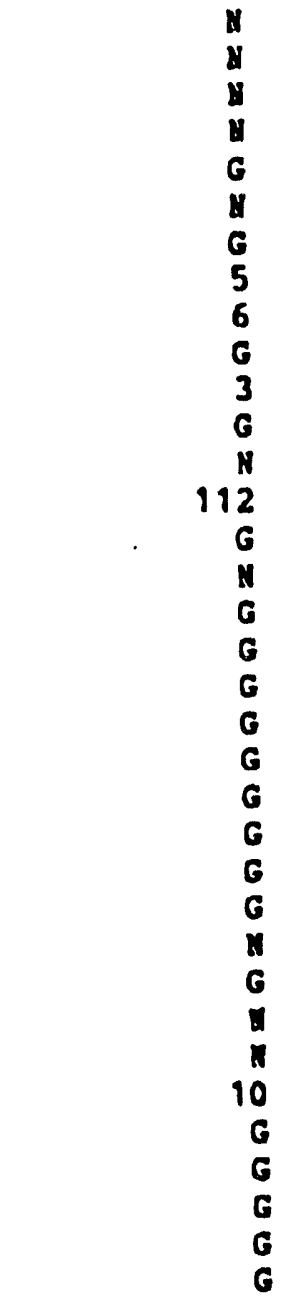 \\
\hline
\end{tabular}


RESUITS OF 1986 K25 GROUNDKATER SABPLIMG

CAESTHUT AIDGE SECORITI PITS

HERBICIDES AND PESTICIDES

UNIT IS UG/L

\begin{tabular}{|c|c|c|c|}
\hline HELL & $68-176$ & GD- 176 & $G H-176$ \\
\hline $\begin{array}{l}\text { DATE SAMPLED } \\
\text { TIAE SAMPIED }\end{array}$ & $\begin{array}{l}02 / 04 / 86 \\
10: 10: 00\end{array}$ & $\begin{array}{l}04 / 14 / 86 \\
14: 15: 00\end{array}$ & $\begin{array}{r}\text { FIELD DUPE } \\
04 / 14 / 86 \\
14: 15: 00\end{array}$ \\
\hline $\begin{array}{l}\text { 2.4-D } \\
\text { BUDRIN } \\
\text { IINDANE } \\
\text { HETHOXYCHIOR } \\
\text { STLVEX } \\
\text { TOXAPHENE }\end{array}$ & $\begin{array}{r}<1 \\
<0.05 \\
<0.01 \\
<0.04 \\
<0.1 \\
<1\end{array}$ & $\begin{array}{r}<2 \\
<0.1 \\
<0.02 \\
<0.08 \\
<0.2 \\
<2\end{array}$ & $\begin{array}{r}<2 \\
<0.1 \\
<0.02 \\
<0.08 \\
<0.2 \\
<2\end{array}$ \\
\hline
\end{tabular}


RESUITS OF 1986 K25 GROUNDHATEB SAMPLING CHESTNOT RIDGE SECORITY PITS

HERBICIDES AND PESTICIDES

UNIT IS OG/L

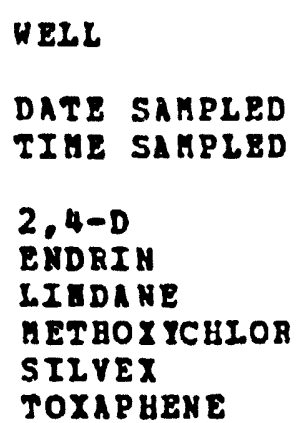

$$
\text { GH-176 GR-176 }
$$

$07 / 2.9 / 86$ $14: 15: 00$

$10 / 15 / 86$ $12: 00: 00$ GD- 176
PIELD DOPE
$10 / 15 / 86$
$12: 00: 00$

$<2$
$<0.1$
$<0.02$
$<0.08$
$<0.2$
$<2$

$<1$
$<0.05$
$<0.01$
$<0.04$
$<0.1$
$<1$

$<1$
$<0.05$
$<0.01$
$<0.04$
$<0.1$
$<1$ 
RRSULTS OF 1986 R25 GROONDHATER SA GPLING

CHESTNUT RIDGE SECURITY PITS

BASE-NEUTRAL EYTBACTABLE OBC DEGANIC PRIORIT
DNII IS UG/L

KELI

DATE SAMPLED

PIXP SAMPLED

N-NITROSODIMETHYLAMINE

PHENOL

ANIIINE

OIS (2-CHLOROETHYL) ETAER

2-CHLOROP HE NOI

1.3-DICHLOROBZNZENE

1. 4-DICHLOBOBENZENE

BENZYI ALCOHOL

1,2-DICHLOROBENZENE

2- HETH RLP REMOL

aIS (2-CHLOROI SCPROP II) ETHER

4- MEIH YLP HENOL

N- IITROSODI-N-PROPILAVINR

HEXACHIOROETHANE

NI TROBENZENE

ISOPHORONE

2- HITROP\&EMOL

2.4-DIMETHYLPUTNOL

BENZOIC ACID

BIS (2-CHLOROETHOXY) METRARE

2, 4-DICH LOROPUENOI

1.2,4-TR ICHLOROBENZ ENE

NAPHTHALENE

4-CNLOROA NIIIAE

IIEX ACHLOROBOTAOTENE

4-CALORO-3-NETHYLPHEHOL

2- UETHYLNAPATHALENE

HEXACHLOROCYCLOPENTADIENE

2. 4,6-TEICR O ROP E ENOL

2, 4,5-TR ICHLOROP HENOL

2-C HLOROHAP RTHALENE

2- NITBOANILINB

DIMETUILPUTHALATE

ACENAP RT HYLENE

$$
\text { GN-176 GH-176 }
$$

$02 / 04 / 86$

10:10:00

$04 / 14 / 86$

14: 15:00

GH-176

PIELD DUPE

$04 / 14 / 86$

14: 15:00 
P.ESOLTS OF 1986 K25 GROUNDWATER SAMPLING CHESTNUT RIDGE SECURITY PITS

ACID E BASE-NENTRAL EXTRACTABLE ORGANIC PRIORITI AND NON-PRIORITY POLLOTANTS-I ONIT IS UE/L

WELL

DATE SAEPIED

TIME SAEPLED

N- NITROSODIMETHYLAMIAD

PAEROI

ANILIRE.

BIS (2-CHLOROETAYL) ETKER

2-CHLOBOP HENOI

1.3-DICELOROBENZEXE

1. 4-DICELOBOBENZEKE

BEXZYI A LCOROL

1. 2-DICHIOROBENZENE

2- METHTLPHENOL

BIS (2-CBLOROISOPROPYL) ETHER

4- IETAYLPHENOL

N- NITROSODI-N-PBOPILAMINE

IIEX ACRLOROETHANE

NITROBENZENE

ISOPLIOBORE

2- NITROPHEHOL

2. 4-DI RET HIIPAENOL

BENZOIC ACID

BIS (2-CHI OROETHOXY) GETAANE 2.4-DICALOROPAENOL

$1,2,4-T R$ ICALORODENZENE

MAPATRALERE

4-CBLOBOA UILI RE

HEX ACALOROBUT ADIEAE

4- CHLO 8O-3-METHYLPHZNOL

2- YETHILNAPHTH ALENE

HEX ACALOROCYCLORENTADIEAB

$2,4,6-T R I$ CH IO ROPHEXOL

$2,4,5-T B I C H I O R O P$ HEROL

2-C BLORONAPHTHALERB

2-NTTBOANILINE

DIM ETH ILPIITHALATE

ACENAP HT UILENE

$\begin{array}{rrr}\text { GH-176 } & \text { GR-176 } & \text { GH-176 } \\ 07 / 29 / 86 & 10 / 15 / 86 & \text { PIELD DUPE } \\ 14: 15: 00 & 12: 00: 00 & 12: 15 / 86 \\ & \end{array}$

ב


RESULTS OP 1986 K25 GROONDRATRR SAMPLIHG CHESTNUT RIDGE SECURITI PITS

ACID \& BASE-NEOTZAL EXTRACTABLE

ORGANIC PRIORITY AND NON-PRIORITI POLLOTANTS-II ONIT IS UG/L

\begin{tabular}{|c|c|c|c|}
\hline $\begin{array}{l}\text { HELL } \\
\text { DATE SAAPLED } \\
\text { TIAE SAMPIED }\end{array}$ & $\begin{array}{l}G D-176 \\
02 / 04 / 86 \\
10: 10: 00\end{array}$ & $\begin{array}{l}G H-176 \\
04 / 14 / 86 \\
14: 15: 00\end{array}$ & $\begin{array}{r}\text { GU-176 } \\
\text { FIELD DUPE } \\
04 / 14 / 86 \\
14: 15: 00\end{array}$ \\
\hline 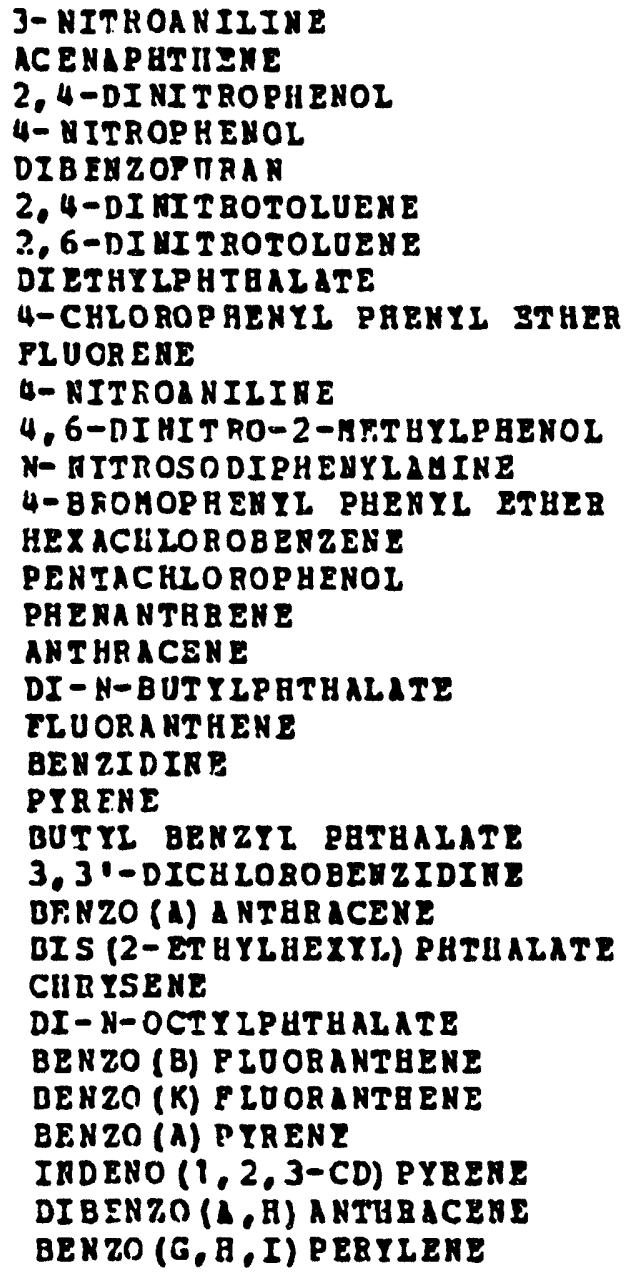 & 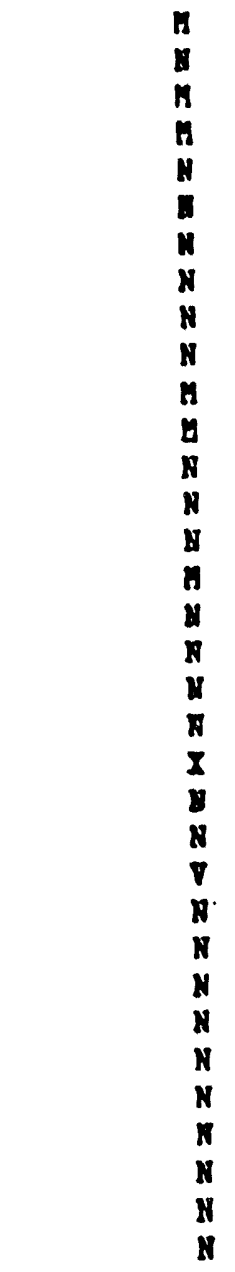 & 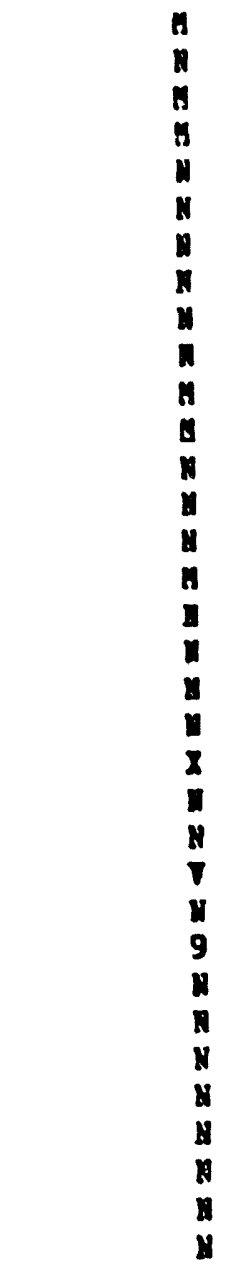 & 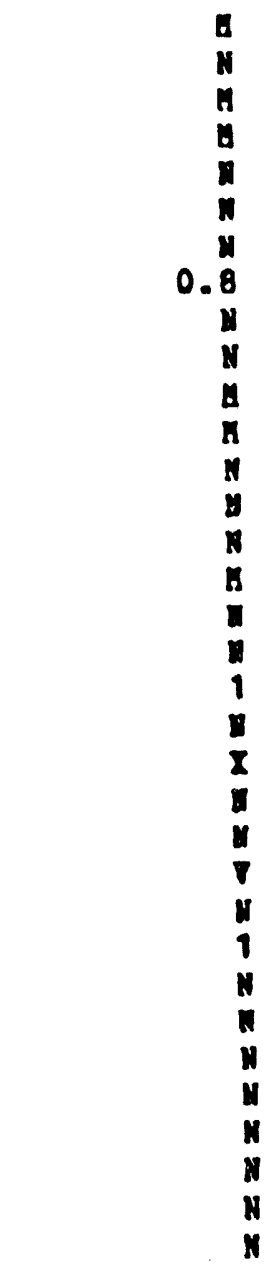 \\
\hline
\end{tabular}


RESUITS OP 1906 K25 GROUNDAATRE SA HPIIAG

CHESTIOT RIDGE SECORITY PITS

ACID E BASE-NEUTRAL EXTRACTABLE ORGAKIC PRIORITY IND MON-PRIORITY POLLOTANTS-IT ONIT IS UG/L

KELI.

$\begin{array}{rr}\text { Git-176 } & \text { GH-176 } \\ \text { C7/29/86 } & 10 / 15 / 86 \\ 14: 15: 00 & 12: 00: 00\end{array}$

G1- -176

DATE SAHPIED

$14: 15: 00$

12:00:00

FIELD DOPE

$10 / 15 / 86$

TIER SAMPLED

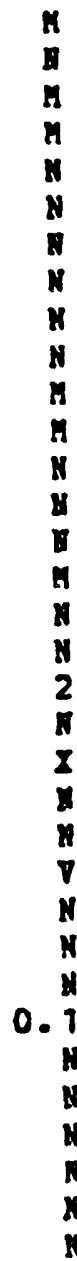

12:00:00

3- NITROAN ILINE

ACENAP QTH RIE

2.4-DI HI TROPHENOL

4-NITROPHENOL

DIB FNZOP ORA

2.4-DI UI TROTOLUENE

2,6-JI KI TROTOIOTME

DI ETHYIPHTRALATE

4-CHLOROPHENYI PHENYL ETHER

FLUORENE

4- MITROLNILINE

4,6-DI UIT TO-2-UETHILPBEBOL

H-NITROSODIPHERTLAMINE

4-BROMOPHENYL PHENTL ETHER

HEX ACH LOROBEMZENE

PENTICRLO ROPHENOL

PBEMANTHRENE

AHT TR ICENE

DI-N-BUTYLPHTRALATE

PLOCPANTHEKE

DENTIDINE

PYRENE

BUTYL BEHZTL PATHALATE

3. $3^{\circ}$-D ICH LO BO BEXZ IDIKE

BEH 20 (d) ARTURACENE

BIS (2-ETRTLAEXIL) PHTRALATE

CHRYSENE

DI-N-OCTYIPHTIALATE

DENZO (B) PINORANTHENE

BENZO (K) PLUCRANTHENE

BENZO (A) PTBENE

IRDEKO (1,2,3-CD) PYRZNE

DI B EHZO (A . II) A MTRBACENE

BENZO (G, H, I) PERYIENB 
RESULTS OP 19 A6 K25 GROUNDWATER SA HPLING

CHESTNUT RIDGE SECURITY PITS

LAB REPLICATES

DHIT IS UG $\Omega$ FOR TOX - MG/L POR TOC

\begin{tabular}{|c|c|c|c|}
\hline $\begin{array}{l}\text { WEIL } \\
\text { DATE SAMPLED } \\
\text { TIUE SAHPLED }\end{array}$ & $\begin{array}{r}G H-176 \\
02 / 04 / 86 \\
10: 10: 00\end{array}$ & $\begin{array}{r}64-176 \\
04 / 14 / 86 \\
14: 15: 00\end{array}$ & $\begin{array}{r}\text { GH- } 176 \\
\text { PIELD DUPE } \\
04 / 14 / 86 \\
14: 15: 00\end{array}$ \\
\hline CONDUCTIVITY (IN UUHOS/CH) & $\begin{array}{l}464 \\
458 \\
456 \\
457\end{array}$ & $\begin{array}{l}415 \\
415 \\
414 \\
413\end{array}$ & $\begin{array}{l}401 \\
407 \\
408 \\
409\end{array}$ \\
\hline PR (IN P\& ONITS) & $\begin{array}{l}7.1 \\
7.1 \\
7.1 \\
7.3\end{array}$ & $\begin{array}{l}7.6 \\
7.2 \\
7.2 \\
7.6\end{array}$ & $\begin{array}{l}7.4 \\
7.4 \\
7.4 \\
7.7\end{array}$ \\
\hline TOTAL ORGAKIC CARBON & $\begin{array}{l}62 \\
57 \\
58 \\
59\end{array}$ & $\begin{array}{l}72 \\
71 \\
72 \\
71\end{array}$ & $\begin{array}{l}71 \\
72 \\
70 \\
72\end{array}$ \\
\hline TOTAL ORGANIC CHIORIDE & $\begin{array}{l}31 \\
30 \\
29 \\
30\end{array}$ & $\begin{array}{l}27 \\
15 \\
19 \\
18\end{array}$ & $\begin{array}{l}17 \\
21 \\
19 \\
17\end{array}$ \\
\hline
\end{tabular}




\section{RESUITS OP 1986 R25 GROUNDHATER SAMPIIEG} CHESTNUT RIDGE SECURITI PITS

LAB REPIICATES

UNIT IS OG/L FOR TOX - MG/L FOR TOC

\begin{tabular}{|c|c|c|c|}
\hline $\begin{array}{l}\text { DELL } \\
\text { DATE SAMPLED } \\
\text { TIGE SAMPLED }\end{array}$ & $\begin{array}{r}6 H-176 \\
07 / 29 / 86 \\
14: 15: 00\end{array}$ & $\begin{array}{r}G H-176 \\
10 / 15 / 86 \\
12: 00: 00\end{array}$ & $\begin{array}{r}G H-176 \\
\text { PIELD DOPE } \\
10 / 15 / 86 \\
12: 00: 00\end{array}$ \\
\hline CONDUCTIVITY (IN UHHOS/CA) & $\begin{array}{l}480 \\
482 \\
482 \\
479\end{array}$ & $\begin{array}{l}376 \\
374 \\
376 \\
375\end{array}$ & $\begin{array}{l}374 \\
373 \\
373 \\
374\end{array}$ \\
\hline Pн (IN Qн ONITS) & $\begin{array}{l}7.2 \\
7.2 \\
7.2 \\
7.2\end{array}$ & $\begin{array}{l}6.9 \\
6.9 \\
6.9 \\
6.9\end{array}$ & $\begin{array}{l}6.9 \\
6.9 \\
6.9 \\
6.9\end{array}$ \\
\hline FOTAL ORGANIC CARBON & $\begin{array}{l}55 \\
43 \\
46 \\
41\end{array}$ & $\begin{array}{l}83 \\
85 \\
87 \\
87\end{array}$ & $\begin{array}{l}78 \\
86 \\
87 \\
86\end{array}$ \\
\hline TOTAL OBGANIC CALOBIDE & $\begin{array}{l}140 \\
120 \\
110 \\
140\end{array}$ & $\begin{array}{l}<10 \\
<10 \\
<10 \\
<10\end{array}$ & $\begin{array}{l}<10 \\
<10 \\
<10 \\
<10\end{array}$ \\
\hline
\end{tabular}


RESUITS OF 1996 K25 GRODNDHATER SAMPLING

CAESTMOT RIDGE SECORITY PITS

TOTLL GETALS-RADIOACTIVITI-RADIUH

URIT IS HG/L - INLBSS OTHERKISE STATED

NELI

DATE SAMPLED
TEXP. SAMPLED

METHOD

AL TMI NO:

AHTIHONY

BA P.IUK

BERYLIIOK

BOROR

CA DNIOM

CA ICI OM

CHROMIOA

COBALT

COPPE

IRON

IITUIU:

MA GUESIOH

MA NG A NFSE

MO L. TBDENUK

NI CKEL

NIOBIDE

PH OSP HOROOS

POTASSIU日

SIIICON

SIIVER

SODIUA

STRORTIOB

THORIDT

TITANIOA

VA NADIOG

ZINC

ZI RCONIOH

HETUOD

AR SENIC

IEAD

SELEYIOB

THALIIUA

MERCORT

ALPIA ACTIVITI (PCI/L)

BETA $\triangle C T I V I T I$ (PCI/L)

OR ANI OH

RADIOM (BQ/L)
6น- 177

TOTAI

$02 / 04 / 86$

$14: 45: 00$

ICAP

0.045

$<0.05$

0.0062

$<0.0003$

0.026

$<0.003$

41

$<0.01$

$<0.005$

0.057

4.9

$<0.004$

28

0.15

$<0.01$

$<0.01$

$<0.007$

$<0.2$

15

4. 8

$<0.006$

3. 4

0.031

$<0.2$

$<0.003$

$<0.005$

$<0.001$

$<0.005$

RAS

$<0.005$

0.031

$<0.005$

$<0.01$

$<0.0002$
2.37
18.5
0.004
$<0.1$
$6 \pi-177$

TOTA 1.

$04 / 17 / 86$

16:10:00

ICAP

$$
<0.02
$$

0.0056

$<0.0003$

0.049

$<0.003$

38

$<0.01$

$<0.005$

0.053

7.5

$<0.004$

28

0.16

$<0.01$

$<0.01$

$<0.007$

$<0.2$

11

2. 9

$<0.006$

4.2

0.033

$<0.2$

$<0.003$

$<0.005$

0.13

$<0.005$

ANS

$<0.005$

0.039

$<0.005$

$<0.01$
$<0.0002$
1.6
8.29
0.003
$<0.1$

GN-177

roTAL

$07 / 29 / 86$

16:00:00

ICAP

0.27

$<0.05$

0.037

$<0.0003$

0.047

$<0.003$

59

0.034

$<0.005$

0.045

4.3

0.0042

30

0.098

0.01

0.054

$<0.007$

$<0.2$

5.8

3.3

$<0.006$

5.9

0.077

$<0.2$

$<0.003$

$<0.005$

$<0.001$

$<0.005$

As

$<0.005$

0.016

$<0.005$

$<0.01$

$<0.0002$

4
8
$<0.001$
$<0.1$
6D- 177

TOTAL

$10 / 10 / 86$

13:30:00

ICAP

0.072

$<0.05$

0.012

$<0.0003$

0.022

$<0.003$

45

0.013

$<0.005$

0.012

0.19

$<0.004$ 27

0.033

$<0.01$

0.02

$<0.007$

$<0.2$

2. 3

4.3

$<0.006$

1.3

0.041

$<0.2$

$<0.003$

$<0.005$

0.0034

$<0.005$

AnS

$<0.005$

0.014

$<0.005$

$<0.01$

$<0.0002$

2
4
0.007

$<0.1$ 
RESOLTS OP 1986 K25 GROUNDYATER SAMPIING CHESTAUT RIDGE SECURITY PITS

DISSOLVED METALS-RADIOACTIVITY-RADIOH OHIT IS BG/L - ONLPSS OTHERKISE STATED

DELL

DATE SAHPLED

TIKE SAMPLED

AETROD

AL UN INOE

A NTI MON 1

BARI UR

BERI LIUK

BOBON

CADH IUA

CAIC IU日

CHBOHIOH

COBA LT

COPP ER

IBON

IIIR IDA

MAGN RSIUN

MA RG ANESE

HOZY BDERUY

BICK BL

NIOBIOH

FHOS PHO ROOS

POTR SSI OH

SILICOA

SIIVER

SODI OH

STRO NTI OX

THORIOA

TITA NIOH

vaAa DIUn

ZINC

ZIRCONIOE

METH OD

ARSENIC
LEAD
SELENIOY
TAALIIUG

MERC ORY

ALPHA NCTIVITT (PCI/L)

BETA ACTIVITY (PCI/L)

UBAN IO

RADIUM (BQ/)
6H- 177

DISSOLVED

$02 / 04 / 86$

$14: 45: 00$

ICXP

0.054

$<0.05$

0.0049

$<0.0003$

0.029

$<0.003$

$<0.01$

$<0.005$

$<0.004$

0.057

0.0058

27

0. 14

$<0.01$

$<0.01$

$<0.007$

$<0.2$

21

3.8

$<0.006$

$$
4.2
$$

0.034

$<0.2$

0.0067

$<0.005$

$<0.001$

0.0054

IAS

$<0.005$

0.005

$<0.005$

20.01

$<0.0002$

1. 0B-0j
Gㅅ- 177 DISSOLVED

$04 / 17 / 96$

$16: 10: 00$

ICAP

$$
<0.02
$$

0.0029

$<0.0003$

0.015

$<0.003$

36

$<0.01$

$<0.005$

$<0.004$

0.086

$<0.004$

27

0.13

co. 01

20.01

$<0.007$

$<0.2$

10

2. 8

$<0.006$

0.03

$<0.2$

$<0.003$

$<0.005$

0.031

$<0.005$

AnS

$<0.005$

$<0.004$

$<0.005$

$<0.01$

$<0.0002$

1. 0z-0i
6D- 177 DISSOLVED

$07 / 29 / 86$

16:00:00

ICAP

$<0.02$

$<0.05$

0.033

$<0.0003$

0.04

$<0.003$

37

$<0.01$

$<0.005$

0.015

$<0.004$

$<0.004$

0.036

0.01

0.033

$<0.007$

$<0.2$

5.8

2.5

$<0.006$

6.1

0.029

$<0.2$

$<0.003$

$<0.005$

$<0.001$

$<0.005$

A AS

$<0.005$

0.005

$<0.005$

$<0.01$

$<0.0002$

0.003
$<0.0002$

64- 177

DISSOLVED

$10 / 10 / 86$

13: $30: 00$

ICAP

0.064

$<0.05$

0.011

$<0.0003$

0.031

$<0.003$

45

0.011

$<0.005$

0.006

0.021

$<0.004$

27

0.017

$<0.01$

0.017

$<0.007$

$<0.2$

2.2

4.5

$<0.006$

1.4

0.04

$<0.2$

$<0.003$

$<0.005$

0.0086

$<0.005$

145

$<0.005$

0.004

$<0.005$

$<0.01$

0.007 
RESUITS OF 1986 K.25 GROUNDHATER SALPLIRG CHESTNOT RIDGE SECURITY PITS

MISCELLAREONS CONPENTIONAL ARD NON-CONVENTIONAL POLLUTAKTS AND RELATED PARAMETEE UHIT IS MG/L - UULESS OTHERHISE STITED

VELL

CATE SA HPLED

TIME SA HPIED

WATER LEVEL (FT + / GRADE)

HA TER TEMP (DEG. CENT.)

DISSOLVED OXYGEN

COUDUCTIVITI (IH OHHOS/CH)

PH (IN PH UNITS)

REDOX (IN NV)

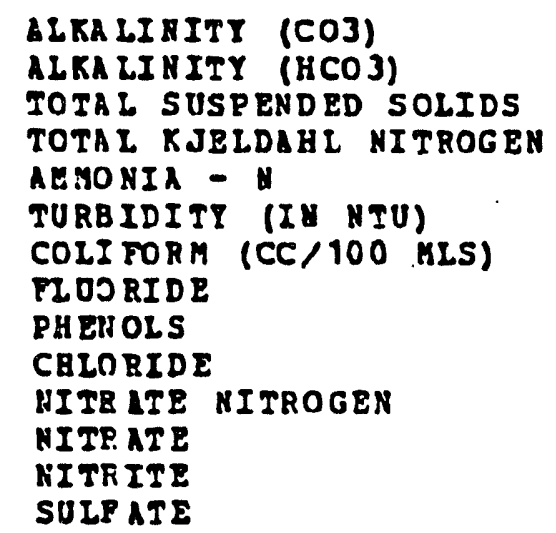

\begin{tabular}{|c|c|}
\hline GH- 177 & GW- 177 \\
\hline $\begin{array}{l}02 / 04 / 86 \\
14: 45: 00\end{array}$ & $\begin{array}{l}04 / 17 / 86 \\
16: 10: 00\end{array}$ \\
\hline $\begin{array}{r}-118 \\
15 \\
1.4 \\
440 \\
7 \\
120\end{array}$ & $\begin{array}{r}-114.7 \\
12.4 \\
7 \\
400 \\
7 \\
98\end{array}$ \\
\hline $\begin{array}{r}. \\
\dot{ } \\
36 \\
36 \\
0.15 \\
0.013 \\
1.8 \\
<0.11\end{array}$ & $\begin{array}{r}. \\
\dot{ } \\
\dot{ } \\
\dot{G} \\
4 \\
0.2 \\
0.008 \\
0.4 \\
<0.11\end{array}$ \\
\hline 24 & 24 \\
\hline
\end{tabular}

GN- 177

64- 177
$07 / 29 / 86$
$16: 00: 00$
$10 / 10 / 86$
$13: 30: 00$

$-115.2$

21.9

12.3

110

6.3

188

$-116$

24.3

16.4

$36 ?$

7.8 300

0.2

0.011

6.4

<0. 11

11
0.003
0.003

0.16

10.2 


\section{A-40 \\ RESOLIS OP 1986 R25 GROUNDHATER SA BPLING \\ CHESTNOT RIDGE SBCURITY PITS \\ VOLATILE ORGANIC PRIORITY AND YON-PRIORITY POLIUTARTS ONIT IS UG/L}

NELL

$$
\text { GW-177 }
$$

$02 / 04 / 86$

$14: 45: 00$

GW-177

G4- 177

$04 / 17 / 96$

16: 10:00

$07 / 29 / 86$

16:00:00

TIMC SAMPIBD

CH LOROAETARNE

BROMOM ETHLHE

VINYL CHLORIDE

CHLOROETHANE

METHYLENE CHLORIDE

ACETONE

CARBOH DISURFIDE

1. 1-DICHLOROETHENE

1. 1-DICHLOROETHAHE

TRAN S-1,2-DICALOROETHENE

CHZO ROFORM

1. 2-DICBLOROETHLNE

2-BUTA YOUE

1. 1. 1-TKICALOROETHANE

CARBON TETRACGLORIDE

VIRYL ACETITE

BROM UDICALOROEETHAHE

$1,1,2,2-T$ ETR A CBLOBOETHANE

1. 2- DICHLOROP ROP A RE

I? AN S-1,3-DICHLOROPBOPENE

TRIC ULOROETHENE

CALO FOD I BB OM OHETIIHE

1. 1. 2-TEICHLOROETHANE

BEAZ ENS

CIS- 1, 3-DICALOBOP BOPEAE

2-CILOROETBILVIAIL ETHER BRONORO BH

2-HEXANONB

4- HETAYI-2-PENT ANONE

TETR ACH LOROETREYE

TOLU ENE

CH LO ROBENZ EN E

PT HI LBENZENE

ST IR EXE

XILENES

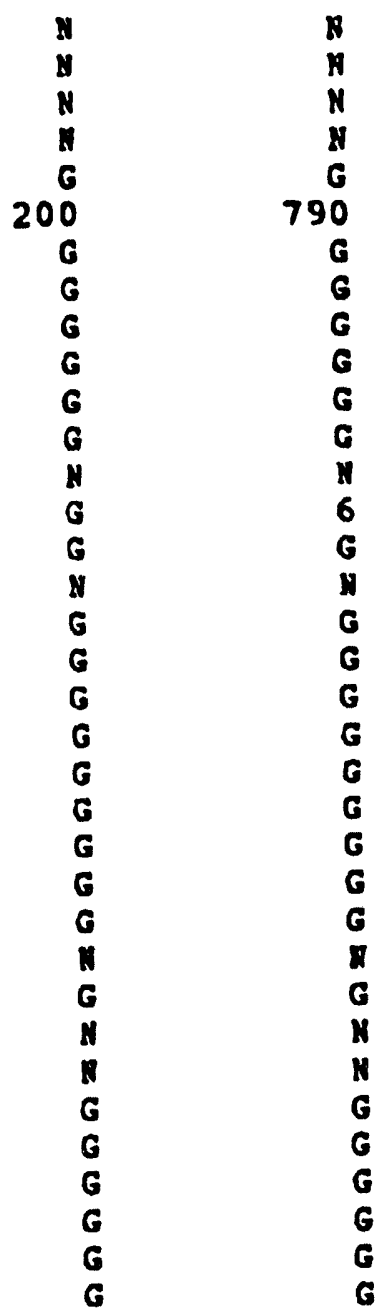

68-177

$10 / 10 / 86$

$13: 30: 00$ 
RESULTS OP 1986 K25 GROUNDHATER SA APIING CAESTNUT RIDGE SECURITY PITS

\section{RERBICIDES AND PESTICIDES UNIT IS UG/L}

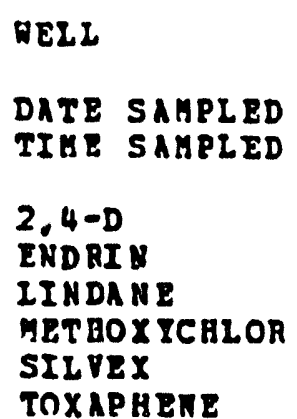

$G H-177$
$02 / 04 / 86$
$14: 45: 00$
$<1$
$<0.05$
$<0.01$
$<0.04$
$<0.1$
$<1$

$$
\text { GH-177 }
$$

GH-177

6D-177

\section{DATE SAMPLED}

$04 / 17 / 86$ 16:10:00

$07 / 29 / 86$ 16:00:00

$10 / 10 / 86$

13:30:00

\section{4-D \\ ENDRI : \\ MET BOX YCALOR \\ TOXAPHETE}

$$
\begin{array}{r}
<2 \\
<0.1 \\
<0.02 \\
<0.08 \\
<0.2
\end{array}
$$$$
0.08
$$$$
<0.2
$$$$
<1<2
$$

$<1$

$<0.05$

$<0.01$

$<0.04$

$<0.1$ 
RESUITS OF 1986 K25 GROUNDFATER SAMPIING CHESTHOT RIDGE SECURITI PITS

ACID E BASE-NETTRAL EXTRACTABLE ORGANIC PRIORITY AND NON-PRIORITY
UNIT IS OG/L POLLOTINTS-I

LELI.

$$
\text { GR-177 }
$$

$60-177$

68-177

$68-177$

DATE SAMPLED

$02 / 04 / 85$

$14: 45: 100$

$04 / 17 / 86$

$07 / 29 / 86$

$10 / 10 / 86$

TIME SAMPIED $16: 10: 00$

$16: 00: 00$

13:30:00

\author{
N-RIT ROSODIMETHYLAMINE \\ PHENOT. \\ A NILINE \\ BIS (2-CHLOROETIYL) 2THER \\ 2-CRLORO PHE ROL \\ 1.3-DICHIOROBENZEME \\ 1,4-DICHLOROBENZENE \\ BEKZYI ALCOHOL \\ 1,2-D ICH LOROBENZEH \\ 2-MEL HYI PHENOL \\ BIS (2-CHIOBOISOPROPIL) ETYEI \\ 4- \\ N-NIT ROSODI-N-PROP ILAIIAE \\ HRXAC HLOROETHANE \\ MITRO BEN ZENE \\ ISOPHORONE \\ 2-NIT ROPHENOL \\ 2,4-D IMETHY LPRENOL \\ BENZOIC ACID \\ BIS (2-CRLOROET YOXY) METHAN \\ 2.4-DICIIIOROP KEROL \\ 1.2.4-TBICHLOBOBEYZENE \\ NAPHTHALENE \\ 4-CHL OROAUILIHE \\ HEX AC HLOROBOTADIEYE \\ 4-CAL ORO-3- MET HI LP RENOL \\ 2-HET UY LNAP HT HALENE \\ HEXAC HLOROCYCIOPEHT ADIEHE \\ $2,4,6$-TB ICH LO BOP HENOL \\ $2,4.5$-TR ICH LO ROP HE NOL \\ 2-CIIL ORONAPHTHALENE \\ 2-NIT ROA NILIME \\ DIFET HYLPPTHALATE \\ ACENA PHTHTLENE
}


BESOLTS OF 1986 K25 GROUNDWATER SAMPLIMG

CHESTNUT RIDGE SRCURITY PITS

ACID E EASE-NEOTRAL EXTRACTADLE

ORGANIC PRIORITY AND NOR-PBIORITY POLLUTAKTS-II UNIT IS OG/I

NELL

611- 177

60-177

$68-177$

68-177

DATL SAHPLED

$02 / 04 / 86$

$04 / 17 / 86$

$07 / 29 / 86$

$16: 00: 00$

$10 / 10 / 86$

TIKE SAMPLED

$14: 45: 00$

16:10:00

$13: 30: 00$

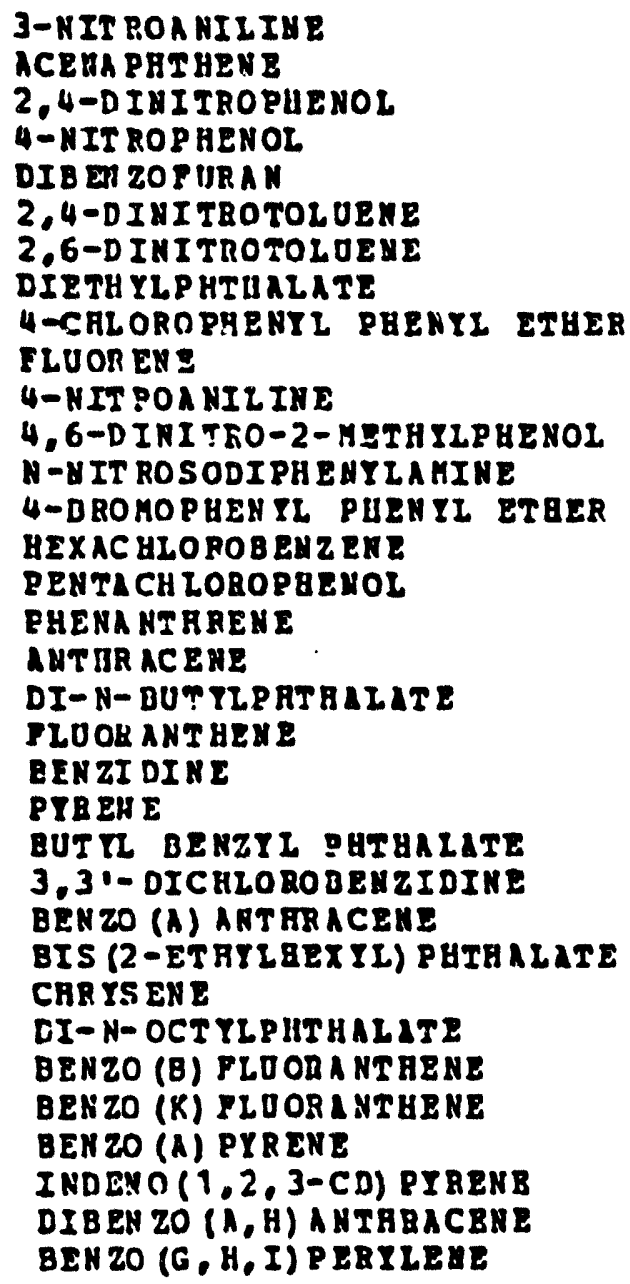




\section{RESUITS OF 1986 K25 GROONDWATER SAGPIING} CAESTNOT RIDGE SECORITY PITS

\section{LAB REPLICATES}

URIT IS OG/L FOR TOY - HO/L FOR TOC

WELL

DATE SAMPLED

TIME SABPLED

COHD OCIIVITI (IE UHHOS/CA)

PR (IM PA ONITS)

IOTAL ORGAHIC CHLORIDI

TOTA I ORGAMIC CARBOR

$$
\text { Gห-177 }
$$

$02 / 04 / 86$ $14: 45: 00$

446

478

474

486

7.5

7.4

7.4

7.4

52

54

57

57

510

480

5.30

510

$$
\text { GR-177 }
$$

$04 / 17 / 86$ $16: 10: 00$

402

425

429

427

7.4

7.5

7.5

7.5

59

59

60

59

6
195
166
248

68-177

$07 / 29 / 86$ $16: 00: 00$

479

478

479

.478

7.8

7.8

7.8

7. 8

47

49

43

47

38

40

41

42
6 11- 177

$10 / 20 / 86$ 13:30:00

420

424

422

423

7.6

7.6

7.6

7.8

68

68

70

68

$<10$

$<10$

16

$<10$ 
RESOLTS OP 1986 K25 GROUNDHATER SA BPLING CHESTNOT EIDGE SECURITY PITS

TOTAL RETALS-RADIOACTIVITY-RADIOM OHIT IS HG/L - UNLESS OTHERIISE STATED

HELI

DATE SAMPLED

TI MR. SAEPLED

MEรBOD

AL IIMI NOH

ANTIMONY

BLRIOW

BERTLIIOA

BO RON

CA DMIOH

CALCIOH

CHROHIU

COBALT

COPPER

IRON

LITKI OH

MA GNESIOH

HA HG $\triangle$ NESE

HOLTBDEROA

MICKEI

NIOBIUn

PU OSP HOROUS

POTASSIOU

SI IICOR

SIIVER

SODIOH

STROATION

THORIUH

IITAMIUA

VA NADINE

ZINC

ZIBCONIOA

METHOD

AR SENIC

LEAD

SFLERIUK

IHALLIUN

MERCOAX

ALPHA ACTIVITY (PCI/L) BETA ACTIVITI (PCI/L)

OR ANIOH

BADIUA (BQ/I)
6H- 179

TOTAL

$02 / 10 / 86$

$13: 25: 00$

ICAP

0.011

0.0013

0.19

$<0.003$

990

0.22

0.013

0.66

38

0.02

490

0.99

$<0.01$

0.15

0.0074

0.75

9.9

$<0.006$

1.3

0.0084

$<0.2$

0.33

0.045

0.72

0.016

AAS

0.013
0.069
$<0.005$
$<0.01$

GH- 179

TOTAL

$04 / 23 / 86$

$13: 20: 00$

ICAP

0.11

$0.0 \dot{2}$

$<0.0003$

0.021

$<0.003$

76

$<0.01$

$<0.005$

0.12

0.52

$<0.004$

37

0.042

$<0.01$

$<0.01$

$<0.007$

$<0.2$

$<0.6$

4.1

$<0.006$

1.3

0.015

$<0.2$

$<0.003$

$<0.005$

0.049

$<0.005$

uns

$$
\begin{array}{r}
<0.005 \\
0.022 \\
<0.005 \\
<0.01
\end{array}
$$
$3.08-04$
6.8
216
0.008
0.15

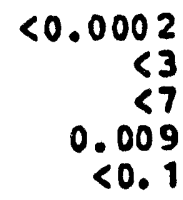

$8 H-179$
TOIAL

68- 179

TOTAL

$08 / 05 / 86 \quad 10 / 20 / 86$

$9: 20: 00 \quad 14: 30: 00$

ICLP

ICNP

$\begin{array}{rr}0.22 & 0.29 \\ <0.05 & <0.05 \\ 0.016 & 0.019\end{array}$

i0.0003

0.034

$<0.003$

110

0.012

$<0.005$

0.077

1.1

$<0.004$

55

0.072

$<0.01$

<0.01

$<0.007$

$<0.2$

1.4

4.7

$<0.006$

1.7

0.029

$<0.2$

0.0049

$<0.005$

0.076

0.008

aLs

$<0.0003$

0.033

60.003

79

$<0.01$

<0.005

0.041

1.1

$<0.004$

44

0.047

0.016

<0.01

$<0.007$

$<0.2$

1.7

4.5

$<0.006$

1.5

0.057

$<0.2$

<0. 003

c0.005

0.015

$<0.005$

MS

$$
\begin{array}{r}
<0.005 \\
0.007 \\
<0.005 \\
<0.01
\end{array}
$$

$<0.005$

0.015

$<0.005$

$<0.01$
$<0.0002$
4
0.002
$<0.1$

<0. 0002 
DISSOIVED METALS-RADIOACTIVITY-BADIOB OHIT IS HG/L - ONLRSS OTBERHISE STATED

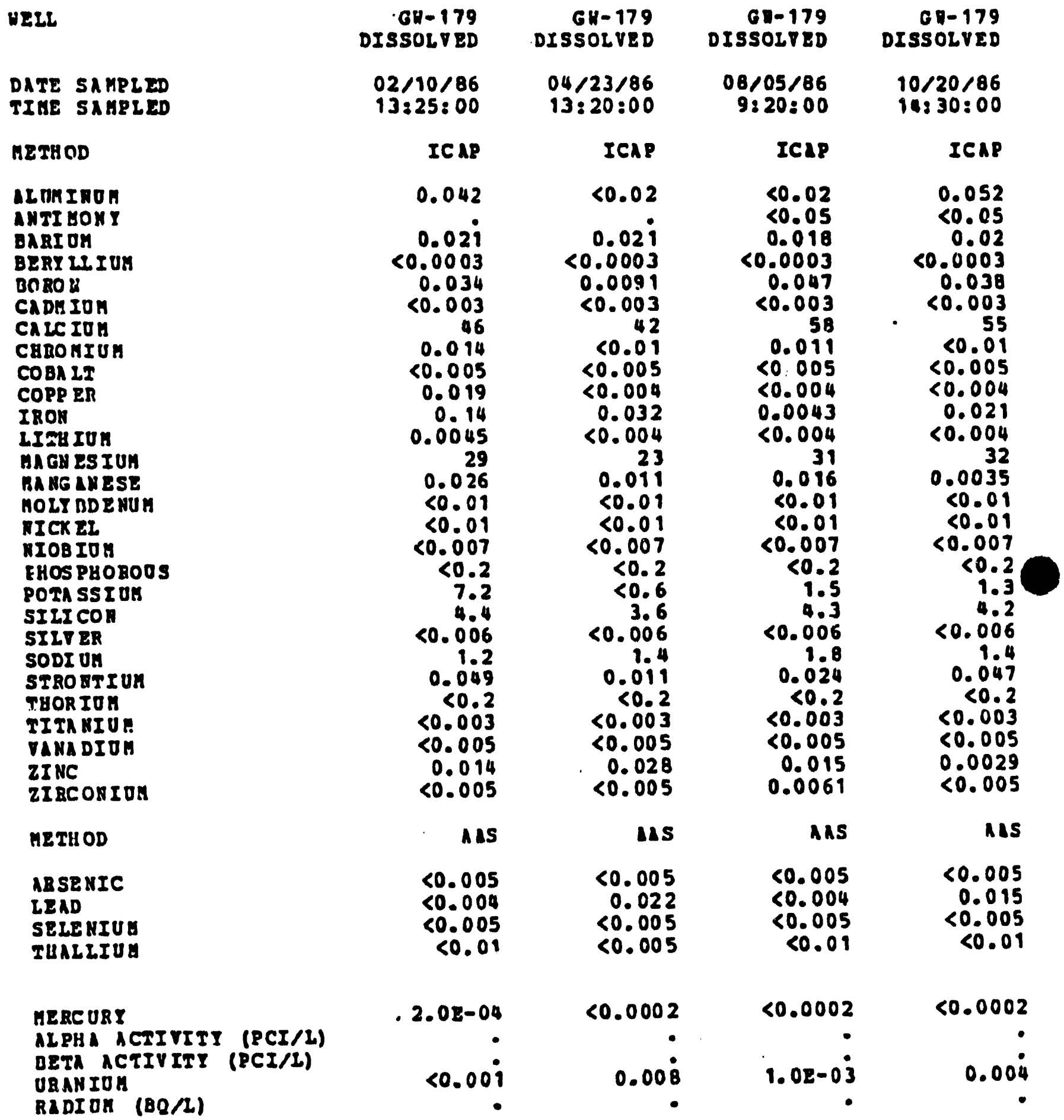




\section{RESOLTS OP 1986 R25 GROUNDWATER SAHPLIXG}

CHESTNUT RIDGE SECURITY PITS

MISCELLANEOHS CONVERTIONAL AND NON-CONVEYTIONGL POLLUTANTS IND RELATED PARAGATER UNIT IS MG/L - UNLESS OTAERUISR STATED

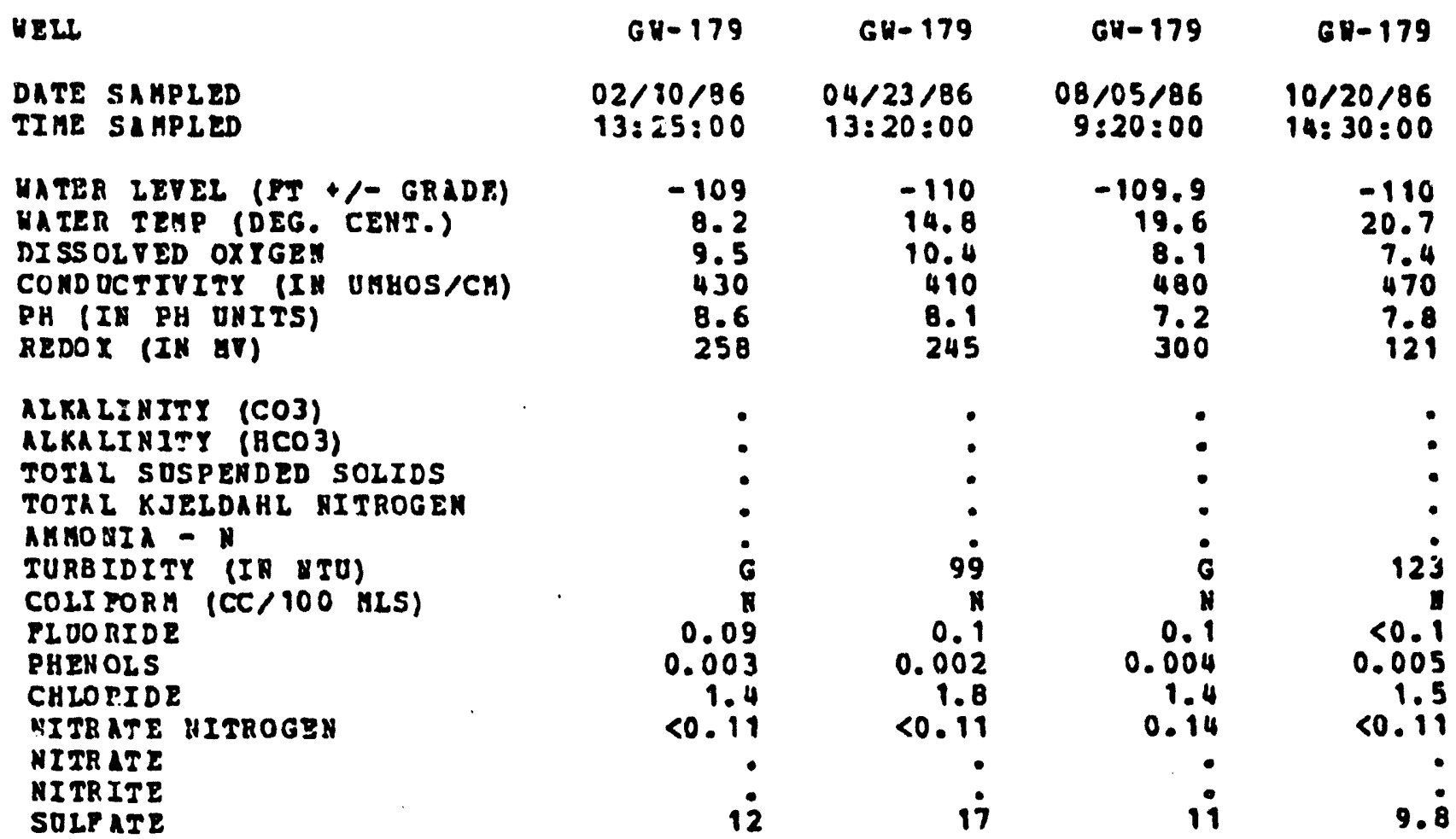


VOLATILE ORGAKIC PRIORITY AND NON-PRIORITY POLLOTARTS

DNIT IS $O G / L$

MELL

DITE SAMPLED

TIME SAMPLED

CHLORONETAAKE

BROM ORETHAHE

VIUYI CHLORIDE

CALOROETHANE

METHYLENE CRLORIDE

ACETONE

CIRBON DISULFIDE

- 1,1-DICULOROETHEN

1, 1-DICHLOROETHANE

TRAR S-1,2-DICULOROETHENE CALOROFOKA

1.2-DICHLOROETAAHE

2-BOTAKONE

-1, 1, 1-TRI CRLoroethane

CARBON TETRACALOBIDE

VINYI ACETATE

BRON OD ICHLOROHETHANE

1 1, 2, 2-TETBACHIOROETALAE

1.2-DICHLOROP BOPAHE

TRAII 5-1,3-DICELCB CPROPEHE

TB IC RLOROETHENE

CHLO RODIBROMORETHARE

1, 1, 2-TRICHLOROETHAHE EENR ENE

CIS-1,3-DICAL OBOP ROPEWB

2-CHLOROETAILVIMYL ETHER

BRONOFORH

2- HEXA ONB

4-METHII-2-PENTANOTE

TETR ACH LOROET HEHE

TOLU ENE

CULOROBENZENE

ET IT LBENZENE

STY ENE

XYLENES

$\begin{array}{rrrr}G H-179 & G N-179 & G H-179 & G N-179 \\ 02 / 10 / 86 & 04 / 23 / 86 & 08 / 05 / 85 & 10 / 20 / 86 \\ 13: 25: 00 & 13: 20: 00 & 9: 20: 00 & 14: 30: 00\end{array}$

$02 / 10 / 86$

13:20:00

9:20:00

$10 / 20 / 86$
$14: 30: 00$

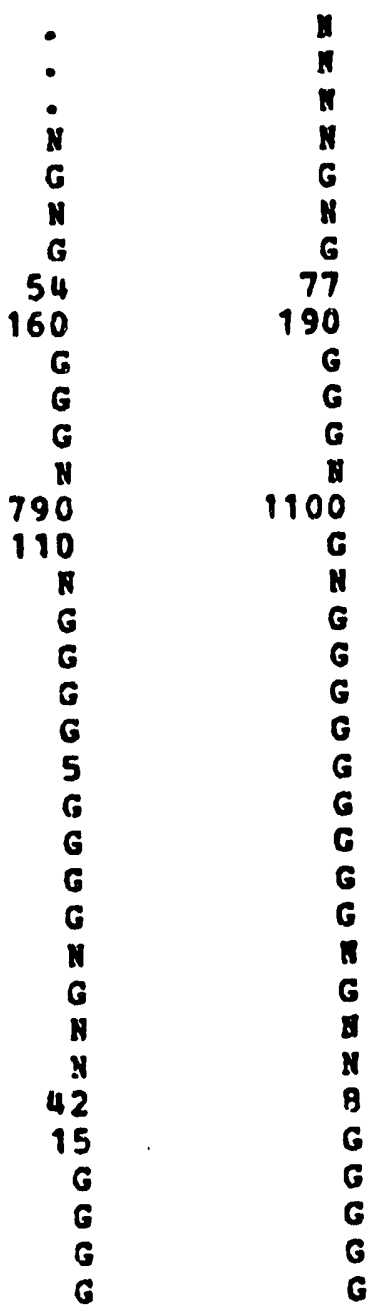


RESOLTS OP $19 B 6$ K25 GROUKDRATER SAMPIING

CHESTNUT P.IDGE SECORITY PITS

RERBICIDES AND PESTICIDES

ONIT IS UG/L

MELL

GW-179

GN-179

GN-179

GR-179

DATE SAHPLED

$02 / 10 / 86$

$04 / 23 / 86$

$08 / 05 / 86$

$9: 20: 00$

$10 / 20 / 86$

TIME SARPLED

$13: 25: 00$

$13: 20: 00$

$<2$

$14: 30: 00$

2. 4-D

EHDRIN

LINDANE

$<1$

$<0.05$

$<0.01$

HET HOX YCHLOR

STIVEX

TOXAPGERE

$<0.04$

$<0.1$

$<1$

$<2$
$<0.1$
$<0.02$
$<0.08$
$<0.2$
$<2$

$<0.1$

$<0.02$

$<0.08$

$<0.2$

$<2$

$$
\begin{array}{r}
<0.05 \\
<0.01 \\
<0.05 \\
<0.1 \\
<1
\end{array}
$$


RESTITS OF 1986 K25 GROONDWATER SAHPLIMG

CHESTRUT RIDGF. SECORITY PITS

ACID E AA SE-NEUTRAL EXIRICTABLE ORGANIC PRIORITY AND MOR-PBIORITI POLLUTARTS-I ONIT IS OG/I

VELL

G)-179

6น-179

GH- 179

$6 D-179$

DATE SAMPLED

$02 / 10 / 96$

TIHE SAMPLED

13:25:00

$04 / 23 / 86$

$13: 20: 00$

$08 / 05 / 86$

$9: 20: 00$

$10 / 20 / 86$

M-YIT ROSODI HETHILA MINL

PHENOL

AIIIINE

BIS (2-CAIOROETHYL) EIRER

2-CHLORO PHEHOL

1.3-D ICH LOROB EMZENE

1,4-D ICIILOROBEAZENE

BENZI L A ICOBOL

1.2-D IC.HLOROBEAZ ENE

2- HET HYLPHENOL

BIS (2-CALOROISORAOPYL) ETHER

4-MET IILPRE HOL

N-NITROSODI - N - PROP YLAAIME

HEXAE ILOBNETHANE

NITRO DEN ZENE

ISOPHORONE

2-NIT IIOP HENOI

2.4-D IEETHIIDEENOL.

BENZOIC ICID

BIS (2-CULOROETHOXI) METHANE

2. 4-D ICH LOROP II EROL

$9,2,4-T R I C B L O R O B E H Z E H E$

FAP НT 月A LEHE

4-CALOROAKILIAE

BEXAC ILO ROB OTA DI ENE

4-CILORO-3-EETRILPAEAOL

2-MEI KTLRAPBT BALZNE HEX AC HLOROC ICIOPENTADIENE

2.4 .6 -TRICBIO ROPBENOL

$2,4,5-T R$ ICH LO BOPHENOL.

2-CUIL ORO NA P HT IIALEKE

2-N IT BOA NILIUB

DIN ET TI I PRTBL L ATE

ACENA PHT HY LEAE

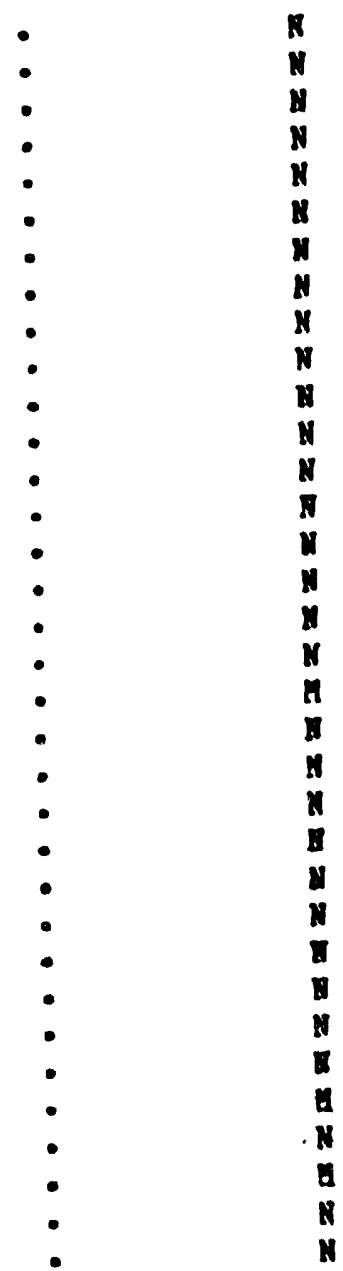

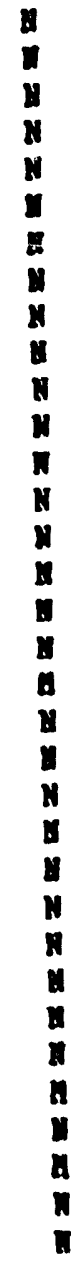


RESULTS OP 1986 K25 GROONDRATER SA MPIING

CHESTNUT RIDGE SECORITY PITS

ACID E BASE-NEUTRAL BXTRACTABLE ORGAHIC PRIORITI A ND NOH-PRIORITI POLLCIATS-II OUIT IS UG/L

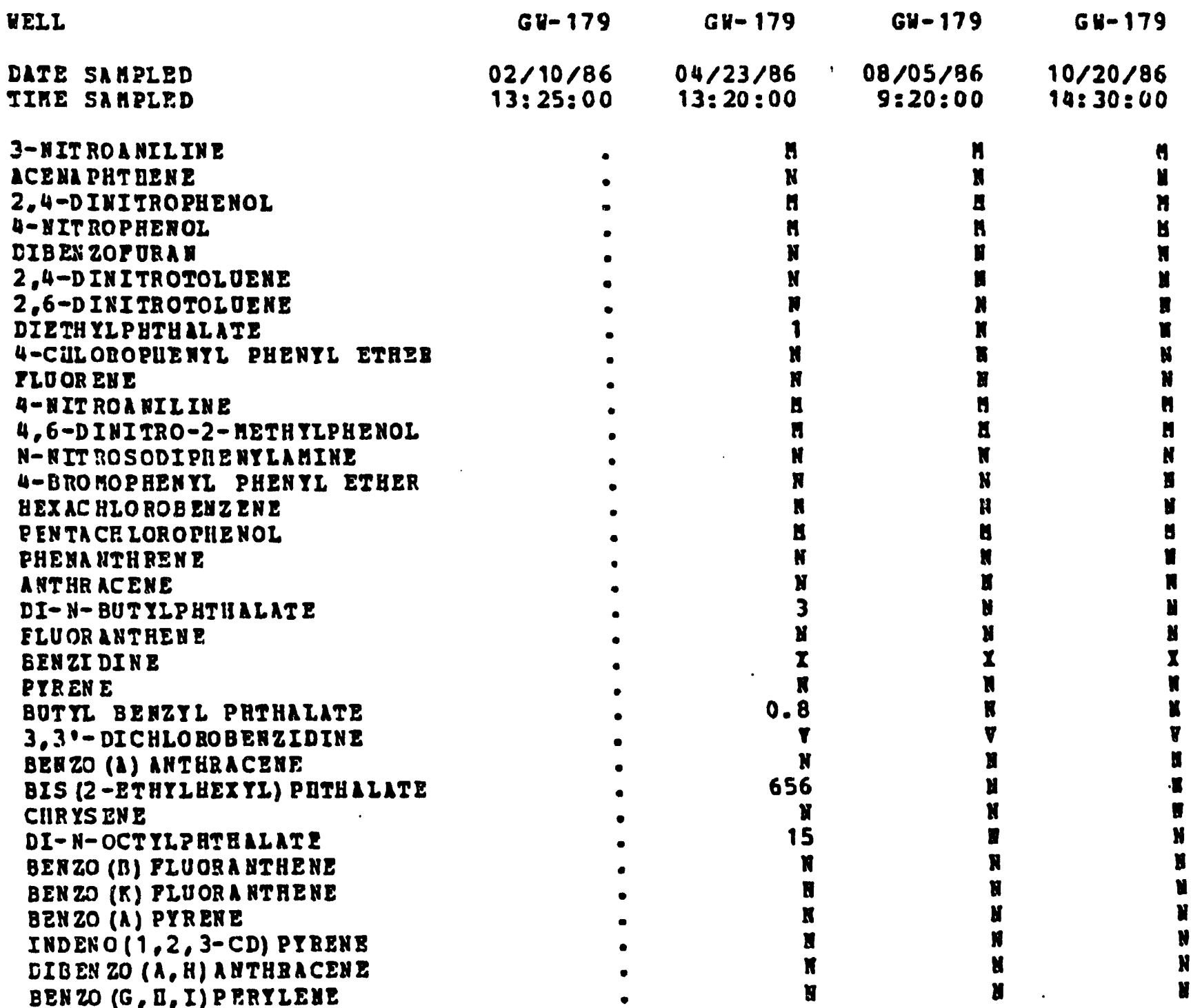


RESULTS OF 1986 R25 GROONDWATER SA UPIIHG

CHESTNUT RIDGE SRCURITY PITS

IAB BEPLICATES

UKIT IS UG/L FOR TOX - MG/L FOR TOC

QELL

DATE SARPLED

TIME SAMPLED

CONDUCEIVITI (IN OHHOS/CE)

PA (IA PB ONITS)

TOTAL ORGAHIC CARBOH

TOTAL ORGAUIC CALORIDE

$$
\text { GD-179 }
$$

$02 / 10 / 86$ $13: 25: 00$

380

393

433

330

7. 7

7.7

7. 8

7. 8

95

120

80

158

131

121

126

129

$$
\text { GW- } 179
$$

$04 / 23 / 86$ $13: 20: 00$

4.76

492

492

491

8
8
8
7.9

79

74

72

73

70

69

69

69
GH- 179

$08 / 05 / 86$ 9:20:00

452

463

464

460

7.9

7.9

7.9

7.8

85

86

89

87

160

170

180

180
6N-179

$10 / 20 / 86$

14:30:00

492

427

491

492

7. 9

7.9

8.1

73

72 100 99

$<10$ $<10$ $<10$ 15 
TOTAL METALS-BADIOLCTIVITI-RADIUH

OAIT IS HG/L - ONLESS OTHERHISE STATED

\begin{tabular}{|c|c|c|c|c|}
\hline QELL & $\begin{array}{r}1080 \\
\text { TOTAL }\end{array}$ & $\begin{array}{r}1080 \\
\text { TOTAL }\end{array}$ & $\begin{array}{r}1080 \\
\text { TOTAL }\end{array}$ & $\begin{array}{r}1080 \\
\text { T0T2L }\end{array}$ \\
\hline $\begin{array}{ll}\text { DATE } & \text { SAMPLED } \\
\text { TI AE SAMPLED }\end{array}$ & $\begin{array}{r}02 / 19 / 86 \\
9: 45: 00\end{array}$ & $\begin{array}{l}04 / 15 / 86 \\
16: 00: 00\end{array}$ & $\begin{array}{l}07 / 29 / 86 \\
11: 05: 00\end{array}$ & $10 / 14 / 86$ \\
\hline METEOD & ICAP & ICAP & ICLP & ICAP \\
\hline 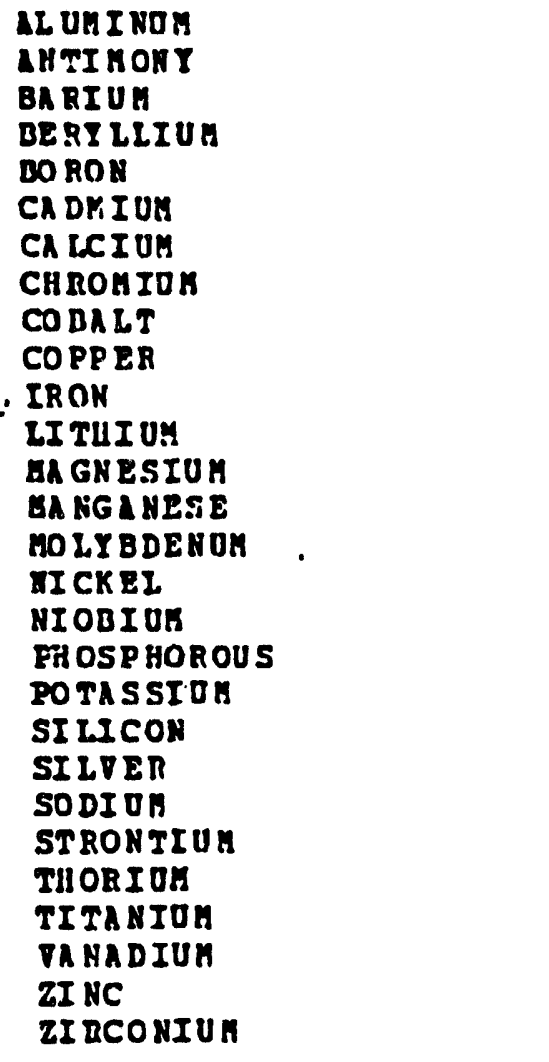 & $\begin{array}{r}4.1 \\
0.013 \\
<0.0003 \\
0.95 \\
<0.003 \\
45 \\
<0.01 \\
<0.005 \\
<0.004 \\
6.77 \\
0.032 \\
28 \\
0.32 \\
<0.01 \\
<0.01 \\
<0.007 \\
<0.2 \\
1.5 \\
9.4 \\
<0.006 \\
2.1 \\
<0.0004 \\
<0.2 \\
0.065 \\
0.0069 \\
0.086 \\
<0.005\end{array}$ & $\begin{array}{r}<0.02 \\
0.0018 \\
<0.0003 \\
0.23 \\
<0.003 \\
38 \\
<0.01 \\
<0.005 \\
<0.004 \\
0.055 \\
<0.004 \\
23 \\
0.0037 \\
<0.01 \\
<0.01 \\
<0.007 \\
<0.2 \\
<0.6 \\
3.6 \\
<0.006 \\
0.91 \\
<0.0004 \\
<0.2 \\
<0.003 \\
<0.005 \\
<0.001 \\
<0.005\end{array}$ & $\begin{array}{r}0.044 \\
<0.05 \\
0.0031 \\
<0.0003 \\
0.14 \\
<0.003 \\
33 \\
<0.01 \\
<0.005 \\
0.022 \\
0.023 \\
<0.004 \\
201 \\
<0.001 \\
<0.01 \\
<0.01 \\
<0.007 \\
<0.22 \\
0.72 \\
3.7 \\
<0.006 \\
0.82 \\
<0.0004 \\
<0.2 \\
<0.003 \\
<0.005 \\
<0.001 \\
<0.005\end{array}$ & $\begin{array}{r}3.8 \\
<0.05 \\
0.017 \\
0.0012 \\
0.16 \\
<0.003 \\
42 \\
0.019 \\
<0.005 \\
0.0065 \\
7 \\
0.0041 \\
25 \\
0.32 \\
<0.01 \\
0.024 \\
<0.007 \\
<0.22 \\
1.9 \\
9.1 \\
<0.006 \\
0.87 \\
0.015 \\
<0.2 \\
0.06 \\
0.014 \\
0.076 \\
<0.005\end{array}$ \\
\hline RETBDD & ALS & MS & as & Als \\
\hline $\begin{array}{l}\text { AR SENIC } \\
\text { IEAD } \\
\text { SEIENIUA } \\
\text { INALIIUA }\end{array}$ & $\begin{array}{r}0.012 \\
0.019 \\
<0.005 \\
<0.01\end{array}$ & $\begin{array}{r}<0.005 \\
0.005 \\
<0.005 \\
<0.01\end{array}$ & $\begin{array}{l}<0.005 \\
<0.004 \\
<0.005 \\
<0.01\end{array}$ & $\begin{array}{r}0.013 \\
0.019 \\
<0.005 \\
<0.01\end{array}$ \\
\hline $\begin{array}{l}\text { GERCURY } \\
\text { ALPHA ACTIVITI (PCI/L) } \\
\text { BETA ACTIVITI (PCI/L) } \\
\text { URANIUH } \\
\text { RADIOH }(B Q / I)\end{array}$ & $\begin{array}{r}<0.0002 \\
15 \\
21 \\
<0.001 \\
<0.1\end{array}$ & $\begin{array}{r}<0.0002 \\
3.55 \\
7.34 \\
0.002 \\
0.09\end{array}$ & $\begin{array}{r}<0.0002 \\
1 \\
<2 \\
0.004 \\
<0.1\end{array}$ & $\begin{array}{r}<0.0002 \\
<3 \\
9 \\
<0.001 \\
<0.1\end{array}$ \\
\hline
\end{tabular}




\section{RESOLTS OF 1986 K25 GROUNDHATER SAMPIING CIESTNUT RIDGE SECORITI PITS}

\section{DISSOLVED YETALS-RIDIOLCTIVITY-RADIOA}

UNIT IS MG/L - UNLESS OTAEBUISE STATED

HELน

DATE SAMPLED

TIEE SARPLED

METH ON

\begin{tabular}{|c|c|}
\hline 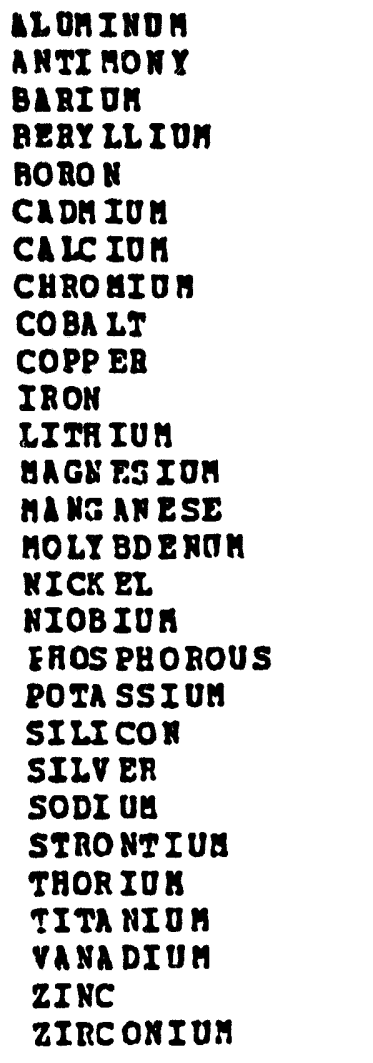 & \\
\hline METE OD & \\
\hline $\begin{array}{l}\text { ARSENIC } \\
\text { LEAD } \\
\text { SELENIOH } \\
\text { THALLIUE }\end{array}$ & \\
\hline $\begin{array}{l}\text { ARBCOBY } \\
\text { ALPIIA ICIIVITY } \\
\text { BETA ACTIVITY } \\
\text { URAKIOU } \\
\text { RADIUE (BQ/L) }\end{array}$ & $\begin{array}{l}\text { (PCI/I) } \\
\text { PCI/L) }\end{array}$ \\
\hline
\end{tabular}

$\begin{array}{rrr}1080 & 1080 & 1080 \\ \text { DISSOLVED } & \text { DISSOIVED } & \text { DISSOIVED }\end{array}$

\section{$02 / 19 / 86$} $9: 45: 00$

$\operatorname{rene}$

<0. 02

0.0037

$<0.0003$

0.77

$<0.003$

39

$<0.01$

$<0.005$

$<0.004$

0.012

0.028

23

$<0.001$

$<0.01$

$<0.01$

$<0.007$

$<0.2$

$<0.5$

3.8

$<0.006$

$<0.0004$

$<0.2$

$<0.003$

$<0.005$

0.0042

$<0.005$

as

$$
\begin{array}{r}
<0.005 \\
0.008 \\
<0.005 \\
<0.01
\end{array}
$$

$<0.0002$

1.02-03
$04 / 15 / 86$

16:00:00

ICAP

$<0.02$

0.0013

$<0.0003$

0.21

$<0.003$

37

$<0.01$

$<0.005$

$<0.004$

$<0.004$

$<0.004$

22

$<0.001$

$<0.01$

$<0.01$

$<0.007$

<0. 2

$<0.6$

3.9

$<0.006$

0.8

$<0.0004$

$<0.2$

$<0.003$

$<0.005$

$<0.001$

$<0.005$

145

$$
\begin{array}{r}
<0.005 \\
0.005 \\
<0.005 \\
<0.01
\end{array}
$$

$<0.0002$

0.012
$07 / 29 / 86$

11:05:00

ICAP

0.03

$<0.05$

0.0036

$<0.0003$

0.14

$<0.003$

33

$<0.01$

$<0.005$

0.11

0.071

$<0.004$

0.0037

$<0.01$

0.019

0.012

$<0.2$

$<0.6$

3.9

$<0.006$

$<0.0004$

$<0.2$

$<0.003$

$<0.005$

$<0.001$

$<0.005$

ALS

$<0.005$

0.004

$<0.005$

$<0.01$

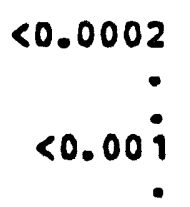

1080

DISSOL TED

$10 / 14 / 86$

ICAP

0.064

0.055

0.0035

$<0.0003$

0.14

$<0.003$

36

0.01

$<0.005$

$<0.004$

0.017

$<0.004$

21

$<0.001$

$<0.01$

$<0.01$

$<0.007$

$<0.2$

$<0.6$

4.1

$<0.006$

0.91

0.014

$<0.2$

$<0.003$

$<0.005$

0.007

$<0.005$

Ans

$<0.005$

$<0.004$

$<0.005$

$<0.01$

$<0.0002$

$<0.001^{\circ}$ 
RESULTS OF 1996 R25 GROUYDHATER SA APLING

CHESTNUT RIDGE SECORITY PITS

MISCELLANEOHS CONPENTIOHAL AND NOH-CONVENTIONAL POLLUTAUTS AKD RILATED PARAMETEE ONIT IS RG/L - ONLESS OTHERISE STATID

HELL

DATE SA MPLED
TIEE SA GPLED

HATER LEVEL (PT +/- GRADE)

HATER TEHP (DEG. CERT.) DISSOLVED OXYGEY

CONDUCTIYITY (IN OHHOS/CM)

PH (IN PH UNITS)

FEDOX (IN GV)

ALKALIAITY (CO3)

ALRALIRITI (HCO3)

TOTAL SDSPENDED SOLIDS

TOTAL KJELDARL NITROGEN

AHEOUIA - N

TORBIDIII (IN NTO)

COLIPORA (CC/100 ULS)

PLUNRIDE

PEENOLS

CHLORIDE.

NITR ATE NITROGEn

RITR ATE

NITRITE

SUREATE
1090

1080

1080

1080

$02 / 19 / 86$
$9: 45: 00$
-113.5
14
6.2
320
6

$04 / 15 / 86$

16:00:00

$07 / 29 / 86$

11:05:00

$10 / 14 / 86$

$-117.5$

16.4

12

330

7.5

179.8

$-127.8$

22

8.2

320

7.9

176

$-131.7$

16.7

7.1

310

8.4

315

$\begin{array}{rr}i & i \\ 135 & i \\ 0.08 & <i \\ 00.001 & <0.001 \\ 2.4 & 1.8 \\ 0.47 & 0.32 \\ 2.2 & <i\end{array}$

$:$
1.
1.
0.1
006
1.6
.29
$\bullet$
$<1$
:

$<0.1$

$<0.001$

1.6

0.2

<i 
RESOLTS OF 1986 K25 GROUNDWATER SAMPLING

CQESTHOT RIDGE SECURITI PITS

VOLATILE ORGANIC PRIORITY ARD NON-PRIORITI POLLUTABTS

UNIT IS $0 G / L$

NELL

1080

1080

1080

1080

DATE SAMPLED

TIME SAMPLED

$02 / 19 / 86$
9845800

CH LO RONTTA ANE

BROMONETHAME

VIMIL CALORIDE

CHLO ROETIIA HE

METHYLENE CRLORIDE

AC ETON

CARBON DISULFIDE

- 1.1-DICALOROETAEHE

- 1,1-DICHLORORTEANE

TRAN 5-1,2-DICHZOROETnENE

CHLO RO YORH

1.2-DICHLOROETHAHE

2-BO TANON:

- 1, 1, 1-тrichlodoethane

CARBOA TETRACHIORIDE

VINI L ACETATE

9HOH ON ICILOROMETHAKE

1, 1, 2, 2-TETEACELOBOETAAHE

1. 2- DICHLOROR ROPARE

JRAMS-1,3-DICHLOROPBOPEAE

TIIC RLOROETHTHE

CELO RODIBR ONOSETEAME

1. 1, 2-TKICALOROETHANE

BENZ ENE

CIS-1, 3-DICAL OROP ROPEHE

2-CH LOBOETAYLVIXYL ETAEB

BROMOPORE

2-HEXANORE

4- HETAYL-2-PE ATANONE

TETR ACA LOR OET HENE

TOLU ENE

CIILO BOBFNZERE

ETAY LBERZENE

STYR FNE

XYLENES
$04 / 15 / 86$

16:00:00

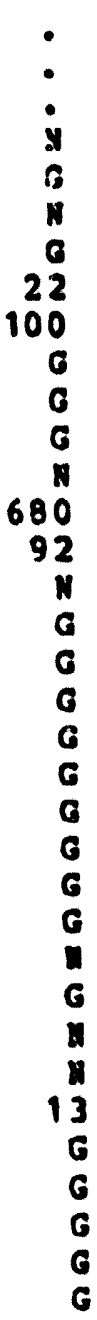

$07 / 29 / 86$

11:05:00

$10 / 19 / 86$

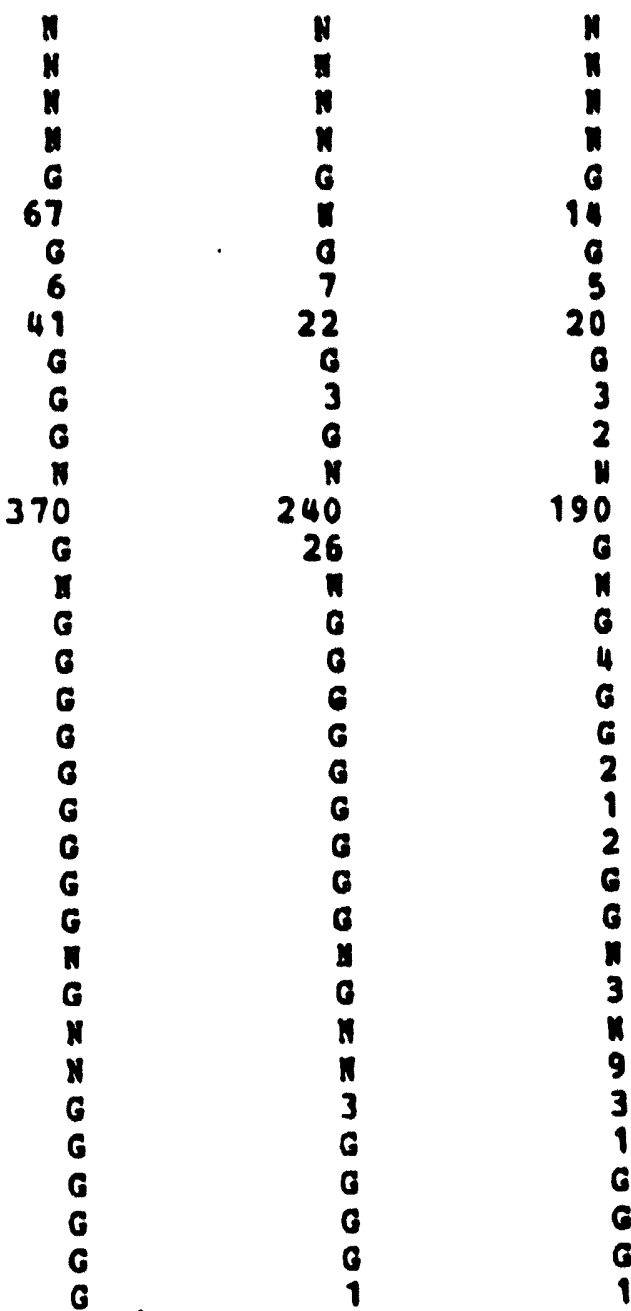


RESOLTS OP 19A6 K25 GROONDUATER SAMPLING

CHESTHOT RIDGE SECURITY PITS

HERBICIDES AND PESTICIDES

ONIT IS UG/L

WELL

1080

1080

1080

1080

DATE SAMPLED
TIME SAMPLED

$02 / 19 / 86$

$04 / 15 / 86$

$07 / 29 / 86$

$9845: 00$

16:00:00

11:05:00

$10 / 14 / 86$

2. 4-D

ENDQI:

IINDANE

GET HOY ICHLOR

SILVEX

TOX

$<1$
$<0.05$
$<0.01$
$<0.04$
$<0.1$
$<1$

$<2$
$<0.1$
$<0.02$
$<0.08$
$<0.2$
$<2$

$<0.1$

$<0.02$

$<0.08$

$<0.2$

$<2$

$<1$

$<0.05$

$<0.01$

$<0.04$

$<0.1$

$<1$ 
RESOITS OI 1986 K25 GROUNDAATER SAMPLINO

CH8STNUT RIDGE SECORITY PITS

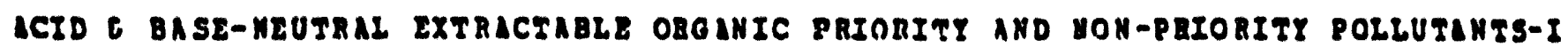
ONIT IS UG/L

N2L

DATE SANPLED

IIAL SANPLED

N-NII ROSODIMETAYLA HINE

PAEMOL

AXILINE

AIS (2 -CKLOR OETETL) ETHER

2-CHLOBOPHENOL.

1.3-D ICB LOROB EAZENE

1. 4-D ICH LOROB BNZENE

BEN2IL A LCOHOL

1.2-DICHLOROBENE2N8

2-HET คI L PHEHOL.

BIS (2-CnLOROISOPBOPYL) ETH2B

4- 1 EI HIZ PHEHOL

N- YIT NOSNOI-N-PROP ILAMIUE

HEX CC RLO ROTREANL

HITRO BEA R.ENE

ISOPHORONR

2- KIT ROPHEMOL

2.4-D InETUTLPBZROL

BBUzOIC ACID

BIS (2-CALOROETHOXI) METHANZ

2.4-0ICHLOROP IIENOL

$1.2,4-$ TB TCHLOROBEA ZETE

MAR GT BALERE

4-CHLOROARILINE

HEX AC ALO ROBOTA DIEN

4-CHL ORO-3-MET IIIP BEHOL

2-MET GTLRAPHT FALEN

HEXAC HLOBOCYCLOPBNTIOIENE

$2.4 .6-T R I C B L O R O P H E$ HOL

2.4 .5 -TR ICALOROPHEUOL

2-CHL ORONAP GTHALERE

2-NIT 801 AILINE

DIE EI HYL PATEA LATE

ACENA PETHTLENE
1080

1080

1090

1080

$02 / 19 / 86$

9:45:00

$04 / 15 / 86$

16:00:00

$07 / 29 / 86$

11:05:00

$10 / 14 / 86$

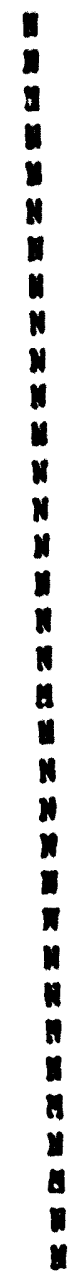

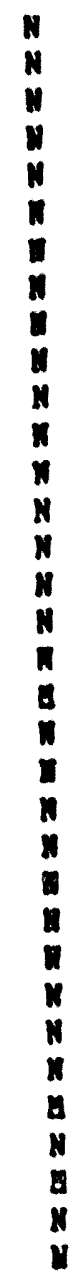

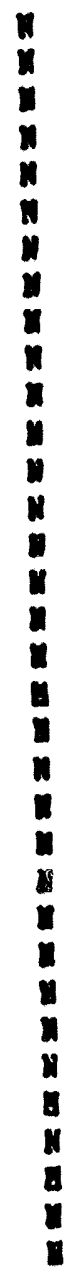

nב


RESOLTS OF 1986 K25 GROUHDHATER SAMPLIMG

CHESTHUT RIDGE SECORITY PITS

LAB REPLICATES

OUIT IS UB/L PCR TOX - HG/L POR TOC

MELL

DATE SAMPLED

IIUE SAMPLED

CONDUCTIVITY (IN ONUOS/CM)

PI (IN PR ONITS)

TOTAL ORGAHIC CABBON

TOTAL ORGANIC CALORIDE

$\begin{array}{rrrr}1080 & 1080 & 1080 & 1080 \\ 02 / 19 / 86 & 04 / 15 / 86 & 07 / 29 / 86 & 10 / 14 / 86 \\ 9: 45: 00 & 16: 00: 00 & 11: 05: 00 & \cdot \\ 396 & 330 & 349 & 339 \\ 398 & 327 & 346 & 340 \\ 397 & 325 & 346 & 339 \\ 399 & 326 & 349 & 340 \\ 7.1 & 7.9 & 7.5 & 7.8 \\ 7.2 & 7.6 & 7.5 & 7.7 \\ 7.3 & 7.8 & 7.5 & 7.7 \\ 7.9 & 7.9 & 7.5 & 7.7 \\ 78 & 42 & 40 & 60 \\ 70 & 45 & 36 & 62 \\ 72 & 53 & 40 & 59 \\ 71 & 32 & 39 & 59 \\ 490 & 441 & 480 & <10 \\ 460 & 183 & 410 & 310 \\ 520 & 329 & 380 & <10 \\ 530 & 460 & 410 & <10\end{array}$




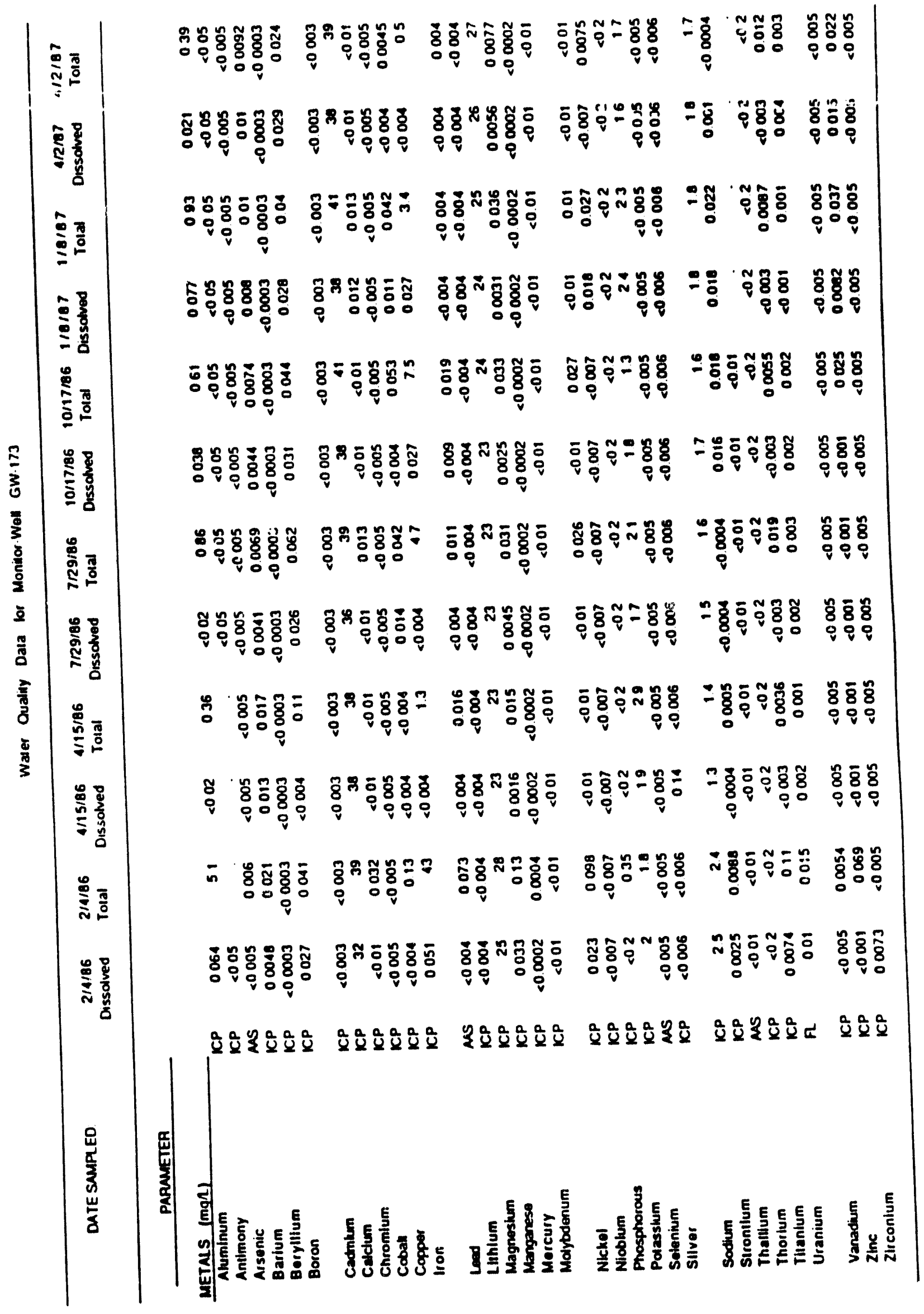




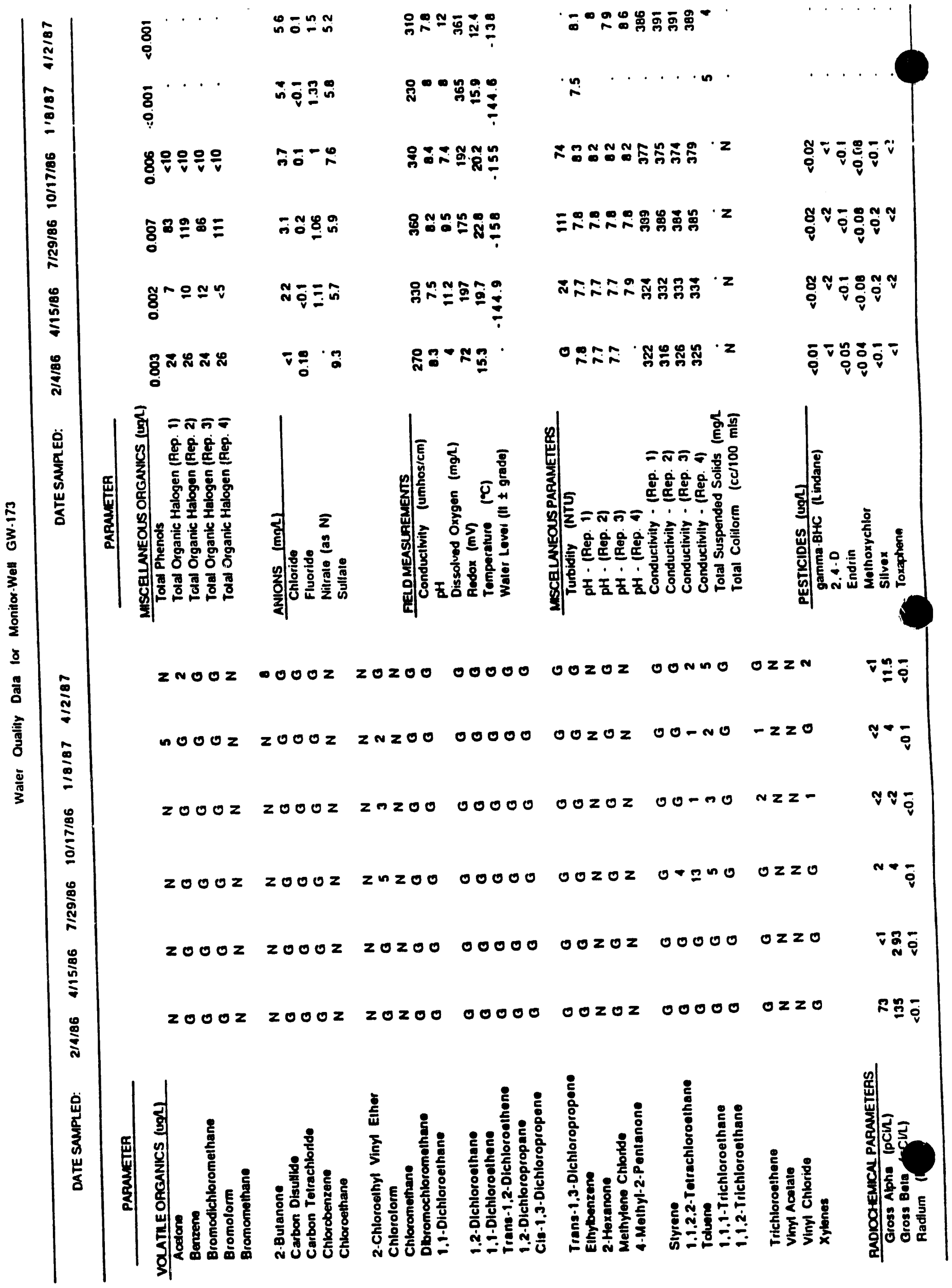




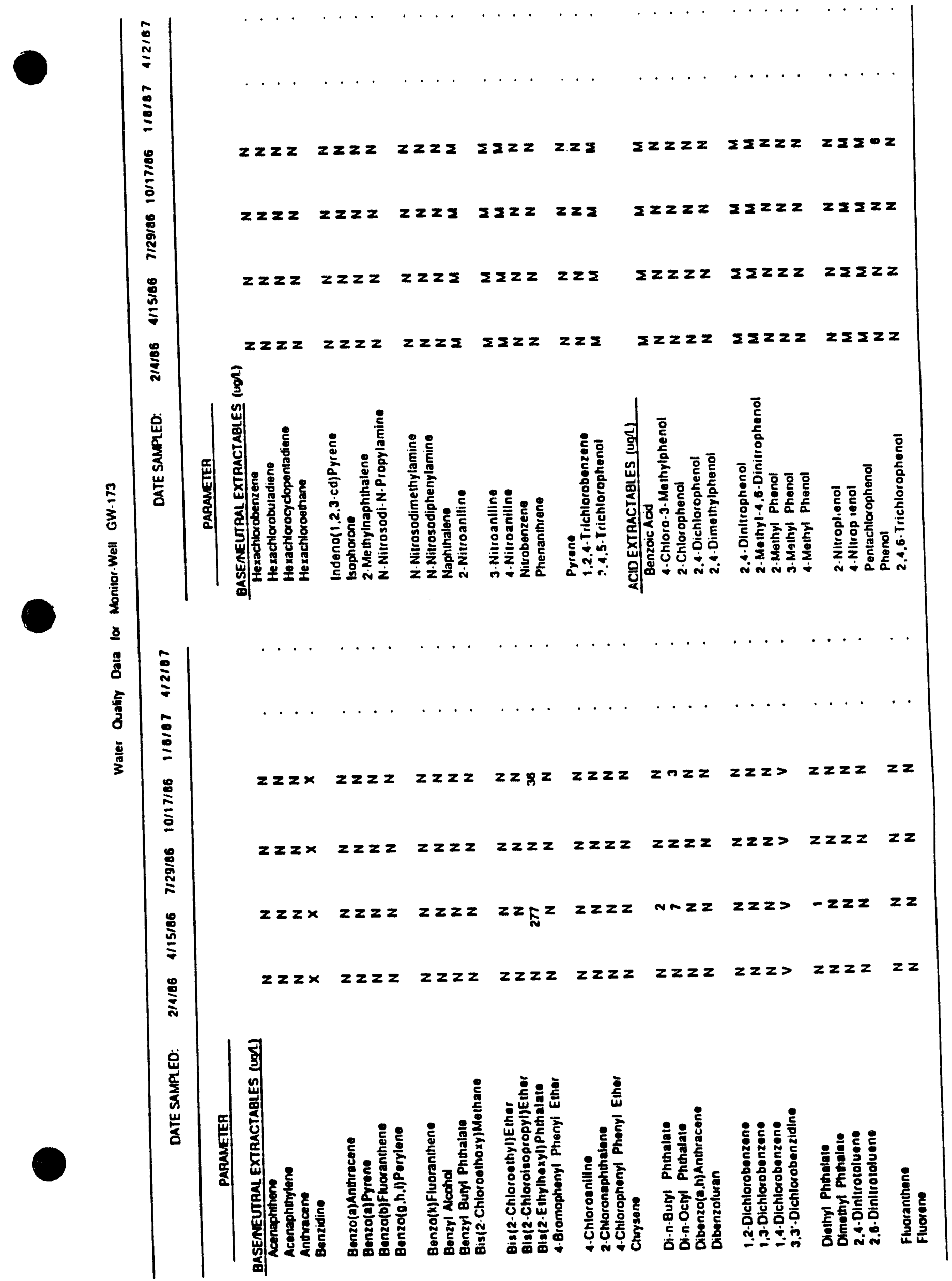




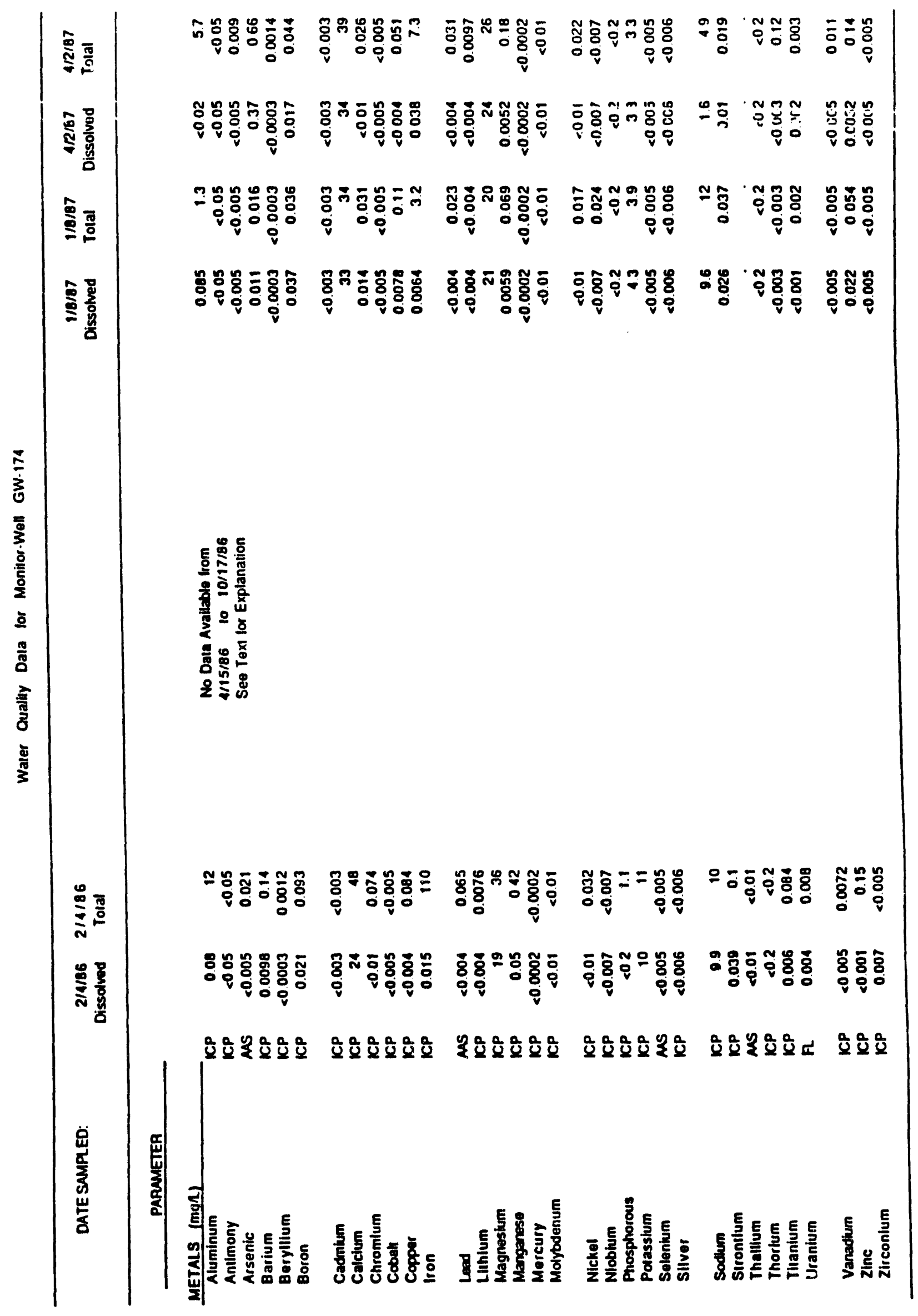




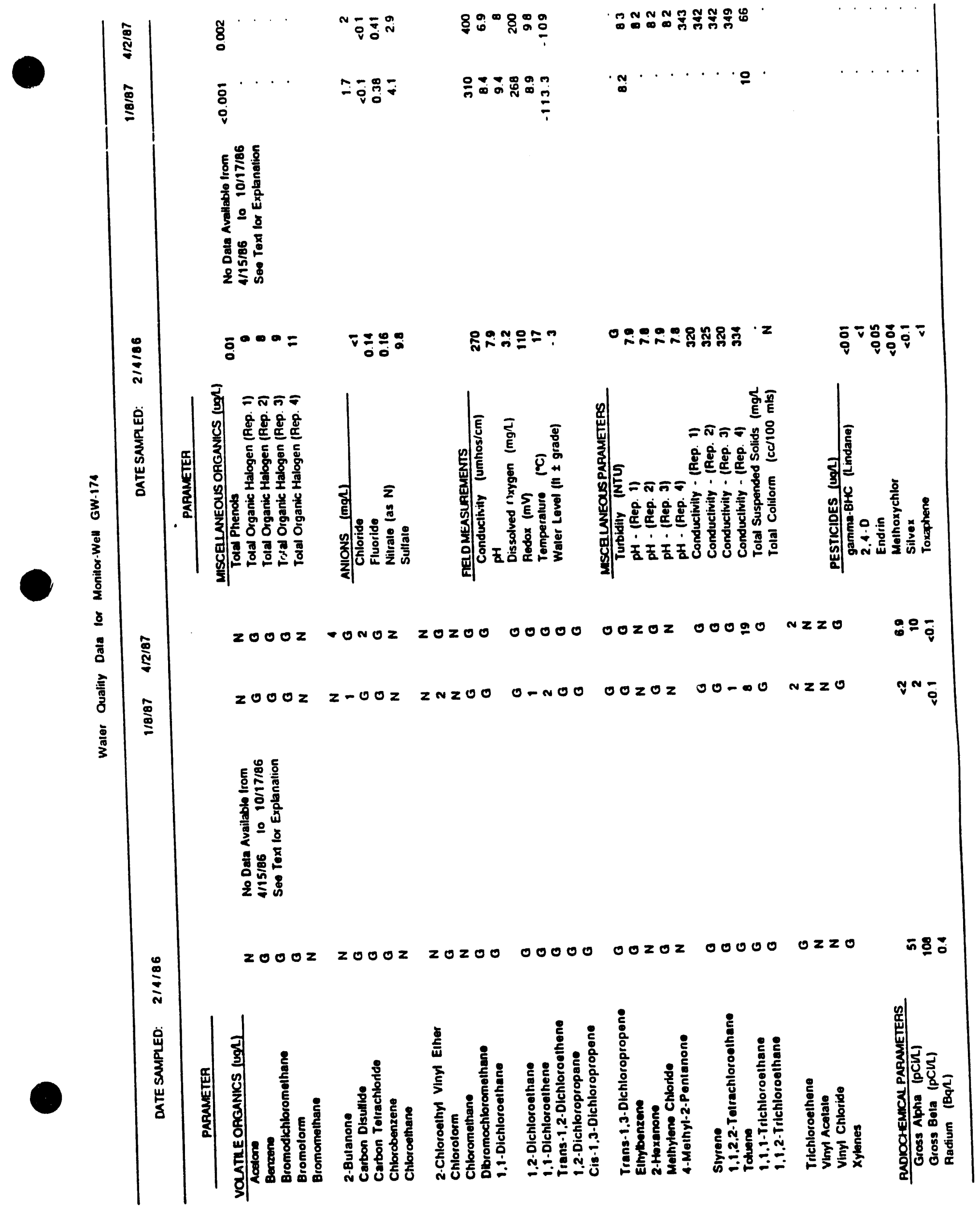




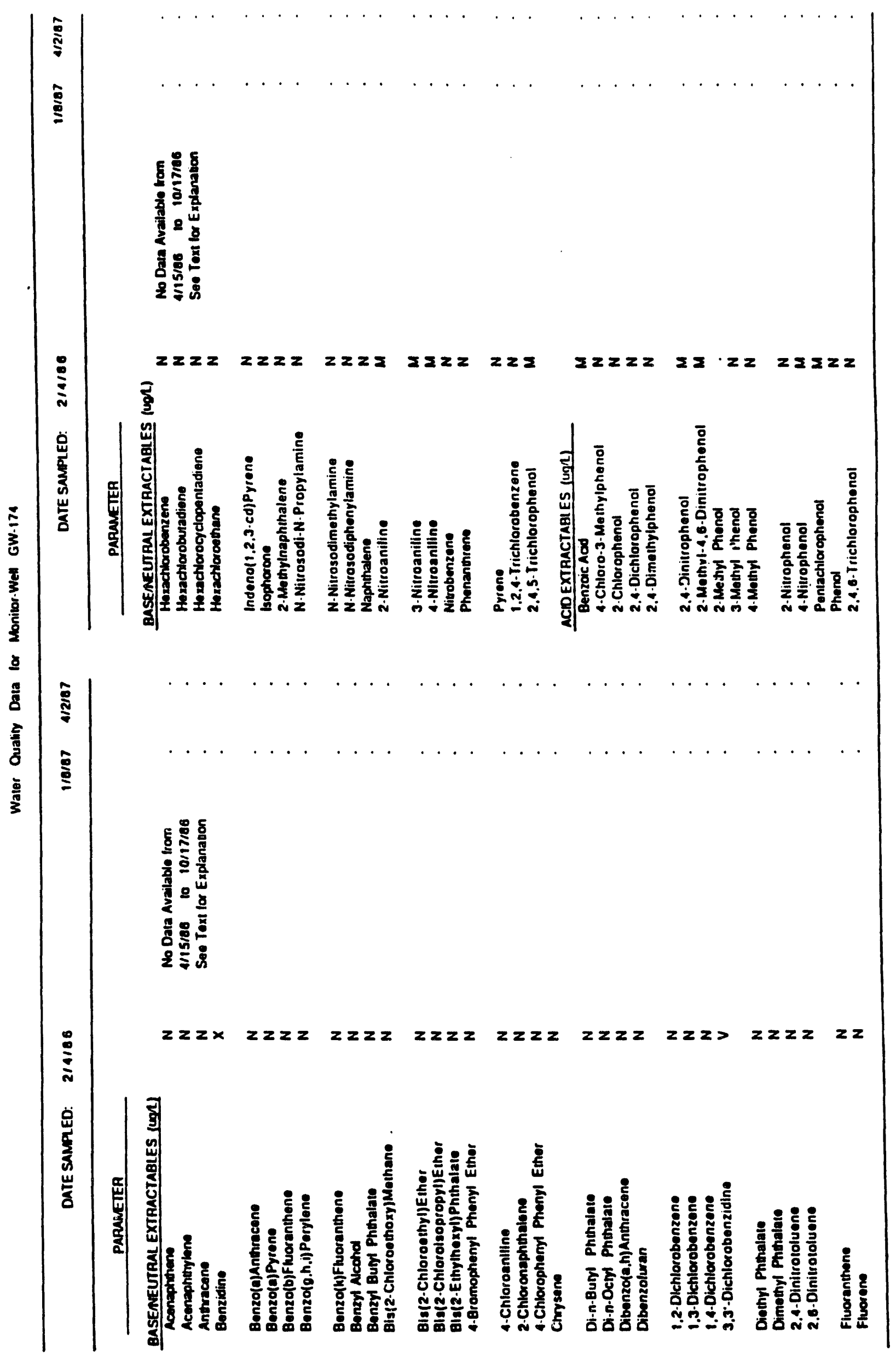




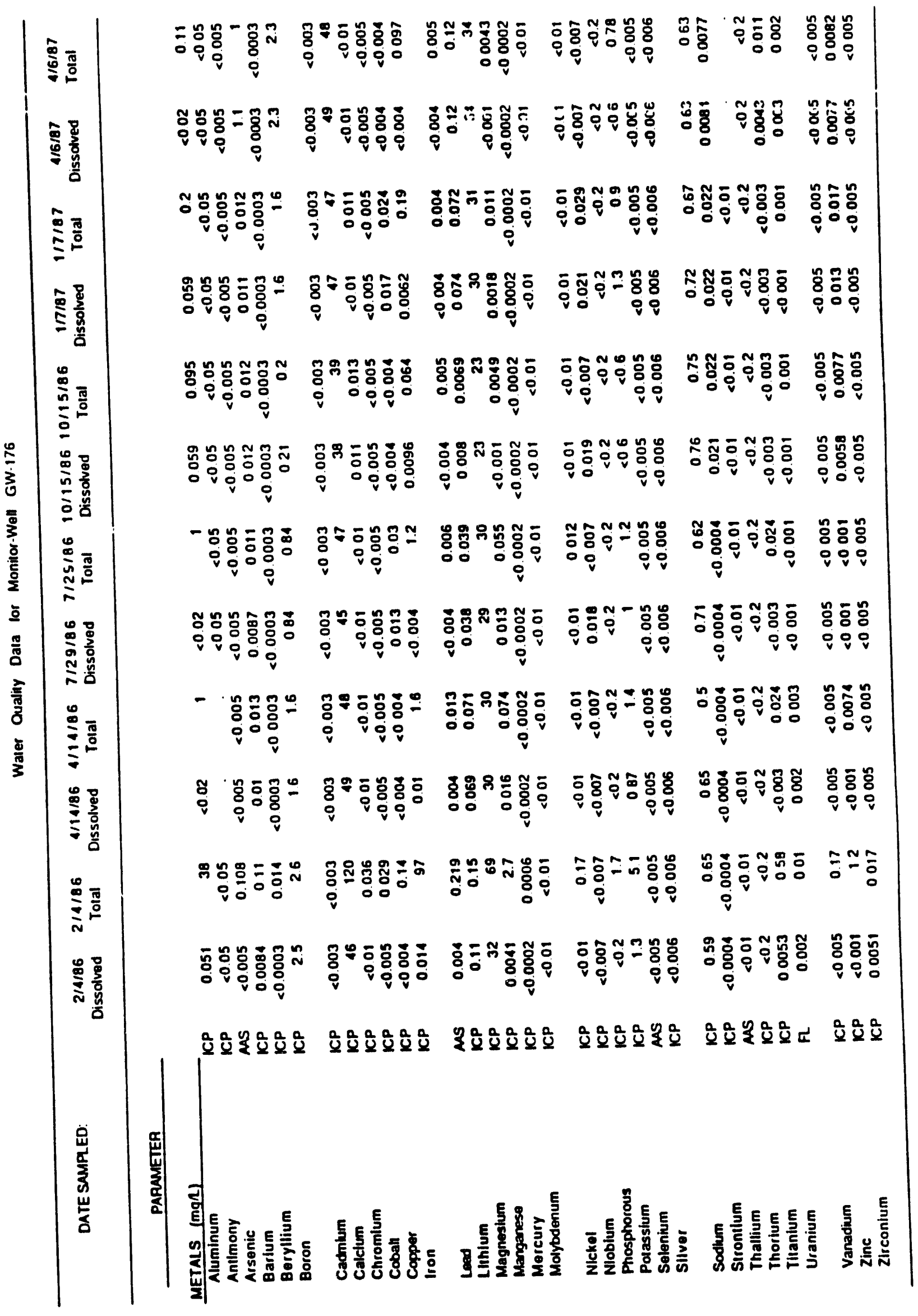




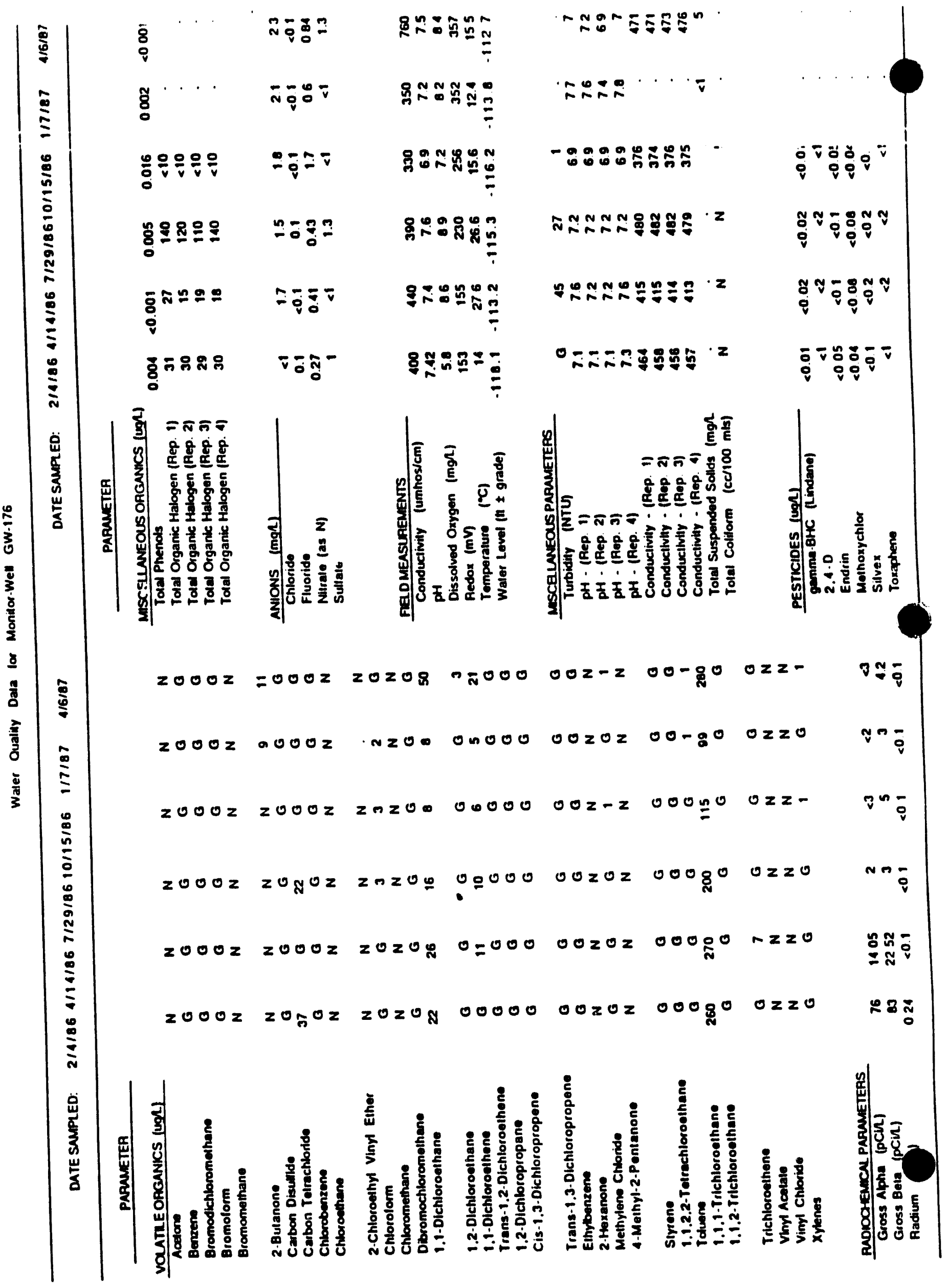




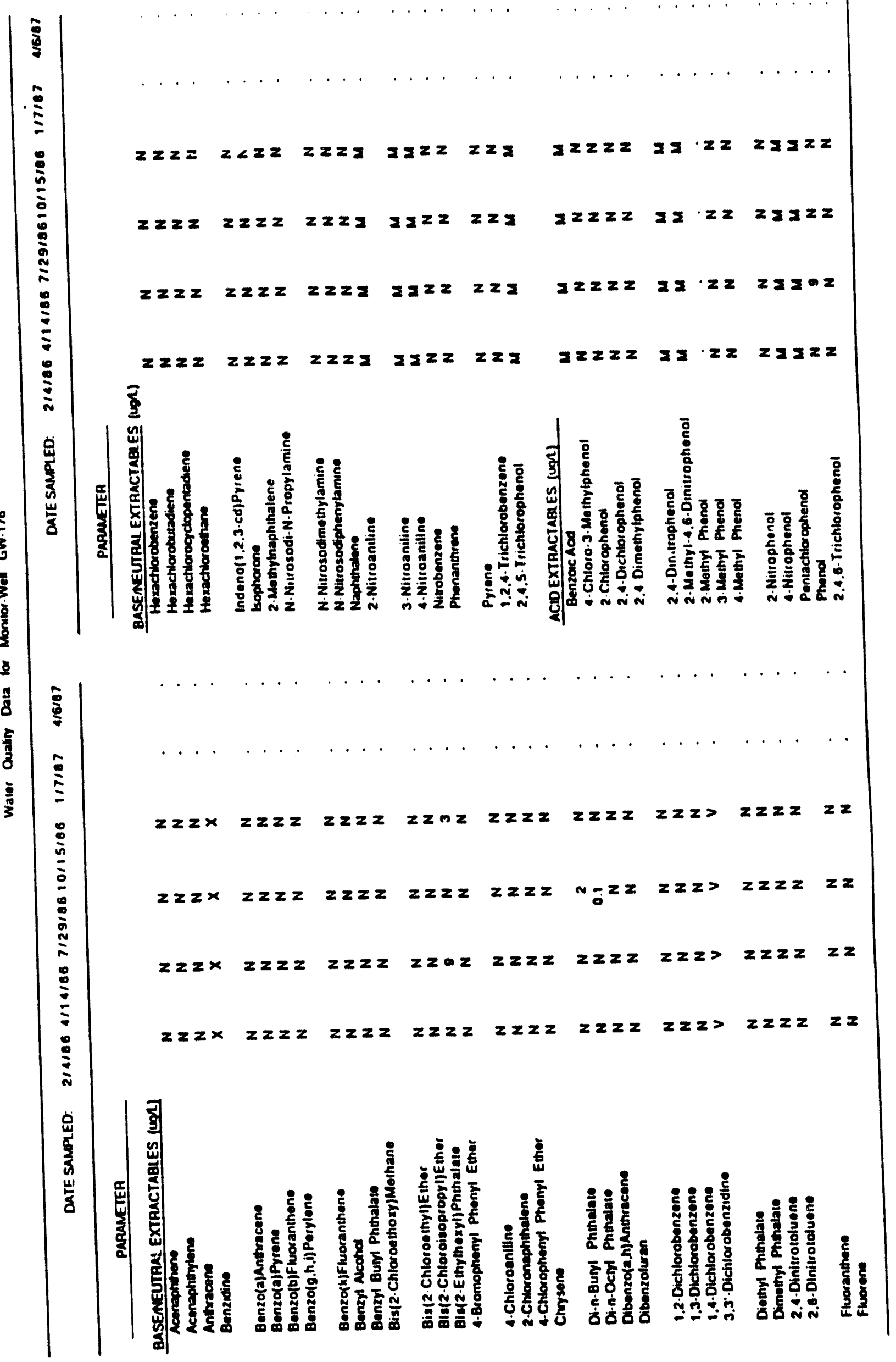




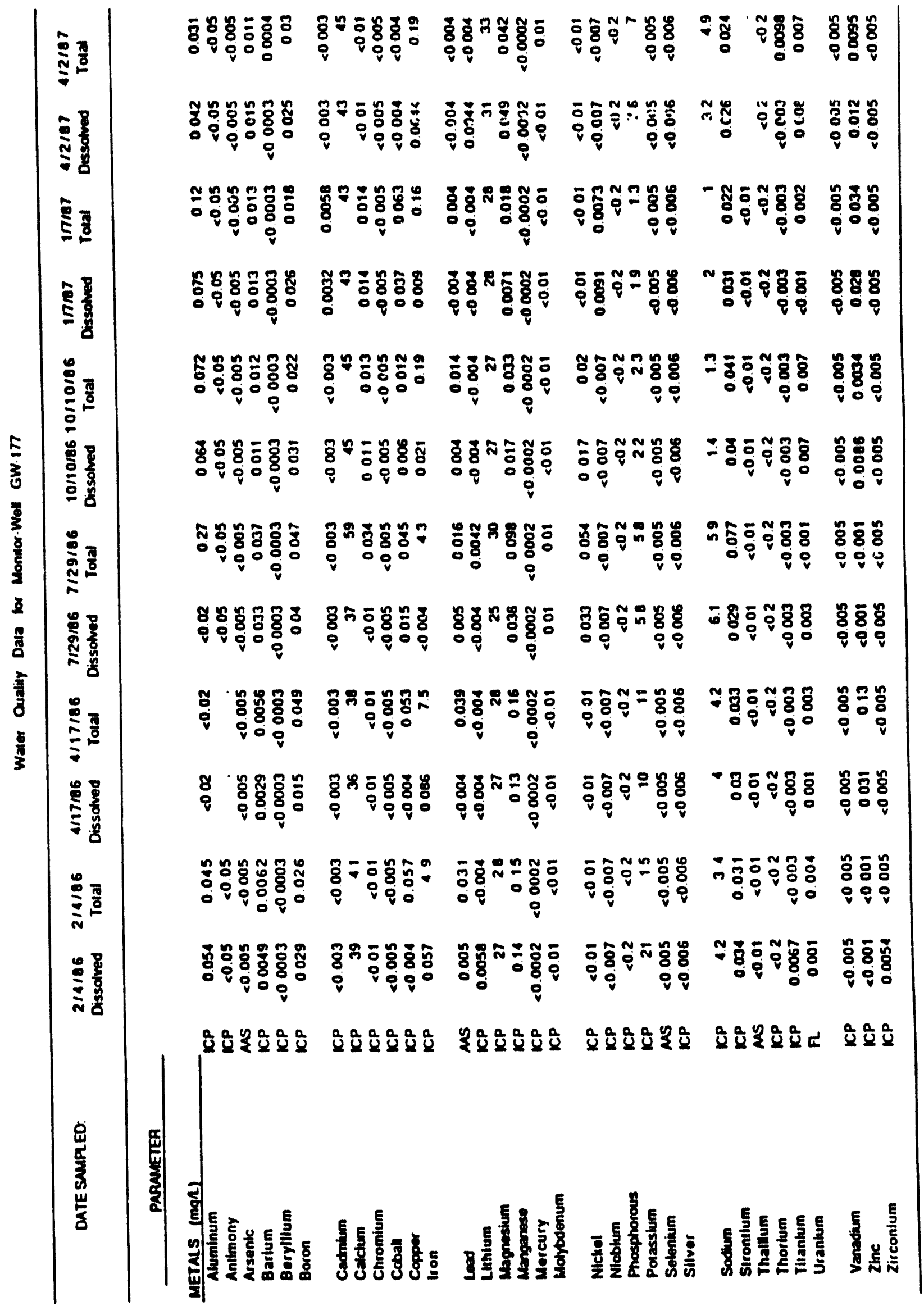




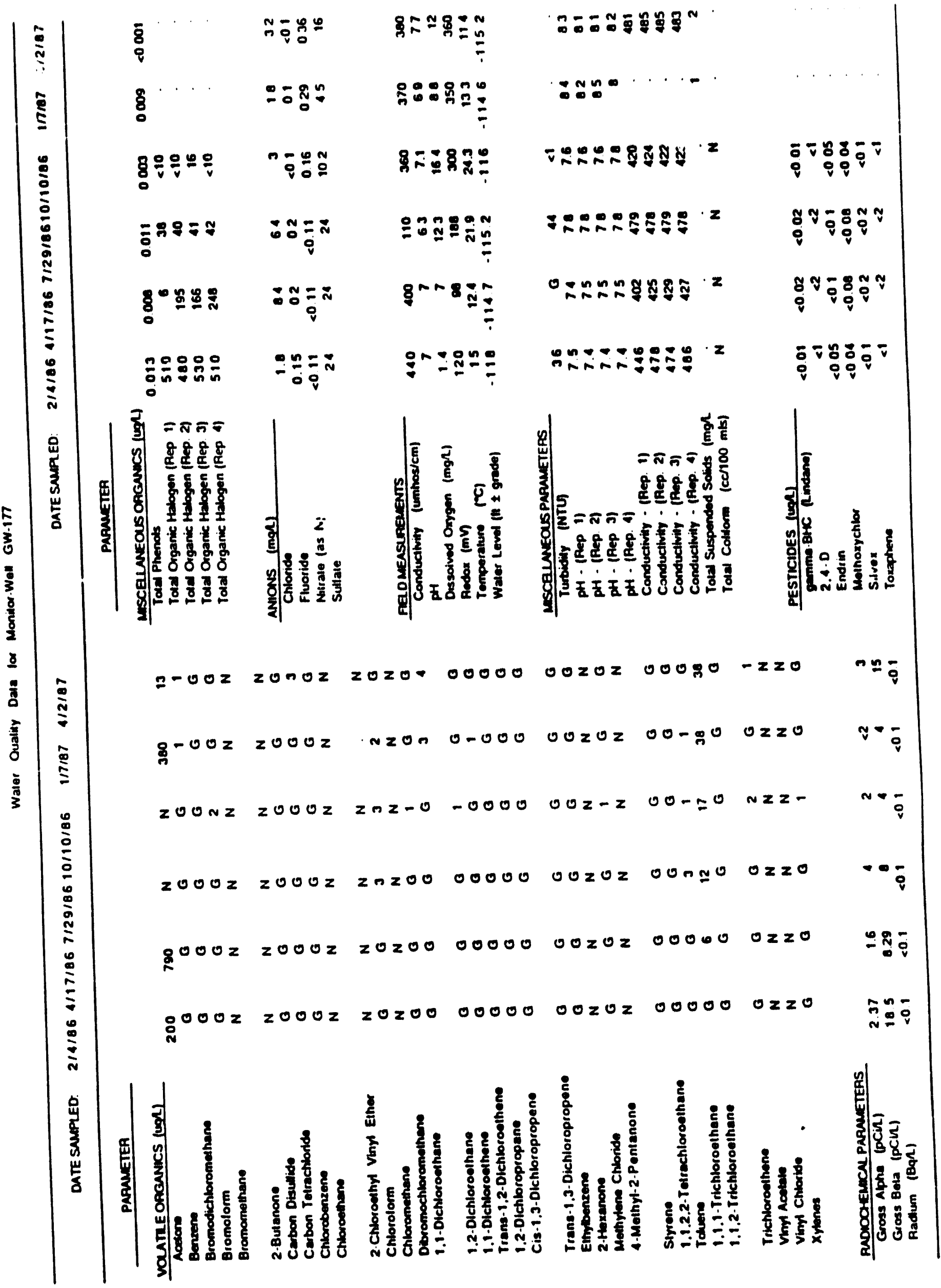




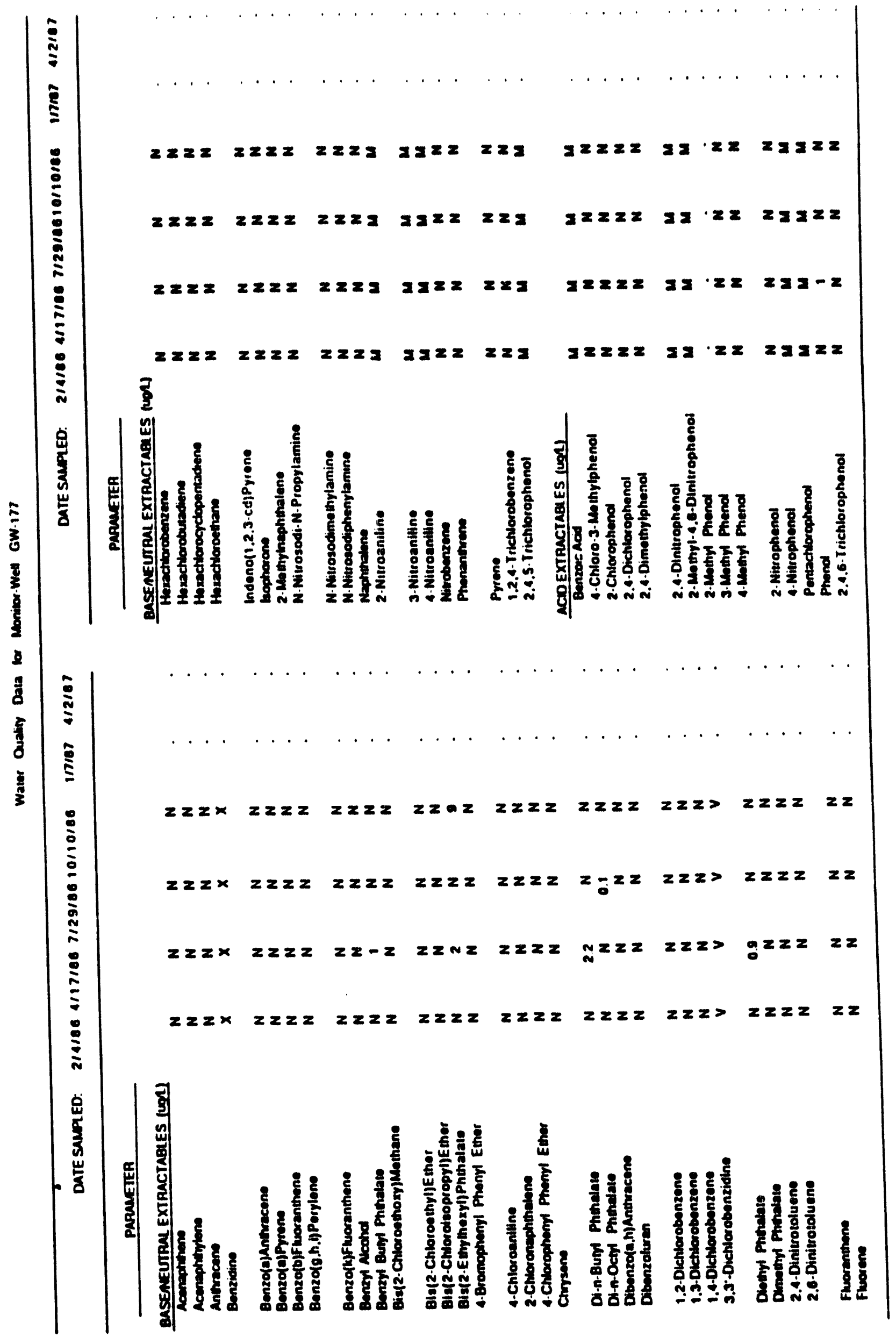




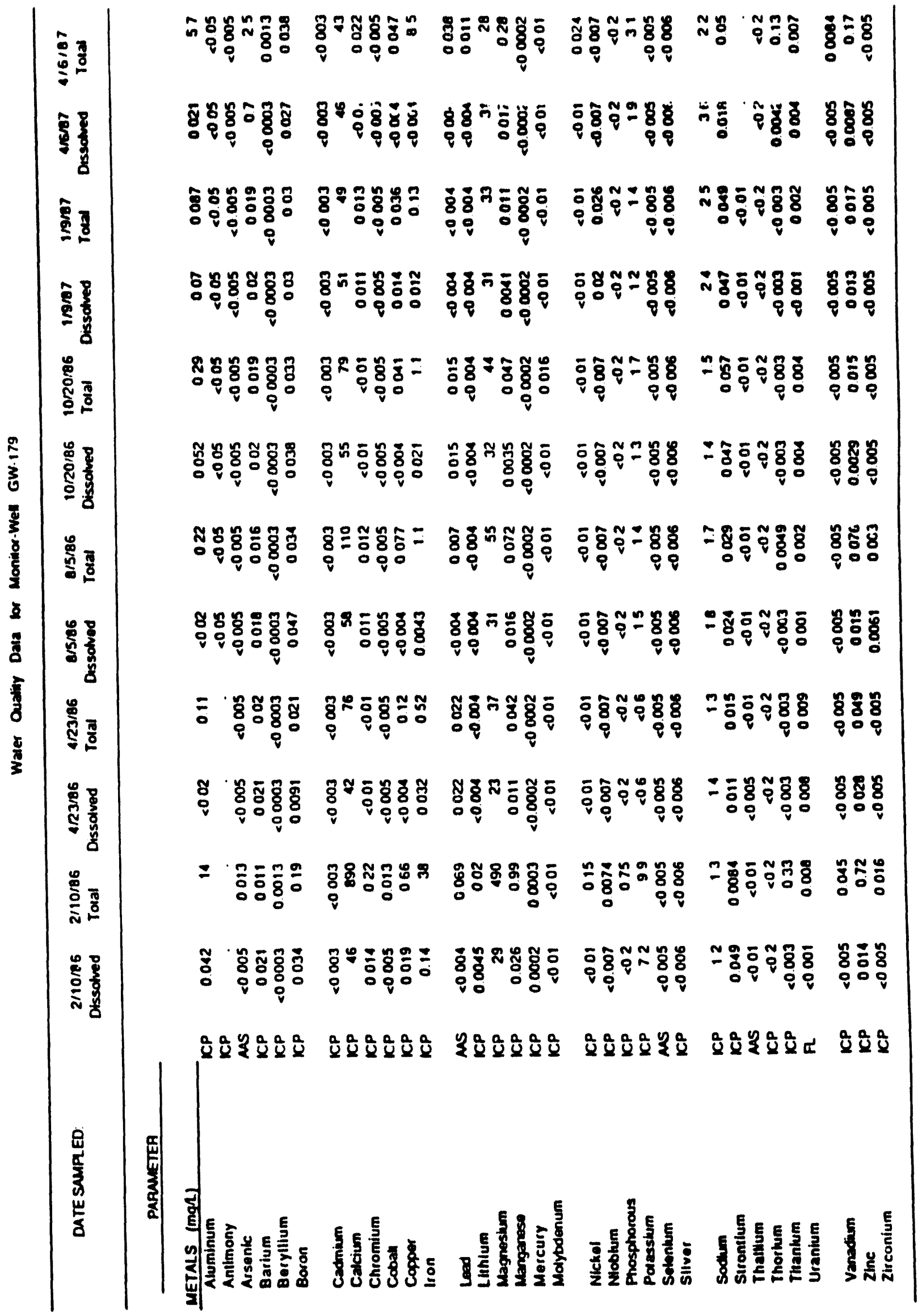


A-74

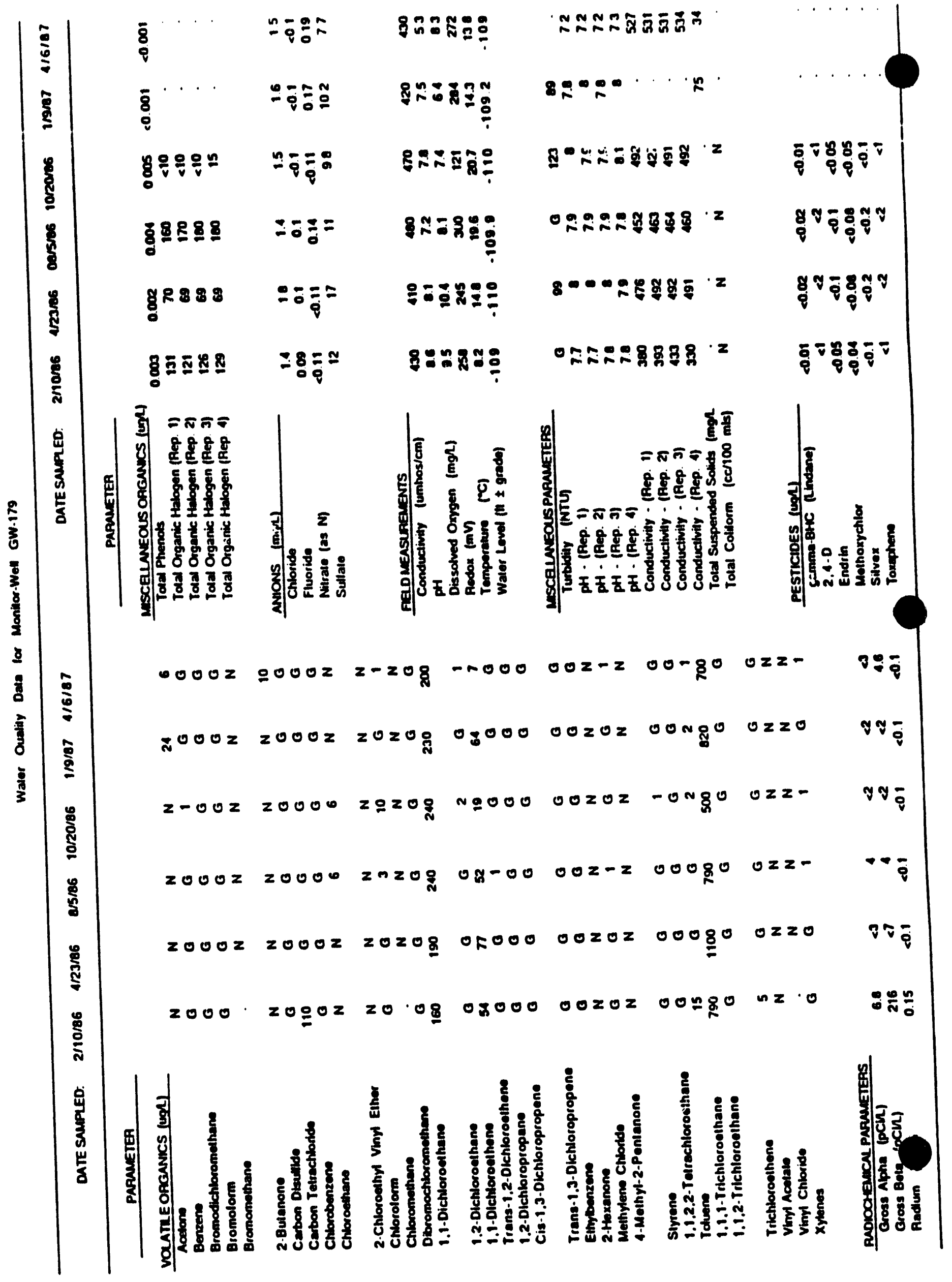




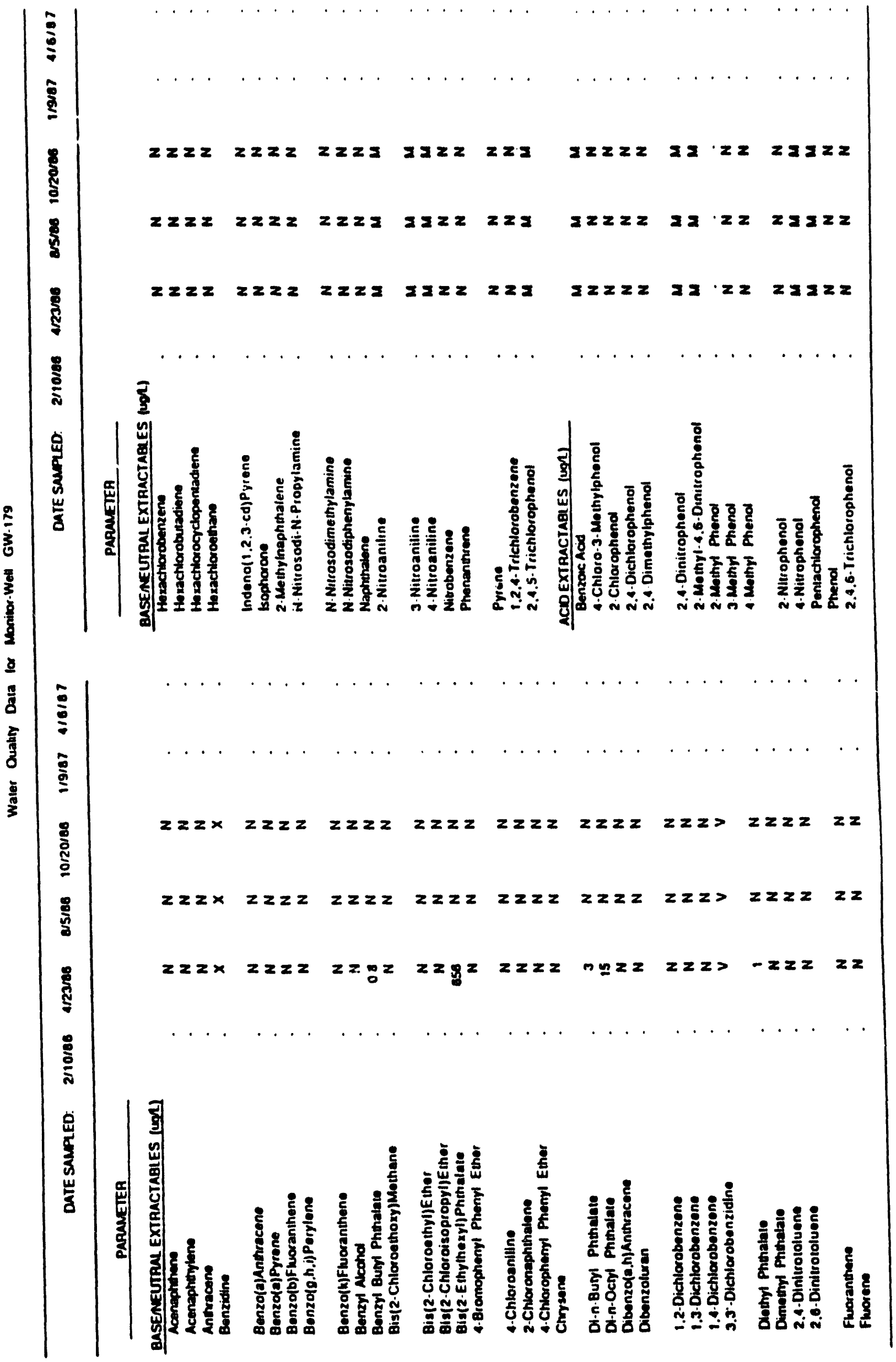




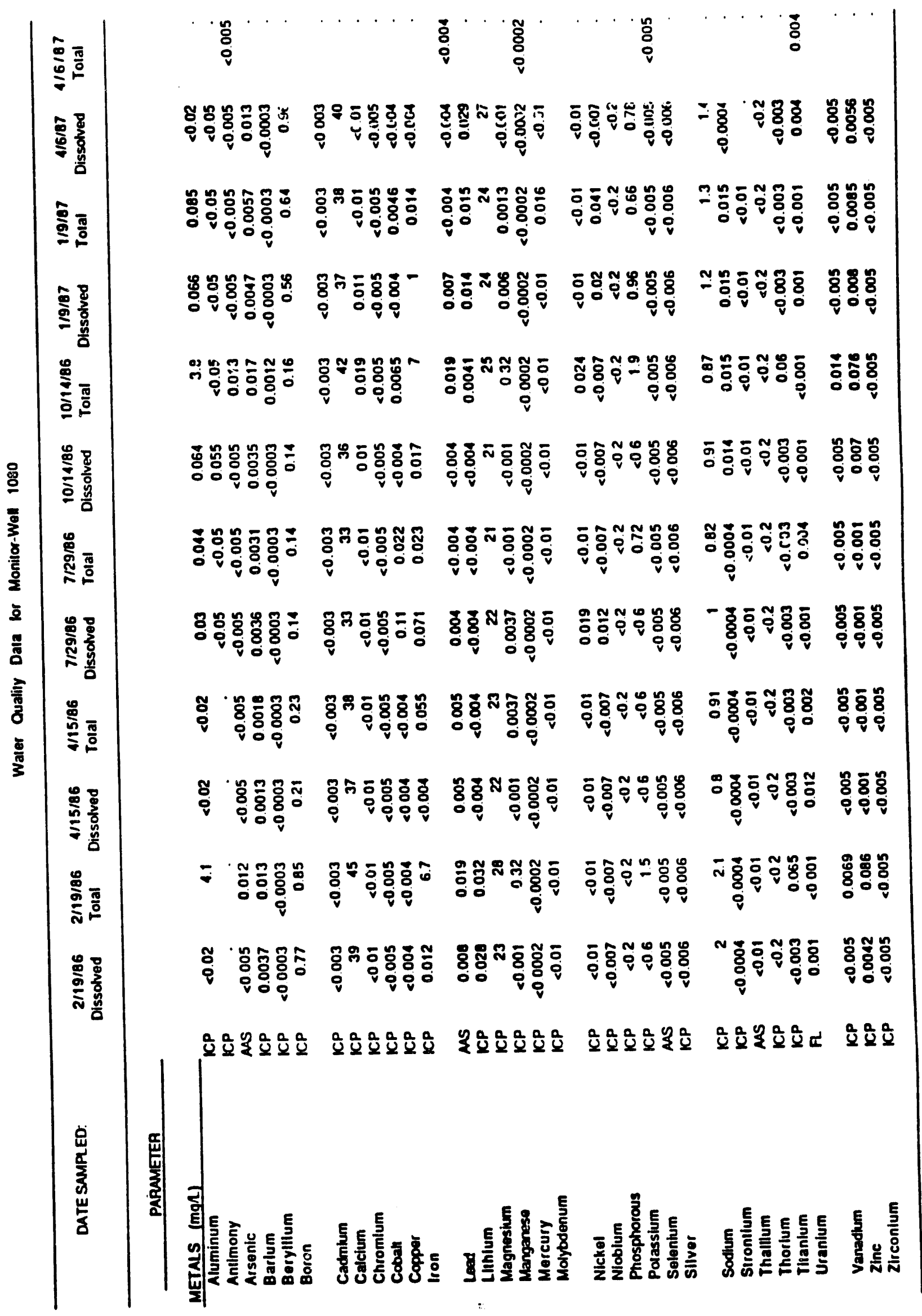




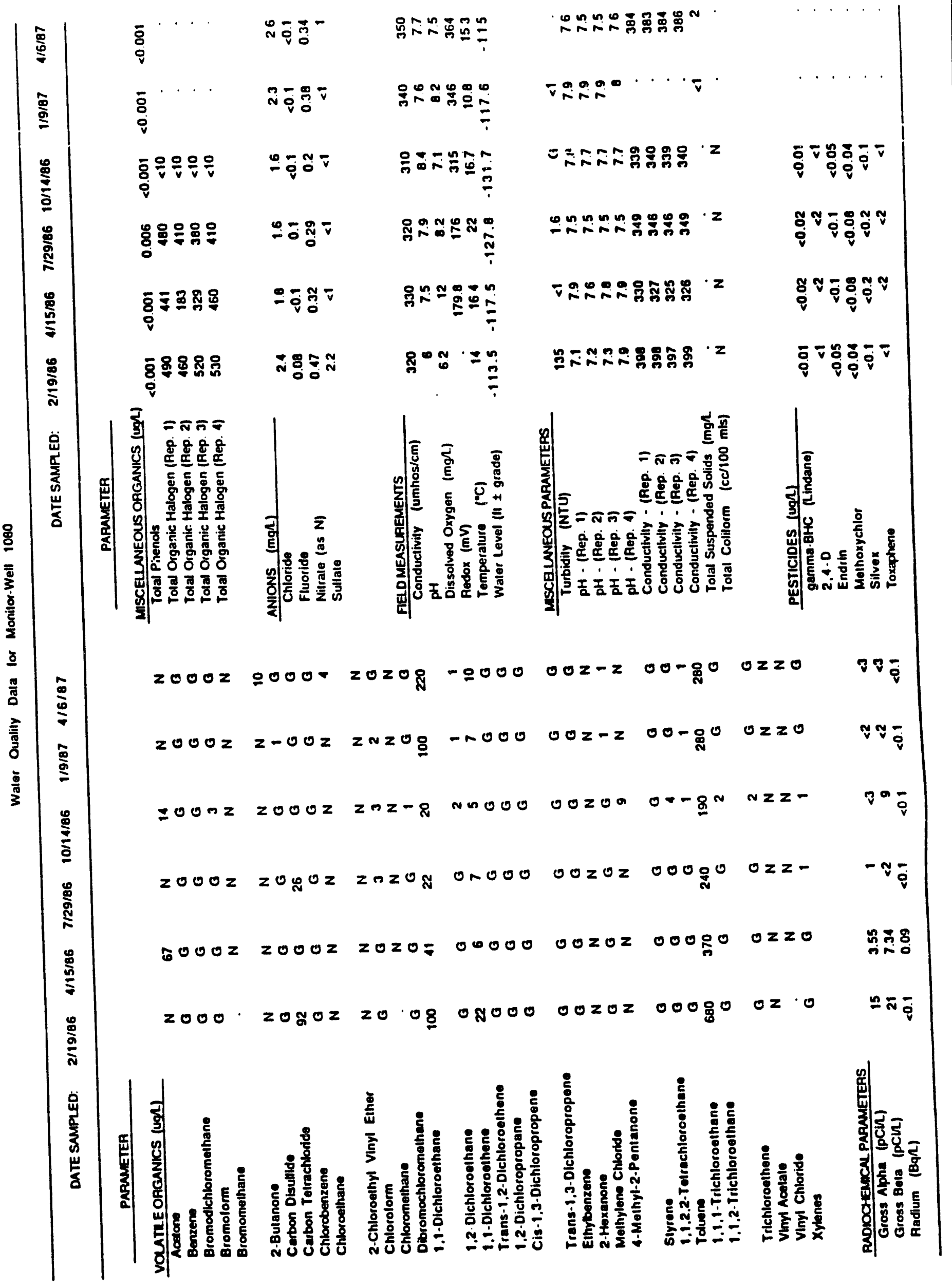




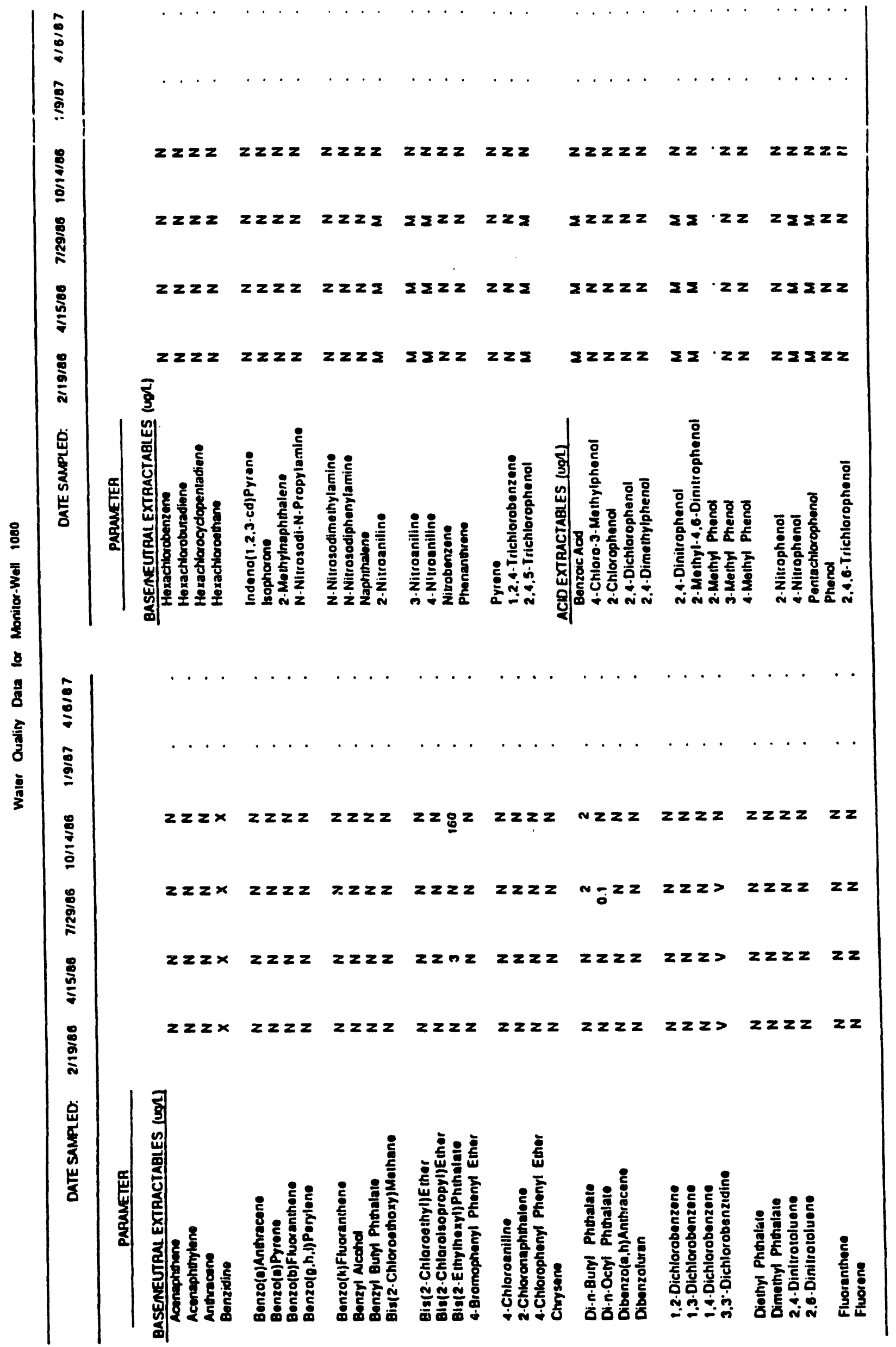


Assessment Data tor Monnor-Well GW-173

\begin{tabular}{|c|c|c|c|c|c|c|c|c|}
\hline \multirow[b]{2}{*}{ METALS (mg/L) } & \multicolumn{2}{|c|}{$\begin{array}{l}181 \text { Ounner } \\
\text { Y12/88 }\end{array}$} & \multicolumn{2}{|c|}{$\begin{array}{l}\text { 2nd Quaner } \\
67 / 88\end{array}$} & \multicolumn{2}{|c|}{$\begin{array}{l}\text { 3rd Ouaner } \\
\text { yess }\end{array}$} & \multicolumn{2}{|c|}{$\begin{array}{l}\text { atn Ouaner } \\
10 / 2488\end{array}$} \\
\hline & Tolal & Dissolved & Total & Dissolved & Tolal & Dinsolved & Tolal & Dissolved \\
\hline Arsenic (MS) & 0.005 & $<0.005$ & $<0.005$ & $<0.005$ & $<0.005$ & $<0.005$ & $<0.005$ & $<0.005$ \\
\hline Barium (AAS) & $<0.1$ & $<0.1$ & $<0.1$ & $<0.1$ & 0.24 & 0.28 & $<0.1$ & $<0.1$ \\
\hline Beryllium (MAS) & & & $<0.001$ & $<0.001$ & $<0.001$ & $<0.001$ & $<0.001$ & $<0.001$ \\
\hline Beryttium (ICAP) & 0.003 & $<0.001$ & & & & . & & \\
\hline Cadmium (AMS) & 0.002 & $<0.002$ & $<0.002$ & $<0.002$ & $<0.002$ & $<0.002$ & $<0.002$ & $<0.002$ \\
\hline Chromum (MAS) & 0.047 & $<0.01$ & 0.018 & $<0.01$ & 0.015 & 0.01 & $<0.01$ & $<0.01$ \\
\hline Lead (AAS) & 0.43 & $<0.004$ & $<0.004$ & $<0.004$ & 0.051 & 0.0052 & 0.01 & $<0.004$ \\
\hline Moraury (CVAM) & 0.0004 & $<0.0002$ & $<0.0002$ & $<0.0002$ & 0.0006 & $<0.0002$ & $<0.0002$ & $<0.0002$ \\
\hline Solonum (AAS) & $<0.005$ & $<0.005$ & $<0.005$ & $<0.005$ & $<0.005$ & $<0.005$ & $<0.005$ & $<0.005$ \\
\hline Silver (AMS) & $<0.01$ & $<0.01$ & $<0.01$ & $<0.01$ & $<0.01$ & $<0.01$ & $<0.01$ & $<0.01$ \\
\hline Thorium (ICAP) & $<0.2$ & $<0.2$ & $<0.2$ & $<0.2$ & $<0.2$ & $<0.2$ & $<0.2$ & $<0.2$ \\
\hline Uranum (Fluor) & 0.009 & 0.003 & 0.003 & 0.003 & 0.002 & 0.002 & $<0.001$ & $<0.001$ \\
\hline \multicolumn{9}{|l|}{ ANONS a CATIONS (mg/h) } \\
\hline Aluatinny. Biearoonale & 150 & & 162 & & 163 & & 166 & \\
\hline Caloum (MAS) & & $\dot{\cdot}$ & . & $\dot{9}$ & - & $\cdot$ & . & \\
\hline Calcum (ICAP) & 140 & 37 & 36 & 37 & 50 & 40 & 30 & 37 \\
\hline Chionde & 3 & & 4 & & 4 & & 3 & \\
\hline Fluorice & $<0.1$ & & 0.11 & & $<0.1$ & & $<0.1$ & \\
\hline Magnesium (ICAP) & 61 & 25 & 25 & 24 & 31 & 25 & 24 & 24 \\
\hline Nirrate (as N) & 1.66 & & 1.42 & & 1.5 & & 1.4 & \\
\hline Potassium & 5 & 2.9 & 4.4 & 3.2 & 4.2 & 3.4 & 2.5 & 2.7 \\
\hline Sodium (ICAP) & 2.4 & 2.3 & 2.2 & 2.9 & 2.5 & 2.4 & 2.2 & 2.4 \\
\hline Suttate & 11.4 & & 12 & & 12 & & 11 & \\
\hline \multicolumn{9}{|l|}{ VOLATILE ORGANICS (Hg/L) } \\
\hline Acrolen & . & & . & & $\cdot$ & & . & \\
\hline Acryionarile & . & & & & $\dot{ }$ & & . & \\
\hline Bonzen & G & & $\mathbf{G}$ & & G & & $<5$ & \\
\hline Bromodichloromethane & $\mathbf{G}$ & & G & & $\mathbf{G}$ & & $<5$ & \\
\hline Bromolorm & G & & G & & $\mathbf{G}$ & & $<5$ & \\
\hline Bromomeinam & $\mathbf{N}$ & & N & & N & & $<10$ & \\
\hline Carbon teirnchioride & $\mathbf{G}$ & & G & & G & & $<5$ & \\
\hline Chiorobenzen & $\mathbf{G}$ & & $\mathbf{G}$ & & $\mathbf{G}$ & & $<5$ & \\
\hline Chiorodbromomotrane & $\mathbf{G}$ & & G & & G & & $<5$ & \\
\hline Chlorostinans & $\mathbf{N}$ & & $\mathbf{N}$ & & $\mathbf{N}$ & & $<10$ & \\
\hline 2-Choroethyl unyl elher & $\mathbf{N}$ & & $N$ & & $\mathbf{N}$ & & . & \\
\hline Chlorolorm & $\mathbf{G}$ & & G & & 0.5 & & 0.4 & \\
\hline Chioromethane & $\mathbf{N}$ & & $\mathbf{N}$ & & $\mathbf{N}$ & & $<10$ & \\
\hline Dichlorodilluoromelnan & . & & & & 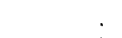 & & & \\
\hline 1.1-Dicnloroelnane & $\mathbf{G}$ & & G & & G & & $<5$ & \\
\hline 1.2-Dietioroelnane & $\mathbf{G}$ & & G & & G & & $<5$ & \\
\hline 1.1-Dichloroolnene & $\mathbf{G}$ & & $G$ & & $\mathbf{G}$ & & $<5$ & \\
\hline Irans-1.2-Dichioroethere & $\bar{G}$ & & $\mathbf{G}$ & & $G$ & & & \\
\hline 1.2-Dichioropropane & $\mathbf{G}$ & & G & & $\mathbf{G}$ & & $<5$ & \\
\hline Cas-1.3-Dictitoropropane & G & & $\mathbf{G}$ & & $\mathbf{G}$ & & $<5$ & \\
\hline Irans-1.3-Dichloropropene & $\mathbf{G}$ & & $\mathbf{G}$ & & $\mathbf{G}$ & & $<5$ & \\
\hline Elnybenzene & $\mathbf{G}$ & & $\mathbf{G}$ & & $\mathbf{G}$ & & $<5$ & \\
\hline Fluoroinchioromoiname & . & & . & & . & & . & \\
\hline Moimyione chionde & $\mathbf{G}$ & & G & & 0.8 & & 2 & \\
\hline 1.1.2.2-Tetrachioroethane & $\mathbf{G}$ & & $\mathbf{G}$ & & G & & $<5$ & \\
\hline Totrechiorosinone & 15 & & 17 & & 15 & & 19 & \\
\hline Tobven & $\mathbf{G}$ & & $\mathbf{G}$ & & $\mathbf{G}$ & & 45 & \\
\hline 1.1.1-Triehloroeliname & 1 & & 2 & & 2 & & 2 & \\
\hline 1.12.Tnechiorosinam & $\mathbf{G}$ & & $\mathbf{G}$ & & G & & $<5$ & \\
\hline Trichioroetmens & $\mathbf{G}$ & & $\mathbf{G}$ & & $\mathbf{G}$ & & 0.7 & \\
\hline Venyl enloride & $\mathbf{N}$ & & $\mathbf{N}$ & & $N$ & & $<10$ & \\
\hline \multicolumn{9}{|l|}{ RADIOCHEMICAL PARAMETERS } \\
\hline Gross Alpha, neo. (DCin) & 13 & & 0.15 & & 2 & & 8 & \\
\hline Gross Beta, noo. (pCin) & 2697 & & 5 & & 3 & & 11 & \\
\hline \multicolumn{9}{|l|}{ MISCELLANEOUS PARAMETERS } \\
\hline pH (average) & 7.7 & & 8.0 & & 7.5 & & 7.7 & \\
\hline Conducrivily (average) & 369 & & 389 & & 319 & & 392 & \\
\hline Toral Dissoived Solids (mgh) & 270 & & 222 & & 198 & & 242 & \\
\hline Tolal Susponded Solicts (mon) & 26 & & 13 & & 222 & & 4 & \\
\hline Waler-Level Elevalions (in, msl) & 075.9 & & 962.0 & & 962.0 & & 858.5 & \\
\hline
\end{tabular}


Assessmom Date top Monmor-Well GW.174

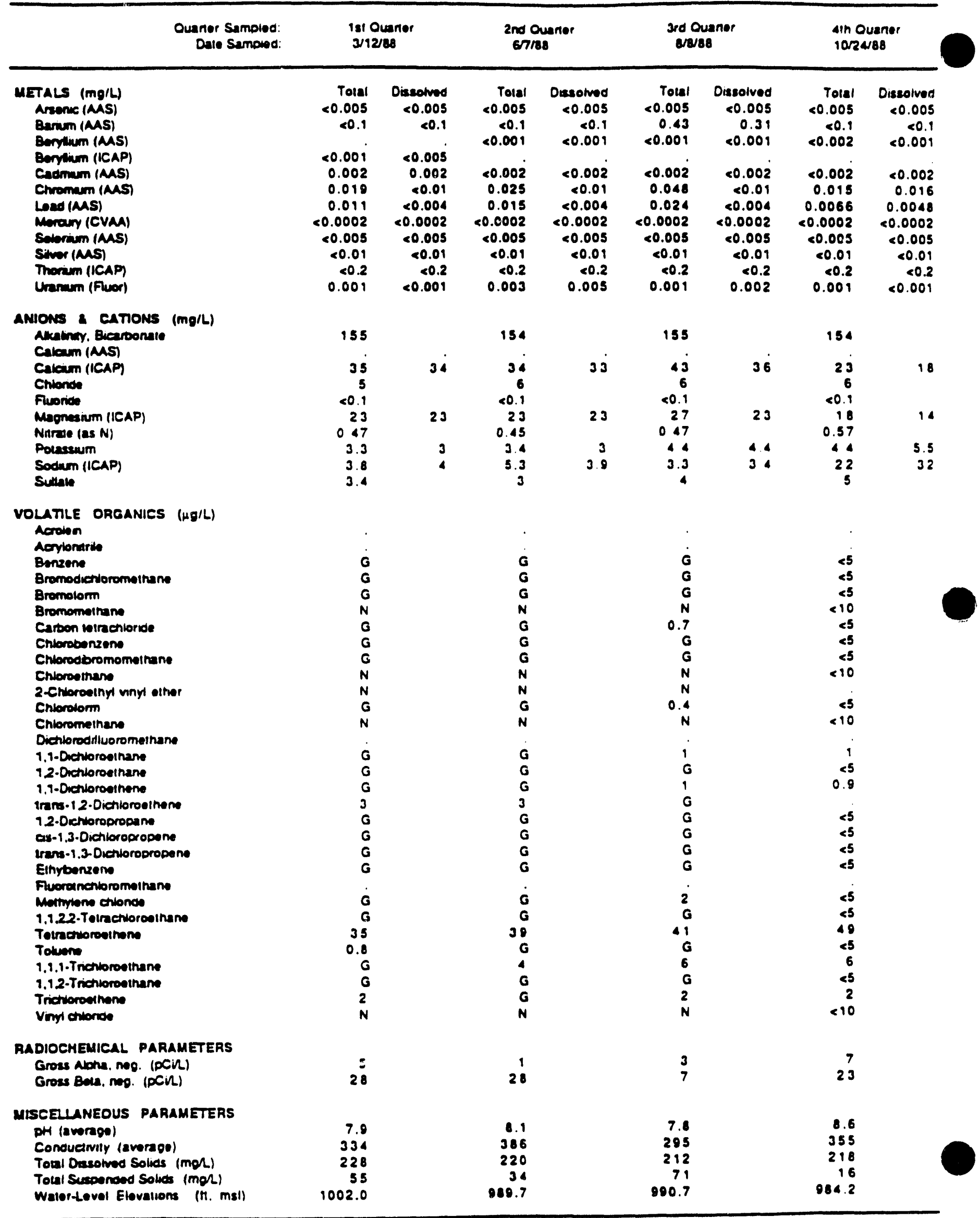

\footnotetext{
R02.05.89BE
} 


\section{A-81}

Aseresmom Dala tor Monnor-Woll OW-175

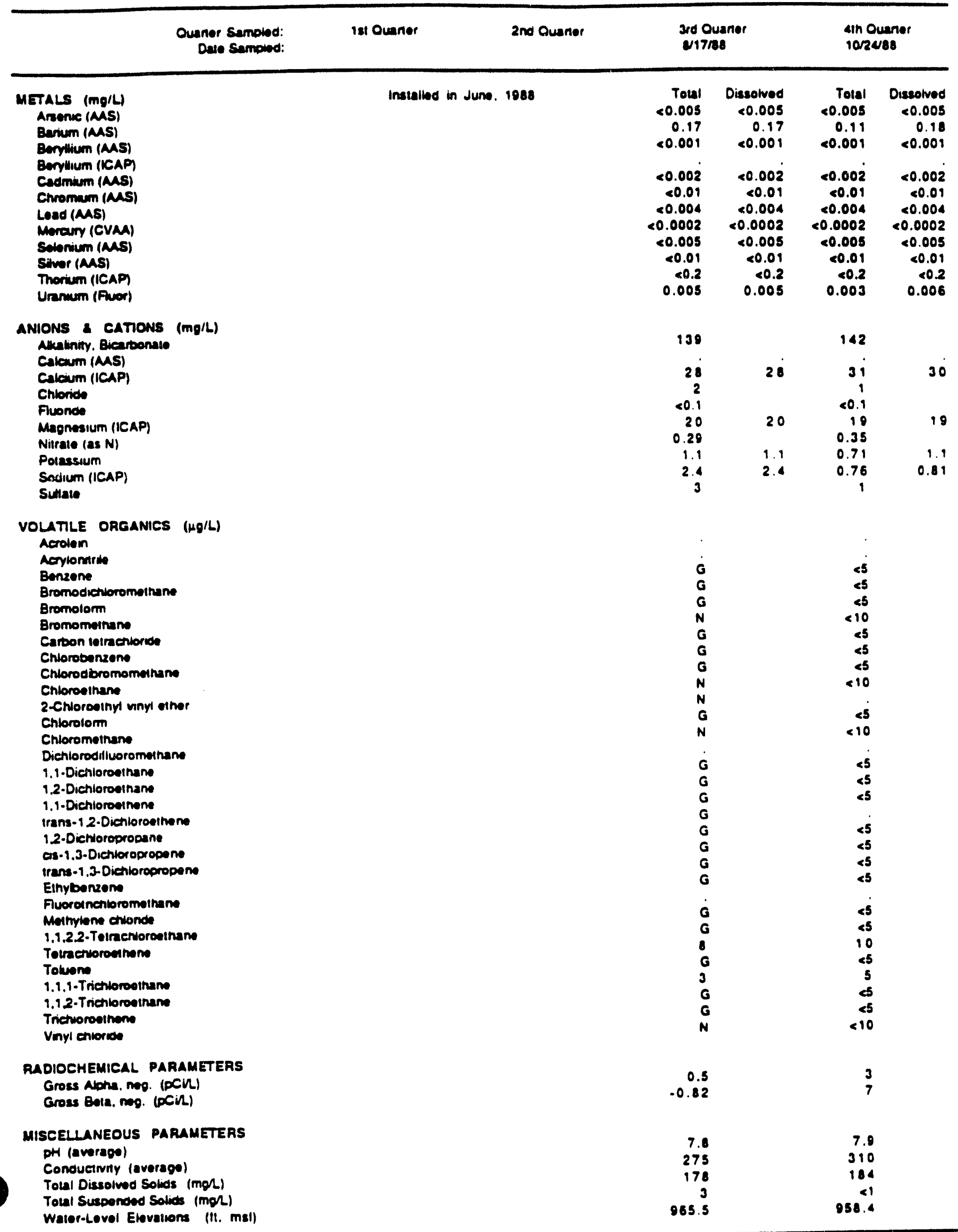

R02.09.8089 
Assessmont Dala lor Monmor-WeH OW.176

\begin{tabular}{|c|c|c|c|c|c|c|c|c|}
\hline $\begin{array}{l}\text { Ouner Sampiod. } \\
\text { Dele Sampied: }\end{array}$ & $\begin{array}{l}181 C \\
311\end{array}$ & iner & $\begin{array}{l}\text { and } 0 \\
\text { entr }\end{array}$ & & $\begin{array}{l}\text { ard } 0 \\
\text { a12 }\end{array}$ & & $\begin{array}{l}\sin 0 \\
10 / 26\end{array}$ & 80 \\
\hline 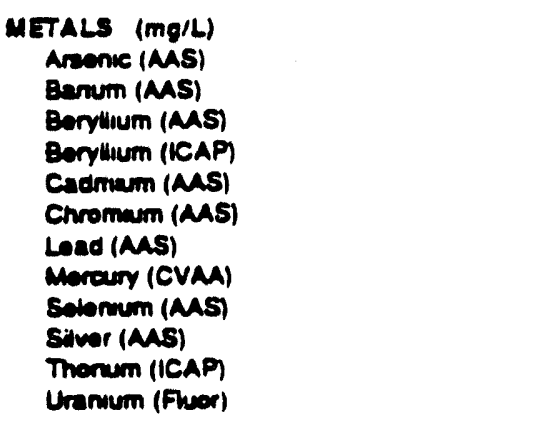 & $\begin{array}{r}\text { Tolal } \\
<0.005 \\
<0.1 \\
<0.001 \\
<0.002 \\
<0.01 \\
0.005 \\
<0.0002 \\
<0.005 \\
<0.01 \\
<0.2 \\
<0.001\end{array}$ & $\begin{array}{r}\text { Dissolved } \\
<0.005 \\
<0.1 \\
<0.001 \\
<0.002 \\
<0.01 \\
<0.004 \\
<0.0002 \\
<0.005 \\
<0.01 \\
<0.2 \\
<0.001\end{array}$ & $\begin{array}{r}\text { Toual } \\
<0.005 \\
<0.1 \\
<0.001 \\
<0.002 \\
<0.01 \\
<0.004 \\
<0.0002 \\
<0.005 \\
<0.01 \\
<0.2 \\
<0.001\end{array}$ & $\begin{array}{r}\text { Diesoned } \\
<0.005 \\
<0.1 \\
<0.001 \\
<0.002 \\
0.013 \\
<0.004 \\
<0.0002 \\
<0.005 \\
<0.01 \\
<0.2 \\
0.006\end{array}$ & $\begin{array}{r}\text { Total } \\
<0.005 \\
0.22 \\
<0.001 \\
<0.002 \\
<0.01 \\
<0.001 \\
<0.0002 \\
<0.005 \\
<0.01 \\
<0.2 \\
<0.001\end{array}$ & $\begin{array}{r}\text { Oseolved } \\
<0.005 \\
0.19 \\
<0.001 \\
<0.002 \\
<0.01 \\
<0.004 \\
<0.0002 \\
<0.005 \\
<0.01 \\
<0.2 \\
0.001\end{array}$ & $\begin{array}{r}\text { Tolal } \\
<0.005 \\
<0.1 \\
<0.001 \\
<0.002 \\
<0.01 \\
0.0056 \\
<0.0002 \\
<0.008 \\
<0.01 \\
<0.2 \\
<0.001\end{array}$ & $\begin{array}{r}\text { Dissolved } \\
<0.005 \\
<0.1 \\
<0.001 \\
<0.002 \\
<0.01 \\
0.0088 \\
<0.0002 \\
<0.003 \\
<0.01 \\
<0.2 \\
<0.001\end{array}$ \\
\hline 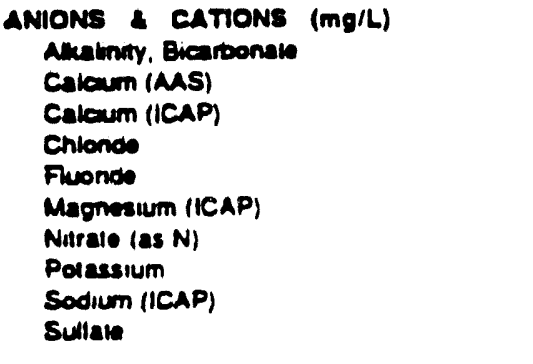 & $\begin{array}{r}202 \\
40 \\
3 \\
0.2 \\
26 \\
1.24 \\
2.1 \\
0.84 \\
1.1\end{array}$ & $\begin{array}{r}43 \\
29 \\
2.5 \\
0.83\end{array}$ & $\begin{array}{r}210 \\
44 \\
3 \\
<0.1 \\
31 \\
0.44 \\
2.3 \\
0.62 \\
<1\end{array}$ & $\begin{array}{r}43 \\
31 \\
24 \\
0.73\end{array}$ & $\begin{array}{r}232 \\
13 \\
2 \\
201 \\
6.7 \\
0.5 \\
3 \\
0.18 \\
1\end{array}$ & $\begin{array}{l}48 \\
31 \\
18 \\
07\end{array}$ & $\begin{array}{r}233 \\
52 \\
2 \\
<0.1 \\
33 \\
0.51 \\
1.8 \\
11 \\
<1\end{array}$ & $\begin{array}{r}33 \\
27 \\
0.73\end{array}$ \\
\hline 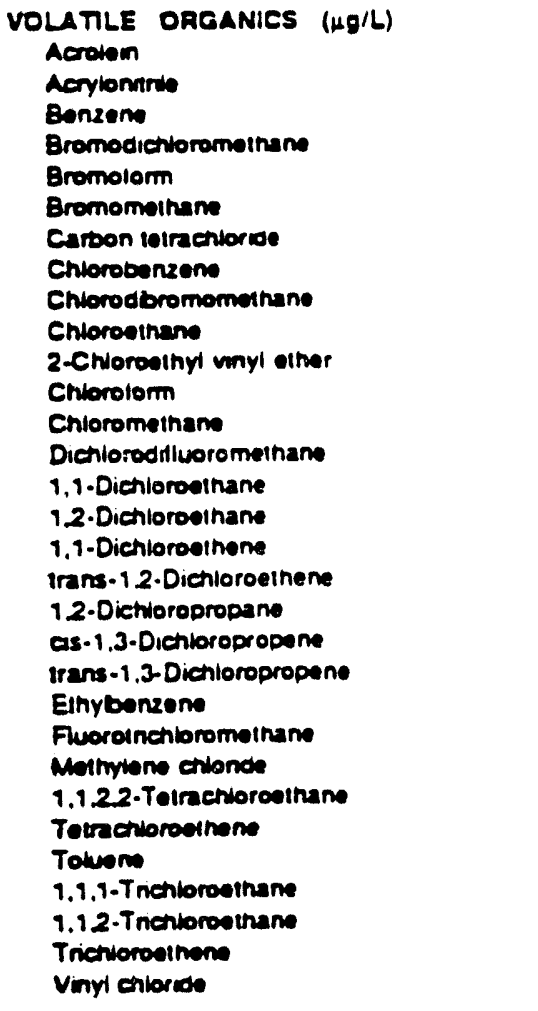 & $\begin{array}{r}G \\
G \\
G \\
N \\
G \\
G \\
G \\
N \\
N \\
0.7 \\
N \\
B 3 \\
3 \\
30 \\
G \\
G \\
G \\
G \\
G \\
G \\
G \\
G \\
14 \\
G \\
G \\
G \\
N\end{array}$ & & $\begin{array}{r}\text { G } \\
G \\
G \\
N \\
G \\
G \\
G \\
N \\
N \\
G \\
N \\
26 \\
G \\
12 \\
G \\
G \\
G \\
G \\
G \\
\text { G } \\
\mathbf{G} \\
\mathbf{G} \\
\mathbf{G} \\
\mathbf{G} \\
\mathbf{G} \\
\mathbf{N}\end{array}$ & & $\begin{array}{r}\text { G } \\
G \\
G \\
N \\
16 \\
G \\
G \\
N \\
N \\
0.5 \\
N \\
16 \\
G \\
10 \\
G \\
G \\
G \\
G \\
G \\
G \\
G \\
\text { G } \\
130 \\
G \\
G \\
\text { G }\end{array}$ & & $\begin{array}{r}<5 \\
<5 \\
<5 \\
<10 \\
<5 \\
<5 \\
<5 \\
<10 \\
<5 \\
<10 \\
12 \\
<5 \\
8 \\
<5 \\
<5 \\
<5 \\
<5 \\
<5 \\
<5 \\
< \\
<5 \\
100 \\
<5 \\
<5 \\
<10\end{array}$ & \\
\hline $\begin{array}{l}\text { RADIOCHEMICAL PARAMETERS } \\
\text { Gross Alon. noO. (DCiL) } \\
\text { Gross BOIa. noo. (DCiL) }\end{array}$ & $\begin{array}{l}1 \\
1\end{array}$ & & 26 & & $\begin{array}{l}2 \\
1\end{array}$ & & $\begin{array}{r}0.7 \\
2\end{array}$ & \\
\hline $\begin{array}{l}\text { MISCELLANEOUS PARAMETERS } \\
\text { PH (average) } \\
\text { Conductmily (average) } \\
\text { Tolal Dissolved Solids (mgl) } \\
\text { Tolal Suspanded Solida (mgl) } \\
\text { Waler-Levol Elovalions (II, msl) }\end{array}$ & $\begin{array}{r}6.7 \\
417 \\
274 \\
3 \\
1012.1\end{array}$ & & $\begin{array}{r}7.2 \\
464 \\
292 \\
4 \\
1009.1\end{array}$ & & $\begin{array}{r}7.0 \\
455 \\
312 \\
5 \\
1005.5\end{array}$ & & $\begin{array}{r}6.6 \\
477 \\
308 \\
<1 \\
1008.6\end{array}$ & \\
\hline
\end{tabular}


Assessmom Data lor Monmor.WoH OW.17

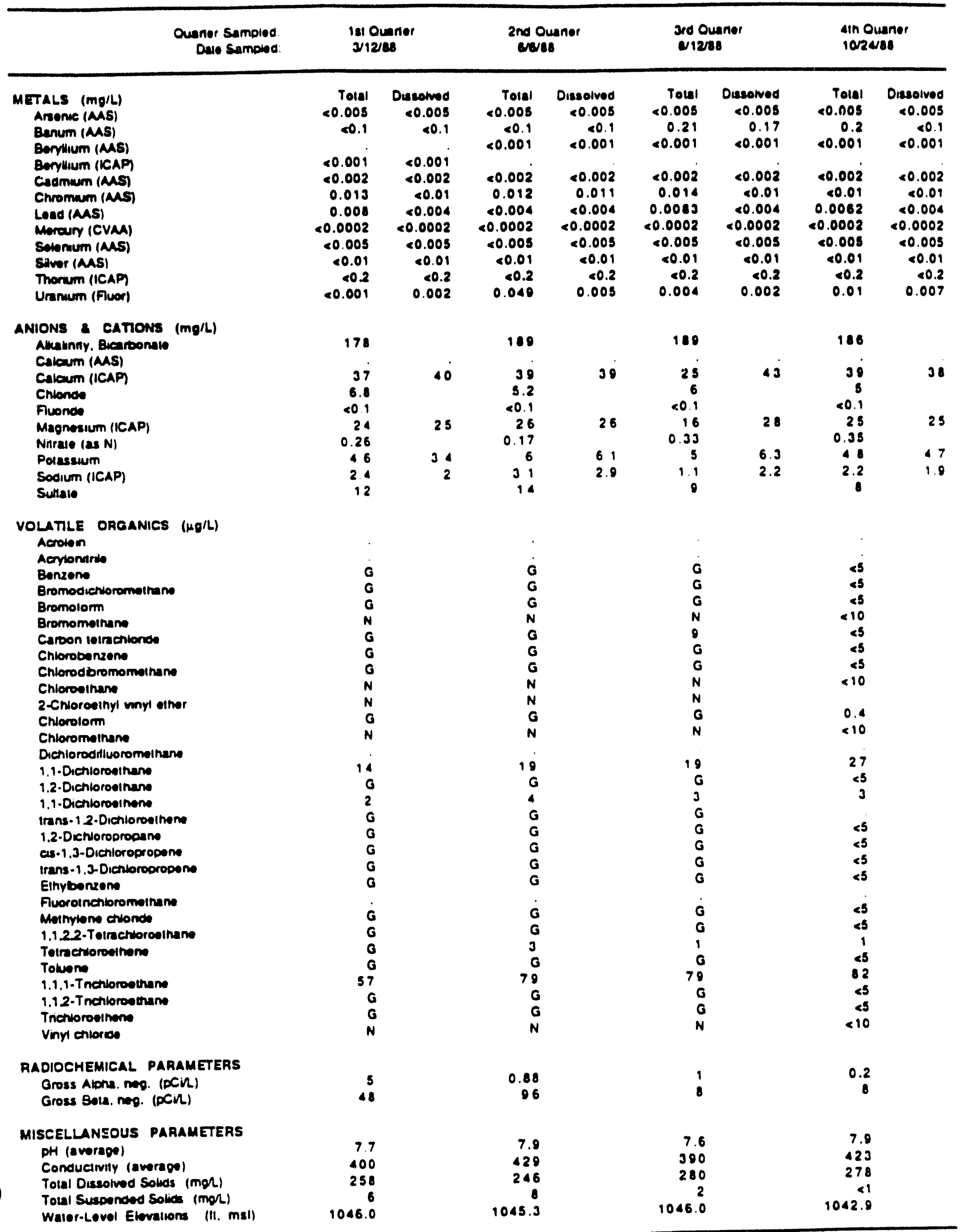




\section{A.84}

Asesemon Date ier Clemer.Woll OW.178

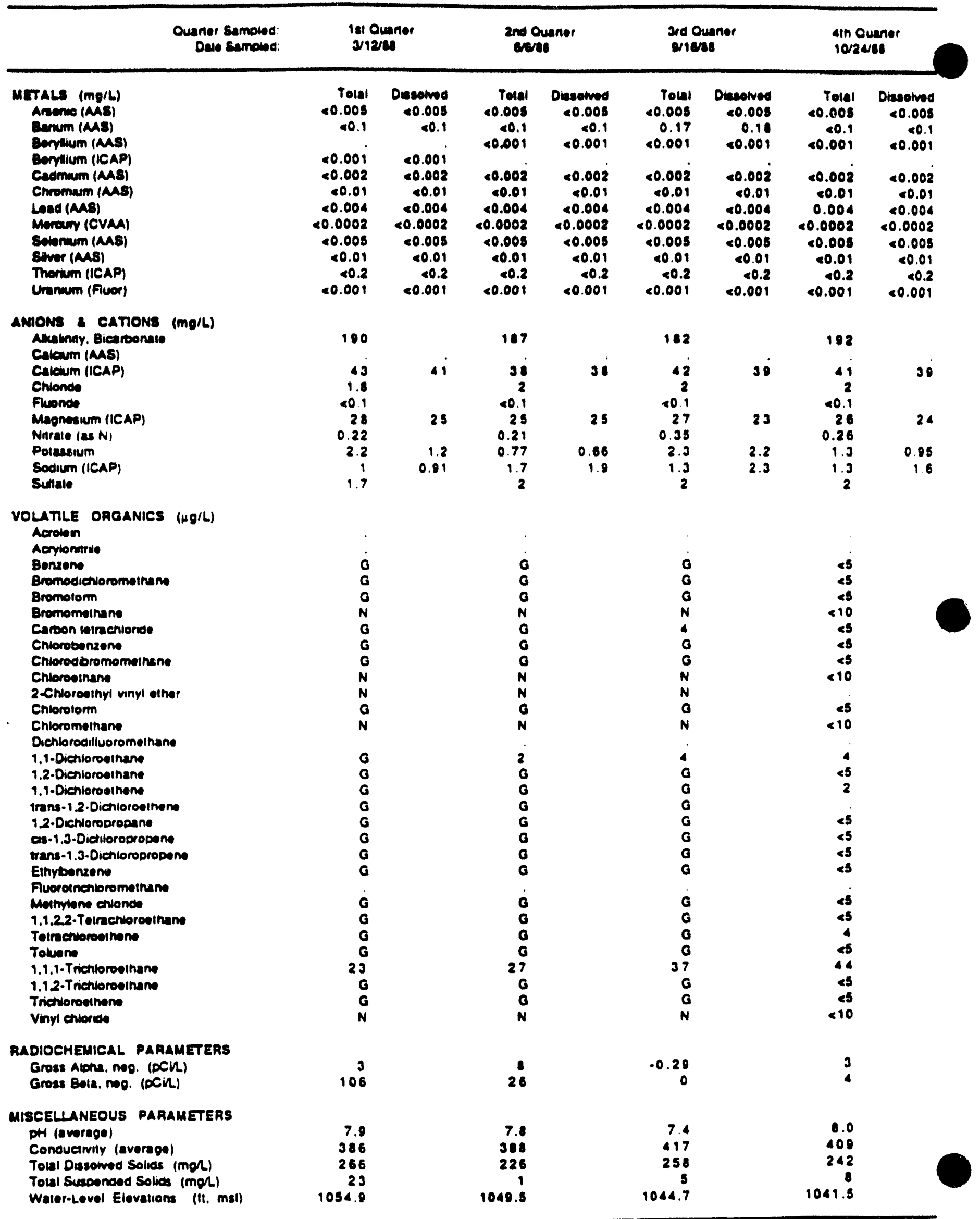


Assessmont Dala tor Monmor.Woll OW.170

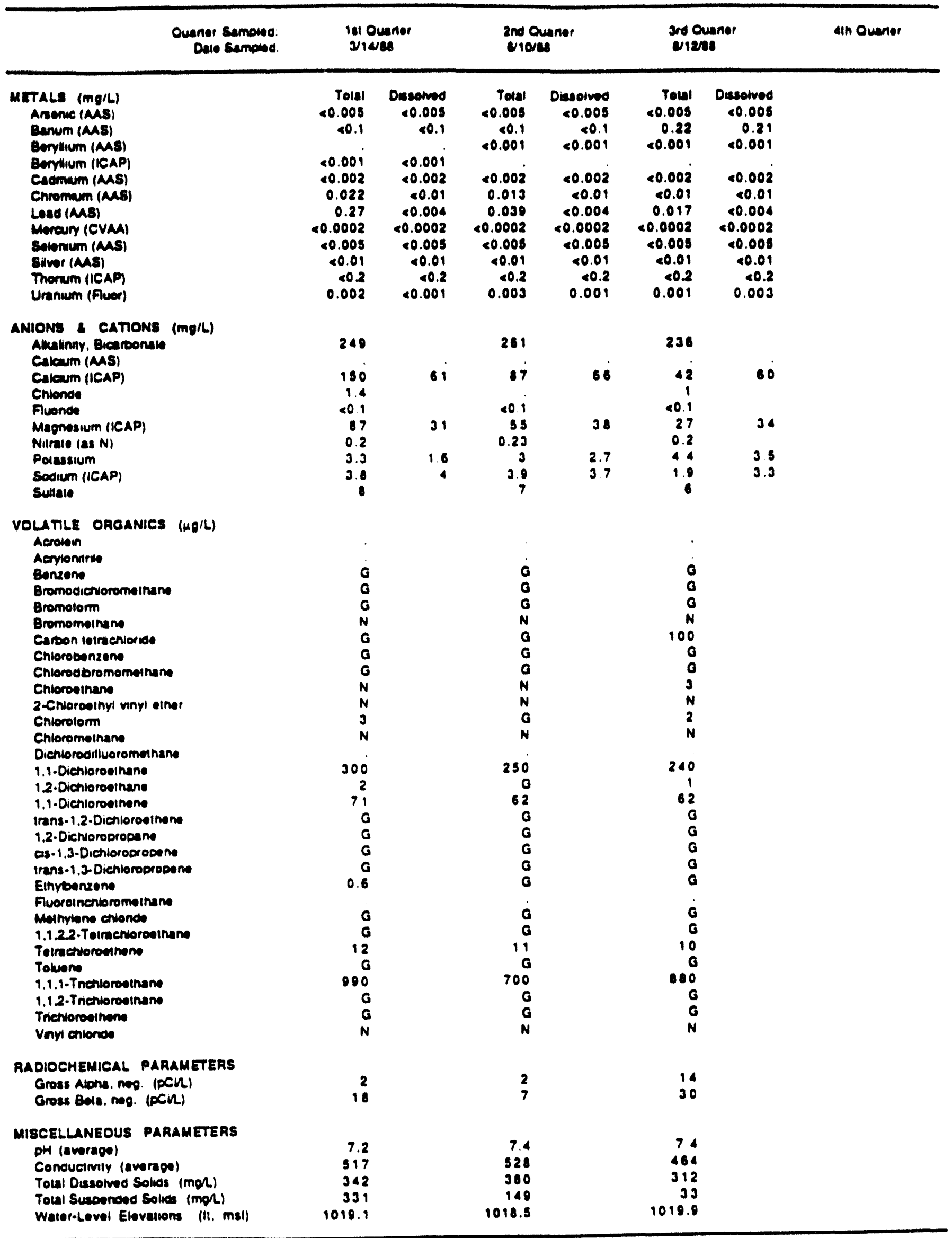


Assessmom Dale for Menmer.Well aw.180

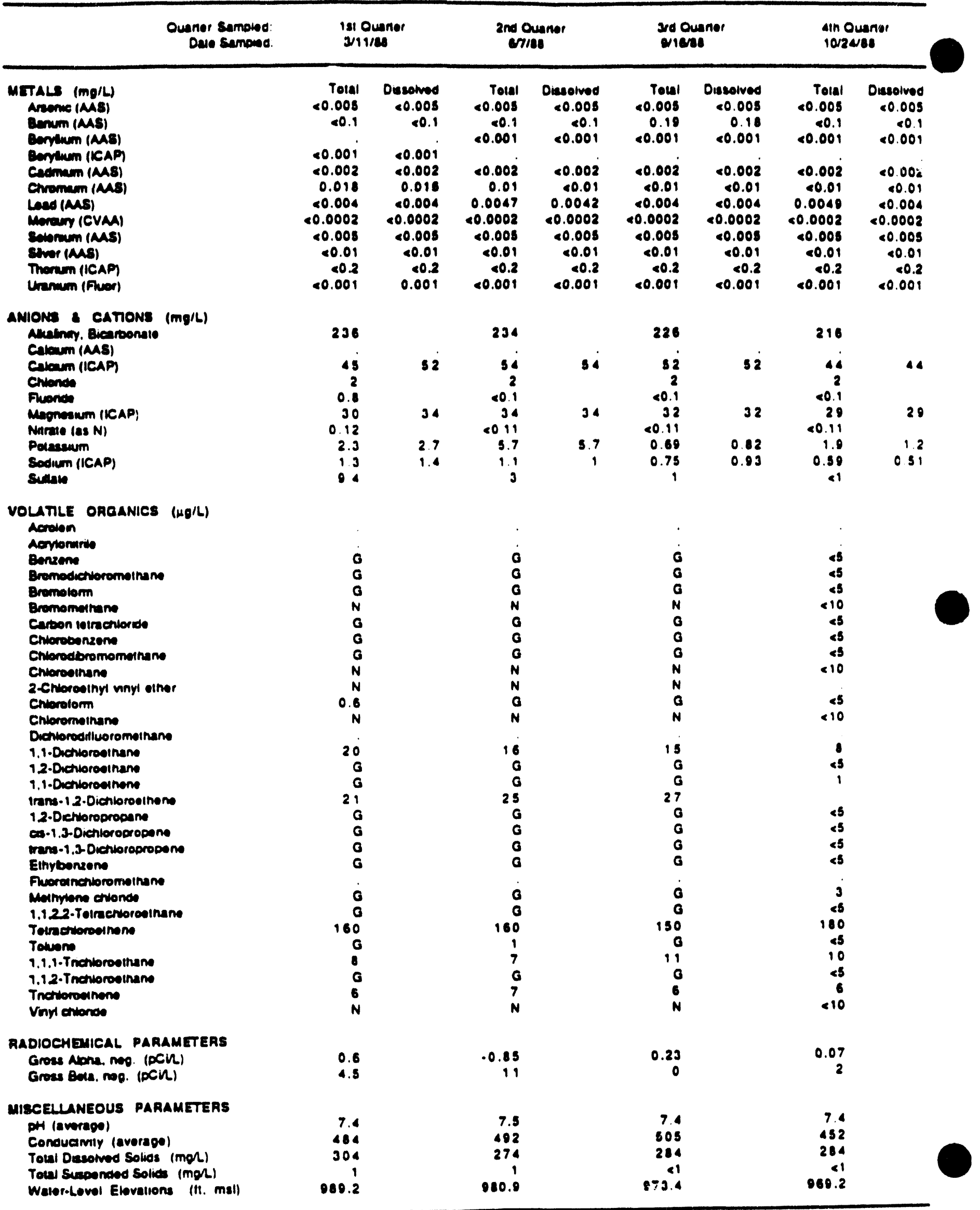


Asessement Date tor Monmer-Woll OW.181

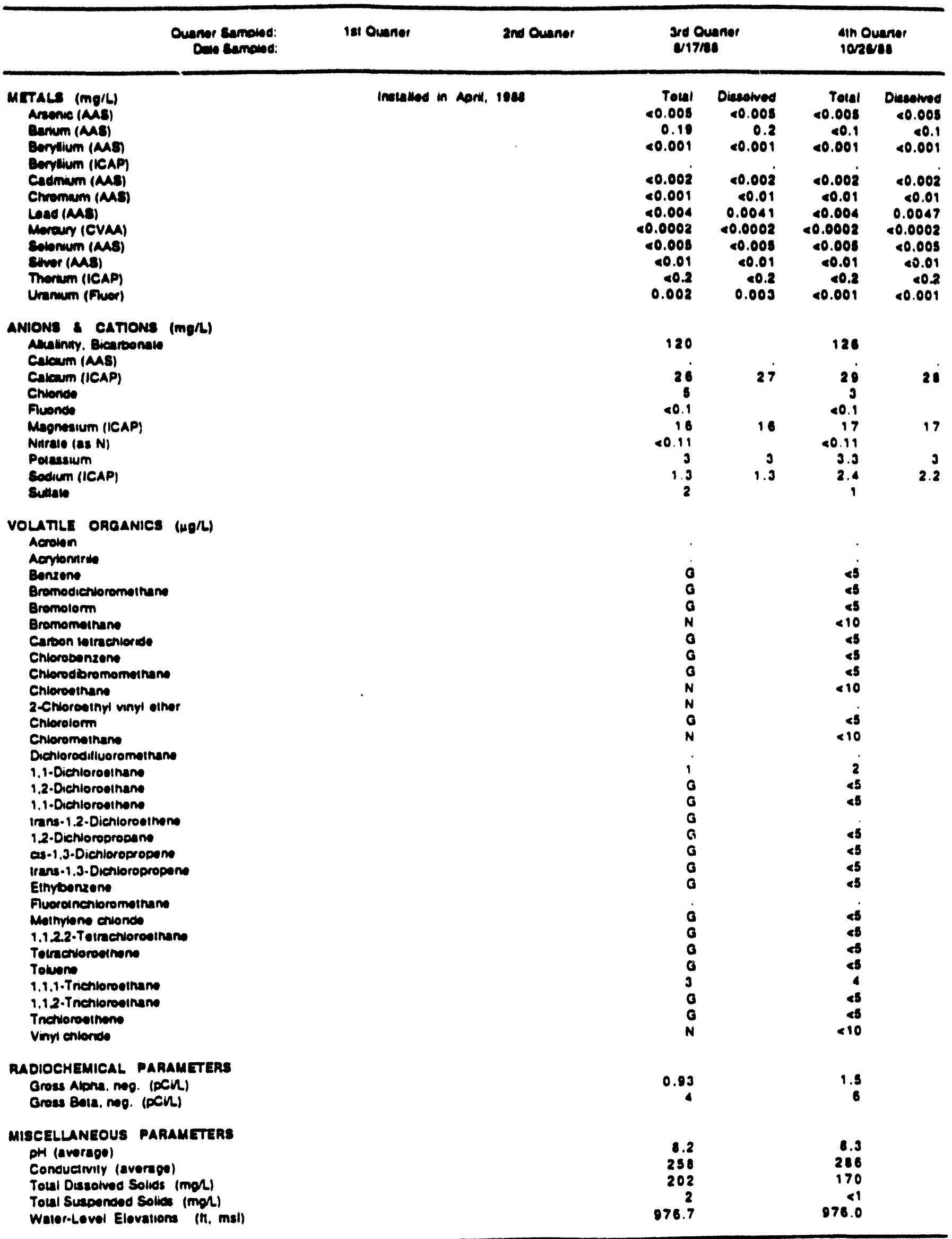




\section{A-88}

Asscasmom Dala ler Monmor.Woll OW.322

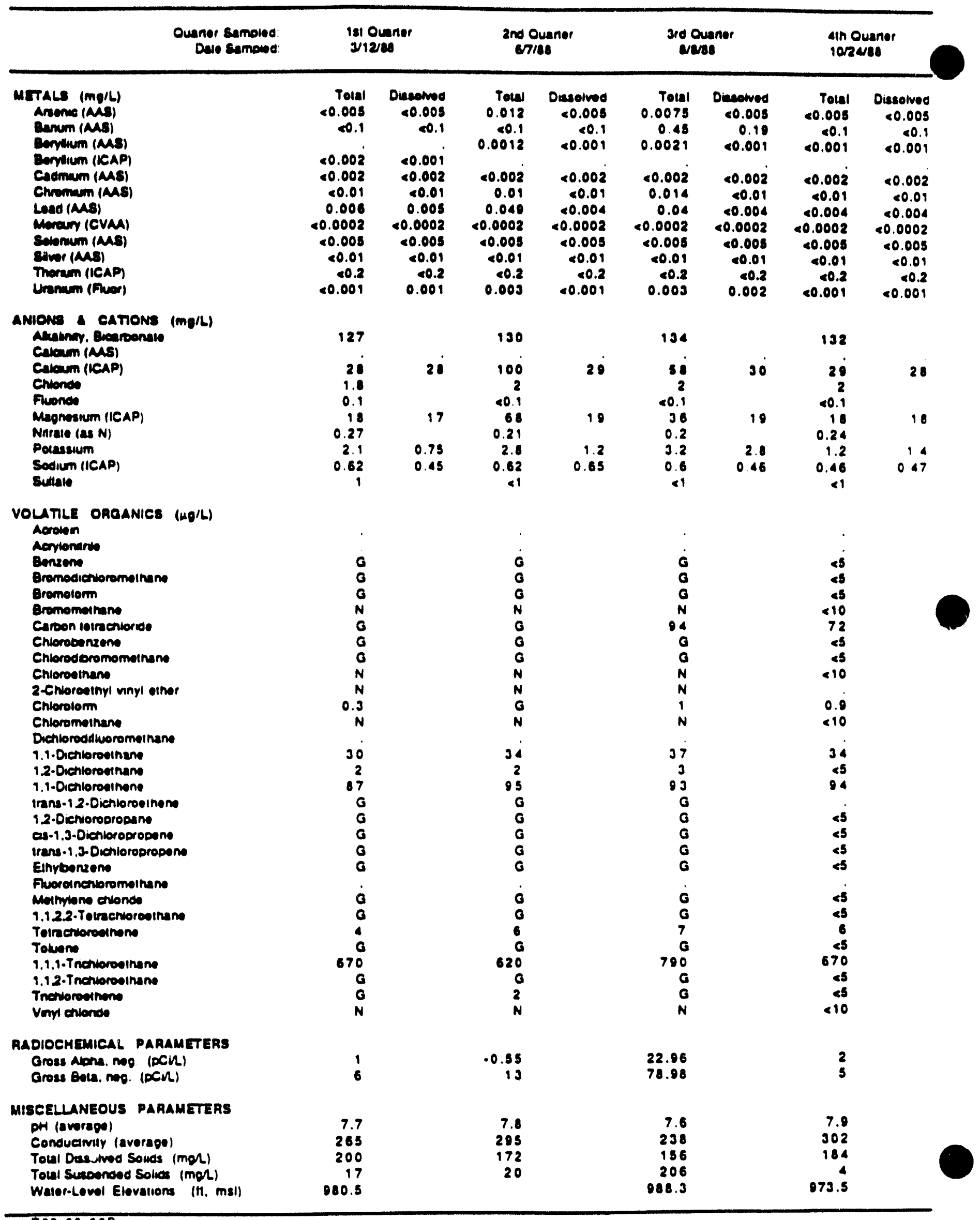


Acsessmon Date lor Monmer.Woll GW.s11

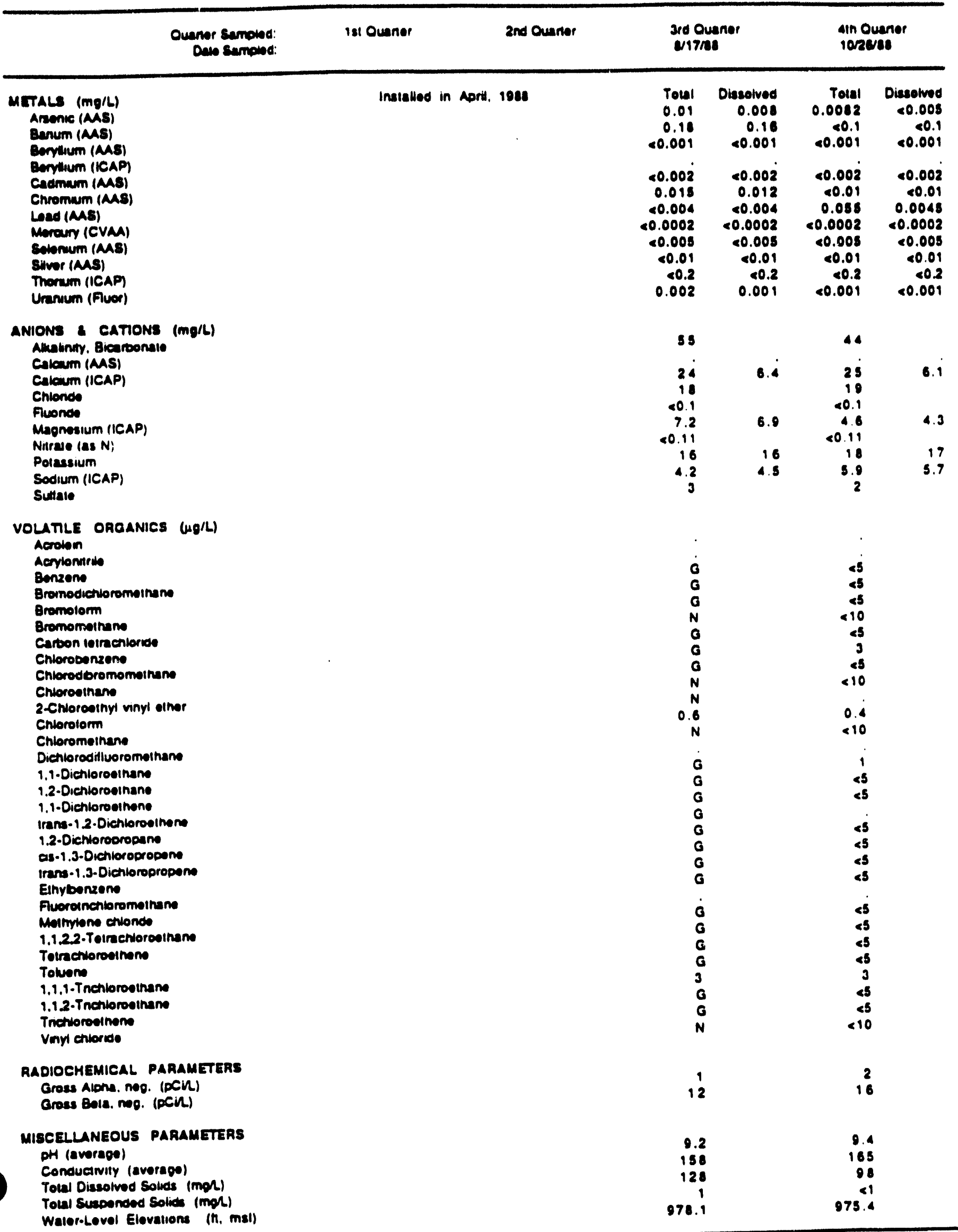




\section{A-90}

Appendix IX Dala lor Monmor-Wolls al Chosinun Aidge Socunty Pins Hazardous-Wasie Disposal Unit. 1988

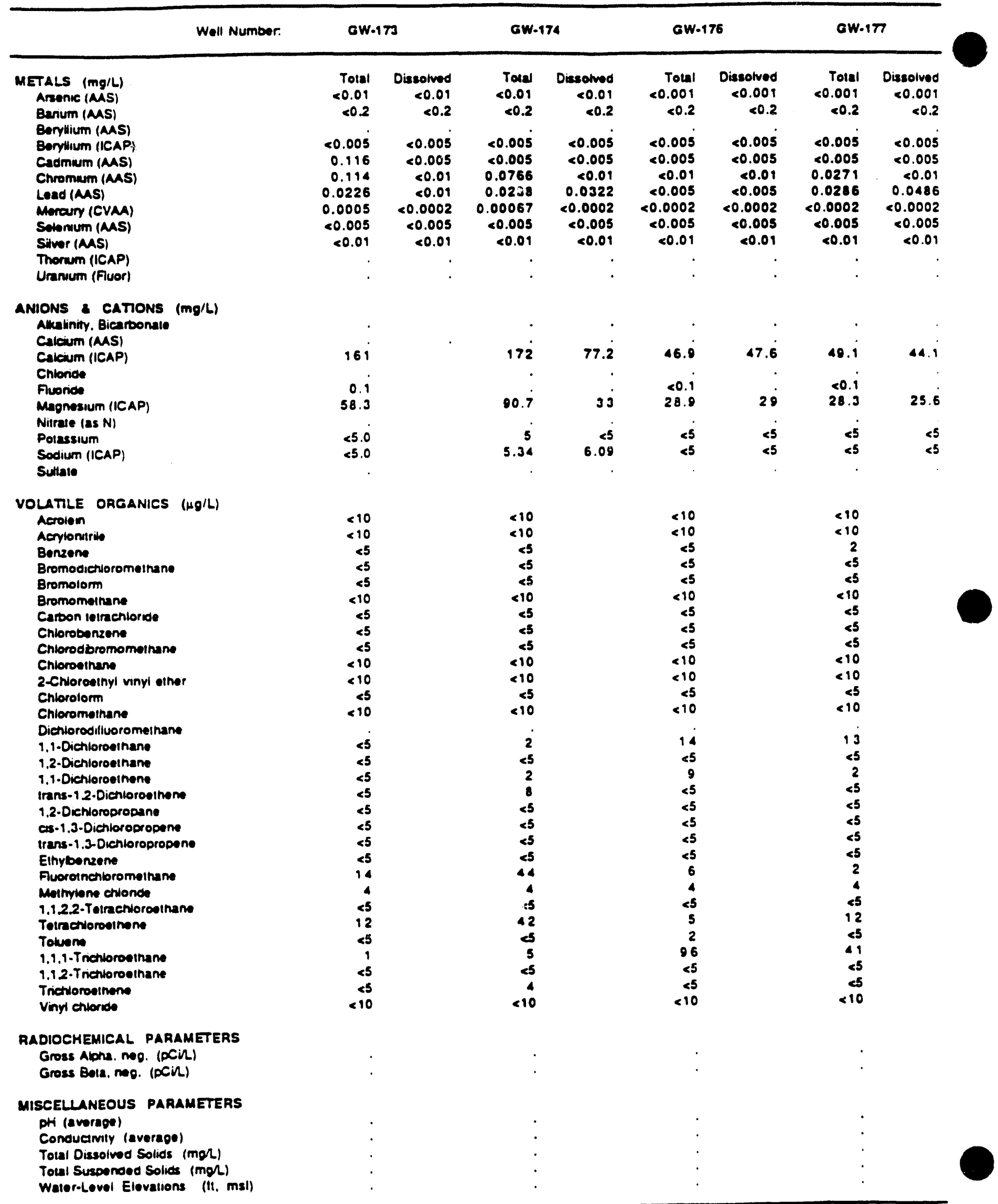

R02-14.898a 


\section{A-91}

Apoendix IX Data lop Monnor-Welis at Chestnut Ridge Secumy Pits Hazardous-Waste Disposal Unit. 1988

\begin{tabular}{|c|c|c|c|c|c|c|}
\hline Well Number: & \multicolumn{2}{|c|}{ GW.178 } & \multicolumn{2}{|c|}{ GW.180 } & \multicolumn{2}{|c|}{ GW-322 } \\
\hline $\begin{array}{l}\text { METALS (mg/L) } \\
\text { Arsenic (MAS) }\end{array}$ & $\begin{array}{r}\text { Toral } \\
<0.001\end{array}$ & $\begin{array}{l}\text { Dissolvod } \\
<0.001\end{array}$ & $\begin{array}{r}\text { Total } \\
<0.001\end{array}$ & $\begin{array}{r}\text { Disselved } \\
<0.001\end{array}$ & $\begin{array}{r}\text { Total } \\
<0.001\end{array}$ & $\begin{array}{r}\text { Dissolved } \\
<0.001\end{array}$ \\
\hline $\begin{array}{l}\text { Benum (NAS) } \\
\text { Beryllium (AAS) }\end{array}$ & $<0.2$ & $<0.2$ & $<0.2$ & $<0.2$ & $<0.2$ & $<0.2$ \\
\hline Beryllium (KCAP) & $<0.005$ & $<0.005$ & $<0.005$ & $<0.005$ & $<0.005$ & $<0.005$ \\
\hline Cadmum (MSS) & $\times 0.005$ & $<0.005$ & 0.0612 & $<0.005$ & $<0.005$ & $<0.005$ \\
\hline Chromum (MAS) & $\begin{array}{l}0.023 \\
0.024\end{array}$ & $\begin{array}{r}<0.01 \\
<0.005\end{array}$ & $\begin{array}{r}<0.01 \\
<0.005\end{array}$ & $\begin{array}{l}<0.01 \\
<0.005\end{array}$ & $\begin{array}{l}0.047 \\
0.017\end{array}$ & $\begin{array}{l}<0.01 \\
<0.005\end{array}$ \\
\hline & $<0.0002$ & $<0.0002$ & $<0.0002$ & $<0.0002$ & $<0.0002$ & $<0.0002$ \\
\hline $\begin{array}{l}\text { Mercury (CVA) } \\
\text { Selenium (AAS) }\end{array}$ & $<0.005$ & $<0.005$ & $<0.005$ & $<0.005$ & $<0.005$ & $<0.005$ \\
\hline Siver (AMS) & $<0.01$ & $<0.01$ & $<0.01$ & $<0.01$ & $<0.01$ & $<0.01$ \\
\hline Thorium (ICAP) & . & . & . & • & . & . \\
\hline Uranium (Fluor) & . & . & $\cdot$ & . & . & . \\
\hline ANIONS \& CATIONS (mg/L) & & & & & & \\
\hline $\begin{array}{l}\text { Allahniry. Bicarbonave } \\
\text { Calcum (AMS) }\end{array}$ & . & & $\cdot$ & $\cdot$ & $\cdot$ & . \\
\hline Calcum (ICAP) & 48.3 & $4 i$ & 47 & 46.5 & $\sin$ & : \\
\hline Cnloride & & . & $\begin{array}{r}47 \\
.\end{array}$ & $\begin{array}{r}46.3 \\
.\end{array}$ & 150 & 30.6 \\
\hline Fluonde & $<0.1$ & & $<0 . i$ & . & $<0 . i$ & · \\
\hline Magnesium (ICAP) & 26.9 & 24.7 & 28.2 & $28 . i$ & 90.1 & 18 \\
\hline Nitrate (as N) & & & . & 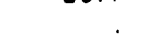 & . & 18 \\
\hline Polassium & $<5$ & $<5$ & \& & $<5$ & $<5$ & $<5$ \\
\hline Sodium (ICAP) & $<5$ & $<5$ & $<5$ & $<5$ & $<5$ & $<5$ \\
\hline Sullate & $\cdot$ & $\cdot$ & . & · & & . \\
\hline VOLATILE ORGANICS ( $\mu g / L)$ & & & & & & \\
\hline $\begin{array}{l}\text { Acrobien } \\
\text { Acryionitide }\end{array}$ & $<10$ & & $<10$ & & $<10$ & \\
\hline $\begin{array}{l}\text { Acrylonitrite } \\
\text { Benzoma }\end{array}$ & $<10$ & & $<10$ & & $<10$ & \\
\hline & $<5$ & & $<5$ & & $<5$ & \\
\hline $\begin{array}{l}\text { Bromodictioromolinane } \\
\text { Bromotorm }\end{array}$ & $<5$ & & $<5$ & & $<5$ & \\
\hline & $<5$ & & es & & $<5$ & \\
\hline & $<10$ & & $<10$ & & $<10$ & \\
\hline & $<5$ & & 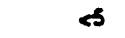 & & $<5$ & \\
\hline $\begin{array}{l}\text { Chlorobenzene } \\
\text { Chlorodibromomeinane }\end{array}$ & $<5$ & & $<5$ & & $<5$ & \\
\hline $\begin{array}{l}\text { Chlorodibromomeinane } \\
\text { Chlorosthan }\end{array}$ & $<5$ & & es & & $<5$ & \\
\hline & $<10$ & & $<10$ & & $<10$ & \\
\hline $\begin{array}{l}\text { 2-Chorosthyl vinyl ether } \\
\text { Chlorolom }\end{array}$ & $<10$ & & $<10$ & & $<10$ & \\
\hline & $<5$ & & <s & & $<5$ & \\
\hline & $<10$ & & $<10$ & & $<10$ & \\
\hline $\begin{array}{l}\text { Dichlorodifluoromethane } \\
\text { 1.1-Diehloroethane }\end{array}$ & 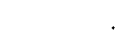 & & . & & & \\
\hline & $<10$ & & 7 & & 27 & \\
\hline & $<5$ & & $<5$ & & 3 & \\
\hline & $<5$ & & 2 & & 68 & \\
\hline & $<5$ & & 25 & & $<5$ & \\
\hline $\begin{array}{l}\text { 1.2-Dichloroprodane } \\
\text { as-1.3-Dienloropropene }\end{array}$ & $<5$ & & $<5$ & & $<5$ & \\
\hline $\begin{array}{l}\text { as-1.3-Dienloropropene } \\
\text { Irans-1.J-Dichloropropone }\end{array}$ & $<5$ & & $<5$ & & $<5$ & \\
\hline $\begin{array}{l}\text { Irans-1.3-Dichloropropene } \\
\text { Elhybenzene }\end{array}$ & $<5$ & & $<5$ & & $<5$ & \\
\hline $\begin{array}{l}\text { Elhybenzene } \\
\text { Fluoroinchioromoinam }\end{array}$ & es & & $<5$ & & $<5$ & \\
\hline $\begin{array}{l}\text { Fuoroinchioromoiname } \\
\text { Methyiene chionde }\end{array}$ & 2 & & 39 & & 18 & \\
\hline $\begin{array}{l}\text { Methyien chionde } \\
\text { 1.1.2.2-Telrechiorosiname }\end{array}$ & 3 & & 5 & & 6 & \\
\hline $\begin{array}{l}\text { 1.1.2.2-Telrachiorootham } \\
\text { Tetracrioroethom }\end{array}$ & $\infty$ & & 4 & & $<5$ & \\
\hline & $<5$ & & 170 & & 4 & \\
\hline $\begin{array}{l}\text { Toluen } \\
\text { 1,1,1-Trichkroetnans }\end{array}$ & es & & $\infty$ & & 1 & \\
\hline $\begin{array}{l}\text { 1,1,1-Trichlarootinans } \\
\text { 1,12.Trietioroothane }\end{array}$ & 15 & & 8 & & 550 & \\
\hline & es & & 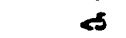 & & $<5$ & \\
\hline & $<5$ & & 7 & & $<5$ & \\
\hline Vinyl chioride & $<10$ & & $<10$ & & $<10$ & \\
\hline RADIOCHENICAL PARAMETERS & & & & & & \\
\hline Gross Alona, nog. (pCin) & . & & . & & & \\
\hline Gross Bala, nog. (pCin) & . & & . & & $\cdot$ & \\
\hline MISCELLANEOUS PARAMETERS & & & & & & \\
\hline pH (average) & . & & . & & . & \\
\hline Conduearvily (averape) & . & & $\cdot$ & & $\cdot$ & \\
\hline Total Dissolved Solids (mon) & . & & . & & & \\
\hline Tolal Susponded Solvas (mel) & . & & . & & . & \\
\hline Water-Level Elevalions (fi, msl) & . & & · & & & \\
\hline
\end{tabular}

R02.14.8988 
THIS PAGE INTENTIONALLY

LEFT BLANK 


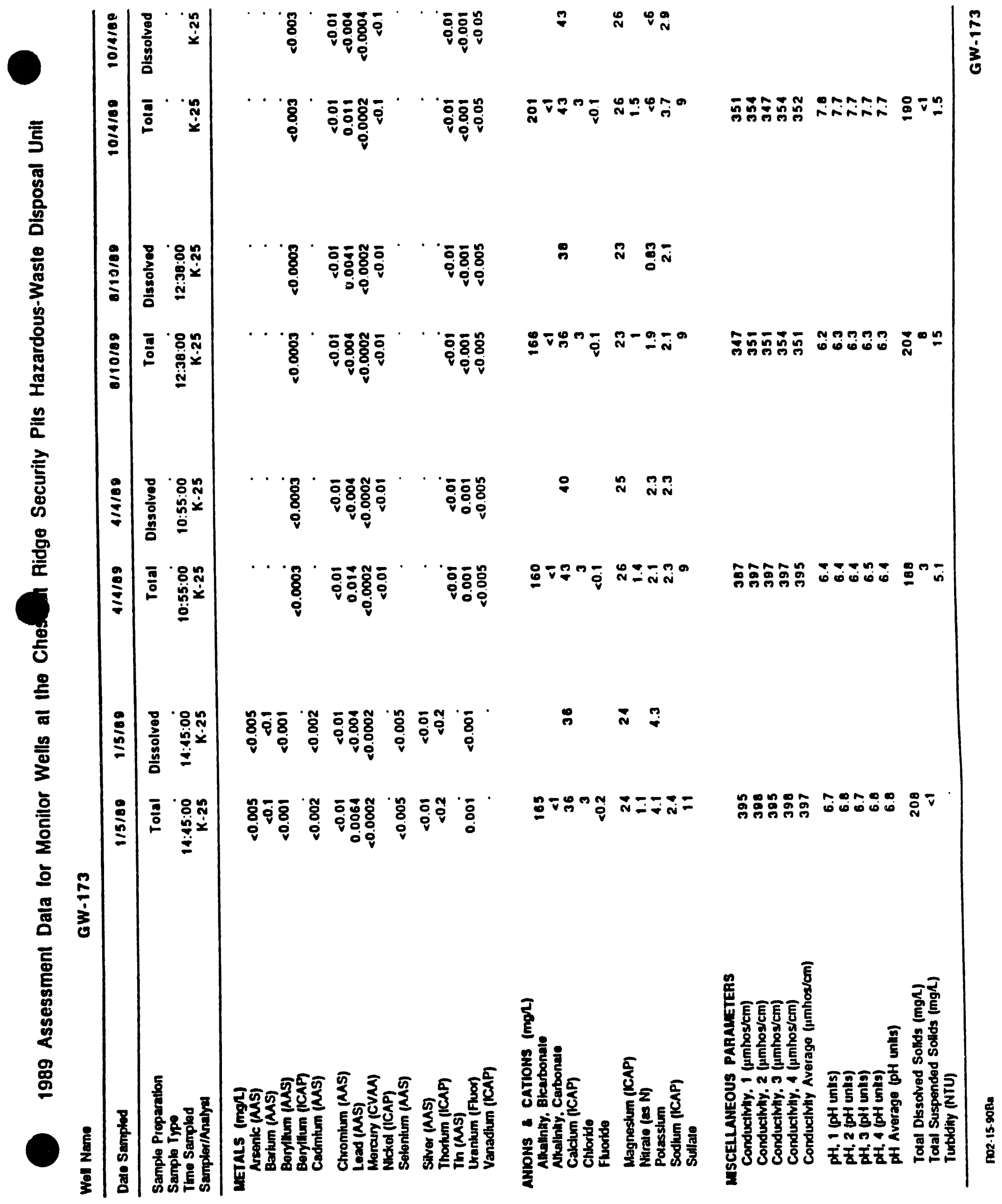




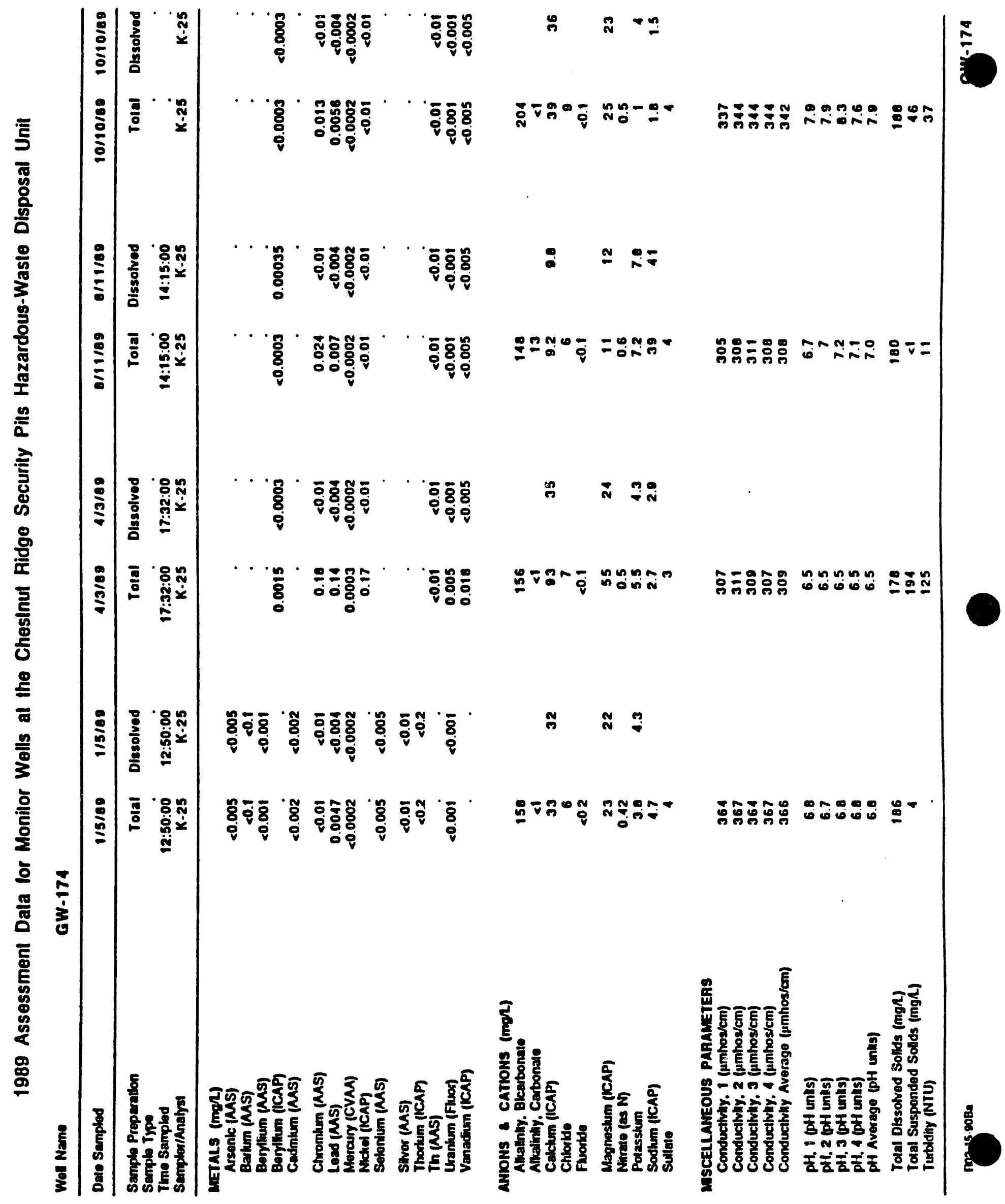




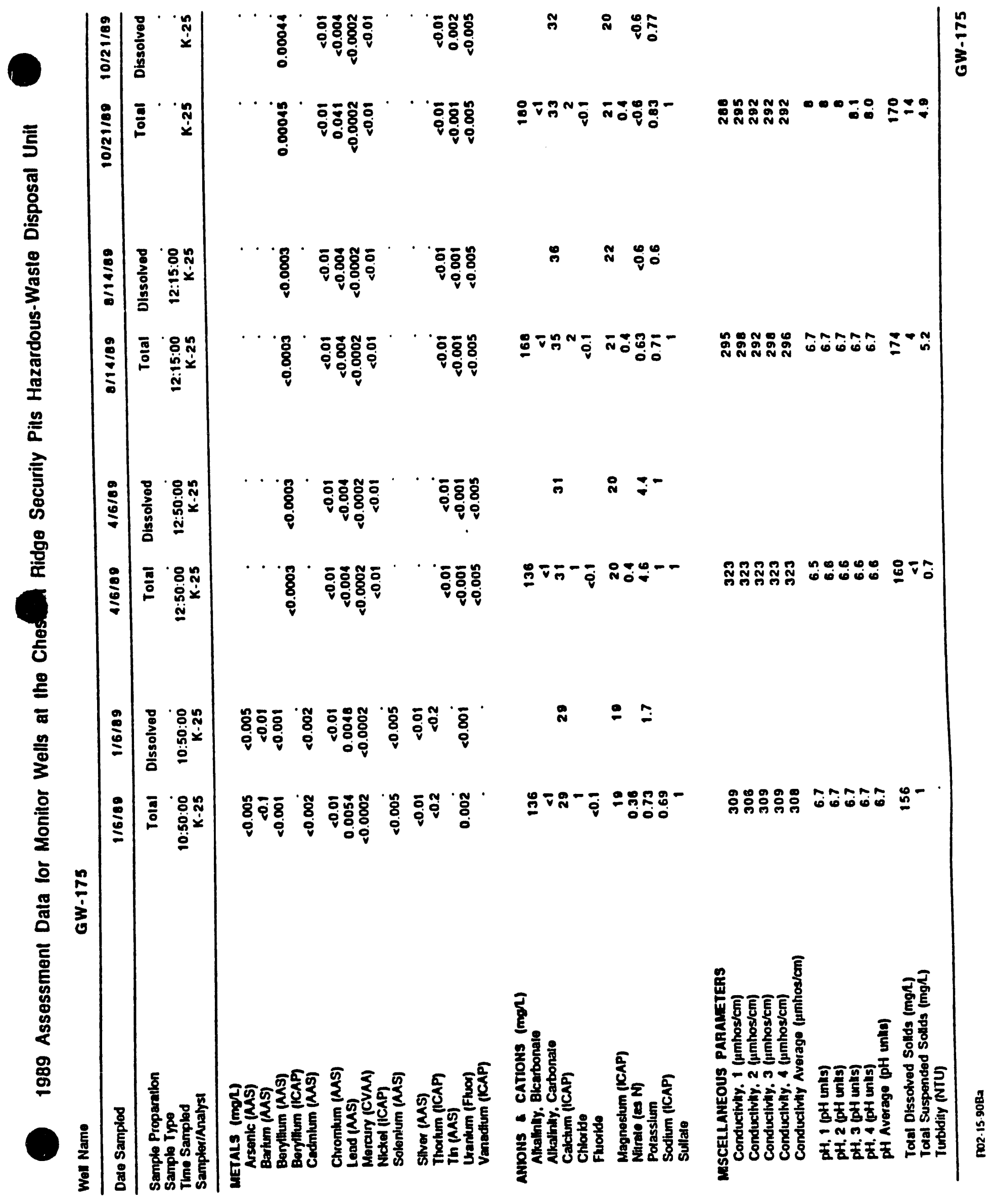




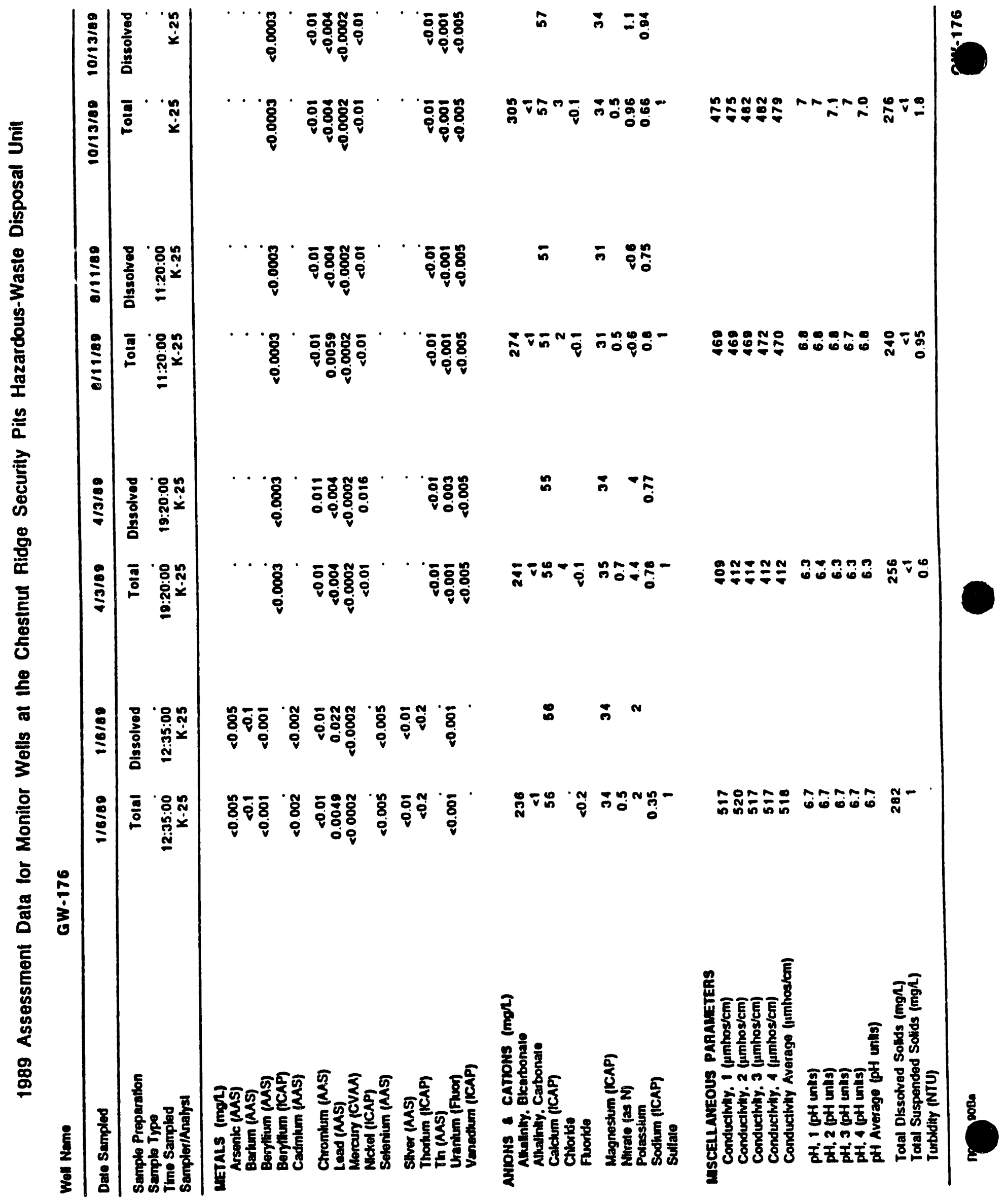




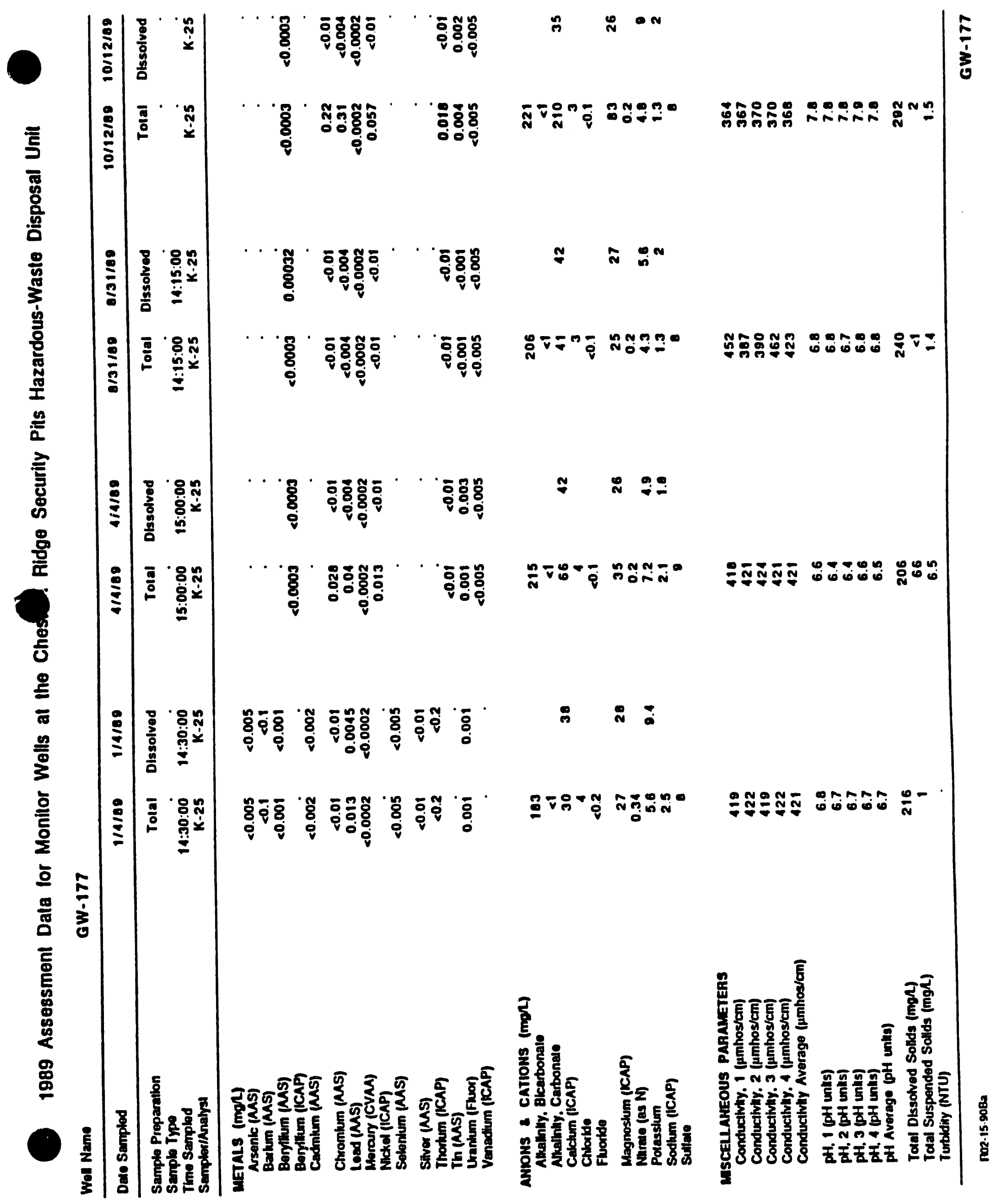




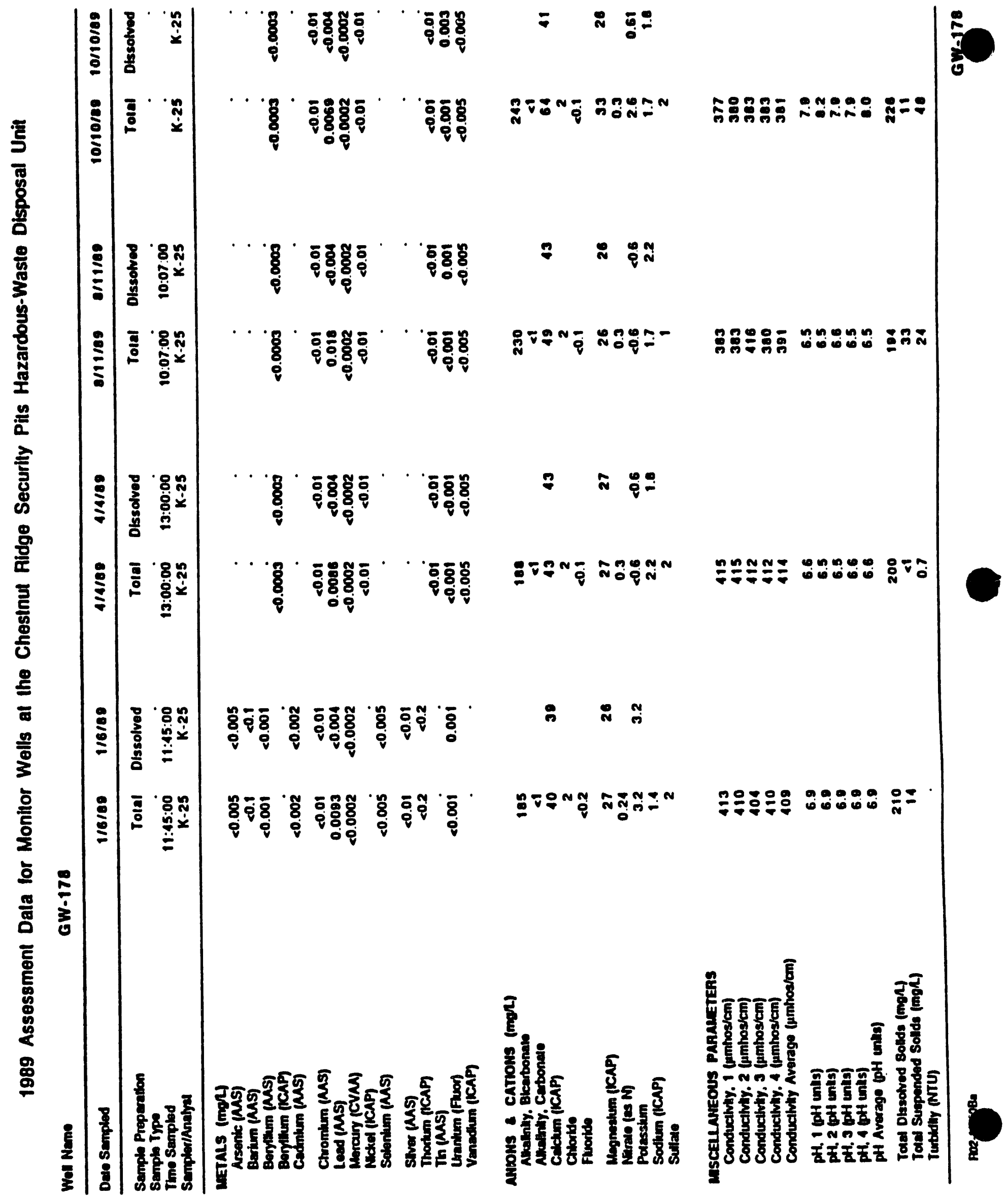




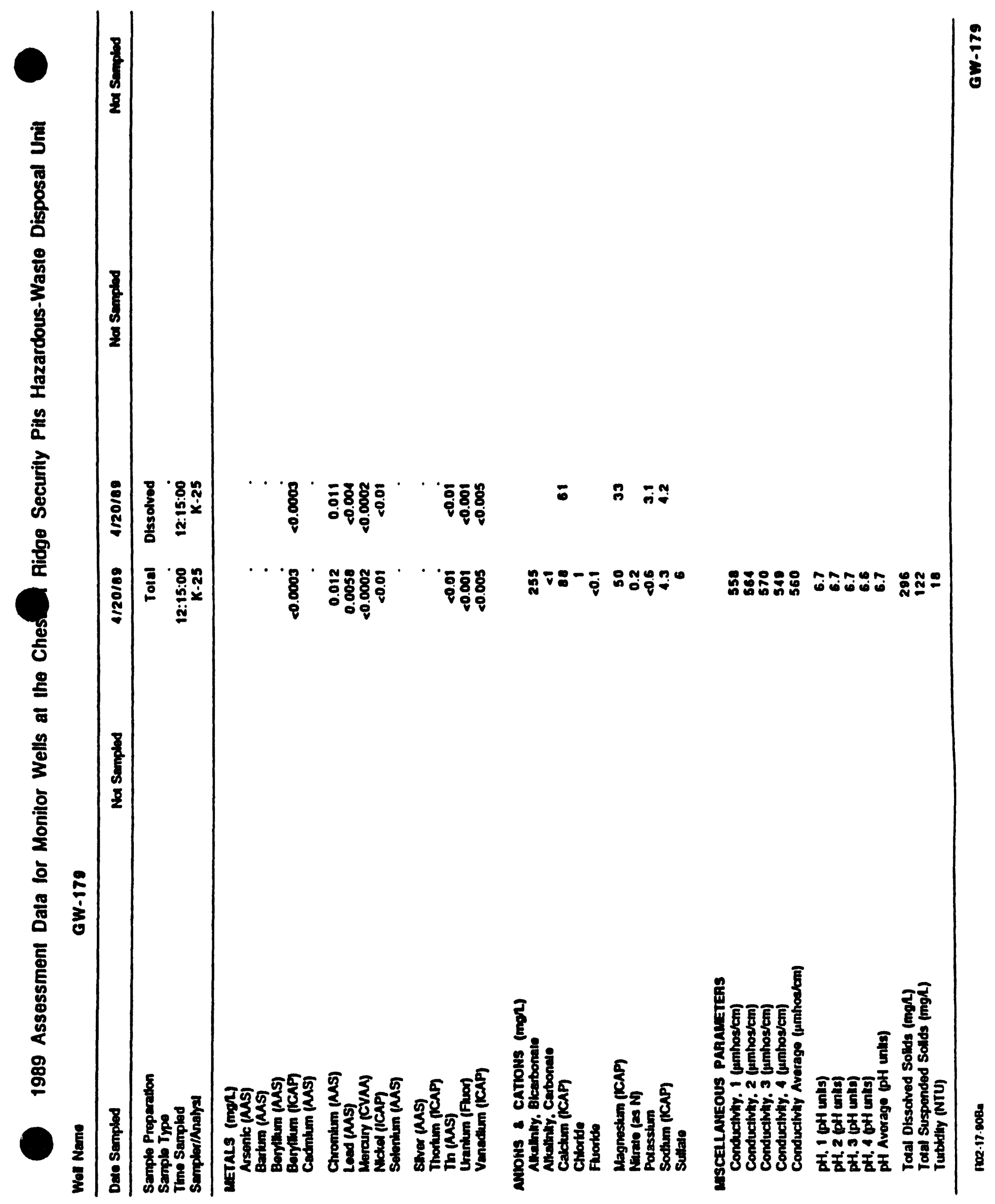




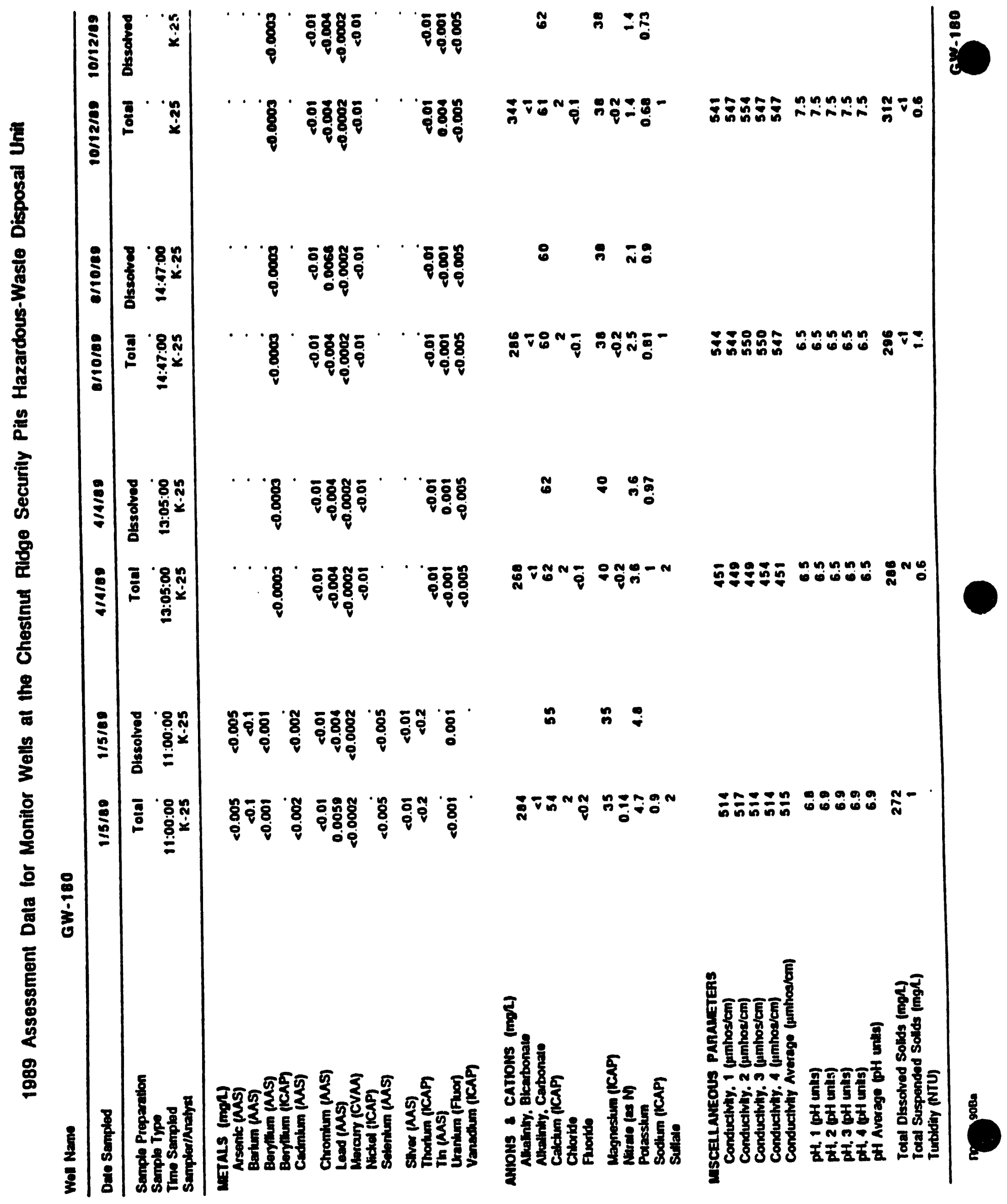




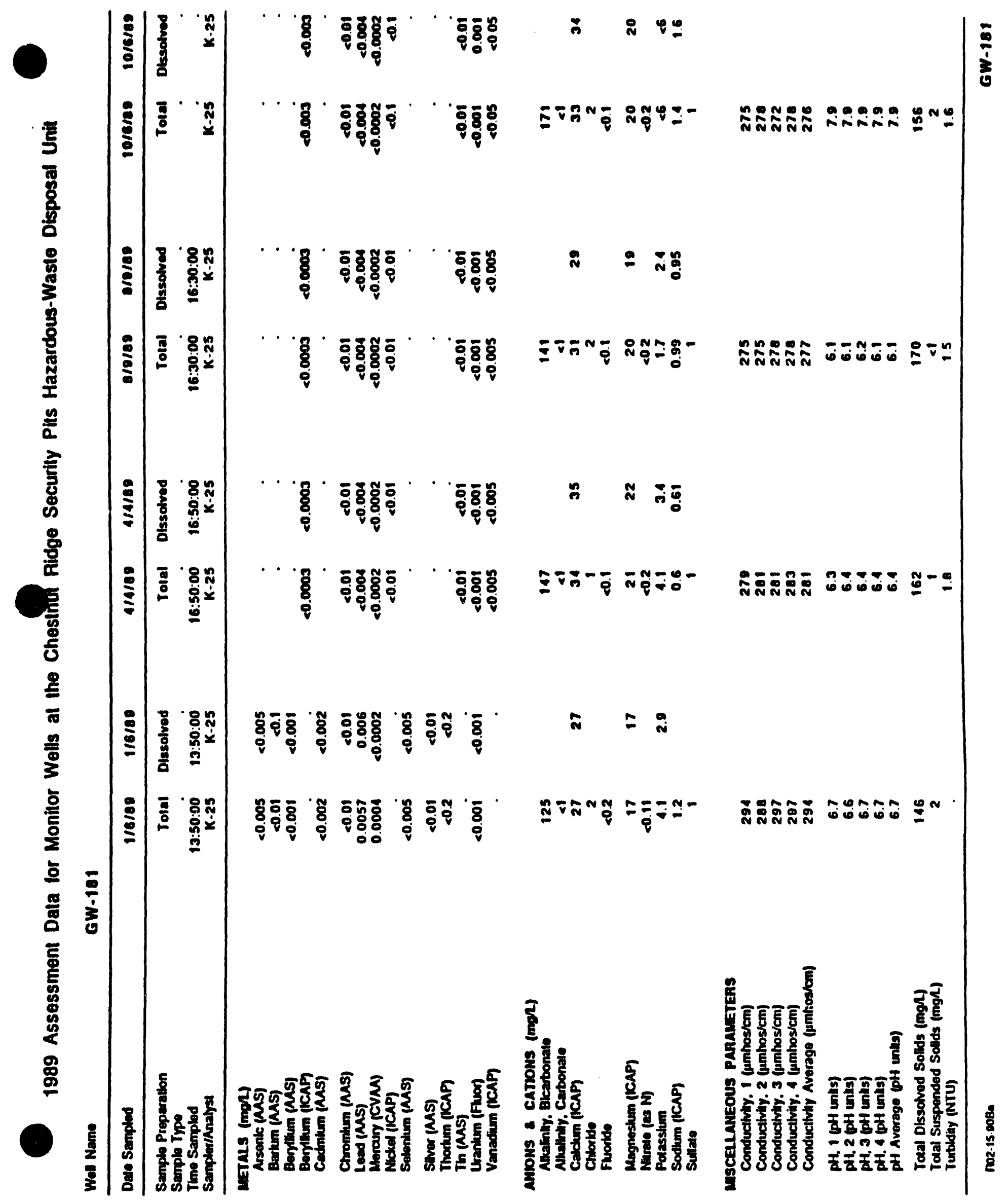




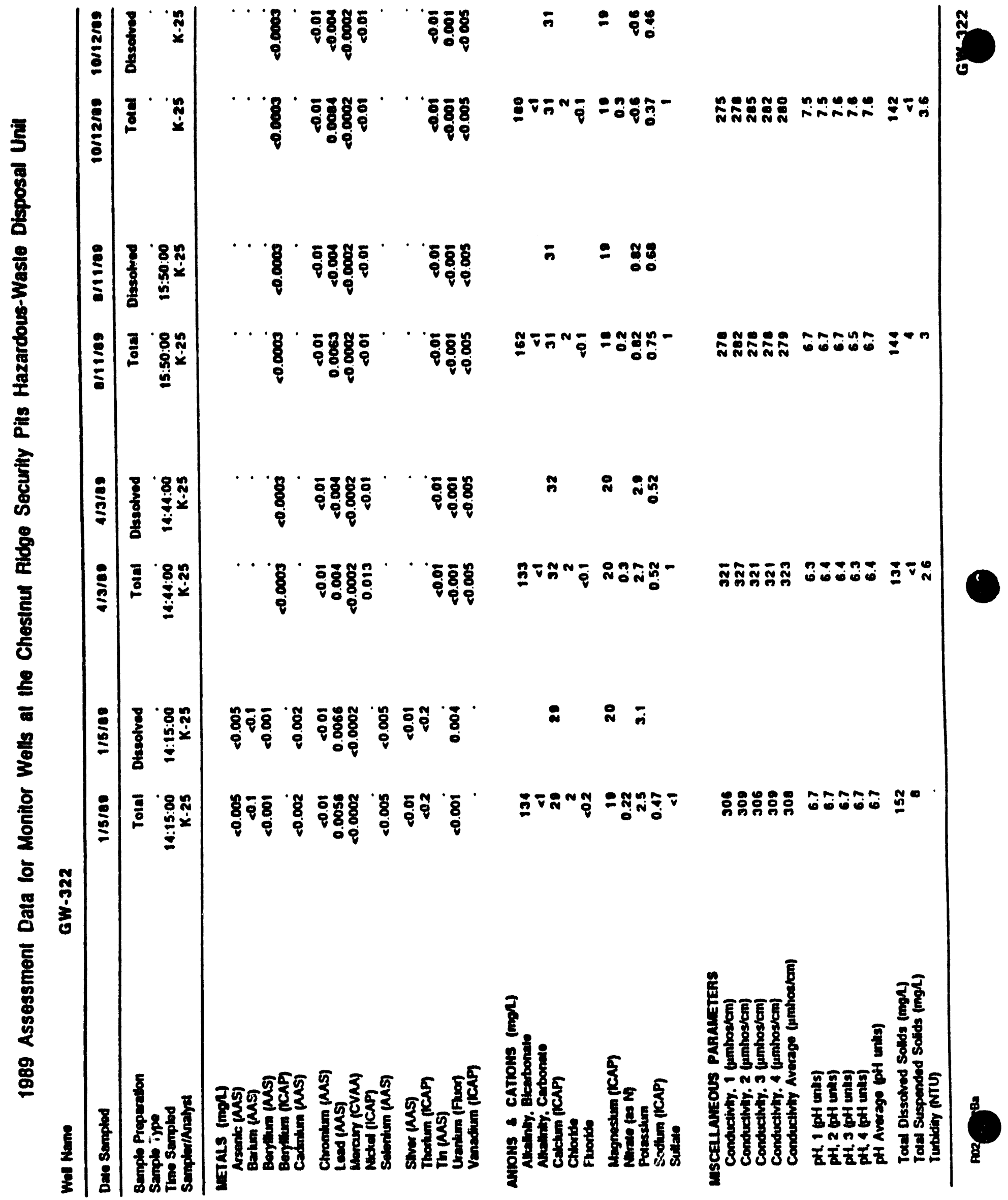




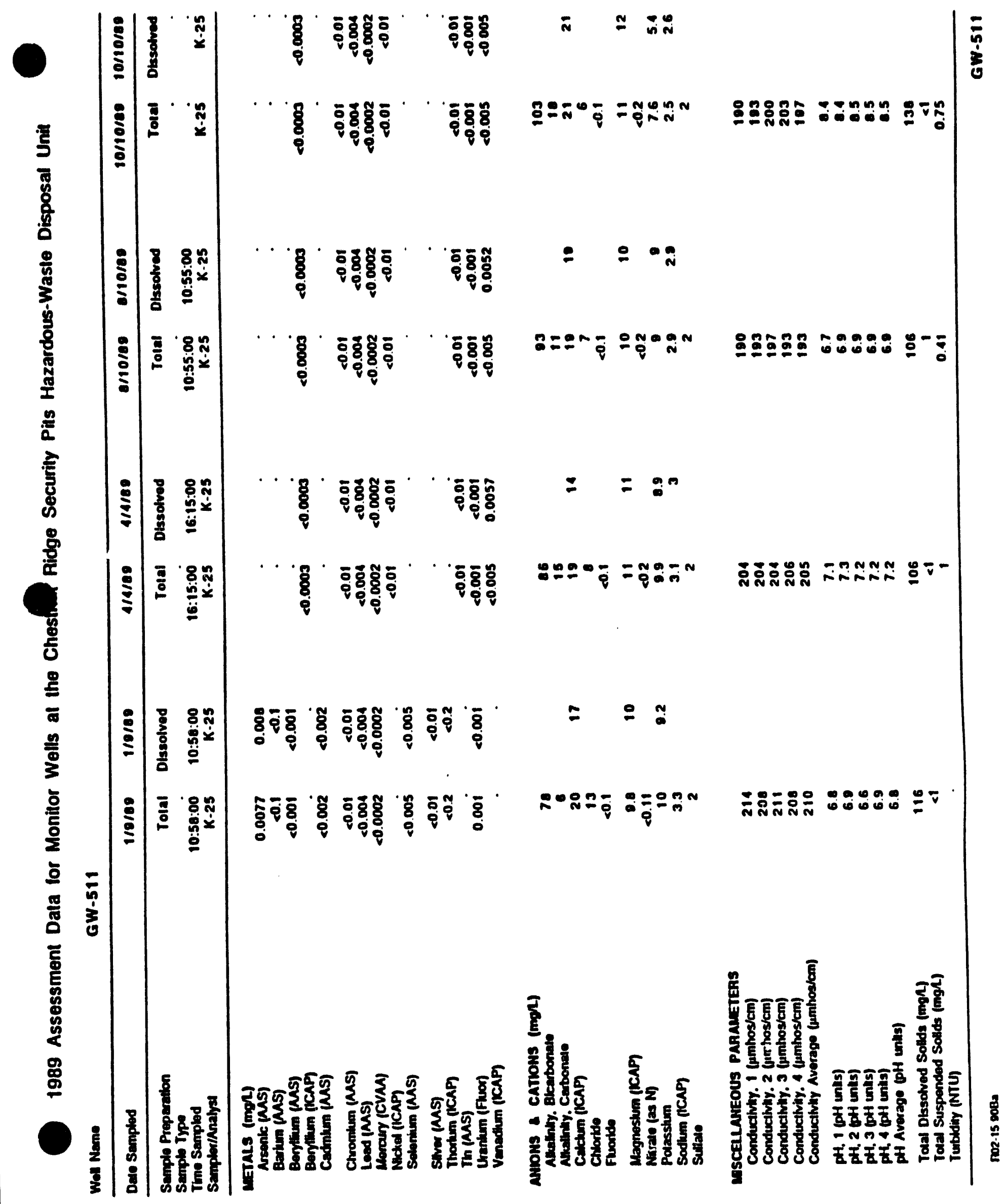




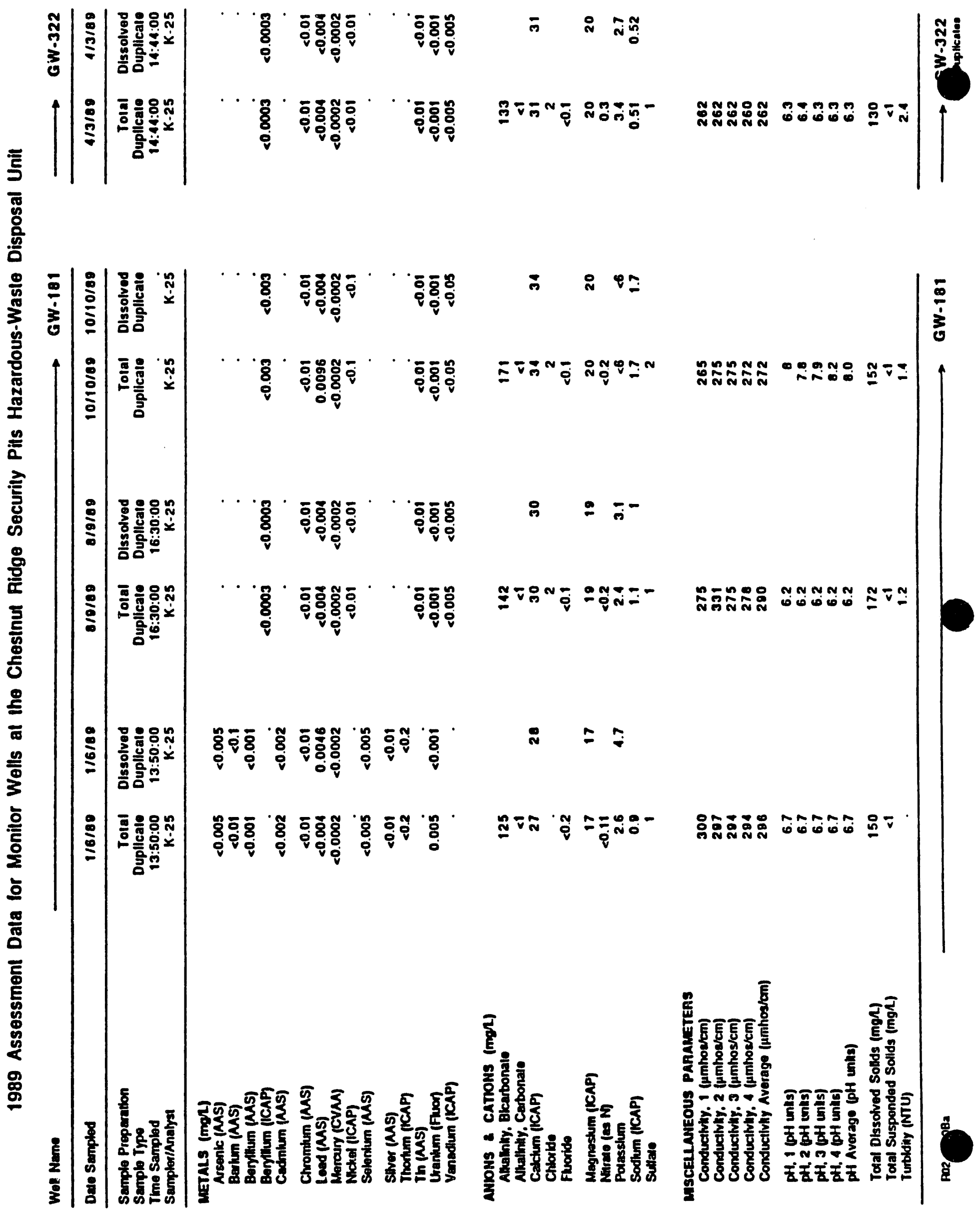




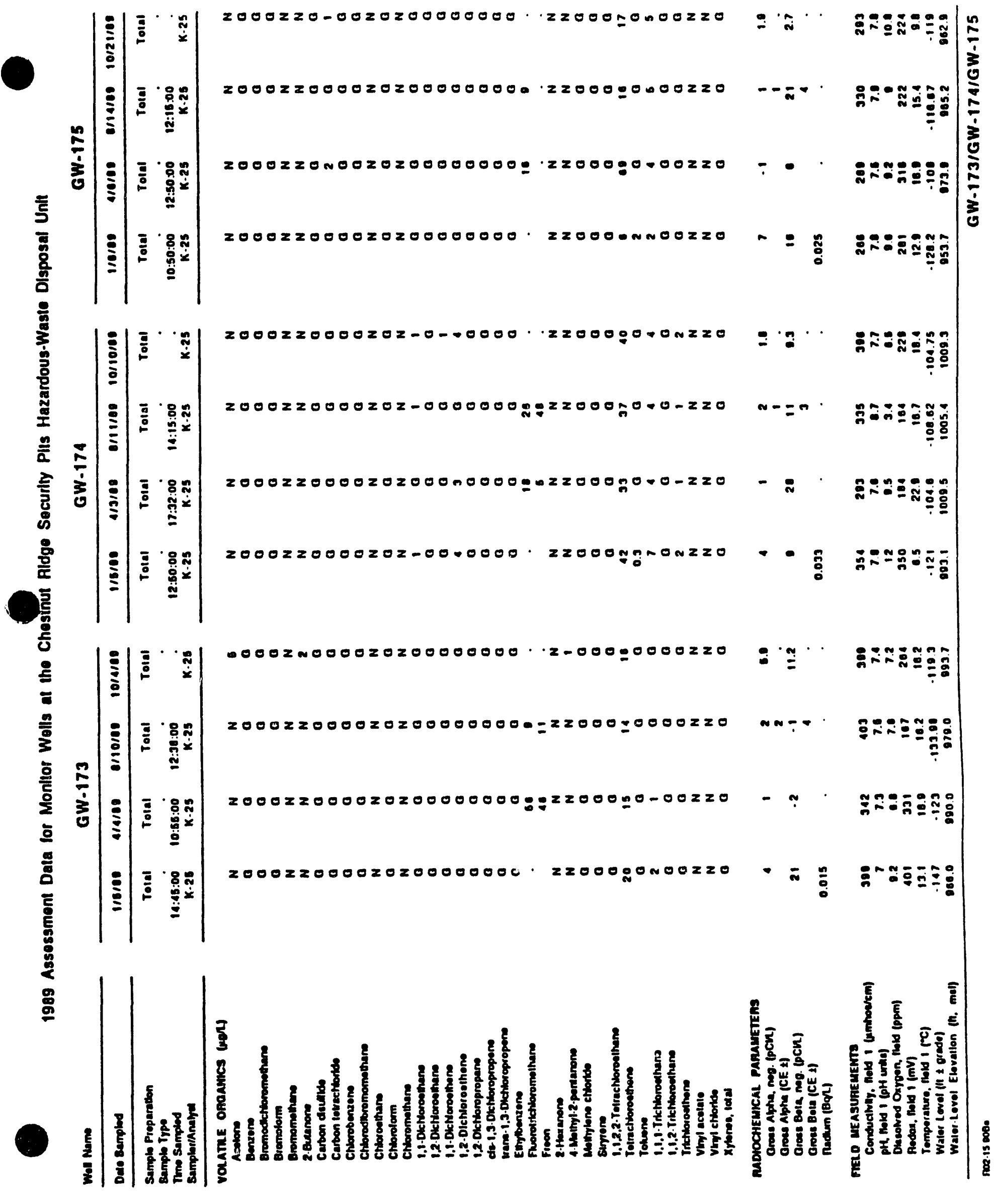




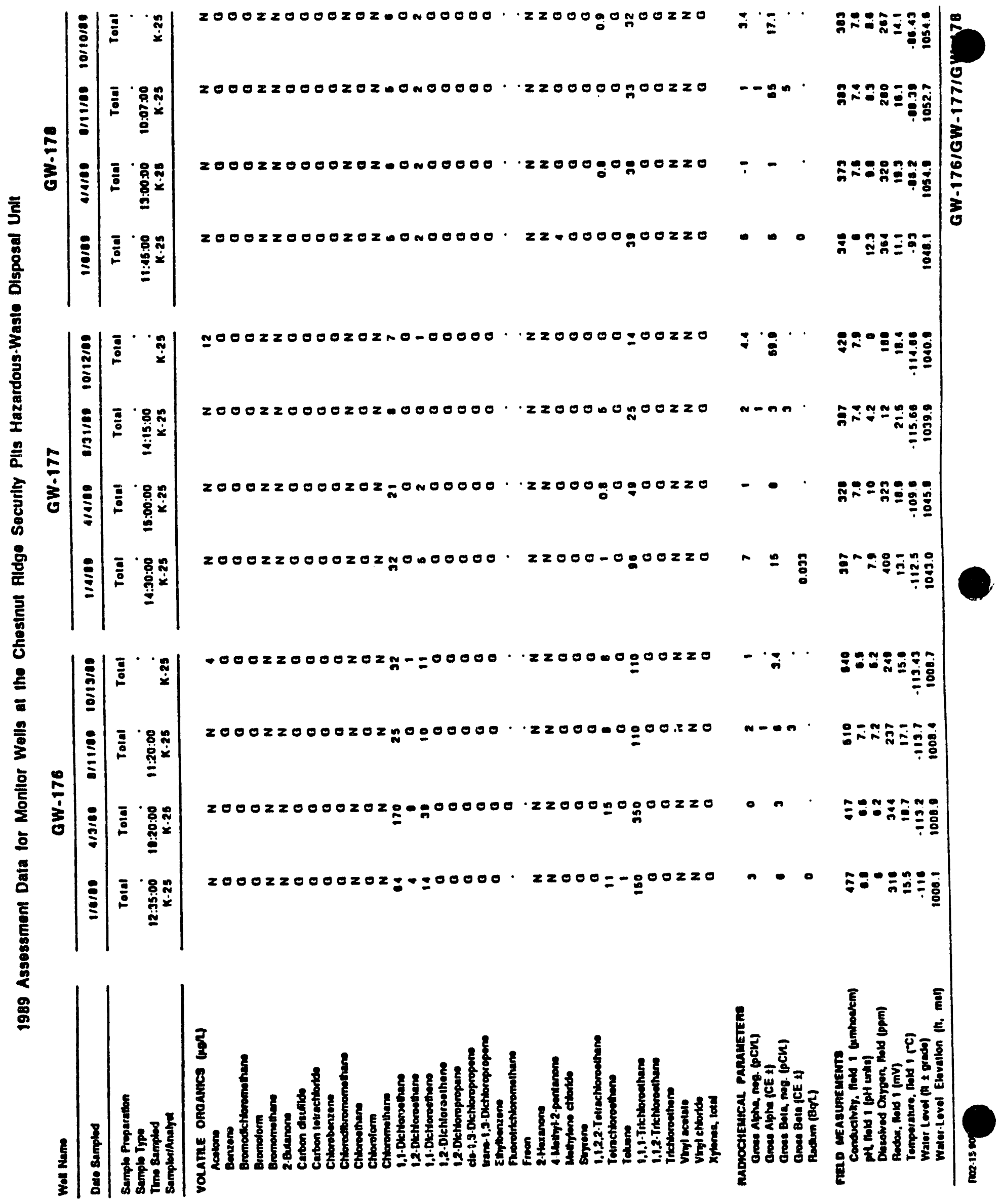




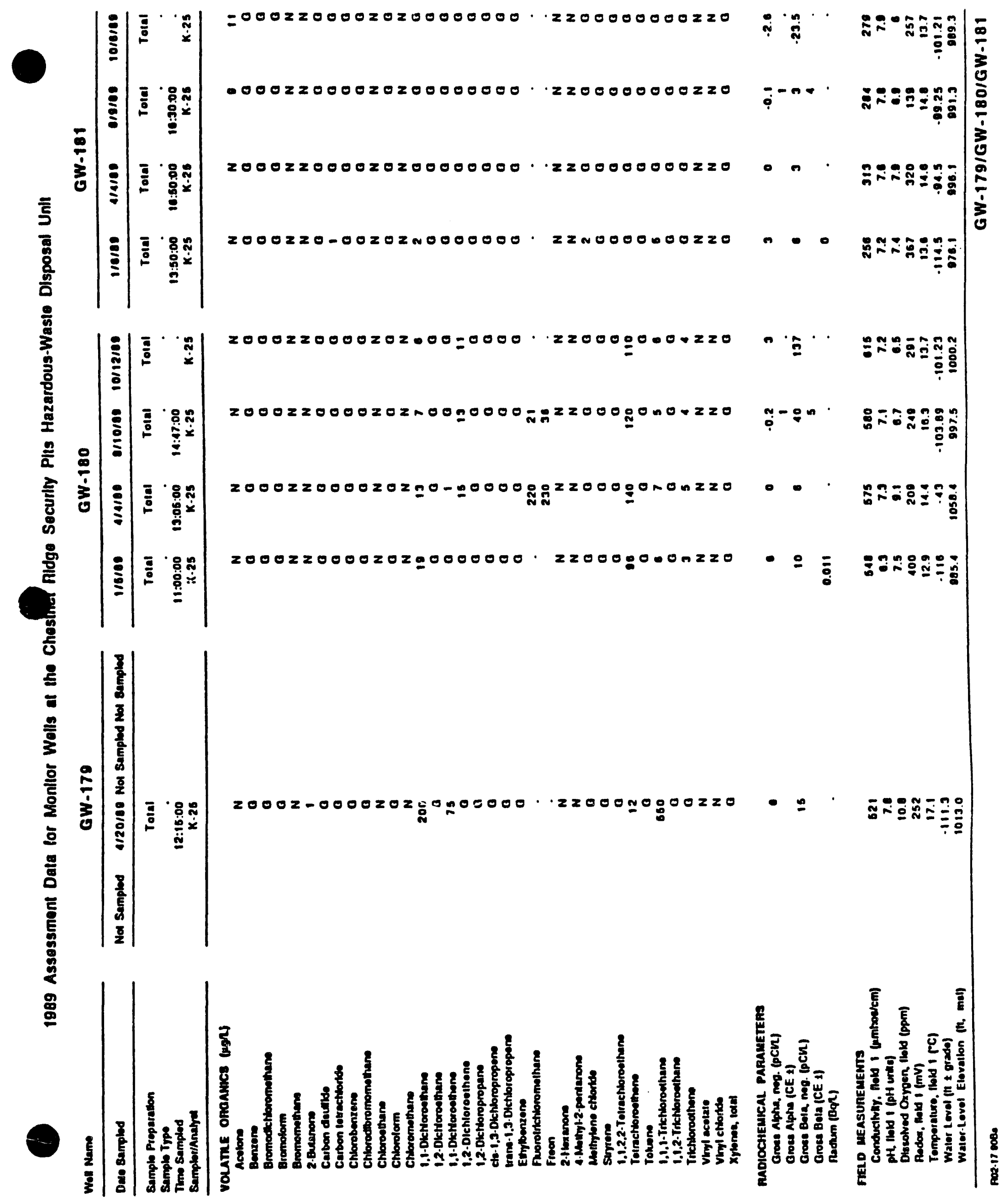




\section{A-108}

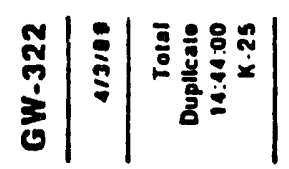

$2000220000202808000000 n 2200000000220 \quad$ N

๕)

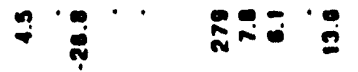

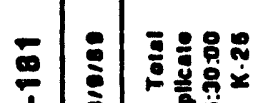

200022000020200000000

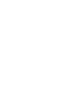

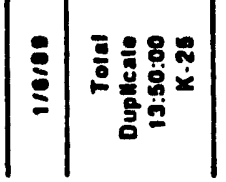

$200022000020200000000^{\circ} 22200000000220$

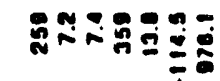

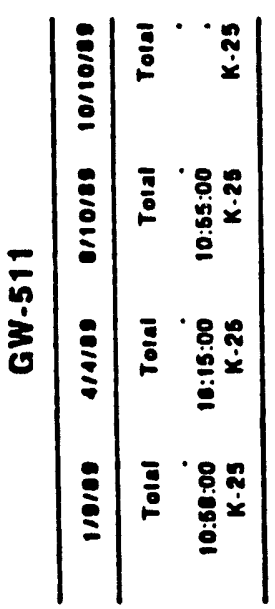

$000022000020200000000 \cdot .2200000000220$

I.

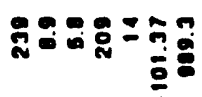

$200022000020200000000 \cdots 2200000000220$

$+\infty: \infty \cdot$

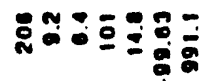

$200022000020200000000 \cdot .2200000-00220$

$\div$

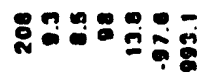

$0000220000202-0000000 \cdot 2200000000220 N=0$

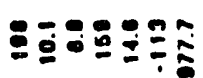

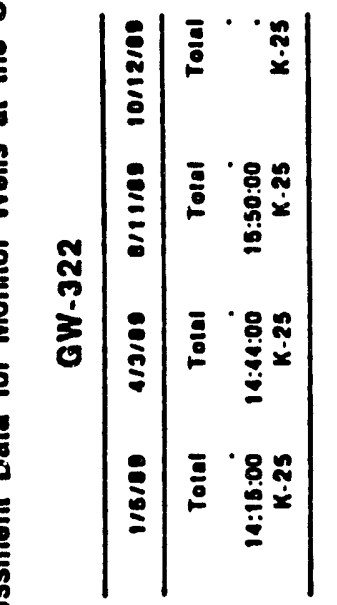

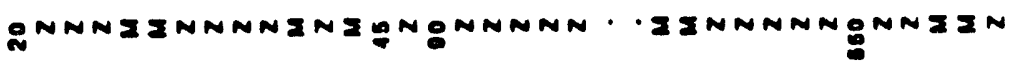

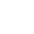

$20002200002-2 h n g 00000 h \cdot 2300000000220$

$\stackrel{\text { : }}{\circ}-\mathbf{0}$

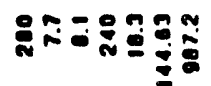

200022000020290900000202200000000220

i. :

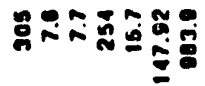
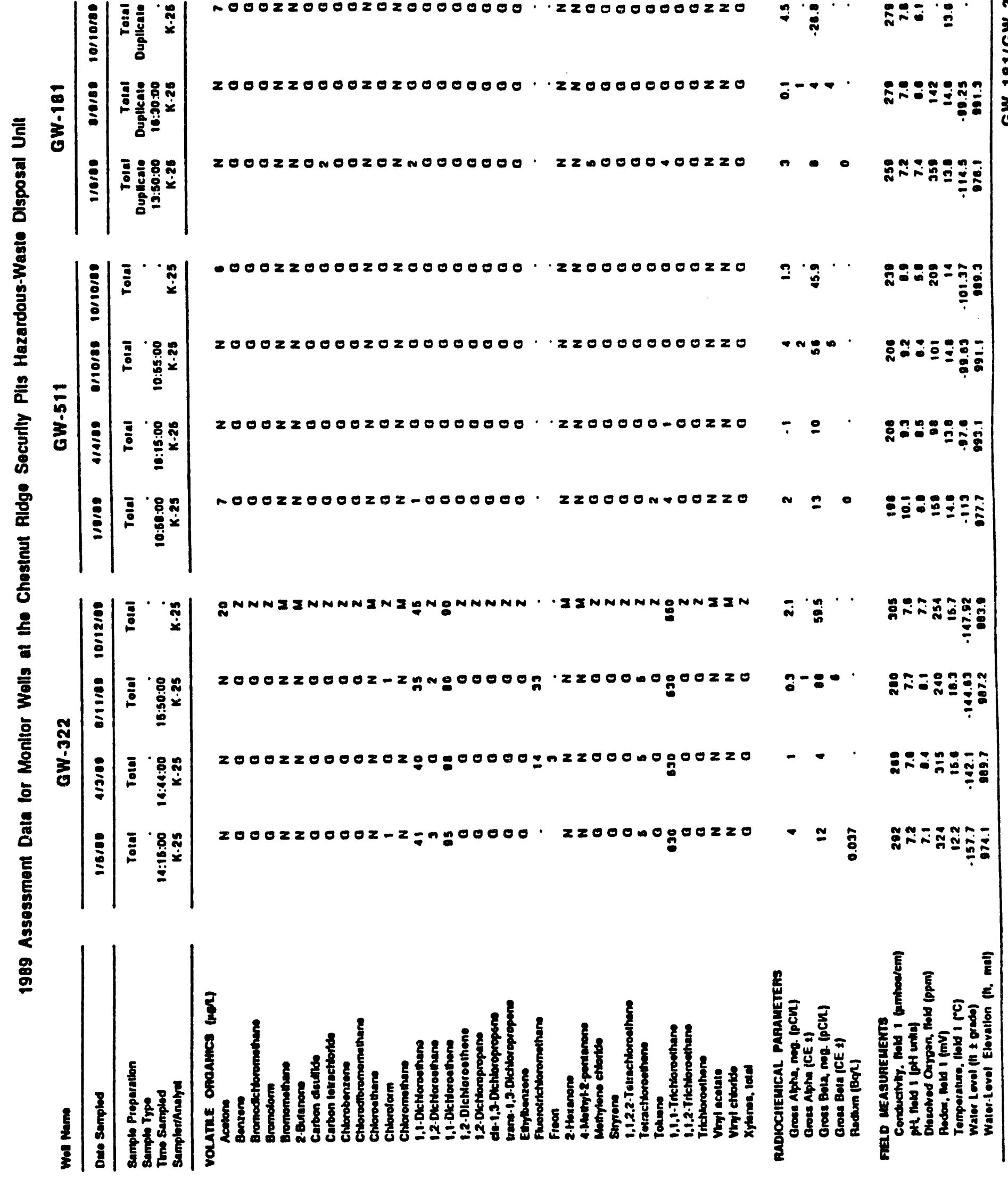


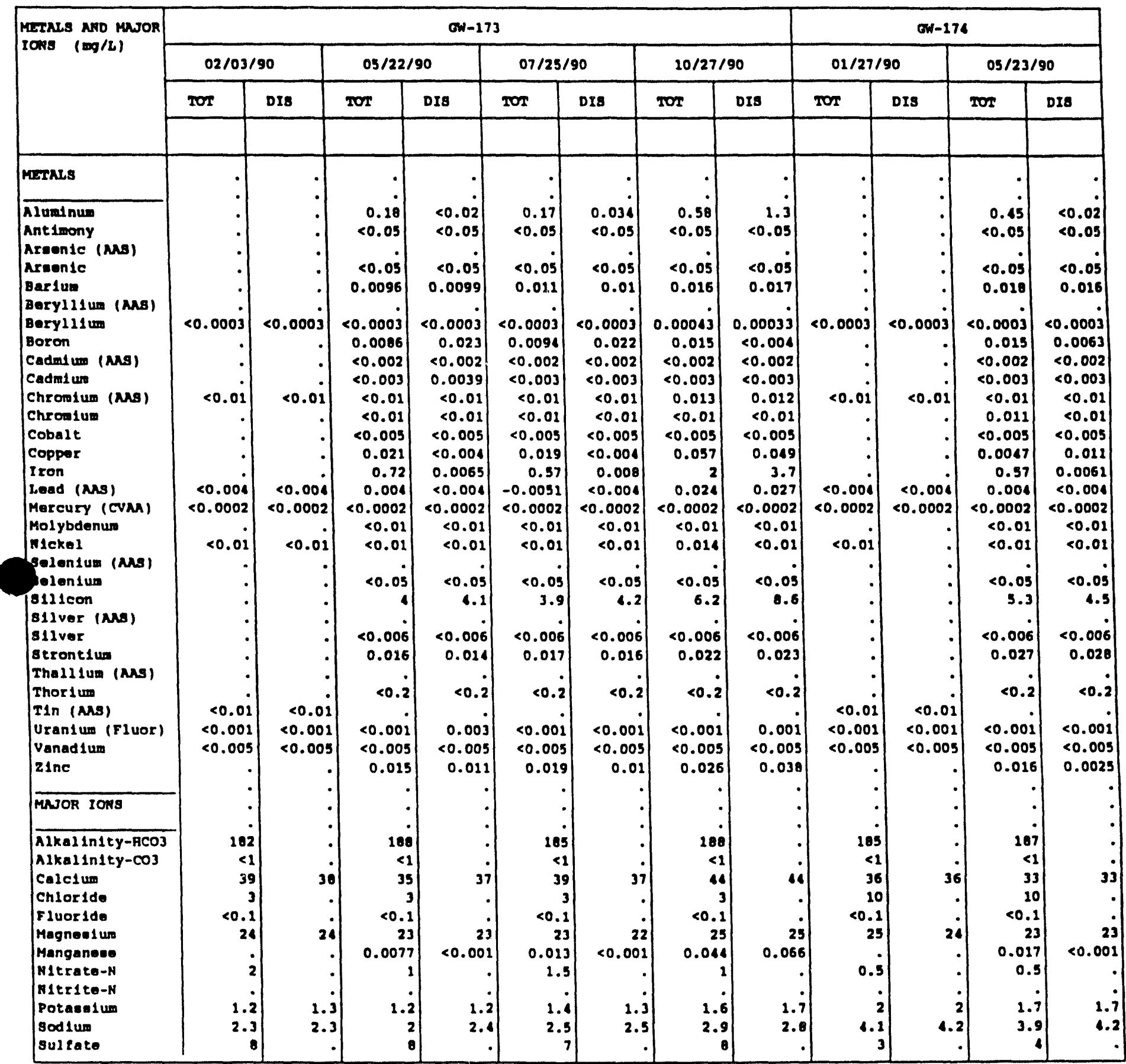




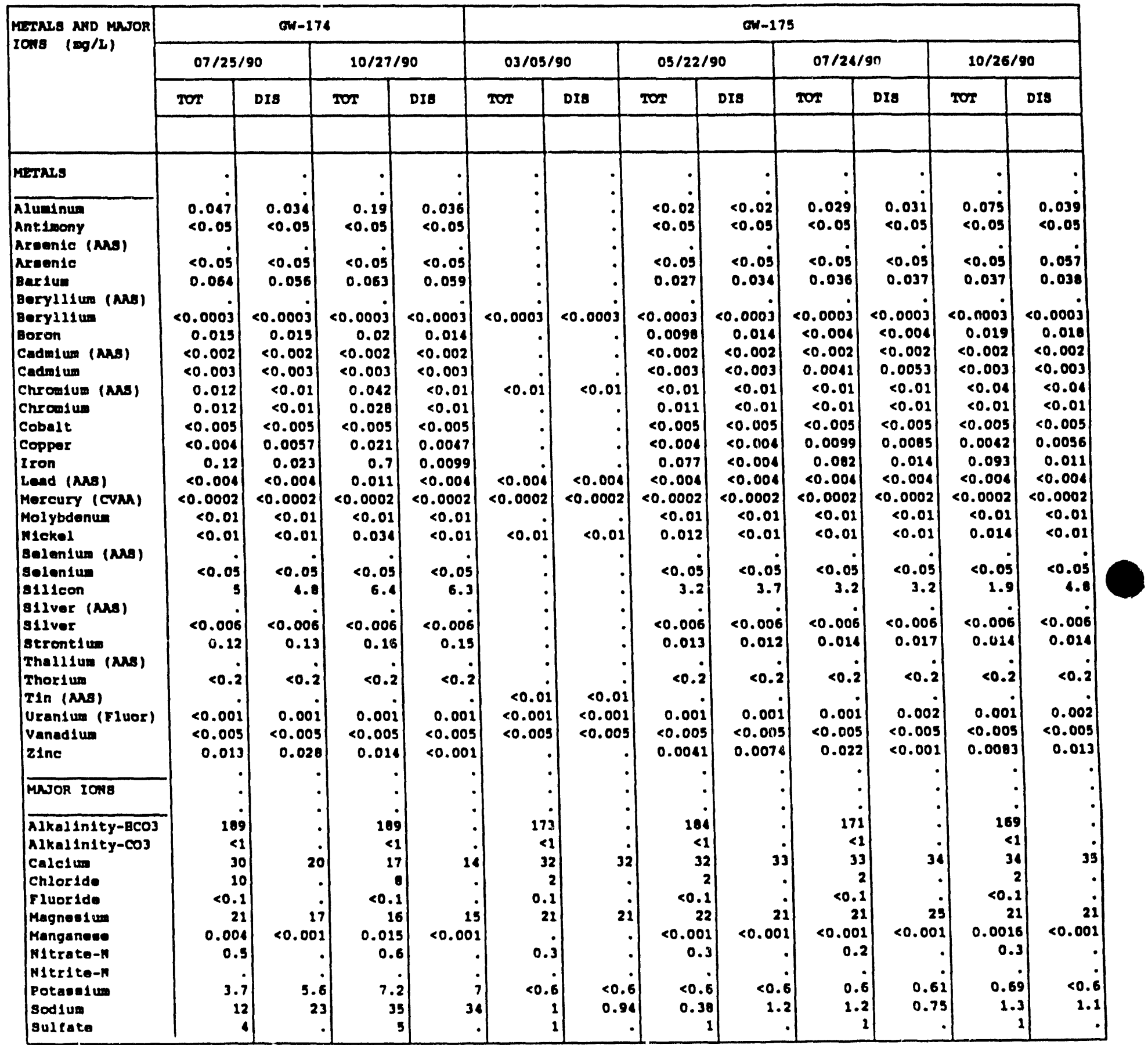

(CONTINUED) 


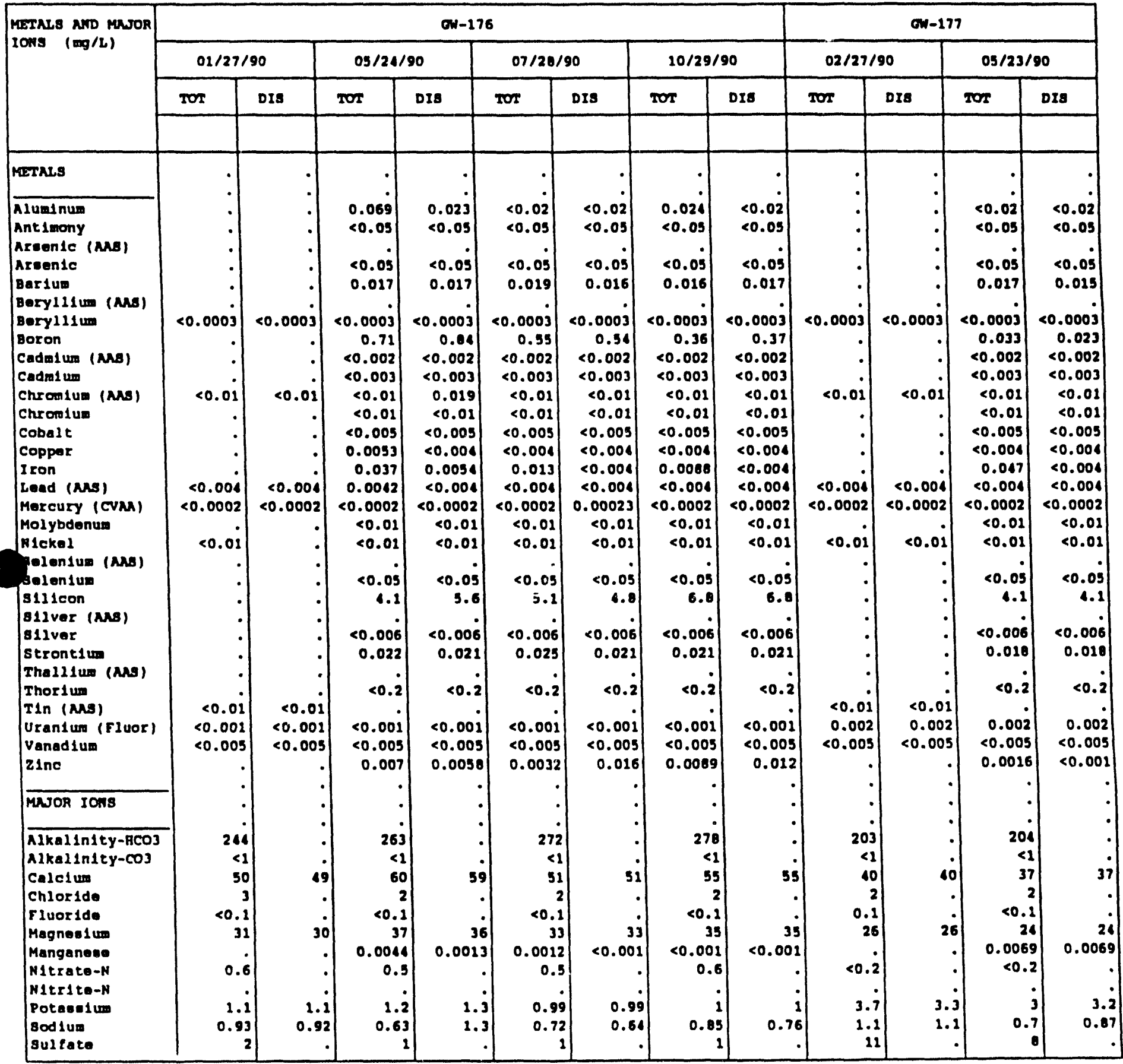

(CONTINUED) 


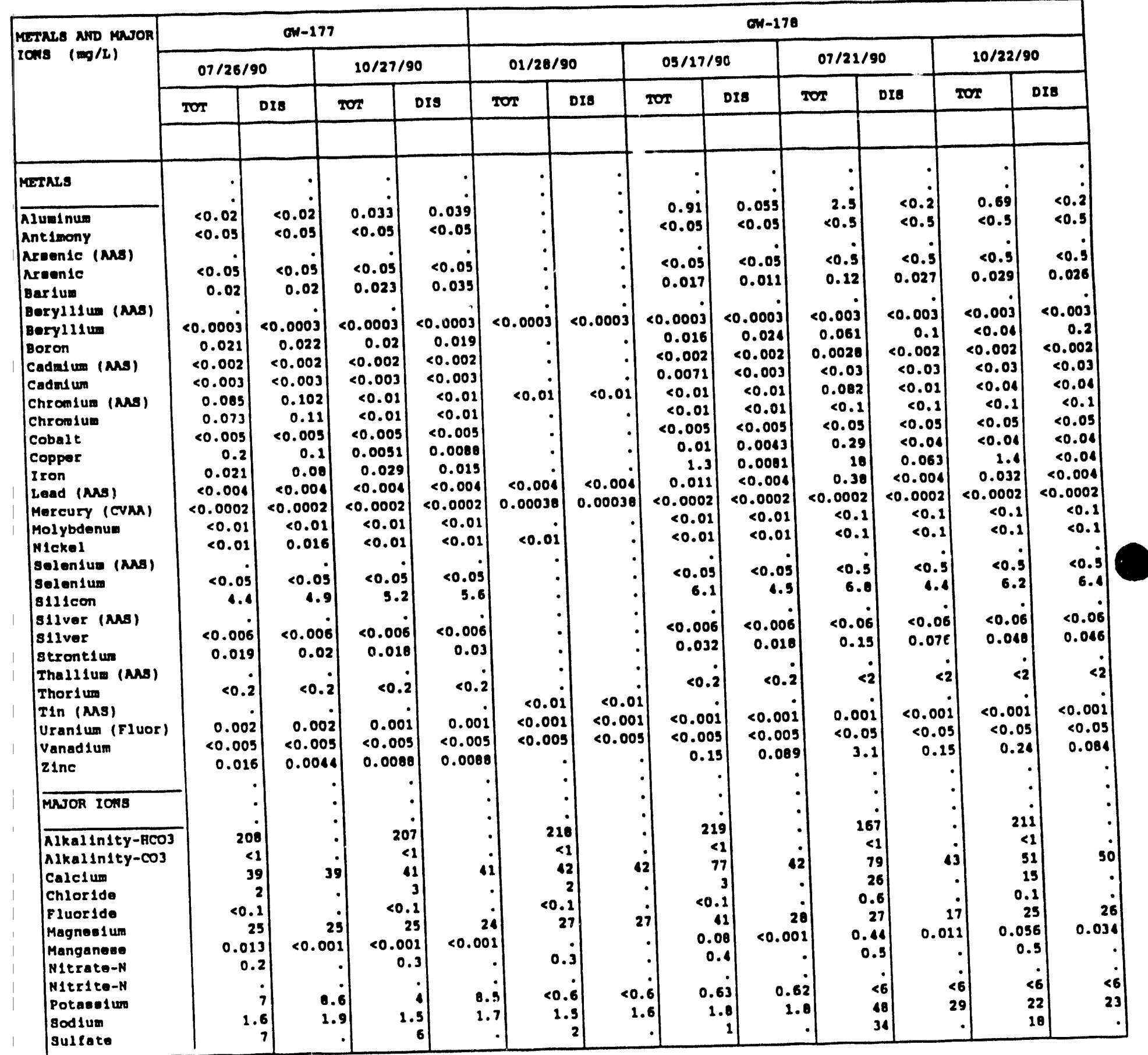

(CONTImUEo) 
R OUNLITY 1990

Cuestivi RIDGs secunity PITS

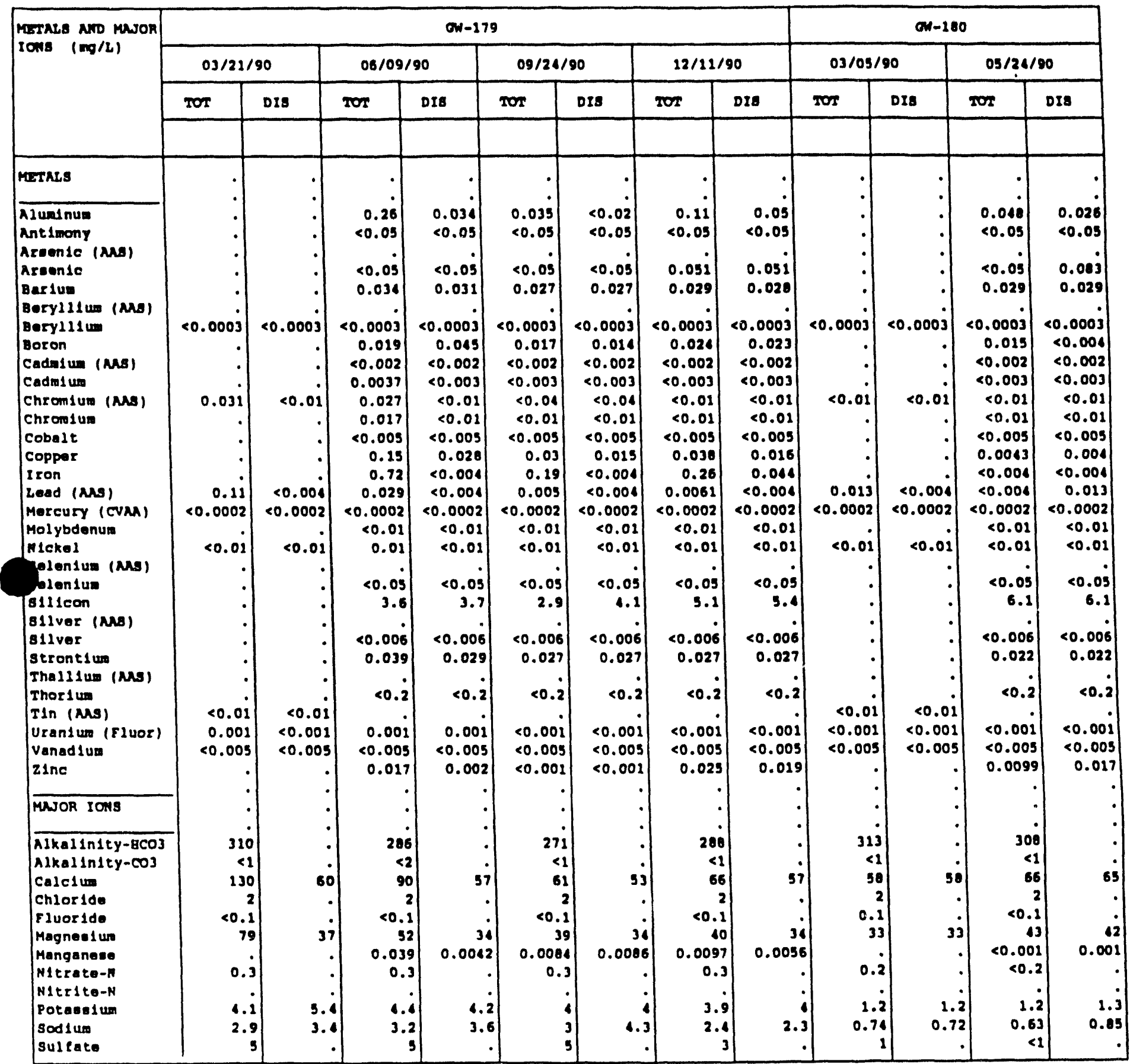

(CONTI NURD) 
WhIYR CUNITTY 1990

Citamur RIDes azcunIT PITa

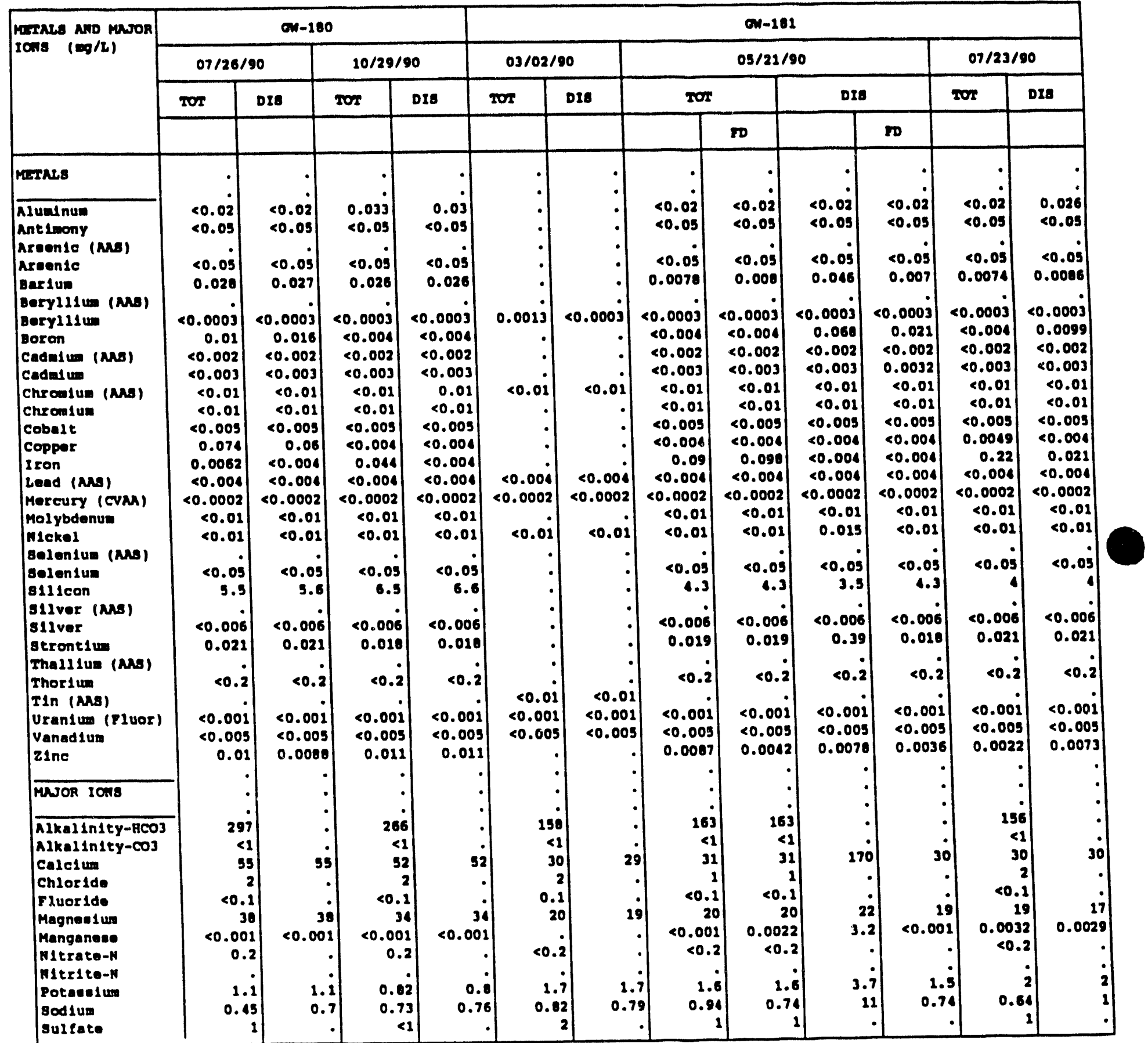

(CONTINUED) 
R CUALITX 1990

TMUT NIDE AECURITY PITS

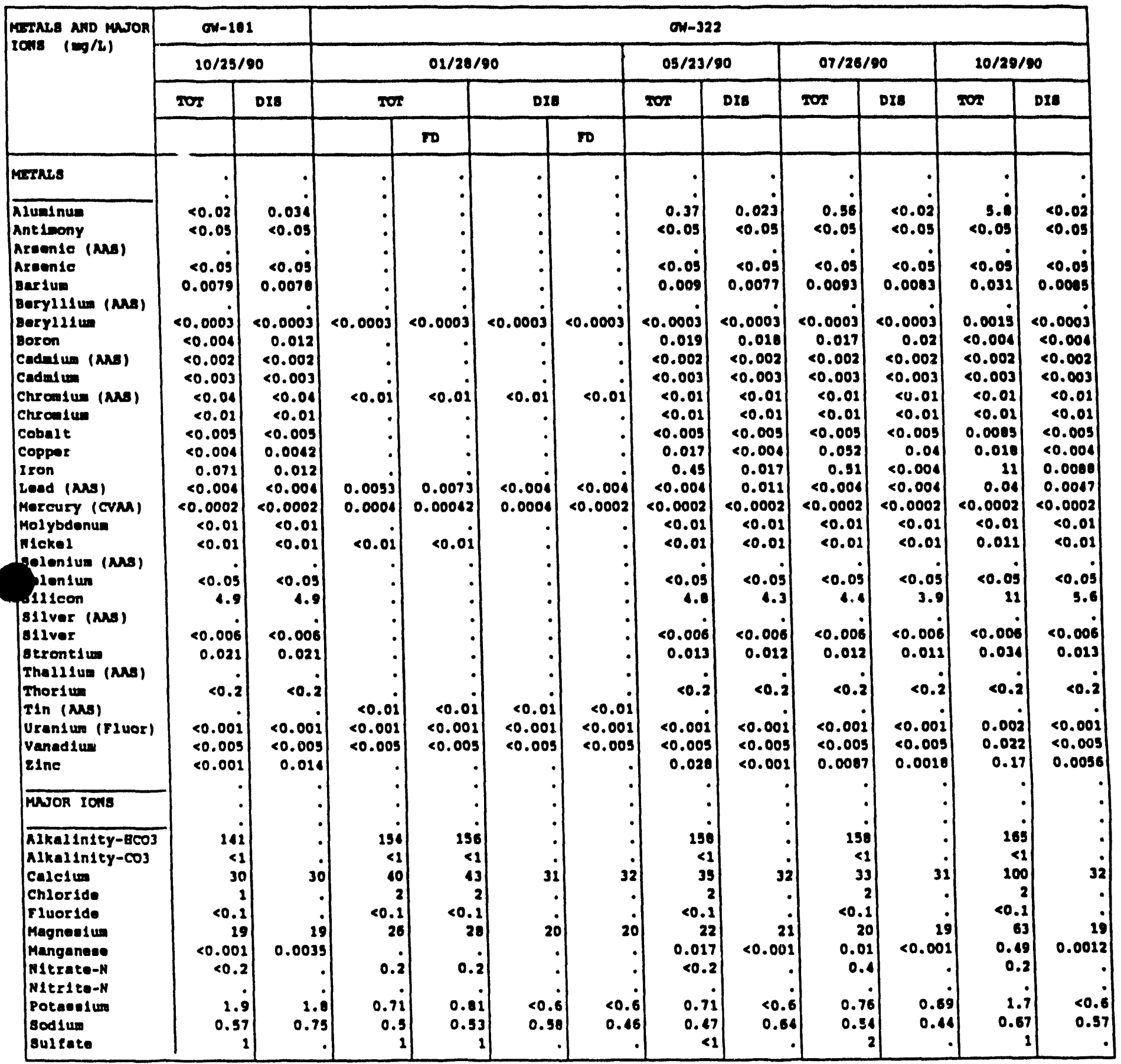

(contrinued) 
WhTER OUALITY 1990

cratur nroes azcuntry PITH

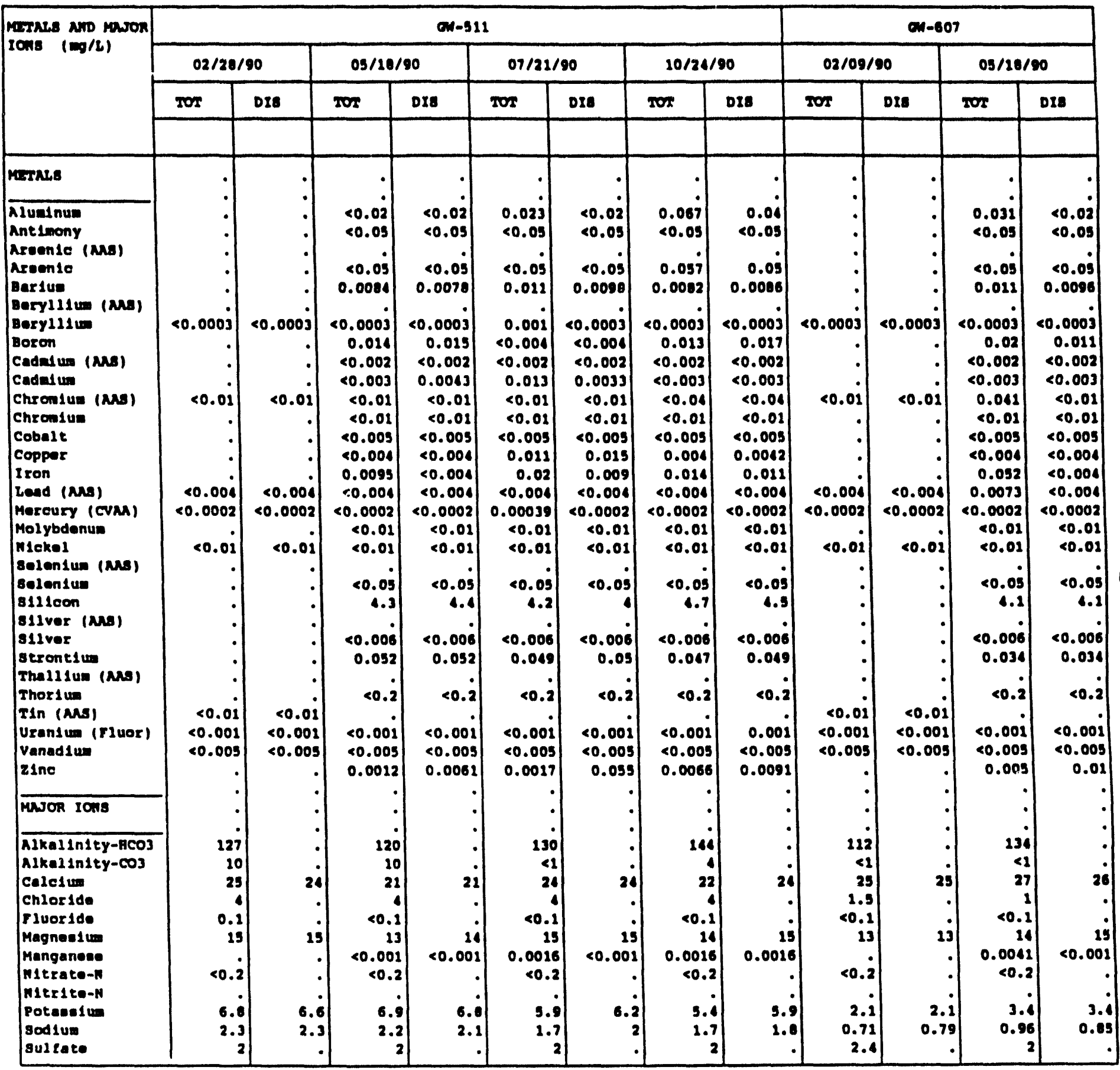

(CONTINute) 
A QunLITY 1990

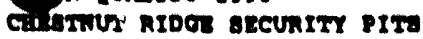

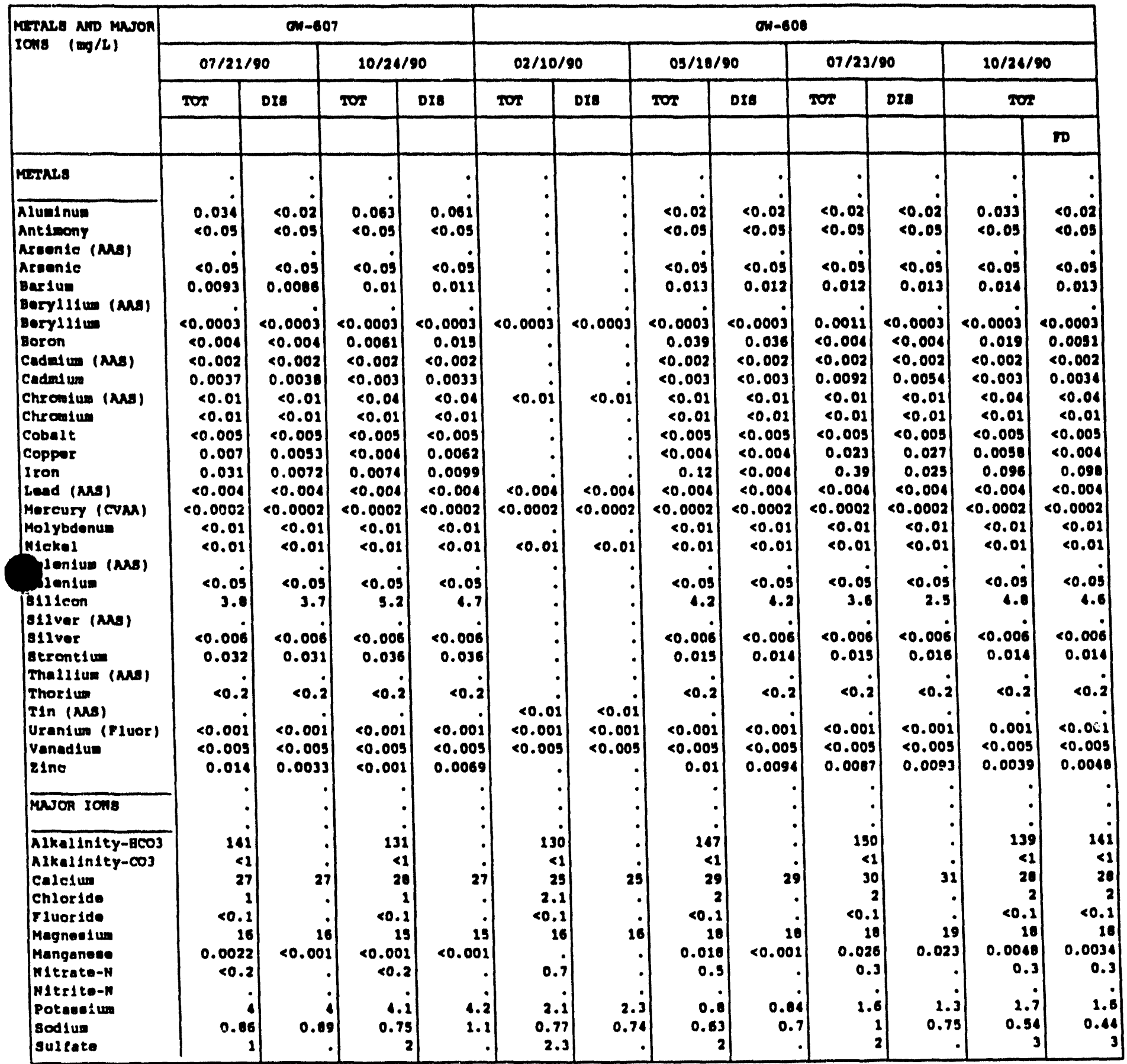

(conrrinued) 


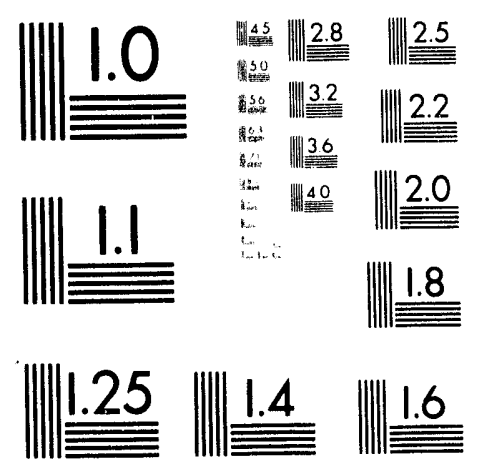



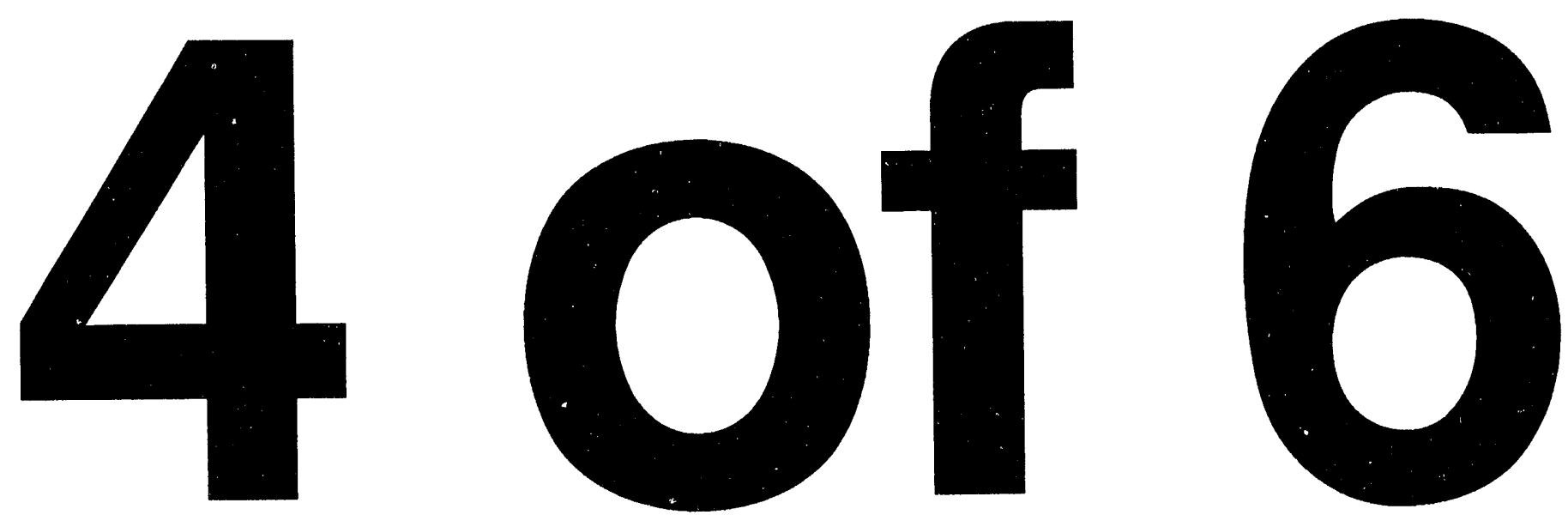
WATER QUALITY 1990

CHESTHUT RIDGE SECURITY PITS

\begin{tabular}{|c|c|c|c|c|c|c|c|c|c|c|c|c|}
\hline \multirow{4}{*}{$\begin{array}{l}\text { METALS NND MAJOR } \\
\text { IONS }(\mathrm{mg} / \mathrm{L})\end{array}$} & \multirow{2}{*}{\multicolumn{2}{|c|}{$\frac{G N-608}{10 / 24 / 90}$}} & \multicolumn{10}{|c|}{$6 N-609$} \\
\hline & & & \multicolumn{2}{|c|}{$02 / 14 / 90$} & \multicolumn{2}{|c|}{$05 / 17 / 90$} & \multicolumn{4}{|c|}{$07 / 21 / 90$} & \multicolumn{2}{|c|}{$10 / 23 / 90$} \\
\hline & \multicolumn{2}{|c|}{ DI8 } & $\operatorname{Tor}$ & DIs & TOr & DIs & \multicolumn{2}{|c|}{ TOT } & \multicolumn{2}{|c|}{ DIs } & \multirow[t]{2}{*}{$20 r$} & \multirow[t]{2}{*}{ DI8 } \\
\hline & & FD & & & & & & TD & & $\mathbf{F D}$ & & \\
\hline Merals &. & & - & $\cdot$ & $\cdot$ & $\cdot$ & $\cdot$ & - & - & - & - & - \\
\hline Aluminum & 0.052 & $<0.02$ &. & . & 0.051 & 0.023 & $<0.02$ & $<0.02$ & $0.02 i$ & $<0.02$ & 0.039 & 0.037 \\
\hline Ant1wony & $<0.05$ & $<0.05$ & $\cdot$ & - & $<0.05$ & $<0.05$ & $<0.05$ & $<0.05$ & $<0.05$ & $<0.05$ & $<0.05$ & $<0.05$ \\
\hline $\begin{array}{l}\text { Areenic (MAs) } \\
\text { Areenic }\end{array}$ & $<0.05$ & $<0.05$ & . & $\dot{\bullet}$ & 0.062 & $<0.05$ & $<0.0 \dot{s}$ & $<0.05$ & $<0.05$ & $<0.05$ & $<0.05$ & 0.068 \\
\hline Bar 1us & 0.013 & 0.013 & - & - & 0.012 & 0.011 & 0.015 & 0.025 & 0.015 & 0.015 & 0.012 & 0.021 \\
\hline $\begin{array}{l}\text { Beryl11um (NAs) } \\
\text { Beryl11um }\end{array}$ & $<0.0003$ & $<0.0003$ & $<0.0003$ & $<0.0003$ & $<0.0003$ & $<0.0003$ & $<0.0003$ & $<0.0003$ & $<0.0003$ & $<0.0003$ & $<0.0003$ & $<0.0003$ \\
\hline Boron & 0.023 & 0.0082 & $\cdot$ & $\bullet$ & 0.031 & 0.0080 & $<0.004$ & $<0.004$ & $<0.008$ & $<0.004$ & $<0.004$ & 0.017 \\
\hline Cadml un (MNS) & $<0.002$ & $<0.002$ &. & . & $<0.002$ & $<0.002$ & $<0.002$ & $<0.002$ & $<0.002$ & $<0.002$ & $<0.002$ & $<0.002$ \\
\hline Cadmi un & 0.004 & $<0.003$ &. & . & 0.0052 & $<0.003$ & $<0.003$ & $<0.003$ & 0.0063 & $<0.003$ & $<0.003$ & $<0.003$ \\
\hline Chromlum (NMs) & $<0.04$ & $<0.04$ & $<0.01$ & $<0.01$ & $<0.01$ & $<0.02$ & $<0.01$ & $<0.01$ & $<0.02$ & $<0.01$ & $<0.04$ & $<0.04$ \\
\hline Chromlum & $<0.01$ & $<0.01$ &. & $\cdot$ & $<0.01$ & $<0.01$ & $<0.01$ & $<0.01$ & $<0.02$ & $<0.02$ & $<0.01$ & $<0.01$ \\
\hline Cobalt & $<0.005$ & $<0.005$ & . &. & $<0.005$ & $<0.005$ & $<0.005$ & $<0.005$ & $<0.005$ & $<0.005$ & $<0.005$ & $<0.005$ \\
\hline Copper & 0.0064 & 0.0073 & . &. & 0.011 & 0.0049 & $<0.004$ & $<0.004$ & 0.013 & 0.0042 & 0.0067 & 0.0091 \\
\hline Iron & 0.015 & 0.027 & . &. & 0.022 & 0.029 & 0.042 & 0.0063 & 0.034 & $<0.004$ & $<0.004$ & 0.012 \\
\hline Lead (MNS) & $<0.004$ & $<0.004$ & 0.018 & $<0.004$ & $<0.004$ & $<0.004$ & $<0.004$ & $<0.004$ & $<0.004$ & $<0.004$ & $<0.004$ & $<0.004$ \\
\hline Mercury (CVMA) & $<0.0002$ & $<0.0002$ & $<0.0002$ & $<0.0002$ & $<0.0002$ & $<0.0002$ & $<0.0002$ & $<0.0002$ & $<0.0002$ & $<0.0002$ & $<0.0002$ & $<0.0002$ \\
\hline Mol ybdenun & $<0.01$ & $<0.01$ & & & $<0.01$ & $<0.01$ & $<0.01$ & $<0,01$ & $<0.01$ & $<0.01$ & $<0.01$ & $<0.01$ \\
\hline Nlekel & $<0.01$ & $<0.01$ & $<0.01$ & $<0.01$ & $<0.01$ & $<0.01$ & $<0.01$ & $<0,01$ & $<0.01$ & $<0.01$ & $<0.01$ & $<0.01$ \\
\hline $\begin{array}{l}\text { Selentua (NMS) } \\
\text { selentum }\end{array}$ & $<0.05$ & $<0.0 \dot{5}$ & $\cdot$ & $\bullet$ & $<0.05$ & $<0.05$ & $<0.05$ & $<0.05$ & $<0.05$ & $<0.05$ & $<0.05$ & $<0.05$ \\
\hline s111con & 4.1 & 4.4 & $\cdot$ & - & 4.3 & 4.4 & 4 & 4.2 & 4.5 & 4.2 & 1.4 & 5.3 \\
\hline $\begin{array}{l}\text { S11ver (NAS) } \\
\text { 911var }\end{array}$ & $<0.006$ & $<0.006$ &. &. & $<0.006$ & $<0.006$ & $<0.008$ & $<0.006$ & $<0.006$ & $<0.006$ & $<0.006$ & $<0.006$ \\
\hline stront1u & 0.024 & 0.028 & $\cdot$ &. & 0.025 & 0.013 & 0.023 & 0.024 & 0.023 & 0.013 & 0.015 & 0.024 \\
\hline $\begin{array}{l}\text { Thall Ium (NAs) } \\
\text { Thorlum }\end{array}$ & 20.2 & $<0 . \dot{2}$ &. &. & $<0.2$ & $<0.2$ & $<0.2$ & $<0.2$ & $<0.2$ & $<0.2$ & $<0.2$ & $<0.2$ \\
\hline $\operatorname{Tin}(M A 8)$ & & & $<0.01$ & $<0.01$ & & & &. & & & & \\
\hline Urantum (Fluor) & $<0.001$ & $<0.001$ & $<0.001$ & $<0.001$ & $<0.001$ & $<0.001$ & $<0.001$ & $<0.001$ & $<0.001$ & $<0.001$ & $<0.001$ & $<0.001$ \\
\hline Vanad Ium & $<0.005$ & $<0.005$ & $<0.005$ & $<0.005$ & $<0.005$ & $<0.005$ & $<0.005$ & $<0.005$ & $<0.005$ & $<0.005$ & $<0.005$ & $<0.005$ \\
\hline Zine & 0.0078 & 0.0029 & $\bullet$ & $\bullet$ & 0.025 & 0.038 & 0.0082 & 0.0072 & 0.0097 & $<0.001$ & 0.031 & 0.0046 \\
\hline MNOR IONS & $\cdot$ & $\cdot$ & $\cdot$ & $\cdot \dot{ }$ & $\cdot$ & $\cdot$ & $\cdot \dot{ }$ & - & $\dot{0}$ & $\dot{\bullet}$ & $\cdot$ & $\cdot \dot{ }$ \\
\hline Alkalinity-HCO3 & $\cdot \dot{ }$ & $\cdot$ & $17 \dot{0}$ &. & $18 \dot{3}$ &. & $18 \dot{7}$ & $10 \dot{6}$ &. & - & 162 & 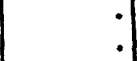 \\
\hline Alkalindty-cos & . & $\cdot$ & $<1$ & . & $<1$ &. & $<1$ & $<1$ & - & • & $<1$ & - \\
\hline Calciun & 27 & 20 & 33 & 35 & 35 & 35 & 33 & 35 & 35 & 39 & 35 & 34 \\
\hline Chlorlde & • & • & 2 & • & 2 & • & 1.6 & 1.6 & $\cdot$ & • & 2 & • \\
\hline Fluoride &. & $\cdot$ & 0.2 & $\bullet$ & $<0.1$ & $\therefore$ & $<0.1$ & $<0.1$ & $\therefore$ & $\therefore$ & & is \\
\hline Magnes 1 un & $\begin{array}{r}17 \\
0\end{array}$ & 17 & 23 & 22 & 22 & 22 & 21 & 23 & $\begin{array}{r}23 \\
0.0056\end{array}$ & $<0.001$ & $\begin{array}{r}22 \\
<0.001\end{array}$ & $\begin{array}{r}21 \\
0.0019\end{array}$ \\
\hline $\begin{array}{l}\text { Manganeee } \\
\text { N1trate-N }\end{array}$ & $\begin{array}{r}0.005 \\
.\end{array}$ & 0.0026 & $0 . \dot{9}$ &. & $\begin{array}{r}<0.001 \\
0.9\end{array}$ & $<0.001$ & $\begin{array}{r}<0.001 \\
1\end{array}$ & $\begin{array}{r}<0.001 \\
0.9\end{array}$ & $\begin{array}{r}0.0056 \\
.\end{array}$ & $\begin{array}{r}<0.001 \\
.\end{array}$ & $\begin{array}{r}<0.001 \\
1\end{array}$ & 0.0019 \\
\hline N1tr1te-N & - & $\cdot$ & $\cdot$ & .1 & - & $:$ & - & & - & $\dot{0}$ & $:$ & : \\
\hline Potanesur & 1.7 & 1.7 & 1.1 & 1.2 & 2.7 & 1.3 & 0.79 & 0.83 & 0.76 & 0.82 & 1.1 & \\
\hline Sod 1un & 0.65 & 0.77 & 0.57 & 0.54 & 1.1 & 0.79 & 0.37 & 0.38 & 0.41 & 0.41 & 0.66 & 0.69 \\
\hline sulfate & $\cdot$ & $\cdot$ & 2 & $\cdot$ & 2 & • & 2 & 2 & $\bullet$ & $\bullet$ & 2 & \\
\hline
\end{tabular}

(conTrmuxa) 


\begin{tabular}{|c|c|c|c|c|c|c|c|c|c|c|c|c|}
\hline \multirow{3}{*}{$\begin{array}{l}\text { METASE AND MNOOR } \\
\text { IONS }(\mathrm{g} / \mathrm{L})\end{array}$} & \multicolumn{8}{|c|}{ ON-610 } & \multicolumn{4}{|c|}{$0 N-611$} \\
\hline & \multicolumn{2}{|c|}{$02 / 09 / 90$} & \multicolumn{2}{|c|}{$05 / 22 / 90$} & \multicolumn{2}{|c|}{$07 / 24 / 90$} & \multicolumn{2}{|c|}{$10 / 26 / 90$} & \multicolumn{2}{|c|}{$02 / 09 / 90$} & \multicolumn{2}{|c|}{$05 / 22 / 90$} \\
\hline & Tox & Dra & TOT & DIs & 2001 & DI8 & TOT & Drs & TOT & DIs & 200 & Dro \\
\hline METALS & - & - & . & - & - & - & - & - & - & - & - & - \\
\hline Aluminus &. &. & 0.64 & $<0.02$ & 0.63 & $<0.02$ & 0.36 & $0.04 \dot{5}$ & $\because$ & $\because$ & 0.069 & $<0.02$ \\
\hline Antimony & $\cdot$ & - & $<0.05$ & $<0.03$ & $<0.05$ & $<0.05$ & $<0.05$ & $<0.05$ & $\cdot$ & • & $<0.05$ & $<0.05$ \\
\hline $\begin{array}{l}\text { Arsente (MS) } \\
\text { Arseente }\end{array}$ &. & $:$ & $<0.05$ & $0.06 i$ & $<0.05$ & $<0.05$ & $<0.05$ & $<0.05$ &. & : & $0.06 \dot{1}$ & $<0.05$ \\
\hline Bariua & . & & 0.082 & 0.072 & 0.081 & 0.069 & 0.092 & 0.1195 & $\cdot$ & . & 0.02 & 0.028 \\
\hline $\begin{array}{l}\text { Bery111um (MS) } \\
\text { Bory111um }\end{array}$ & $<0.0003$ & $<0.0003$ & $<0.0003$ & $<0.0003$ & $<0.0003$ & $<0.0003$ & $<0.0003$ & 0.00053 & $<0.0003$ & $<0.0003$ & $<0.0003$ & $<0.0003$ \\
\hline Boron & &. & 0.016 & 0.012 & $<0.008$ & $<0.004$ & 0.072 & 0.0079 &. &. & 0.018 & 0.013 \\
\hline Cadnl un (MAS) & $\cdot$ & . & $<0.002$ & $<0.002$ & $<0.002$ & $<0.002$ & $<0.002$ & $<0.002$ & - & $\cdot$ & $<0.002$ & $<0.002$ \\
\hline Cadral un & & & $<0.003$ & $<0.003$ & $<0.003$ & $<0.003$ & $<0.003$ & $<0.003$ & $\cdot$ & $\cdot$ & 0.003 & $<0.003$ \\
\hline Chromius (ANS) & 0.033 & $<0.01$ & $<0.02$ & $<0.01$ & $<0.01$ & $<0.01$ & $\begin{array}{l}<0.04 \\
<0.01\end{array}$ & $<0.04$ & 0.018 & 0.015 & $<0.01$ & $<0.01$ \\
\hline $\begin{array}{l}\text { Chromiua } \\
\text { Cobalt }\end{array}$ & &. & $\begin{array}{l}<0.01 \\
<0.005\end{array}$ & $\begin{array}{l}<0.01 \\
<0.005\end{array}$ & $\begin{array}{l}<0.01 \\
<0.005\end{array}$ & $\begin{array}{l}<0.01 \\
<0.005\end{array}$ & $\begin{array}{r}<0.01 \\
<0.005\end{array}$ & $\begin{array}{r}<0.01 \\
<0.005\end{array}$ &. & $\cdot$ & $\begin{array}{r}<0.01 \\
<0.005\end{array}$ & $\begin{array}{r}<0.01 \\
<0.003\end{array}$ \\
\hline Copper & & & 0.011 & $<0.004$ & 0.0099 & 0.0044 & 0.0033 & $<0.004$ & $\because$ &. & 0.0055 & $<0.008$ \\
\hline Iron & & & 0.80 & 0.0078 & 0.74 & 0.012 & 0.35 & 0.011 &. & & 0.099 & $<0.004$ \\
\hline Lead (ANS) & 0.016 & $<0.004$ & $<0.004$ & $<0.004$ & $<0.006$ & $<0.004$ & $<0.004$ & $<0.006$ & $<0.004$ & $<0.004$ & $<0.004$ & $<0.004$ \\
\hline Morcury (CVMA) & $<0.0002$ & $<0.0002$ & $<0.0002$ & $<0.0002$ & $<0.0002$ & 0.00026 & $<0.0002$ & $<0.0002$ & $<0.0002$ & $<0.0002$ & $<0.0002$ & $<0.0002$ \\
\hline Molybdenum & $0.060^{\circ}$ & <n: & $<0.01$ & $\begin{array}{l}<0.01 \\
<0.01\end{array}$ & $\begin{array}{l}<0.01 \\
<0.01\end{array}$ & $\begin{array}{l}<0.01 \\
<0.01\end{array}$ & $<0.01$ & $<0.01$ & $<0.01$ & $<0.01$ & $\begin{array}{l}<0.01 \\
<0.01\end{array}$ & $\begin{array}{l}<0.01 \\
<0.01\end{array}$ \\
\hline & $\begin{array}{r}0.068 \\
.\end{array}$ & $\begin{array}{r}<0.01 \\
.1\end{array}$ & $\begin{array}{r}0.012 \\
.\end{array}$ & $<0.01$ & $\begin{array}{r}<0.01 \\
.\end{array}$ & $<0.01$ & $\begin{array}{r}0.014 \\
.\end{array}$ & $<0.01$ & $\begin{array}{r}8.01 \\
.\end{array}$ &. & $\begin{array}{r}<0.01 \\
.\end{array}$ & 80.01 \\
\hline lentum & $\cdot$ & . & $<0.05$ & $<0.05$ & $<0.05$ & $<0.05$ & $<0.03$ & $<0.05$ & $\cdot$ & • & $<0.05$ & $<0.05$ \\
\hline Al1con & : & $\cdot$ & 3.6 & 4.1 & 5.1 & 4.1 & 6.5 & 4.0 &. & $\because$ & $\begin{array}{r}4.3 \\
.1\end{array}$ & $\begin{array}{r}8.3 \\
.\end{array}$ \\
\hline $\begin{array}{l}\text { S11ver }(\mathrm{NH}) \\
\text { s11ver }\end{array}$ & $\dot{0}$ & $\dot{.}$ & $<0.006$ & $<0.006$ & $<0.006$ & $<0.006$ & $<0.006$ & $<0.006$ & : & $\because$ & $<0.008$ & $<0.006$ \\
\hline strontiuw & - &. & 0.021 & 0.016 & 0.023 & 0.016 & 0.02 & 0.010 & . & $\cdot$ & 0.021 & 0.018 \\
\hline Thall1um (NNS) & & & $<0 . \dot{2}$ & $<0 . \dot{2}$ & $<0 . \dot{2}$ & $<0 . \dot{2}$ & $<0 . \dot{2}$ & $<0 . \dot{2}$ &. & & $<0 . \dot{2}$ & $<0 . \dot{2}$ \\
\hline $\operatorname{Tin}$ (MAs) & $<0.01$ & $<0.01$ & & & & & & & $<0.01$ & $<0.01$ & & \\
\hline Uranlum (Fluor) & $<0.001$ & $<0.001$ & 0.001 & $<0.001$ & 0.001 & 0.001 & 0.001 & 0.001 & $<0.001$ & $<0.001$ & 0.002 & 0.002 \\
\hline Vanad lum & $<0.005$ & $<0.005$ & $<0.003$ & $<0.005$ & $<0.005$ & $<0.009$ & $<0.005$ & $<0.005$ & $<0.005$ & $<0.005$ & $<0.005$ & $<0.005$ \\
\hline zine & & & 0.018 & 0.0062 & 0.0042 & $<0.001$ & 0.0062 & $<0.001$ & $\cdot 1$ & .1 & 0.0096 & 0.0059 \\
\hline MANOR IONS &. & $\dot{.}$ &. & &. & & . & &. & 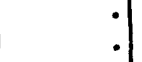 & 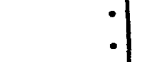 & \\
\hline & 170 & & 170 &. & $16 \dot{6}$ &. & $16 \dot{2}$ &. & $18 \dot{9}$ & •. & $21 \dot{6}$ & \\
\hline $\begin{array}{l}\text { Alkalln1ty-RCO3 } \\
\text { Alkalln1ty-CO3 }\end{array}$ & $<1$ & $\dot{.}$ & $<1$ &. & $<1$ &. & $<2$ & $\dot{.}$ & $\begin{array}{r}12 \\
12\end{array}$ & $: 1$ & $\begin{array}{r}210 \\
<1\end{array}$ & \\
\hline $\begin{array}{l}\text { Alkallnity-CO3 } \\
\text { Calcium }\end{array}$ & 69 & 33 & 37 & 33 & 39 & 33 & 37 & 34 & 26 & 18 & 42 & 43 \\
\hline Chlor1de & 2.1 & . & 2 & . & 2 & . & 2 & .1 & 2 &. & 1 & . \\
\hline Fluor1de & 7.1 & . & $<0.1$ & . & $<0.1$ &. & $<0.1$ & . & 0.1 & $\cdot$ & $<0.1$ & - \\
\hline Magnose 1 un & 26 & 22 & 21 & 20 & 22 & 20 & 20 & 20 & 23 & 20 & & 28 \\
\hline Manganeses &. & . & 0.03 & 0.0060 & 0.035 & 0.0062 & 0.019 & 0.0059 & .1 & .1 & 0.008 & 0.0033 \\
\hline Nitrate-n & 0.5 & . & 0.6 & $\cdot 1$ & 0.5 & $\cdot$ & 0.5 & .1 & 2.6 & . & 3 & \\
\hline $\begin{array}{l}\text { M1tr1te-N } \\
\text { Potaselum }\end{array}$ & & $\dot{5}$ & $\dot{1}$ & i. & 0.01 & 0.7 & $0 . \dot{6}$ & 0.53 & $\dot{23}$ & 23. & 1.3 & 0.99 \\
\hline 8od 1uw & & 1.3 & 1.1 & 1.1 & $\begin{array}{l}0.86 \\
0.71\end{array}$ & $\begin{array}{l}0.77 \\
0.74\end{array}$ & 1.1 & 0.06 & 3.3 & 3.2 & 1.2 & 1.3 \\
\hline suleate & 1.8 & . & 2 &. & 1 & & $<1$ & & 17 & $\cdot 1$ & 2 & \\
\hline
\end{tabular}

(CONTINUED) 
MATER OUNLITY 1990

CHEBTTUT RIDGE BECURITY PITS

\begin{tabular}{|c|c|c|c|c|c|c|c|c|c|c|c|c|}
\hline \multirow{3}{*}{$\begin{array}{l}\text { METASB AND MWOR } \\
\text { YONS (mg/h) }\end{array}$} & \multicolumn{4}{|c|}{$0 n-611$} & \multicolumn{8}{|c|}{ CW-612 } \\
\hline & \multicolumn{2}{|c|}{$07 / 24 / 90$} & \multicolumn{2}{|c|}{$10 / 26 / 90$} & \multicolumn{2}{|c|}{$02 / 20 / 90$} & \multicolumn{2}{|c|}{$05 / 25 / 90$} & \multicolumn{2}{|c|}{$07 / 31 / 90$} & \multicolumn{2}{|c|}{$10 / 30 / 90$} \\
\hline & TOT & DIs & TOT & DIO & TOT & Drs & TOT & DIs & $20 r$ & DIs & 201 & Drs \\
\hline Merns & - & - & - & - & - & • & - & - & - & - & • & - \\
\hline Aluminum & 0.15 & $<0.02$ & $0 . \dot{12}$ & 0.039 & $\dot{.}$ & $\dot{.}$ & $<0.02$ & $<0.0 \dot{0}$ & $<0 . \dot{02}$ & $<0.0 \dot{0}$ & $0.03 \dot{6}$ & $<0.02$ \\
\hline Antimony & $<0.05$ & $<0.05$ & $<0.03$ & $<0.05$ & - & - & $<0.05$ & 20.05 & $<0.05$ & $<0.03$ & $<0.05$ & $<0.05$ \\
\hline $\begin{array}{l}\text { Arsente (MS) } \\
\text { Armonte }\end{array}$ & $<0.0 \dot{0}$ & $<0.0 \dot{s}$ & $<0.0 \dot{0}$ & $<0.05$ & $\dot{.}$ & $\dot{.}$ & $0.07 \dot{2}$ & $<0.05$ & $<0.05$ & $<0.05$ & $<0.05$ & $<0.05$ \\
\hline Barlue & 0.021 & 0.024 & 0.029 & 0.028 & - & - & 0.013 & 0.013 & 0.014 & 0.014 & 0.014 & 0.014 \\
\hline Boryl11um (AMS) & $<0,003$ & $<0003$ & & & $<00003$ & 00003 & $<0,0003$ & & : & (2) & 20.0003 & $<0.000 ;$ \\
\hline $\begin{array}{l}\text { Bery } 111 \text { um } \\
\text { Boron }\end{array}$ & $\begin{array}{r}<0.0003 \\
<0.004\end{array}$ & $\begin{array}{r}<0.0003 \\
<0.004\end{array}$ & $\begin{array}{r}0.00033 \\
0.011\end{array}$ & $\begin{array}{r}<0.0003 \\
0.0091\end{array}$ & $<0.0003$ & $<0.0003$ & $\begin{array}{r}<0.0003 \\
0.24\end{array}$ & $\begin{array}{r}<0.0003 \\
0.29\end{array}$ & $\begin{array}{r}<0.0003 \\
0.13\end{array}$ & $\begin{array}{r}<0.0003 \\
0.14\end{array}$ & $\begin{array}{r}<0.0003 \\
0.14\end{array}$ & $\begin{array}{r}<0.0003 \\
0.16\end{array}$ \\
\hline Cadmlum (ARS) & $<0.002$ & $<0.002$ & $<0.002$ & $<0.002$ & . & - & $<0.002$ & $<0.002$ & $<0.002$ & $<0.002$ & $<0.002$ & $<0.002$ \\
\hline Cadentura & $<0.003$ & $<0.003$ & $<0.003$ & $<0.003$ & &. & $<0.003$ & $<0.003$ & $<0.003$ & $<0.003$ & $<0.003$ & $<0.003$ \\
\hline Chrontus (ANS) & $<0.01$ & $<0.01$ & $<0.04$ & $<0.04$ & $<0.01$ & $<0.01$ & $<0.01$ & $<0.02$ & $<0.01$ & $<0.01$ & $<0.01$ & $<0.01$ \\
\hline Chromiun & $<0.01$ & $<0.01$ & $<0.01$ & $<0.01$ &. & • & $<0.01$ & $<0.01$ & $<0.01$ & $<0.01$ & $<0.01$ & $<0.01$ \\
\hline Cobalt & $<0.005$ & $<0.003$ & $<0.005$ & $<0.005$ & - & - & $<0.005$ & $<0.005$ & $<0.005$ & $<0.005$ & $<0.005$ & $<0.005$ \\
\hline Copper & 0.014 & 0.0071 & 0.013 & 0.0053 & - & - & $<0.004$ & $<0.004$ & $<0.004$ & 0.023 & 0.017 & 0.012 \\
\hline Iron & 0.35 & 0.01 & 0.16 & 0.012 & & & 0.029 & 0.026 & 0.3 & 0.013 & 0.2 & 0.021 \\
\hline Lead (MAS) & $<0.006$ & $<0.004$ & $<0.004$ & $<0.004$ & $<0.004$ & $<0.004$ & $<0.004$ & $<0.004$ & 0.0074 & $<0.004$ & 0.011 & $<0.004$ \\
\hline Mercury (CVM) & $<0.0002$ & $<0.0002$ & $<0.0002$ & $<0.0002$ & $<0.0002$ & $<0.0002$ & $<0.0002$ & $<0.0002$ & $<0.0002$ & $<0.0002$ & $<0.0002$ & $<0.0002$ \\
\hline Molybdenut & $<0.01$ & $<0.01$ & $<0.01$ & $<0.01$ & & & $<0.02$ & $<0.01$ & $<0.01$ & $<0.01$ & $<0.01$ & $<0.01$ \\
\hline $\begin{array}{l}\text { Mlekel } \\
\text { solentum (MS) }\end{array}$ & $<0.01$ & $<0.01$ & 0.019 & $<0.01$ & $<0.01$ & $<0.01$ & $<0.02$ & $<0.01$ & $<0.01$ & $<0.01$ & $<0.02$ & $<0.01$ \\
\hline $\begin{array}{l}\text { Solentum (MS) } \\
\text { Solentum }\end{array}$ & $<0.05$ & $<0.05$ & $<0.05$ & $<0.05$ & $\dot{.}$ & $\dot{.}$ & $<0.05$ & $<0.05$ & $<0.05$ & $<0.05$ & $<0.05$ & $<0.05$ \\
\hline s111con & 4.3 & 4.4 & 3.2 & 3.5 & - & - & 4.5 & 4.4 & 3.6 & 3.9 & 4.7 & 4.6 \\
\hline $\begin{array}{l}\text { ollver (NNS) } \\
\text { s11ver }\end{array}$ & $<0.006$ & $<0.006$ & $<0.006$ & $<0.006$ & . & $\dot{.}$ & $<0.006$ & $<0.008$ & $<0.006$ & $<0.006$ & $<0.006$ & $<0.006$ \\
\hline stront1um & 0.02 & 0.02 & 0.023 & 0.021 & - & . & 0.034 & 0.014 & 0.018 & 0.018 & 0.025 & 0.013 \\
\hline $\begin{array}{l}\text { Thall1um (MAS) } \\
\text { Thordum }\end{array}$ & $<0 . \dot{2}$ & $<0 . \dot{2}$ & $<0 . \dot{2}$ & $<0 . \dot{2}$ & & $\dot{.}$ & $<0 . \dot{2}$ & $<0 . \dot{2}$ & $<0 . \dot{2}$ & $<0 . \dot{2}$ & $<0 . \dot{2}$ & $<0 . \dot{2}$ \\
\hline $\begin{array}{l}\text { Thordum } \\
\operatorname{T1n}(\mathrm{MAS})\end{array}$ & & & & & $<0.01$ & $<0.01$ & & & & & & \\
\hline Uranture (Fluor) & 0.001 & 0.003 & 0.002 & 0.002 & $<0.001$ & $<0.001$ & $<0.001$ & $<0.001$ & $<0.001$ & $<0.001$ & $<0.001$ & $<0.001$ \\
\hline Vanad Iuw & $<0.005$ & $<0.005$ & $<0.005$ & $<0.005$ & $<0.005$ & $<0.005$ & $<0.005$ & $<0.005$ & $<0.005$ & $<0.005$ & $<0.003$ & $<0.005$ \\
\hline zine & 0.000 & $<0.001$ & 0.016 & 0.0072 & • & & 0.022 & 0.0000 & 0.0082 & 0.35 & 0.018 & 0.011 \\
\hline MANOR IONS & - & : & $\dot{.}$ & $\dot{.}$ & $\dot{.}$ & $\dot{\bullet}$ & $\dot{.}$ & $\dot{\bullet}$ & & $\dot{0}$ & $\dot{.}$ & : \\
\hline Alkal In1ty-ACO3 & 210 & - & & & $19 \dot{0}$ &. & 197 & $\dot{.}$ & $19 \dot{1}$ & $\dot{\bullet}$ & $20 \dot{0}$ & \\
\hline $\begin{array}{l}\text { Alkalinity-ACOJ } \\
\text { Alkalinity-co3 }\end{array}$ & $\begin{array}{r}210 \\
<1\end{array}$ & - & $\begin{array}{l}217 \\
<1\end{array}$ & $\dot{0}$ & 2 & . & $<1$ &. & $<1$ & - & $<1$ & . \\
\hline Calc1um & so & 43 & 31 & 47 & 34 & 32 & 39 & 34 & 34 & 34 & 37 & 30 \\
\hline Chlor lde & 1 & - & 2 & • & 2.3 & - & 2 & - & 2 & • & 2 & - \\
\hline Fluor 1de & $<0.1$ & & $<0.1$ & - & $<0.1$ & - & $<0.1$ & $\cdot$ & $<0.1$ & $\cdot$ & $<0.1$ & - \\
\hline Magnee1um & 29 & 29 & 31 & 29 & 24 & 23 & & 28 & 27 & 27 & & 26 \\
\hline Manganene & 0.01 & $<0.001$ & 0.0041 & $<0.001$ & $\cdot$ & - & $<0.001$ & $<0.001$ & 0.017 & 0.015 & 0.004 & 0.0034 \\
\hline N1trato-n & 4 & & 3 & & 0.2 & - & 0.3 & $\cdot$ & 0.2 & $\cdot$ & 0.2 & \\
\hline $\begin{array}{l}\text { M1tr1to-N } \\
\text { Potanelum }\end{array}$ & $0.6 \dot{9}$ & 0.83 & $0.8 \dot{s}$ & $0.7 \dot{2}$ & 4.6 & $3 . \dot{1}$ & $1 . \dot{1}$ & $1 . \dot{5}$ & $1 . \dot{1}$ & $1 . \dot{5}$ & $1 . \dot{2}$ & 1.1 \\
\hline $\begin{array}{l}\text { Potaendum } \\
\text { Sodiue }\end{array}$ & 1.4 & 1.1 & 1.7 & 1.7 & 0.86 & 0.92 & 0.82 & 0.83 & 0.62 & 0.7 & 0.7 & 0.74 \\
\hline sulfate & 3 & & 4 & & 2.4 & . & 3 &. & 3 & • & 3 & \\
\hline
\end{tabular}


MER QUALITY 1990

CFRSTIUT RIDGB SECURITY PITS

\begin{tabular}{|c|c|c|c|c|c|c|c|c|c|c|}
\hline \multirow[t]{2}{*}{ VOUMTILE ORCNNICS (ug/L) } & \multicolumn{4}{|c|}{$6 N-173$} & \multicolumn{4}{|c|}{$6 N-174$} & \multicolumn{2}{|c|}{$6 w-175$} \\
\hline & $02 / 03 / 90 \mid 0$ & $05 / 22 / 90 \mid$ & $07 / 25 / 90 \mid 1$ & $10 / 27 / 90$ & $01 / 27 / 90$ & $05 / 23 / 90$ & $07 / 25 / 90$ & $10 / 27 / 90$ & $03 / 05 / 90 \mid 0$ & $05 / 22 / 90$ \\
\hline Acetone & $<10$ & $<10$ & $<10$ & $<10$ & 3 & $<10$ & 12 & $<10$ & $<10$ & $<10$ \\
\hline Benzene & $<5$ & $<5$ & $<5$ & $<3$ & $<5$ & $<3$ & $<5$ & $<5$ & $<5$ & $<5$ \\
\hline Brorood lehlorowethane & $<5$ & $<5$ & $<5$ & $<5$ & $<5$ & $<5$ & $<3$ & $<5$ & $<5$ & $<3$ \\
\hline Bromotorm & $<5$ & $<5$ & $<5$ & $<5$ & $<5$ & $<5$ & $<5$ & $<5$ & $<5$ & $<5$ \\
\hline Bromomethane & $<10$ & $<10$ & $<10$ & $<10$ & $<10$ & $<10$ & $<10$ & $<10$ & $<20$ & $<10$ \\
\hline 2-Butanone & $<10$ & $<10$ & $<10$ & $<10$ & $<10$ & $<10$ & $<10$ & $<10$ & $<10$ & $<10$ \\
\hline Carbon dieulelde & $<5$ & $<3$ & $<5$ & $<5$ & $<5$ & $<5$ & $<5$ & $<5$ & $<5$ & $<5$ \\
\hline Carbon tetrachloride & $<3$ & $<5$ & $<5$ & $<3$ & $<5$ & $<5$ & $<5$ & $<5$ & $<3$ & $<5$ \\
\hline Chlorobenzene & $<5$ & $<3$ & $<5$ & $<5$ & $<5$ & $<5$ & $<5$ & $<5$ & $<5$ & $<5$ \\
\hline Chlorod1browoma thane & $<5$ & $<3$ & $<5$ & $<5$ & $<5$ & $<5$ & $<5$ & $<5$ & $<5$ & $<5$ \\
\hline Chloroethane & $<10$ & $<10$ & $<10$ & $<10$ & $<10$ & $<10$ & $<10$ & $<10$ & $<10$ & $<10$ \\
\hline Chloroform & $<5$ & $<5$ & $<3$ & $<5$ & $<3$ & $<5$ & $<5$ & $<3$ & $<5$ & $<5$ \\
\hline Chloromethane & $<10$ & $<10$ & $<10$ & $<10$ & $<10$ & $<10$ & $<10$ & $<10$ & $<10$ & $<10$ \\
\hline 1,1-D1chloroethane & $<5$ & $<5$ & $<5$ & $<5$ & 2 & $<5$ & 1 & $<5$ & $<5$ & $<5$ \\
\hline 1.2-D1ehloroethane & $<5$ & $<5$ & $<5$ & $<5$ & $<5$ & $<5$ & $<5$ & $<3$ & $<5$ & $<5$ \\
\hline 1.1-D1chloroethene & $<5$ & $<5$ & $<3$ & $<5$ & 1 & $<5$ & $<5$ & $<5$ & $<5$ & 2 \\
\hline 1,2-Dichloroethene & $<3$ & $<5$ & $<5$ & $<3$ & 4 & 3 & $<5$ & 6 & $<5$ & $<5$ \\
\hline 1.2-D1chloropropane & $<s$ & $<5$ & $<5$ & $<5$ & $<5$ & $<5$ & $<5$ & $<5$ & $<3$ & $<5$ \\
\hline C1E-1,3-D1chloropropene & $<5$ & $<5$ & $<5$ & $<5$ & $<3$ & $<3$ & $<5$ & $<5$ & $<5$ & $<5$ \\
\hline trana-1,3-D1chloropropene & $<5$ & $<5$ & $<5$ & $<5$ & $<5$ & $<5$ & $<5$ & $<5$ & $<5$ & $<5$ \\
\hline Ethylbenzene & $<5$ & $<5$ & $<5$ & $<5$ & $<5$ & $<5$ & $<5$ & $<5$ & $<5$ & $<5$ \\
\hline 2-fexanone & $<10$ & $<10$ & $<10$ & $<10$ & $<10$ & $<10$ & $<10$ & $<10$ & $<10$ & $<10$ \\
\hline 4-Methy 1-2-pentanono & $<10$ & $<10$ & $<10$ & $<10$ & $<10$ & $<10$ & $<10$ & $<10$ & $<10$ & $<10$ \\
\hline ethylene chloride & $<5$ & $<5$ & $<3$ & $<5$ & $<5$ & $<5$ & $<5$ & $<5$ & $<5$ & $<5$ \\
\hline tyrene & $<5$ & $<5$ & $<5$ & $<5$ & $<5$ & $<5$ & $<5$ & $<5$ & $<5$ & $<5$ \\
\hline 1, 1,2,2-Tetrach loroethane & $<5$ & $<3$ & $<5$ & $<5$ & $<5$ & $<5$ & $<5$ & $<5$ & $<5$ & es \\
\hline Tetrachloroethene & 13) & 11 & 13 & 14 & 45 & 32 & 34 & 44 & 32 & 35 \\
\hline Toivene & $<5$ & $<5$ & $<5$ & $<3$ & $<5$ & $<5$ & $<5$ & $<5$ & $<5$ & $<5$ \\
\hline 1,1,1-Triehloroethane & 0.9 & 0.9 & $<5$ & 1 & 6 & 3 & 3 & 4 & 10 & 12 \\
\hline 1,1,2-Tr1ehloroethane & $<5$ & $<5$ & $<5$ & $<5$ & $<5$ & $<5$ & $<5$ & $<5$ & $<5$ & $<5$ \\
\hline Trichloroethene & $<5$ & $<5$ & $<5$ & $<s$ & 2 & 1 & 1 & 2 & $<5$ & $<3$ \\
\hline VInyl acetate & $<10$ & $<10$ & $<10$ & $<10$ & $<10$ & $<10$ & 2 & $<10$ & $<10$ & $<10$ \\
\hline vinyl chlorlde & $<10$ & $<10$ & $<10$ & $<10$ & $<10$ & $<10$ & $<10$ & $<10$ & $<10$ & $<10$ \\
\hline Xylenes & $<5$ & $<5$ & $<5$ & es & es & $<5$ & $<5$ & $<5$ & $<5$ & $<5$ \\
\hline
\end{tabular}

( CONTIFUED) 
WATER QUAIITY 1990

CEESTTUT RIDGS GECURITY PITS

\begin{tabular}{|c|c|c|c|c|c|c|c|c|c|c|}
\hline \multirow[t]{2}{*}{ VOURTILE ORENAICS (ug/h) } & \multicolumn{2}{|c|}{ GW-175 } & \multicolumn{4}{|c|}{ ON-176 } & \multicolumn{4}{|c|}{$0 N-177$} \\
\hline & $07 / 24 / 90 \mid 1$ & $10 / 26 / 90$ & $01 / 27 / 90$ & $05 / 24 / 90$ & $07 / 28 / 90$ & $10 / 29 / 90$ & $02 / 27 / 90$ & $05 / 23 / 90 \mid$ & $07 / 26 / 90$ & $10 / 27 / 90$ \\
\hline Acetone & $<10$ & 11 & 43 & $<20$ & $<20$ & $<10$ & $<10$ & $<10$ & 6 & $<10$ \\
\hline Benzene & $<5$ & 0.9 & $<5$ & $<10$ & $<10$ & 0.8 & $<5$ & $<5$ & $<5$ & $<5$ \\
\hline Browod1 chloromethane & $<3$ & $<5$ & $<5$ & $<10$ & $<10$ & $<5$ & $<5$ & $<5$ & $<5$ & $<5$ \\
\hline Bromotorm & $<3$ & $<5$ & $<3$ & $<10$ & $<10$ & $<3$ & $<5$ & $<5$ & $<5$ & $<5$ \\
\hline Browowethane & $<10$ & $<10$ & $<10$ & $<20$ & $<20$ & $<10$ & $<10$ & $<10$ & $<10$ & $<10$ \\
\hline 2-Butanone & $<10$ & $<10$ & $<10$ & $<20$ & $<20$ & $<10$ & $<10$ & $<10$ & $<10$ & $<10$ \\
\hline Carbon disulelde & $<5$ & $<5$ & $<5$ & $<10$ & $<10$ & $<5$ & $<3$ & $<5$ & $<5$ & $<5$ \\
\hline Carbon tetrachlor1de & $<3$ & $<5$ & $<5$ & $<10$ & 14 & $<5$ & $<3$ & $<5$ & $<5$ & $<5$ \\
\hline Chlorobenzene & $<5$ & $<5$ & $<5$ & $<10$ & $<10$ & $<5$ & $<3$ & $<3$ & $<5$ & $<5$ \\
\hline Chlorod1bromone thwite & $<5$ & $<5$ & $<5$ & $<10$ & $<10$ & $<5$ & es & $<5$ & $<5$ & $<5$ \\
\hline Chloroathane & $<10$ & $<10$ & $<10$ & $<20$ & $<20$ & $<10$ & $<20$ & $<20$ & $<10$ & $<10$ \\
\hline Chloroform & $<5$ & $<5$ & $<5$ & $<10$ & $<10$ & $<5$ & $<5$ & $<5$ & $<5$ & $<5$ \\
\hline Chlorowethane & $<10$ & $<10$ & $<10$ & $<20$ & $<20$ & $<10$ & $<10$ & $<10$ & $<10$ & $<10$ \\
\hline 1,1-D 1eh1oroethane & <3 & $<\mathbf{s}$ & 93 & 57 & 27 & 45 & 5 & 4 & 4 & 8 \\
\hline 1,2-D1chloroethane & $<5$ & $<5$ & 3 & $<10$ & $<10$ & 2 & $<5$ & $<5$ & $<5$ & $<5$ \\
\hline 1.1-Dlchloroethene & $<5$ & $<5$ & 32 & 19 & 16 & 15 & $<5$ & $<3$ & $<5$ & 1 \\
\hline 1,2-Dlchloroathene & $<5$ & $<5$ & $<5$ & $<10$ & $<10$ & $<5$ & $<5$ & $<5$ & $<5$ & $<5$ \\
\hline 1,2-D1chloropropane & $<3$ & $<5$ & $<5$ & $<10$ & $<10$ & $<3$ & $<5$ & $<5$ & $<5$ & $<5$ \\
\hline cle-1,3-Dichloropropene & $<3$ & $<3$ & $<5$ & $<10$ & $<10$ & $<5$ & $<5$ & $<5$ & $<5$ & $<5$ \\
\hline trana-1,3-D1chloropropeno & $<5$ & $<5$ & 25 & $<20$ & $<10$ & es & $<5$ & $<3$ & $<5$ & $<5$ \\
\hline Ethylbanzene & $<5$ & $<5$ & $<5$ & $<10$ & $<10$ & $<5$ & $<5$ & $<5$ & $<5$ & $<5$ \\
\hline 2-Fexanone & $<10$ & $<10$ & $<10$ & $e 20$ & $<20$ & $<10$ & $<10$ & $<10$ & $<10$ & $<10$ \\
\hline 4-Methy 1-2-pentanone & $<10$ & $<10$ & $<10$ & $<20$ & $<20$ & $<10$ & $<10$ & $<10$ & $<10$ & $<10$ \\
\hline Methylene chloride & $<5$ & 2 & $<5$ & $<10$ & $<10$ & 2 & $<5$ & $<5$ & $<5$ & $<5$ \\
\hline Styrene & $<3$ & $<5$ & $<5$ & $<10$ & $<10$ & $<5$ & $<5$ & $<5$ & $<5$ & $<5$ \\
\hline 1,1,2,2-Tetrachloronthane & $<5$ & $<5$ & $<5$ & $<10$ & $<10$ & $<5$ & $<5$ & $<5$ & $<5$ & $<5$ \\
\hline Tetrachloroethene & 27 & 12 & 12 & 6 & 10 & $\mathbf{3}$ & 2 & $<5$ & $<5$ & $<5$ \\
\hline Tol uene & $<5$ & $<5$ & $<5$ & $<10$ & $<10$ & $<5$ & $<5$ & $<3$ & $<5$ & $<5$ \\
\hline 1,1,1-Tr1chlorowthane & $\bullet$ & 4 & 220 & 150 & 100 & 120 & 13) & 6 & 12 & 20 \\
\hline 1,1,2-Tr1chloroethane & $<3$ & es & $<\boldsymbol{s}$ & $<10$ & $<10$ & $<5$ & $<5$ & $<3$ & $<5$ & $<5$ \\
\hline Trlehloroethene & $<5$ & $<3$ & $<3$ & $<10$ & $<10$ & $<5$ & $<5$ & $<5$ & $<5$ & $<5$ \\
\hline VInyl acetate & $<10$ & $<10$ & $<10$ & $<20$ & $<20$ & $<10$ & $<10$ & $<10$ & 2 & $<10$ \\
\hline VInyl chlorlde & $<10$ & $<10$ & $<10$ & $<20$ & $<20$ & $<10$ & $<10$ & $<10$ & $<10$ & $<10$ \\
\hline Xylenee & $<5$ & $<5$ & $<5$ & $<10$ & $<10$ & $<5$ & $<5$ & $<5$ & $<3$ & $<5$ \\
\hline
\end{tabular}

(CONTINUE) 
ER QUNSITY 1990

ESTINTT RIDGE SECURITY PITS

\begin{tabular}{|c|c|c|c|c|c|c|c|c|c|c|}
\hline \multirow[t]{2}{*}{ VOLATILE ORCANICS (ug/L) } & \multicolumn{4}{|c|}{ GW-178 } & \multicolumn{4}{|c|}{$G W-179$} & \multicolumn{2}{|c|}{ GW-180 } \\
\hline & $01 / 28 / 90 \mid c$ & $|05 / 17 / 90| 0$ & $|07 / 21 / 90| 1$ & $10 / 22 / 90$ & $03 / 21 / 90$ & $06 / 09 / 90$ & $09 / 24 / 90 \mid 2$ & $12 / 11 / 90$ & $03 / 05 / 90 \mid$ & $05 / 24 / 90$ \\
\hline Ace tone & $<10$ & $<10$ & $<10$ & $<10$ & $<50$ & 4 & 11 & $<10$ & $<10$ & $<10$ \\
\hline Benzene & es & $<5$ & $<5$ & $<5$ & $<25$ & $<10$ & $<10$ & 1 & $<5$ & $<5$ \\
\hline Browodl ch loroun thane & $<5$ & $<5$ & 2 & $<5$ & $<25$ & $<10$ & $<10$ & $<5$ & $<5$ & $<5$ \\
\hline Bromotorno & $<5$ & $<5$ & $<5$ & $<3$ & $<25$ & $<10$ & $<10$ & $<5$ & $<5$ & $<5$ \\
\hline Bromomethane & $<10$ & $<10$ & $<10$ & $<10$ & eso & $<20$ & $<20$ & $<10$ & $<10$ & $<10$ \\
\hline 2-Butanone & $<10$ & $<10$ & $<10$ & $<10$ & $<50$ & $<20$ & $<20$ & $<10$ & $<10$ & $<10$ \\
\hline Carbor dieulfide & $<3$ & $<5$ & $<5$ & $<5$ & $<25$ & $<10$ & $<10$ & $<5$ & $<5$ & $<5$ \\
\hline Carbon tetrachloride & $<5$ & $<5$ & $<5$ & $<5$ & 10 & $<10$ & $<10$ & $<3$ & $<5$ & $<5$ \\
\hline Chlorobenzene & $<5$ & $<5$ & $<5$ & $<5$ & $<25$ & $<10$ & $<10$ & $<5$ & $<3$ & $<5$ \\
\hline Chlorod1bromomethane & $<5$ & $<5$ & $<5$ & $<5$ & $<25$ & $<10$ & $<10$ & $<5$ & $<5$ & $<5$ \\
\hline Chloroethane & $<10$ & $<10$ & $<10$ & $<10$ & $<50$ & $<20$ & $<20$ & $<10$ & $<10$ & $<10$ \\
\hline Chloroform & $<5$ & $<5$ & 20 & 10 & $<25$ & $<10$ & $<10$ & $<3$ & $<5$ & $<3$ \\
\hline Chloromethane & $<10$ & $<10$ & $<10$ & $<10$ & $<30$ & $<20$ & $<20$ & $<10$ & $<10$ & $<10$ \\
\hline 1,1-D1Chloroe thane & 6 & $<5$ & $<5$ & 3 & 120 & 120 & 110 & 110 & 3) & 4 \\
\hline 1,2-D1Chloroethane & $<5$ & $<5$ & $<5$ & $<5$ & $<23$ & $<10$ & $<10$ & $<5$ & $<5$ & $<5$ \\
\hline 1.1-D1Chlorosthane & $<5$ & $<5$ & $<5$ & $<5$ & 59 & 51 & 40 & 32 & $<5$ & $<5$ \\
\hline 1.2-D1ehloroethene & $<5$ & $<5$ & $<5$ & $<5$ & $<25$ & $<10$ & $<10$ & $<5$ & 10 & - \\
\hline 1,2-D1Ch1oropropane & $<3$ & $<5$ & $<5$ & $<5$ & $<25$ & $<10$ & $<10$ & $<3$ & $<3$ & $<5$ \\
\hline C16-1,3-D1chloropropane & $<5$ & $<5$ & $<5$ & $<5$ & $<25$ & $<10$ & $<10$ & $<5$ & $<5$ & $<5$ \\
\hline trane-1, J-Dichloropropene & $<5$ & $<5$ & $<5$ & $<5$ & $<25$ & $<10$ & $<10$ & $<3$ & $<5$ & $<5$ \\
\hline Ethylbenzene & $<3$ & $<5$ & $<5$ & $<3$ & $<25$ & $<10$ & $<10$ & $<5$ & $<5$ & $<5$ \\
\hline 2-8exanone & $<10$ & $<10$ & $<10$ & $<10$ & $<30$ & $<20$ & $<20$ & $<10$ & $<10$ & $<10$ \\
\hline 4-Methy 1-2-pontanone & $<10$ & $<10$ & $<10$ & $<10$ & $<30$ & $<20$ & $<20$ & $<10$ & $<10$ & $<10$ \\
\hline Methylene ehlor1de & $<5$ & $<5$ & $<5$ & $<5$ & $<25$ & $<10$ & $<10$ & 2 & $<5$ & $<5$ \\
\hline cyrene & $<5$ & $<5$ & $<5$ & $<5$ & $<25$ & $<10$ & $<10$ & $<5$ & $<5$ & $<5$ \\
\hline X,1,2,2-Tetrachloroethane & $<5$ & $<5$ & $<5$ & $<5$ & $<25$ & $<10$ & 13 & $<5$ & $<3$ & $<5$ \\
\hline Tetrachloroethene & 0.0 & $<5$ & $<5$ & $<5$ & $<23$ & 5 & 4 & 6 & 100 & 67 \\
\hline Toluene & $<5$ & $<5$ & $<5$ & $<5$ & $<25$ & $<10$ & $<10$ & $<5$ & $<5$ & es \\
\hline 1,1,1-Tr1eh1oroothane & 33 & 27 & 6 & 16 & 290 & 200 & 210 & 310 & 4 & 3 \\
\hline 1,1,2-Tr1ch 1oroethane & $<3$ & $<5$ & $<5$ & $<5$ & $<25$ & $<10$ & $<10$ & $<5$ & $<5$ & $<5$ \\
\hline Trlchloroethene & $<5$ & $<5$ & $<5$ & $<5$ & $<25$ & $<10$ & $<10$ & $<5$ & 3 & 2 \\
\hline Vinyl acetate & $<10$ & $<10$ & $<10$ & $<10$ & $<30$ & $<20$ & $<25$ & $<10$ & $<10$ & $<10$ \\
\hline Vinyl chloride & $<10$ & $<10$ & $<10$ & $<10$ & $<30$ & $<20$ & $<20$ & $<10$ & $<10$ & $<10$ \\
\hline xylenes & $<5$ & $<3$ & $<5$ & $<5$ & $<23$ & $<10$ & $<10$ & $<5$ & $<5$ & $<3$ \\
\hline
\end{tabular}

(CONTINUED) 
WATER OUNLITY 1990

CHESTTUI RIDGS BECURITY PITS

\begin{tabular}{|c|c|c|c|c|c|c|c|c|c|c|}
\hline \multirow[t]{3}{*}{ vOLATILE ORGAnICS (ug/L) } & \multicolumn{2}{|c|}{$0 N-180$} & \multicolumn{5}{|c|}{ ON-181 } & \multicolumn{3}{|c|}{ OW-322 } \\
\hline & \multirow[t]{2}{*}{$07 / 26 / 90$} & \multirow[t]{2}{*}{$10 / 29 / 90$} & \multirow[t]{2}{*}{$03 / 02 / 90$} & \multicolumn{2}{|c|}{$05 / 21 / 90$} & \multirow[t]{2}{*}{$07 / 23 / 90$} & \multirow[t]{2}{*}{$10 / 25 / 90$} & \multicolumn{2}{|c|}{$01 / 28 / 90$} & \multirow[t]{2}{*}{$05 / 23 / 90$} \\
\hline & & & & & Fo & & & & Fo & \\
\hline Acetone & 6 & $<10$ & 17 & $<10$ & $<10$ & 8) & $<10$ & 30 & $<50$ & $<50$ \\
\hline Benzene & $<5$ & 0.9 & $<5$ & $<5$ & $<5$ & $<5$ & $<5$ & $<25$ & $<25$ & $<25$ \\
\hline Browodlchloromethane & $<5$ & $<3$ & $<5$ & $<5$ & $<5$ & $<5$ & $<5$ & $<25$ & $<25$ & $<25$ \\
\hline Bromotorw & $<3$ & $<5$ & $<5$ & $<5$ & $<5$ & $<5$ & $<5$ & $<23$ & $<25$ & $<25$ \\
\hline B romone thane & $<10$ & $<10$ & $<10$ & $<10$ & $<10$ & $<10$ & $<10$ & $<50$ & $<50$ & $<50$ \\
\hline 2-Butanone & $<10$ & $<10$ & $<10$ & $<10$ & $<10$ & $<10$ & $<10$ & $<90$ & $<30$ & $<50$ \\
\hline Carbon dieulelde & $<5$ & $<5$ & $<5$ & $<5$ & $<5$ & $<5$ & $<5$ & $<25$ & $<25$ & $<25$ \\
\hline Carbon tetrachlor 1 de & $<5$ & $<s$ & $<3$ & $<5$ & $<5$ & $<5$ & $<5$ & $<25$ & $<25$ & $<25$ \\
\hline Chlorobenzene & $<5$ & $<5$ & $<5$ & $<5$ & $<5$ & $<3$ & $<3$ & $<25$ & $<25$ & $<25$ \\
\hline Chlorodibromomethane & $<3$ & $<5$ & $<5$ & $<3$ & $<3$ & $<.3$ & $<3$ & $<25$ & $<25$ & $<25$ \\
\hline Chloroethane & $<10$ & $<10$ & $<10$ & $<10$ & $<10$ & $<10$ & $<10$ & $<50$ & $<50$ & $<50$ \\
\hline Chloroform & $<3$ & $<3$ & $<3$ & $<5$ & $<5$ & $<5$ & $<3$ & $<25$ & $<25$ & $<25$ \\
\hline Chlorowethane & $<10$ & $<10$ & $<10$ & $<10$ & $<10$ & $<10$ & $<10$ & $<50$ & $<50$ & $<50$ \\
\hline 1,1-Dlehloroethane & 3 & 2 & $<5$ & $<5$ & $<5$ & $<3$ & $<3$ & 34 & 33 & 54 \\
\hline 1.2-D1chloroethane & $<5$ & $<5$ & $<3$ & $<5$ & $<5$ & $<5$ & $<3$ & $<25$ & $<25$ & $<25$ \\
\hline 1,1-Dichloroethene & $<3$ & $<5$ & $<5$ & $<5$ & $<3$ & $<5$ & $<5$ & 100 & 98 & 110 \\
\hline 1,2-D1chloroethene & $\bullet$ & 5 & $<5$ & $<3$ & $<5$ & $<5$ & $<5$ & $<23$ & $<25$ & $<25$ \\
\hline 1,2-Dlehloropropane & $<3$ & $<5$ & $<5$ & $<3$ & $<5$ & $<5$ & $<5$ & $<25$ & $<25$ & $<25$ \\
\hline c1-1,3-Dichloropropene & $<3$ & $<5$ & $<5$ & $<5$ & es & $<3$ & $<5$ & $<25$ & $<25$ & $<23$ \\
\hline trans-1,3-D1chloropropene & $<5$ & $<3$ & $<5$ & $<5$ & $<5$ & $<5$ & $<3$ & $<25$ & $<25$ & $<25$ \\
\hline Ethylbenzene & $<5$ & $<5$ & $<3$ & <s & $<5$ & $<5$ & $<3$ & $<25$ & $<25$ & $<25$ \\
\hline 2-Aexanone & $<10$ & $<10$ & $<10$ & $<10$ & $<10$ & $<10$ & $<\mathbf{1 0}$ & $<50$ & $<50$ & $<50$ \\
\hline 4-Methy 1-2-pentanone & $<10$ & $<10$ & $<10$ & $<10$ & $<10$ & $<10$ & $<10$ & $<50$ & $<50$ & $<50$ \\
\hline Methylene chloride & $<5$ & 2 & $<3$ & $<3$ & $<5$ & $<5$ & $<3$ & $<25$ & $<25$ & $<25$ \\
\hline otyrene & $<s$ & $<3$ & $<5$ & $<3$ & $<5$ & $<5$ & es & $<25$ & $<25$ & $<25$ \\
\hline 1,1,2,2-Tetrachloroethane & $<3$ & $<3$ & $<5$ & $<$ & $<3$ & $<5$ & $<s$ & $<25$ & $<25$ & $<25$ \\
\hline Tetrachloroethene & 09 & 73 & $<5$ & $<5$ & $<3$ & $<5$ & $<5$ & 6 & 6 & 6 \\
\hline Toluene & $<5$ & $<5$ & $<5$ & $<3$ & $<5$ & $<3$ & 25 & $<23$ & $<25$ & $<25$ \\
\hline 1,1,1-Tr1chloroethane & 4 & 3 & $<3$ & $<5$ & $<5$ & $<3$ & $<5$ & 580 & 390 & 360 \\
\hline 1,1,2-Tr1chloroethane & $<3$ & $<5$ & $<5$ & $<5$ & $<3$ & $<5$ & $<9$ & $<25$ & $<25$ & $<25$ \\
\hline Trichloroethene & 3 & 2 & $<5$ & $<3$ & $<5$ & $<5$ & $<5$ & $<25$ & $<25$ & $<25$ \\
\hline VInyl acotate & 2 & $<10$ & $<10$ & $<10$ & $<10$ & 2 & $<10$ & $<50$ & $<50$ & $<50$ \\
\hline vinyl chloride & $<10$ & $<10$ & $<10$ & $<10$ & $<10$ & $<10$ & $<10$ & $<50$ & $<50$ & $<50$ \\
\hline XYlenes & $<5$ & $<5$ & $<5$ & $<9$ & $<3$ & $<3$ & $<5$ & $<25$ & $<25$ & $<25$ \\
\hline
\end{tabular}

(COATINUED) 
R QUNLITY 1990

STWUT RIDGE BECURITY PITS

\begin{tabular}{|c|c|c|c|c|c|c|c|c|c|c|}
\hline \multirow[t]{2}{*}{ VoTATILE ORCANICB (ug/h) } & \multicolumn{2}{|c|}{ ON-322 } & \multicolumn{4}{|c|}{$G N-511$} & \multicolumn{4}{|c|}{$6 W-607$} \\
\hline & $07 / 26 / 90 \mid$ & $10 / 29 / 900$ & $02 / 28 / 90$ & $03 / 18 / 90$ & $|07 / 21 / 90|$ & $10 / 24 / 90$ & $02 / 09 / 90$ & $05 / 18 / 90$ & $07 / 21 / 90$ & $10 / 24 / 90$ \\
\hline Acetone & $<50$ & $<50$ & $<10$ & $<10$ & $<10$ & $<10$ & $<10$ & $<10$ & $<10$ & 16) \\
\hline Benzene & $<25$ & 4 & $<5$ & $<5$ & $<5$ & 0.9 & $<5$ & $<5$ & $<3$ & 0.9 \\
\hline Browodl ch lorowethane & $<23$ & $<23$ & $<5$ & $<5$ & $<5$ & $<5$ & $<5$ & $<5$ & $<5$ & $<5$ \\
\hline Bromofora & $<25$ & $<25$ & $<5$ & $<5$ & $<3$ & $<5$ & $<5$ & $<5$ & $<5$ & $<5$ \\
\hline Bromowo thane & $<50$ & $<50$ & $<10$ & $<10$ & $<10$ & $<10$ & $<10$ & $<10$ & $<10$ & $<10$ \\
\hline 2-Butanone & $<30$ & $<50$ & $<10$ & $<10$ & $<10$ & $<10$ & $<10$ & $<10$ & $<10$ & $<10$ \\
\hline Carbon dieuleldo & $<25$ & $<25$ & $<5$ & $<3$ & $<5$ & $<3$ & $<3$ & $<5$ & $<5$ & $<5$ \\
\hline Carbon tetrachloride & $<23$ & $<25$ & $<5$ & $<5$ & $<5$ & $<5$ & $<5$ & $<5$ & $<5$ & $<5$ \\
\hline Chlorobenzene & $<25$ & $<25$ & $<5$ & $<5$ & $<5$ & $<3$ & $<5$ & $<5$ & $<5$ & $<5$ \\
\hline Chlorodibromomothane & $<25$ & $<25$ & 25 & $<5$ & $<5$ & $<5$ & $<5$ & $<5$ & $<5$ & $<5$ \\
\hline Chloroethane & $<50$ & $<30$ & $<10$ & $<10$ & $<10$ & $<10$ & $<10$ & $<10$ & $<10$ & $<10$ \\
\hline Chloroform & $<23$ & $<25$ & $<3$ & $<3$ & $<5$ & $<5$ & $<5$ & $<5$ & $<5$ & $<5$ \\
\hline Chloromethane & $<30$ & $<30$ & $<10$ & $<10$ & $<10$ & $<10$ & $<10$ & $<10$ & $<10$ & $<10$ \\
\hline 1,1-D1chlorouthane & 63 & 39 & $<5$ & $<5$ & $<5$ & $<3$ & $<5$ & $<5$ & $<5$ & $<5$ \\
\hline 1,2-D1ehlorosthane & $<25$ & $<25$ & $<5$ & $<5$ & $<3$ & $<5$ & $<5$ & $<5$ & $<5$ & $<5$ \\
\hline 1,1-DIchloroethene & 110 & 95 & $<5$ & $<5$ & $<5$ & $<3$ & $<5$ & $<5$ & $<3$ & $<5$ \\
\hline 1,2-D1ch lor oethene & $<25$ & $<25$ & $<5$ & $<5$ & $<5$ & $<5$ & $<5$ & $<5$ & $<5$ & $<5$ \\
\hline 1,2-D1chloropropane & $<25$ & $<25$ & $<5$ & $<5$ & $<5$ & $<5$ & $<5$ & $<5$ & $<3$ & $<5$ \\
\hline C18-1,3-D1ehloropropene & $<25$ & $<25$ & $<5$ & $<5$ & $<5$ & $<5$ & $<5$ & $<5$ & $<5$ & $<5$ \\
\hline Erane-1, 3-D 1ehloropropene & $<23$ & $<23$ & $<5$ & $<5$ & $<3$ & $<5$ & $<5$ & $<5$ & $<5$ & $<5$ \\
\hline Ethylbenzene & $<25$ & $<25$ & $<5$ & $<5$ & $<3$ & $<5$ & $<5$ & $<3$ & $<5$ & $<3$ \\
\hline 2-Bexanone & $<50$ & $<50$ & $<10$ & $<10$ & $<10$ & $<10$ & $<10$ & $<10$ & $<10$ & $<10$ \\
\hline 4-Methy 1-2-pentanone & $<30$ & $<50$ & $<10$ & $<10$ & $<10$ & $<10$ & $<10$ & $<10$ & $<10$ & $<10$ \\
\hline Methylene chlor1de & $<23$ & 11 & $<5$ & $<5$ & $<5$ & $\mathbf{3}$ & $<5$ & $<5$ & $<3$ & 2 \\
\hline$y r e n e$ & $<25$ & $<25$ & $<5$ & $<3$ & $<5$ & $<5$ & $<5$ & $<5$ & $<5$ & $<5$ \\
\hline 1,2,2-Tetrach loroethane & $<25$ & $<25$ & $<3$ & $<5$ & $<3$ & $<5$ & $<5$ & $<5$ & $<5$ & $<5$ \\
\hline Tetrachloroethene & 7 & $<23$ & $<5$ & $<5$ & $<5$ & $<5$ & $<5$ & $<3$ & $<5$ & $<5$ \\
\hline Tol uene & $<23$ & $<25$ & $<5$ & $<3$ & $<5$ & $<3$ & $<5$ & $<5$ & $<5$ & $<5$ \\
\hline 1,1,1-Tr1chloroethane & 390 & 520 & $<5$ & $<5$ & $<5$ & $<5$ & $<5$ & $<5$ & $<5$ & $<5$ \\
\hline 1,1,2-Tr1chloroethane & $<25$ & $<25$ & $<5$ & $<5$ & $<5$ & $<5$ & $<3$ & $<5$ & $<5$ & $<5$ \\
\hline Tr1chloroethene & $<25$ & $<25$ & $<3$ & $<5$ & $<5$ & $<5$ & $<3$ & $<3$ & $<5$ & $<5$ \\
\hline VInyl acetate & 9) & $<50$ & $<10$ & $<10$ & $<10$ & $<10$ & $<10$ & $<10$ & $<10$ & $<10$ \\
\hline Vinyl chloride & $<30$ & $<30$ & $<10$ & $<10$ & $<10$ & $<10$ & $<10$ & $<10$ & $<10$ & $<10$ \\
\hline Xylenea & $<25$ & $<25$ & $<5$ & $<5$ & $<5$ & $<3$ & $<5$ & $<3$ & $<3$ & $<3$ \\
\hline
\end{tabular}

(CONTINUED) 
WATER QUALITY 1990

CHESTIUU RIDG SECURITY PITS

\begin{tabular}{|c|c|c|c|c|c|c|c|c|c|c|}
\hline \multirow[t]{3}{*}{ vounTILE ORGNires (ug/h) } & \multicolumn{5}{|c|}{$0 N-608$} & \multicolumn{5}{|c|}{ ON-609 } \\
\hline & \multirow[t]{2}{*}{$02 / 10 / 90$} & \multirow[t]{2}{*}{$05 / 18 / 90$} & \multirow[t]{2}{*}{$07 / 23 / 90$} & \multicolumn{2}{|c|}{$10 / 24 / 90$} & \multirow[t]{2}{*}{$02 / 14 / 90$} & \multirow[t]{2}{*}{$05 / 17 / 90$} & \multicolumn{2}{|c|}{$07 / 21 / 90$} & \multirow[t]{2}{*}{$10 / 23 / 90$} \\
\hline & & & & & FD & & & & ro & \\
\hline Acetone & $<10$ & $<10$ & $<10$ & $<10$ & $<10$ & $<10$ & $<10$ & $<10$ & $<10$ & $<10$ \\
\hline Benzene & $<3$ & $<5$ & $<5$ & $<3$ & es & $<5$ & $<5$ & $<3$ & $<5$ & $<5$ \\
\hline Bromodlch lorom thane & $<3$ & $<5$ & $<5$ & $<5$ & $<5$ & $<5$ & $<5$ & $<3$ & $<5$ & $<5$ \\
\hline Browotorm & $<5$ & $<5$ & $<5$ & $<5$ & $<3$ & $<3$ & es & $<5$ & $<5$ & $<5$ \\
\hline Browomethane & $<10$ & $<10$ & $<10$ & $<10$ & $<10$ & $<10$ & $<10$ & $<10$ & $<10$ & $<10$ \\
\hline 2-Butanone & $<10$ & $<10$ & $<10$ & $<10$ & $<10$ & $<10$ & $<10$ & $<10$ & $<10$ & $<10$ \\
\hline Carbon dieulelde & $<5$ & es & $<5$ & $<5$ & $<5$ & $<5$ & $<5$ & $<5$ & $<5$ & $<3$ \\
\hline Carbon tetrachloride & $<5$ & $<5$ & $<3$ & $<5$ & $<5$ & $<5$ & $<5$ & $<5$ & $<5$ & $<5$ \\
\hline Chlorobenzene & $<5$ & $<5$ & $<5$ & $<5$ & $<5$ & $<3$ & $<5$ & $<5$ & $<5$ & $<5$ \\
\hline Chlorodibromomethane & $<5$ & $<5$ & $<5$ & $<5$ & $<5$ & $<5$ & $<5$ & $<3$ & $<5$ & $<5$ \\
\hline Chloroethane & $<10$ & $<10$ & $<10$ & $<10$ & $<10$ & $<10$ & $<10$ & $<10$ & $<10$ & $<10$ \\
\hline Chloroform & <s & $<5$ & $<5$ & $<3$ & $<5$ & $<5$ & $<5$ & $<5$ & $<5$ & $<5$ \\
\hline Chloromethane & $<10$ & $<10$ & $<10$ & $<10$ & $<10$ & $<10$ & $<10$ & $<10$ & $<10$ & $<10$ \\
\hline 1,1-01ehloroethane & 5 & $<5$ & $<5$ & 2 & 2 & 2 & $<5$ & $<3$ & $<3$ & 2 \\
\hline 1.2-D1chloroethane & $<3$ & $<5$ & $<5$ & $<5$ & $<5$ & $<5$ & $<3$ & $<5$ & $<5$ & $<5$ \\
\hline 1,1-D1ehlor oethene & 2 & $<5$ & $<5$ & $<5$ & $<5$ & $<5$ & $<5$ & $<5$ & $<5$ & $<5$ \\
\hline 1.2-Dlchloroethene & $<5$ & $<3$ & $<5$ & $<5$ & $<5$ & 25 & 47 & 39 & 39 & 28 \\
\hline 1,2-D1chloropropane & $<5$ & $<5$ & $<5$ & $<5$ & $<5$ & $<5$ & $<5$ & $<3$ & $<5$ & $<5$ \\
\hline c10-1,3-D1ehloropropene & $<5$ & $<5$ & <5 & $<5$ & $<5$ & $<5$ & $<5$ & $<5$ & $<5$ & $<3$ \\
\hline trane-1, 3-D 1 chloropropane & $<3$ & $<5$ & $<5$ & $<3$ & $<5$ & $<5$ & $<3$ & $<5$ & $<5$ & $<5$ \\
\hline Ethylbenzene & $<3$ & $<3$ & $<3$ & $<3$ & $<5$ & $<5$ & $<5$ & $<3$ & $<5$ & $<5$ \\
\hline 2-Rexanone & $<10$ & $<10$ & $<10$ & $<20$ & $<10$ & $<10$ & $<10$ & $<10$ & $<10$ & $<10$ \\
\hline 4-Methy 1-2-pentanone & $<10$ & $<10$ & $<10$ & $<10$ & $<10$ & $<10$ & $<10$ & $<10$ & $<10$ & $<10$ \\
\hline Methylene chloride & $<5$ & $<5$ & es & $<s$ & $<3$ & $<5$ & $<5$ & $<5$ & $<5$ & $<5$ \\
\hline styrene & $<3$ & $<5$ & $<5$ & $<5$ & $<5$ & $<5$ & es & $<5$ & $<5$ & $<5$ \\
\hline 1,1,2,2-Tetrach loroethane & $<5$ & $<3$ & $<5$ & $<5$ & $<5$ & $<3$ & $<3$ & $<5$ & $<5$ & $<5$ \\
\hline Tetrachloroethene & 2 & $<5$ & 6 & 2 & 2 & 27 & s4) & 31 & 43 & 22 \\
\hline Toluene & $<5$ & $<5$ & $<5$ & $<5$ & $<5$ & $<5$ & $<s$ & $<5$ & $<3$ & $<5$ \\
\hline 1,1,1-Tr1ch loroethane & 16 & 12 & 23 & $<5$ & $<3$ & 2 & $<5$ & $<5$ & $<5$ & 2 \\
\hline 1,1,2-Tr1eh1oroethane & $<3$ & $<5$ & $<5$ & $<5$ & $<3$ & $<5$ & $<3$ & $<5$ & $<5$ & $<9$ \\
\hline Trichloroethene & $<5$ & $<9$ & $<5$ & $<3$ & es & 3 & 3 & $<3$ & $<5$ & 3 \\
\hline vinyl acetate & $<10$ & $<10$ & $<10$ & $<10$ & $<10$ & $<10$ & $<10$ & $<10$ & $<10$ & $<10$ \\
\hline vinyl chloride & $<10$ & $<10$ & $<10$ & $<10$ & $<10$ & $<10$ & $<10$ & $<10$ & $<10$ & $<10$ \\
\hline Xylenes & $<5$ & $<3$ & es & $<5$ & $<3$ & $<3$ & $<5$ & $<5$ & $<3$ & $<5$ \\
\hline
\end{tabular}

(CONTINUED) 
R QUNLITY 1990

TWUT RIDGE GECURITY PITS

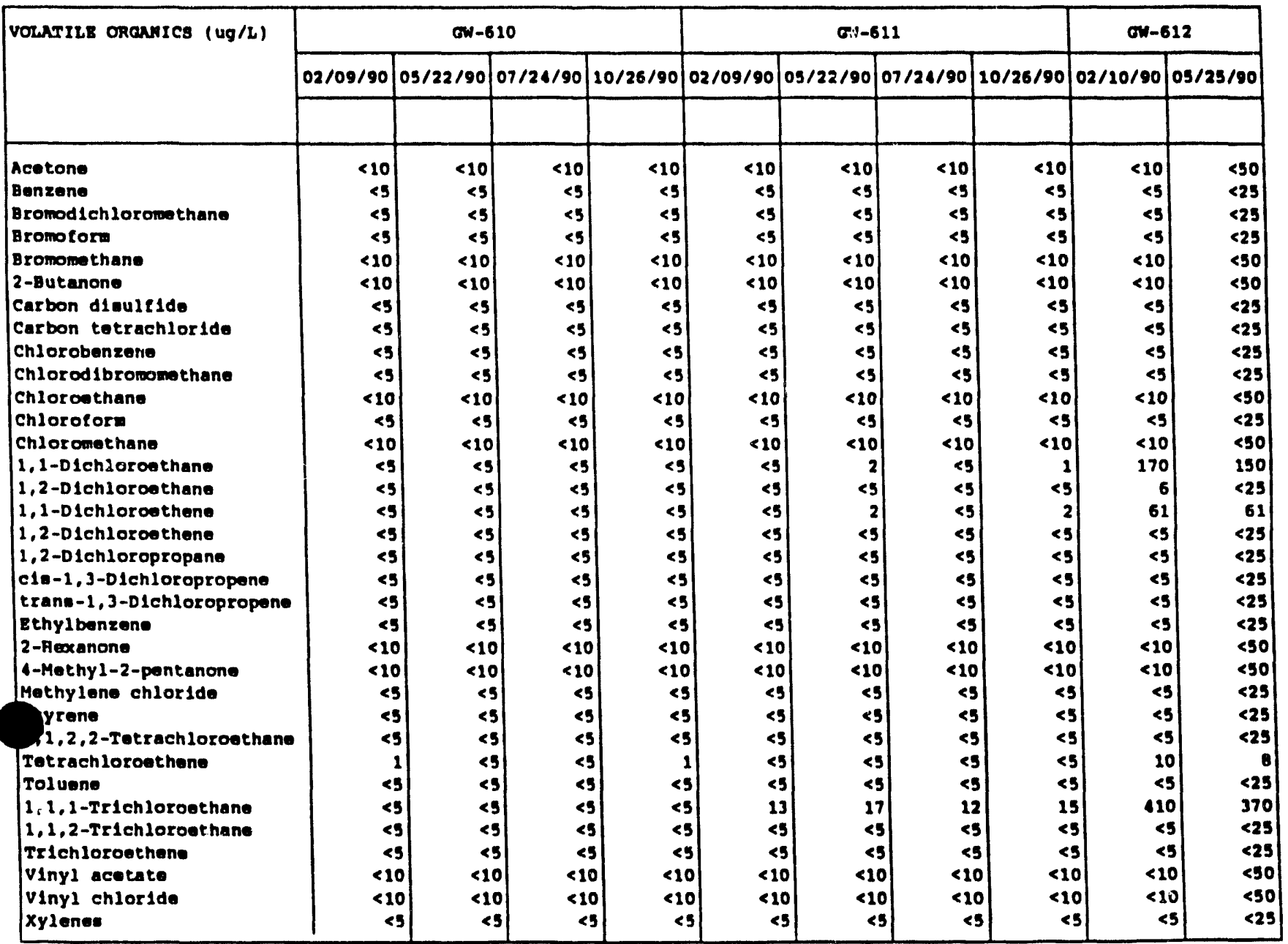

(CONTINUND) 
WATER QUALITY 1990

CHESTMUT RIDCE SECURITY PITS

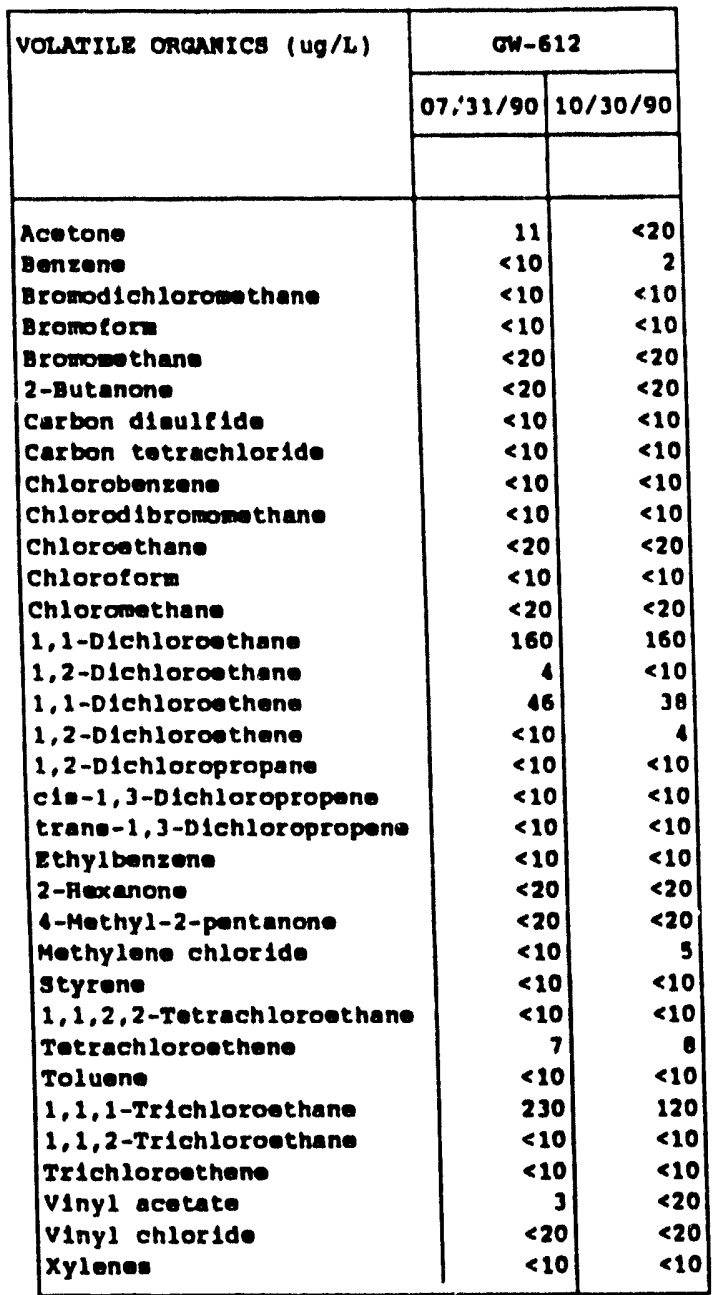


R CUALITY 1990

LETIUY RIDG: aECURITY PITE

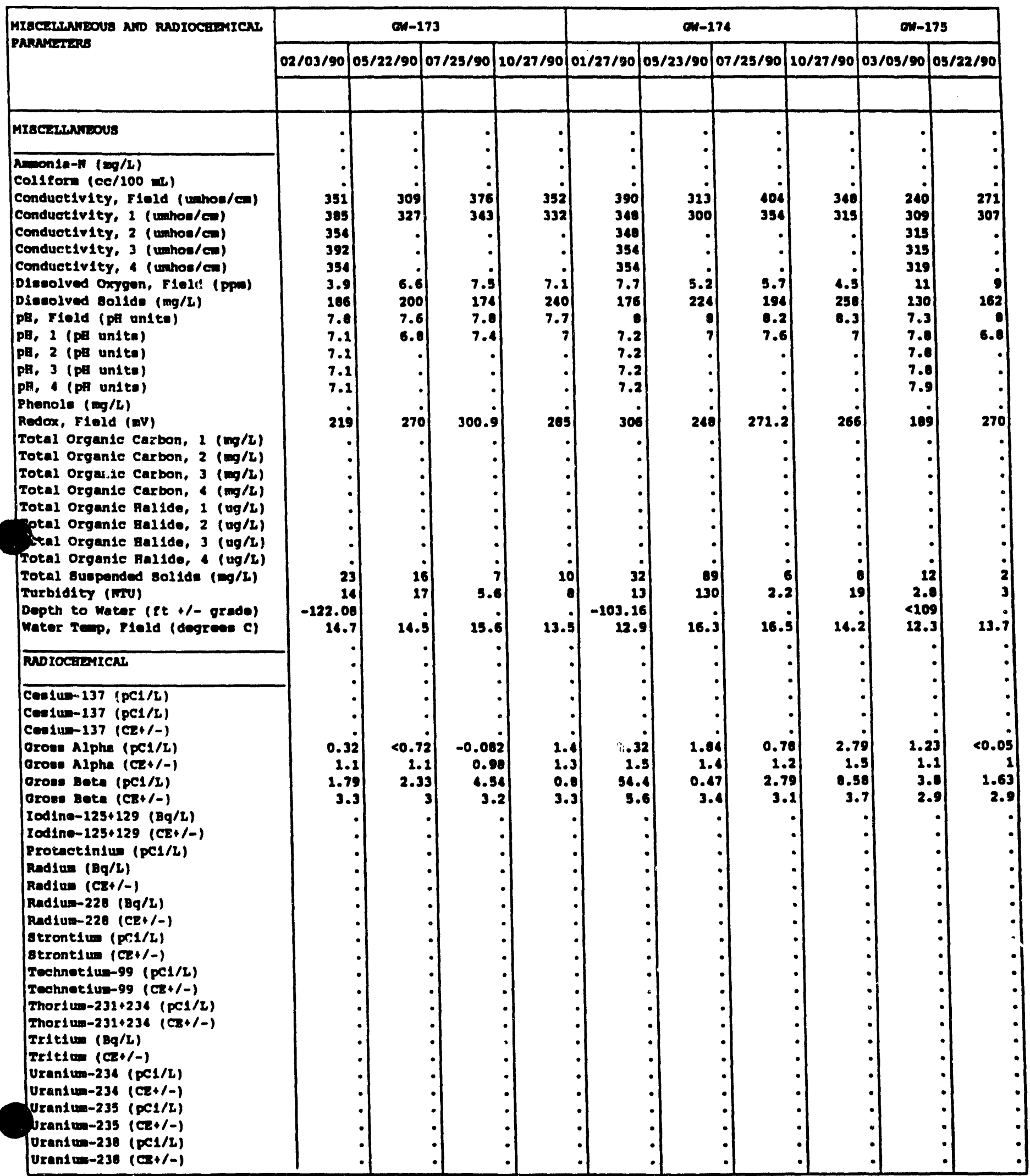

(constnuse) 
WATER QUNLITY 1990

CFESTIUI RIDGE BECURITY PITS

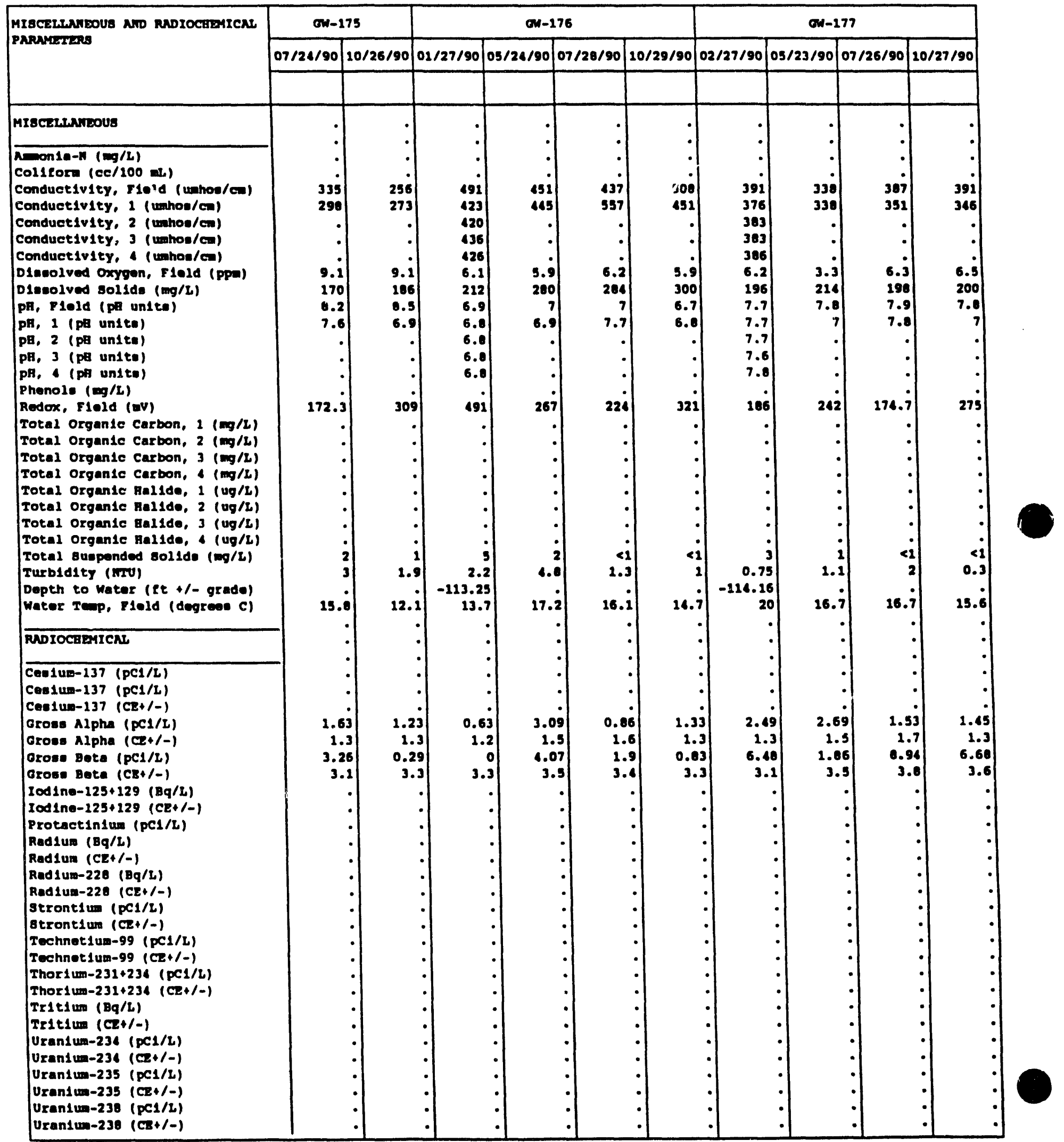

(CONIInUtes) 
OURIIIX 1990

MUT RIDG BECURTY PITS

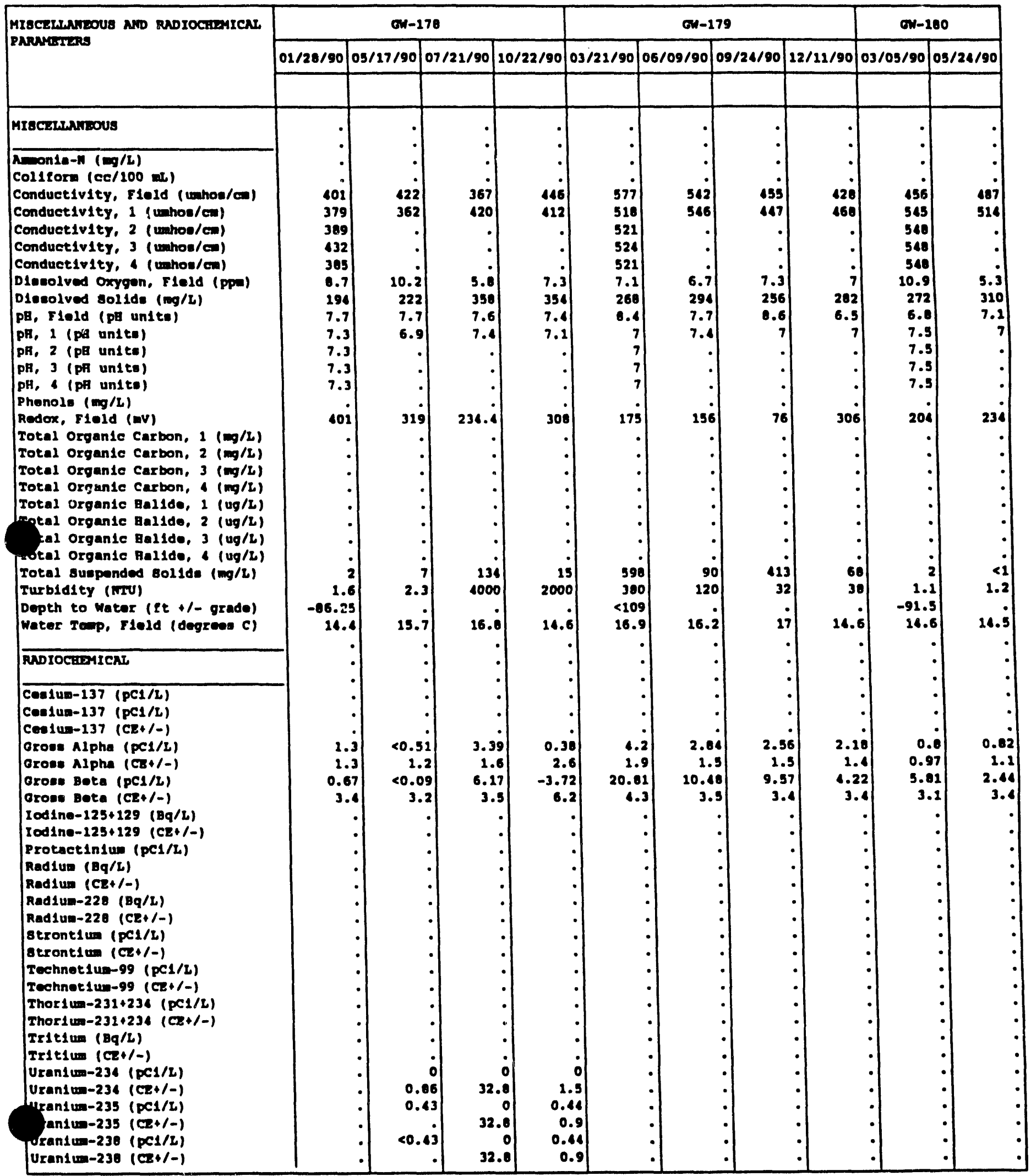

(Contumuse) 
MAXAR QUNLITY 1990

CRESTIUT RIDGB gECURITY PITS

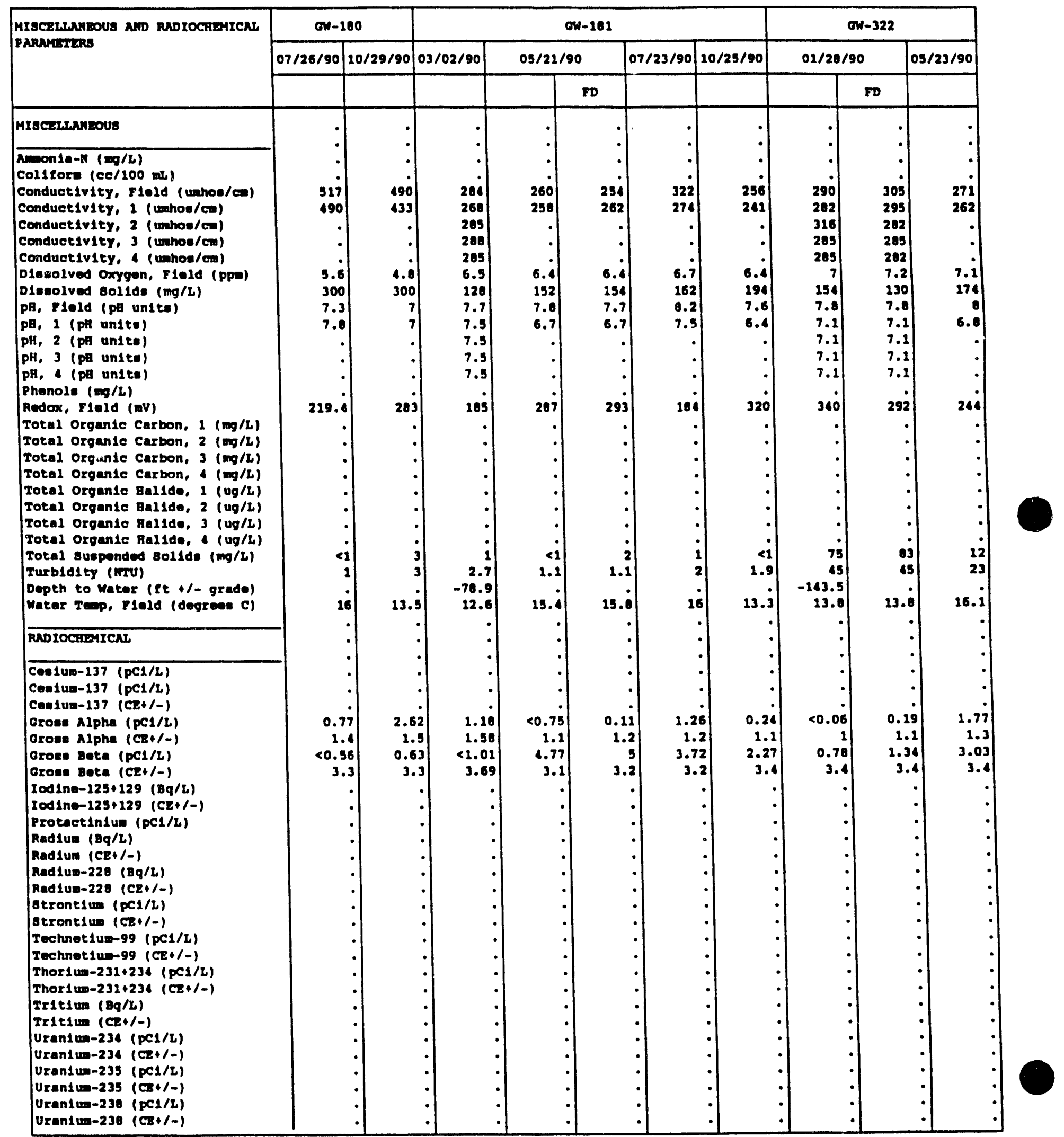

(CONr2muto) 
Y.R OUNIII 1990

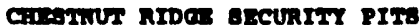

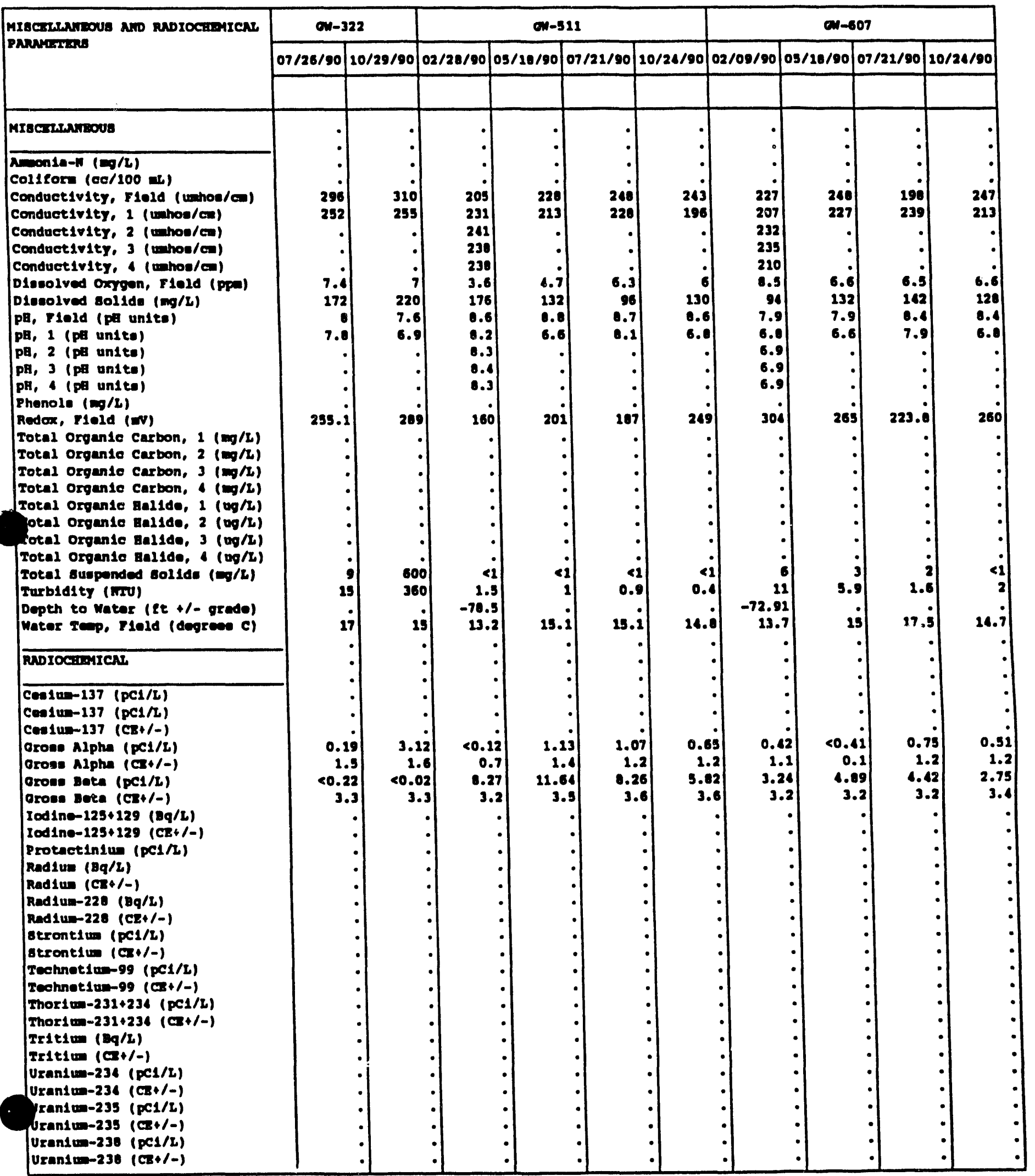

(CONIInULD) 
R QUASITY 1990

ATWUT RIDGE BECURITY PITS

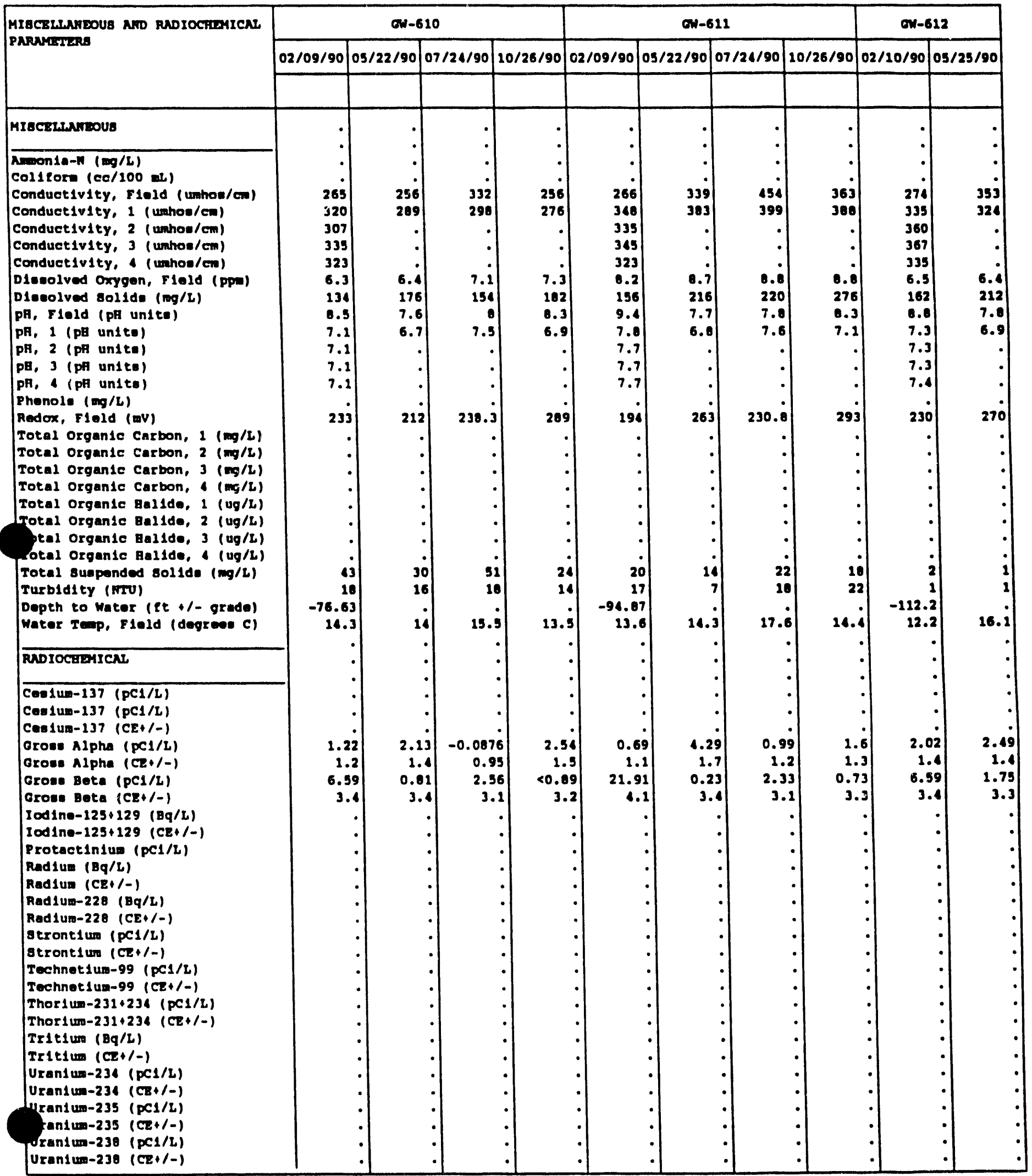

(COATIMUED) 
WATER QUALITY 1990

CHESTNUT RIDGS ABCURITY PITS

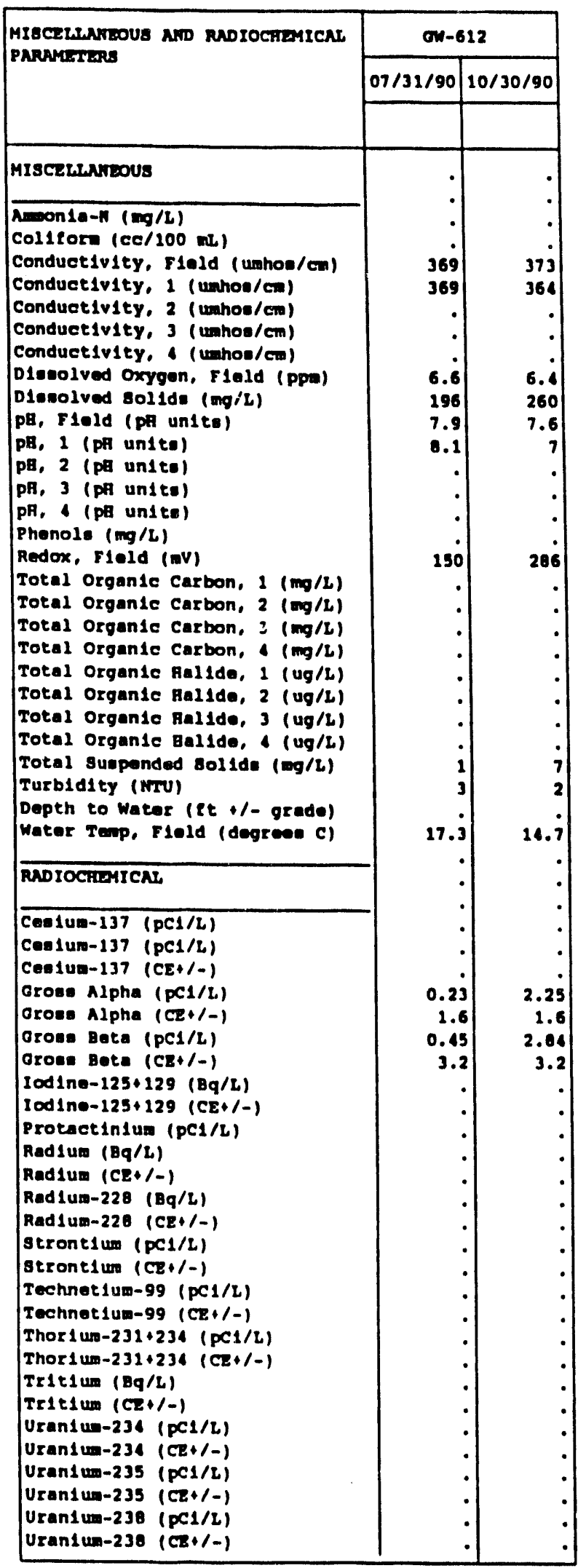




\begin{tabular}{|c|c|c|c|c|c|c|c|c|}
\hline \multirow{4}{*}{$\begin{array}{l}\text { Well No. } \\
\text { Loeation } \\
\text { Date sampled } \\
\text { Date }\end{array}$} & OW-166 & \multicolumn{7}{|c|}{$9 w-173$} \\
\hline & $\cos x$ & \multicolumn{7}{|c|}{ CRsP } \\
\hline & $06 / 08 / 91$ & \multicolumn{2}{|c|}{$02 / 01 / 91$} & \multicolumn{2}{|c|}{$05 / 03 / 91$} & \multicolumn{2}{|c|}{$08 / 06 / 91$} & \multirow{2}{*}{$\frac{10 / 10 / 91}{202}$} \\
\hline & DIS & TOT & DIs & Tor & DIs & TOr & Drs & \\
\hline Mencs (mg/L) & $\cdot$ & • & $\cdot$ & $\cdot$ & - & $\cdot$ & - & - \\
\hline Aluminum & 0.063 & 0.048 & 0.055 & 0.22 & $<0.02$ & 0.11 & $<0.02$ & 0.11 \\
\hline Natimony & $<0.05$ & $<0.05$ & $<0.05$ & $<0.05$ & $<0.05$ & $<0.05$ & $<0.05$ & $<0.05$ \\
\hline Arsentc & $<0.05$ & $<0.05$ & $<0.05$ & $<0.05$ & $<0.05$ & $<0.05$ & $<0.05$ & $<0.05$ \\
\hline Barium & 0.0098 & 0.013 & 0.012 & 0.01 & 0.021 & 0.013 & 0.016 & 0.016 \\
\hline Baryl11um & $<0.0003$ & $<0.0003$ & $<0.0003$ & $<0.0003$ & $<0.0003$ & $<0.0003$ & $<0.0003$ & $<0.0003$ \\
\hline Boron & 0.02 & 0.031 & 0.014 & $<0.004$ & $<0.004$ & $<0.004$ & $<0.004$ & 0.029 \\
\hline Cadminum (MS) & $<0.002$ & $<0.002$ & $<0.002$ & $<0.002$ & $<0.002$ & $<0.002$ & $<0.002$ & $<0.002$ \\
\hline Cadmium & $<0.003$ & $<0.003$ & $<0.003$ & $<0.003$ & $<0.003$ & $<0.003$ & $<0.003$ & $<0.003$ \\
\hline Chromium (MS) & $<0.01$ & $<0.01$ & $<0.01$ & $<0.01$ & $<0.01$ & $<0.01$ & $<0.01$ & $<0.01$ \\
\hline Chromitum & 0.043 & $<0.01$ & $<0.01$ & $<0.02$ & $<0.01$ & $<0.01$ & $<0.01$ & $<0.01$ \\
\hline Cobalt & $<0.005$ & $<0.005$ & $<0.005$ & $<0.005$ & $<0.005$ & $<0.005$ & $<0.005$ & $<0.005$ \\
\hline Copper & $<0.004$ & 0.014 & 0.0062 & 0.0069 & 0.006 & $<0.004$ & $<0.004$ & $<0.004$ \\
\hline I50n & 0.057 & 0.052 & $<0.004$ & 0.34 & $<0.005$ & 0.2 & $<0.005$ & 0.22 \\
\hline Laed (MS) & $<0.004$ & $<0.004$ & $<0.004$ & $<0.004$ & $<0.004$ & $<0.004$ & $<0.004$ & $<0.004$ \\
\hline mercury (CVMA) & $<0.0002$ & $<0.0002$ & $<0.0002$ & $<0.0002$ & $<0.0002$ & $<0.0002$ & $<0.0002$ & $<0.0002$ \\
\hline Molgbodeaum & $<0.01$ & $<0.01$ & $<0.01$ & $<0.01$ & $<0.01$ & $<0.01$ & $<0.01$ & $<0.01$ \\
\hline mLakel & 0.039 & $<0.01$ & $<0.01$ & $<0.01$ & $<0.01$ & $<0.01$ & $<0.01$ & $<0.02$ \\
\hline 8alentum & $<0.05$ & $<0.05$ & $<0.05$ & $<0.05$ & $<0.05$ & $<0.05$ & $<0.05$ & $<0.05$ \\
\hline 8111000 & 3.4 & 3.8 & 3.7 & 3.8 & 3.9 & 3.7 & 3.6 & $\cdot$ \\
\hline 811ver & $<0.006$ & $<0.006$ & $<0.006$ & $<0.006$ & $<0.006$ & $<0.006$ & $<0.006$ & $<0.006$ \\
\hline 8trontlum & 0.059 & 0.017 & 0.026 & 0.015 & 0.014 & 0.015 & 0.015 & 0.016 \\
\hline Thorium & $<0.2$ & $<0.2$ & $<0.2$ & $<0.2$ & $<0.2$ & $<0.2$ & $<0.2$ & $<0.2$ \\
\hline Oranium (rluor) & 0.001 & $<0.001$ & $<0.001$ & $<0.001$ & $<0.001$ & $<0.002$ & 0.001 & $<0.001$ \\
\hline Vanadium & $<0.005$ & $<0.005$ & $<0.005$ & $<0.005$ & $<0.005$ & $<0.005$ & $<0.005$ & $<0.005$ \\
\hline elne & 0.0033 & 0.019 & 0.0018 & 0.0068 & $<0.002$ & $<0.002$ & $<0.002$ & 0.018 \\
\hline MWOR IOA8 (mg/L) & . & $\cdot$ & $\cdot$ & . & $\cdot$ & - & $\cdot$ & - \\
\hline$\overline{\text { MkalLatty-4CO3 }}$ & $\cdot$ & 180 & $\cdot$ & 191 &. & 284 &. & 192 \\
\hline 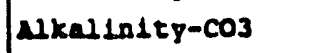 & $\cdot$ & $<1$ & $\cdot$ & $<1$ & $\cdot$ & $<1$ & - & $<1$ \\
\hline Calclum & 31 & 38 & 37 & 32 & 32 & 37 & 38 & 42 \\
\hline Chloride & $\cdot$ & 3 & $\cdot$ & 3 & $\cdot$ & 2 & $\cdot$ & 2 \\
\hline Fluorida & $\cdot$ & $<0.1$ & $\cdot$ & $<0.1$ & $\cdot$ & $<0.1$ & $\cdot$ & $<0.1$ \\
\hline Magnesium & 27 & 23 & 23 & 24 & 24 & 22 & 22 & 25 \\
\hline Manganese & 0.012 & 0.0048 & 0.001 & 0.0041 & $<0.001$ & 0.0032 & $<0.001$ & 0.0035 \\
\hline Mitrate-N & $\cdot$ & $<0.2$ & $\cdot$ & 1 & $\cdot$ & 2.3 & • & 1.19 \\
\hline potaseium & 3.7 & 2.7 & 1.5 & 0.98 & 2.3 & 1.3 & 1.2 & 1.7 \\
\hline sodium & 1.2 & 2.9 & 2.5 & 1.9 & 2.2 & 2.2 & 2.2 & 2 \\
\hline sulfate & $\cdot$ & 6 & $\cdot$ & 6 & $\cdot$ & 6 & $\cdot$ & 7 \\
\hline
\end{tabular}




\begin{tabular}{|c|c|c|c|c|c|c|c|c|}
\hline \multirow{4}{*}{$\begin{array}{l}\text { Well uo. } \\
\text { iocation } \\
\text { Date sampled }\end{array}$} & $O N-173$ & \multicolumn{7}{|c|}{ GW-174 } \\
\hline & CRSP & \multicolumn{7}{|c|}{ CRSP } \\
\hline & $10 / 10 / 91$ & \multicolumn{2}{|c|}{$02 / 01 / 91$} & \multicolumn{2}{|c|}{$05 / 03 / 91$} & \multicolumn{2}{|c|}{$08 / 06 / 91$} & \multirow{2}{*}{$\frac{10 / 11 / 91}{201}$} \\
\hline & DIs & ror & DIS & TOT & DI8 & TOT & DIs & \\
\hline Marnis $(\mathrm{mg} / \mathrm{L})$ & $\cdot$ & - & $\cdot$ & - & - & $\cdot$ & - & • \\
\hline Muninum & 0.02 & 0.027 & $<0.02$ & 0.062 & $<0.02$ & 0.064 & 0.025 & 0.022 \\
\hline Antimony & $<0.05$ & $<0.05$ & $<0.03$ & $<0.05$ & $<0.05$ & $<0.05$ & $<0.05$ & $<0.05$ \\
\hline Arsanic & $<0.05$ & $<0.05$ & $<0.05$ & $<0.05$ & $<0.05$ & $<0.05$ & $<0.05$ & $<0.05$ \\
\hline Barlum & 0.022 & 0.065 & 0.065 & 0.069 & 0.062 & 0.051 & 0.052 & 0.031 \\
\hline Bary111um & $<0.0003$ & $<0.0003$ & $<0.0003$ & $<0.0003$ & $<0.0003$ & $<0.0003$ & $<0.0003$ & $<0.0003$ \\
\hline Boron & 0.021 & 0.016 & 0.013 & $<0.004$ & $<0.004$ & $<0.004$ & $<0.004$ & 0.021 \\
\hline Cadmilum (MNS) & $<0.002$ & $<0.002$ & $<0.002$ & $<0.002$ & $<0.002$ & $<0.002$ & $<0.002$ & $<0.002$ \\
\hline Cadraium & $<0.003$ & $<0.003$ & $<0.003$ & $<0.003$ & $<0.003$ & $<0.003$ & $<0.003$ & $<0.003$ \\
\hline Chromitum (MAs) & $<0.02$ & $<0.01$ & $<0.01$ & $<0.01$ & $<0.01$ & $<0.02$ & $<0.01$ & $<0.01$ \\
\hline Chromium & $<0.01$ & $<0.01$ & 0.025 & $<0.01$ & $<0.01$ & $<0.01$ & $<0.01$ & $<0.01$ \\
\hline Cabalt & $<0.005$ & $<0.005$ & $<0.005$ & $<0.005$ & $<0.005$ & $<0.005$ & $<0.005$ & $<0.005$ \\
\hline Copper & 0.0055 & 0.0041 & $<0.004$ & 0.0057 & 0.0049 & $<0.004$ & $<0.004$ & $<0.004$ \\
\hline Iron & $<0.005$ & 0.055 & $<0.004$ & 0.062 & $<0.005$ & 0.034 & $<0.005$ & 0.028 \\
\hline raad (MS) & $<0.004$ & $<0.004$ & $<0.004$ & $<0.004$ & $<0.004$ & $<0.004$ & $<0.004$ & $<0.004$ \\
\hline Marcury (CVM) & $<0.0002$ & $<0.0002$ & $<0.0002$ & $<0.0002$ & $<0.0002$ & $<0.0002$ & $<0.0002$ & $<0.0002$ \\
\hline nolgbolenum & $<0.01$ & $<0.01$ & $<0.01$ & $<0.01$ & $<0.01$ & $<0.01$ & $<0.01$ & $<0.01$ \\
\hline nlekel & $<0.01$ & $<0.01$ & $<0.01$ & $<0.01$ & $<0.01$ & $<0.01$ & $<0.01$ & $<0.01$ \\
\hline colonium & $<0.05$ & $<0.05$ & $<0.05$ & $<0.05$ & $<0.05$ & $<0.05$ & $<0.05$ & $<0.05$ \\
\hline $812100 n$ & & 4.7 & 4.5 & 3.2 & 1.9 & 4.7 & 4.5 & $\bullet$ \\
\hline s11ver & $<0.006$ & $<0.006$ & $<0.006$ & $<0.006$ & $<0.006$ & $<0.006$ & $<0.006$ & $<0.006$ \\
\hline strontium & 0.018 & 0.091 & 0.15 & 0.1 & 0.14 & 0.084 & 0.14 & 0.04 \\
\hline Thorium & $<0.2$ & $<0.2$ & $<0.2$ & $<0.2$ & $<0.2$ & $<0.2$ & $<0.2$ & $<0.2$ \\
\hline Orantum (rluor) & $<0.001$ & $<0.001$ & 0.001 & 0.001 & 0.001 & 0.001 & 0.001 & $<0.001$ \\
\hline Vanadsum & $<0.005$ & $<0.005$ & $<0.005$ & $<0.005$ & $<0.005$ & $<0.005$ & $<0.005$ & $<0.005$ \\
\hline zinc & 0.0042 & $<0.001$ & $<0.001$ & $<0.002$ & $<0.002$ & $<0.002$ & $<0.002$ & 0.0041 \\
\hline MwOR IOAs $(\mathrm{mg} / \mathrm{x})$ & $\cdot$ & $\cdot$ & $\cdot$ & $\cdot$ & $\cdot$ & - & $\cdot$ & - \\
\hline Mkalinity-aco3 & $\cdot$ & $188^{\circ}$ &. & 291 & $\cdot$ & 187 &. & 199 \\
\hline Nkaldolty-CO3 & $\cdot$ & $<1$ & $\cdot$ & $<1$ & $\cdot$ & $<1$ & $\cdot 1$ & $<1$ \\
\hline Calclum & 41 & 34 & 20 & 32 & 22 & 36 & 27 & 43 \\
\hline Chloride & $\cdot$ & 9 & $\cdot 1$ & 10 & $\cdot$ & 9 & $\cdot$ & 9 \\
\hline Fluoride & • & $<0.2$ & $\cdot$ & $<0.1$ & $\cdot$ & $<0.2$ & - & $<0.1$ \\
\hline Magneaium & 24 & 24 & 19 & 25 & 23 & 23 & 21 & 26 \\
\hline Manganase & 0.0035 & 0.001 & 0.0021 & 0.0063 & 0.0055 & $<0.001$ & $<0.001$ & 0.0013 \\
\hline ultrate-N & - & 2 & $\bullet$ & 0.58 & $\cdot$ & 0.6 & $\bullet$ & 0.6 \\
\hline Potassium & 2 & 2.8 & 6.8 & 3.1 & 5.4 & 2.7 & 4.6 & 1.4 \\
\hline Sodium & 2.5 & 6 & 23 & 5.8 & 18 & 6.6 & 14 & 2.7 \\
\hline sulfate & $\cdot$ & 4 & $\cdot$ & 3 & $\cdot$ & 4 & - & 4 \\
\hline
\end{tabular}

(COArrlived) 
Groundwater Quallty Data, 1991

\begin{tabular}{|c|c|c|c|c|c|c|c|c|}
\hline \multirow{4}{*}{$\begin{array}{l}\text { Well No. } \\
\text { Location } \\
\text { Date sampled }\end{array}$} & $6 w-174$ & \multicolumn{7}{|c|}{$a w-175$} \\
\hline & Crsp & \multicolumn{7}{|c|}{ CRsP } \\
\hline & $10 / 11 / 91$ & \multicolumn{2}{|c|}{$01 / 31 / 91$} & \multicolumn{2}{|c|}{$05 / 01 / 91$} & \multicolumn{2}{|c|}{$08 / 08 / 91$} & \multirow{2}{*}{$\frac{10 / 13 / 91}{205}$} \\
\hline & DIs & TOT & DI8 & TOT & DI8 & Tor & DIs & \\
\hline MenNes (mg/L) & $\cdot$ & $\cdot$ & - & - & $\cdot$ & - & - & - \\
\hline Numinum & $<0.02$ & $<0.02$ & $<0.02$ & 0.032 & $<0.02$ & 0.026 & $<0.02$ & $<0.02$ \\
\hline Antimony & $<0.03$ & $<0.05$ & $<0.05$ & $<0.05$ & $<0.05$ & $<0.05$ & $<0.03$ & $<0.05$ \\
\hline Araanic & $<0.05$ & $<0.05$ & $<0.05$ & $<0.05$ & $<0.05$ & $<0.05$ & $<0.05$ & $<0.05$ \\
\hline Barium & 0.051 & 0.043 & 0.042 & 0.037 & 0.034 & 0.033 & 0.032 & 0.034 \\
\hline Baryl11um & $<0.0003$ & $<0.0003$ & $<0.0003$ & $<0.0003$ & $<0.0003$ & $<0.0003$ & $<0.0003$ & $<0.0003$ \\
\hline Boron & 0.011 & $<0.004$ & $<0.004$ & $<0.004$ & $<0.004$ & $<0.004$ & $<0.004$ & 0.011 \\
\hline Cactmlun (ANS) & $<0.002$ & $<0.002$ & $<0.002$ & $<0.002$ & $<0.002$ & $<0.002$ & $<0.002$ & $<0.002$ \\
\hline Cactonium & $<0.003$ & $<0.003$ & 0.0031 & $<0.003$ & $<0.003$ & $<0.003$ & $<0,003$ & $<0.003$ \\
\hline Chromium (Ms) & $<0.01$ & 0.014 & $<0.01$ & $<0.01$ & $<0.01$ & $<0.01$ & $<0.02$ & $<0.01$ \\
\hline Chronium & $<0.02$ & 0.021 & 0.043 & $<0.01$ & $<0.02$ & $<0.01$ & $<0.02$ & $<0.01$ \\
\hline Cobalt & $<0.005$ & $<0.005$ & $<0.005$ & $<0.005$ & $<0.005$ & $<0.005$ & $<0.005$ & $<0.005$ \\
\hline Copper & $<0.004$ & $<0.004$ & $<0.004$ & $<0.004$ & $<0.004$ & $<0.004$ & $<0.004$ & $<0.004$ \\
\hline Iron & 0.007 & 0.38 & $<0.004$ & 0.056 & $<0.005$ & 0.092 & $<0.00 s$ & 0.059 \\
\hline Land (MS) & $<0.004$ & 0.026 & $<0.004$ & $<0.004$ & $<0.004$ & $<0.004$ & $<0.004$ & $<0.004$ \\
\hline maroury (Cran) & $<0.0002$ & $<0.0002$ & $<0.0002$ & $<0.0002$ & $<0.0002$ & $<0.0002$ & $<0.0002$ & $<0.0002$ \\
\hline Molgbdonum & $<0.02$ & $<0.01$ & $<0.02$ & $<0.02$ & $<0.01$ & $<0.01$ & $<0.01$ & $<0.02$ \\
\hline mLekel & $<0.01$ & 0.012 & $<0.01$ & $<0.01$ & $<0.01$ & $<0.01$ & $<0.01$ & $<0.01$ \\
\hline Eolontum & $<0.05$ & $<0.08$ & $<0.05$ & $<0.05$ & $<0.05$ & $<0.05$ & $<0.05$ & $<0.05$ \\
\hline as21con & & 3.3 & 3.2 & 3.5 & 3.5 & 0.9 & $<0.03$ & • \\
\hline 811ver & $<0.006$ & $<0.006$ & $<0.006$ & $<0.006$ & $<0.006$ & $<0.006$ & $<0.006$ & $<0.006$ \\
\hline strontium & 0.053 & 0.0081 & 0.0079 & 0.013 & 0.014 & 0.012 & 0.012 & 0.021 \\
\hline Thorium & $<0.2$ & $<0.2$ & $<0.2$ & $<0.2$ & $<0.2$ & $<0.2$ & $<0.2$ & $<0.2$ \\
\hline Oranium (Pluor) & $<0.001$ & $<0.001$ & $<0.001$ & $<0.001$ & 0.001 & 0.001 & 0.002 & 0.001 \\
\hline Vanadium & $<0.003$ & $<0.003$ & $<0.005$ & $<0.005$ & $<0.005$ & $<0.005$ & $<0.005$ & $<0.005$ \\
\hline inc & 0.0027 & $<0.001$ & 0.01122 & $<0.002$ & $<0.002$ & $<0.002$ & $<0.002$ & 0.0048 \\
\hline MUJOR IOAS $(\mathrm{mg} / \mathrm{L})$ & . & . &. &. & . & . & . & . \\
\hline Akalindty-HCO3 &. & 271 & $\cdot$ & 173 & . & 185 &. & 176 \\
\hline Mxaldnity-co3 & • & $<1$ & - & $<1$ & $\cdot$ & $<1$ & $\cdot$ & $<1$ \\
\hline Calcium & 45 & 37 & 33 & 37 & 37 & 39 & 40 & 37 \\
\hline Chloride & $\cdot$ & 2 & $\cdot$ & 2 & $\cdot$ & 2 & • & 2 \\
\hline Pluoride & $\cdot$ & $<0.1$ & $\cdot$ & $<0.1$ & $\cdot$ & $<0.1$ & $\cdot$ & $<0.1$ \\
\hline Magnesium & 27 & 24 & 22 & 22 & 22 & 23 & 23 & 23 \\
\hline Manganose & 0.0031 & 0.0096 & $<0.001$ & $<0.001$ & $<0.001$ & 0.0021 & $<0.001$ & $<0.001$ \\
\hline MLtrate-N & $\cdot$ & 0.3 & $\cdot$ & 0.3 & $\bullet$ & 0.25 & $\bullet$ & 0.28 \\
\hline potans Lum & 2.1 & $<0.6$ & $<0.6$ & $<0.6$ & $<0.6$ & $<0.6$ & $<0.6$ & $<0.6$ \\
\hline sodium & 3.9 & $<0.02$ & $<0.02$ & 0.75 & 0.59 & 0.55 & 0.55 & 1.1 \\
\hline suleate & - & 1 & . & 1 & - & $<1$ & - & 1 \\
\hline
\end{tabular}


Groundwater Qundity Data, 1991

\begin{tabular}{|c|c|c|c|c|c|c|c|c|}
\hline \multirow{4}{*}{$\begin{array}{l}\text { Woll No. } \\
\text { Loontion } \\
\text { Date sampled }\end{array}$} & $0 N-175$ & \multicolumn{7}{|c|}{$9 x-176$} \\
\hline & CRsP & \multicolumn{7}{|c|}{ CRsP } \\
\hline & $10 / 13 / 91$ & \multicolumn{2}{|c|}{$02 / 04 / 91$} & \multicolumn{2}{|c|}{$05 / 04 / 91$} & \multicolumn{2}{|c|}{$08 / 09 / 91$} & \multirow{2}{*}{$\frac{10 / 14 / 91}{201}$} \\
\hline & DI8 & TOT & DIs & 200 & DI8 & TOr & DI8 & \\
\hline norus $(m g / r)$ & $\cdot$ & $\cdot 1$ & .1 & $\cdot$ & • & - & $\bullet$ & - \\
\hline Aluminum & 0.023 & 0.027 & $<0.02$ & $<0.02$ & $<0.02$ & 0.03 & $<0.02$ & 0.25 \\
\hline Antimony & $<0.05$ & $<0.05$ & $<0.05$ & $<0.05$ & $<0.05$ & $<0.05$ & $<0.05$ & $<0.05$ \\
\hline Areonic & $<0.03$ & $<0.05$ & $<0.05$ & $<0.05$ & $<0.05$ & $<0.05$ & $<0.05$ & $<0.05$ \\
\hline Darium & 0.035 & 0.021 & 0.026 & 0.018 & 0.028 & 0.016 & 0.026 & 0.018 \\
\hline Baryl11um & $<0.0003$ & $<0.0003$ & $<0.0003$ & $<0.0003$ & $<0.0003$ & $<0.0003$ & $<0.0003$ & $<0.0003$ \\
\hline Doron & 0.018 & 0.89 & 0.88 & 0.63 & 0.77 & 0.39 & 0.38 & 0.35 \\
\hline Cadmium (MAS) & $<0.002$ & $<0.002$ & $<0.002$ & $<0.002$ & $<0.002$ & $<0.002$ & $<0.002$ & $<0.002$ \\
\hline Cadmilum & $<0.003$ & $<0.003$ & $<0.003$ & $<0.003$ & $<0.003$ & $<0.003$ & $<0.003$ & $<0.003$ \\
\hline Chromium (MS) & $<0.01$ & $<0.01$ & $<0.01$ & $<0.01$ & $<0.01$ & $<0.01$ & $<0.01$ & $<0.01$ \\
\hline Chromium & $<0.01$ & $<0.02$ & $<0.01$ & $<0.01$ & $<0.01$ & $<0.01$ & $<0.01$ & $<0.01$ \\
\hline Cobalt & $<0.00 s$ & $<0.005$ & $<0.005$ & $<0.005$ & $<0.005$ & $<0.005$ & $<0.005$ & $<0.005$ \\
\hline Copper & $<0.004$ & $<0.004$ & $<0.004$ & $<0.004$ & $<0.004$ & $<0.004$ & $<0.004$ & $<0.004$ \\
\hline Iron & 0.027 & 0.063 & $<0.004$ & $<0.005$ & $<0.005$ & 0.031 & $<0.005$ & 0.38 \\
\hline Laad (MS) & $<0.004$ & $<0.004$ & $<0.004$ & $<0.004$ & $<0.004$ & $<0.004$ & $<0.004$ & $<0.004$ \\
\hline neroury (Cova) & $<0.0002$ & $<0.0002$ & $<0.0002$ & $<0.0002$ & $<0.0002$ & $<0.0002$ & $<0.0002$ & $<0.0002$ \\
\hline Molybdenum & $<0.01$ & $<0.01$ & $<0.01$ & $<0.01$ & $<0.01$ & $<0.01$ & $<0.01$ & $<0.01$ \\
\hline alckal & $<0.01$ & $<0.01$ & $<0.01$ & $<0.01$ & $<0.02$ & $<0.01$ & $<0.01$ & $<0.01$ \\
\hline Selonium & $<0.05$ & $<0.05$ & $<0.05$ & $<0.05$ & $<0.05$ & $<0.05$ & $<0.05$ & $<0.05$ \\
\hline 8111000 & & 4.9 & 4.0 & 2.5 & 4.8 & 2.6 & 2.3 & \\
\hline 8117er & $<0.006$ & $<0.006$ & $<0.006$ & $<0.006$ & $<0.006$ & $<0.006$ & $<0.006$ & 0.0068 \\
\hline strontlum & 0.012 & 0.023 & 0.022 & 0.021 & 0.021 & 0.019 & 0.029 & 0.021 \\
\hline Thorlum & $<0.2$ & $<0.2$ & $<0.2$ & $<0.2$ & $<0.2$ & $<0.2$ & $<0.2$ & $<0.2$ \\
\hline Oranium (rluor) & 0.001 & $<0.001$ & $<0.001$ & $<0.001$ & $<0.001$ & 0.001 & 0.001 & $<0.001$ \\
\hline Vanadium & $<0.003$ & $<0.005$ & $<0.005$ & $<0.005$ & $<0.005$ & $<0.005$ & $<0.005$ & $<0.005$ \\
\hline ine & 0.0074 & 0.0072 & 0.006 & 0.0023 & 0.0048 & 0.0024 & 0.0053 & 0.017 \\
\hline MWOR IOUs $(\mathrm{mg} / \mathrm{L})$ & - & - & - & - & - & $\cdot$ & $\cdot$ & $\bullet$ \\
\hline Alkalinity-HCO3 &. & $27 \dot{0}$ & $\cdot$ & 201 & $\cdot \dot{1}$ & 260 & $\cdot 1$ & 269 \\
\hline Nkalinlty-CO3 & . & $<1$ & - & $<1$ & $\cdot$ & $<1$ & • & $<1$ \\
\hline Calcium & 37 & se & 49 & 36 & 37 & s4 & 53 & 38 \\
\hline Chloride & - & 2 & $\cdot$ & 2 & $\cdot$ & 1.9 & $\cdot$ & 2 \\
\hline Fluoride & $\cdot$ & $<0.1$ & $\cdot$ & $<0.1$ & $\cdot$ & $<0.1$ & $\cdot$ & $<0.1$ \\
\hline Magneadum & 22 & 33 & 34 & 35 & 34 & 32 & $\mathbf{3 2}$ & 34 \\
\hline Kanganese & $<0.001$ & 0.0015 & 0.001 & $<0.001$ & .00 .001 & $<0.001$ & $<0.001$ & 0.012 \\
\hline altrate-n & & 0.5 & $\cdot$ & 0.5 & $\cdot$ & 0.5 & - & 0.44 \\
\hline Potasedum & 0.61 & 2.2 & 1 & 2.1 & 1.1 & 0.95 & 0.76 & 2.1 \\
\hline sodium & 2.4 & 0.77 & 0.8 & 0.74 & 0.87 & 0.6 & 0.6 & 0.7 \\
\hline sudzato & $\cdot$ & 1 & $\bullet$ & 2 & - & 1.3 & $\cdot$ & 1 \\
\hline
\end{tabular}

(COArnitro) 
Groundwater Quallty Data, 1991

\begin{tabular}{|c|c|c|c|c|c|c|c|c|}
\hline \multirow{4}{*}{$\begin{array}{l}\text { Mell No. } \\
\text { Location } \\
\text { Date sampled }\end{array}$} & $a w-176$ & \multicolumn{7}{|c|}{$9 N-177$} \\
\hline & CRsP & \multicolumn{7}{|c|}{ CRsP } \\
\hline & $10 / 14 / 91$ & \multicolumn{2}{|c|}{$02 / 02 / 91$} & \multicolumn{2}{|c|}{$05 / 03 / 91$} & \multicolumn{2}{|c|}{$08 / 08 / 91$} & \multirow{2}{*}{$\frac{10 / 13 / 91}{202}$} \\
\hline & DIs & 202 & DI8 & 201 & DIs & 202 & DIs & \\
\hline nevass $(\mathrm{mg} / \mathrm{L})$ & - & $\cdot$ & $\cdot$ & - & $\cdot$ & $\cdot 1$ & $\cdot 1$ & - \\
\hline Numinum & $<0.02$ & 0.029 & 0.044 & 0.027 & 0.021 & 0.022 & 0.03 & 0.02 \\
\hline Natimony & $<0.05$ & $<0.05$ & $<0.05$ & $<0.05$ & $<0.05$ & $<0.05$ & $<0.08$ & $<0.05$ \\
\hline Areenic & $<0.05$ & $<0.05$ & $<0.05$ & $<0.05$ & $<0.05$ & $<0.05$ & $<0.05$ & $<0.05$ \\
\hline Barium & 0.026 & 0.024 & 0.025 & 0.023 & 0.024 & 0.018 & 0.016 & 0.015 \\
\hline Beryl11um & $<0.0003$ & $<0.0003$ & 0.00033 & $<0.0003$ & $<0.0003$ & $<0.0003$ & $<0.0003$ & $<0.0003$ \\
\hline Boron & 0.33 & 0.035 & 0.014 & $<0.004$ & $<0.004$ & $<0.004$ & 0.046 & 0.0093 \\
\hline Cactulum (MNS) & $<0.002$ & $<0.002$ & $<0.002$ & $<0.002$ & $<0.002$ & $<0.002$ & $<0.002$ & $<0.002$ \\
\hline Cedratum & $<0.003$ & $<0.003$ & $<0.003$ & $<0.003$ & $<0.003$ & $<0.003$ & $<0.003$ & $<0.003$ \\
\hline Chroulium (MS) & $<0.01$ & $<0.02$ & $<0.02$ & $<0.01$ & $<0.01$ & $<0.01$ & $<0.01$ & $<0.01$ \\
\hline Chronium & $<0.01$ & $<0.01$ & $<0.01$ & $<0.01$ & $<0.01$ & $<0.01$ & $<0.01$ & $<0.01$ \\
\hline Cobalt & $<0.005$ & $<0.005$ & $<0.005$ & $<0.005$ & $<0.005$ & $<0.005$ & $<0.005$ & $<0.005$ \\
\hline copper & $<0.004$ & $<0.004$ & $<0.004$ & 0.006 & $<0.004$ & 0.0085 & $<0.004$ & $<0.004$ \\
\hline $150 n$ & $<0.003$ & $<0.004$ & $<0.004$ & 0.027 & $<0.005$ & 0.087 & 0.0063 & 0.011 \\
\hline read (MS) & $<0.004$ & $<0.004$ & $<0.004$ & $<0.004$ & $<0.004$ & 0.0065 & $<0.004$ & $<0.004$ \\
\hline mareury (CVM) & $<0.0002$ & $<0.0002$ & $<0.0002$ & $<0.0002$ & $<0.0002$ & $<0.0002$ & $<0.0002$ & $<0.0002$ \\
\hline Molybdanum & $<0.01$ & $<0.01$ & 0.013 & $<0.02$ & $<0.01$ & $<0.01$ & $<0.02$ & $<0.01$ \\
\hline alokel & $<0.01$ & $<0.01$ & $<0.01$ & $<0.01$ & $<0.01$ & $<0.01$ & $<0.01$ & $<0.01$ \\
\hline colondu & $<0.05$ & $<0.05$ & $<0.05$ & $<0.05$ & $<0.05$ & $<0.05$ & $<0.05$ & $<0.05$ \\
\hline $811100 n$ & & 4.3 & 4.2 & 3.7 & 4.2 & 1.9 & 4.7 & $\bullet$ \\
\hline 811ver & 0.042 & $<0.006$ & $<0.006$ & $<0.006$ & $<0.006$ & $<0.006$ & $<0.005$ & $<0.006$ \\
\hline strontlum & 0.02 & 0.024 & 0.024 & 0.023 & 0.023 & 0.018 & 0.027 & 0.014 \\
\hline Thordum & $<0.2$ & $<0.2$ & $<0.2$ & $<0.2$ & $<0.2$ & $<0.2$ & $<0.2$ & $<0.2$ \\
\hline Oranium (rluor) & $<0.001$ & 0.002 & 0.002 & 0.002 & 0.002 & 0.002 & 0.002 & 0.001 \\
\hline Vanadium & $<0.005$ & $<0.005$ & $<0.005$ & $<0.005$ & $<0.005$ & $<0.005$ & $<0.005$ & $<0.005$ \\
\hline $2 \ln 0$ & 0.02 & 0.0058 & 0.0023 & $<0.002$ & $<0.002$ & $<0.002$ & 0.022 & 0.007 \\
\hline MWOR IOMS (mg/L) & . & . &. & $\cdot$ & $\cdot$ & . & . & - \\
\hline Alkaldndty-HCO3 &. & 213 &. & 207 & $\cdot$ & 290 &. & 203 \\
\hline NkadLintty-CO3 & $\cdot$ & $<1$ & $\cdot$ & $<1$ & $\cdot$ & $<1$ & $\cdot$ & $<1$ \\
\hline Calcium & 57 & 41 & 40 & 33 & 33 & 42 & 44 & 46 \\
\hline Chloride & • & 2 & $\cdot$ & 2 & $\cdot$ & 2 & • & 3 \\
\hline Tluoride & - & $<0.1$ & $\cdot$ & $<0.1$ & • & $<0.1$ & $\cdot 1$ & $<0.1$ \\
\hline Magnosium & 34 & 23 & 25 & 25 & 25 & 24 & 28 & 27 \\
\hline Manganeae & 0.0029 & 0.0055 & 0.0025 & 0.0078 & 0.0026 & 0.021 & $<0.001$ & $<0.001$ \\
\hline mLErate-N & $\cdot$ & $<0.2$ & $\cdot$ & 0.27 & $\cdot$ & $<0.2$ & $\cdot$ & 0.31 \\
\hline potanedum & 2.3 & 6.8 & 6.2 & 4.2 & 4.1 & 2.8 & $<0.6$ & 1.7 \\
\hline sodium & 2.5 & 2.6 & 2.3 & 0.92 & 0.9 & 0.87 & 12 & 1.1 \\
\hline sulfate & $\cdot$ & 7 & $\cdot$ & 8 & $\cdot$ & 6 & $\cdot$ & 7 \\
\hline
\end{tabular}

(Convinued) 
Oroundwater Quallty Data, 1991

\begin{tabular}{|c|c|c|c|c|c|c|c|c|}
\hline \multirow{4}{*}{$\begin{array}{l}\text { Well No. } \\
\text { Location } \\
\text { Date sempled }\end{array}$} & ON-177 & \multicolumn{7}{|c|}{$O W-178$} \\
\hline & CRsP & \multicolumn{7}{|c|}{ CRsp } \\
\hline & $10 / 13 / 91$ & \multicolumn{2}{|c|}{$01 / 15 / 91$} & \multicolumn{2}{|c|}{$04 / 22 / 91$} & \multicolumn{2}{|c|}{$08 / 08 / 91$} & \multirow{2}{*}{$\frac{20 / 13 / 92}{202}$} \\
\hline & DI8 & 202 & DIs & 202 & DI8 & 202 & DIs & \\
\hline Meres (mg/L) & • & $\cdot$ & - & $\cdot$ & $\cdot$ & $\cdot$ & $\cdot$ & $\cdot$ \\
\hline Aluminum & $<0.02$ & 2.1 & 0.039 & 0.42 & 0.027 & 0.024 & 0.45 & 0.031 \\
\hline Antimony & $<0.05$ & $<0.03$ & $<0.05$ & $<0.03$ & $<0.05$ & $<0.03$ & $<0.03$ & $<0.05$ \\
\hline Areenic & $<0.05$ & $<0.03$ & $<0.05$ & $<0.05$ & $<0.05$ & $<0.05$ & $<0.05$ & $<0.05$ \\
\hline Barium & 0.016 & 0.035 & 0.018 & 0.019 & 0.014 & 0.017 & 0.03 & 0.014 \\
\hline Baryldium & $<0.0003$ & $<0.0003$ & $<0.0003$ & $<0.0003$ & $<0.0003$ & $<0.0003$ & 0.0024 & $<0.0003$ \\
\hline Boron & 0.016 & 0.02 & 0.018 & 0.017 & 0.023 & 0.03 & 1.3 & 0.0068 \\
\hline Cactmitum (MAS) & $<0.002$ & $<0.002$ & $<0.002$ & $<0.002$ & $<0.002$ & $<0.002$ & $<0.002$ & $<0.002$ \\
\hline Cadmitum & $<0.003$ & 0.003 & $<0.003$ & $<0.003$ & $<0.0 \times 3$ & $<0.003$ & $<0.003$ & $<0.003$ \\
\hline Chromiun (MS) & $<0.01$ & $<0.01$ & $<0.01$ & $<0.01$ & $<0.01$ & $<0.01$ & $<0.01$ & $<0.01$ \\
\hline Chromiun & $<0.01$ & 0.02 & $<0.01$ & $<0.01$ & $<0.01$ & $<0.01$ & 0.042 & $<0.01$ \\
\hline Cobart & $<0.005$ & $<0.005$ & $<0.005$ & $<0.005$ & $<0.005$ & $<0.005$ & $<0.005$ & $<0.005$ \\
\hline Copper & $<0.004$ & 0.049 & 0.0067 & 0.011 & $<0.004$ & $<0.004$ & 0.028 & $<0.004$ \\
\hline Iron & $<0.005$ & 8.4 & 0.021 & 1 & 0.0095 & 0.022 & 3 & 0.022 \\
\hline Iond (MAs) & $<0.004$ & 0.093 & $<0.004$ & 0.016 & $<0.004$ & $<0.004$ & $<0.004$ & $<0.004$ \\
\hline nareury (CVM) & $<0.0002$ & $<0.0002$ & $<0.0002$ & $<0.0002$ & $<0.0002$ & $<0.0002$ & $<0.0002$ & $<0.0002$ \\
\hline Nolybolanum & $<0.01$ & $<0.01$ & $<0.01$ & $<0.01$ & $<0.01$ & $<0.01$ & 0.011 & $<0.01$ \\
\hline mlakel & $<0.01$ & $<0.01$ & $<0.01$ & $<0.01$ & $<0.01$ & $<0.01$ & 0.038 & $<0.02$ \\
\hline selentum & $<0.05$ & $<0.05$ & $<0.05$ & $<0.05$ & $<0.05$ & $<0.05$ & $<0.05$ & $<0.05$ \\
\hline 8111con & $\cdot$ & 5.2 & 4.2 & 5.1 & 4.5 & 4.6 & 4.3 & $\bullet$ \\
\hline s11ver & $<0.006$ & $<0.006$ & $<0.006$ & $<0.006$ & $<0.006$ & $<0.006$ & $<0.006$ & $<0.006$ \\
\hline strontium & 0.015 & 0.045 & 0.034 & 0.03 & 0.026 & 0.028 & 0.12 & 0.022 \\
\hline Thorium & $<0.2$ & $<0.2$ & $<0.2$ & $<0.2$ & $<0.2$ & $<0.2$ & $<0.2$ & $<0.2$ \\
\hline drantum (Fluor) & 0.001 & $<0.001$ & $<0.002$ & $<0.001$ & $<0.001$ & $<0.001$ & $<0.001$ & $<0.001$ \\
\hline Vanadium & $<0.005$ & $<0.005$ & $<0.005$ & $<0.005$ & $<0.005$ & $<0.005$ & 0.024 & $<0.005$ \\
\hline 2Lnc & 0.0082 & 0.53 & 0.064 & 0.15 & 0.053 & 0.038 & 0.095 & 0.035 \\
\hline MWOR IOU8 $(\mathrm{mg} / \mathrm{x})$ & . & . & $\cdot$ & $\cdot$ & $\cdot$ & . & - & - \\
\hline Akalinity-HCO3 & $\cdot$ & 221 & . & 362 & $\cdot$ & 213 & • & $22 \dot{0}$ \\
\hline Nkalindty-CO3 & $\cdot$ & $<1$ & $\cdot$ & $<1$ & $\cdot$ & $<1$ & $\cdot$ & $<1$ \\
\hline Calcium & 45 & 54 & 40 & 45 & 40 & 45 & 42 & 47 \\
\hline Chloride & $\cdot$ & 11 & $\cdot$ & 10 & $\cdot$ & 7 & $\cdot$ & $<5$ \\
\hline rluoride & $\cdot$ & 0.2 & $\cdot 1$ & 0.1 & $\cdot$ & $<0.1$ & $\cdot$ & $<0.1$ \\
\hline Magneaium & 27 & 28 & 22 & 25 & 23 & 29 & 23 & 28 \\
\hline Manganese & $<0.001$ & 0.097 & 0.02 & 0.038 & 0.0036 & $<0.001$ & 0.05 & 0.0031 \\
\hline mitrate-n & $\cdot$ & 0.5 & $\cdot$ & 0.5 & $\cdot$ & 0.42 & $\cdot$ & $<1$ \\
\hline Potansium & 1.9 & 0.89 & 0.78 & 0.71 & 0.6 & $<0.6$ & 5.3 & $<0.6$ \\
\hline sodium & 1.2 & 16 & 26 & 9.7 & 9.5 & 15 & 130 & 7.6 \\
\hline 8udeate & • & 12 & . & 9 & - & 5 & $\cdot$ & 6 \\
\hline
\end{tabular}

(COArrivos) 


\begin{tabular}{|c|c|c|c|c|c|c|c|c|}
\hline \multirow{4}{*}{$\begin{array}{l}\text { Well No. } \\
\text { Location } \\
\text { Date sampled }\end{array}$} & $G N-178$ & \multicolumn{7}{|c|}{ GW-179 } \\
\hline & CRsP & \multicolumn{7}{|c|}{ CRsP } \\
\hline & $10 / 23 / 91$ & \multicolumn{2}{|c|}{$02 / 08 / 91$} & \multicolumn{2}{|c|}{$05 / 08 / 91$} & \multicolumn{2}{|c|}{$08 / 12 / 91$} & \multirow{2}{*}{$\frac{10 / 17 / 91}{201}$} \\
\hline & Drs & Tor & DIS & TOT & DIS & Tor & DI8 & \\
\hline rernzs (mg/L) & • & - & $\cdot$ & • & - & $\cdot$ & - & - \\
\hline Auminum & $<0.02$ & 2 & 0.046 & 0.16 & $<0.02$ & 0.21 & $<0.02$ & 0.025 \\
\hline Antimony & $<0.05$ & $<0.05$ & $<0.05$ & $<0.05$ & $<0.05$ & $<0.05$ & $<0.05$ & $<0.05$ \\
\hline Armonle & $<0.05$ & $<0.05$ & $<0.05$ & $<0.05$ & $<0.05$ & $<0.05$ & $<0.05$ & $<0.05$ \\
\hline Barium & 0.024 & 0.034 & 0.032 & 0.029 & 0.028 & 0.022 & 0.023 & 0.027 \\
\hline Bary111um & $<0.0003$ & $<0.0003$ & $<0.0003$ & $<0.0003$ & $<0.0003$ & $<0.0003$ & $<0.0003$ & $<0.0003$ \\
\hline Boron & 0.0075 & 0.026 & 0.016 & $<0.004$ & 0.017 & 0.013 & 0.0076 & 0.023 \\
\hline Cadmitum (MAS) & $<0.002$ & $<0.002$ & $<0.002$ & $<0.002$ & $<0.002$ & $<0.002$ & $<0.002$ & $<0.002$ \\
\hline Cadmitum & $<0.003$ & 0.0042 & $<0.003$ & $<0.003$ & $<0.003$ & $<0.003$ & $<0.003$ & $<0.003$ \\
\hline Chromium (MS) & $<0.01$ & 0.01 & $<0.01$ & $<0.01$ & $<0.02$ & $<0.01$ & $<0.02$ & $<0.01$ \\
\hline Chromiun & $<0.02$ & 0.033 & $<0.01$ & $<0.01$ & $<0.01$ & $<0.01$ & $<0.01$ & $<0.01$ \\
\hline cabelt & $<0.005$ & $<0.005$ & $<0.005$ & $<0.005$ & $<0.005$ & $<0.005$ & $<0.005$ & $<0.005$ \\
\hline copper & $<0.004$ & 0.12 & $<0.004$ & 0.045 & 0.0095 & 0.042 & 0.023 & 0.032 \\
\hline Iron & $<0.005$ & 4.4 & 0.014 & 2 & $<0.005$ & 0.49 & 0.03 & 0.11 \\
\hline Land (MS) & $<0.004$ & 0.025 & $<0.004$ & 0.0072 & $<0.004$ & 0.0059 & $<0.004$ & $<0.004$ \\
\hline Marcury (CDNA) & $<0.0002$ & $<0.0002$ & $<0.0002$ & $<0.0002$ & $<0.0002$ & $<0.0002$ & $<0.0002$ & $<0.0002$ \\
\hline molybodanum & $<0.02$ & $<0.02$ & $<0.01$ & $<0.01$ & $<0.01$ & $<0.01$ & $<0.02$ & $<0.01$ \\
\hline mlakel & $<0.01$ & $<0.01$ & $<0.01$ & $<0.02$ & $<0.01$ & $<0.02$ & $<0.01$ & $<0.01$ \\
\hline coleniun & $<0.05$ & $<0.05$ & $<0.05$ & $<0.05$ & $<0.05$ & $<0.05$ & $<0.05$ & $<0.05$ \\
\hline $811100 n$ & & 6.8 & 3.3 & 2.2 & 4.4 & 4.2 & 3.8 & $\bullet$ \\
\hline sliver & $<0.006$ & $<0.006$ & $<0.006$ & $<0.006$ & $<0.006$ & $<0.006$ & $<0.006$ & $<0.006$ \\
\hline strontium & 0.023 & 0.046 & 0.042 & 0.027 & 0.024 & 0.025 & 0.022 & 0.023 \\
\hline Thorium & $<0.2$ & $<0.2$ & $<0.2$ & $<0.2$ & $<0.2$ & $<0.2$ & $<0.2$ & $<0.2$ \\
\hline Oranium (Tluor) & $<0.001$ & 0.001 & $<0.002$ & 0.001 & $<0.001$ & 0.001 & 0.001 & $<0.001$ \\
\hline Vanadium & $<0.005$ & 0.005 & $<0.005$ & $<0.005$ & $<0.005$ & $<0.005$ & $<0.005$ & $<0.005$ \\
\hline 21nc & 0.022 & 0.04 & 0.0027 & 0.018 & 0.0055 & 0.0092 & 0.011 & 0.0093 \\
\hline MUJOR IOAS $(\mathrm{mg} / \mathrm{L})$ & - &. & $\cdot$ & $\cdot$ & . & $\cdot$ & $\bullet$ & - \\
\hline Alkallnitp- $\mathrm{HCO} 3$ & $\cdot$ & 309 &. & 290 & $\cdot$ & 252 & . & $26 \dot{\circ}$ \\
\hline Nxad InIty-CO3 & $\cdot$ & $<1$ & - & $<2$ & - & $<2$ & $\bullet$ & $<1$ \\
\hline Calcium & 47 & 120 & 58 & 69 & 57 & 56 & 46 & 56 \\
\hline Chlorido & $\cdot$ & 2 & $\cdot$ & 3 & $\cdot$ & 2 & $\cdot$ & 2 \\
\hline Pluorida & $\cdot$ & $<0.1$ & $\cdot$ & $<0.2$ & - & $<0.1$ & $\cdot$ & $<0.1$ \\
\hline Magnesium & 28 & 62 & 32 & 30 & 31 & 36 & 30 & 35 \\
\hline Mnganese & $<0.001$ & 0.1 & 0.004 & 0.025 & 0.0061 & 0.01 & 0.0034 & 0.0034 \\
\hline mitrate-N & & 0.7 & $\cdot$ & 0.5 & • & 0.48 & - & 0.5 \\
\hline potaselum & 0.72 & 4.6 & 4.3 & 3.9 & 4.2 & 4.2 & 4.1 & 4.2 \\
\hline sodium & 7.2 & 2.5 & 7 & 3 & 2.8 & 2.5 & 2.6 & 2.2 \\
\hline 8uleate & $\bullet$ & 4 & ? & 4 & $\cdot$ & 4 & $\bullet$ & 4 \\
\hline
\end{tabular}


A-144

Groundwater Quality Data, 1991

\begin{tabular}{|c|c|c|c|c|c|c|c|c|}
\hline \multirow{4}{*}{$\begin{array}{l}\text { Well No. } \\
\text { Location } \\
\text { Date sampled }\end{array}$} & GW-179 & \multicolumn{7}{|c|}{$0 x-180$} \\
\hline & CRsP & \multicolumn{7}{|c|}{ Crsp } \\
\hline & $10 / 17 / 91$ & \multicolumn{2}{|c|}{$02 / 02 / 91$} & \multicolumn{2}{|c|}{$05 / 04 / 91$} & \multicolumn{2}{|c|}{$08 / 09 / 91$} & \multirow{2}{*}{$\frac{10 / 24 / 91}{202}$} \\
\hline & DIS & TOT & DIS & TOT & DIS & 205 & DIS & \\
\hline marnss (mg/L) & - & • & - & • & • & - & - & - \\
\hline Aluminum & $<0.02$ & $<0.02$ & $<0.02$ & $<0.02$ & $<0.02$ & 0.04 & $<0.02$ & 0.085 \\
\hline Antimony & $<0.05$ & $<0.05$ & $<0.05$ & $<0.05$ & $<0.05$ & $<0.05$ & $<0.05$ & $<0.05$ \\
\hline Araenic & $<0.05$ & $<0.05$ & $<0.05$ & $<0.05$ & $<0.05$ & $<0.05$ & $<0.05$ & $<0.05$ \\
\hline Dartum & 0.027 & 0.029 & 0.028 & 0.029 & 0.029 & 0.026 & 0.025 & 0.026 \\
\hline Beryl11um & $<0.0003$ & $<0.0003$ & $<0.0003$ & $<0.0003$ & $<0.0003$ & $<0.0003$ & $<0.0003$ & $<0.0003$ \\
\hline Boron & 0.0095 & 0.0089 & 0.013 & $<0.004$ & $<0.004$ & $<0.004$ & $<0.004$ & 0.007 \\
\hline Cadnitum (MS) & $<0.002$ & $<0.002$ & $<0.002$ & $<0.002$ & $<0.002$ & $<0.002$ & $<0.002$ & $<0.002$ \\
\hline Cadincium & $<0.003$ & $<0.003$ & $<0.003$ & $<0.003$ & $<0.003$ & $<0.003$ & $<0.003$ & $<0.003$ \\
\hline Chroutum (MS) & $<0.01$ & $<0.02$ & $<0.01$ & $<0.01$ & $<0.01$ & $<0.01$ & $<0.01$ & $<0.02$ \\
\hline Chroulum & $<0.01$ & $<0.01$ & $<0.02$ & $<0.01$ & $<0.01$ & $<0.01$ & $<0.01$ & $<0.02$ \\
\hline Cobalt & $<0.005$ & $<0.005$ & $<0.005$ & $<0.005$ & $<0.005$ & $<0.005$ & $<0.005$ & $<0.005$ \\
\hline Copper & 0.012 & $<0.004$ & $<0.004$ & $<0.004$ & 0.0043 & $<0.004$ & $<0.004$ & $<0.004$ \\
\hline Iron & $<0.005$ & $<0.004$ & $<0.004$ & $<0.005$ & $<0.005$ & 0.049 & $<0.005$ & 0.049 \\
\hline Ioed (MS) & $<0.004$ & $<0.004$ & $<0.004$ & $<0.004$ & $<0.004$ & $<0.004$ & $<0.004$ & $<0.004$ \\
\hline Marcury (CYM) & $<0.0002$ & $<0.0002$ & $<0.0002$ & $<0.0002$ & $<0.0002$ & $<0.0002$ & $<0.0002$ & $<0.0002$ \\
\hline Mol pbodonum & $<0.02$ & $<0.01$ & $<0.01$ & $<0.01$ & $<0.01$ & $<0.01$ & $<0.01$ & $<0.01$ \\
\hline mlekel & $<0.01$ & $<0.01$ & $<0.01$ & $<0.02$ & $<0.01$ & $<0.01$ & $<0.01$ & $<0.01$ \\
\hline Selondum & $<0.05$ & $<0.05$ & $<0.05$ & $<0.05$ & $<0.05$ & $<0.05$ & $<0.05$ & $<0.05$ \\
\hline $8111 c 0 n$ & & 5.2 & 5.1 & 5.3 & 2.7 & 2.7 & 2.7 & $\bullet$ \\
\hline 8slver & $<0.006$ & $<0.006$ & $<0.006$ & $<0.006$ & $<0.006$ & $<0.006$ & $<0.006$ & $<0.006$ \\
\hline strontium & 0.022 & 0.018 & 0.018 & 0.02 & 0.02 & 0.019 & 0.018 & 0.019 \\
\hline Inorium & $<0.2$ & $<0.2$ & $<0.2$ & $<0.2$ & $<0.2$ & $<0.2$ & $<0.2$ & $<0.2$ \\
\hline Orantum (Fluor) & $<0.001$ & $<0.001$ & $<0.001$ & $<0.001$ & $<0.001$ & $<0.001$ & 0.001 & $<0.001$ \\
\hline Vanadium & $<0.005$ & $<0.005$ & $<0.005$ & $<0.005$ & $<0.005$ & $<0.005$ & $<0.005$ & $<0.005$ \\
\hline $2 \operatorname{lnc}$ & 0.021 & 0.0077 & 0.0066 & 0.005 & 0.011 & 0.0086 & 0.0092 & 0.015 \\
\hline MnJOR IOAs $(\mathrm{mg} / \mathrm{I})$ &. & . & • & . & • &. & • & - \\
\hline Mkalindty-HCO3 &. & ${ }_{300}$ &. & 326 &. & 285 & . & 276 \\
\hline Adkalinity-CO3 & . & $<1$ & . & $<1$ &. & $<2$ & - & $<1$ \\
\hline Calcium & 54 & 58 & 58 & 60 & 64 & $\mathbf{5 7}$ & 56 & 57 \\
\hline Chloride & - & 2 & - & 2 & $\cdot$ & 2 & • & 2 \\
\hline Fluortde & $\cdot$ & $<0.1$ & $\cdot$ & $<0.1$ & $\cdot$ & $<0.1$ & $\bullet$ & $<0.1$ \\
\hline Magnesium & 34 & 37 & 37 & 40 & 40 & 34 & 34 & 35 \\
\hline Manganese & $<0.001$ & $<0.001$ & $<0.001$ & $<0.002$ & $<0.001$ & $<0.001$ & $<0.001$ & 0.029 \\
\hline Mitrato-n & $\cdot$ & 0.5 & $\cdot$ & 0.29 & $\cdot$ & 0.3 & $\cdot$ & 0.24 \\
\hline Potaneium & 4 & 0.71 & 0.76 & 2 & 1.1 & 0.77 & 0.56 & 1.4 \\
\hline Sodium & 2.3 & 0.71 & 0.58 & 0.86 & 0.74 & 0.65 & 0.51 & 0.86 \\
\hline suleato & • & $<2$ & $\bullet$ & $<1$ & $\cdot$ & $<1$ & $\bullet$ & $<1$ \\
\hline
\end{tabular}

(Comernute) 
Groundwater Quality Data, 1991

\begin{tabular}{|c|c|c|c|c|c|c|c|c|}
\hline \multirow{4}{*}{$\begin{array}{l}\text { Well No. } \\
\text { iocation } \\
\text { - } \\
\text { Date Sampled }\end{array}$} & GW-180 & \multicolumn{7}{|c|}{$G W-181$} \\
\hline & CRSP & \multicolumn{7}{|c|}{ CRSP } \\
\hline & $10 / 24 / 91$ & \multicolumn{2}{|c|}{$02 / 29 / 91$} & \multicolumn{2}{|c|}{$04 / 30 / 91$} & \multicolumn{2}{|c|}{$08 / 05 / 91$} & \multirow{2}{*}{$\frac{10 / 08 / 91}{201}$} \\
\hline & DIS & TOT & DIS & TOT & DIS & 202 & DIs & \\
\hline IDTnIS $(m g / L)$ & - & $\cdot$ & $\cdot$ & $\cdot$ & $\cdot$ & $\cdot$ & $\cdot$ & - \\
\hline Muminum & $<0.02$ & 0.042 & 0.027 & 0.032 & $<0.02$ & 0.046 & 0.032 & $<0.02$ \\
\hline Antimony & $<0.05$ & $<0.05$ & $<0.05$ & $<0.05$ & $<0.05$ & $<0.05$ & $<0.05$ & $<0.05$ \\
\hline Arsenic & $<0.05$ & $<0.05$ & $<0.05$ & $<0.05$ & 0.08 & $<0.05$ & $<0.05$ & $<0.05$ \\
\hline Barium & 0.027 & 0.0078 & 0.0074 & 0.0082 & 0.0076 & 0.0097 & 0.016 & 0.0076 \\
\hline Bery111um & $<0.0003$ & $<0.0003$ & $<0.0003$ & $<0.0003$ & $<0.0003$ & $<0.0003$ & $<0.0003$ & $<0.0003$ \\
\hline Boron & 0.0048 & 0.015 & 0.033 & 0.0066 & 0.0087 & 0.01 & 0.029 & 0.028 \\
\hline Cadmium (MS) & $<0.002$ & $<0.002$ & $<0.002$ & $<0.002$ & $<0.002$ & $<0.002$ & $<0.002$ & $<0.002$ \\
\hline Cadmium & $<0.003$ & $<0.003$ & 0.0035 & $<0.003$ & $<0.003$ & $<0.003$ & $<0.003$ & $<0.003$ \\
\hline Chromium (MS) & $<0.01$ & $<0.01$ & $<0.01$ & $<0.01$ & $<0.01$ & $<0.01$ & $<0.01$ & $<0.01$ \\
\hline Chromium & $<0.01$ & $<0.01$ & $<0.01$ & $<0.01$ & $<0.01$ & $<0.01$ & $<0.01$ & $<0.01$ \\
\hline Cobalt & $<0.005$ & $<0.005$ & $<0.005$ & $<0.005$ & $<0.005$ & $<0.005$ & $<0.005$ & $<0.005$ \\
\hline Copper & 0.0057 & $<0.004$ & $<0.004$ & 0.0059 & 0.0097 & 0.0057 & $<0.004$ & $<0.004$ \\
\hline Iron & $<0.005$ & 0.15 & 0.0081 & 0.22 & 0.012 & 0.39 & $<0.005$ & 0.52 \\
\hline rand (MNS) & $<0.004$ & $<0.004$ & $<0.004$ & $<0.004$ & $<0.004$ & $<0.004$ & $<0.004$ & $<0.004$ \\
\hline nercury (CTMA) & $<0.0002$ & $<0.0002$ & $<0.0002$ & $<0.0002$ & $<0.0002$ & $<0.0002$ & $<0.0002$ & $<0.0002$ \\
\hline molybodanum & $<0.01$ & $<0.01$ & $<0.01$ & $<0.02$ & $<0.01$ & $<0.01$ & $<0.01$ & $<0.01$ \\
\hline nlekel & $<0.01$ & $<0.01$ & $<0.01$ & 0.01 & $<0.01$ & $<0.01$ & $<0.01$ & $<0.01$ \\
\hline Selentum & $<0.05$ & $<0.05$ & $<0.05$ & $<0.05$ & $<0.05$ & $<0.05$ & $<0.05$ & $<0.05$ \\
\hline 8111 con & & 4.4 & 4.2 & 4.1 & 4.2 & 3.9 & 3.9 & • \\
\hline 811var & $<0.006$ & $<0.006$ & $<0.006$ & $<0.006$ & $<0.006$ & $<0.006$ & $<0.006$ & $<0.006$ \\
\hline strontlum & 0.017 & 0.018 & 0.017 & 0.02 & 0.021 & 0.019 & 0.031 & 0.02 \\
\hline Thordum & $<0.2$ & $<0.2$ & $<0.2$ & $<0.2$ & $<0.2$ & $<0.2$ & $<0.2$ & $<0.2$ \\
\hline Oranium (Fluor) & $<0.001$ & $<0.002$ & $<0.001$ & $<0.001$ & $<0.001$ & $<0.001$ & $<0.001$ & $<0.001$ \\
\hline Vanadium & $<0.005$ & $<0.005$ & $<0.005$ & $<0.005$ & $<0.005$ & $<0.005$ & $<0.005$ & $<0.005$ \\
\hline zine & 0.013 & 0.0034 & 0.0037 & 0.0046 & 0.0059 & 0.0058 & $<0.002$ & 0.003 \\
\hline MWOR IOAs $(\mathrm{mg} / \mathrm{L})$ & - & . & . & . & . & . & - & - \\
\hline & $\cdot$ & 267 & $\cdot \mid$ & 165 & $\cdot$ & 258 & $\cdot$. & 162 \\
\hline $\begin{array}{l}\text { Mkalinity-HCO3 } \\
\text { Mlkalindty-CO3 }\end{array}$ & $\cdot$ & $<1$ &. & $<1$ & $\cdot$ & $<2$ & . & $<1$ \\
\hline Calcium & 56 & 31 & 32 & 32 & 32 & 31 & 30 & 32 \\
\hline Chlorida &. & 1 &. & 1 & - & 1 & - & 1 \\
\hline rivoride & $\cdot$ & $<0.1$ & $\cdot$ & $<0.1$ & $\cdot$ & $<0.1$ & . & $<0.1$ \\
\hline Magnealum & 35 & 20 & 20 & 20 & 20 & 19 & 19 & 20 \\
\hline Manganeee & 0.0012 & 0.0022 & 0.0028 & 0.0015 & $<0.001$ & 0.0018 & 0.0016 & 0.0052 \\
\hline Mitrato-N & $\cdot$ & $<0.2$ & $\cdot$ & $<0.2$ & $\cdot$ & $<0.2$ & $\cdot$ & $<0.2$ \\
\hline Potaseium & 2.3 & 1.3 & 1.3 & 1.8 & 1.9 & 1.6 & 1.9 & 1.7 \\
\hline sodium & 0.82 & 0.62 & 0.69 & 0.7 & 0.84 & 0.7 & 2.1 & 0.76 \\
\hline sulfate & . & 1 & $\cdot$ & 1 & $\cdot$ & 2 & $\cdot$ & 1 \\
\hline
\end{tabular}

(COATIRUDD) 
Grouncwater Quallty Data, 1991

\begin{tabular}{|c|c|c|c|c|c|c|c|c|}
\hline \multirow{4}{*}{$\begin{array}{l}\text { Well No. } \\
\text { Location } \\
\text { Date sampled } \\
\text { Date }\end{array}$} & \multirow{3}{*}{\begin{tabular}{|c|} 
CW-181 \\
CRSP \\
$20 / 08 / 91$ \\
\end{tabular}} & \multicolumn{4}{|c|}{$G W-184$} & \multicolumn{3}{|c|}{$G W-186$} \\
\hline & & \multicolumn{4}{|c|}{$\mathbf{R Q}$} & \multicolumn{3}{|c|}{ RQ } \\
\hline & & \multicolumn{2}{|c|}{$09 / 08 / 91$} & \multicolumn{2}{|c|}{$11 / 18 / 91$} & \multicolumn{2}{|c|}{$09 / 08 / 91$} & \multirow{2}{*}{$\frac{11 / 18 / 91}{20 x}$} \\
\hline & DIs & TOT & DIS & $20 \mathrm{~T}$ & DIs & TOT & DIs & \\
\hline Mrdus (mg/L) & - & - & $\cdot$ & $\cdot$ & $\cdot$ & - & - & - \\
\hline Muninum & 0.033 & $<0.02$ & 0.029 & 0.028 & $<0.02$ & 0.021 & $<0.02$ & $<0.02$ \\
\hline Nntimony & $<0.05$ & $<0.05$ & $<0.05$ & $<0.05$ & $<0.05$ & $<0.05$ & $<0.05$ & $<0.05$ \\
\hline Arsenic & $<0.05$ & $<0.05$ & $<0.05$ & $<0.05$ & $<0.05$ & $<0.05$ & $<0.05$ & $<0.05$ \\
\hline Barium & 0.0078 & 0.028 & 0.032 & 0.025 & 0.026 & 0.12 & 0.12 & 0.13 \\
\hline Beryllium & $<0.0003$ & $<0.0003$ & 0.00035 & $<0.0003$ & $<0.0003$ & $<0.0003$ & $<0.0003$ & $<0.0003$ \\
\hline Boron & 0.023 & 0.069 & 0.048 & 0.042 & 0.03 & 0.13 & 0.13 & 0.25 \\
\hline Cactmium (MS) & $<0.002$ & $<0.002$ & $<0.002$ & $<0.002$ & $<0.002$ & $<0.002$ & $<0.002$ & $<0.002$ \\
\hline Cadincium & $<0.003$ & $<0.003$ & $<0.003$ & $<0.003$ & $<0,003$ & $<0.003$ & $<0.003$ & $<0.003$ \\
\hline Chromiun (MAS) & $<0.01$ & $<0.02$ & $<0.01$ & $<0.01$ & $<0.01$ & $<0.01$ & $<0.01$ & $<0.01$ \\
\hline Chromiun & $<0.01$ & $<0.02$ & $<0.01$ & $<0.01$ & $<0.01$ & $<0.01$ & $<0.01$ & $<0.01$ \\
\hline Cobalt & $<0.005$ & $<0.005$ & $<0,005$ & $<0.005$ & $<0.005$ & $<0.005$ & $<0.005$ & $<0.005$ \\
\hline Copper & $<0.004$ & $<0.004$ & 0.0079 & 0.02 & 0.0078 & $<0.004$ & $<0.004$ & $<0.004$ \\
\hline Iron & 0.023 & 0.039 & 0.068 & 0.026 & $<0.005$ & 0.88 & 0.88 & 0.82 \\
\hline Ined (MS) & $<0.004$ & $<0.004$ & $<0.004$ & $<0.004$ & $<0.004$ & $<0.004$ & $<0.004$ & $<0.004$ \\
\hline Marcury (CVMA) & $<0.0002$ & $<0.0002$ & $<0.0002$ & $<0.0002$ & $<0.0002$ & 0.00031 & $<0.0002$ & $<0,0002$ \\
\hline Molybdanum & $<0.01$ & $<0.01$ & $<0.02$ & $<0.01$ & $<0.01$ & $<0.02$ & $<0.02$ & $<0.01$ \\
\hline mlckel & $<0.01$ & $<0.01$ & $<0.02$ & $<0.01$ & $<0.01$ & $<0.01$ & $<0.01$ & $<0.01$ \\
\hline selentum & $<0.05$ & $<0.05$ & $<0.05$ & $<0.05$ & $<0.05$ & $<0.05$ & $<0.05$ & $<0.05$ \\
\hline 8111 con & & & $\cdot$ &. & $\cdot$ & $\cdot$ & $\cdot$ & • \\
\hline s1lver & $<0.006$ & $<0.006$ & $<0.006$ & $<0.006$ & $<0.006$ & $<0.006$ & $<0.006$ & $<0.006$ \\
\hline strontium & 0.02 & 0.19 & 0.22 & 0.2 & 0.2 & 1.7 & 2.7 & 2.8 \\
\hline Thorium & $<0.2$ & $<0.2$ & $<0.2$ & $<0.2$ & $<0.2$ & $<0.2$ & $<0.2$ & $<0.2$ \\
\hline Oranium (Fluor) & $<0.002$ & $<0.001$ & $<0.001$ & $<0.001$ & $<0.001$ & $<0.001$ & $<0.001$ & $<0.001$ \\
\hline Venadium & $<0.005$ & $<0.005$ & $<0.005$ & $<0.005$ & $<0.005$ & $<0.005$ & $<0.005$ & $<0.005$ \\
\hline 21nc & 0.0086 & 0.0091 & 0.015 & 0.013 & 0.013 & 0.004 & 0.0071 & 0.0044 \\
\hline MUTOR IOAS $(\mathrm{mg} / \mathrm{L})$ & $\cdot$ & $\cdot$ & $\cdot$ & $\cdot$ & - & - & - & - \\
\hline 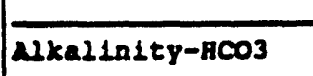 & .1 & 202 & $\cdot$ & 198 & $\cdot$ & 380 &. & $388^{\circ}$ \\
\hline Alkallnity-CO3 & $\cdot$ & $<2$ & $\cdot$ & $<1$ & $\cdot$ & $<2$ & $\cdot$ & $<2$ \\
\hline Calcium & 33) & 80 & 83 & 80 & 92 & 120 & 110 & 120 \\
\hline Chloride & $\cdot$ & 1 & $\cdot$ & 1.5 & • & 13 & $\cdot$ & 13.6 \\
\hline Fluoride & $\cdot$ & $<0.1$ & $\cdot$ & $<0.2$ & - & 0.2 & - & 0.1 \\
\hline Magnesium & 20 & 9 & 9.5 & 9.8 & 20 & 34 & 34 & 34 \\
\hline menganese & 0.0031 & 0.0064 & 0.015 & 0.018 & 0.016 & 0.16 & 0.16 & 0.15 \\
\hline mitrata-n & $\cdot$ & 7.2 & $\cdot$ & 5.2 & $\cdot$ & $<0.2$ & $\cdot$ & $<1.1$ \\
\hline Potassium & 1.9 & 2.3 & 1.4 & 1.9 & 2.8 & 2.6 & 2.8 & 3.3 \\
\hline Sodium & 0.77 & 1.7 & 1.7 & 2.1 & 2.2 & 26 & 25 & 35 \\
\hline sulfate & $\cdot$ & 27 & $\cdot \mid$ & 28.8 & $\cdot$ & 67 & $\cdot$ & 70.2 \\
\hline
\end{tabular}

(CONTIRTED) 
Groundwater Quality Data, 1991

\begin{tabular}{|c|c|c|c|c|c|c|c|c|}
\hline \multirow{4}{*}{$\begin{array}{l}\text { Woll No. } \\
\text { Location } \\
\text { Dete sampled }\end{array}$} & \multicolumn{3}{|c|}{ CW-322 } & \multicolumn{5}{|c|}{ GW-339 } \\
\hline & \multicolumn{3}{|c|}{ CRsP } & \multicolumn{5}{|c|}{ mics } \\
\hline & \multirow{2}{*}{\begin{tabular}{|c|}
$08 / 13 / 91$ \\
018
\end{tabular}} & \multicolumn{2}{|c|}{$10 / 21 / 91$} & \multicolumn{2}{|c|}{$01 / 13 / 91$} & \multicolumn{2}{|c|}{$04 / 13 / 91$} & \multirow{2}{*}{$\frac{07 / 30 / 91}{202}$} \\
\hline & & 200 & DIs & Tor & DIs & 20r & DIs & \\
\hline Wrents (mg/L) & $\cdot$ & $\cdot$ & $\cdot$ & $\cdot$ & $\cdot$ & $\cdot$ & • & - \\
\hline Aluminum & $<0.02$ & 3.5 & $<0.02$ & 0.052 & $<0.02$ & $<0.02$ & 0.034 & $<0.03$ \\
\hline Antimony & $<0.05$ & $<0.05$ & $<0.05$ & $<0.05$ & $<0.05$ & $<0.05$ & $<0.05$ & $<0.05$ \\
\hline areonic & $<0.05$ & $<0.05$ & $<0.05$ & $<0.05$ & $<0.05$ & $<0.05$ & $<0.05$ & $<0.05$ \\
\hline Bartum & 0.0084 & 0.02 & 0.0089 & 0.023 & 0.021 & 0.02 & 0.02 & 0.02 \\
\hline Berpl11um & $<0.0003$ & 0.00092 & $<0.0003$ & $<0.0003$ & $<0.0003$ & $<0.0003$ & 0.00033 & $<0.0003$ \\
\hline Boron & 0.017 & 0.017 & 0.02 & 0.0091 & 0.045 & 0.032 & 0.0073 & 0.0061 \\
\hline Cadintum (MSS) & $<0.002$ & $<0.002$ & $<0.002$ & $<0.002$ & $<0.002$ & $<0.002$ & $<0.002$ & $<0.002$ \\
\hline Cactonium & $<0.003$ & $<0.003$ & $<0.003$ & $<0.003$ & $<0.003$ & $<0.003$ & $<0.003$ & $<0.003$ \\
\hline Chromium (MAs) & $<0.01$ & $<0.01$ & $<0.01$ & $<0.02$ & $<0.01$ & $<0.01$ & $<0.02$ & 0.021 \\
\hline Chromium & $<0.01$ & $<0.01$ & $<0.01$ & 0.013 & $<0.01$ & 0.023 & $<0.02$ & 0.021 \\
\hline Cobalt & $<0.005$ & $<0.005$ & $<0.005$ & $<0.005$ & $<0.005$ & $<0.005$ & $<0.005$ & $<0.003$ \\
\hline Copper & $<0.004$ & 0.021 & $<0.004$ & $<0.004$ & $<0.004$ & $<0.004$ & 0.0045 & 0.0064 \\
\hline Iron & $<0.005$ & 5.8 & $<0.005$ & 0.075 & 0.0069 & 0.063 & 0.0086 & 0.64 \\
\hline Inead (MSS) & $<0.004$ & 0.024 & $<0.004$ & $<0.004$ & $<0.004$ & $<0.004$ & $<0.004$ & $<0.004$ \\
\hline Hercury (CVM) & $<0.0002$ & $<0.0002$ & $<0.0002$ & $<0.0002$ & $<0.0002$ & $<0.0002$ & $<0.0002$ & $<0.0002$ \\
\hline Nolpbodonue & $<0.02$ & $<0.01$ & $<0.01$ & $<0.01$ & $<0.01$ & $<0.02$ & $<0.02$ & $<0.02$ \\
\hline alekel & $<0.01$ & $<0.01$ & $<0.01$ & 0.024 & 0.023 & 0.028 & 0.02 & 0.043 \\
\hline selentum & $<0.05$ & $<0.05$ & $<0.05$ & $<0.05$ & $<0.05$ & $<0.05$ & $<0.05$ & $<0.05$ \\
\hline 8111 con & 3.7 & & $\cdot$ & 5.3 & 5 & 3.1 & 4.5 & 4.2 \\
\hline 811ver & $<0.006$ & $<0.006$ & $<0.006$ & $<0.006$ & $<0.006$ & $<0.006$ & $<0.006$ & $<0.006$ \\
\hline strontium & 0.011 & 0.017 & 0.012 & 0.028 & 0.027 & 0.023 & 0.024 & 0.026 \\
\hline Thorium & $<0.2$ & $<0.2$ & $<0.2$ & $<0.2$ & $<0.2$ & $<0.2$ & $<0.2$ & $<0.2$ \\
\hline Oranium (Fluor) & $<0.002$ & $<0.001$ & $<0.001$ & $<0.001$ & $<0.001$ & $<0.001$ & $<0.001$ & 0.001 \\
\hline Vanadium & $<0.005$ & 0.016 & $<0.005$ & $<0.005$ & $<0.005$ & $<0.005$ & $<0.005$ & $<0.005$ \\
\hline 2Lnc: & 0.0041 & 0.099 & 0.0052 & 0.0019 & $<0.001$ & 0.0049 & 0.012 & $<0.002$ \\
\hline MnJOR IOAs (mg/I) & . & . & $\cdot$ & . &. & . & - & . \\
\hline Akal Ladty-HCO3 & $\cdot$ & 164 &. & 250 & $\dot{.}$ & 252 & $\bullet$ & • \\
\hline Alkalln1ty-CO3 & $\cdot$ & $<1$ & $\cdot$ & $<1$ & $\cdot$ & $<1$ & • & $\cdot$ \\
\hline Calcium & 34 & 50 & 32 & 52 & 55 & 45 & 41 & 54 \\
\hline Chloride & • & 2 & $\cdot$ & 20 & $\cdot$ & 17 & • & - \\
\hline Inoride & $\cdot$ & $<0.1$ & $\cdot$ & $<0.1$ & $\cdot$ & $<0.1$ & • & • \\
\hline Magneadum & 20 & 33 & 19 & 31 & 33 & 29 & 30 & 32 \\
\hline Manganeae & $<0.001$ & 0.11 & $<0.001$ & 0.0063 & 0.0062 & 0.0041 & 0.0042 & 0.026 \\
\hline mitrate-N & & $<0.2$ & $\bullet$ & 0.9 & $\bullet$ & 0.9 & $\bullet$ & • \\
\hline potaselum & $<0.6$ & 1.5 & $<0.6$ & 1.2 & 1.2 & 1.1 & 0.98 & 0.95 \\
\hline sodium & 0.57 & 0.6 & 0.59 & 7.5 & 8 & 8.2 & 9.2 & 8.2 \\
\hline 8ullate & $\cdot$ & 1 & - & 5 & - & 4 & $\cdot$ & • \\
\hline
\end{tabular}

(CONrInOED) 
Groundwater Quality Data, 1991

\begin{tabular}{|c|c|c|c|c|c|c|c|c|}
\hline \multirow{4}{*}{$\begin{array}{l}\text { Woll Ho. } \\
\text { Location } \\
\text { Date sampled }\end{array}$} & \multicolumn{4}{|c|}{ ow-339 } & \multicolumn{4}{|c|}{$0 N-512$} \\
\hline & \multicolumn{4}{|c|}{ Uacs } & \multicolumn{4}{|c|}{ Cnsp } \\
\hline & \multirow{2}{*}{\begin{tabular}{|c|}
$07 / 30 / 91$ \\
$D I 8$
\end{tabular}} & \multirow{2}{*}{$\frac{08 / 13 / 91}{201}$} & \multicolumn{2}{|c|}{$10 / 06 / 91$} & \multicolumn{2}{|c|}{$02 / 29 / 91$} & \multicolumn{2}{|c|}{$04 / 30 / 91$} \\
\hline & & & Tor & DIs & TOT & DX8 & $\operatorname{Tor}$ & DIs \\
\hline menss (mg/L) & $\cdot$ & $\cdot$ & - & $\cdot$ & • & $\cdot$ & - & - \\
\hline Aluminum & $<0.02$ & $\cdot$ & 0.052 & $<0.02$ & 0.041 & 0.044 & 0.052 & $<0.02$ \\
\hline Antimony & $<0.05$ & $\cdot$ & $<0.05$ & $<0.05$ & $<0.05$ & $<0.05$ & $<0.05$ & $<0.05$ \\
\hline Armonic & $<0.05$ & $\cdot$ & $<0.05$ & $<0.05$ & $<0.05$ & $<0.05$ & $<0.05$ & $<0.05$ \\
\hline Barium & 0.018 & $\cdot$ & 0.021 & 0.021 & 0.008 & 0.0082 & 0.0076 & 0.0078 \\
\hline Beryl11um & $<0.0003$ & $\cdot 1$ & $<0.0003$ & $<0.0003$ & $<0.0003$ & $<0.0003$ & $<0.0003$ & $<0.0003$ \\
\hline Boron & 0.011 & . & 0.012 & 0.013 & 0.012 & 0.02 & $<0.004$ & 0.0094 \\
\hline Cadmilum (MS) & $<0.002$ & $\cdot$ & $<0.002$ & $<0.002$ & $<0.002$ & $<0.002$ & $<0.002$ & $<0.002$ \\
\hline Cectonlum & $<0.003$ & $\cdot$ & $<0.003$ & $<0.003$ & 0.0045 & $<0.003$ & $<0.003$ & $<0.003$ \\
\hline Chromium (Ms) & $<0.01$ & $\cdot$ & 0.021 & $<0.01$ & $<0.01$ & $<0.01$ & $<0.01$ & $<0.01$ \\
\hline Chromium & $<0.01$ & $\cdot$ & $<0.01$ & 0.022 & $<0.01$ & $<0.01$ & $<0.02$ & $<0.01$ \\
\hline cobalt & $<0.005$ & $\cdot$ & $<0.005$ & $<0.005$ & $<0.005$ & $<0.005$ & $<0.005$ & $<0.005$ \\
\hline Coppar & $<0.004$ & $\cdot 1$ & $<0.004$ & 0.0043 & $<0.004$ & $<0.004$ & 0.0044 & 0.0094 \\
\hline Iron & $<0.005$ & $\cdot$ & 0.29 & 0.19 & 0.022 & 0.0043 & 0.031 & $<0.005$ \\
\hline road (MS) & $<0.004$ & $\cdot 1$ & $<0.004$ & $<0.004$ & $<0.004$ & $<0.004$ & $<0.004$ & $<0.004$ \\
\hline Mereury (CVMA) & $<0.0002$ & • & $<0.0002$ & $<0.0002$ & $<0.0002$ & $<0.0002$ & $<0.0002$ & $<0.0002$ \\
\hline Molybdenum & $<0.01$ & $\cdot$ & $<0.01$ & $<0.01$ & $<0.01$ & $<0.01$ & $<0.01$ & $<0.01$ \\
\hline nlckel & $<0.01$ & $\cdot 1$ & 0.025 & 0.028 & $<0.01$ & $<0.01$ & $<0.01$ & $<0.01$ \\
\hline selenium & $<0.05$ & $\cdot 1$ & $<0.05$ & $<0.05$ & $<0.05$ & $<0.05$ & $<0.05$ & $<0.05$ \\
\hline 8111 con & 4.2 & $\cdot$ & & & 4.6 & 5.2 & 4 & 4 \\
\hline 8117er & $<0.006$ & $\cdot$ & $<0.006$ & $<0.006$ & $<0.006$ & $<0.006$ & $<0.006$ & $<0.006$ \\
\hline stront1um & 0.023 & $\cdot$ & 0.023 & 0.022 & 0.044 & 0.045 & 0.042 & 0.042 \\
\hline Thorium & $<0.2$ & $\cdot$ & $<0.2$ & $<0.2$ & $<0.2$ & $<0.2$ & $<0.2$ & $<0.2$ \\
\hline Oranium (Fluor) & $<0.001$ & $\cdot$ & $<0.001$ & $<0.001$ & $<0.001$ & $<0.001$ & $<0.002$ & 0.001 \\
\hline Venadium & $<0.005$ & $\cdot$ & $<0.005$ & $<0.005$ & $<0.005$ & $<0.005$ & $<0.005$ & $<0.005$ \\
\hline 210 & $<0.002$ & $\cdot 1$ & 0.0072 & 0.075 & 0.0036 & 0.0028 & 0.0031 & 0.0025 \\
\hline MUJOR IOMS $(\mathrm{mg} / \mathrm{I})$ & . &. & $\cdot$ & $\cdot$ & $\cdot$ & $\cdot$ & - & - \\
\hline AlkalLitty-HCO3 &. & 249 & 243 & $\cdot$ & 245 & $\cdot$ & 141 & - \\
\hline Nkalinity-CO3 & $\cdot$ & $<1$ & $<1$ & $\cdot$ & 4 & $\cdot$ & $<2$ & $\cdot$ \\
\hline Calcium & 52 & $\cdot$ & 60 & 60 & 26 & 26 & 27 & 27 \\
\hline Chloride & $\cdot$ & 9 & 14 & $\cdot$ & 3 & $\cdot 1$ & 3 & - \\
\hline Pluoride & $\cdot$ & $<0.1$ & $<0.2$ & $\cdot$ & $<0.1$ & $\cdot$ & $<0.1$ & $\cdot$ \\
\hline Magnenium & 32 & $\cdot$ & 32 & 32 & 16 & 16 & 16 & 26 \\
\hline Manganese & $<0.002$ & $\cdot$ & 0.0086 & 0.0064 & $<0.001$ & $<0.001$ & $<0.001$ & $<0.001$ \\
\hline altrate-n & & 0.86 & 0.74 & $\cdot$ & $<0.2$ & $\cdot 1$ & $<0.2$ & • \\
\hline Potaselum & 0.89 & - & 0.96 & 2.2 & 4.8 & s & 5.8 & 5.2 \\
\hline $\operatorname{cod} 14 \mathrm{~m}$ & 8.8 & - & 7 & 7.4 & 2.6 & 2 & 2.6 & 1.5 \\
\hline sulfate & $\cdot$ & 4 & 4 & $\cdot$ & 2 & $\cdot$ & 2 & - \\
\hline
\end{tabular}

(CORTrives) 
Oroundwater Quality Data, 1991

\begin{tabular}{|c|c|c|c|c|c|c|c|c|}
\hline \multirow{4}{*}{$\begin{array}{l}\text { Woll Ho. } \\
\text { Loention } \\
\text { Date sampled }\end{array}$} & \multicolumn{4}{|c|}{$a w-511$} & \multicolumn{4}{|c|}{$O W-512$} \\
\hline & \multicolumn{4}{|c|}{ CRsP } & \multicolumn{4}{|c|}{$\mathrm{ADB}$} \\
\hline & \multicolumn{2}{|c|}{$08 / 05 / 91$} & \multicolumn{2}{|c|}{$10 / 08 / 91$} & \multicolumn{2}{|c|}{$03 / 19 / 91$} & \multicolumn{2}{|c|}{$06 / 16 / 91$} \\
\hline & nor & DIS & 202 & DI8 & $20 x$ & DIs & Tor & DI8 \\
\hline Moves (mg/L) & $\cdot$ & $\cdot$ & $\cdot$ & - & $\cdot$ & $\cdot$ & $\cdot$ & - \\
\hline Numinum & 0.061 & 0.024 & $<0.02$ & 0.02 & 0.05 & 0.067 & 0.25 & 0.043 \\
\hline Ant'inony & $<0.05$ & $<0.05$ & $<0.05$ & $<0.05$ & $<0.05$ & $<0.05$ & $<0.05$ & $<0.05$ \\
\hline Araenie & $<0.05$ & $<0.05$ & $<0.05$ & $<0.05$ & $<0.05$ & $<0.03$ & $<0.05$ & $<0.05$ \\
\hline Barlum & 0.0084 & 0.0075 & 0.0082 & 0.0085 & 0.031 & 0.027 & 0.026 & 0.024 \\
\hline Baryl11um & $<0.0003$ & $<0.0003$ & $<0.0003$ & $<0.0003$ & 0.00034 & 0.00032 & $<0.0003$ & $<0.0003$ \\
\hline Boron & $<0.004$ & $<0.004$ & 0.031 & 0.023 & 0.037 & 0.028 & 0.023 & 0.02 \\
\hline Cadmlum (MS) & $<0.002$ & $<0.023$ & $<0.002$ & $<0.002$ & $<0.002$ & $<0.002$ & $<0.002$ & $<0.002$ \\
\hline Cadmitum & $<0.003$ & $<0.003$ & $<0.003$ & $<0.003$ & $<0.003$ & $<0.003$ & $<0.003$ & $<0.003$ \\
\hline Chromiun (MAs) & $<0.02$ & $<0.012$ & $<0.01$ & $<0.01$ & $<0.01$ & $<0.01$ & $<0.01$ & $<0.01$ \\
\hline Chrosatum & $<0.01$ & $<0.01$ & $<0.01$ & $<0.01$ & 0.023 & $<0.01$ & $<0.01$ & $<0.01$ \\
\hline Cobalt & $<0.005$ & $<0.005$ & $<0.005$ & $<0.005$ & $<0.005$ & $<0.005$ & $<0.005$ & $<0.005$ \\
\hline copper & $<0.004$ & 0.007 & $<0.004$ & $<0.004$ & $<0.004$ & $<0.004$ & 0.0062 & 0.0053 \\
\hline Iron & 0.032 & $<0.005$ & 0.026 & $<0.005$ & 0.11 & $<0.005$ & 0.23 & 0.032 \\
\hline Ioed (MS) & $<0.004$ & $<0.0045$ & $<0.004$ & $<0.004$ & $<0.004$ & $<0.004$ & $<0.004$ & $<0.004$ \\
\hline Maroury (CVMA) & $<0.0002$ & $<0.0002$ & $<0.0002$ & $<0.0002$ & $<0.0002$ & $<0.0002$ & $<0.0002$ & $<0.0002$ \\
\hline Molybdenum & $<0.02$ & $<0.01$ & $<0.02$ & $<0.01$ & $<0.01$ & $<0.01$ & $<0.01$ & $<0.01$ \\
\hline mlekel & $<0.02$ & $<0.02$ & $<0.01$ & $<0.01$ & $<0.01$ & $<0.01$ & $<0.02$ & 0.039 \\
\hline selonium & $<0.05$ & $<0.05$ & $<0.05$ & $<0.05$ & $<0.05$ & $<0.05$ & $<0.05$ & $<0.05$ \\
\hline 8111eon & 3.0 & 3.5 & $\cdot$ &. & 6 & 5.9 & 6.1 & 3.6 \\
\hline 811ver & $<0.006$ & $<0.006$ & $<0.006$ & $<0.006$ & $<0.006$ & $<0.006$ & $<0.006$ & $<0.006$ \\
\hline stront1um & 0.045 & 0.045 & 0.05 & 0.051 & 0.023 & 0.022 & 0.024 & 0.022 \\
\hline Thoriun & $<0.2$ & $<0.2$ & $<0.2$ & $<0.2$ & $<0.2$ & $<0.2$ & $<0.2$ & $<0.2$ \\
\hline Orantum (Fluor) & $<0.001$ & $<0.001$ & $<0.001$ & $<0.001$ & $<0.002$ & $<0.001$ & $<0.001$ & $<0.002$ \\
\hline Vanadium & $<0.005$ & $<0.005$ & $<0.005$ & $<0.005$ & 0.0064 & $<0.005$ & $<0.005$ & $<0.005$ \\
\hline Ine & $<0.002$ & 0.026 & 0.004 & 0.0051 & 0.017 & 0.006 & 0.017 & 0.0094 \\
\hline MHOR IOWS (mg/L) & $\cdot$ & $\cdot$ & $\cdot$ & . & . & $\cdot$ & • & - \\
\hline Mkalinlty-HCO3 & $\begin{array}{r}\cdot \\
123\end{array}$ &. & 222 &. & 273 & $\cdot$ & 171 & $\dot{\bullet}$ \\
\hline Mkalln1ty-CO3 & 4 & . & 4 & . & $<1$ & $\cdot$ & $<1$ & • \\
\hline calcium & 25 & 25 & 25 & 25 & 33 & 33 & 32 & 32 \\
\hline Chloride & 3 & - & 3 & $\cdot$ & $<1$ & $\cdot$ & $<\mathbf{1}$ & - \\
\hline rluoride & $<0.1$ & $\cdot$ & $<0.1$ & $\cdot$ & $<0.1$ &. & 0.2 & - \\
\hline Magnesium & 25 & 15 & 15 & 15 & 20 & 20 & 19 & 28 \\
\hline Manganese & $<0.001$ & $<0.001$ & $<0.001$ & $<0.001$ & 0.0036 & $<0.001$ & 0.0045 & $<0.001$ \\
\hline M1:rate-n & $<0.2$ & $\cdot$ & $<0.2$ & $\cdot$ & $<0.2$ & $\cdot$ & $<0.2$ & • \\
\hline Potaselum & 3.8 & 5.1 & 5.8 & 8 & 3.8 & 4.4 & 3.3 & 3.4 \\
\hline sodium & 1.5 & 1.4 & 1.7 & 2.3 & 0.92 & 0.91 & 0.83 & 0.96 \\
\hline suleato & 1.8 & • & 2 & .1 & 3 & $\cdot$ & 2 & • \\
\hline
\end{tabular}

(Comrrivos) 
Oroundwater Quallty Data, 1991

\begin{tabular}{|c|c|c|c|c|c|c|c|c|}
\hline \multirow{4}{*}{$\begin{array}{l}\text { Woll Mo. } \\
\text { Looution } \\
\text { Date sampled }\end{array}$} & \multicolumn{4}{|c|}{$0 x-512$} & \multicolumn{4}{|c|}{ ON-513 } \\
\hline & \multicolumn{4}{|c|}{$\operatorname{ADS}$} & \multicolumn{4}{|c|}{ ADB } \\
\hline & \multicolumn{2}{|c|}{$09 / 06 / 91$} & \multicolumn{2}{|c|}{$11 / 16 / 91$} & \multicolumn{2}{|c|}{$03 / 19 / 91$} & \multicolumn{2}{|c|}{$06 / 16 / 91$} \\
\hline & IOT & DI8 & $20 x$ & DI8 & TOT & DIs & $20 x$ & DI8 \\
\hline henes $(\mathrm{mg} / \mathrm{L})$ & $\cdot$ & • & - & - & $\cdot$ & - & - & - \\
\hline Aluminum & 0.22 & $<0.02$ & 0.04 & 0.35 & $<0.02$ & 0.026 & 0.087 & 0.037 \\
\hline Antimony & $<0.05$ & $<0.03$ & $<0.03$ & $<0.05$ & $<0.05$ & $<0.05$ & $<0.05$ & $<0.05$ \\
\hline Araenie & $<0.05$ & $<0.05$ & $<0.03$ & $<0.05$ & $<0.05$ & $<0.05$ & $<0.05$ & $<0.05$ \\
\hline Barium & 0.024 & 0.025 & 0.024 & 0.033 & 0.0061 & 0.0068 & 0.0081 & 0.0072 \\
\hline Beryl11um & $<0.0003$ & $<0.0003$ & $<0.0003$ & $<0.0003$ & 0.00033 & $<0.0003$ & $<0.0003$ & $<0.0003$ \\
\hline Boron & $<0.004$ & $<0.004$ & 0.016 & 0.016 & 0.0083 & 0.016 & 0.026 & 0.018 \\
\hline Cadmitum (MS) & $<0.002$ & $<0.002$ & $<0.002$ & $<0.002$ & $<0.002$ & $<0.002$ & $<0.002$ & $<0.002$ \\
\hline Cadmitum & $<0.003$ & $<0.003$ & $<0.003$ & $<0.003$ & $<0.003$ & $<0.003$ & $<0.003$ & $<0.003$ \\
\hline Chromium (NAS) & $<0.01$ & $<0.02$ & $<0.01$ & $<0.01$ & $<0.01$ & $<0.02$ & $<0.02$ & $<0.01$ \\
\hline Chromium & $<0.01$ & $<0.01$ & $<0.01$ & $<0.01$ & 0.012 & $<0.01$ & $<0.02$ & $<0.01$ \\
\hline Cobelt & $<0.005$ & $<0.005$ & $<0.005$ & $<0.005$ & $<0.005$ & $<0.005$ & $<0.005$ & $<0.005$ \\
\hline Copper & $<0.004$ & $<0.004$ & $<0.004$ & 0.0079 & $<0.004$ & $<0.004$ & 0.0041 & $<0.004$ \\
\hline Iron & 0.25 & $<0.005$ & 0.023 & 1.6 & 0.039 & $<0.005$ & 0.085 & 0.013 \\
\hline Inad (MS) & $<0.004$ & $<0.004$ & $<0.004$ & $<0.004$ & $<0.004$ & $<0.004$ & $<0.004$ & $<0.004$ \\
\hline Meroury (CVM) & $<0.0002$ & $<0.0002$ & $<0.0002$ & $<0.0002$ & $<0.0002$ & $<0.0002$ & $<0.0002$ & $<0.0002$ \\
\hline Mol gbodenum & $<0.01$ & $<0.01$ & $<0.01$ & $<0.01$ & $<0.02$ & $<0.01$ & $<0.01$ & $<0.01$ \\
\hline mlekel & $<0.01$ & $<0.01$ & $<0.01$ & $<0.01$ & $<0.01$ & $<0.01$ & 0.020 & $<0.01$ \\
\hline enlentum & $<0.03$ & $<0.05$ & $<0.05$ & $<0.05$ & $<0.05$ & $<0.05$ & $<0.03$ & $<0.05$ \\
\hline 8111con & & & $\cdot$ & $\cdot$ & 4.1 & 4.2 & 4.1 & 4.2 \\
\hline 8stvar & $<0.006$ & $<0.006$ & $<0.006$ & $<0.006$ & $<0.006$ & $<0.006$ & $<0.006$ & $<0.006$ \\
\hline strontium & 0.022 & 0.026 & 0.022 & 0.026 & 0.021 & 0.021 & 0.02 & 0.02 \\
\hline Thorium & $<0.2$ & $<0.2$ & $<0.2$ & $<0.2$ & $<0.2$ & $<0.2$ & $<0.2$ & $<0.2$ \\
\hline Oranium (rluor) & $<0.001$ & $<0.001$ & $<0.001$ & $<0.001$ & $<0.001$ & $<0.001$ & $<0.001$ & $<0.001$ \\
\hline Venadium & $<0.005$ & $<0.005$ & $<0.005$ & $<0.005$ & $<0.005$ & $<0.005$ & $<0.005$ & $<0.005$ \\
\hline zine & 0.026 & 0.011 & 0.026 & 0.023 & $<0.002$ & $<0.002$ & 0.01 & 0.0061 \\
\hline MWOR IOMS $(\mathrm{mg} / \mathrm{L})$ & $\dot{.}$ &. &. & $\cdot$ & $\bullet$ & $\bullet$ &. & • \\
\hline AlkalLnd.ty-HCO3 & 260 &. & 257 & $\cdot$ & 174 & . & $272^{\circ}$ & • \\
\hline Arkalinity-CO3 & $<1$ &. & $<1$ & . & 2 & • & $<1$ & • \\
\hline Calcium & 35 & 38 & 36 & 38 & 33 & 34 & 32 & 32 \\
\hline Chloride & $<1$ & $\cdot$ & $<1$ & $\cdot$ & 1 & $\cdot$ & 1 & • \\
\hline Fluorlde & $<0.1$ & $\cdot$ & $<0.1$ & • & $<0.1$ & - & $<0.1$ & • \\
\hline Magnesium & 20 & 21 & 22 & 23 & 20 & 21 & - 28 & 18 \\
\hline Manganese & 0.0048 & 0.0033 & 0.0012 & 0.024 & $<0.001$ & $<0.001$ & $<0.001$ & $<0.001$ \\
\hline Mltrate-N & $<0.2$ & $\cdot$ & $<0.2$ &. & $<0.2$ &. & $<0.2$ & \\
\hline Potaseium & 3.9 & 4.1 & 2.9 & 3.6 & 2.4 & 1.3 & 1.5 & 1.6 \\
\hline sodium & 1.2 & 2.2 & 1 & 2.2 & 0.59 & 0.59 & 1 & 0.92 \\
\hline sultate & 3 & • & 3.9 & • & 2 & . & 2 & \\
\hline
\end{tabular}

(COArImORD) 
Groundwater Quellty Data, 1991

\begin{tabular}{|c|c|c|c|c|c|c|c|c|}
\hline \multirow{4}{*}{$\begin{array}{l}\text { Woll No. } \\
\text { iocation } \\
\text { Date sampled }\end{array}$} & \multicolumn{4}{|c|}{$a n-545$} & \multicolumn{4}{|c|}{$0 w-546$} \\
\hline & \multicolumn{4}{|c|}{$\operatorname{IIIX}$} & \multicolumn{4}{|c|}{ IIIX } \\
\hline & \multicolumn{2}{|c|}{$09 / 15 / 91$} & \multicolumn{2}{|c|}{$11 / 26 / 91$} & \multicolumn{2}{|c|}{$03 / 17 / 91$} & \multicolumn{2}{|c|}{$04 / 11 / 91$} \\
\hline & 202 & DI8 & 202 & DIs & xor & DIs & xor & D28 \\
\hline Mencs (mg/L) & $\cdot$ & $\cdot$ & - & - & - & $\cdot$ & $\cdot$ & - \\
\hline Numinum & 4.3 & 1 & 1.7 & 1.5 & $<0.02$ & 0.028 & $<0.02$ & 0.043 \\
\hline Antimony & $<0.05$ & $<0.05$ & $<0.05$ & $<0.05$ & $<0.03$ & $<0.05$ & $<0.08$ & $<0.05$ \\
\hline Areenic & $<0.05$ & $<0.05$ & $<0.05$ & $<0.05$ & $<0.05$ & $<0.05$ & $<0.03$ & $<0.05$ \\
\hline Darlum & 0.039 & 0.025 & 0.02 & 0.024 & 0.0057 & 0.0052 & 0.026 & 0.023 \\
\hline Bery111um & $<0.0003$ & $<0.0003$ & $<0.0003$ & $<0.0003$ & $<0.0003$ & $<0.0003$ & $<0.0003$ & $<0.0003$ \\
\hline Boron & 0.027 & 0.024 & 0.017 & 0.013 & 0.0097 & 0.035 & 0.036 & 0.052 \\
\hline Cadmium (AMS) & 40.002 & $<0.002$ & $<0.002$ & $<0.002$ & $<0.002$ & $<0.002$ & $<0.002$ & $<0.002$ \\
\hline Cadantion & $<0.003$ & $<0.003$ & $<0.003$ & $<0.003$ & $<0.003$ & $<0.003$ & $<0.003$ & $<0.003$ \\
\hline Chromium (MS) & 0.024 & 0.013 & 0.019 & 0.029 & $<0.01$ & $<0.01$ & $<0.02$ & $<0.01$ \\
\hline Chromium & 0.03 & 0.024 & 0.025 & 0.023 & $<0.01$ & $<0.01$ & 0.049 & 0.057 \\
\hline Cobalt & $<0.005$ & $<0.005$ & $<0.005$ & $<0.00 s$ & $<0.005$ & $<0.005$ & $<0.00 s$ & $<0.005$ \\
\hline Coppar & 0.025 & 0.024 & 0.0061 & 0.0065 & 0.0072 & 0.0041 & 0.0098 & 0.0088 \\
\hline Iron & 1.5 & 0.034 & 0.21 & 0.0059 & 0.052 & 0.015 & 0.035 & 0.012 \\
\hline Lead (MAs) & 0.0071 & $<0.004$ & $<0.004$ & $<0.004$ & $<0.004$ & $<0.004$ & $<0.004$ & $<0.004$ \\
\hline mercusy (CVMa) & $<0.0002$ & $<0.0002$ & $<0.0002$ & $<0.9002$ & $<0.0002$ & $<0.0002$ & $<0.0002$ & $<0.0002$ \\
\hline Molybdenum & 0.023 & 0.022 & 0.039 & 0.04 & $<0.01$ & $<0.01$ & $<0.01$ & $<0.01$ \\
\hline nlekel & $<0.01$ & $<0.01$ & $<0.02$ & $<0.01$ & $<0.02$ & $<0.01$ & $<0.02$ & $<0.01$ \\
\hline Selentum & $<0.05$ & $<0.05$ & $<0.05$ & $<0.05$ & $<0.05$ & $<0.05$ & $<0.05$ & $<0.05$ \\
\hline s111con & & & & $\cdot$ & 4.3 & 4.7 & & 4.2 \\
\hline 811ver & $<0.006$ & $<0.006$ & $<0.006$ & $<0.006$ & $<0.006$ & $<0.006$ & $<0.006$ & $<0.006$ \\
\hline strontium & 0.24 & 0.11 & 0.098 & 0.097 & 0.018 & 0.017 & 0.039 & 0.024 \\
\hline Thorium & $<0.2$ & $<0.2$ & $<0.2$ & $<0.2$ & $<0.2$ & $<0.2$ & $<0.2$ & $<0.2$ \\
\hline Orantum (Pluor) & $<0.001$ & $<0.001$ & $<0.001$ & $<0.001$ & $<0.001$ & $<0.001$ & $<0.001$ & $<0.001$ \\
\hline Venadium & 0.021 & 0.023 & 0.024 & 0.025 & $<0.005$ & $<0.005$ & 0.0052 & 0.0052 \\
\hline zlne & 0.02 & 0.019 & 0.013 & 0.0078 & 0.0095 & 0.0087 & 0.011 & 0.014 \\
\hline MHOR IOMS $(\mathrm{mg} / L)$ &. &. &. &. & $\cdot$ &. &. & - \\
\hline & $<1$ &. & $<1$ &. & 139 &. & 232 & • \\
\hline $\begin{array}{l}\text { Akallnity-4CO3 } \\
\text { Akallnity-CO3 }\end{array}$ & 30 &. & 36 & .1 & $<1$ &. & $<1$ & . \\
\hline $\begin{array}{l}\text { Alkaldnity-CO3 } \\
\text { Calclum }\end{array}$ & 110 & 66 & 62 & 59 & 28 & 27 & 28 & 23 \\
\hline $\begin{array}{l}\text { Calcium } \\
\text { chlorida }\end{array}$ & 2 & $\cdot$ & 2 & $\cdot$ & 2 & $\cdot$ & 2 & - \\
\hline Fluoride & 0.1 & $\cdot$ & 0.1 &. & $<0.1$ & $\cdot$ & $<0.1$ & • \\
\hline Magnealum & 21 & 0.083 & 0.86 & 0.02 & 26 & 15 & 16 & 15 \\
\hline Manganese & 0.038 & $<0.001$ & 0.003 & $<0.001$ & 0.003 & $<0.002$ & $<0.002$ & $<0.001$ \\
\hline mitrate-n & 0.64 & $\cdot$ & 0.63 & $\cdot$ & $<0.2$ & $\cdot$ & $<0.2$ & • \\
\hline Potanelum & 22 & 21 & 28 & 29 & 1.8 & 1.8 & 2.4 & 1.8 \\
\hline sodium & 5.2 & 5.5 & 3.4 & 7 & 2.9 & 2.2 & 2.4 & 2.6 \\
\hline sulfate & 13 & $\cdot$ & 28 & $\cdot$ & 7 & • & 6 & $\bullet$ \\
\hline
\end{tabular}

(corrrinued) 
Groundwater Queddty Date, 1991

\begin{tabular}{|c|c|c|c|c|c|c|c|c|}
\hline \multirow{4}{*}{$\begin{array}{l}\text { Well Ho. } \\
\text { Loention } \\
\text { Date sampled }\end{array}$} & \multicolumn{4}{|c|}{$a v-546$} & \multicolumn{4}{|c|}{$0 N-607$} \\
\hline & \multicolumn{4}{|c|}{$253 x$} & \multicolumn{4}{|c|}{ CRAP } \\
\hline & \multicolumn{2}{|c|}{$09 / 23 / 91$} & \multicolumn{2}{|c|}{$11 / 26 / 91$} & \multicolumn{2}{|c|}{$01 / 28 / 91$} & \multicolumn{2}{|c|}{$04 / 29 / 91$} \\
\hline & 200 & DI8 & 202 & DI8 & 202 & D28 & IOr & D88 \\
\hline Mroves (mg/L) & - & $\cdot$ & $\cdot$ & - & $\cdot$ & $\cdot$ & $\bullet$ & - \\
\hline Mundnum & 3.6 & 0.042 & 1.0 & $<0.02$ & 0.081 & 0.03 & 0.083 & $<0.02$ \\
\hline Anedmony & $<0.05$ & $<0.03$ & $<0.05$ & $<0.08$ & $<0.05$ & $<0.05$ & $<0.05$ & $<0.05$ \\
\hline Areunde & $<0.05$ & $<0.03$ & $<0.08$ & $<0.0 s$ & $<0.05$ & $<0.05$ & $<0.05$ & $<0.05$ \\
\hline Deriug & 0.025 & 0.0097 & 0.013 & 0.0086 & 0.0097 & 0.0092 & 0.006 & 0.0091 \\
\hline Baryl11um & 0.00067 & $<0.0003$ & $<0.0003$ & $<0.0003$ & $<0.0003$ & $<0.0003$ & $<0.0003$ & $<0.0003$ \\
\hline Baron & 0.012 & 0.037 & 0.0086 & 0.022 & 0.02 & 0.012 & $<0.004$ & 0.021 \\
\hline Cadulum (MS) & $<0.002$ & $<0.002$ & $<0.002$ & $<0.002$ & $<0.002$ & $<0.002$ & $<0.002$ & $<0.002$ \\
\hline Cadndum & $<0.003$ & $<0.003$ & $<0.003$ & $<0.003$ & $<0.003$ & $<0.003$ & $<0.003$ & $<0.003$ \\
\hline Chrondum (MS) & 0.022 & $<0.01$ & 0.012 & $<0.01$ & $<0.01$ & $<0.01$ & $<0.01$ & $<0.01$ \\
\hline Chromium & 0.018 & 0.027 & 0.02 & $<0.01$ & 0.034 & $<0.01$ & 0.079 & $<0.01$ \\
\hline Cobult & $<0.005$ & $<0.00 s$ & $<0.005$ & $<0.00 s$ & $<0.005$ & $<0.008$ & $<0.00 s$ & $<0.003$ \\
\hline Copper & 0.016 & 0.0067 & 0.022 & 0.0077 & $<0.004$ & $<0.004$ & $<0.004$ & $<0.004$ \\
\hline Iron & 6.6 & 0.055 & 1.7 & 0.0061 & 0.07 & 0.028 & 0.037 & $<0.003$ \\
\hline road (MAS) & 0.016 & $<0.004$ & 0.0056 & $<0.004$ & $<0.004$ & $<0.004$ & $<0.004$ & $<0.004$ \\
\hline neroury (CVM) & 0.0004 & $<0.0002$ & $<0.0002$ & $<0.0002$ & $<0.0002$ & $<0.0002$ & $<0.0002$ & $<0.0002$ \\
\hline nolybdenum & $<0.01$ & $<0.02$ & $<0.02$ & 40.02 & $<0.02$ & $<0.01$ & $<0.02$ & $<0.01$ \\
\hline alokel & 0.021 & $<0.01$ & 0.012 & $<0.01$ & 0.026 & $<0.01$ & 0.025 & 0.011 \\
\hline Celentum & $<0.05$ & $<0.08$ & $<0.03$ & $<0.05$ & $<0.05$ & $<0.05$ & $<0.05$ & $<0.05$ \\
\hline 811100n & & & & & 1.8 & 3.8 & 3.4 & 3.9 \\
\hline s11ver & $<0.006$ & $<0.006$ & $<0.006$ & $<0.006$ & $<0.006$ & $<0.006$ & $<0.006$ & $<0.006$ \\
\hline strontium & 0.035 & 0.016 & 0.022 & 0.018 & 0.031 & 0.031 & 0.024 & 0.029 \\
\hline Thortum & $<0.2$ & $<0.2$ & $<0.2$ & $<0.2$ & $<0.2$ & $<0.2$ & $<0.2$ & $<0.2$ \\
\hline Orantum (Fluor) & 0.001 & $<0.002$ & 0.002 & $<0.001$ & $<0.001$ & $<0.001$ & $<0.001$ & $<0.001$ \\
\hline Venadium & 0.018 & $<0.003$ & $<0.005$ & $<0.005$ & $<0.005$ & $<0.005$ & 0.0051 & $<0.005$ \\
\hline $\operatorname{sine}$ & 0.09 & 0.015 & 0.025 & 0.0087 & 0.0045 & 0.0026 & 0.0095 & 0.0021 \\
\hline MWOR IOAS (mg/L) & - & . &. & $\cdot$ & . &. & . & . \\
\hline NKalinity-HCO3 & $230^{\circ}$ & $\cdot$ & $239^{\circ}$ & $\cdot$ & 130 & $\cdot$ & $12 \dot{1}^{\circ}$ & • \\
\hline Mkaldn1ty-CO3 & $<1$ & $\cdot$ & $<1$ & $\cdot$ & $<1$ & $\cdot$ & $<2$ & • \\
\hline Calcium & 74 & 29 & 34 & 29 & 26 & 26 & 23 & 25 \\
\hline Chloride & $<0.2$ & $\cdot$ & 2 & $\cdot$ & 1 & $\cdot$ & 1 & - \\
\hline Fluoride & $<0.1$ & $\cdot$ & 0.1 & $\cdot$ & $<0.1$ & $\cdot$ & $<0.2$ & • \\
\hline Magnealum & 41 & 16 & 20 & 16 & 14 & 24 & 13 & 13 \\
\hline Mnganese & 0.54 & $<0.002$ & 0.075 & $<0.001$ & 0.0024 & $<0.001$ & 0.0027 & $<0.002$ \\
\hline nitrate-N & $<0.2$ & $\cdot$ & $<0.2$ & $\cdot$ & $<0.2$ & $\bullet$ & $<0.2$ & • \\
\hline Potaneium & 4 & 2.2 & 2.9 & 3.7 & 2.7 & 2.8 & 2.8 & 3.3 \\
\hline sodium & 2.6 & 2.4 & 2.8 & 4.6 & 1 & 0.9 & 0.89 & 0.79 \\
\hline suleate & 6 & $\cdot$ & 5 & • & 2 & $\cdot$ & 2 & • \\
\hline
\end{tabular}

(Consrives) 
Oroundweter Qualdty Data, 1991

\begin{tabular}{|c|c|c|c|c|c|c|c|c|}
\hline \multirow{4}{*}{$\begin{array}{l}\text { Moll No. } \\
\text { Loention } \\
\text { Date sempled }\end{array}$} & \multicolumn{4}{|c|}{$0 x-607$} & \multicolumn{4}{|c|}{$a w-600$} \\
\hline & \multicolumn{4}{|c|}{ conse } & \multicolumn{4}{|c|}{ Genp } \\
\hline & \multicolumn{2}{|c|}{$08 / 06 / 91$} & \multicolumn{2}{|c|}{$10 / 01 / 91$} & \multicolumn{2}{|c|}{$01 / 28 / 91$} & \multicolumn{2}{|c|}{$04 / 29 / 91$} \\
\hline & 202 & DIs & 205 & D28 & 205 & DI8 & 200 & Drs \\
\hline coreves (mo/h) & $\cdot$ & - & $\cdot$ & - & - & - & $\cdot$ & - \\
\hline Nuninum & 0.005 & 0.03 & 0.047 & $<0.02$ & $<0.02$ & 0.027 & $<0.02$ & 0.022 \\
\hline Anelmogr & $<0.08$ & $<0.05$ & $<0.08$ & $<0.03$ & $<0.05$ & $<0.05$ & $<0.08$ & $<0.08$ \\
\hline Areande & $<0.08$ & $<0.05$ & $<0.08$ & $<0.05$ & $<0.05$ & $<0.08$ & $<0.05$ & $<0.05$ \\
\hline Derlum & 0.012 & 0.012 & 0.01 & 0.02 & 0.012 & 0.02 & 0.0053 & 0.0078 \\
\hline Bor7111um & $<0.0003$ & $<0.0003$ & $<0.0003$ & $<0.0003$ & $<0.0003$ & $<0.0003$ & 0.00031 & $<0.0003$ \\
\hline Eoron & $<0.004$ & $<0.004$ & 0.013 & 0.023 & 0.069 & 0.03 & 0.032 & 0.040 \\
\hline Cadilum (MN) & $<0.002$ & $<0.002$ & $<0.002$ & $<0.002$ & $<0.002$ & $<0.002$ & $<0.002$ & $<0.002$ \\
\hline Cactulin & $<0.003$ & $<0.003$ & $<0.003$ & $<0.003$ & $<0.003$ & $<0.003$ & $<0.003$ & $<0.003$ \\
\hline Chrosidum (MS) & $<0.01$ & $<0.01$ & $<0.02$ & $<0.02$ & $<0.01$ & $<0.01$ & $<0.02$ & $<0.02$ \\
\hline Chroaiun & $<0.01$ & $<0.02$ & $<0.02$ & $<0.01$ & $<0.01$ & $<0.02$ & 0.071 & $<0.01$ \\
\hline Cobedt & $<0.005$ & $<0.005$ & $<0.003$ & $<0.005$ & $<0.00 s$ & $<0.005$ & $<0.00 s$ & $<0.00 s$ \\
\hline Copper & $<0.004$ & $<0.004$ & $<0.004$ & $<0.004$ & $<0.004$ & $<0.004$ & $<0.004$ & 0.0061 \\
\hline 2500 & 0.039 & $<0.005$ & 0.025 & $<0.003$ & 0.63 & 0.043 & 1.7 & 0.062 \\
\hline read (MN) & $<0.004$ & $<0.004$ & $<0.004$ & $<0.004$ & $<0.004$ & $<0.004$ & $<0.004$ & $<0.004$ \\
\hline Maroung (CVNA) & $<0.0002$ & $<0.0002$ & $<0.0002$ & $<0.0002$ & $<0.0002$ & $<0.0002$ & $<0.0002$ & $<0.0002$ \\
\hline Molybdonim & $<0.02$ & $<0.01$ & $<0.01$ & $<0.01$ & $<0.01$ & $<0.02$ & $<0.02$ & $<0.01$ \\
\hline nlakel & $<0.02$ & $<0.01$ & $<0.02$ & $<0.01$ & $<0.01$ & $<0.02$ & $<0.01$ & 0.012 \\
\hline solentum & $<0.08$ & $<0.05$ & $<0.05$ & $<0.05$ & $<0.05$ & $<0.05$ & $<0.05$ & $<0.05$ \\
\hline 81100n & 3.6 & 3.6 & $\cdot$ & $\cdot$ & 2.9 & 3.1 & 1 & 2.2 \\
\hline stlver & $<0.006$ & $<0.006$ & $<0.006$ & $<0.006$ & $<0.006$ & $<0.006$ & $<0.006$ & $<0.006$ \\
\hline stront1us & 0.042 & 0.041 & 0.039 & 0.039 & 0.018 & 0.018 & 0.013 & 0.015 \\
\hline rnorium & $<0.2$ & $<0.2$ & $<0.2$ & $<0.2$ & $<0.2$ & $<0.2$ & $<0.2$ & $<0.2$ \\
\hline Oranlum (Fluor) & 0.001 & $<0.001$ & $<0.001$ & $<0.001$ & $<0.001$ & $<0.001$ & $<0.001$ & $<0.001$ \\
\hline Venadium & $<0.005$ & $<0.008$ & $<0.005$ & $<0.00 s$ & $<0.005$ & $<0.005$ & $<0.005$ & $<0.005$ \\
\hline 810e & $<0.002$ & $<0.002$ & 0.0028 & $<0.002$ & 0.0058 & 0.0049 & 0.0088 & 0.024 \\
\hline unon roms $(m / L)$ & $\cdot$ & $\cdot$ & - & $\cdot$ & $\cdot$ & $\cdot$ & - & • \\
\hline AkedLnLty-HCO3 & 229 & $\cdot$ & 227 & $\cdot$ & 267 & • & 222 & • \\
\hline Mradindty-CO3 & $\bullet$ & $\cdot$ & $\bullet$ & $\cdot$ & $<1$ & $\cdot$ & $<1$ & - \\
\hline calolum & 28 & 27 & 29 & 29 & 29 & 29 & 16 & 27 \\
\hline Chloride & $<1$ & $\cdot$ & $<1$ & • & 2 & - & 2 & - \\
\hline Fluoride & $<0.1$ & $\cdot$ & $<0.1$ & $\cdot$ & $<0.1$ & $\cdot$ & $<0.1$ & - \\
\hline Magnaclum & 25 & 25 & 25 & 15 & 18 & 27 & 17 & 18 \\
\hline Manganeese & 0.0099 & $<0.001$ & $<0.002$ & $<0.001$ & 0.047 & 0.042 & 0.26 & 0.25 \\
\hline mitrate-n & $<0.2$ & $\cdot$ & $<0.2$ & $\cdot$ & 0.4 & • & $<0.2$ & \\
\hline potensium & 5.1 & 3.2 & 6.6 & 5.4 & 1.6 & 1.5 & 2.7 & 3.1 \\
\hline sodium & 1.6 & 1.2 & 1.3 & 2.1 & 0.93 & 0.84 & 0.02 & 0.99 \\
\hline sulfate & 2 & $\cdot$ & 1 & $\cdot$ & 2 & • & 2 & \\
\hline
\end{tabular}

(cotrrruroso) 
Oroundwater Qued1ty Deta, 1991

\begin{tabular}{|c|c|c|c|c|c|c|c|c|}
\hline \multirow{4}{*}{$\begin{array}{l}\text { Woll Mo. } \\
\text { Loeation } \\
\text { Date sampled }\end{array}$} & \multicolumn{4}{|c|}{$a w-608$} & \multicolumn{4}{|c|}{$c N-609$} \\
\hline & \multicolumn{4}{|c|}{ CRSP } & \multicolumn{4}{|c|}{ CReP } \\
\hline & \multicolumn{2}{|c|}{$08 / 07 / 91$} & \multicolumn{2}{|c|}{$10 / 12 / 91$} & \multicolumn{2}{|c|}{$01 / 25 / 91$} & \multicolumn{2}{|c|}{$04 / 22 / 91$} \\
\hline & 202 & DIE & 202 & Drs & $x$ & Dr8 & 202 & DIS \\
\hline neness (mg/L) & - & $\cdot$ & - & - & - & - & $\cdot$ & - \\
\hline Nuntoun & $<0.02$ & $<0.02$ & 0.023 & $<0.02$ & 0.033 & 0.028 & 0.043 & 0.038 \\
\hline Antimon & $<0.08$ & $<0.05$ & $<0.05$ & $<0.08$ & $<0.05$ & $<0.05$ & $<0.05$ & $<0.05$ \\
\hline Araenie & $<0.08$ & $<0.05$ & $<0.05$ & $<0.05$ & $<0.05$ & $<0.05$ & $<0.08$ & $<0.05$ \\
\hline Bartun & 0.022 & 0.022 & 0.013 & 0.013 & 0.022 & 0.022 & 0.0052 & 0.0076 \\
\hline Deryd11um & $<0.0003$ & $<0.0003$ & $<0.0003$ & $<0.0003$ & $<0.0003$ & $<0.0003$ & $<0.0003$ & $<0.0003$ \\
\hline Boron & $<0.004$ & $<0.004$ & 0.035 & 0.022 & 0.013 & 0.013 & 0.012 & 0.022 \\
\hline Cadisiun (MS) & $<0.002$ & $<0.002$ & $<0.002$ & $<0.002$ & $<0.002$ & $<0.002$ & $<0.002$ & $<0.002$ \\
\hline Cectuliun & $<0.003$ & $<0.003$ & $<0.003$ & $<0.003$ & $<0.003$ & 0.0035 & $<0.003$ & $<0.003$ \\
\hline Chroenium (MS) & $<0.01$ & $<0.01$ & $<0.01$ & $<0.01$ & $<0.02$ & $<0.02$ & $<0.02$ & $<0.01$ \\
\hline Chroniun & $<0.01$ & $<0.01$ & $<0.01$ & $<0.01$ & $<0.02$ & 0.01 & $<0.02$ & $<0.01$ \\
\hline Cobalt & $<0.005$ & $<0.003$ & $<0.005$ & $<0.00 s$ & $<0.005$ & $<0.005$ & $<0.005$ & $<0.005$ \\
\hline Copper & $<0.004$ & $<0.004$ & $<0.004$ & $<0.004$ & 0.0041 & $<0.004$ & $<0.004$ & $<0.004$ \\
\hline Ison & 0.21 & $<0.005$ & 0.078 & $<0.005$ & 0.021 & 0.0065 & 0.03 & $<0.005$ \\
\hline read (Mns) & $<0.004$ & $<0.004$ & $<0.004$ & $<0.004$ & $<0.004$ & $<0.004$ & $<0.004$ & $<0.004$ \\
\hline marcusy (CVM) & $<0.0002$ & $<0.0002$ & $<0.0002$ & $<0.0002$ & $<0.0002$ & $<0.0002$ & $<0.0002$ & $<0.0002$ \\
\hline nolybdanua & $<0.01$ & $<0.01$ & $<0.02$ & $<0.02$ & $<0.01$ & $<0.01$ & $<0.02$ & 0.011 \\
\hline alckel & $<0.01$ & $<0.02$ & $<0.02$ & $<0.01$ & $<0.01$ & $<0.02$ & $<0.02$ & $<0.02$ \\
\hline Belentum & $<0.05$ & $<0.05$ & $<0.05$ & $<0.08$ & $<0.05$ & $<0.05$ & $<0.05$ & $<0.05$ \\
\hline sL110on & 3.6 & 3.2 & & $\cdot$ & 4.1 & 4 & 3.0 & 3.0 \\
\hline eldrex & $<0.006$ & $<0.006$ & $<0.006$ & $<0.006$ & $<0.006$ & $<0.006$ & $<0.006$ & $<0.006$ \\
\hline steronetus & 0.013 & 0.013 & 0.022 & 0.012 & 0.014 & 0.013 & 0.013 & 0.013 \\
\hline Thorium & $<0.2$ & $<0.2$ & $<0.2$ & $<0.2$ & $<0.2$ & $<0.2$ & $<0.2$ & $<0.2$ \\
\hline Orantum (Pluor) & 0.007 & 0.001 & $<0.002$ & 4000.1 & $<0.001$ & $<0.001$ & $<0.001$ & $<0.001$ \\
\hline Vanadlum & $<0.005$ & $<0.005$ & $<0.003$ & $<0.005$ & $<0.005$ & $<0.005$ & $<0.005$ & $<0.005$ \\
\hline 2100 & $<0.002$ & $<0.002$ & 0.0035 & 0.0059 & 0.011 & 0.0093 & 0.024 & 0.013 \\
\hline MWOR IOns $(\mathrm{mg} / \mathrm{I})$ & • & . & $\cdot$ & . & - & - & . & - \\
\hline NkaLLaLty-HCO3 & 248 &. & ${ }_{243}$ &. & 187 & • & 192 & • \\
\hline Alxaldaler-CO3 & $<2$ &. & $<1$ & • & $<1$ & $\cdot$ & $<1$ & • \\
\hline Calcium & 30 & 30 & 30 & 30 & 34 & 34 & 35 & 34 \\
\hline Chlorida & 1 & $\cdot$ & 1.3 & $\cdot$ & 2 & • & 2 & • \\
\hline Iluoride & $<0.1$ & $\cdot$ & $<0.1$ & $\cdot$ & $<0.1$ & - & $<0.1$ & • \\
\hline Magnes Lum & 10 & 20 & 18 & 18 & 21 & 22 & 22 & 21 \\
\hline Mangenese & 0.0016 & $<0.002$ & 0.0024 & 0.0016 & $<0.001$ & $<0.001$ & $<0.001$ & $<0.002$ \\
\hline mitrate-N & 0.33 & $\cdot$ & 0.3 & $\cdot$ & 0.9 & $\bullet$ & 0.9 & $\bullet$ \\
\hline Potaseium & 0.86 & 0.05 & 2.6 & 2.2 & 1.3 & 2.1 & 0.8 & 0.85 \\
\hline cod1um & 0.51 & 0.52 & 0.75 & 0.94 & 0.67 & 0,59 & 0.66 & 0.65 \\
\hline sulsate & 2 & $\cdot$ & 2.4 & $\cdot$ & 2 & • & 2 & $\bullet$ \\
\hline
\end{tabular}

(conserword) 
A-155

Groundwater Quadlty Data, 1991

\begin{tabular}{|c|c|c|c|c|c|c|c|c|}
\hline \multirow{4}{*}{$\begin{array}{l}\text { Woll Ho. } \\
\text { Location } \\
\text { Date sampled }\end{array}$} & \multicolumn{4}{|c|}{$O N-609$} & \multicolumn{4}{|c|}{$O N-610$} \\
\hline & \multicolumn{4}{|c|}{ Crap } & \multicolumn{4}{|c|}{ casp } \\
\hline & \multicolumn{2}{|c|}{$08 / 09 / 91$} & \multicolumn{2}{|c|}{$10 / 14 / 91$} & \multicolumn{2}{|c|}{$01 / 30 / 91$} & \multicolumn{2}{|c|}{$05 / 01 / 91$} \\
\hline & $\operatorname{son}$ & DIE & 200 & DI8 & 202 & DIs & 202 & DI8 \\
\hline mernes $(n g / L)$ & - & - & - & - & - & $\cdot$ & - & - \\
\hline Aluminim & $<0.02$ & 0.024 & $<0.02$ & $<0.02$ & 0.093 & $<0.02$ & 0.032 & $<0.02$ \\
\hline Antinony & $<0.05$ & $<0.05$ & $<0.05$ & $<0.05$ & $<0.08$ & $<0.05$ & $<0.05$ & $<0.05$ \\
\hline Areonic & $<0.05$ & $<0.05$ & $<0.05$ & $<0.03$ & $<0.03$ & $<0.03$ & $<0.03$ & $<0.03$ \\
\hline Darium & 0.012 & 0.011 & 0.012 & 0.022 & 0.079 & 0.074 & 0.12 & 0.21 \\
\hline Daryl11um & $<0.0003$ & $<0.0003$ & $<0.0003$ & $<0.0003$ & $<0.0003$ & $<0.0003$ & $<0.0003$ & $<0.0003$ \\
\hline Doron & $<0.004$ & $<0.004$ & 0.03 & $<0.004$ & $<0.004$ & $<0.004$ & $<0.004$ & $<0.004$ \\
\hline Cactusiun (MS) & $<0.002$ & $<0.002$ & $<0.002$ & $<0.002$ & 0.0022 & $<0.002$ & $<0.002$ & $<0.002$ \\
\hline Cadminim & $<0.003$ & $<0.003$ & $<0.003$ & $<0.003$ & $<0.003$ & $<0.003$ & $<0.003$ & $<0.003$ \\
\hline Chromiun (MS) & $<0.01$ & $<0.01$ & $<0.01$ & $<0.01$ & $<0.02$ & $<0.01$ & $<0.01$ & $<0.01$ \\
\hline Chrondun & $<0.01$ & $<0.02$ & $<0.01$ & $<0.01$ & $<0.01$ & $<0.01$ & $<0.02$ & $<0.01$ \\
\hline Cobalt & $<0.008$ & $<0.00 s$ & $<0.005$ & $<0.005$ & $<0.005$ & $<0.005$ & $<0.005$ & $<0.005$ \\
\hline copper & $<0.004$ & $<0.004$ & $<0.004$ & 0.0042 & $<0.004$ & $<0.004$ & $<0.004$ & $<0.004$ \\
\hline Ison & 0.012 & $<0.00 s$ & 0.0005 & $<0.005$ & 0.19 & $<0.005$ & 0.04 & 0.006 \\
\hline reand (NM) & $<0.004$ & $<0.004$ & $<0.004$ & $<0.004$ & $<0.004$ & $<0.004$ & $<0.004$ & $<0.004$ \\
\hline mereury (CVM) & $<0.0002$ & $<0.0002$ & $<0.0002$ & $<0.0002$ & $<0.0002$ & $<0.0002$ & $<0.0002$ & $<0.0002$ \\
\hline Nolfbedenum & $<0.01$ & $<0.02$ & $<0.01$ & $<0.02$ & $<0.01$ & $<0.02$ & $<0.02$ & $<0.02$ \\
\hline mlokel & $<0.01$ & $<0.02$ & $<0.01$ & $<0.01$ & $<0.02$ & $<0.01$ & 0.028 & $<0.01$ \\
\hline selentun & $<0.08$ & $<0.05$ & $<0.05$ & $<0.05$ & $<0.03$ & $<0.05$ & $<0.05$ & $<0.05$ \\
\hline 811100n & 1.2 & 1.7 & $\cdot$ & $\cdot$ & 4 & 3.8 & 4.1 & 4.2 \\
\hline 811ver & $<0.006$ & $<0.006$ & $<0.006$ & $<0.006$ & $<0.006$ & $<0.006$ & $<0.006$ & $<0.006$ \\
\hline Itront1um & 0.024 & 0.013 & 0.024 & 0.013 & 0.026 & 0.015 & 0.019 & 0.018 \\
\hline Thoriun & $<0.2$ & $<0.2$ & $<0.2$ & $<0.2$ & $<0.2$ & $<0.2$ & $<i .2$ & $<0.2$ \\
\hline Orandum (rluor) & 0.001 & $<0.001$ & $<0.001$ & $<0.001$ & $<0.001$ & $<0.001$ & $<0.001$ & $<0.001$ \\
\hline Vanadlum & $<0.005$ & $<0.005$ & $<0.005$ & $<0.005$ & $<0.005$ & $<0.005$ & $<0.00 s$ & $<0.005$ \\
\hline ILne & 0.016 & 0.0079 & 0.022 & 0.01 & 0.0036 & $<0.002$ & $<0.002$ & $<0.002$ \\
\hline MUOR IONS $(\mathrm{gg} / \mathrm{L})$ & $\cdot$ & $\cdot$ & $\cdot$ & • & - & - & - & - \\
\hline Akaldndty-HCO3 & 177 &. & 204 & $\cdot$ & 100 & . & 290 & $\bullet$ \\
\hline 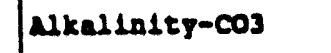 & $<1$ & $\cdot$ & $<1$ & $\cdot$ & $<1$ & • & $<2$ & $\cdot$ \\
\hline Cascium & 37 & 30| & 39 & 39 & 35 & 34 & 40 & 39 \\
\hline Chlorido & 2.4 & $\cdot$ & 1 & • & 2 & $\cdot$ & 2 & - \\
\hline Fluoride & $<0.1$ & $\cdot$ & $<0.1$ & $\cdot$ & $<0.1$ & $\cdot$ & $<0.1$ & • \\
\hline Magnesium & 22 & 22 & 23 & 23 & 22 & 22 & 24 & 24 \\
\hline Manganease & $<0.001$ & $<0.001$ & 0.0027 & $<0.002$ & 0.021 & 0.0062 & 0.0026 & 0.0015 \\
\hline mitratem & 2 & $\bullet$ & 0.93 & $\bullet$ & 0.6 & & 0.5 & \\
\hline Potene 1um & 1 & 1.1 & 1.1 & 2.5 & $<0.6$ & $<0.6$ & $<0.6$ & $<0.6$ \\
\hline Sodium & 0.66 & 0.64 & 0.06 & 0.09 & 0.75 & 0.64 & 0.52 & 0.54 \\
\hline sulfate & 2.3 & $\cdot$ & 2 & - & 1 & - & $<1$ & • \\
\hline
\end{tabular}

(COnysuroso) 
Oroundwater Quel1ty Date, 1991

\begin{tabular}{|c|c|c|c|c|c|c|c|c|}
\hline \multirow{4}{*}{$\begin{array}{l}\text { Moll Ho. } \\
\text { Loention } \\
\text { Date sempled }\end{array}$} & \multicolumn{4}{|c|}{$0 w-610$} & \multicolumn{4}{|c|}{$a w-611$} \\
\hline & \multicolumn{4}{|c|}{ Cnsp } & \multicolumn{4}{|c|}{ Cnep } \\
\hline & \multicolumn{2}{|c|}{$08 / 06 / 91$} & \multicolumn{2}{|c|}{$10 / 10 / 91$} & \multicolumn{2}{|c|}{$02 / 31 / 91$} & \multicolumn{2}{|c|}{$05 / 02 / 91$} \\
\hline & 202 & DI8 & 200 & D28 & 201 & DI8 & 201 & DI8 \\
\hline corsus (mg/L) & & $\cdot$ & & & - & $\cdot$ & $\cdot$ & - \\
\hline Aumlnum & 0.02 & $<0.02$ & 0.027 & $<0.02$ & 0.27 & $<0.02$ & 0.12 & $0.02 \dot{2}$ \\
\hline Antimony & $<0.05$ & $<0.05$ & $<0.05$ & $<0.05$ & $<0.05$ & $<0.05$ & $<0.08$ & $<0.03$ \\
\hline areonic & $<0.05$ & $<0.05$ & $<0.05$ & $<0.03$ & $<0.05$ & 0.061 & $<0.05$ & $<0.05$ \\
\hline Darium & 0.082 & 0.081 & 0.066 & 0.07 & 0.026 & 0.024 & 0.02 & 0.022 \\
\hline Deryl11um & $<0.0003$ & $<0.0003$ & $<0.0003$ & $<0.0003$ & $<0.0003$ & $<0.0003$ & $<0.0003$ & $<0.0003$ \\
\hline Doron & $<0.004$ & $<0.004$ & 0.033 & 0.017 & $<0.004$ & $<0.004$ & 0.04 & $<0.004$ \\
\hline Cadmiun (MS) & $<0.002$ & $<0.002$ & $<0.002$ & $<0.002$ & $<0.002$ & $<0.002$ & $<0.002$ & $<0.002$ \\
\hline Cecturium & $<0.003$ & $<0.003$ & $<0.003$ & $<0.003$ & $<0.003$ & 0.0045 & $<0.003$ & $<0.003$ \\
\hline Chromiun (MS) & $<0.01$ & $<0.01$ & $<0.01$ & $<0.01$ & $<0.02$ & $<0.02$ & $<0.02$ & $<0.02$ \\
\hline Chromive & $<0.02$ & $<0.01$ & $<0.01$ & $<0.02$ & 0.024 & 0.024 & $<0.01$ & $<0.01$ \\
\hline Cobalt & $<0.005$ & $<0.003$ & $<0.005$ & $<0.005$ & $<0.005$ & $<0.005$ & $<0.005$ & $<0.005$ \\
\hline copper & $<0.004$ & $<0.004$ & $<0.004$ & $<0.004$ & $<0.004$ & $<0.004$ & $<0.004$ & $<0.004$ \\
\hline Iron & 0.066 & $<0.005$ & 0.012 & $<0.005$ & 2.4 & 0.02 & 0.27 & $<0.005$ \\
\hline road (MS) & $<0.004$ & $<0.004$ & $<0.004$ & $<0.004$ & 0.0074 & $<0.004$ & $<0.004$ & $<0.004$ \\
\hline mareury (CTM) & $<0.0002$ & $<0.0002$ & $<0.0002$ & $<0.0002$ & $<0.0002$ & $<0.0002$ & $<0.0002$ & $<0.0002$ \\
\hline Nolybdanum & $<0.02$ & $<0.01$ & $<0.01$ & $<0.02$ & $<0.01$ & $<0.01$ & $<0.02$ & $<0.02$ \\
\hline ulokel & $<0.01$ & $<0.02$ & $<0.02$ & $<0.01$ & $<0.02$ & 0.021 & 0.012 & $<0.02$ \\
\hline colentum & $<0.05$ & $<0.05$ & $<0.05$ & $<0.05$ & $<0.05$ & $<0.05$ & $<0.05$ & $<0.05$ \\
\hline 811100n & 3.0 & 3.8 & & & 4.4 & 4.2 & 4.3 & 4.4 \\
\hline 81var & $<0.006$ & $<0.006$ & $<0.006$ & $<0.006$ & $<0.006$ & $<0.006$ & $<0.006$ & $<0.006$ \\
\hline otrontiu & 0.023 & 0.025 & 0.027 & 0.028 & 0.022 & 0.026 & 0.022 & 0.022 \\
\hline Itorium & $<0.2$ & $<0.2$ & $<0.2$ & $<0.2$ & $<0.2$ & $<0.2$ & $<0.2$ & $<0.2$ \\
\hline Orantum (rluor) & 0.002 & 0.002 & $<0.001$ & $<0.001$ & 0.001 & 0.001 & $<0.002$ & 0.001 \\
\hline Vanadium & $<0.005$ & $<0.005$ & $<0.005$ & $<0.005$ & $<0.005$ & $<0.005$ & $<0.005$ & $<0.005$ \\
\hline elne & $<0.002$ & $<0.002$ & 0.0027 & 0.0056 & 0.023 & $<0.001$ & $<0.002$ & $<0.002$ \\
\hline MWOR IOAs $(\mathrm{mg} / \mathrm{L})$ & - & $\cdot 1$ &. &. & $\cdot$ & . & - & $\bullet$ \\
\hline NKaldolt5-UCO3 & $\begin{array}{r}\bullet \\
170\end{array}$ & .1 & 287 & $\cdot$ & 246 & $\cdot$. & $\begin{array}{r}\bullet \\
253\end{array}$ & • \\
\hline$\mu 1 k n 1 \operatorname{Ln} 1 E y-\infty 03$ & $<1$ &. & $<1$ & - & $<2$ &. & $<1$ & - \\
\hline Calcium & 36 & 36 & 37 & 39 & 63 & 56 & 51 & 49 \\
\hline Chlorldo & 2 & . & 2 & . & 1 & $\cdot$ & 1 & • \\
\hline Fluoride & $<0.2$ & $\cdot$ & $<0.1$ & $\cdot$ & $<0.1$ & $\cdot$ & $<0.1$ & • \\
\hline Magnoesium & 22 & 21 & 22 & 23 & 33 & 32 & 32 & 32 \\
\hline Manganeae & 0.0045 & 0.0035 & 0.005 & 0.0046 & 0.027 & $<0.001$ & 0.0025 & $<0.001$ \\
\hline Mitratom & 0.5 & & $<0.2$ & $\cdot$ & & • & 3 & • \\
\hline potasedum & $<0.6$ & $<0.6$ & $<0.6$ & $<0.6$ & 0.69 & 0.61 & 1 & 2.4 \\
\hline sodtum & 0.78 & 0.79 & 0.77 & 0.68 & $<0.02$ & $<0.02$ & 1.2 & 1.4 \\
\hline suleate & $<1$ & $\bullet$ & $<1$ & • & 2 & $\cdot 1$ & 1 & - \\
\hline
\end{tabular}




\begin{tabular}{|c|c|c|c|c|c|c|c|c|}
\hline \multirow{3}{*}{$\begin{array}{l}\text { Woll Ho. } \\
\text { rocation } \\
\text { - } \\
\text { Dece sampled }\end{array}$} & \multicolumn{4}{|c|}{ GN-611 } & \multicolumn{4}{|c|}{$G N-612$} \\
\hline & \multicolumn{4}{|c|}{ CRSP } & \multicolumn{4}{|c|}{ CRBP } \\
\hline & \multicolumn{2}{|c|}{$08 / 08 / 91$} & \multicolumn{2}{|c|}{$10 / 13 / 91$} & \multicolumn{2}{|c|}{$02 / 07 / 91$} & \multicolumn{2}{|c|}{$05 / 08 / 91$} \\
\hline Iapres (mg/x) & $\cdot$ & - & - & - & $\bullet$ & $\bullet$ & $\bullet$ & $\cdot$ \\
\hline Mumbnom & 0.033 & $<0.02$ & 0.03 & $<0.02$ & 0.068 & 0.072 & $<0.02$ & $<0.02$ \\
\hline nedmony & $<0.05$ & $<0.05$ & $<0.05$ & $<0.05$ & $<0.05$ & $<0.05$ & $<0.05$ & $<0.05$ \\
\hline Areonic & $<0.05$ & $<0.05$ & $<0.05$ & $<0.05$ & $<0.05$ & 0.066 & $<0.05$ & $<0.05$ \\
\hline Derlum & 0.026 & 0.026 & 0.015 & 0.017 & 0.018 & 0.017 & 0.024 & 0.024 \\
\hline Deryld1um & $<0.0003$ & $<0.0003$ & $<0.0003$ & $<0.0003$ & $<0.0003$ & $<0.0003$ & $<0.0003$ & $<0.0003$ \\
\hline Doron & $<0.004$ & $<0.004$ & 0.0072 & 0.008 & 0.23 & 0.049 & 0.15 & 0.13 \\
\hline Cactulum (MS) & $<0.002$ & $<0.002$ & $<0.002$ & $<0.002$ & $<0.002$ & $<0.002$ & $<0.002$ & $<0.002$ \\
\hline Cadinitum & $<0.003$ & $<0.003$ & $<0.003$ & $<0.003$ & $<0.003$ & $<0.003$ & $<0.003$ & $<0.003$ \\
\hline Chromium (MS) & $<0.01$ & $<0.01$ &.$<0.01$ & $<0.02$ & $<0.02$ & $<0.01$ & $<0.02$ & $<0.01$ \\
\hline Curcondum ; & $<0.01$ & $<0.01$ & $<0.01$ & $<0.01$ & $<0.01$ & $<0.01$ & $<0.01$ & $<0.01$ \\
\hline cobalt & $<0.005$ & $<0.005$ & $<0.005$ & $<0.005$ & $<0.005$ & $<0.005$ & $<0.005$ & $<0.005$ \\
\hline copper & $<0.004$ & $<0.004$ & $<0.004$ & 0.0046 & 0.0091 & $<0.004$ & 0.0087 & $<0.004$ \\
\hline Iron & 0.044 & $<0.005$ & 0.046 & $<0.005$ & 0.16 & $<0.005$ & 0.33 & $<0.005$ \\
\hline Ind (MS) & $<0.004$ & $<0.004$ & $<0.004$ & $<0.004$ & $<0.004$ & $<0.004$ & $<0.004$ & $<0.004$ \\
\hline nercury (con) & $<0.0002$ & $<0.0002$ & $<0.0002$ & $<0.0002$ & $<0.0002$ & $<0.0002$ & $<0.0002$ & $<0.0002$ \\
\hline molybdanm & $<0.01$ & 60.02 & $<0.01$ & $<0.01$ & $<0.02$ & $<0.02$ & $<0.01$ & $<0.01$ \\
\hline alckel & $<0.01$ & $<0.02$ & $<0.01$ & $<0.02$ & $<0.01$ & 0.025 & $<0.02$ & $<0.01$ \\
\hline Colentum & $<0.05$ & $<0.05$ & $<0.05$ & $<0.05$ & $<0.05$ & $<0.05$ & $<0.05$ & $<0.05$ \\
\hline 811100n & 1.4 & 1.5 & & & 3.8 & 1.2 & 3.8 & 3.6 \\
\hline sLrar & $<0.006$ & $<0.006$ & $<0.006$ & $<0.006$ & $<0.006$ & $<0.006$ & $<0.006$ & $<0.006$ \\
\hline etront1un & 0.016 & 0.016 & 0.025 & 0.026 & 0.025 & 0.014 & 0.015 & 0.025 \\
\hline Thordum & $<0.2$ & $<0.2$ & $<0.2$ & $<0.2$ & $<0.2$ & $<0.2$ & $<0.2$ & $<0.2$ \\
\hline Orantum (Fluor) & 0.001 & 0.002 & $<0.002$ & 0.002 & 0.001 & 0.001 & 0.001 & 50.001 \\
\hline Venadlum & $<0.005$ & $<0.005$ & $<0.005$ & $<0.005$ & $<0.005$ & $<0.005$ & $<0.005$ & $<0.005$ \\
\hline elne & $<0.002$ & $<0.002$ & 0.02 & 0.0092 & 0.023 & 0.0053 & $<0.002$ & $<0.002$ \\
\hline MTOR IOMS $(\mathrm{mg} / \mathrm{L})$ &. & $\cdot$ & - & - & $\bullet$ & - & - & - \\
\hline MkadLn1ty-1003 & 232 & - & 231 & • & 205 & $\bullet$ & 203 & - \\
\hline Alkaldn1ty-CO3 & $<1$ & $\cdot$ & $<2$ & $\cdot$ & $<1$ & $\cdot$ & $<2$ & $\bullet$ \\
\hline Culesum & 52 & 50 & 51 & 51 & 37 & 37 & 33 & 33 \\
\hline Chlorlde & & $\bullet$ & 4 & $\cdot$ & 2 & $\bullet$ & 2 & - \\
\hline IrvorLde & $<0.2$ & $\bullet$ & $<0.2$ & $\bullet$ & $<0.2$ & $\bullet$ & $<0.1$ & - \\
\hline Mngnesium & 28 & 28 & 30 & 30 & 25 & 25 & 24 & 24 \\
\hline Mngeneee & $<0.001$ & $<0.002$ & $<0.001$ & $<0.001$ & 0.0066 & 0.0042 & 0.026 & 0.012 \\
\hline alterateori & 3 & $\bullet$ & 2.12 & $\cdot$ & 0.3 & & 0.3 & \\
\hline Potne1um & 0.83 & 0.69 & 0.08 & 1.1 & 1.3 & 0.84 & & $<0.6$ \\
\hline Codtum & 2 & 2.6 & 2.5 & $2 \cdot 0$ & 0.05 & 0.0 & 0.51 & 0.5 \\
\hline suleate & 3 & & & & 3 & & 2 & - \\
\hline
\end{tabular}

(cocrszoso) 
Groundwater Qual1ty Data, 2991

\begin{tabular}{|c|c|c|c|c|c|c|c|c|}
\hline \multirow{4}{*}{$\begin{array}{l}\text { Mell No. } \\
\text { rocation } \\
\text { - } \\
\text { Date sampled }\end{array}$} & \multicolumn{4}{|c|}{$G N-612$} & \multicolumn{4}{|c|}{ GN-709 } \\
\hline & \multicolumn{4}{|c|}{ CRsP } & \multicolumn{4}{|c|}{ III } \\
\hline & \multicolumn{2}{|c|}{$08 / 12 / 91$} & \multicolumn{2}{|c|}{$10 / 17 / 91$} & \multicolumn{2}{|c|}{$06 / 19 / 91$} & \multicolumn{2}{|c|}{$09 / 11 / 91$} \\
\hline & $20 x$ & DIS & $\operatorname{xox}$ & DIS & $20 x$ & DIS & 202 & DIs \\
\hline Aress (mg/L) & - & - & - & - & - & - & $\bullet$ & - \\
\hline Number & $<0.02$ & $<0.02$ & $<0.02$ & $<0.02$ & 0.022 & 0.02 & $<0.02$ & 0.028 \\
\hline Antimony & $<0.05$ & $<0.05$ & $<0.05$ & $<0.05$ & $<0.05$ & $<0.05$ & $<0.05$ & $<0.05$ \\
\hline sroonte & $<0.05$ & $<0.05$ & $<0.05$ & $<0.05$ & $<0.05$ & $<0.05$ & $<0.05$ & $<0.05$ \\
\hline Berium & 0.011 & 0.012 & 0.014 & 0.024 & 0.1 & 0.21 & 0.033 & 0.2 \\
\hline Deryl11um & $<0.0003$ & $<0.0003$ & $<0.0003$ & $<0.0003$ & $<0.0003$ & $<0.0003$ & $<0.0003$ & $<0.0003$ \\
\hline Doron & 0.28 & 0.16 & 0.26 & 0.26 & 0.0082 & 0.0089 & 0.0085 & 0.034 \\
\hline Coctinium (NSS) & $<0.002$ & $<0.002$ & $<0.002$ & $<0.002$ & $<0.002$ & $<0.002$ & $<0.002$ & $<0.002$ \\
\hline Coctudum & $<0.003$ & $<0.003$ & $<0.003$ & $<0.003$ & $<0.003$ & $<0.003$ & $<0.003$ & $<0.003$ \\
\hline Chromiun (MS) & $<0.01$ & $<0.02$ & $<0.01$ & $<0.02$ & $<0.01$ & $<0.02$ & $<0.01$ & $<0.01$ \\
\hline Chromiun & $<0.02$ & $<0.01$ & $<0.02$ & $<0.01$ & $<0.01$ & $<0.01$ & $<0.01$ & $<0.02$ \\
\hline cobalt & $<0.005$ & $<0.005$ & $<0.005$ & $<0.005$ & $<0.005$ & $<0.005$ & $<0.005$ & $<0.005$ \\
\hline copper & 0.023 & 0.0092 & $<0.004$ & $<0.004$ & 0.0049 & $<0.004$ & $<0.004$ & $<0.004$ \\
\hline $\operatorname{Iron}$ & 0.25 & 0.012 & 0.091 & $<0.005$ & 0.019 & $<0.005$ & 0.12 & $<0.005$ \\
\hline rond (MS) & $<0.004$ & $<0.004$ & $<0.004$ & $<0.004$ & $<0.004$ & $<0.004$ & $<0.004$ & $<0.004$ \\
\hline nereusy (Codu) & $<0.0002$ & $<0.0002$ & $<0.0002$ & $<0.0002$ & 0.00022 & $<0.0002$ & $<0.0002$ & $<0.0002$ \\
\hline Molybdonum & $<0.02$ & $<0.02$ & $<0.02$ & $<0.02$ & $<0.01$ & $<0.01$ & $<0.01$ & $<0.01$ \\
\hline alekel & $<0.01$ & $<0.02$ & $<0.02$ & $<0.01$ & $<0.02$ & $<0.01$ & $<0.01$ & $<0.01$ \\
\hline endonder & 40.05 & $<0.05$ & 20.05 & $<0.05$ & $<0.05$ & $<0.05$ & $<0.05$ & $<0.05$ \\
\hline BLdeen & 3.9 & & & & 3.7 & 3.6 & $\cdot$ & \\
\hline 812var & 80.006 & $<0.006$ & $<0.006$ & $<0.006$ & $<0.006$ & $<0.006$ & $<0.006$ & $<0.006$ \\
\hline Berontium & 0.015 & 0.015 & 0.025 & 0.015 & 0.052 & 0.071 & 0.025 & 0.049 \\
\hline snortum & $<0.2$ & $<0.2$ & $<0.2$ & $<0.2$ & $<0.2$ & $<0.2$ & $<0.2$ & $<0.2$ \\
\hline oranium (rluor) & 0.002 & 0.001 & 0.001 & $<0.001$ & 0.002 & 0.002 & 0.002 & 0.002 \\
\hline Venedium & $<0.005$ & $<0.005$ & $<0.005$ & $<0.005$ & $<0.005$ & $<0.005$ & $<0.005$ & $<0.005$ \\
\hline elne & 0.0078 & 0.0032 & 0.022 & 0.0038 & 0.004 & $<0.002$ & 0.0066 & 0.0049 \\
\hline unOR IOAs $(m, / x)$ & $\cdot$ & & $\cdot$ & - & - & - & $\bullet$ & $\bullet$ \\
\hline Altuldindty-1003 & 298 & - & 206 & - & 108 & - & 166 & - \\
\hline Nkaldolt $y-C 03$ & $<1$ & $\bullet$ & $<2$ & $\cdot$ & 4 & • & $<1$ & $\cdot$ \\
\hline Caletum & 39 & 39 & 39 & 39 & 18 & 28 & 3.9 & 12 \\
\hline Chlortde & 2 & $\bullet$ & 2 & - & 2 & $\bullet$ & 2 & - \\
\hline Fuorta & $<0.1$ & $\bullet$ & 20.2 & $\bullet$ & 0.1 & $\bullet$ & 40.2 & $\bullet$ \\
\hline Mgnosdum & 26 & 26 & 26 & 27 & 26 & 16 & 6.1 & 19 \\
\hline Mnganoe & 0.0052 & 0.0034 & 0.0039 & 0.0026 & $<0.002$ & 0.001 & $<0.001$ & $<0.001$ \\
\hline n1treteon & 0.25 & $\because$ & 0.28 & & $<0.2$ & - & 40.2 & 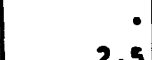 \\
\hline $\begin{array}{l}\text { Potensim } \\
\text { sodim }\end{array}$ & $\begin{array}{l}0.64 \\
0.42\end{array}$ & $\begin{array}{l}0.66 \\
0.42\end{array}$ & $\begin{array}{l}0.97 \\
0.67\end{array}$ & $\begin{array}{l}0.69 \\
0.78\end{array}$ & $\begin{array}{l}3.3 \\
3.2\end{array}$ & $\begin{array}{l}3.3 \\
3.3\end{array}$ & $\begin{array}{l}0.70 \\
0.65\end{array}$ & $\begin{array}{l}2.3 \\
2.4\end{array}$ \\
\hline $\begin{array}{l}\text { sodium } \\
\text { sulenes }\end{array}$ & 2 & $\bullet$ & 3 & • & 7 & - & & • \\
\hline
\end{tabular}

(COArrHUzD) 
Groundwater Qual1ty Data, 1991

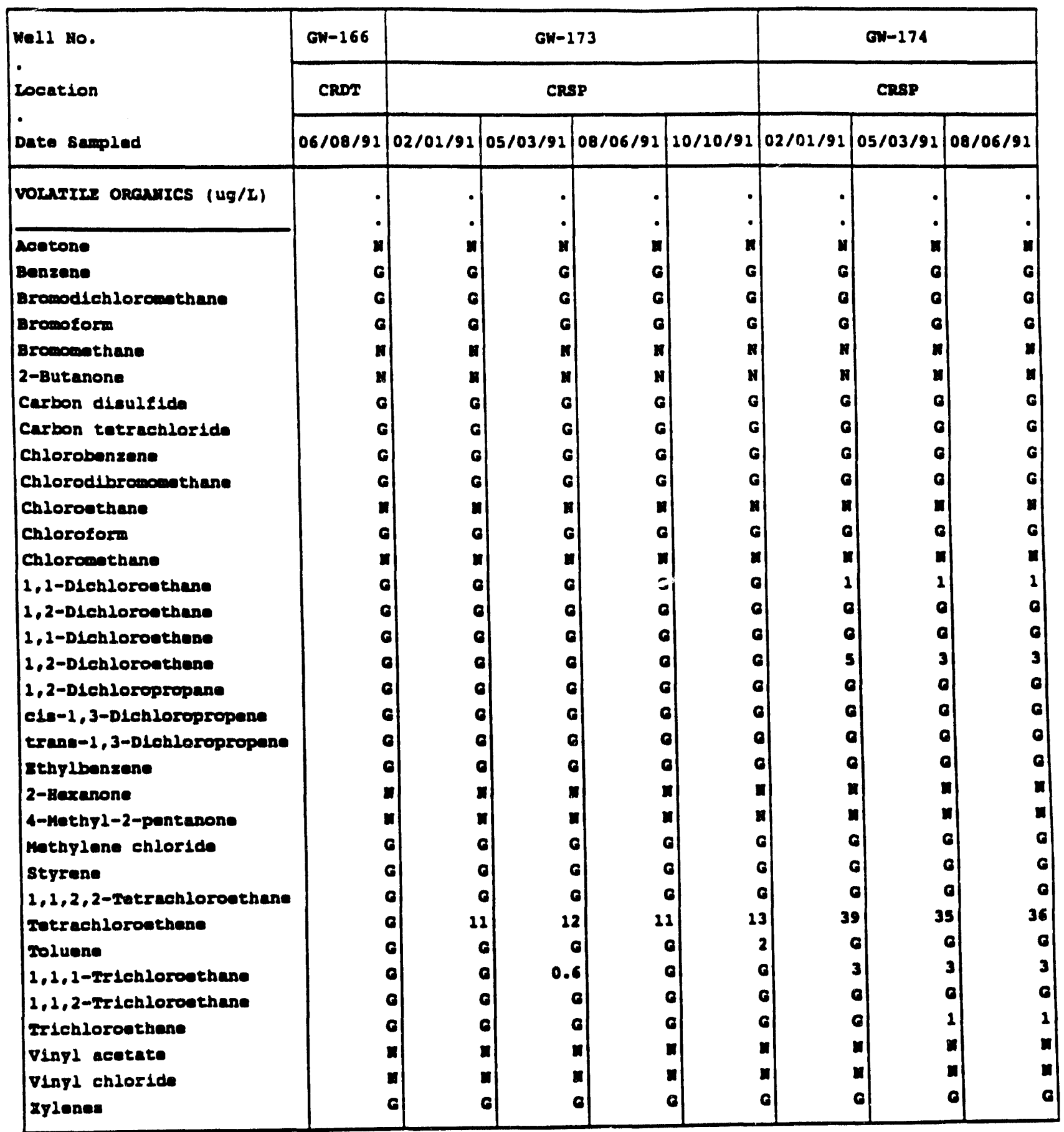

(COArritued) 
Groundwater Qual1ty Data, 1991

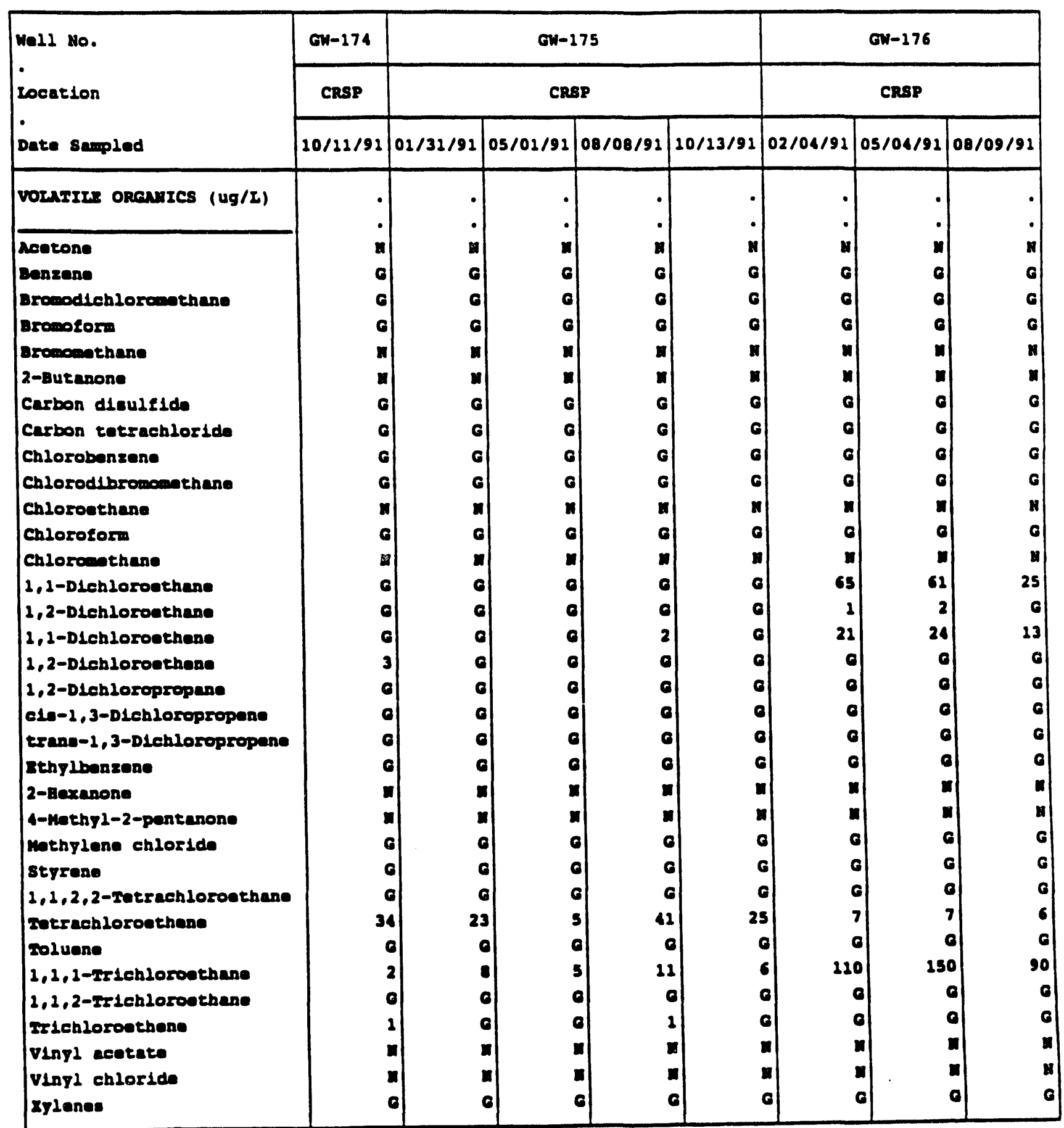

(COMrTivos) 
Groundwater Ounlty Data, 1991

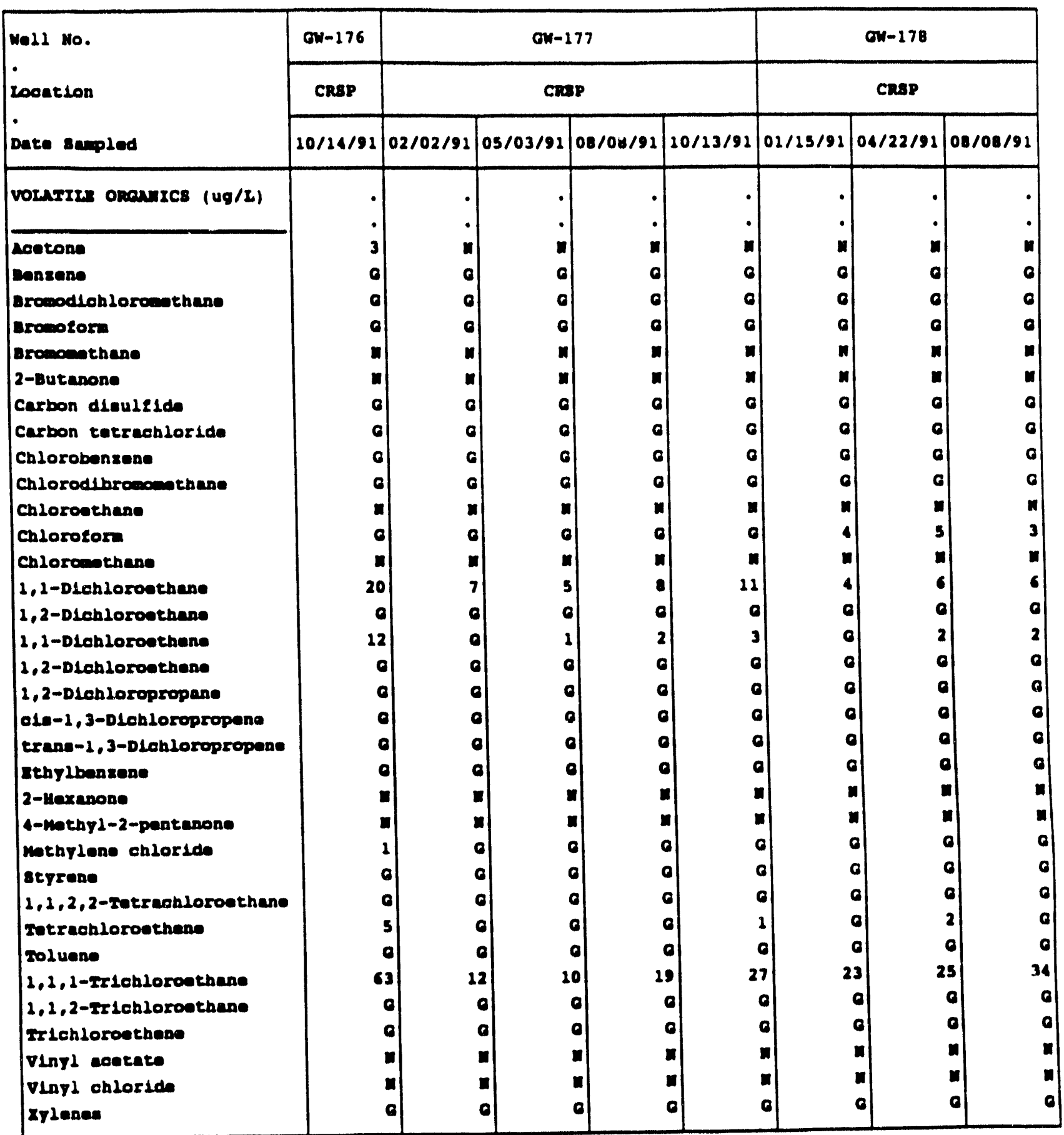

(COArTHORD) 
Groundwater Qual1ty Data, 1991

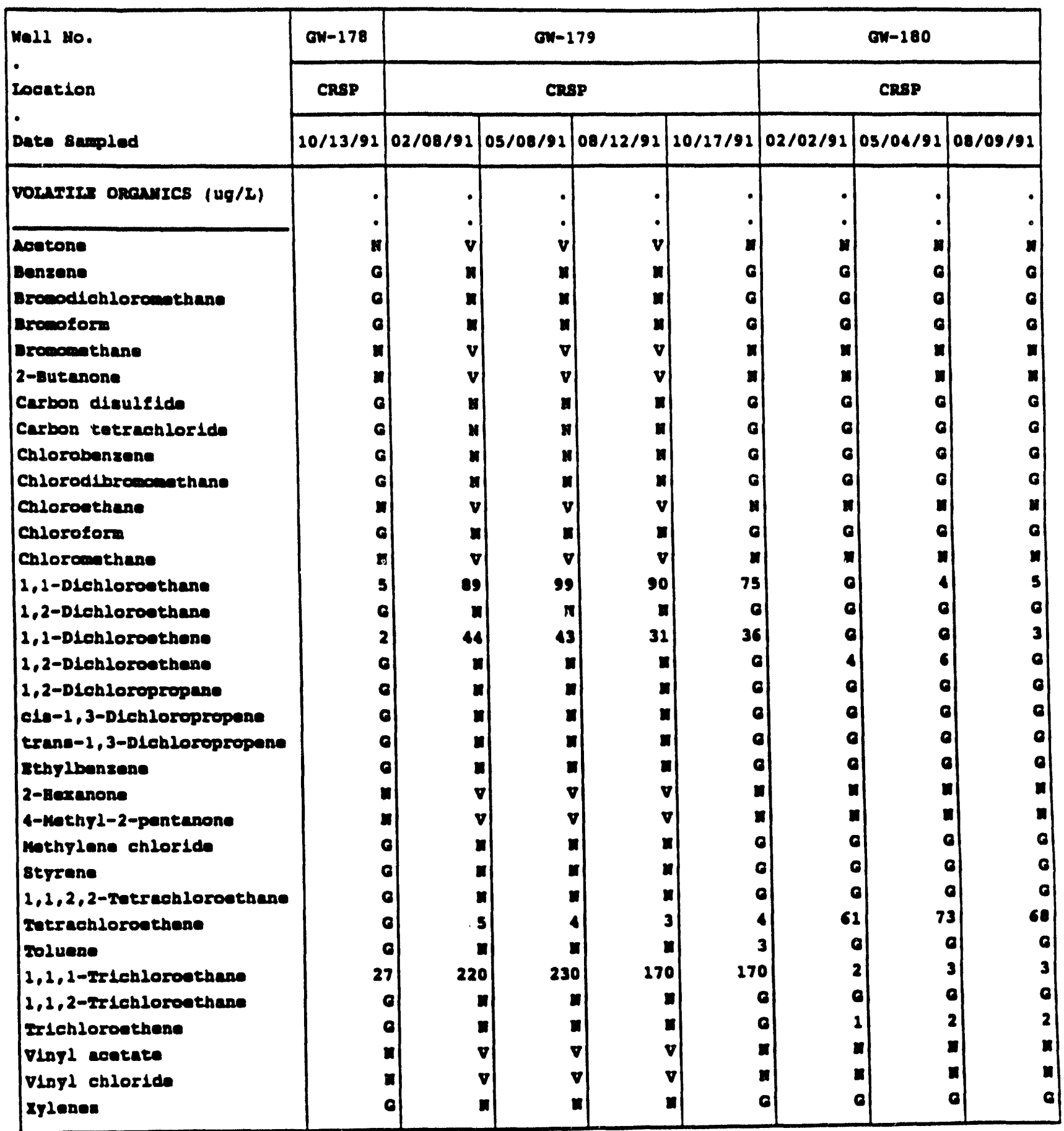

(COArrasos) 
Groundwater Quelity Deta, 1991

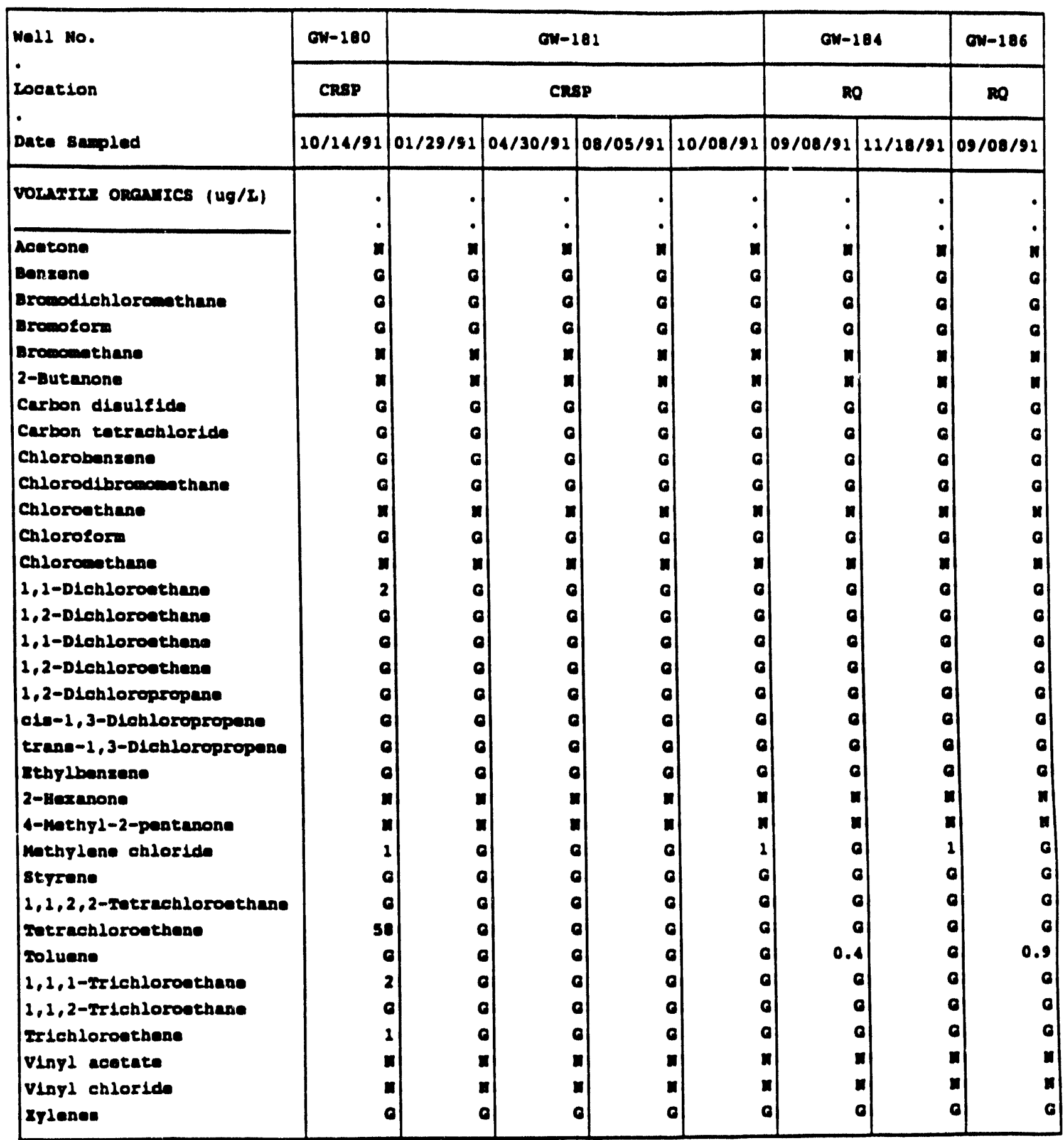

(COATIMULD) 
Oroundwater Quadlty Data, 1992

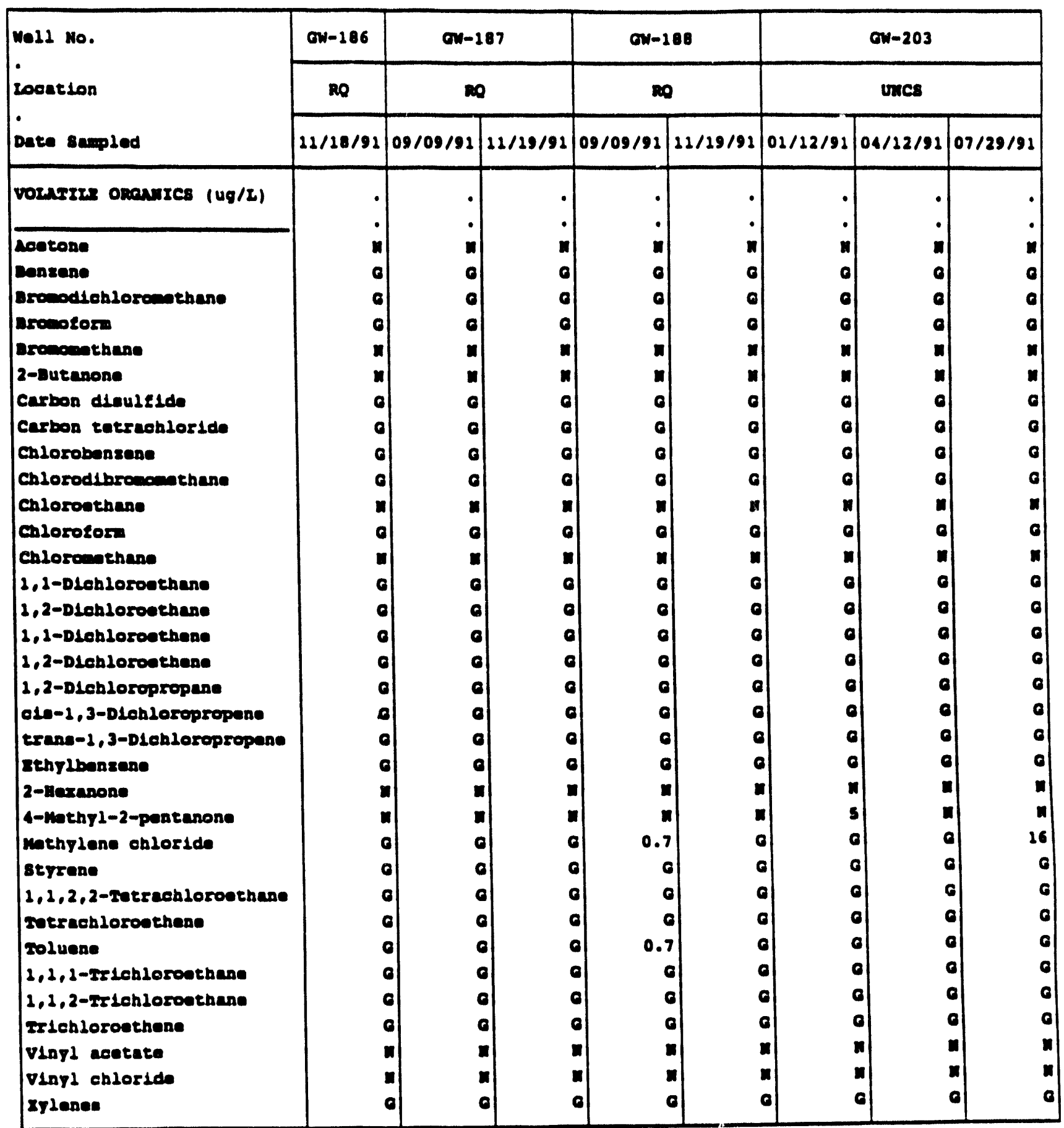

(CONrIRURD) 
Groundwater Quadtey Dete, 1991

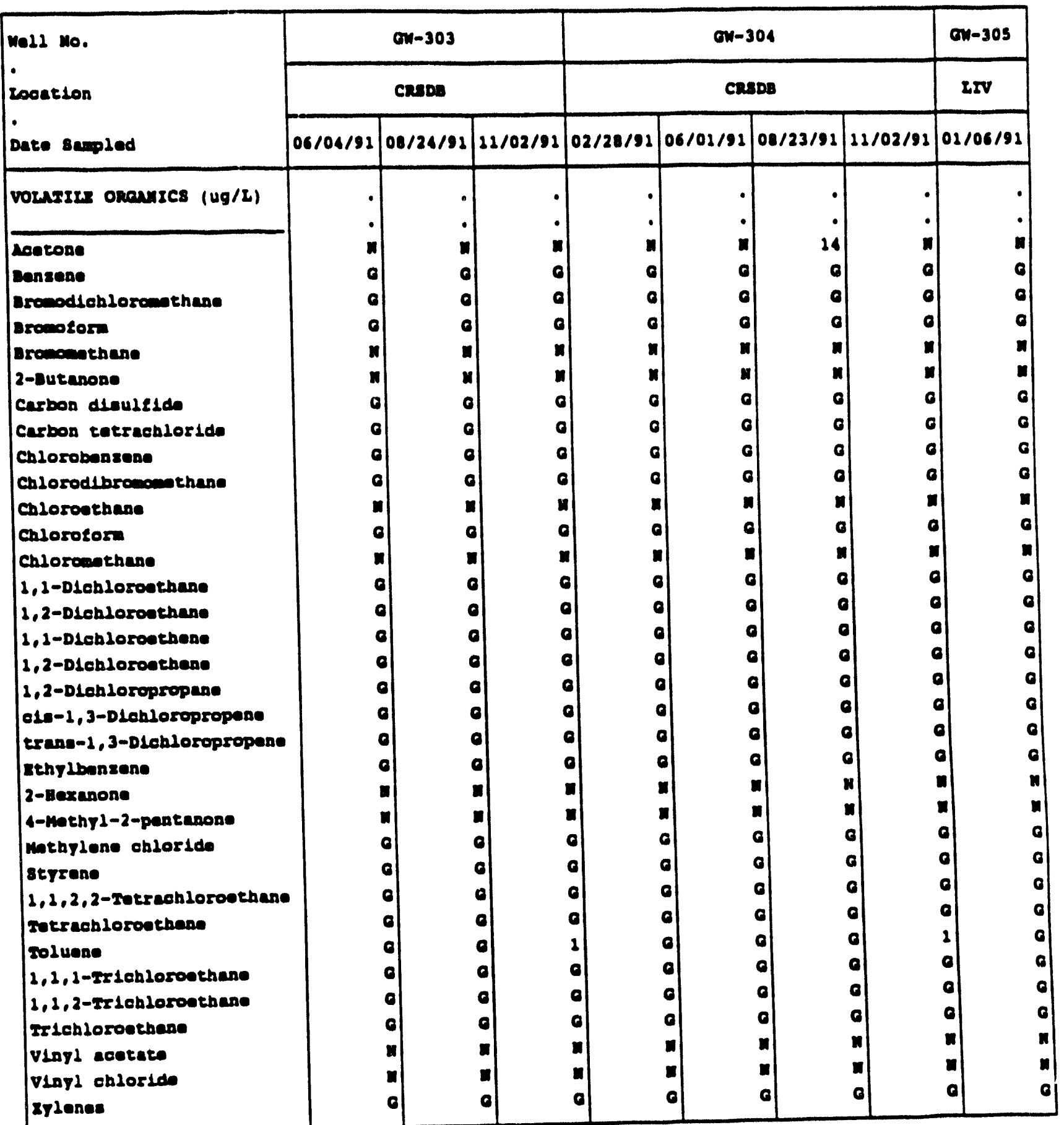

(Comrrnoud) 
Oroundueter Quel1ty Date, 1991

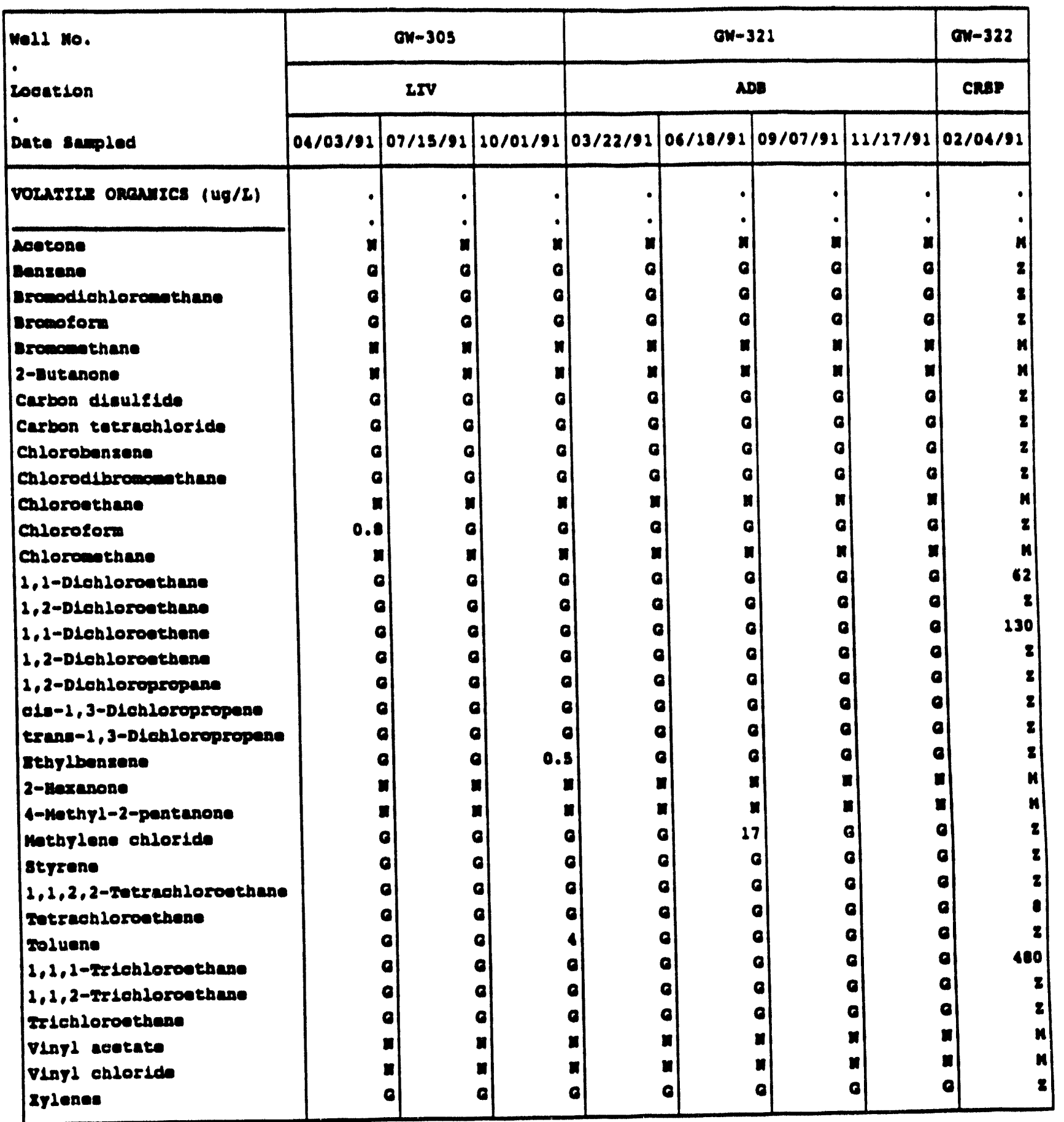

(comrsous) 
Oroundwater Qualley Data, 1991

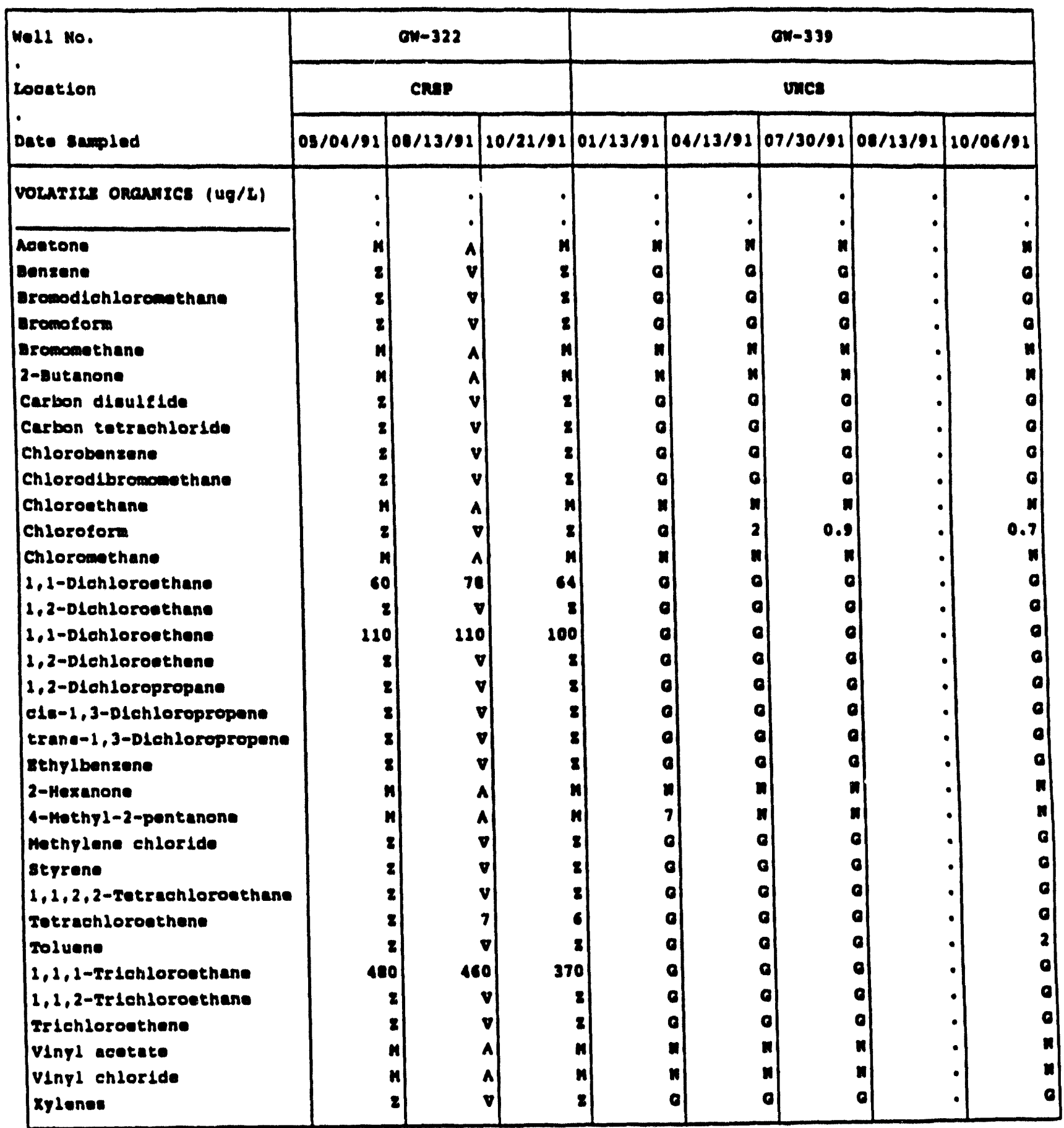

(Conrsmued) 
Oroundwater Qualdty Data, 1991

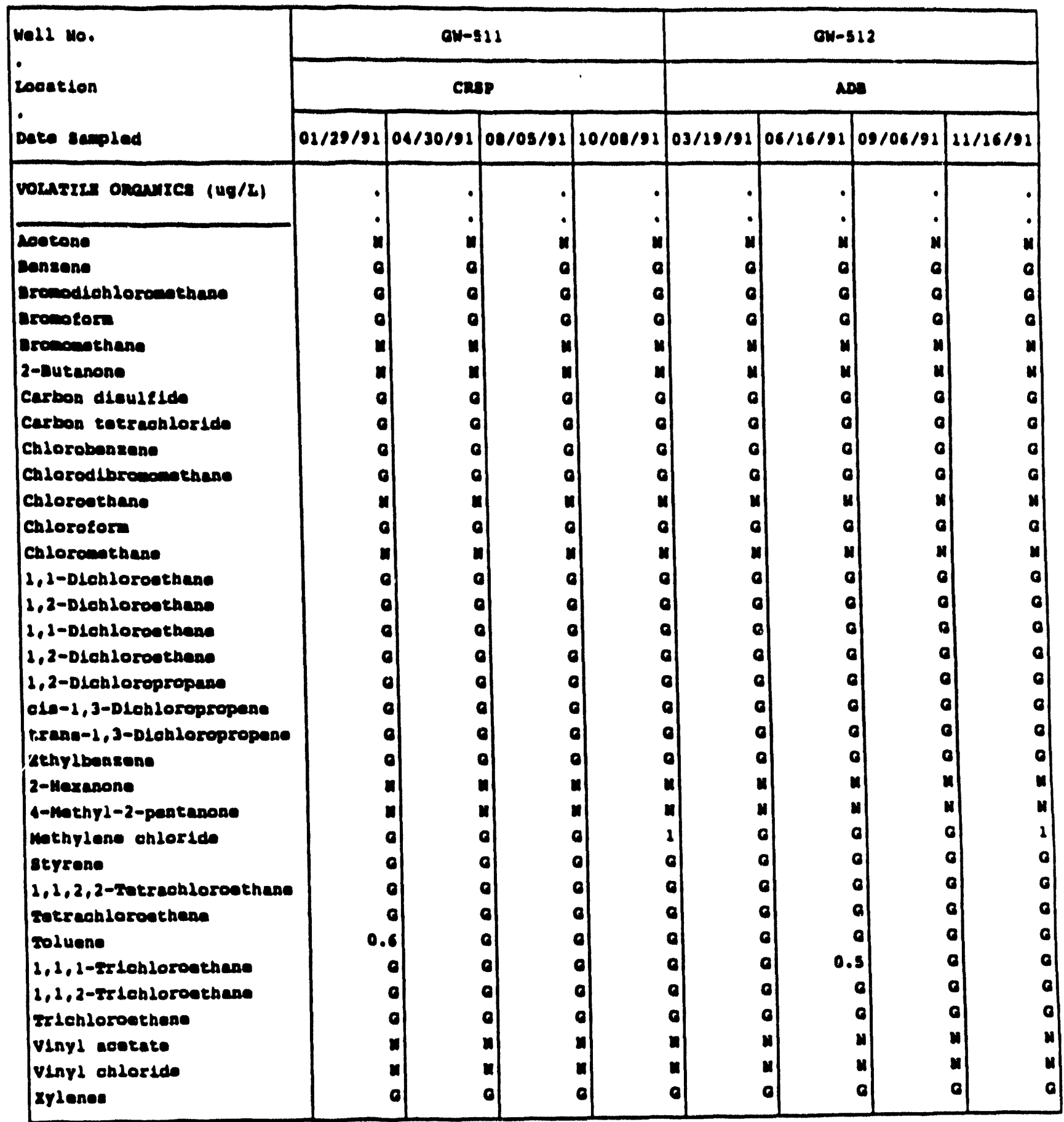

(c0mrrnoso) 
Groundwater Qualdty Data, 1991

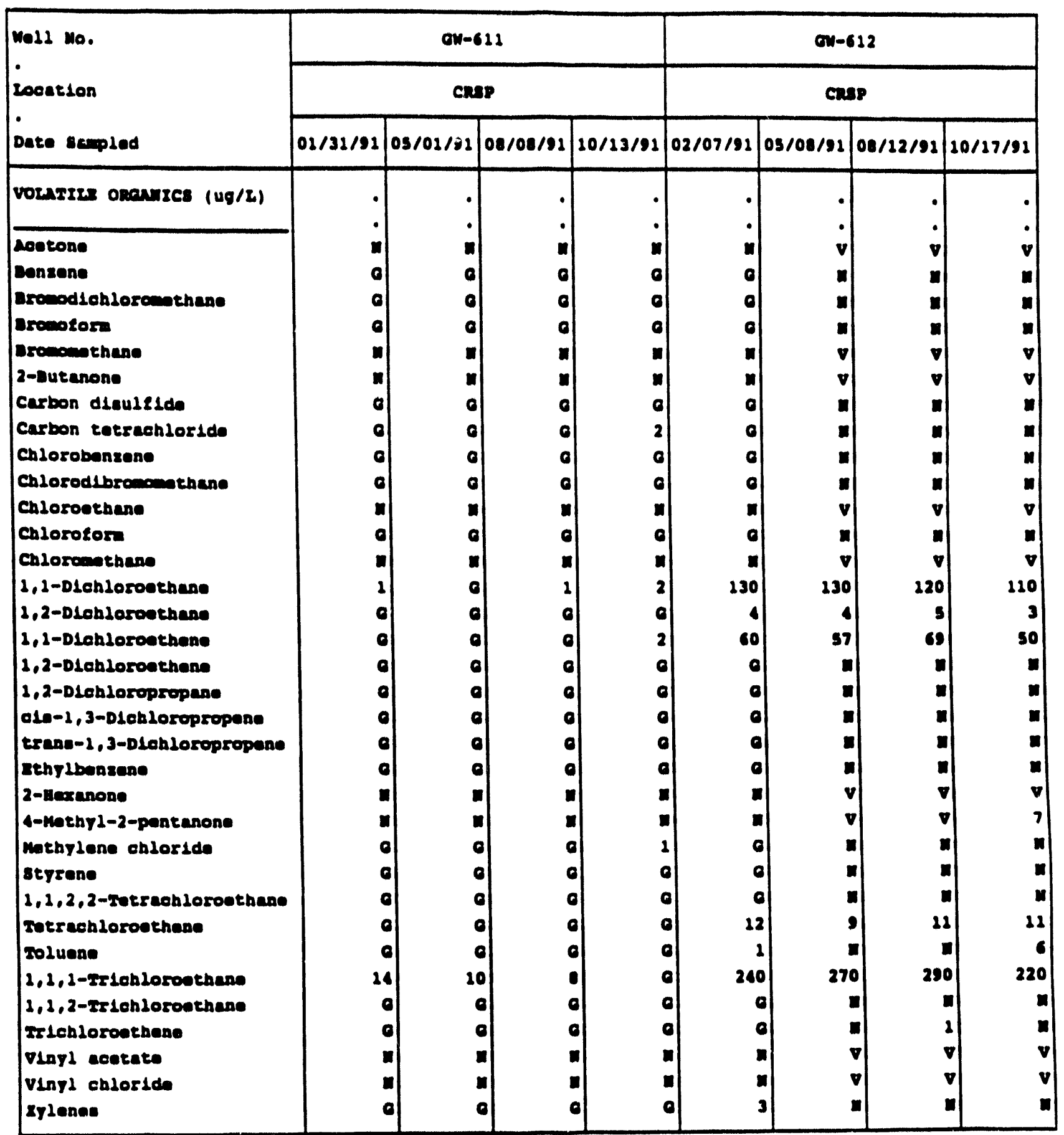

(courrumes) 


\section{A-170}

Qroundweter Quclity Data, 1991

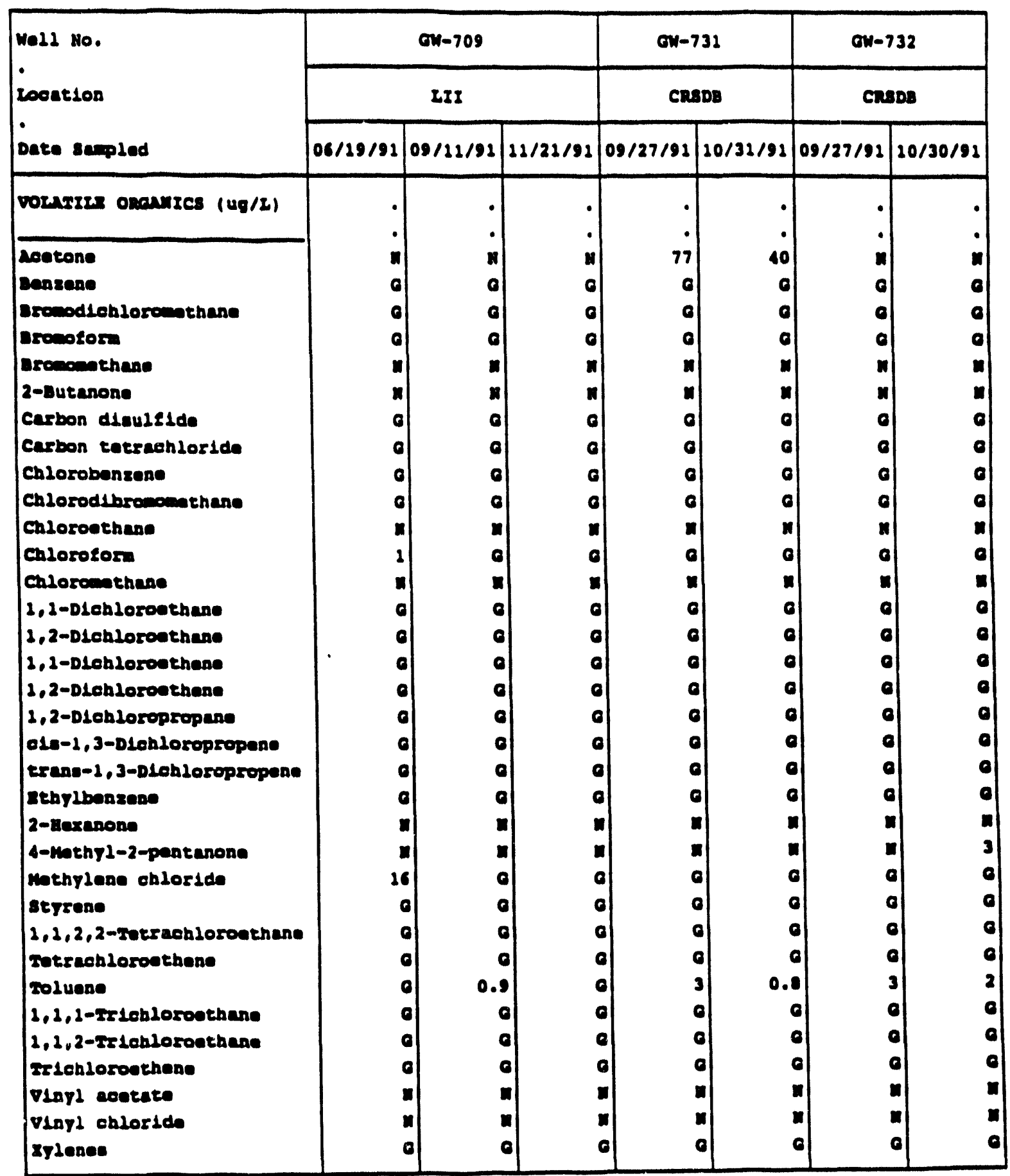




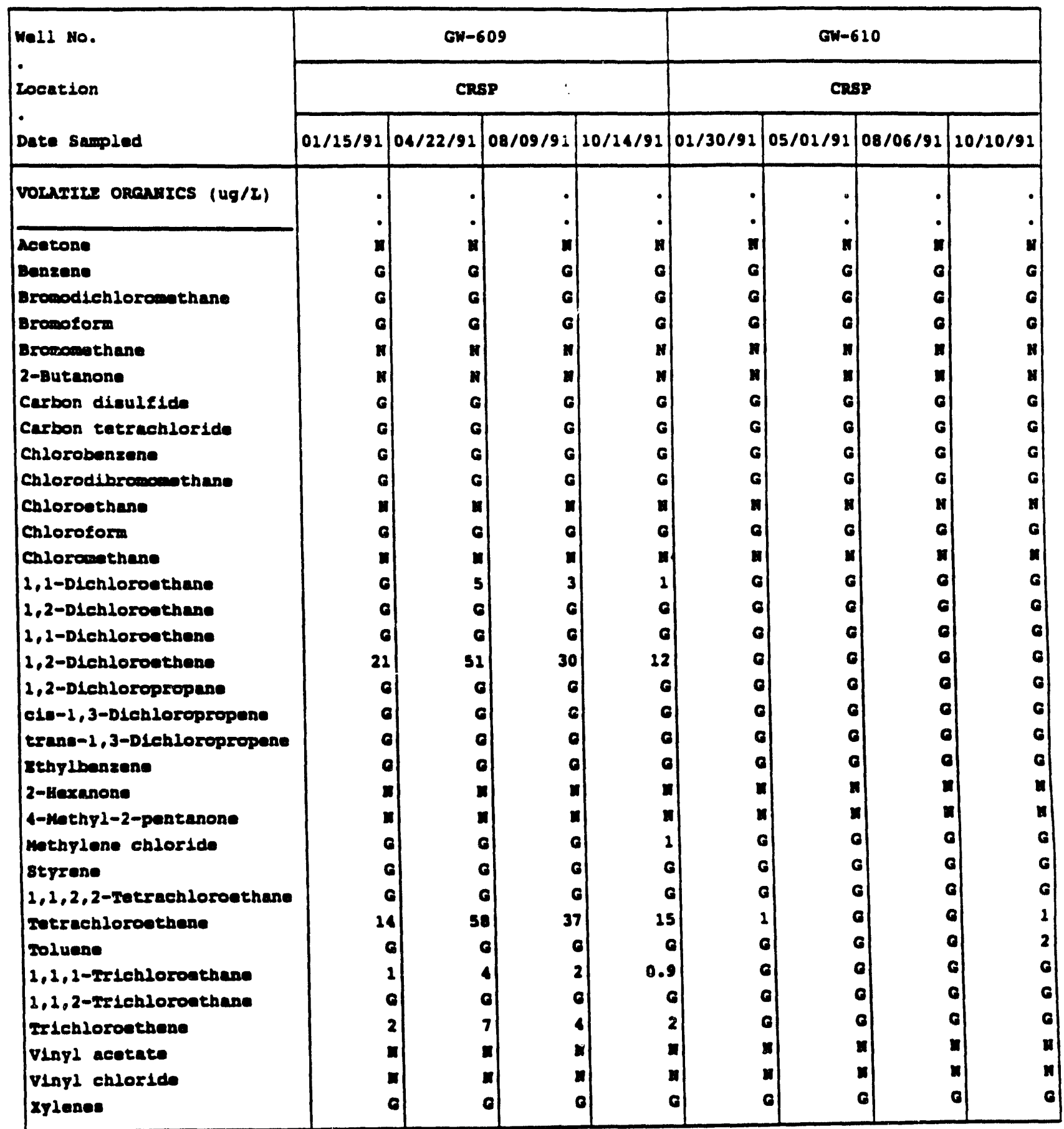

(comrravo) 
Groundwater Qual1ty Deta, 1991

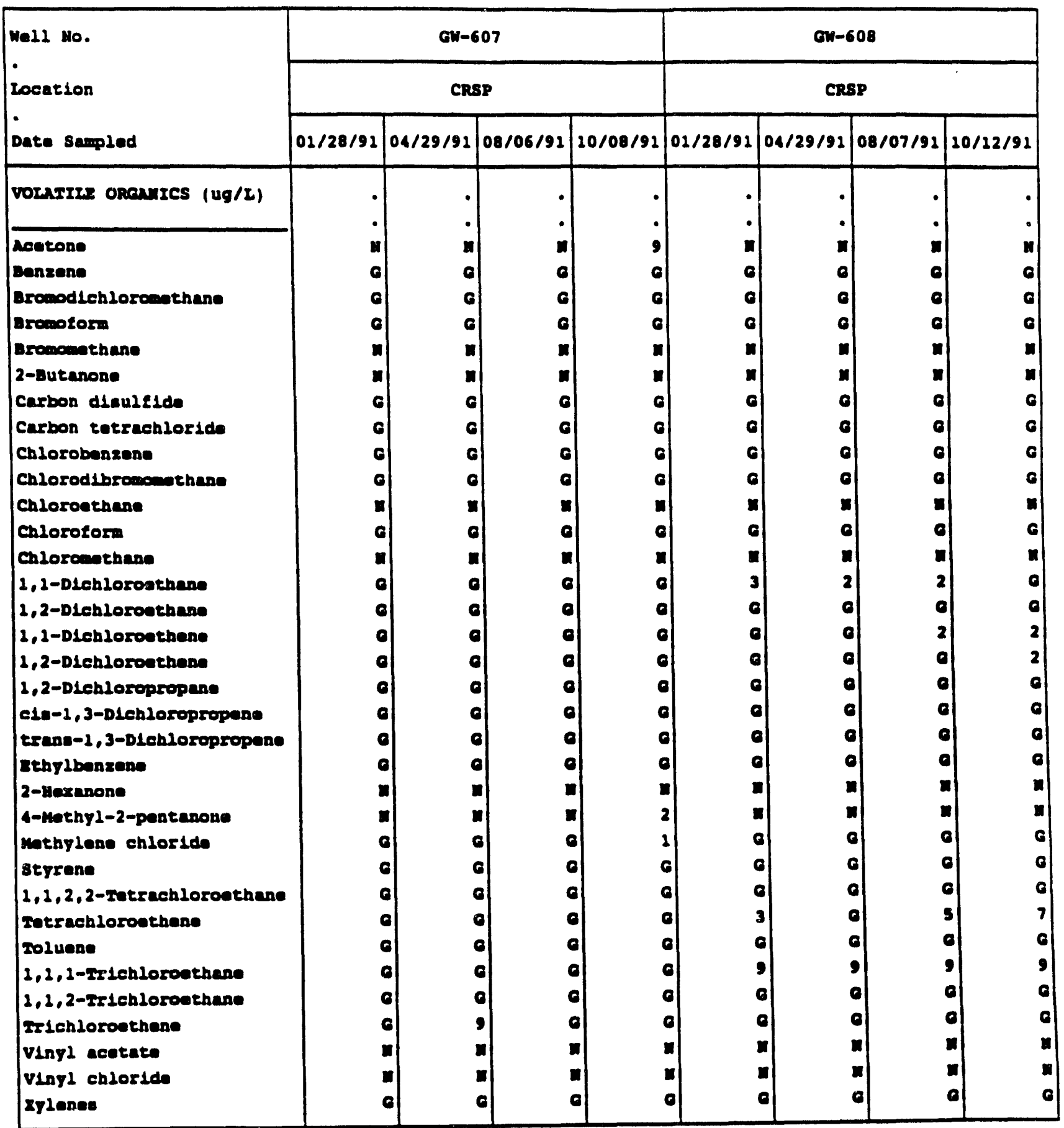

(conrentued) 
Groundwater Qual1ty Data, 1991

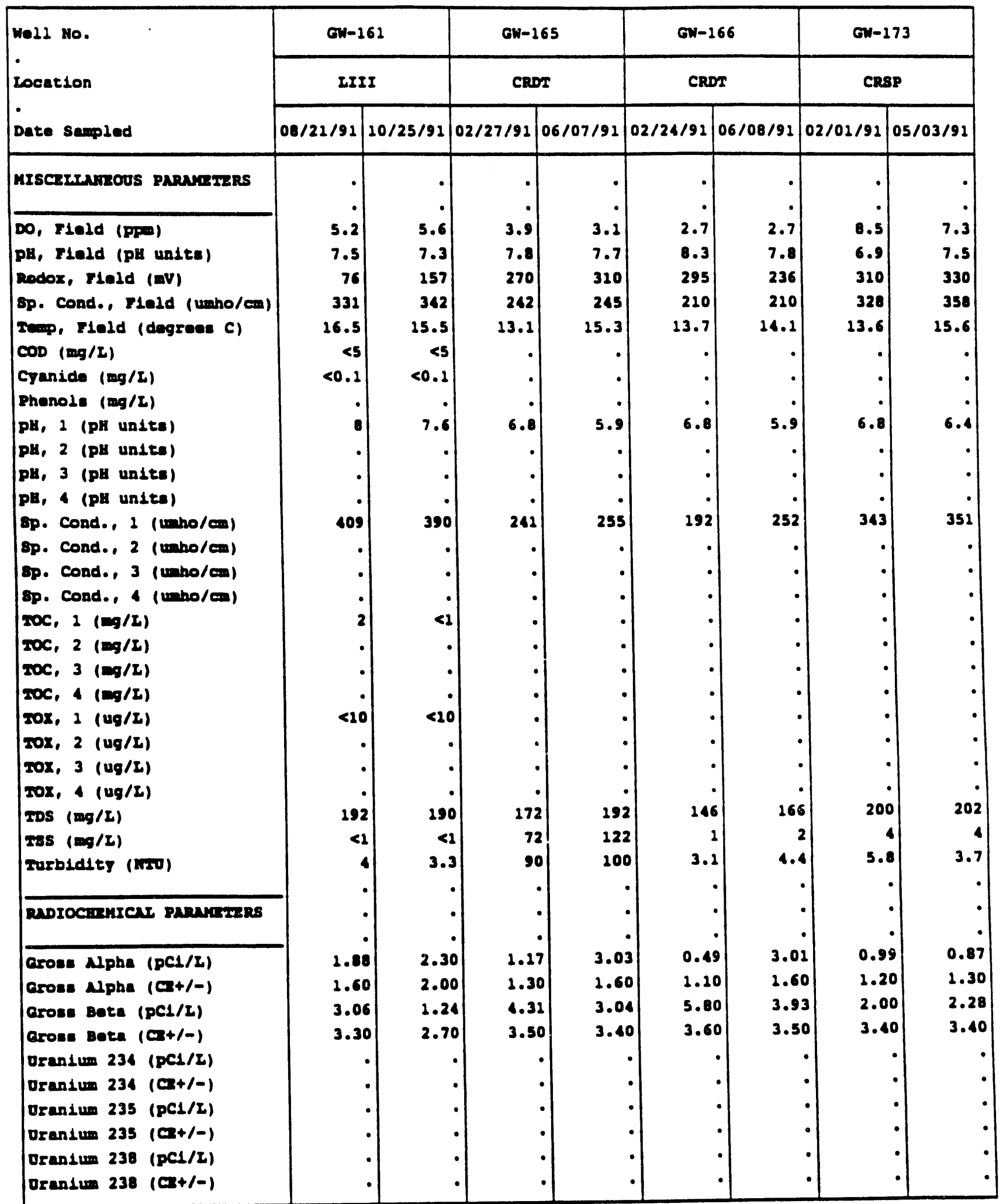

(Consrorso) 
A-174

Groundwater Quellty Data, 1991

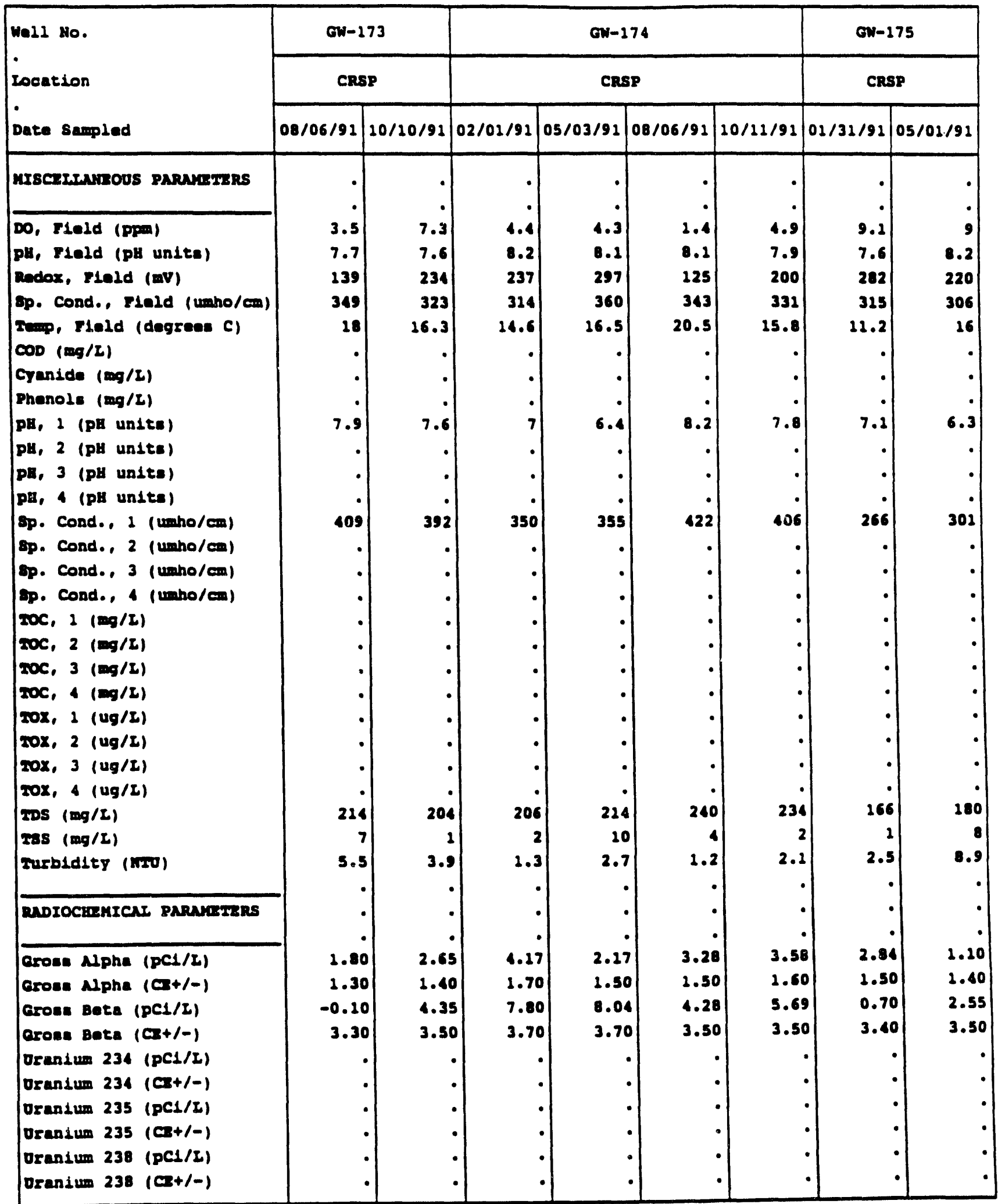

(Comrrnuted) 


\section{A-175}

Groundwater Quallty Data, 1991

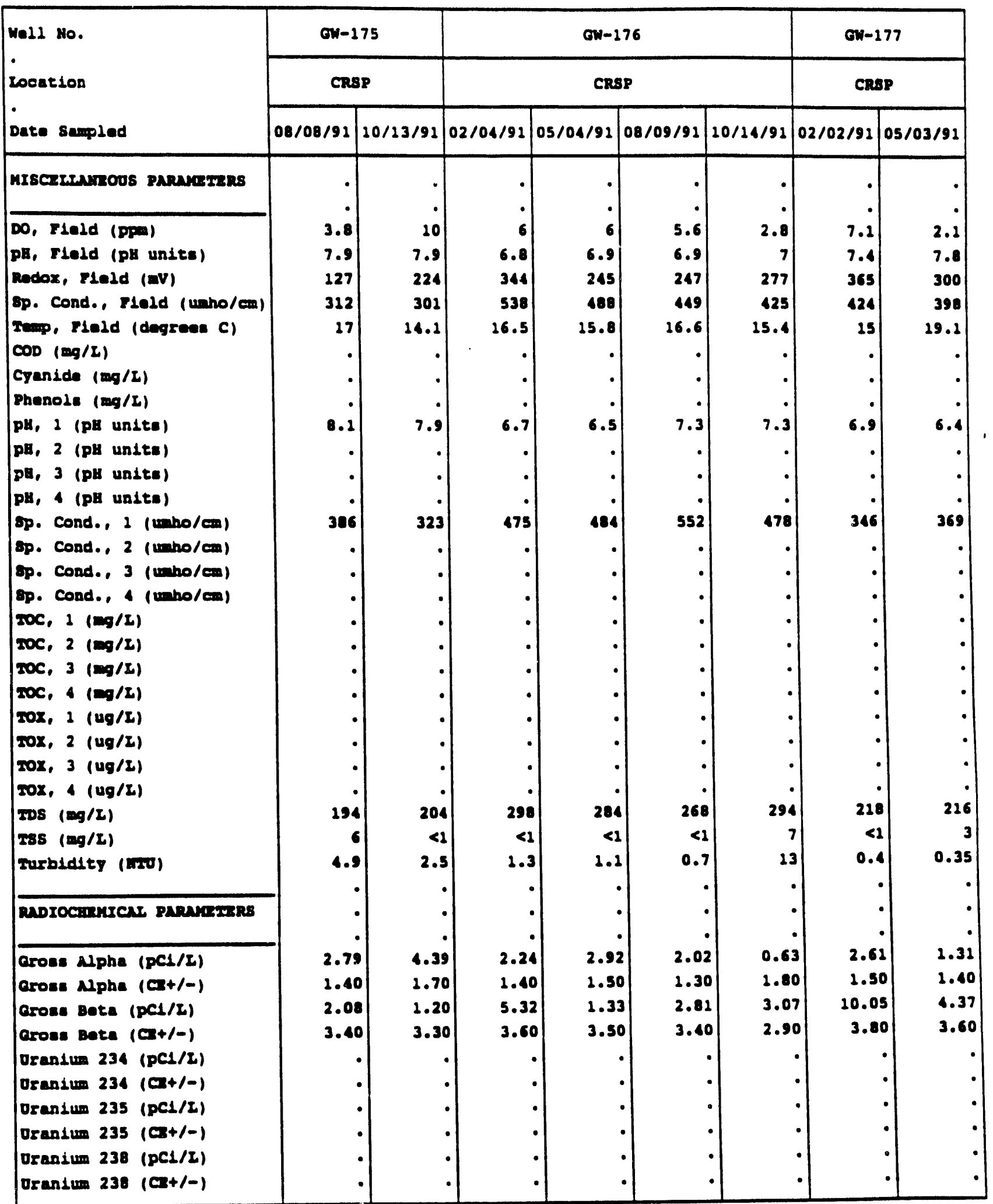

(COArrnoso) 
Groundwater Quallty Data, 1991

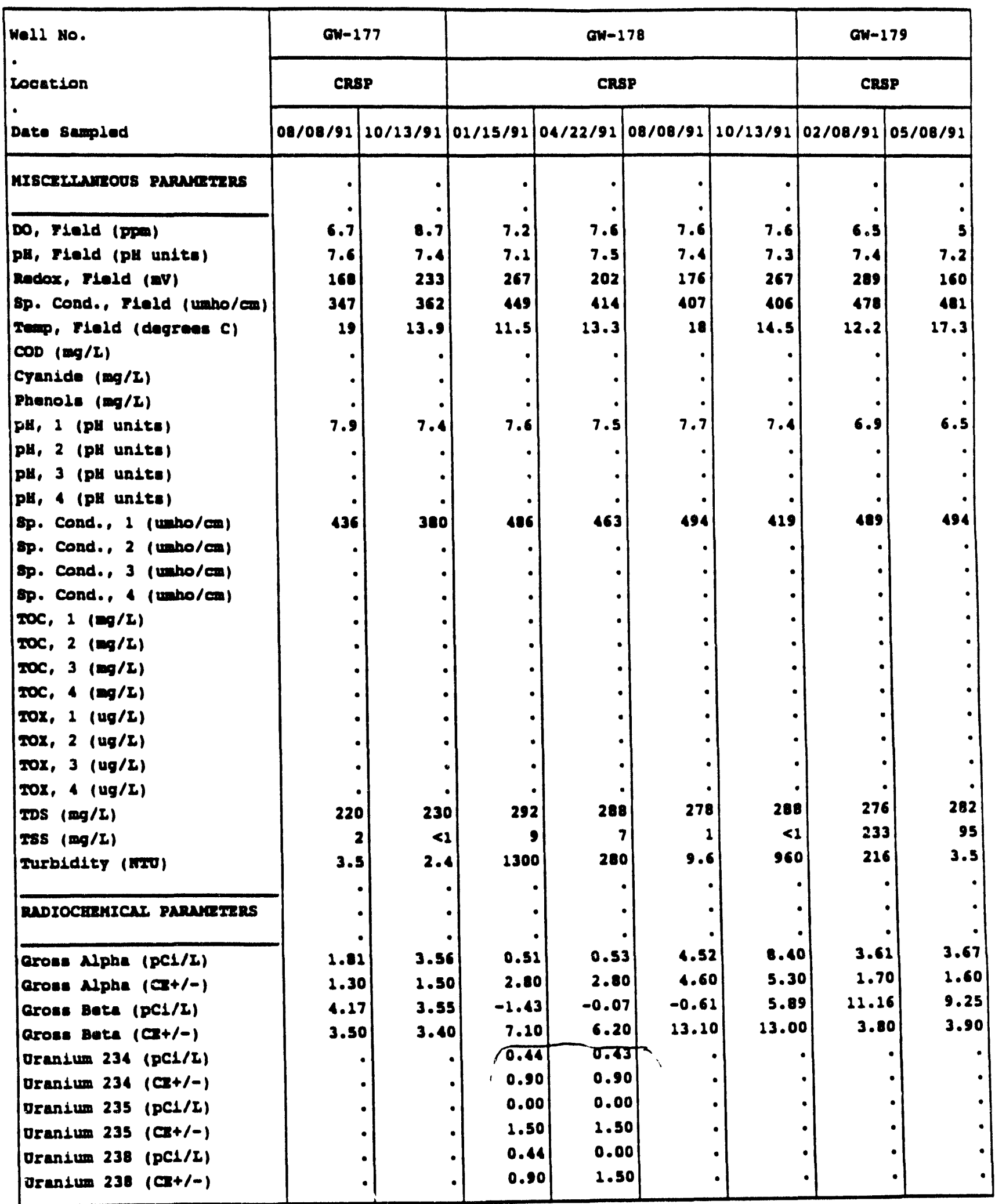

(courstoro) 
Groundwater guellty Date, 1991

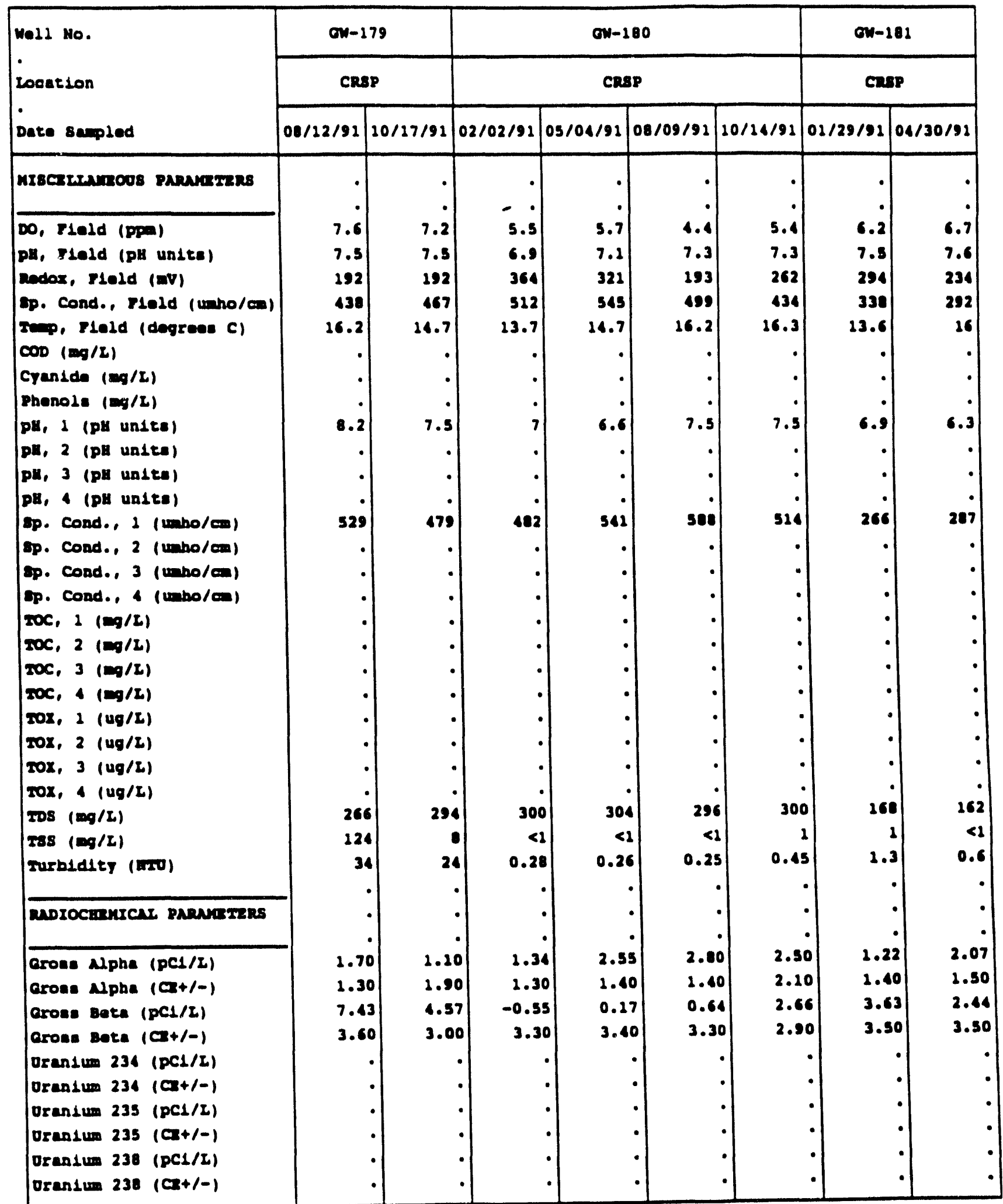

(constrond 
Grouncwater Quadity Deta, 1991

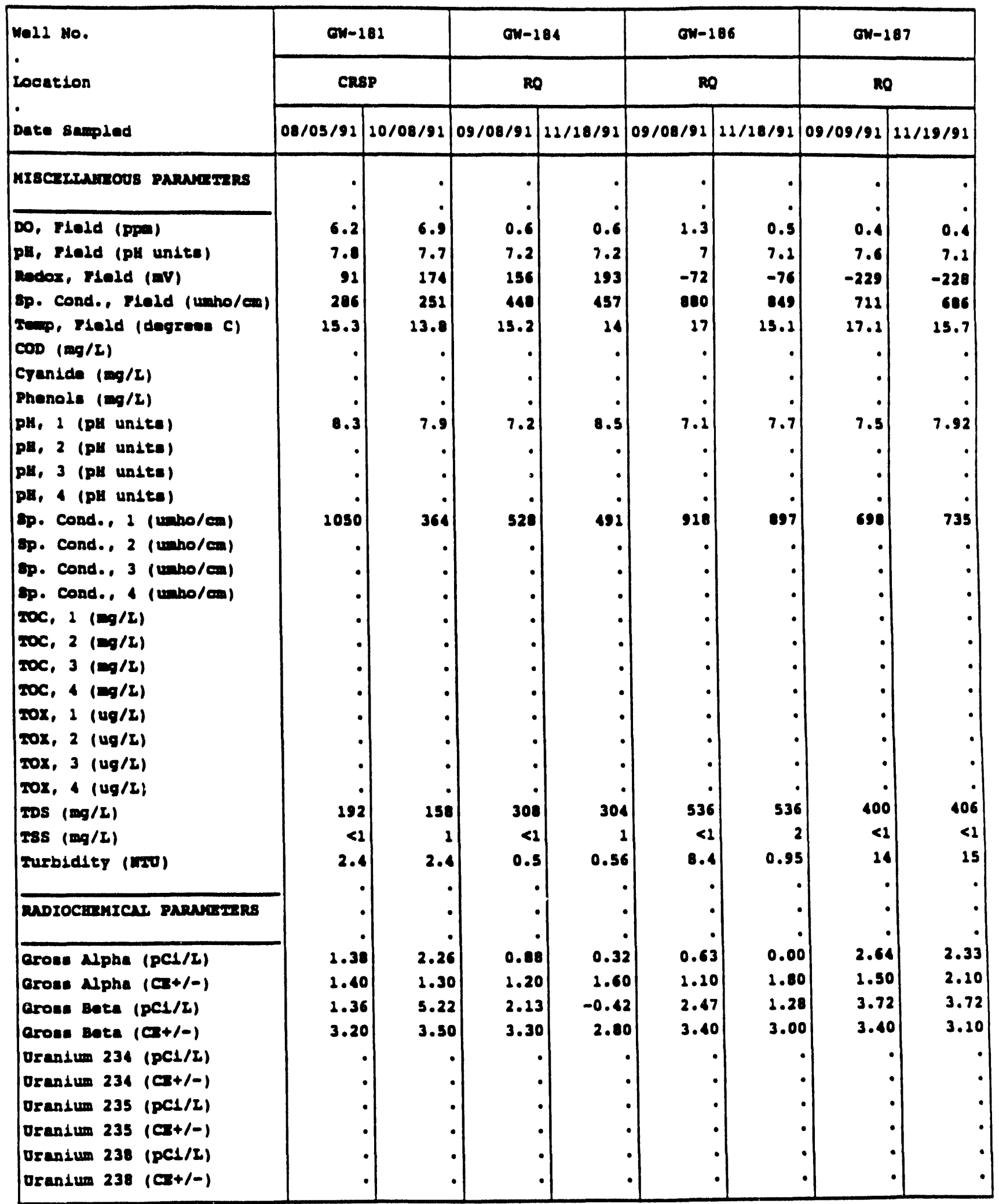

(courronud 
Groundwater Qundty Data, 1991

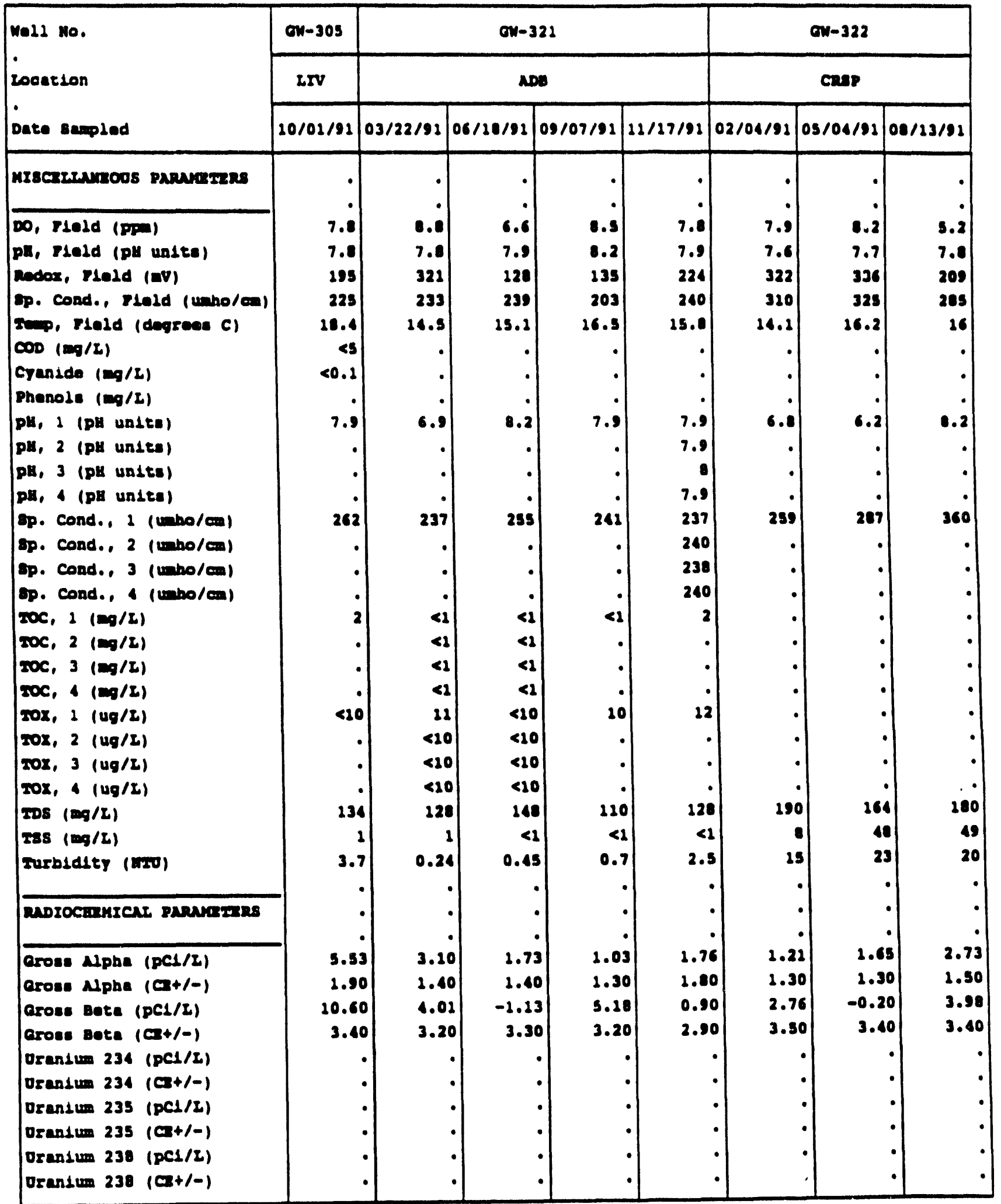

(COArruUso) 
Oroundwater Quadlty Data, 1991

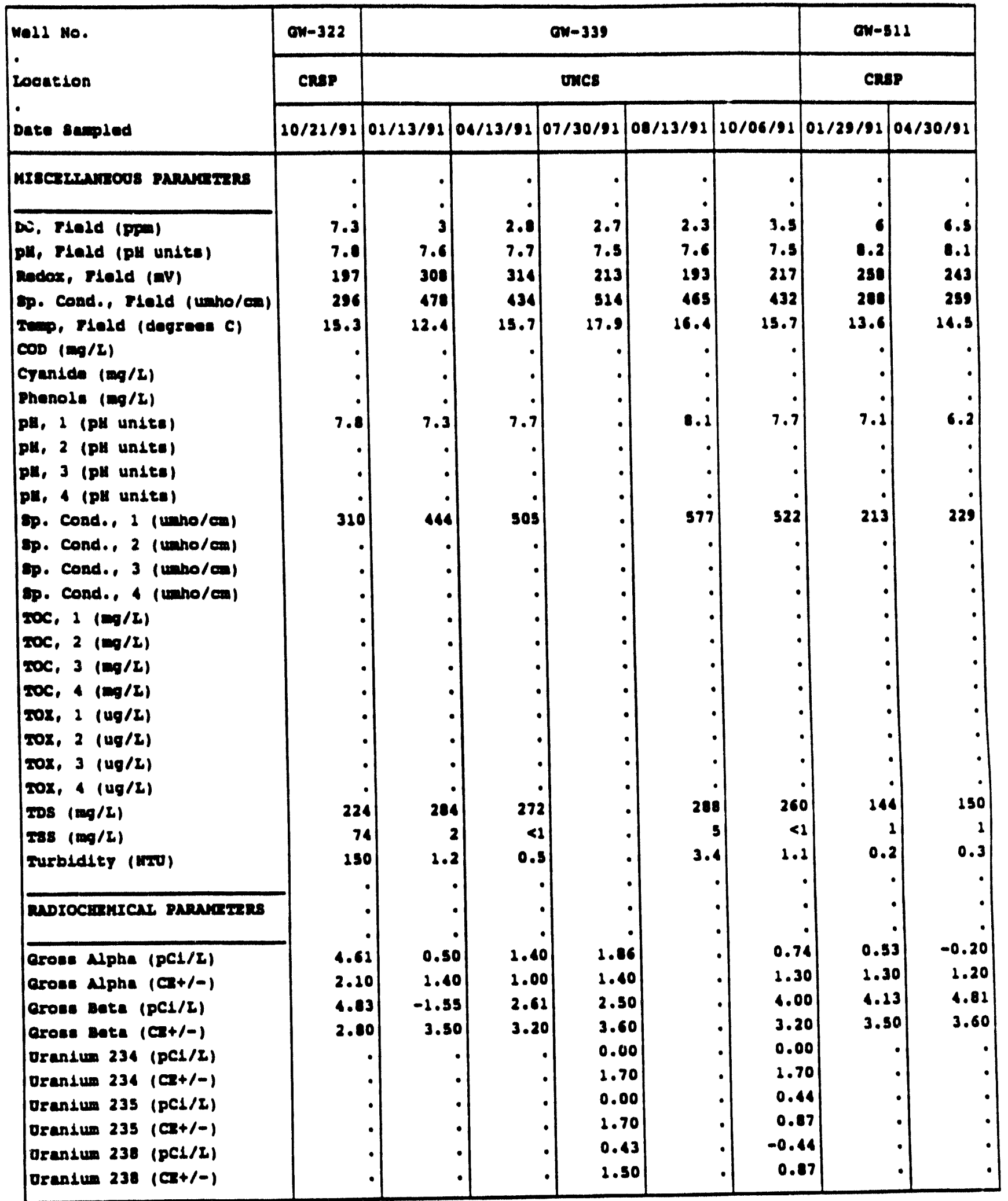




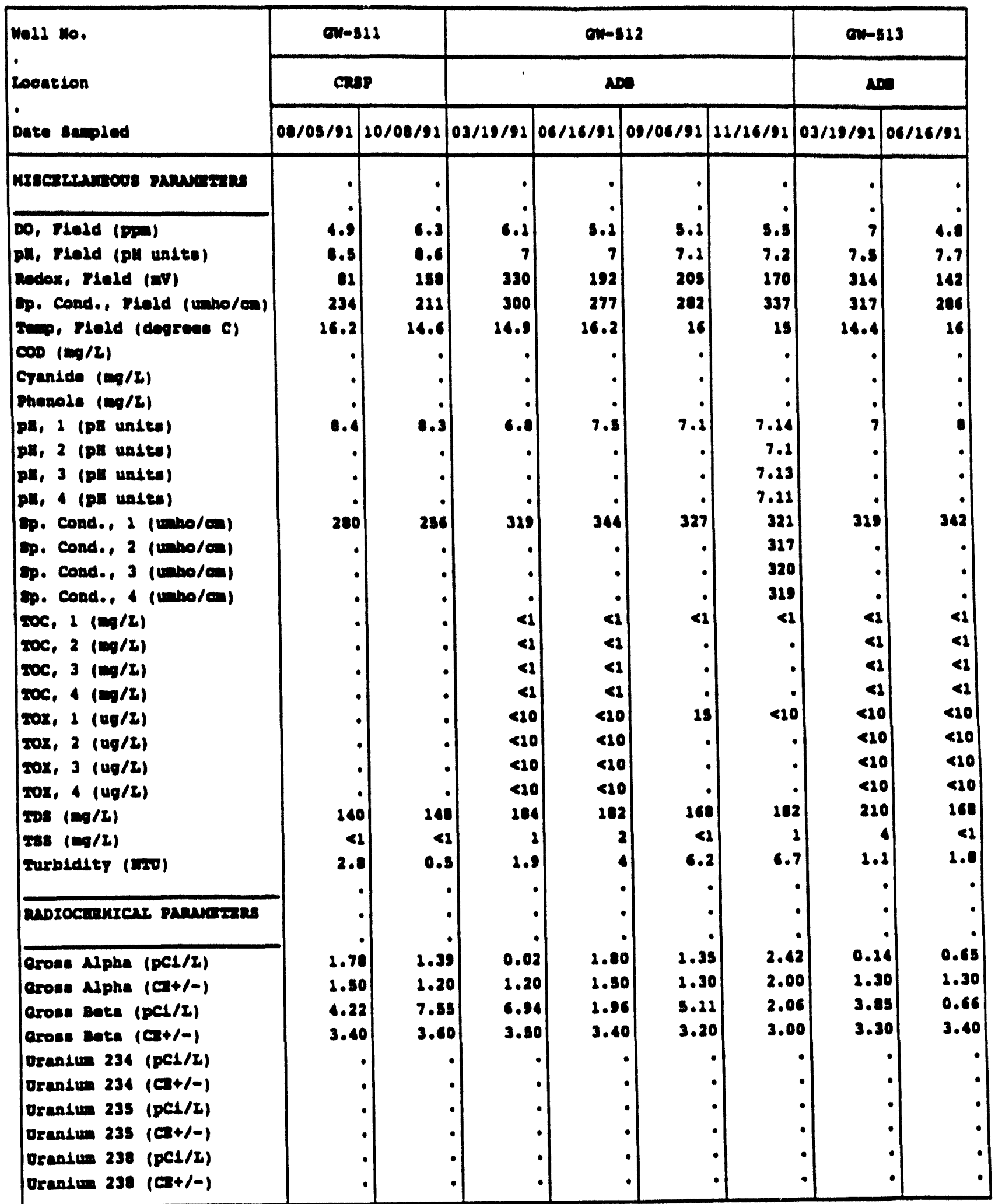

(corrermos) 
A-182

Oroundwatur Queldty Data, 1991

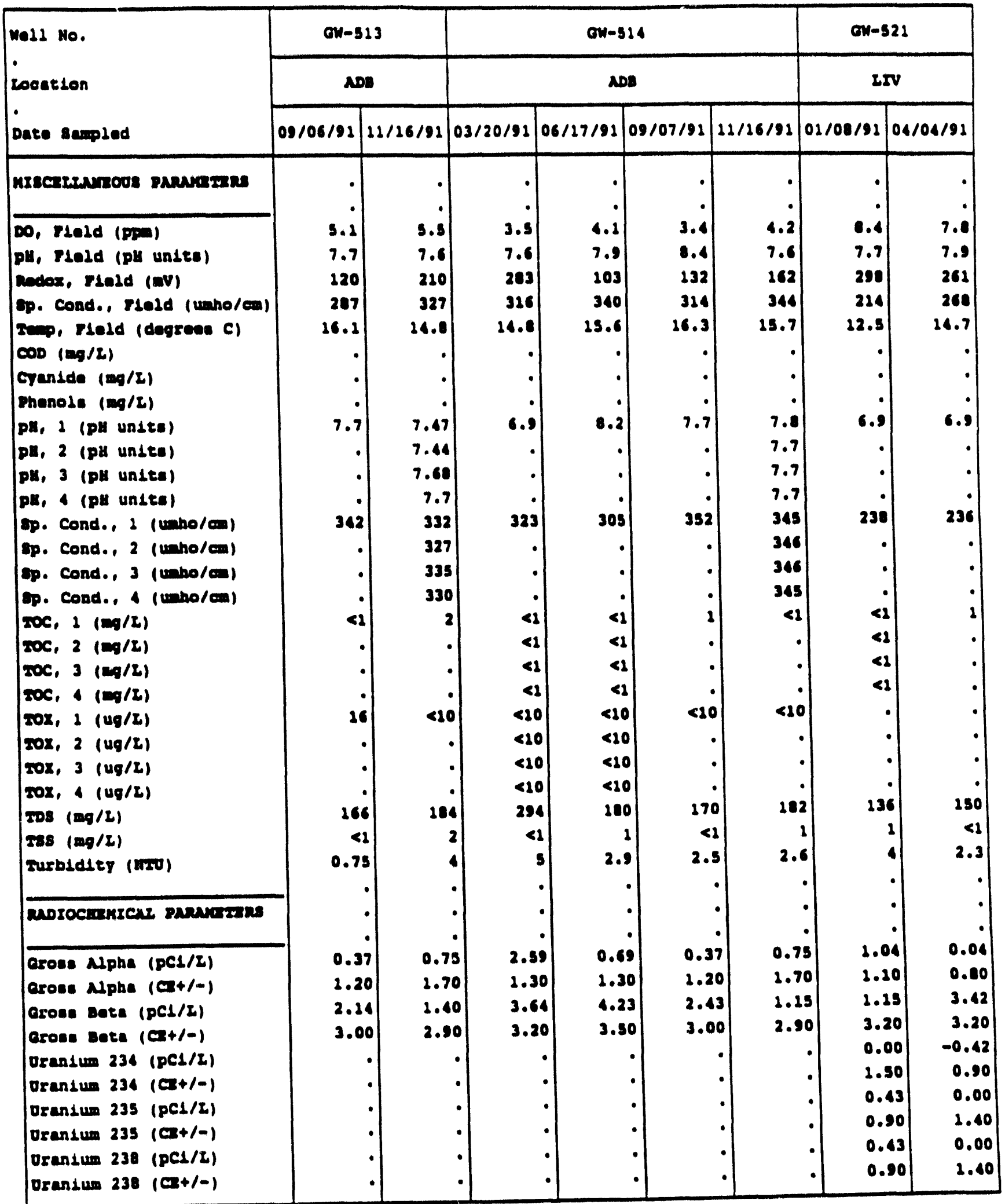


Croundweter Qualdty Date, 1991

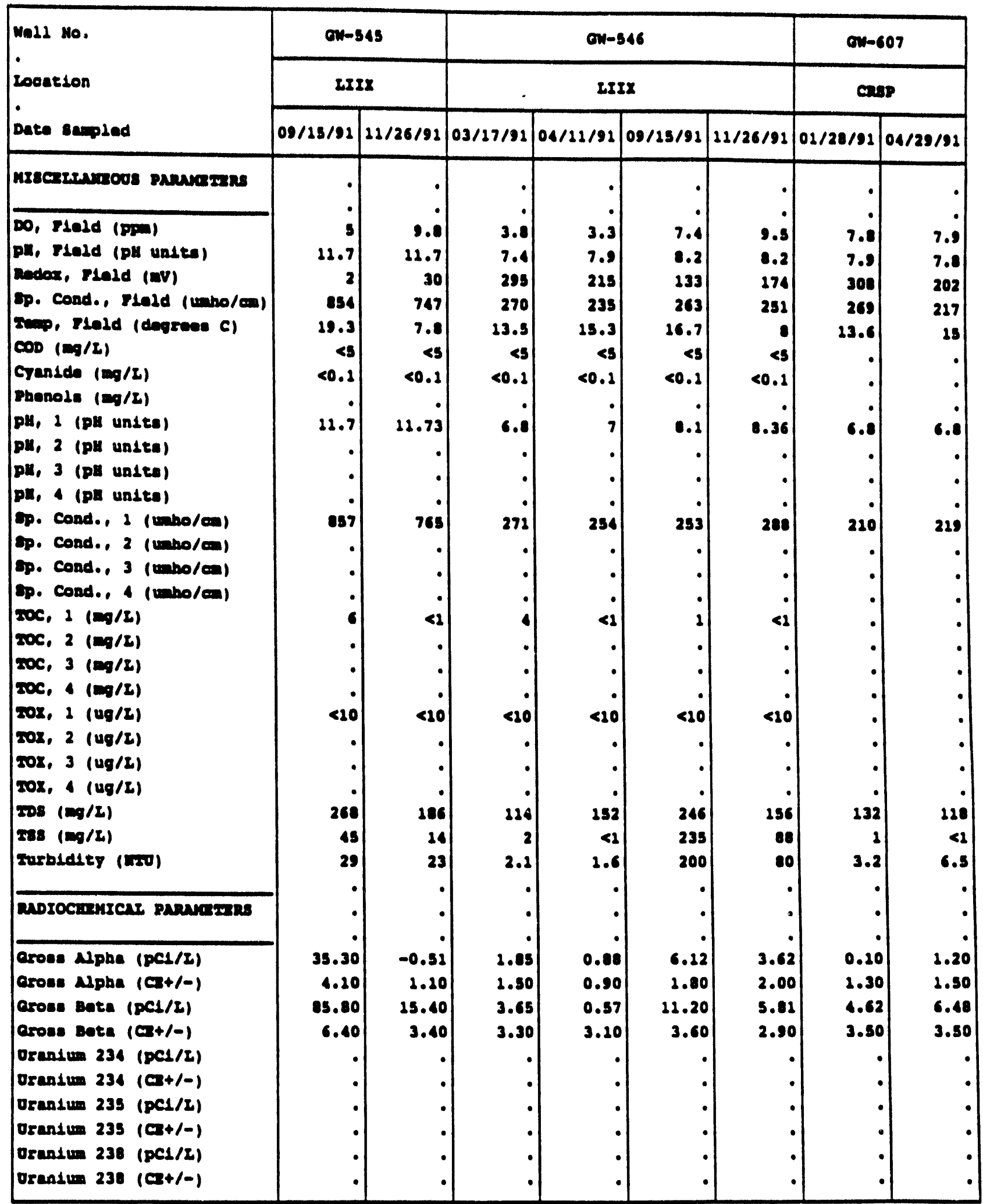


Groundweter Qualdey Date, 1991

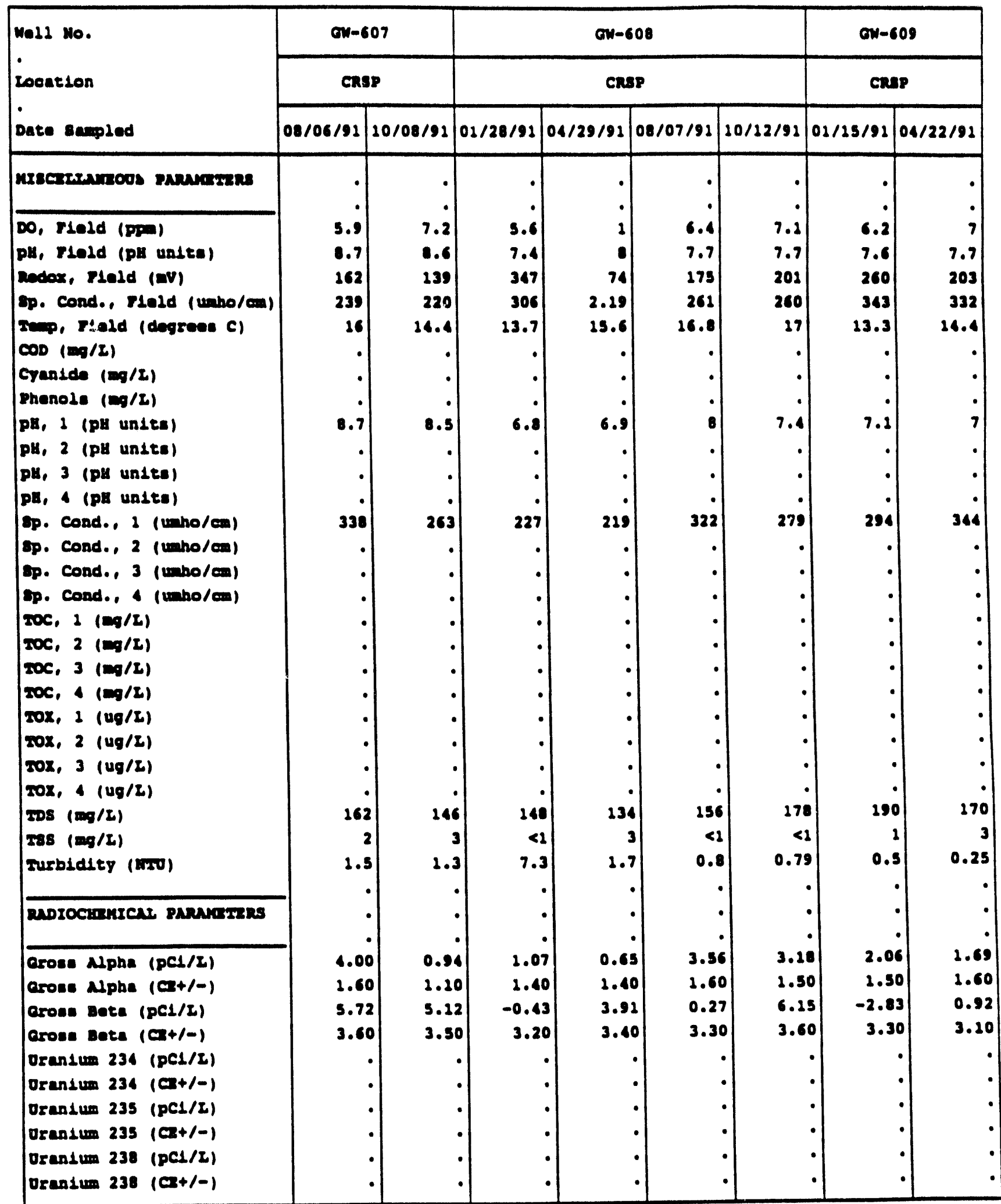

(Comernute) 
Groundwater Quallty Data, 1991

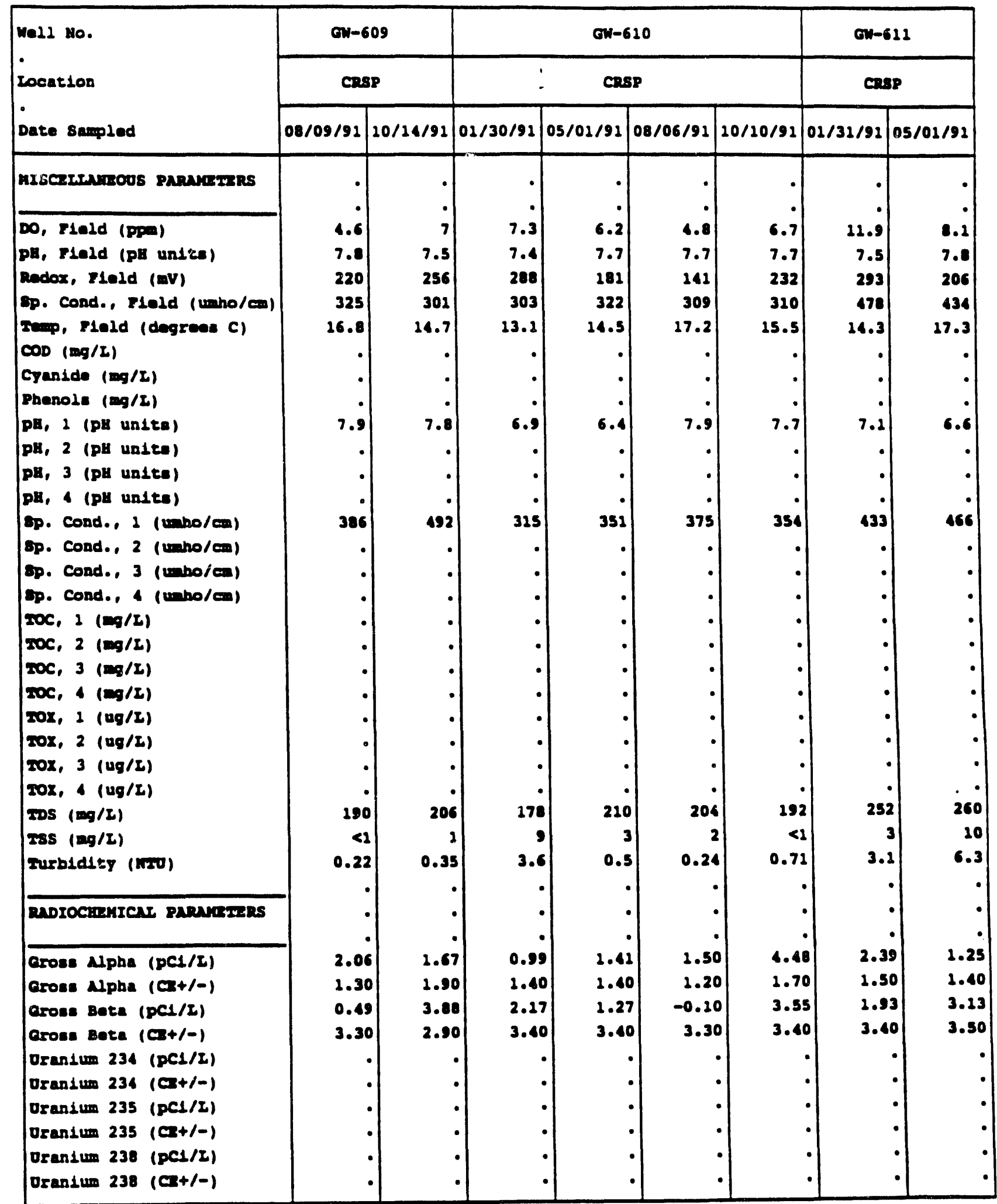

(COArInULD) 
A-186

Groundwater Quality Data, 1991

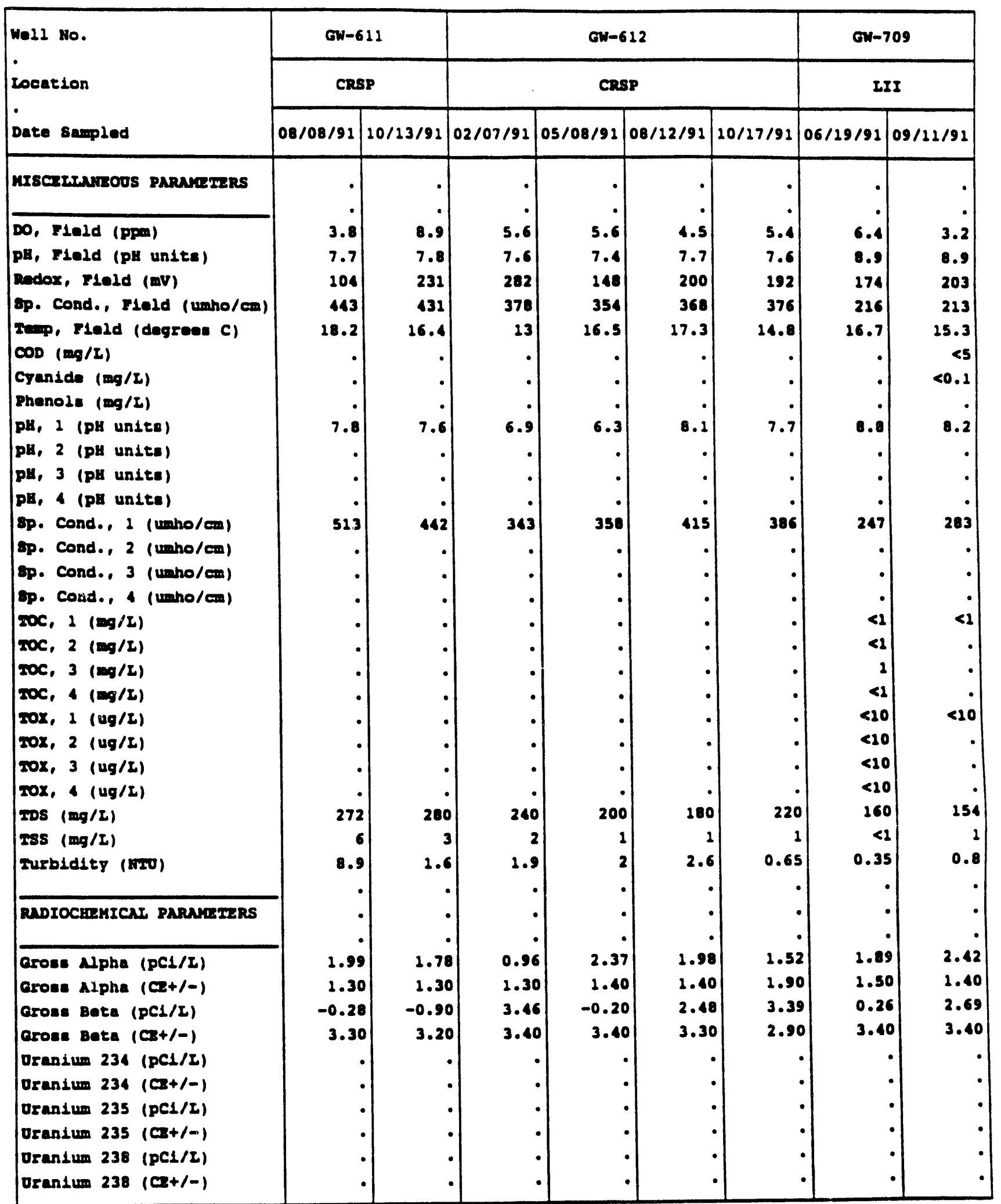


A-187

ANNUAL AVERAOES

GW. 173

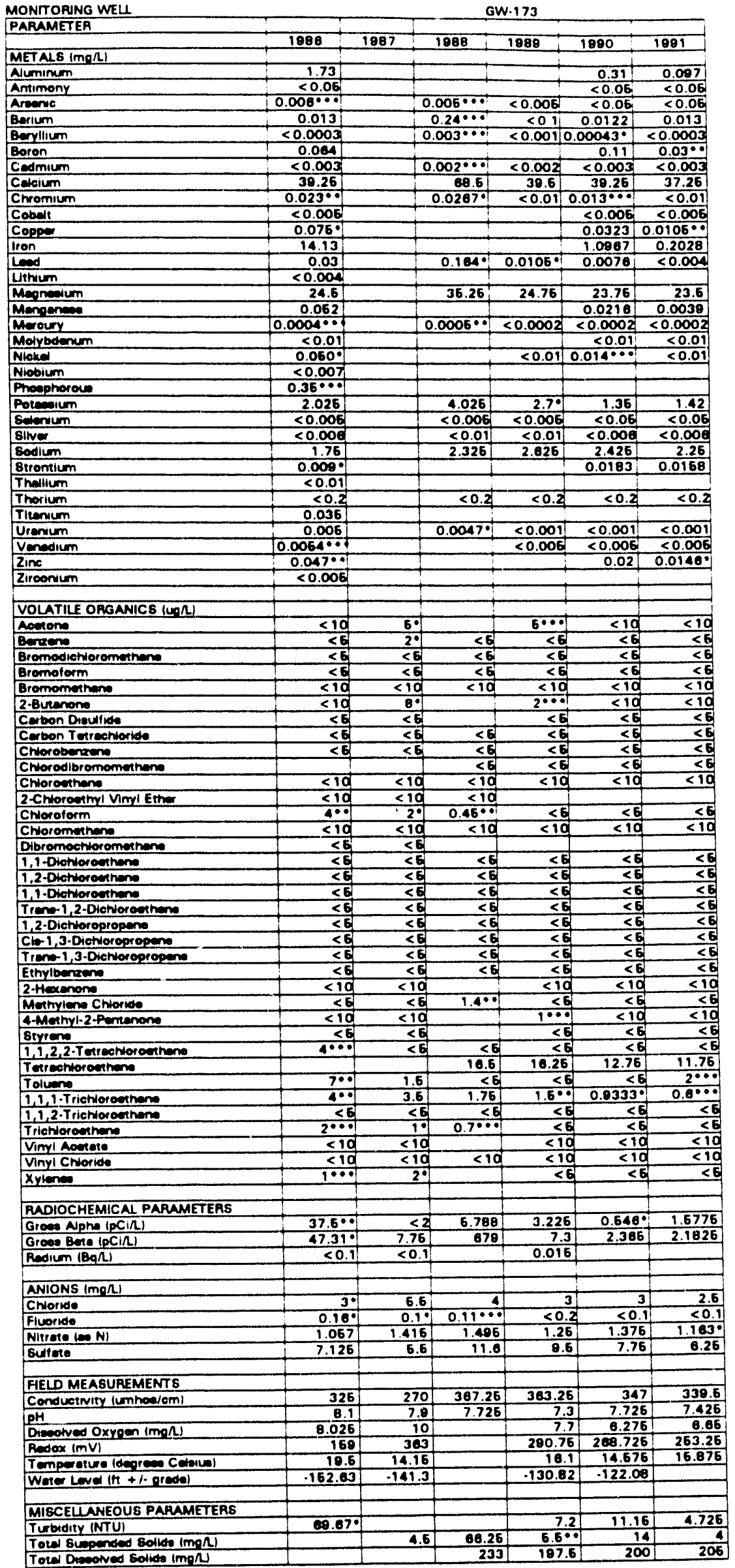


GW.173

\begin{tabular}{|c|c|c|c|c|c|c|}
\hline \multirow{2}{*}{\multicolumn{7}{|c|}{ PARAMETER }} \\
\hline & & & & & & \\
\hline & 1086 & 1887 & 1888 & 1880 & 1980 & 1891 \\
\hline \multicolumn{7}{|l|}{ PESTICIDES $(L O R)$} \\
\hline gemma-BHC (Lindene) & $<0.02$ & & & & & \\
\hline $2,4 \cdot 0$ & $<2$ & & & & & \\
\hline Endrin & $<0.1$ & & & & & \\
\hline Mothoxychlor & $<0.08$ & & & & & \\
\hline Sinex & $<0.2$ & & & & & \\
\hline Toxephene & $<2$ & & & & & \\
\hline \multicolumn{7}{|c|}{ BABE/NEUTRAL EXTRACTABLES (LOR) } \\
\hline Aoenephinene & $<10$ & & & & & \\
\hline Aoenephthyiense & $<10$ & & & & & \\
\hline Anthreome & $<10$ & & & & & \\
\hline Benzidins & $<80$ & & & & & \\
\hline Bereolalanihreoene & $<10$ & & & & & \\
\hline EerroidPriene & $<10$ & & & & & \\
\hline Berevolbifluorenthenes & $<10$ & & & & & \\
\hline Beneola,hlllPeryiene & $\leq 10$ & & & & & \\
\hline Bereolkifluorenthene & $\leq 10$ & & & & & \\
\hline Bensyl Aleohol & $<10$ & & & & & \\
\hline Bersyl Butryl Phthelate & $<10$ & & & & & \\
\hline Bin (2-Chlorecthoxy) Methme & $<10$ & & & & & \\
\hline Bin 12-Chioroenhyli)ethe & $\leq 10$ & & & & & \\
\hline Bh (2-ChworotecoropyllEther & $<10$ & & & & & \\
\hline Bho $(2-$ Ethylheryll)Phthelete & $168.6 \cdot 9$ & & & & & \\
\hline 4-Bromoph m / Phen/ Ether & $<10$ & & & & & \\
\hline 4-Chloroentine & $<10$ & & & & & \\
\hline 2-Chloroncephinatenese & $<10$ & & & & & \\
\hline 4-Chiorophenyl Phenyl Ethe & $<10$ & & & & & \\
\hline Chrovenes & $<10$ & & & & & \\
\hline Dien-butyl Phinclate & $2 \cdots 0$ & & & & & \\
\hline Di-moctyl Phthadate & $6 \cdot 9$ & & & & & \\
\hline Dibenrola, nlampreoene & $<10$ & & & & & \\
\hline Dibenzofuren & $<10$ & & & & & \\
\hline 1,2-Dichloroberemente & $<10$ & & & & & \\
\hline 1,3-Dichioroberemente & $<10$ & & & & & \\
\hline 1,4-Dichlorobenenente & $<10$ & & & & & \\
\hline 3,3.Dichloroberzudine & $<20$ & & & & & \\
\hline Dethyl Prenolote & 1000 & & & & & \\
\hline Dimeenyl Prthelate & $<10$ & & & & & \\
\hline 2,4-Dinitrotoluense & $<10$ & & & & & \\
\hline 2, -Dinitrotoluen & $<10$ & & & & & \\
\hline Fivorenthen & $<10$ & & & & & \\
\hline Fluorene & $<10$ & & & & & \\
\hline Hexechioroberienen & $<10$ & & & & & \\
\hline Hexechloroburiediene & $\leq 10$ & & & & & \\
\hline Hexectioroeyctopentediente & $<10$ & & & & & \\
\hline Hexechiorocthen & $<10$ & & & & & \\
\hline Indeno $(1,2,3$-ed) Pyrene & $<10$ & & & & & \\
\hline Eophorone & $<10$ & & & & & \\
\hline 2-Mathyincentraters & $<10$ & & & & & \\
\hline N-Nitroeodi-N-Propylemine & $\leq 10$ & & & & & \\
\hline Nephnevenes & $<10$ & & & & & \\
\hline 2-Nitroeniline & $<60$ & & & & & \\
\hline 3-Nitroendine & $\leq 50$ & & & & & \\
\hline 4-Nitreaniline & $<60$ & & & & & \\
\hline Nitroberene & $\leq 10$ & & & & & \\
\hline Phenenthrene & $<10$ & & & & & \\
\hline Pyrene & $<10$ & & & & & \\
\hline 1,2,4-Trichlmobenome & $<19$ & & & & & \\
\hline 2,4,6-Trichlorophenol & $<69$ & & & & & \\
\hline \multicolumn{7}{|l|}{ ACID EXTRACTABLEB $(L \cap \Omega)$} \\
\hline Berroue Aoid & $<60$ & & & & & \\
\hline A-Chioro-3-Menhylphenol & $<10$ & & & & & \\
\hline 2-Chiorophemol & $<10$ & & & & & \\
\hline 2,4-Dichiorophenol & $<10$ & & & & & \\
\hline 2,4-Dimeshyiphenol & $<10$ & & & & & \\
\hline 2,4-Dinitrophenol & $<69$ & & & & & \\
\hline 2-Methyl-6,6-Dinitrophenol & $<60$ & & & & & \\
\hline 2-Merhyl Phonol & $\leq 10$ & & & & & \\
\hline 3-Merhyl Phenol & $<10$ & & & & & \\
\hline 4-Marhyl Phenol & $\leq 10$ & & & & & \\
\hline 2-Nitrophenol & $<10$ & & & & & \\
\hline 4-Nitrophenol & $<60$ & & & & & \\
\hline Pentechuorophenol & $<60$ & & & & & \\
\hline Phenol & $8 \cdot 0$ & & & & & \\
\hline $2,4,0$-Triehtorophenol & $\leq 10$ & & & & & \\
\hline
\end{tabular}


ow.174

\begin{tabular}{|c|}
\hline \\
\hline PAMAMETER \\
\hline \\
\hline META 8 (mon) \\
\hline Numinum \\
\hline Antimony \\
\hline Areminc \\
\hline Eerium \\
\hline Eeryllium \\
\hline Boron \\
\hline Cedmium \\
\hline Celotum \\
\hline Chromium \\
\hline Cobelt \\
\hline Copere \\
\hline Iron \\
\hline Led \\
\hline Lithium \\
\hline Meoneium \\
\hline Mengenen \\
\hline Marour \\
\hline Molybdenn \\
\hline Nioked \\
\hline Nloblum \\
\hline Phomphorous \\
\hline Poremium \\
\hline Eecenium \\
\hline elver \\
\hline Bodium \\
\hline Btromilium \\
\hline Thellium \\
\hline Thorlum \\
\hline Tirenium \\
\hline Urenum \\
\hline Venedium \\
\hline Zine \\
\hline Ziroonum \\
\hline \\
\hline VOLATILE ORGANICS $|\sim \cap \Omega|$ \\
\hline Acevion \\
\hline Berenen \\
\hline Bromodiehloromethene \\
\hline Bromoform \\
\hline Bromomethens \\
\hline 2-Bunnone \\
\hline Cerben Deculifiose \\
\hline Certeon Tericontionide \\
\hline Chioroberenen \\
\hline Chlorodibromomenthene \\
\hline Chiorouthere \\
\hline 2-Chloranhyl Viml Ether \\
\hline Chioroform \\
\hline Chloromenters \\
\hline Dibromoshichomethens \\
\hline 1,1-Dhohtorowhen \\
\hline 1,2-Diohioredhen \\
\hline 1,1.Dtentoroethen \\
\hline Tren-1,2-Olotiorominene \\
\hline 1,2-Dichloropropene \\
\hline Citi-1,3-Dithioropropenes \\
\hline Trene-1,3-Diehtoropropene \\
\hline Ethylberenen \\
\hline $2+$ texenone \\
\hline Merhylene Chtoride \\
\hline 4-Methyt-2.Punenons \\
\hline Btyrene \\
\hline $1,1,2,2 \cdot$ Tetrechioracthenes \\
\hline Tetrectioroethen \\
\hline Toluene \\
\hline $1,1,1$. Triehloropthen \\
\hline 1,1,2. Triehtoromenten \\
\hline Triothoroenthene \\
\hline Vinyl Aomate \\
\hline Vinyi Chloride \\
\hline Xriene \\
\hline \\
\hline RADIOCHEMICAL PARAME \\
\hline Groes Nphe $(p C 1 n)$ \\
\hline Groes Bene $(p C i n)$ \\
\hline Redium $(\mathrm{Bg} \Lambda)$ \\
\hline ANIONS $(\mathrm{mm} \Omega)$ \\
\hline Chioride \\
\hline Fluoride \\
\hline Nitrate $[0 N$ \\
\hline Sclitere \\
\hline \\
\hline FIELD MEABUREMENT \\
\hline Conduotivity (umhoelom) \\
\hline$p+1$ \\
\hline Dtepolved Oxyoun $(\mathrm{mg} n)$ \\
\hline Redox $\ln |V|$ \\
\hline Tomperatue ideores Cdeluel \\
\hline Woter Level /n +1. oredel \\
\hline \\
\hline MISCEL LNEOUS PARAMETE \\
\hline Turbidity (NTU) \\
\hline Tord scuepended sollote $(\mathrm{mg} / \mathrm{H}$ \\
\hline Total Dineotred solide (mon) \\
\hline
\end{tabular}


A-190

OW.174

\begin{tabular}{|c|c|c|c|c|c|c|}
\hline \multirow{2}{*}{ PARAMETER } & \multicolumn{6}{|c|}{ QW.174 } \\
\hline & 1088 & 1087 & 1888 & 1888 & 1980 & 1091 \\
\hline \multicolumn{7}{|l|}{ PESTICIDES $(4 \mathrm{NO})$} \\
\hline Semme-BHC (Lndene) & $<0.02$ & & & & & \\
\hline$\frac{2,4 \cdot 0}{\text { Endrin }}$ & $<2$ & & & & & \\
\hline Methoxyehtor & $<0.1$ & & & & & \\
\hline Silvex & $<0.2$ & & & & & \\
\hline Toxeenene & $<2$ & & & & & \\
\hline \multirow{2}{*}{\multicolumn{7}{|c|}{ BABENNEUTRAL EXTRACTARLES (LR/L) }} \\
\hline Acenephthens & & & & & & \\
\hline Aoerephthylene & $\frac{<10}{<10}$ & & & & & \\
\hline Amthreoene & $<10$ & & & & & \\
\hline Beneidine & $<80$ & & & & & \\
\hline Bereolalantheoene & $<10$ & & & & & \\
\hline Bentolalpyrene & $<10$ & & & & & \\
\hline Benololfivorenthene & $<10$ & & & & & \\
\hline Encolo,h,ilpuryien & $<10$ & & & & & \\
\hline Eeroolkiflivoreminen & $\leq 10$ & & & & & \\
\hline Bensy! Noohol & $<10$ & & & & & \\
\hline Beroy Butyl Phthelete & $<10$ & & & & & \\
\hline Bu/2.ChiorecthoxylMethene & $<19$ & & & & & \\
\hline Bal2-ChioroetmyllEthe & $\leq 10$ & & & & & \\
\hline Bial2-ChioroiecpropyllEther & $<10$ & & & & & \\
\hline Bipl2-Ethylh xyll) Phthalete & $<10$ & & & & & \\
\hline A-Bromophenyl Prenyl Ether & $<10$ & & & & & \\
\hline AChioraeniline & $<10$ & & & & & \\
\hline 2-Chioronephinelen & $\leq 10$ & & & & & \\
\hline 4-Chioroghenyl Pheny I Ethe & $<10$ & & & & & \\
\hline Chryene & $<10$ & & & & & \\
\hline Ditn-Butyl Phithelate & $<10$ & & & & & \\
\hline Din-Octyl Pinhelate & $\leq 10$ & & & & & \\
\hline Dibereole, hianthrecene & $<10$ & & & & & \\
\hline Dibereofuren & $<10$ & & & & & \\
\hline 1,2-Diehioroberenene & $\leq 10$ & & & & & \\
\hline 1,3. Oiehlorobentiene & $\leq 10$ & & & & & \\
\hline 1,4-Dichlorobervene & $\leq 10$ & & & & & \\
\hline 3,3'-Diehiorobeneridine & $<20$ & & & & & \\
\hline Diechyl Phithalete & $<10$ & & & & & \\
\hline Dimeinyl Phthelote & $<10$ & & & & & \\
\hline 2,4-Dinitrotoluen & $\leq 10$ & & & & & \\
\hline 2.0-Dinitrotoluen & $<10$ & & & & & \\
\hline Fluereminene & $\leq 10$ & & & & & \\
\hline Fluoren & $\leq 10$ & & & & & \\
\hline Hexechlorobeneren & $\leq 10$ & & & & & \\
\hline Hexechloreburedien & $<10$ & & & & & \\
\hline Hexechlorocyelopemedien & $<10$ & & & & & \\
\hline Hexechiorocethen & $<10$ & & & & & \\
\hline Indenol1,2,3-adpyrene & $<10$ & & & & & \\
\hline Eepherone & $<10$ & & & & & \\
\hline 2- Methyinephinalene & $<10$ & & & & & \\
\hline N-Nitroeodi-NA-PTopylemine & $<10$ & & & & & \\
\hline Mephenthelene & $<10$ & & & & & \\
\hline 2-Nitroeniline & $<60$ & & & & & \\
\hline 3-Nitreenlline & $<60$ & & & & & \\
\hline 4- Nitroeniline & $<60$ & & & & & \\
\hline Nitroberatene & $<10$ & & & & & \\
\hline Pheneminrene & $\leq 10$ & & & & & \\
\hline Pyrene & $<10$ & & & & & \\
\hline 1,2,4-Trichioroberenen & $\leq 10$ & & & & & \\
\hline 2,4,5-T trichtorephenol & $<50$ & & & & & \\
\hline \multicolumn{7}{|l|}{ ACID EXTRACTABLES (LAR) } \\
\hline Bentove Aoid & $<50$ & & & & & \\
\hline 4-Chloro-3.Melhylphenol & $<10$ & & & & & \\
\hline 2-Chiorophenol & $<10$ & & & & & \\
\hline 2,4-Oichiorephenol & $<10$ & & & & & \\
\hline 2,4.Dimethriphenot & $<10$ & & & & & \\
\hline 2,4-Dinitrophenol & $<50$ & & & & & \\
\hline 2-Methyl-4, O-Dinitrophenol & $<50$ & & & & & \\
\hline \multicolumn{7}{|l|}{ 2-Menhyl Phenol } \\
\hline 3-Mernyl Phenol & $<10$ & & & & & \\
\hline A-Alethyl Phenol & $<10$ & & & & & \\
\hline 2-Nitrophenol & $<10$ & & & & & \\
\hline 4-Nitrophenol & $<60$ & & & & & \\
\hline Pentechiorophenol & $<69$ & & & & & \\
\hline Phenol & $<10$ & & & & & \\
\hline $2,4,0$-Trichlorophenol & $<10$ & & & & & \\
\hline
\end{tabular}


QW.176

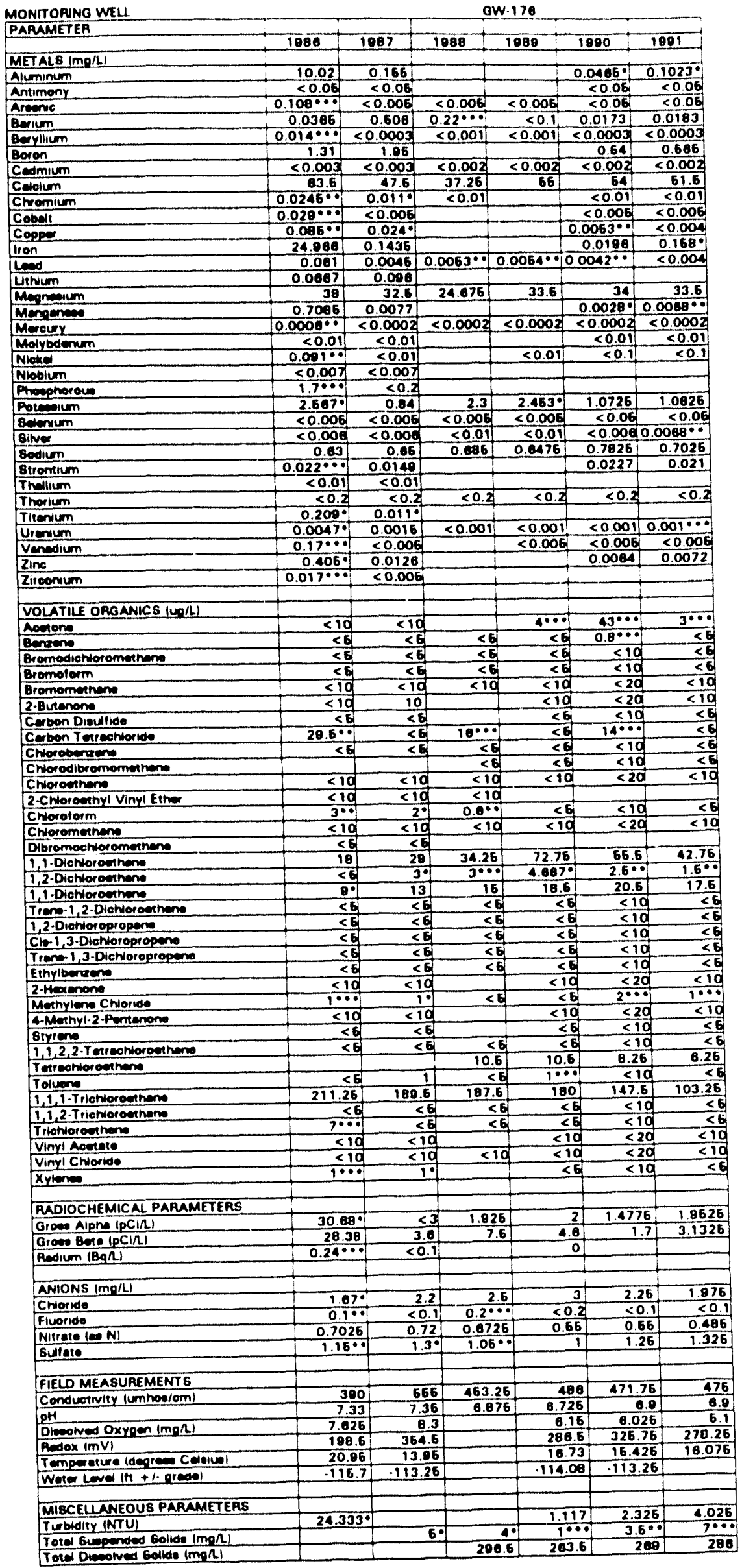




\section{A-192}

aWNUAL AVERAOEB - Comtinued

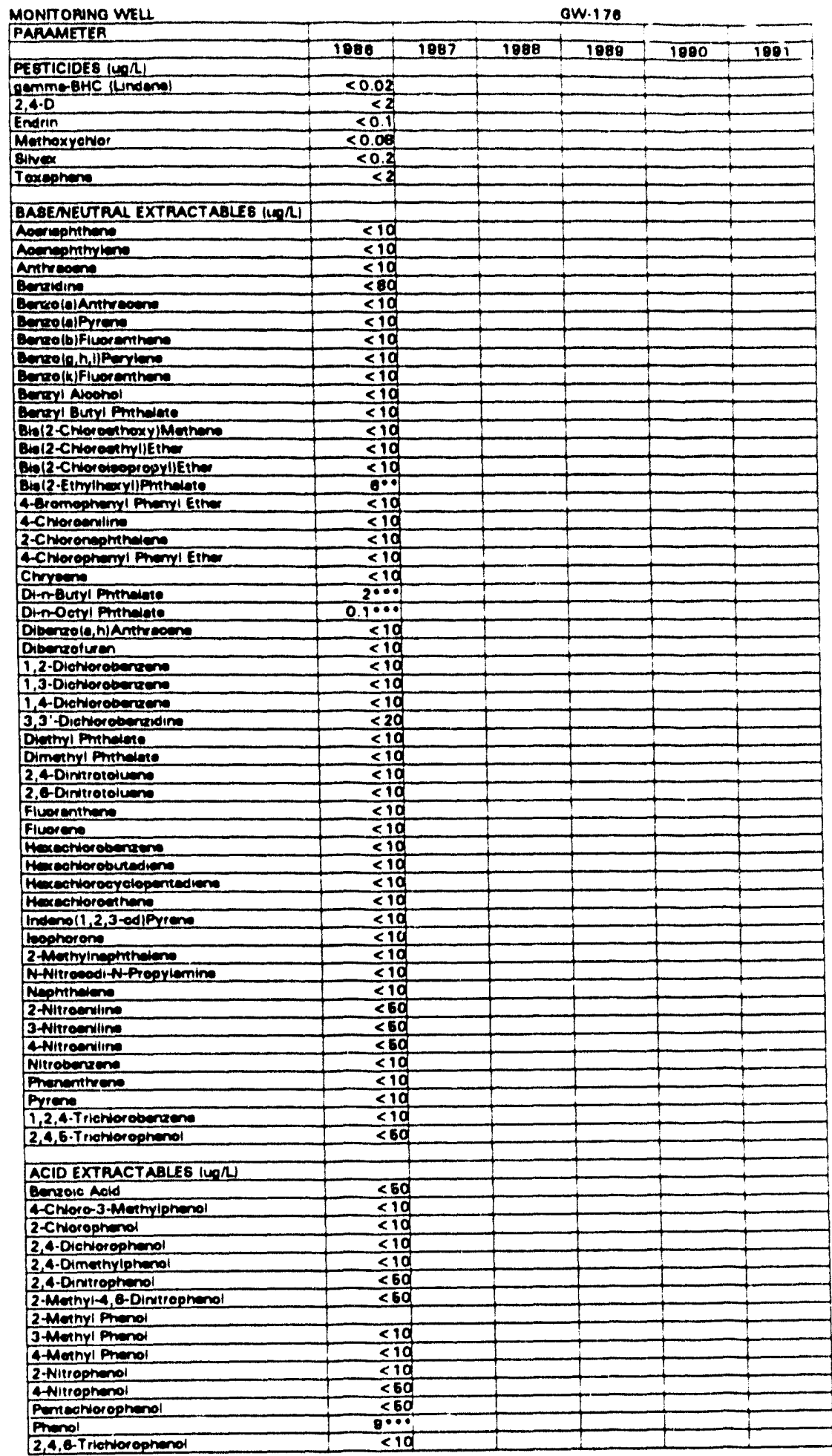




\section{A-193}

OW.17日

\begin{tabular}{|c|c|c|c|}
\hline & & & \\
\hline PAMAMTER & 7000 & 1000 & 1000 \\
\hline METALO $\operatorname{lm} \cap M$ & & . & \\
\hline Numinum & & & 1.3007 \\
\hline$\frac{\text { Antimeny }}{\text { Nonerie }}$ & & & $<0.0$ \\
\hline$\frac{\text { Arande }}{\text { Berium }}$ & $<0.008$ & $<0.000$ & $<0.8$ \\
\hline$\frac{\text { Dexilum }}{\text { Benlitim }}$ & $0.17 \cdots 0$ & $<0.1$ & 0.0653 \\
\hline Benllinm & $<0.001$ & $<0.001$ & $<0.003$ \\
\hline Cenmilum & & & 0.0380 \\
\hline $\begin{array}{l}\text { Cedmilum } \\
\text { Cedeium }\end{array}$ & $<0.002$ & $<0.007$ & $\leq 0.002$ \\
\hline C. velum & 41 & 40 & 02.26 \\
\hline Chremium & $<0.01$ & $<0.01$ & $<0.1$ \\
\hline$\frac{\text { Ceboll }}{\text { Cenet }}$ & & & $<0.06$ \\
\hline Cenet & & & 0.160 \\
\hline Iren & & & 5.175 \\
\hline ten & $<0.004$ & 0.0107 & 0.14100 \\
\hline Ithlum & & & \\
\hline Menenum & 20.0 & 28.20 & 30 \\
\hline Menenten & & & 0.102 \\
\hline Movery & $<0.0002$ & $<0.00020 .0$ & 000300 \\
\hline Molyetmin & & & $<0.1$ \\
\hline Noter & & $\leq 0.01$ & $<0.1$ \\
\hline Nosium & & & \\
\hline Preceporous & & & \\
\hline Pot & 1.0425 & $2.0^{0 \cdot 0}$ & 0.25000 \\
\hline Eenivm & $<0.006$ & $<0.000$ & $<0.6$ \\
\hline enve & $<0.01$ & $<0.01$ & $<0.0$ \\
\hline Cosinn & 1.326 & 1.76 & 18.326 \\
\hline Erremicm & & & 0.0707 \\
\hline Thallium & & & \\
\hline Therium & $<0.2$ & $\leq 0.2$ & $<2$ \\
\hline Tirenium & & & \\
\hline Urenum & $<0.001$ & $<0.0010$ & $.001 \cdots$ \\
\hline Veraivm & & $<0.006$ & $<0.06$ \\
\hline $2 \ln$ & & & 1.1033 \\
\hline Zlioenum & & & \\
\hline & & & \\
\hline YOLATILE OAOANIC $(L O N)$ & & & \\
\hline Aceicen & & $\leq 10$ & $<10$ \\
\hline Denen & $\leq 0$ & $\mathrm{SC}$ & $<$ \\
\hline Cromodiohicionninere & $<$ & $<E$ & 200 \\
\hline Eremotorm & $<\mathrm{g}$ & $<$ & $<0$ \\
\hline Bromementhen & $\leq 10$ & EId & $<10$ \\
\hline 2- Qurenone & & <1d & $<10$ \\
\hline Certeon Doullide & & $<3$ & $<8$ \\
\hline Cerbon Tereoniedide & ano & $\leq$ & $<G$ \\
\hline Cherebentin & $<6$ & SE & $<$ \\
\hline Crioredioremementen & <e & <त & $<0$ \\
\hline Chicoothen & $<10$ & $\leq 10$ & $\leq 10$ \\
\hline 2-Chiorecthri Viny/ Eine & $\leq 10$ & & \\
\hline Chiorolorm & रद & $<0$ & $16 \cdot 0$ \\
\hline Chiorementions & $<10$ & $\mathrm{KIO}$ & $<10$ \\
\hline Dibremeotioromenthen & & & \\
\hline 1, 1-Dighioreonthen & 3.3330 & 8.6 & $4.6^{\circ} \cdot$ \\
\hline 1,2-Otohioreanen & $<\frac{C}{2}$ & $<$ & $<6$ \\
\hline 1,1.0lohiorecenten & 2000 & 2 & $<\mathrm{g}$ \\
\hline Tren-1,2-Dohlorountens & $<$ & $<\theta$ & $<5$ \\
\hline 1,2-Olehtoreprogerie & $<0$ & $<$ & $<0$ \\
\hline $\mathrm{Cl}-1,3 \cdot$ Dhohioropropen & $\leq c$ & <e & $<6$ \\
\hline 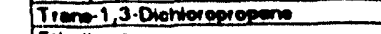 & $<$ & $<\theta$ & $<\theta$ \\
\hline 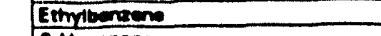 & $<0$ & <द & $<0$ \\
\hline $2+$ thenenon & & $<10$ & $<10$ \\
\hline Metrolere Chioride & $\leq$ & a.0. & $<0$ \\
\hline 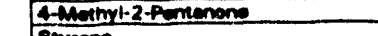 & & $<10$ & $<10$ \\
\hline Espren & & $\leq 0$ & $<8$ \\
\hline 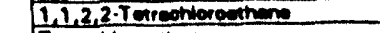 & $<0$ & <द & $<0$ \\
\hline Terpootioroen hem & 400 & $0.06 \cdot 9$ & $0.0 \cdots$ \\
\hline Tolven & $<$ & $<$ & $<5$ \\
\hline 1,1,1.Triohioreethene & 32.76 & 36.6 & 20.5 \\
\hline 1,1,2. Triahlorednene & $<0$ & $<6$ & $<5$ \\
\hline Triohioroenthe & $<4$ & $<$ & $<E$ \\
\hline Vmpl noerete & & $\leq 10$ & $\leq 10$ \\
\hline Vimyl Chloride & $<10$ & $<10$ & $\leq 10$ \\
\hline 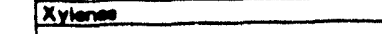 & & $<0$ & $<$ a \\
\hline & & & \\
\hline 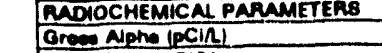 & & & \\
\hline $\begin{array}{l}\text { Oreos Nphe }(\mathrm{pCin}) \\
\text { Oreen Bete (pCin) }\end{array}$ & $\frac{3.4275}{34}$ & 2.1 & $\frac{1.306}{0.0025}$ \\
\hline $\begin{array}{l}\text { Orow Ben (pCin) } \\
\text { Andium (Ban } \\
\end{array}$ & 34 & $\frac{5}{0}$ & 0.8026 \\
\hline Andium lagn & & o. & \\
\hline $\begin{array}{l}\text { AN1ON8 }(\mathrm{mo} \Omega) \\
\text { Chioride }\end{array}$ & & & \\
\hline $\begin{array}{l}\text { Chicoride } \\
\text { Flueride }\end{array}$ & 1.06 & 2 & 11.6 \\
\hline Fluoride & $<0.1$ & $<0.2$ & $0.36^{\circ}$ \\
\hline Nhtrige $|\mathrm{N}|$ & 0.20 & 0.206 & 0.425 \\
\hline Eutere & 1.026 & 1.75 & 13.76 \\
\hline & & & \\
\hline $\begin{array}{l}\text { FIELD MEA GUAEMENTS } \\
\text { Conduorivity (Lmhed/om) }\end{array}$ & & & \\
\hline Condworivity (umbealom) & $\begin{array}{r}400 \\
7775\end{array}$ & $\frac{371}{7.126}$ & $\frac{400}{7.0}$ \\
\hline $\begin{array}{l}\text { PH } \\
\text { Dineotved Oxyoen }(m a n)\end{array}$ & 7.776 & $\frac{7.126}{0.76}$ & 8 \\
\hline 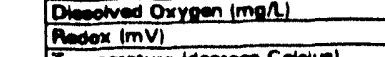 & & $\frac{0.16}{307.76}$ & 316.0 \\
\hline & & 16.16 & 16.376 \\
\hline were Level in + $1 \cdot$ eredel & & 09.51 & +6.26 \\
\hline & & & \\
\hline 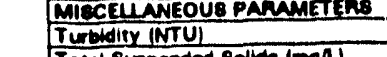 & & 24.2333 & 1600.075 \\
\hline Turbedity (NTU) & 0.25 & $10.333^{\circ}$ & 30.5 \\
\hline Total an ended collde $(\mathrm{m} / \mathrm{h})$ & 240 & 207.6 & 282 \\
\hline
\end{tabular}


OW.170

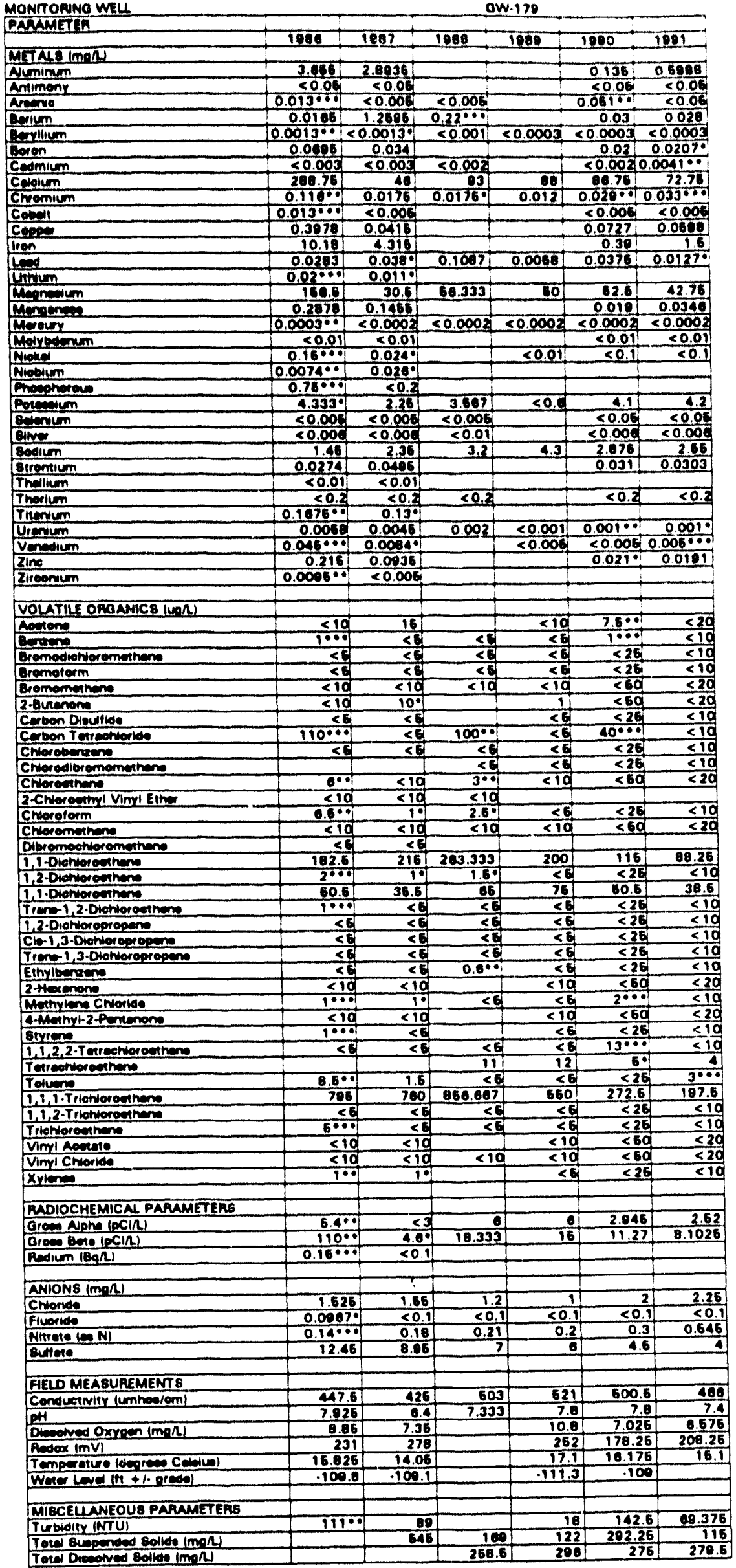


aw.178

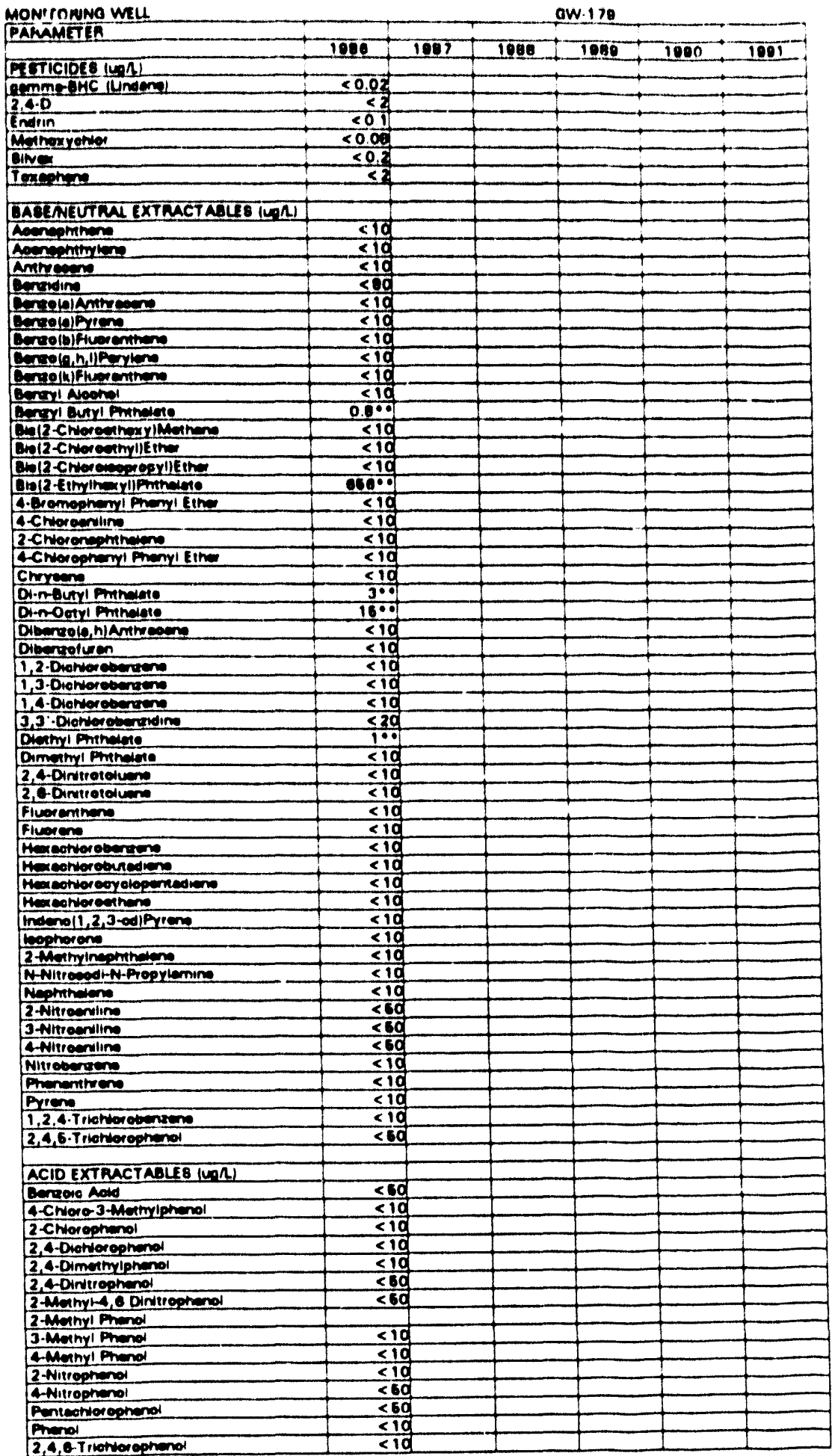




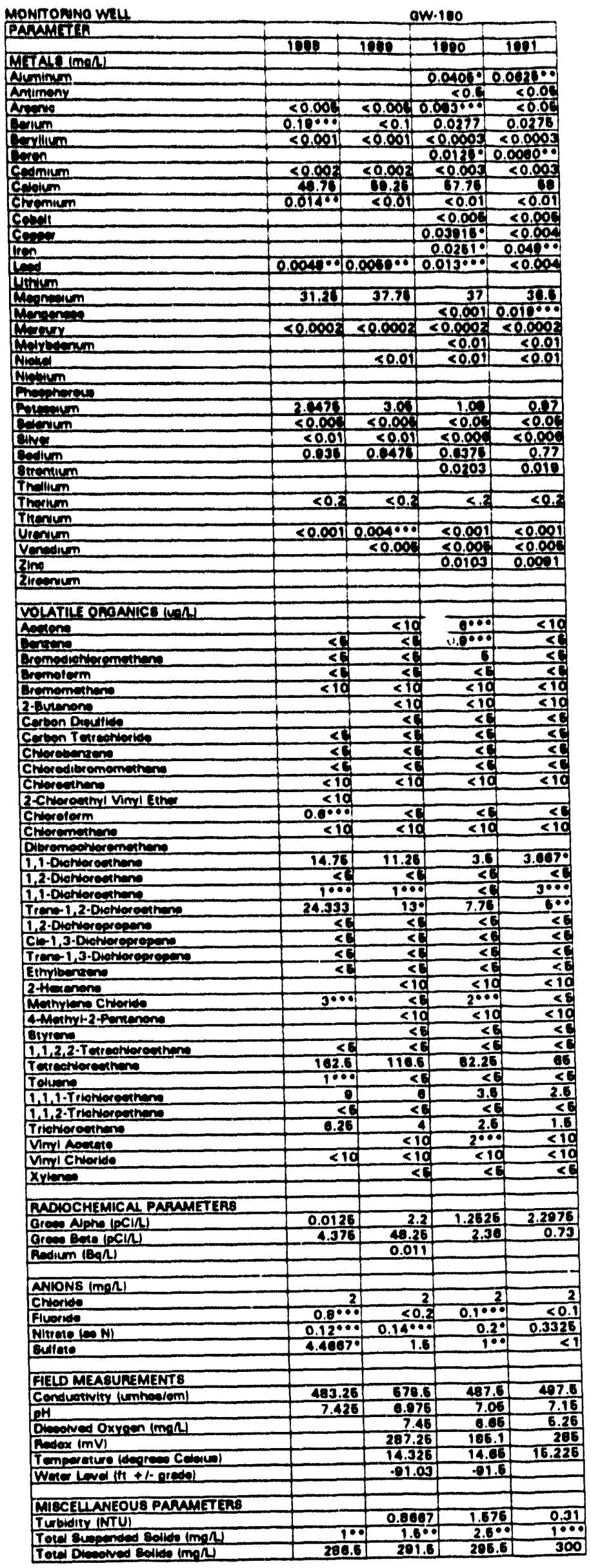


Qw.332

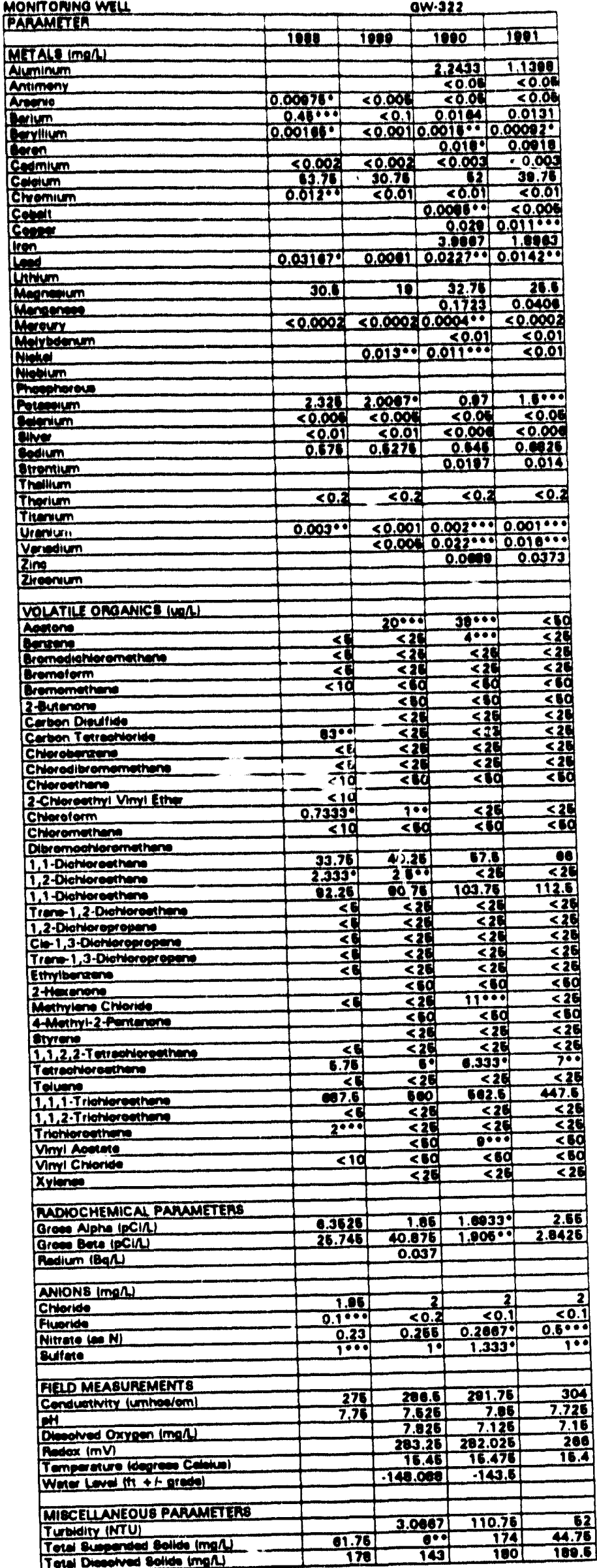


A-198

ANNUAL AVERAOES - Comminu:

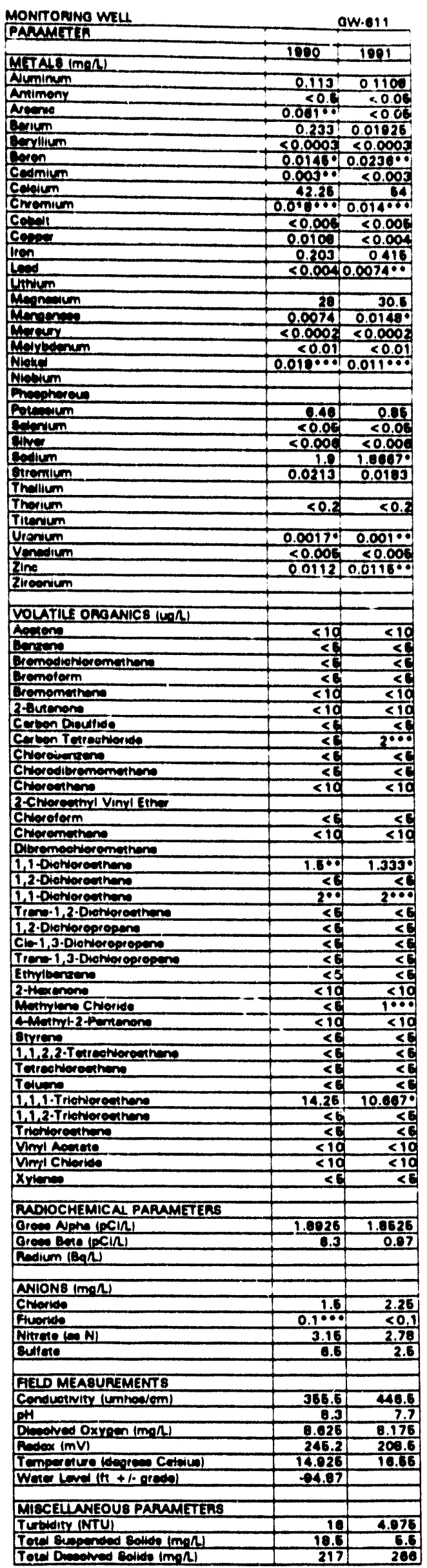




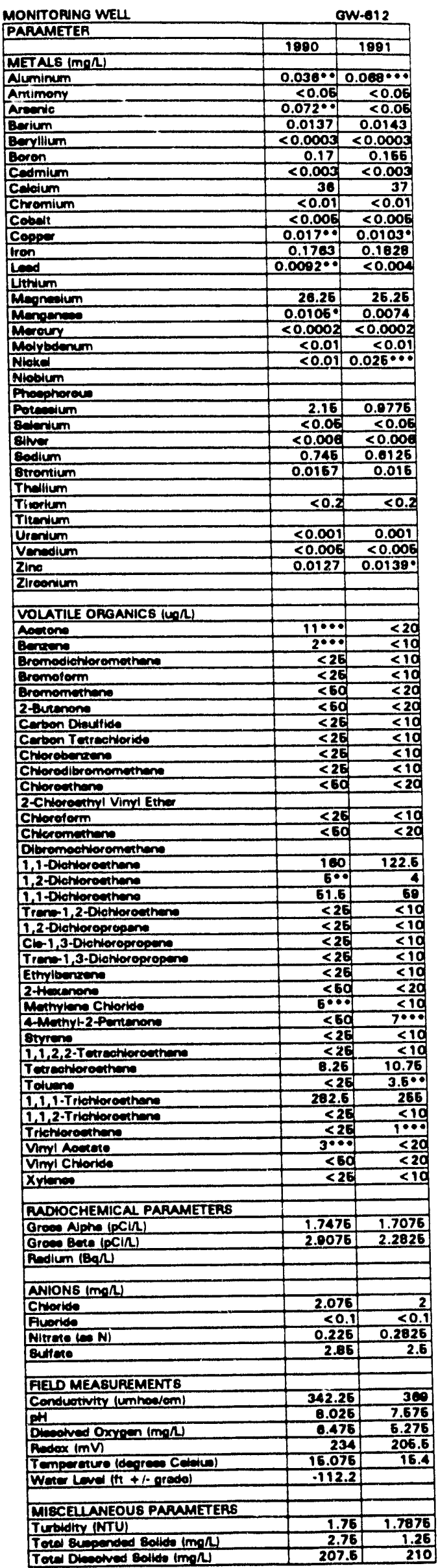




\section{APPENDIX B}

APPLICABLE OR RELEVANT AND APPROPRIATE REQUIREMENTS FOR Y-12 CHESTNUT RIDGE OPERABLE UNIT ONE 


\section{APPLICABLE OR RELEVANT AND APPROPRIATE REQUIREMENTS FOR Y-12 CHESTNUT RIDGE OPERABLE UNIT ONE}

\section{Introduction}

The Comprehensive Environmental Response, Compensation, and Liability Act (CERCLA) of 1980 was passed by Congress and signed into law on December 11, 1980 (Public Law 96510). This act was intended to provide for "liability, compensation, cleanup, and emergency response for hazardous substances released into the environment and the cleanup of inactive waste disposal sites." The Superfund Amendments and Reauthorization Act (SARA), adopted on October 17, 1986 (Public Law 99-499), did not substantially alter the original structure of CERCLA but provided extensive amendments to it.

In particular, $\$ 121$ of CERCLA specifies that remedial actions for cleanup of hazardous substances must comply with requirements or standards under federal or more stringent state environmental laws that are applicable or relevant and appropriate to the hazardous substances or particular circumstances at a site. Inherent in the interpretation of applicable or relevant and appropriate requirements (ARARs) is the assumption that protection of human health and the environment is ensured.

The purpose of this report is to supply a preliminary list of available federal and state chemical- and location-specific ARARs that might be considered for cleanup of Chestnut Ridge Operable Unit 1 (CROU1). CROU1 is the Chestnut Ridge Security Pits Hazardous Waste Disposal Unit (HWDU) located on the crest of Chestnut Ridge, southeast of the central portion of the Y-12 Plant. Operated since 1973, the unit consists of a series of trenches that were used for the disposal of classified hazardous and nonhazardous wastes until December 1984 and November 1988, respectively. The Unit was closed in 1988 in accordance with a Tennessee Department of Environment and Conservation (TDEC)-approved Resource Conservation and Recovery Act (RCRA) closure plan which required a low-permeability, low-maintenance cover over the trenches. Groundwater impacts from the disposal operations are the primary focus of this Remedial Investigation ( $R$ ). Soil samples will be taken around the perimeter of the cap to determine the possible spread of contamination beyond the boundaries of the cap. Remedial alternatives analyzed during the feasibility study (FS) will address on-site control of the source of any groundwater contamination and, possibly, direct remediation of the groundwater itself depending on the nature and extent of the contamination identified. Contaminants of concern identified for CROU1 inciude volatile organic compounds (VOCs), metals and radionuclides.

The Chestnut Ridge Security Pits HWDU was afforded interim status under TDEC Rule 1200-1-11-.07(3). The waste disposed of in the trenches is known to have been RCRAhazardous. Therefore, the Chestnut Ridge HWDU was closed under RCRA as an interim status hazardous waste landfill in 1988, pursuant to TDEC Rule 1200-1-11-.05(14)(e). Final closure certification was approved by TDEC in November 1990, and the site is subject to post-closure care under TDEC Rule 1200-1-11-.06(7)(g) and (h). Accordingly, any ARARs identified under RCRA will be legally applicable at this site for cleanup under CERCLA. RCRA ARARs pertain, for the most part, to specific types of actions or facilities and will be addressed more thoroughly as remedial alternatives are developed during the FS. 
The process of ARAR identification is an iterative one that is continually changing as the RI/FS progresses. Therefore, this list of ARARs represents a compilation of potential ARARs, of which subsets will be used or additional ARARs added as further site characterization is done.

It is understood that the Department of Energy (DOE) will comply with the requirements of the National Environmental Policy Act (NEPA) as specified in DOE. Order 5440.1D (National Environmental Policy Act Compliance Program). Further, DOE Order 5400.4 (Comprehensive Environmental Response, Compensation, and Liability Act Requirements) calls for integration of NEPA and CERCLA requirements for DOE remedial actions at CERCLA sites. This issue has been reaffirmed in the Federal Facilities Agreement (FFA) for the Oak Ridge Reservation (ORR) $\S \mathrm{I}(\mathrm{A})(3)$ and $\S \mathrm{III}(\mathrm{A})(2)$ and Secretary of Energy Notice (SEN) of February 5, 1990 (SEN-15-90), which was issued to ensure that DOE's NEPA activities are carried out in a centralized and uniform manner. Therefore, the regulations found in NEPA will not be addressed in this report as ARARs; however, the regulations that are triggered by the presence of certain resources are discussed below (Sect. 4).

Similarly, DOE addresses occupational safety in DOE Orders 5480.11 (Radiation Protection for Occupational Workers), 5480.4 (Environmental Protection, Safety, and Health Protection Siandards), 5483.1A (Occupational Safety and Health Program for Contractors at GOCO Facilities), 5480.9 (Construction Safety and Health Program), and 5480.10 (Contractor Industrial Hygiene Program). However, ARARs apply to those federal and state regulations that are designed to protect the environment, and do not generally apply to occupational safety regulations. Therefore, the DOE Orders related to occupational safety, as well as the regulations promulgated by the Occupational Safety and Health Administration (OSHA), are not addressed as ARARs unless they specifically apply to remedial action goals. The OSHA regulations will be addressed in the Health and Safety Plan for this OU.

\subsection{Definitions}

Applicable requirements are "those cleanup standards, standards of control, and other substantive requirements, criteria, or limitations promulgated under federal environmental or state environmental or facility siting laws that specifically address a hazardous substance, pollutant, contaminant, remedial action, location, or other circumstance at a CERCLA site" (40 CFR 300.5).

Relevant and appropriate requirements are "those cleanup standards, standards of control, and other substantive requirements, criteria, or limitations promulgated under federal environmental or state environmental or facility siting laws that, while not applicable to a hazardous substance, pollutant, contaminant, remedial action, location, or other circumstance at a CERCLA site, address problems or situations sufficiently similar to those encountered at the CERCLA site that their use is well suited to the particular site" (40 CFR 300.5).

Requirements under federal or state law may be either applicable or relevant and appropriate to CERCLA cleanup actions, but not both. However, requirements must be both relevant and appropriate for compliance to be necessary. In the case where a federal and a state ARAR are available, or where there are two potential ARARs addressing the same issue, the more stringent regulation must be selected. However, CERCLA \$121(d)(4) provides several ARAR waiver options that may be invoked, providing that the basic premise of protection of human health and the environment is not ignored. A waiver is available for state standards that have not been 
applied uniformly in similar circumstances across the state. In addition, CERCLA $\$ 121(\mathrm{~d})(2)(\mathrm{C})$ forbids state standards that effectively prohibit land disposal of hazardous substances.

CERCLA on-site remedial response actions must only comply with the substantive requirements of a regulation and not the administrative requirements to obtain federal, state, or local permits [CERCLA $\$ 121$ (e) and FFA §XXII]. To ensure that CERCLA response actions proceed as rapidly as possible, EPA has reaffirmed this position in the final NCP (55 FR 8756, March 8, 1990). Substantive requirements pertain directly to the actions or conditions at a site, while administrative requirements facilitate their implementation. The Environmental Protection Agency (EPA) recognizes that certain of the administrative requirements, such as consultation with state agencies and reporting, are accomplished through the state involvement and public participation requirements of the NCP. These administrative requirements should be observed if they are useful in determining cleanup standards at the site (55 FR 8757).

In the absence of federal- or state-promulgated regulations, there are many criteria, advisories, guidance values, and proposed standards that are not legally binding but may serve as useful guidance for setting protective cleanup levels. These are not potential ARARs but are "to-be-considered" (TBC) guidance.

\section{Chemical-specific ARARs}

"Chemical-specific requirements set health- or risk-based concentration limits or discharge limitations in various environmental media for specific hazardous substances, pollutants, or contaminants" (53 FR 51437). These requirements generally set protective cleanup levels for the chemicals of concern in the designated media or else indicate a safe level of discharge that may be incorporated when considering a specific remedial activity. Although limited in number, chemical-specific standards have been established under several statutes, including RCRA, the Safe Drinking Water Act (SDWA), the Clean Water Act (CWA), and the Clean Air Act (CAA).

\subsection{Groundwater}

As stated in the NCP (55 FR 8666, March 8, 1990), the goal of EPA's approach to cleanup of contaminated groundwater is to return usable groundwater to its beneficial use within a given time frame that is reasonable for the particular circumstances at a CERCLA site. The Ground Water Management Section of the Tennessee Division of Water Supply is in the process of developing a groundwater classification system for Tennessee groundwaters. The draft classification has been revised several times and will be resubmitted for public comment in July 1993; a final version is expected by late 1993. At that time, the document should be consulted to determine which groundwater classification will be legally applicable to CROU 1 groundwater. Final determination of ARARs will depend on the chosen groundwater classification.

In the NCP, EPA states the preference for SDWA maximum contaminant levels (MCLs) and nonzero maximum contaminant level goals (MCLGs) or other health-based standards, criteria, or guidance for cleanup of Class I and Class II (current or potential sources of drinking water) groundwater at CERCLA sites (55FR 8732). Alternate concentration limits (ACLs) may also be used when active restoration of the groundwater to MCLs or nonzero MCLGs is not practicable (55 FR 8754). For Class IIl (not a potential source of drinking water) groundwaters, EPA establishes remediation levels based on specific site conditions, the beneficial use of the 
groundwater, and environmental receptors (55 FR 8732). Federal MCLs/MCLGs and action levels for contaminants of concern at CROU1 are listed in Table 1.

MCLs are enforceable standards that take into consideration human health effects, available treatment technologies, and costs of treatment. MCLGs are strictly health-based standards that disregard cost or treatment feasibility and are not legally enforceable. MCLs are legally applicable to water "at the tap" but are not usually legally applicable to cleanup of groundwater or surface water. However, they may be considered as relevant and appropriate in situations where groundwater or surface water may be used for drinking water. CERCLA $\$ 121(d)(2)(A)$ specifically mentions that remedial actions must require a level or standard of control that at least attains MCLGs and federal ambient water quality criteria (WQC) where such goals or criteria are relevant and appropriate under the circumstances of the release. Although MCLGs and WQC are nonenforceable guidelines, Congress elevated them to a higher status by specifically mentioning them in CERCLA. Therefore, promulgated MCLGs are also listed in Table 1. At present, EPA is planning to use the SDWA MCLs for remedial action compliance for carcinogens that have an MCLG of zero and any nonzero MCLG for systemic toxicants (55 FR 8752).

EPA has revised its drinking water standards for lead, eliminating the $\mathrm{MCL}$ and replacing it with an "action level" of $15 \mu \mathrm{g} / \mathrm{L}$ (56 FR 26460, June 7, 1991), applicable to community and nontransient, noncommunity water systems. Included in the national primary drinking water regulation is a treatment technique requirement. If the action level for lead is exceeded at the tap, a state is required to analyze source water samples and to decide what treatment levels are necessary to minimize lead levels delivered to users from the affected distribution system. In the instance of contaminated groundwater at CROU1, the action level for lead is neither legally applicable nor relevant and appropriate at this time, although the Tennessee proposed draft rule, Hazardous Substance Site Remedial Action (Chapter 1200-1-13, August 4, 1992), cites federal MCLs and action levels as cleanup levels for groundwater remedial action sites. The EPA Office of Solid Waste and Emergency Response (OSWER) has recommended that a final cleanup level of $15 \mu \mathrm{g} / \mathrm{L}$ for lead in groundwater usable for drinking water is protective of sensitive populations (OSWER memorandum dated June 21, 1990). This might be considered TBC guidance for remediation of lead-contaminated groundwater.

Chapter 1200-5-1 of the Rules of the Tennessee Department of Environment and Conservation (TDEC), as amended effective January 10, 1991, lists MCLs for public water systems which are identical to the federal MCLs in effect at that time. These regulations have since been revised to incorporate the recent revisions in federal MCLs, therefore they are not repeated here.

National Secondary Drinking Water Standards (NSDWS) regulate contaminants that affect the aesthetic qualities related to public acceptance of drinking water and are implemented in 40 CFR 143.3 as secondary maximum contaminant levels (SMCLs). These regulations are not federally enforceable but rather are intended to serve as guidelines for use by states in regulating water supplies. Tennessee has promulgated SMCLs in TDEC Rule 1200-5-.12. These regulations are designed to provide water to the consumer which is aesthetically pleasing. They apply to all community water systems and to those noncommunity water systems "as may be deemed necessary" by TDEC. In that context, they would not be legally applicable to cleanup of groundwater or surface water but may be considered as relevant and appropriate in instances where these media may provide private drinking water sources. SMCLs are listed and footnoted as such in Table 1 for those contaminants which currently have no MCL or MCLG. 
Since CROU1 has been closed under RCRA, it is subject to RCRA corrective action regulations. The 40 CFR 264 Subpart F regulations on groundwater protection at RCRA regulated units are legally applicable; these include groundwater protection standards and groundwater requirements. Subtitle $C$ of RCRA lists maximum concentration levels for 14 chemicals; the concentration of these chemicals in groundwater at the plant boundary of a RCRApermitted treatment, storage, or disposal (TSD) facility may not exceed the stated maximum concentration level [Title 40, Code of Federal Regulations, Part 264, $\$ 94$ (40 CFR 264.94)]. In addition, background concentrations or ACLs are established in 40 CFR 264.94 as groundwater protection standards. Table 1 lists RCRA maximum concentration levels; however, as mentioned above, EPA has specified SDWA MCLs and nonzero MCLGs for cleanup of Class I and Class II groundwater and site-specific remediation levels for Class III groundwaters. This approach is consistent with the substantive requirements of RCRA maximum concentration levels, ACLs, or background limits (53 FR 51433).

The TDEC Division of Superfund has issued a draft rule, Hazardous Substance Site Remedial Action (Chapter 1200-1-13, issued August 4, 1992), governing cleanup of remedial action Superfund sites in the state of Tennessee. Chapter 1200-1-13-.08 of the proposed rule lists cleanup levels for hazardous substance remediation and states that the objectives of this section are "...(a) To establish clear, objective cleanup levels by identifying and/or developing chemical specific ARAR's, and (b) To insure consistent procedures for the development and usage of cleanup levels." The proposed rule states that where groundwater is classified for drinking water, cleanup levels shall either meet federal SDWA MCLs and action levels, SMCLs if MCLs are not available, or naturally occurring background levels. Chapter 1200-1-13-.08(5)(a) states that "Where numerical standards are not available, a ground water cleanup level should be developed based on (a) ingestion and inhalation effects by utilizing the EPA Human Health Evaluation Manual, Part B, December 1991, or (b) a risk assessment shall be developed utilizing sitespecific justifications, or (c) guidance levels established under the RCRA Hazardous Waste Regulations shall be utilized. Where ground water is not classified for drinking water, cleanup levels shall be established in accordance with Chapter 1200-4-3.07(3)(d)(2)." Chapter 1200-4$3.07(3)(d)(2)$ is not yet promulgated; it is part of the TDEC groundwater classification rule which is under development and due to be issued in late 1993. When the draft Hazardous Substance Site Remedial Action rule is promulgated, it will be legally applicable to cleanup of groundwater at CROU1; until that time it can be considered TBC guidance.

\subsection{Surface water}

Chestnut Ridge forms a topographic divide between East Fork Poplar Creek watershed to the northwest and McCoy Branch and several numbered tributaries and their watersheds to the southeast. McCoy Branch and tributary No. 4 are adjacent to CROU1; therefore, they are the most likely to be hydraulically connected to CROU1. Flows in these tributaries originate from surface water run-off from Chestnut Ridge and from groundwater that enters the drainages through the stream beds and springs along the tributaries (Radian 1992).

East Fork Poplar Creek and McCoy Branch are classified by the Tennessee Water Quality Control Board for industrial water supply, fish and aquatic life, recreation, irrigation, and livestock watering and wildlife uses [Tennessee Department of Environment and Conservation (TDEC) Rules, Chap. 1200-4-4]. The state water quality criteria for protection of fish and aquatic life, and for the consumption of aquatic organisms (the criteria for protection of recreation uses), are listed in Table 1 for comparison to any surface water sampling results to determine 
extent of any contamination. In the absence of a state criterion for a specific chemical, a federal criterion is listed if available. If surface water contamination from CROU1 is identified, one goal of any remedial actions taken will be to control the onsite source of that contamination; surface water itself will not be remediated as part of this OU.

\subsection{Soils}

Very little legislation or guidance is available governing cleanup criteria for contaminated soils at CERCLA sites. RCRA has addressed land disposal of treated hazardous wastes in its land disposal restrictions (LDRs) (40 CFR 268), and these will be addressed as action-specific ARARs during the FS. Since CROU1 has been closed under RCRA, it is subject to RCRA corrective action regulations. Requirements for corrective action for solid waste management units (SWMUs) have been proposed as a new Subpart S of 40 CFR 264 (55 FR 30798, July 27, 1990). EPA has proposed a risk-based approach to establish media cleanup standards for surface water, groundwater, soil, and air. These standards are to be established at concentrations that ensure protection of human health and the environment, and are to be set for each media of concern during the remedy selection process. Target cleanup levels may initially be set at the RCRA action levels, but modified as appropriate to reflect site-specific exposure assumptions (55 FR 30826). Final promulgation of this rule is projected for December, 1993.

EPA has determined that the RCRA treatment standards are generally inappropriate or infeasible when applied to contaminated soil or debris (55FR 8760). Therefore, EPA proposed separate rulemakings to establish treatment standards for disposal of such contaminated soil and debris. The Notice of Proposed Rulemaking (NPRM) for debris appeared January 9, 1992 (57 FR 958); final rule, August 18, 1992 (57 FR 37194). The revised standards (40 CFR 268.45) require contaminated debris to be treated prior to land disposal using extraction, destruction, or immobilization technologies.

The ANPRM for soil appeared October 24, 1991 (56 FR 55160); the NPRM is scheduled for August, 1993, final rule August, 1994 (Houlberg et al. 1993). The rule will be analyzed for ARARs or TBC when available. In the interim, EPA has developed guidance for obtaining and complying with a treatability variance for soil and debris that are contaminated with RCRA hazardous wastes for which treatment standards have already been set (OSWER Directive 9347.306FS, July 1989). These will be considered as TBC guidance when remedial alternatives are selected and more information becomes available on waste types.

The TDEC proposed a Hazardous Substance Site Remedial Action Rule (Rules of the TDEC, Chap. 1200-1-13) that is currently undergoing revisions based on public comments. This rule states that, where numerical standards are not available for cleanup of soils at hazardous waste sites, soil cleanup levels shall be developed based on methods approved or determined by TDEC, or by utilizing a site specific risk assessment approved by TDEC. When promulgated, this rule will be legally applicable to cleanup at CROU1; in the interim, it will serve as TBC guidance.

\subsection{Other "to-be-considered" (TBC) guidance}

EPA has suggested cleanup values for lead in soils based on studies of blood lead levels in exposed children. The EPA OSWER Directive 9355.4-02 (dated September 7, 1989) recommends a cleanup level for soils of 500 to $1000 \mathrm{ppm}$ lead. However, EPA has distributed a draft memorandum (dated June 1992) recommending a cleanup level for lead in soil of 500 
ppm, based on a new lead uptake/biokinetic model. This threshold level could be revised based on site-specific information (DOE 1993).

In the absence of federally or state-promulgated ARARs, or in the case where ARARs are not adequately protective, EPA states a preference for Reference Doses (RfDs) or reference concentrations (RfCs) for systemic toxicants, carcinogen slope factors (CSFs) for carcinogens, or Office of Drinking Water (ODW) Health Advisories (HAs) (USEPA 1988) for drinking water contaminants. The RfDs, RfCs, and CSFs are available through IRIS (U'SEPA 1991) and the EPA Health Effects Assessment Summary Tables (USEPA 1992a).

The EPA ODW has developed nonregulatory Hils for concentrations of noncarcinogenic contaminants in drinking water at which no adverse health effects would be expected to occur. Lifetime HAs available for those COCs at CROU1 which do not have promulgated maximum contaminant levels/secondary maximum contaminant levels (MCLs/SMCLs) are listed in Table 1.

\section{Radiation Protection Standards}

Very few applicable standards are available for the cleanup of radioactively contaminated CERCLA sites. The Atomic Energy Act (AEA) of 1954 and its amendments delegated authority for control of nuclear energy to DOE, the U.S. Nuclear Regulatory Commission (NRC), and EPA. In addition, certain states have regulatory authority and programs for radioactive waste. EPA's regulations are derived from several other statutes as well and cover many types of activities and all types of radioactive materials. The NRC licenses the possession and use of various types of radioactive materials at certain types of facilities. Tennessee is an NRCAgreement state and, as such, has its own authority and licensing regulations.

DOE is authorized to control all types of nuclear materials at sites under its jurisdiction and is exempt from the NRC licensing and regulatory requirements. Therefore, NRC regulations are not generally considered to be ARARs for CERCLA cleanup at DOE facilities. The DOE regulations for handling and cleanup of radioactive materials are outlined in a series of internal DOE Orders that are legally binding to DOE contractors but are not considered by EPA to be ARARs. The DOE Orders, however, are functionally equivalent to the NRC requirements, and include all "appropriate" requirements from the NRC regulations. For the purposes of development of ARARs, DOE Orders will be treated as TBC guidance rather than the NRC regulations. Sections of the NRC regulations may supply ARARs or TBC guidance in situations where the DOE Orders do not adequately address a specific situation at a site, and will be addressed during selection of remedial alternatives during the FS.

In addition to RCRA hazardous wastes, CROU1 shows evidence of contamination with radionuclides, including several isotopes of uranium as well as gross alpha and beta activity. The proper definition of "mixed low-level radioactive and hazardous waste" has caused considerable debate with regard to dual jurisdiction by EPA and NRC. However, EPA has published a clarification of the problem (53 FR 37045, September 23, 1988), as did DOE previously [52 FR 15937, May 1, 1987 and DOE Order 5400.3 (Hazardous and Radioactive Mixed Waste Program, dated February 22, 1989)]. In effect, mixed wastes are those containing a RCRA hazardous waste as defined in 40 CFR 261 and a radioactive waste subject to the AEA. RCRA regulations apply to the hazardous component of the waste, and AEA regulations apply to the radioactive component. When the application of both standards is conflicting or inconsistent, RCRA yields 
to the AEA. Tennessee received final authorization to regulate radioactive mixed waste on July 3, 1986 (53 FR 37045, September 23, 1988); however, the state has not implemented any regulations or guidance related to the handling of mixed waste.

On May 26, 1992, EPA published a notice in the Federal Register (57 FR 22024) proposing to find that DOE has made all but one of the demonstrations required in its application, under RCRA rules in 40 CFR 268.5, for a one-year, case-by-case extension of the May 8, 1992 effective date of the LDRs applicable to certain mixed wastes generated or stored at K-25, Y-12, and Oak Ridge National Laboratory, as well as 28 other DOE facilities. Comments were due back to EPA by July 27, 1992, and no official final action has been taken on this proposal as yet. In June, 1992, EPA and DOE signed a Federal Facilities Compliance Agreement (mixed wasteFFCA) to bring mixed waste generation and storage facilities on the Reservation (ORR) into compliance with environmental law. The mixed waste-FFCA allows DOE ORR facilities to continue to generate and store mixed wastes while addressing LDR mixed waste compliance issues. The mixed wastes covered under the mixed waste-FFCA include flammable and corrosive liquids, solvents, paint waste, waste oils and organics, and solid mixed wastes.

\subsection{EPA regulations}

EPA has promulgated MCLs for radionuclides in community water systems (see Table 2). These MCLs appear in two forms-concentration limits for certain alpha-emitting radionuclides (40 CFR 141.15) and an annual dose limit for the ingesțion of certain beta- and gamma-emitting radionuclides (40 CFR 141.16). MCLs and MCLGs were proposed for uranium and reproposed for ${ }^{226} \mathrm{Ra}$ and ${ }^{228} \mathrm{Ra}$, beta emitters, and photon emitters on July 18, 1991, and are included in Table 2. Final promulgation of the concentration limits is not expected until December 1993. These concentration limits may be relevant and appropriate for cleanup of contaminated groundwater at CROU1 and would become legally applicable when the Tennessee Hazardous Substance Site Remedial Action rule is promulgated.

Table 3 lists EPA, NRC, and DOE radiation protection standards that are described below. Subpar H of 40 CFR 61 addresses atmospheric radionuclide emissions from DOE facilities and may be applicable to airborne emissions during cleanup of CROU1. EPA has issued a final National Emissions Standard for Hazardous Air Pollutants (NESHAPs) rule (54 FR 51654, December 15,1989 ) that limits emissions of radionuclides to the ambient air from all sources at DOE facilities to amounts that would not cause any member of the public to receive an effective dose equivalent of $10 \mathrm{mrem} /$ year (40 CFR 61.92).

\subsection{DOE Orders}

DOE Orders are not promulgated regulations and thus are not considered to be ARARs by EPA. They are, however, binding between DOE and Martin Marietta Energy Systems, Inc. (MMES) because of contractual agreements. In particular, the derived maximum radionuclide concentration guidelines for discharges of radioactively contaminated liquids to surface waters, aquifers, and soil that appear in the final DOE Order 5400.5 (Radiation Protection of the Public and the Environment) may be useful as TBC guidance. A basic dose limit of 100 mrem/year is given for routine DOE activities, including remedial action monitoring, cleanup, and control of residual radioactive material, and a dose of less than $500 \mathrm{mrem} / \mathrm{year}$ as a temporary maximum exemption under specially permitted and DOE-approved circumstances (see Table 3). In addition, effluent releases to surface water must not result in exposures to aquatic organisms exceeding an 
absorbed dose of $1 \mathrm{rad} /$ day. The over-riding principle of the Order is that all exposures of the public shall be ALARA. DOE proposed this Order for codification under 10 CFR 834 on March 25, 1993 (58 FR 16268); final rule expected March, 1994. When promulgated, these standards will then become legally applicable to cleanup at CROU1.

DOE Order 5400.5 lists Derived Concentration Guides (DCGs) for radionuclide isotopes which are based on a committed effective dose equivalent of $100 \mathrm{mrem} / \mathrm{year}$ for ingestion of air or water. For liquid wastes containing radionuclides which are discharged to surface waters, the best available technology (BAT) must be used if the receiving water, at the point of discharge, would receive radioactive material at a concentration greater than the DCG. Implementation of the BAT process is not required if annual releases to surface water are below the DCG. In the case of releases of multiple radionuclides, the sum of the fractional DCGs must not exceed unity. In addition, effluent releases to surface water must not result in exposures to aquatic organisms which exceed an absorbed dose of $1 \mathrm{rad} / \mathrm{d}$. These DCGs will be addressed if any remedial alternatives result in effluent releases to air or water.

DOE Order 5820.2A (Radioactive Waste Management, September 9, 1988) states that the management of low-level radioactive waste must ensure that external exposure to the waste and concel. rations of radioactive material that may be released into surface water and soil does not exceed $25 \mathrm{mrem} /$ year to any member of the public. Releases to the atmosphere shall not exceed $10 \mathrm{mrem} /$ year. Reasonable effort should be made to maintain releases to the environment to ALARA levels.

DOE Order 5480.11 (Radiation Protection for Occupational Workers) contains guidelines for worker protection which are similar to those of 10 CFR 20, i.e., $5 \mathrm{rem} /$ year and $50 \mathrm{rem} / \mathrm{year}$ annual effective dose equivalent for stochastic (cancer) and nonstochastic (systemic) effects, respectively, from both internal and external sources for continuous exposures. Also included in the Order are standards for the general public when entering a controlled area. Exposures to the public are limited to an effective dose equivalent of $100 \mathrm{mrem} /$ year. As with other DOE Orders, the ALARA principle prevails. DOE has proposed for codification in 10 CFR 835 the primary standards for radiation protection of occupational workers from normal operation of DOE facilities (56 FR 64334, December 9, 1991). A final.rule is expected in July, 1993. When promulgated, these standards will then be legally applicable to cleanup activities at CROU1.

In the event that DOE Orders are more stringent or cover remedial action activities not addressed by existing ARARs, they should be used as TBC guidance for developing protective remedies at CROU1. The DOE Orders will be addressed in detail following selection of remedial alternatives for CROU1.

\subsection{TBC guidance for radiological risk assessment}

The EPA Office of Radiation Programs has derived slope and unit risk factors for radionuclides of concern at remedial sites for each of three major exposure pathways (inhalation, ingestion, and external exposure to contaminated soil). These are available in the EPA Health Effects Assessment Summary Tables (EPA 1992a), and will be considered as TBC when the radionuclide contamination at CROU1 is more clearly defined. 


\section{Location-specific ARARs}

Location-specific requirements "set restrictions upon the concentration of hazardous substances or the conduct of activities solely because they are in special locations" (53 FR 51437).

Wetlands and noodplains. CROU1 is approximately 200 feet above the highest elevation of the 100-year floodplain (Radian 1992). Although there are a number of wetlands located in and around ORR, a draft report of a recent wetlands survey released in March 1991 does not appear to list any near CROU1 (Cunningham and Pounds 1991). Before any remedial action is taken, this report should be consulted and a survey conducted of the particular site that will be impacted. If wetlands are affected, Executive Order 11990, 40 CFR 6.302(a), 40 CFR 6 (Appendix A), 10 CFR 1022, CWA $\$ 404,40$ CFR 230, and 33 CFR 323 may supply ARARs.

Aquatic resources. There are no known designated wilderness areas, wildlife refuges, or scenic rivers on ORR, or within range of the reservation such that remedial action would likely impact these resources.

Slightly over 5,000 acres of ORR have been designated as a DOE National Environmental Research Park (NERP), which also includes Research Areas (RSAs) both within and without the NERP itself. In addition, DOE has also designated areas on ORR as DOE-NERP Reference Areas (RAs) and DOE-NERP Natural Areas (NAs). However, none of the designated RSAs, RAs or NAs are on or near CROU1 (Parr and Pounds 1987), therefore, none of the uses and restrictions applicable to these resources would be ARARs for CROU1.

Rare, threatened, or endangered species. From a compilation of a number of surveys of the rare plants conducted on the reservation, 14 plant species occurring on the ORR are listed as endangered, threatened, or of special concern by the state of Tennessee, and 3 of these are also candidates for federal listing (Parr 1992). In addition, there are a number of federal and statelisted endangered or threatened animal species on the ORR. An in-depth discussion of these species appears in Volume No. 24 of The Resource Management Plan of the Oak Ridge Reservation (Kroodsma 1987). The state of Tennessee has also designated approximately 80 species of wildlife as "in need of management," and some of those occur in the area including ORR (Tennessee Wildlife Resources Commission Proclamation 86-29). Pursuant to TCA 70-8104(b), it is unlawful for any person to knowingly destroy the habitat of "wildlife in need of management." Should any remedial actions at the CROU1 site impact any federally listed endangered or threat red species, the provisions found in the Endangered Species Act of 1973 (16 USC 1531 et seq.), 50 CFR 492, 40 CFR 6.302(h), and the Fish and Wildlife Coordination Act (16 USC 661 et seq.) may be implicated as ARARs. If any proposed actions impact statelisted endangered or threatened animal species, the Tennessee Non-Game and Endangered or Threatened Wildlife Species Conservation Act of 1974 (TCA 70-8-101 et seq.) may provide ARARs. The prohibitions of the Tennessee Rare Plant Protection and Conservation Act of 1985 (TCA 11-26-201 et seq.) do not apply to a landowner, lessee, or other person entitled to possession of the land on which the species is located (TCA 11-26-209). This also includes managers in the case of publicly-owned land and those with written permission of the landowner or manager (TCA 11-26-209). These exclusions would apparently apply to ORR. However, the purpose of the statute, to protect and preserve rare plants, should be considered TBC guidance for any remedial actions at CROU1 if rare plants are identified. 
Historic sites and archaeological findings. The region surrounding ORR is rich in both archaeological and historic resources and a number of studies have indisated the presence of abundant resources on the reservation. These surveys are summarized in Volume 3, Appendix B of the Resource Management Plan for the U.S. Department of Energy Oak Ridge Reservation (Sanders 1984). No archaeological sites were identified at the $Y-12$ plant. However, in the event a survey indicates the presence of archeological resources at the CROU1 site, the Archaeological Kiesources Recovery Act (16 USC 470aa-11), the Archaeological and Historic Preservation Act (16 USC 469a-c), 43 CFR 7, and 40 CFR 6.301 may provide ARARs.

\subsection{Action-ARARs}

Performance, design, or other action-specific requirements set controls or restrictions on particular kinds of activities related to the management of hazardous waste (52 FR 32496). Selection of a particular remedial action at a site will invoke the appropriate action-specific ARARs that may specify particular performance standards or technologies, as well as specific environmental levels for discharged or residual chemicals. Action-specific ARARs are established under RCRA, CAA, CWA, SDWA, and TSCA. Action-specific ARARs for CROU1 will be developed during selection of remedial alternatives.

\section{References}

Cunningham, M. and L. Pounds. March, 1991. Resource Management Plan for the Oak Ridge Reservation: Wetlands on the Oak Ridge Reservation (V.28), ORNL/NERP-5/V28, Martin Marietta Energy Systems,Inc., Oak Ridge Nat'l Lab., Oak Ridge, Tennessee.

Cunningham, M., L. Pounds, P. Parr, and L. Edwards. 1991 Rare Plants on the Oak Ridge Reservation. Draft Report (April).

U.S. Department of Energy (DOE). 1993. RCRA/CERCLA Update. Vol. 92(4). U.S. Department of Energy Office of Environmental Guidance, January.

EPA (U.S. Environmental Protection Agency). 1988. CERCLA Compliance with Other Laws Manual, Draft Guidance. Vol. I, OSWER Directive 9234.1-01, EPA Office of Emergency and Remedial Response, Washington, D.C.

EPA (U.S. Environmental Protection Agency). 1991. Integrated Risk. Information System IRIS), EPA/600/8-86/032a, EPA Office of Health and Environmental Assessment, Cincinnati, Ohio.

EPA (U.S. Environmental Protection Agency). 1992a. Health Effects Assessment Summary Tables. FY 1992, OERR 9200.6-303-(92), EPA Office of Emergency and Remedial Response, Washington, D.C.

EPA (U.S. Environmental Protection Agency). 1992b. Region IV Criteria Charts (December).

Kroodsma, R. L. January 1987. Resource Management Plan for the Oak Ridge Reservation, Volume 24: Threatened and Endangered Animal Species, ORNL/ESH-1/24, Martin Marietta Energy Systems, Inc., Oak Ridge Natl. Lab., Oak Ridge, Tennessee. 
Parr, P. D. and L. R. Pounds. May 1987. Resource Management Plan for the Oak Ridge Reservation, Volume 23: Oak Ridge National Environmental Research Park, Research Sires, and State Natural Areas, ORNL/ESH-1/V23, Martin Marietta Energy Systems, Inc., Oak Ridge Natl. Lab., Oak Ridge, Tennessee.

Radian Corporation. 1992. Y-12 Plant: Chestnut Ridge Security Pits Remedial Investigation Data Adequacy Summary, DOE/OR-1000\&D2, 92-225-161-77, Radian Corporation, Oak Ridge, Tennessee, December.

Sanders, M. 1984. Resource Management Plan for the U. S. Department of Energy Oak Ridge Reservation, Volume 3, Appendix B: Archaeological Considerations, ORNL-6026/V4, July. 


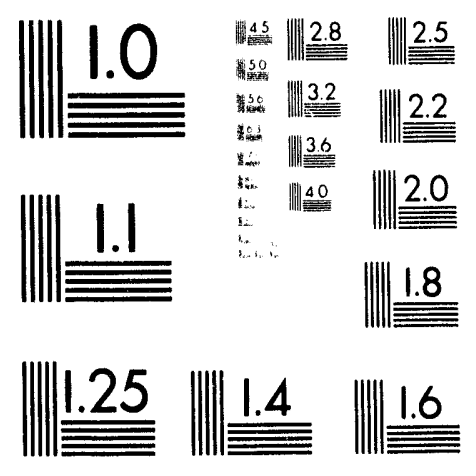



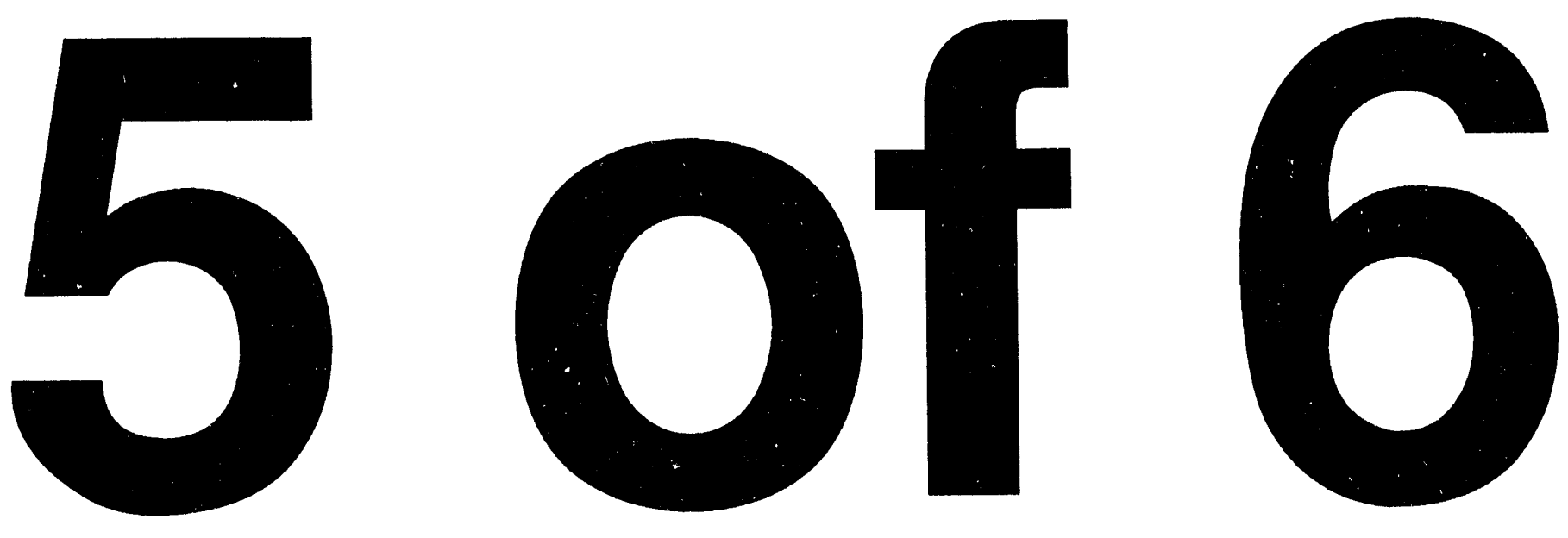


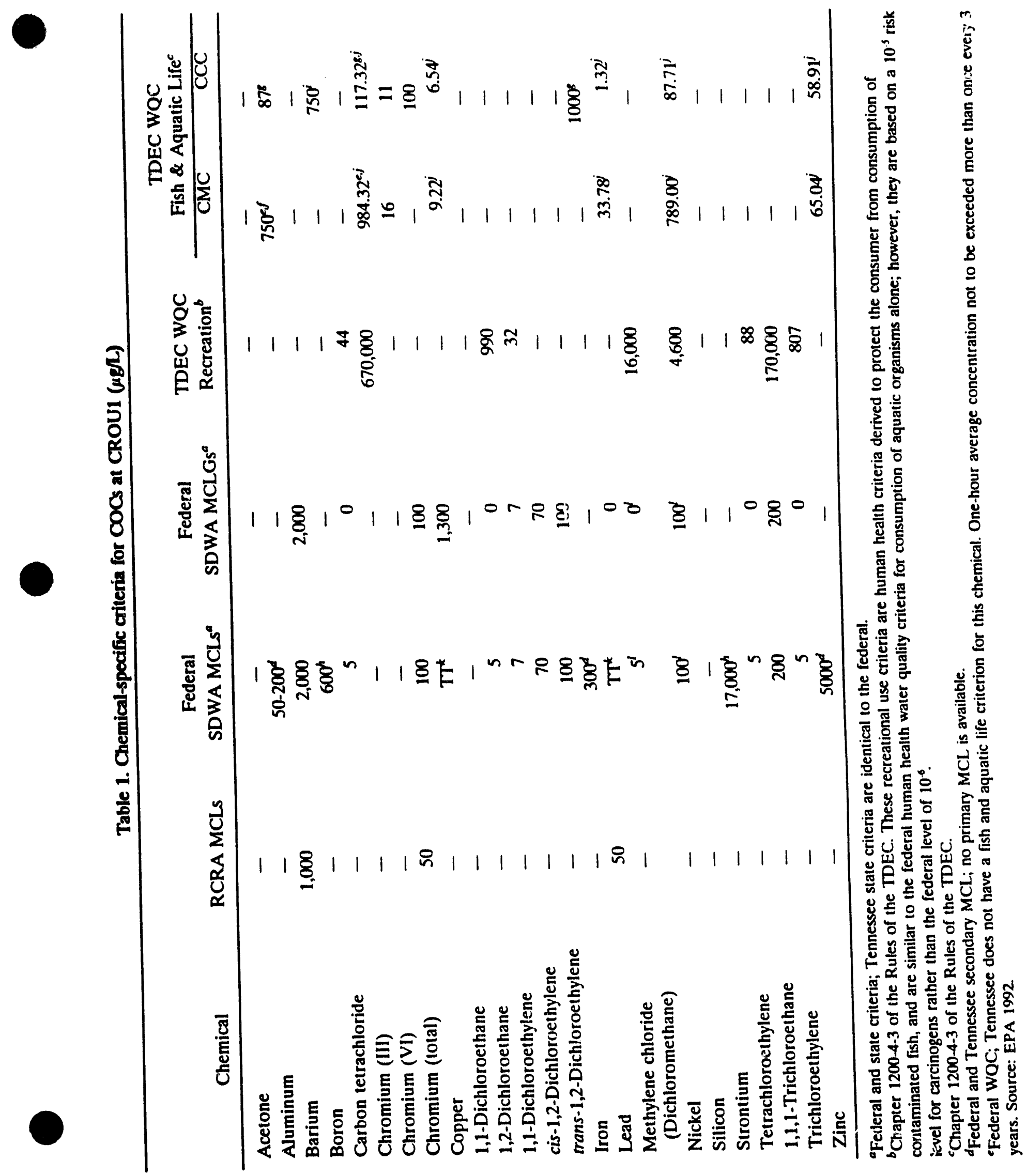




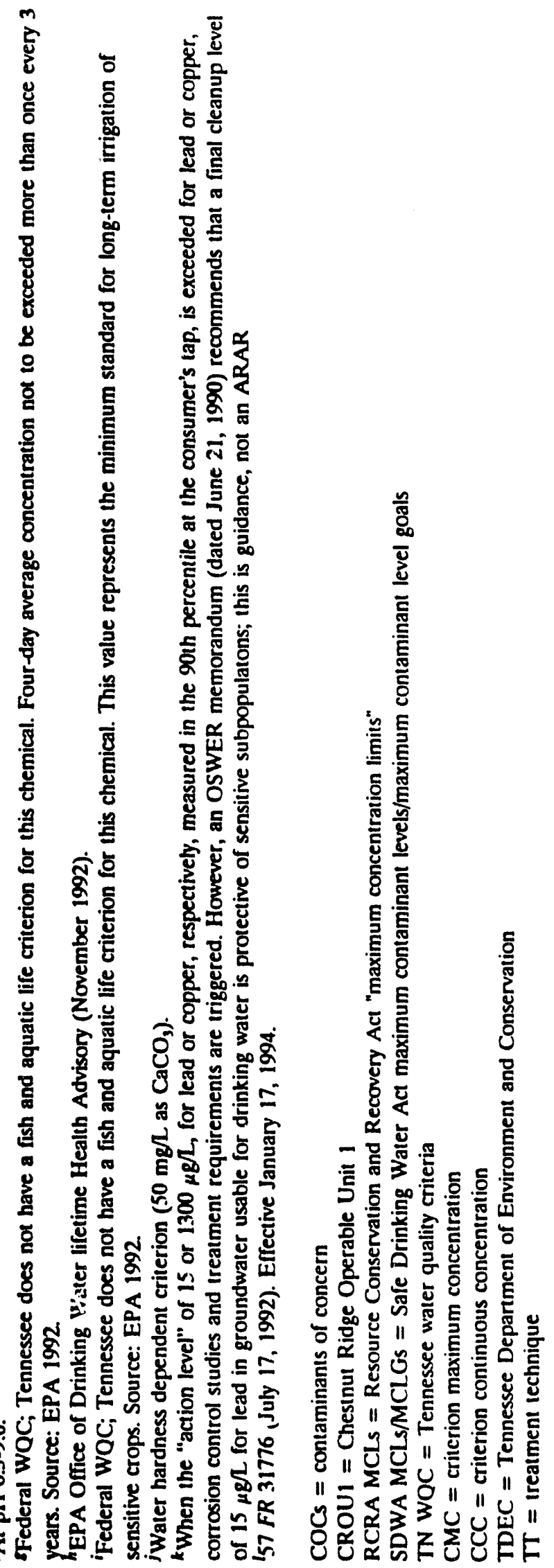


Table 2. Radionuclide-specific standards under the SDWA for potential COCs in groundwater and surface water at CROU1 (pCi/L)

\begin{tabular}{|c|c|c|}
\hline Radionuclide & $\begin{array}{l}\text { Current SDWA } \\
\text { MCLs }\end{array}$ & $\begin{array}{l}\text { Proposed SDWA } \\
\text { MCLs } s^{b}\end{array}$ \\
\hline $\begin{array}{l}\text { Gross alphac } \\
\text { Gross beta } \\
\text { Strontium }-90^{d} \\
\text { Tritium } \\
\text { Natural uranium } \\
\text { All other manmade radionuclides }\end{array}$ & $\begin{array}{l}15 \\
4 \text { mrem/year } \\
8 \\
20,000 \\
4 \text { mrem/year }\end{array}$ & $\begin{array}{l}15 \\
4 \text { mrem/year } \\
42 \\
60,900 \\
20 \mu \mathrm{g} / \mathrm{L}^{\circ} \\
4 \mathrm{mrem} / \text { year }\end{array}$ \\
\hline
\end{tabular}

-SDWA MCL = Safe Drinking Water ACl maximum contaminant level.

'Proposed rule, July 18, 1991 (56 FR 33050); final rule expected December 1993.

The present $\mathrm{MiCl}$. excludes radon and uranium but includes ${ }^{2 \mathrm{Ra}}$; the proposed $\mathrm{MCL}$ excludes all three radionuclides.

${ }^{4}$ These values are not MC.Ls; rather they are concentrations that result in the effective dose equivalent (EDE) of $4 \mathrm{mrem} / \mathrm{year}$, the $\mathrm{MCL}$ for gross beta emissions.

-Approximately equal $1030 \mathrm{pCi} / \mathrm{L}$.

ff two or more radionuclides are present, the sım of their annual dose equivalent to the total body or to any organ shall not exceed 4 mrem/year. 
Table 3. Radiation protection standards that may be ARAR or TBC for CROU1

\begin{tabular}{|c|c|c|c|}
\hline Regulation & Applicability & Exposure conditions & Standard \\
\hline 40 CFR 61 & $\begin{array}{l}\text { National Emission Standards } \\
\text { for Hazardous Air Pollurants } \\
\text { for DOE facilities }\end{array}$ & $\begin{array}{l}\text { Public exposure, } \\
\text { airborn emissions }\end{array}$ & $10 \mathrm{mrem} / \mathrm{year}$ \\
\hline 40 CFR 141 & $\begin{array}{l}\text { Drinking water maximum } \\
\text { contaminant levels }\end{array}$ & $\begin{array}{l}\text { Community water } \\
\text { systems, gross beta }\end{array}$ & 4 mrem/year \\
\hline \multirow[t]{3}{*}{$\begin{array}{l}\text { DOE Order } \\
5400.5^{a}\end{array}$} & $\begin{array}{l}\text { Radiation Protection of the } \\
\text { Public and the Environment }\end{array}$ & $\begin{array}{l}\text { Public exposure, all } \\
\text { sources }\end{array}$ & 100 mrem/year \\
\hline & & $\begin{array}{l}\text { Temporary exemption, } \\
\text { maximum limil }\end{array}$ & $500 \mathrm{mrem} / \mathrm{year}$ \\
\hline & & $\begin{array}{l}\text { Aquatic organism } \\
\text { exposure, absorbed dose }\end{array}$ & $1 \mathrm{rad} / \mathrm{d}$ \\
\hline \multirow[t]{2}{*}{$\begin{array}{l}\text { DOE Order } \\
5820.2 \mathrm{~A}\end{array}$} & $\begin{array}{l}\text { Radioactive Waste } \\
\text { Management }\end{array}$ & $\begin{array}{l}\text { Public exposure, all } \\
\text { sources, excluding air }\end{array}$ & 25 mrem/year \\
\hline & & $\begin{array}{l}\text { Public exposure, } \\
\text { atmospheric releases }\end{array}$ & $10 \mathrm{mrem} / \mathrm{year}$ \\
\hline \multirow[t]{3}{*}{$\begin{array}{l}\text { DOE Order } \\
5480.11^{b}\end{array}$} & $\begin{array}{l}\text { Radiation Protection for } \\
\text { Occupational Workers }\end{array}$ & $\begin{array}{l}\text { Worker exposure limits, } \\
\text { continuous exposure }\end{array}$ & $\begin{array}{l}5 \text { rem/year, cancer } \\
\text { effects }\end{array}$ \\
\hline & & & $\begin{array}{l}50 \text { rem/year, } \\
\text { noncancer effects, } \\
\text { any organ or tissue }\end{array}$ \\
\hline & & $\begin{array}{l}\text { Public exposures, } \\
\text { controlled areas, effective } \\
\text { dose equivalent }\end{array}$ & 100 mrem/year \\
\hline
\end{tabular}

aProposed as 10 CFR 834 (58 FR 16268, March 25, 1993). Final rule expected March, 1994.

bProposed as 10 CFR 83.5 (56 FR 64334, December 9, 1991). Final rule expected July, 1993. 
APPENDIX C

STANDARD OPERATING PROCEDURES

FOR Y-12 CHESTNUT RIDGE OPERABLE UNIT ONE 
C-2

\section{CONTENTS}

Page

Geoprobe Sampling Survey Standard Operating Procedure . . . . . . . . . . C-3

Standard Measurement Procedure for Photovac Portable Gas Chromatograph . . . C C-9

Excerpts from Environmental Compliance Branch Standard Operating

Procedures and Quality Assurance Manual, February 1, $1991 \ldots \ldots \ldots \ldots$ C-23

Protocols for Short Term Toxicity Screening of Hazardous Waste Sites . . . . . C C-39

Environmental Sciences Division Toxicology Laboratory

Quality Assurance Program . . . . . . . . . . . . . . . . . C-55 


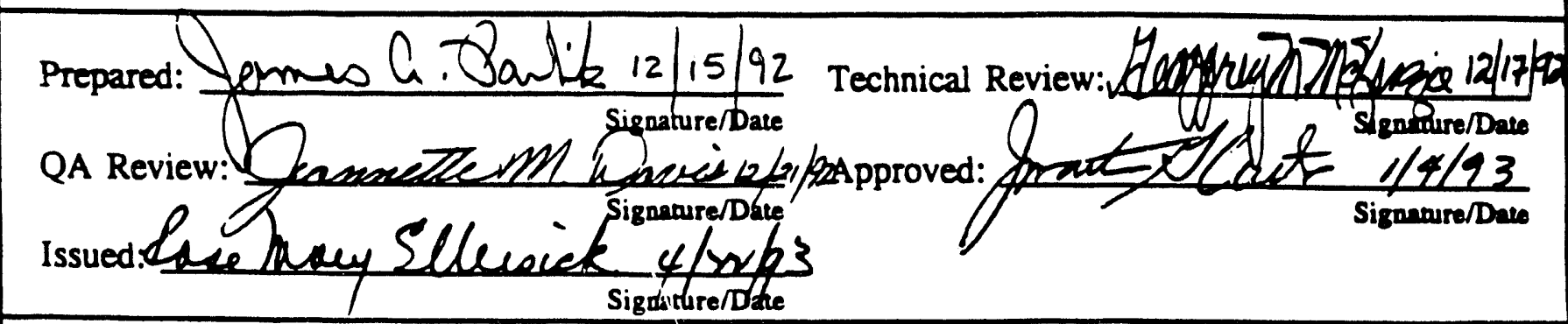

\subsection{OBJECTIVE}

The purpose of this standard operating procedure (SOP) is to collect surface and subsurface soil samples with a Geoprobe in order to determine the extent of soil contamination in a shorter time period compared with conventional boring methods. In addition, the Geoprobe does not produce drill cuttings.

\subsection{BACKGROUND}

\subsection{Definitions}

Geoprobe - A hydraulic device installed in the back of a van or pickup truck, used to advance a hollow stem probe into soil for the purpose of collecting a soil sample.

Probe-Drive Sampler - A soil sampling device designed for use with the Geoprobe.

\subsection{Discussion}

The Geoprobe unit utilizes the Probe-Drive sampler to retrieve approximately 100 gram (or larger) soil samples at the working depth of the Geoprobe. Unlike split-spoon samplers, the Probe-Drive sampler remains completely sealed by a piston tip at the end of the sample tube while it is pushed or driven to the desired sampling depth. A piston stop-pin at the opposite end of the sampler is removed by means of extension rods inserted down the inside diameter of the probe rods after the sampler has been driven to depth. This enables the piston to retract into the sample tube while the sample is taken.

Prior to conducting the Geoprobe survey, ensure that underground utilities and structures have been delineated on the ground. Keep the Geoprobe a safe distance from these utilities and structures during probing. 
GEOPROBE SOIL SAMPLING SURVEY
SOP 3-1

Revision: 0

Date: December 31, 1992

Page 2 of 5

\subsection{RESPONSIBIITIES}

Site Manager - The Site Manager is responsible for ensuring that the field personnel have been trained in conducting the Geoprobe survey in accordance with the project requirements and this and related SOPs.

Field Team Leader - The Field Team Leader is responsible for ensuring that the Field Team conducts the Geoprobe survey in accordance with the project requirements.

\subsection{REQUIRED EQUIPMENT}

The usual Geoprobe rods and driving accessories with the following tools are required to sample soil using the Probe-Drive system:

- Assembled Sampler

- Extension Rods

- Extension Rod Couplers

- Extension Rod Handle

- Extruder Rack*

- Extruder Piston*

* Kansas Stainless and Large Bore Samplers feature removable hardened cutting shoes that thread onto the sample tube. Large Bore Sampler also utilizes an acetate liner inside of the sample tube for easy removal of soil sample.

\subsection{PROCEDURES}

\subsection{Assembly}

After decontaminating probe rods and sampler parts according to FPC SOP 4-5, Field Equipment Decontamination, assemble the soil sampler. All parts must fit tightly. The stop-pin is reverse threaded and should be tightened with a wrench so that it exerts pressure against the piston rod. Damage could occur during probing if pin is not tight. 


\subsection{Probing}

Attach assembled sampler onto leading Geoprobe probe rod. Place the drive cap on top of the probe rod. A 12-inch probe rod is recommended to start the Standard 24-inch and Large Bore Samplers. Replace the 12-inch rod with a 36 -inch rod as soon as the sampler is driven below the surface.

Drive the sampler with the attached probe rods to the top of the interval to be sampled using manual probe rod driver or hydraulically-powered Geoprobe unit. The drive cap must be installed prior to driving the probe.

IMPORTANT: Some soil conditions may warrant using a retractable or solid drive point to preprobe the hole to the desired sampling depth. Do not drive the sampler into bedrock or other impenetrable layers.

\subsection{Stop-pin Removal}

If using the Geoprobe driver, move the driver unit back from the top of the probe rods to allow room to work.

Remove the drive cap and lower extension rods into the inside diameter of the probe rods using couplers to join rods together.

Attach the extension roo handle to the top extension rod. Rotate the extension rod handle clockwise until the leading extension rod is screwed into the piston stop-pin downhole.

Continue to rotate the handle clockwise until the reverse-threaded stop-pin has disengaged from the drive head.

Remove the extension rods and attathed stop-pin from the probe rods.

\subsection{Sampling}

If the top of probe rod is already in the lowest driving position, attach another probe rod before driving. Replace the drive cap onto the top probe rod.

Mark the top probe rod with a marker or tape at the appropriate distance above the ground surface (i.e. 10 inches for Standard Sampler, 12 inches for Kansas Sampler, and 24 inches for Large Bore Sampler). 
Drive the probe rods and sampler the designated distance. Be careful not to over-drive the sampler which could compact the soil sample in the tube making it difficult to extrude.

Retract probe rods from the hole and recover the sampler. Inspect the sampler to confirm that a sample was recovered.

\subsection{Extrusion - Standard And Kansas Samplers}

\section{Machine:}

1. Disassemble the sampler. Remove all parts. Screen sampler with a photoionization detector (PID), if required.

2. Position the extruder rack on the foot of the Geoprobe derrick.

3. Insert the sample tube into the extruder rack with the cutting end up.

4. Position the extruder piston and push the sample out of the tube using the "probe" function on the Geoprobe.

5. Catch the sample as it is extruded beneath the extruder in the sample container or mixing bowl. Volatile organic compound samples will be collected directly into the sample container.

CAUTION: Use care when performing this task. Apply down pressure gradually. Use of excessive force could result in injury to the operator or damage to tools.

Hand: (Good for use with sandy soils)

1. Disassemble the sampler. Remove all parts.

2. Screen sampler with a PID, if required.

3. Deposit sample into container by lightly tapping the side of the sample tube with a hammer.

\subsection{Plugging Geoprobe Holes}

When driving the Geoprobe through pavement or concrete using a hammer attachment, the resultant hole may be plugged with neat cement (cement and water mixture) after the probe rods have been retracted. 


\section{GEOPROBE SOIL SARIPLNG SURVEY}

\section{SOP 3-1}

Revision: 0

Date: December 31, 1992

Page 5 of 5

When driving the Geoprobe through surface soils, the resultant hole may be plugged with neat cement if the soils do not close the hole naturally. The neat cement is poured down the hole after the probe rods have been retracted.

Specific procedures for sealing geoprobe holes will be specified in the site-specific plans.

\subsection{RESTRICTIONS/LIMITATIONS}

The Geoprobe soil sampling system is not intended for collecting large sample volumes. The Standard Sampler will obtain approximately 100 grams of soil.

The Geoprobe is limited to sampling up to depths of approximately $\mathbf{4 0}$ feet in unconsolidated, sandy soils and to shallower depths in compacted gravelly soils and tills.

\subsection{REFERENCES}

Geoprobe Systems, The Probe-Drive Soil Sampling System, September 1991. 
CDM FEDERAL PROGRAMS CORPORATION

standard Measurement Procedure for:

PEOTOVAC PORTABLE GAS CHROMATOGRAPH

SECTION 7

7.0 INTRODUCTION

This document describes procedures that field personnel should follow when using the photovac portable gas chromatograph. The procedures performed by the CDM EPC warehouse manager will be documented in the CDM Field Equipment Operation, Maintenance, and Calibration Manual.

7.1 PURPOSE OF MEASUREMENT

The Photovac identifies and measures specific chemicals in a gas sample. The measurement allows technicians to monitor the concentration of volatile organic compounds in soil gas, ambient air, or other vapors.

7.2 SUPPLIES AND EQUIPMENT

7.2.1 Equipment needed

- Photovac 10555 portable gas chromatograph

- Carbopack BHT backflush gas chromatography column ( $\# S A-315$ )

- High-purity low-pressure (10 psi) compressed gas regulator

- High-purity mid-pressure (40 psi) compressed gas regulator

- Photovac AC power mains cord

- Photovac \#SA-205 dual channel flowmeter

- Flat head screwdrivers; $1 / 8 ", 3 / 16 "$, and $1 / 4 "$

- 3/8" open end box wrench

- Plastic letter opener with hook

7.2.2 supplies needed

- Calibration gases

- 1/8" Teflon tubing (approximately 10')

- 1/4" Teflon tubing (approximately $1^{\prime}$ )

- 4 Swagelock $1 / 8$ " tubing adapters

- Spare ultraviolet lamp

- Ultra-pure air (scott Ultra-zero or equivalent)

- Glass 40 ml. VOA vials (for headspace analysis)

- Tedlar ${ }^{R}$ bags

- 2 adapters (Tedlar bag fitting to 1/8" tubing)

- Photovac plotter paper (\#SA-303)

- Plotter pens

- Laboratory tissues (e.g. Kimwipes ${ }^{R}$ )

DEC7900: 2 
7.3 START UP

a. Check to see that the Photovac has been stored as required by section 7.6 .

b. If the instrument has not been left on, press ON. The machine will read "LAMP NOT READY". After pressing ON, wait 20 minutes for the lamp and circuits to warm up.

c. Rotate the red FLOW valve until one of the float balls on the Photovac \#SA-205 flowmeter rests between 5 and 10 $\mathrm{ml} / \mathrm{minute.}$

d. If the float balls in the two channels of the flowmeter do not rest in the same position, rotate the needle valve on the Aux out port until they agree.

e. Rotate the red flow valve until both flowmeter float balls rest between 10 and $15 \mathrm{ml} / \mathrm{minute}$.

f. Press START STOP P. Press ENTER. The Photovac will analyze the air in the trailer. It will print a chromatogram (a chart of the instrument's response) and some analysis information. If the chromatogram indicates peaks, perform an analytical zero (Section 7.4.3).

g. If the paper in the printer does not move, press FEED.

h. Review the information printed (see example, Exhibit 7-3) change the operating parameters as described in section 7.6.3.2. Note: the information in the setup box will appear only when ON WITH SETUP has been set (section 7.6 .3 .11

i. Perform the calibration procedure (Section 7.4.2)

\subsection{INSTRUMENT CALIBRATION}

\subsubsection{Frequency of Calibration}

$\begin{array}{llll}\text { Test } & \text { Sop section } & \text { Calibration standard } & \text { Frequency } \\ \begin{array}{l}\text { On-board computer } \\ \text { switches }\end{array} & 7.6 .3 & \text { Exhibits } 7-1 \text { to } 7-3 & 1 / \text { week } \\ \text { start-up } & 7.3 & \text { None } & 1 / \text { day } \\ \text { Operational zero } & 7.4 .2 \text { (1) } & \text { Ambient air } & \begin{array}{l}\text { At start up } \\ 1 / 5 \text { samples }\end{array} \\ \text { Field Calibration } 7.4 .2 & \begin{array}{l}\text { Certified gas } \\ \text { standard }\end{array} & \begin{array}{l}\text { At start up } \\ 1 / 5 \text { samples }\end{array} \\ \text { Lab Calibration } & 7.8 & \text { Photovac Service } & 1 / \text { year }\end{array}$

Dept.

DEC7900:2 


\subsubsection{Calibration}

a. Install a calibration standard for the compound(s) you want to analyze for as described in section 7.6.2. Note the concentration of the standard.

b. Perform start up procedures (section 7.3).

c. Press START STOP P. Press the DOWN ARROW to select "CAL IN". (Note: The instrument can also be calibrated against standard gas in a Tedlar" bag by selecting "PROBE IN".]

d. Press ENTER. The Photovac will analyze the calibration standard. If the standard contains only one compound, there should be just one peak. If extra peaks appear. repeat this step before proceeding.

e. When the printer stops printing, press CAL.

$f$. When the LCD says; "PLOTTER PEAK \#?", press 1 and ENTER.

g. When the LCD says; "ID NUMBER 1-25?", enter the number at which you want to store the compound and press ENTER.

h. When the LCD says; "CONC IN PPM?", enter the concentration of the standard in ppm and press ENTER.

i. Repeat steps $c$. and $d$.

j. If the concentration reported in this recalibration differs from the one you entered in step h. by 208 or more, repeat steps e. to $h$.

k. Press EDIT and the ID number of the new peak. Type the name of the compound in.

1. Press START STOP P. Press ENTER. The Photovac will analyze the air in the trailer. If a peak appears on the chromatogram, obtain an analytical zero (section 7.4.3).

m. Proceed to section 7.5.2.

\subsubsection{Analytical zero}

a. Fill a clean Tedlar bag with ultra-pure air.

b. Attach the Tedlar" bag containing ultra-pure air to 1/8" Teflon tubing on the probe in port.

c. Press START STOP P. If the LCD does not SaY "PROBE IN", press the DOWN ARROW to set the inlet to "PROBE IN".

d. Press ENTER. The Photovac will analyze the ultra-pure air.

DEC7900: 2 
e. When the printer stops printing, write "ultra-pure air" next to its chromatogram.

E. No peak should appear. If a peak appears on the chromatogram, repeat steps b. to e. two more times.

9. If the peak appears in either or both of these repeat runs, trouble shoot the problem (Section 7.7.1)

\subsection{FIELD MEASUREMENTS}

\subsubsection{Measuring Compounds}

The Photovac can demonstrate the presence of many compounds, but it identifies and evaluates only those compounds for which it has been calibrated by the procedure described in section 7.4.2. Follow the procedures described in section 7.5 .1 to evaluate the presence of other compounds with the photovac. Be certain to write the analyte and the location sampled on the chromatogram.

a. Perform start up (section 7.3 ) and calibration (Section 7.4.2) each day before taking any measurements.

b. Introduce the sample gas through the $1 / 8$ " Teflon tubing on the probe In port. The sample gas may be collected in the Tediar bags, headspace vials, or from ambient air.

C. Press START STOP $P$. If the LCD does not SaY "PROBE IN", press the DOWN ARROW to set the inlet to "PROBE IN".

d. Press ENTER. The Photovac will analyze the sample gas.

e. When the printer stops printing, write the location sampled (for instance, Probe \#MW-3A) next to its chromatogram.

f. Transfer the concentration value from the printout to the log book or data collection form.

g. Perform steps 7.5 .1 b. - $f$. with each sample.

h. Perform replicate analysis (repeat steps $c$. - f.) on at least two samples a day. Record the replicate readings on the data form.

1. Re-calibrate the instrument (section 7.4.2) at least once every five samples. You may recalibrate less often if the calibration is very stable (section 7.5 .4 a.).

\subsubsection{Calculation and Recording}

a. The photovac prints the date and time of the sample on the print-out. 
b. Write the number of the sample from which each sample was drawn on its chromatogram.

c. Write the number of the sample from which the sample was drawn and the word, "REPLIC" next to any chromatogram that represents a replicate analysis.

d. Write "CALIB" on any chromatogram that represents a calibration run.

e. Write "AIR" beside any chromatogram that represents an analysis of ambient air.

f. The Photovac automatically calculates the concentrations of compounds in the gas sample. Write the concentration that appears on the Photovac's printer down on the logbook or data form.

\subsubsection{Quality Control Measures}

a. Recalibrate the photovac after the first five samples. If the value found on the calibration run differs from previous value by 5 or or less, recalibrate every ten samples. If it differs by more than $5 \%$, recalibrate every five samples.

b. Repeat analysis [(section $7.5 .1(\mathrm{~h})$ ] of at least one sample a day. Record the second value in the "Replicate analysis" space on the logbook or data form.

\subsection{STORAGE}

The Photovac should be permanently installed in the equipment trailer as described in this section.

\subsubsection{Installation Procedure}

a. Attach the DETECTOR OUT port to the left side of the flow meter with $1 / 4^{n}$ Teflon tubing.

b. Attach the AUX OUT port to the right side of the flow meter with 1/4" Teflon tubing.

c. Direct the flowmeter discharge exhaust through the window with $1 / 4^{n}$ Teflon tubing.

d. Exhaust the CAL OUT and PUMP OUT ports through the window with $1 / 4$ " Teflon tubing.

e. Attach the Photovac to a $115 \mathrm{~V}$ electrical outlet with the power cord.

DEC7900: 2 
f. Leave the Photovac on at all times. Unless the Photovac is in use, the LCD should always read "Ready Enter command".

\subsubsection{Calibration and Carrier Gases}

a. The calibration gas cylinder should be permanently installed in an enclosure outside the trailer. The gas should flow through a high-purity gas regulator and a $1 / 8$ " Teflon tube that penetrates the trailer wall to the cal In port of the photovac. Leave the calibration gas line at 10 psi pressure unless changing the cylinder.

b. The carrier gas (ultra-pure compressed air) cylinder should be permanently installed in a corner of the trailer near the photovac. The cylinder must be braced so that it is secure. The carrier gas should flow through a high purity gas regulator and a $1 / 8$ " Teflon tube that terminates in a Swagelock ${ }^{R}$ quick connect fitting to the Carrier In port of the photovac. The discharge gauge on the regulator should always read 40 psi.

c. Maintain a continuous flow of carrier gas, even overnight when the Photovac is not in use. Set the "maintenance Elow" at $1 \mathrm{ml} / \mathrm{min}$ by adjusting the red flow valve until the flow meter reads $1 \mathrm{ml} / \mathrm{min}$ through each column.

d. The Photovac can operate properly without gas in the on-board carrier gas cylinder.

\subsubsection{On-board Computer settings}

\subsubsection{Testing On-board Computer settings}

a. PIESS TEST, then press ENTER.

b. The printer will produce a status report. An example status report with date, time, and event times is shown in Exhibit 7-1. Settings may be changed as described in section 7.6 .3 .2 .

c. Press LIST. When the LCD says; "LIST LIBRARY \#?," press 1 and ENTER

d. An example print-out is shown in Exhibit 7-2. Change the operating parameters as described in section 7.6 .3 .3 . Don't try to correct the calibrant retention times. library listings for all target compounds should appear if the Photovac has been calibrated for them $(7.4 .2)$.

e. Press CHART. Press ENTER. Press DOWN ARROW until the LCD SaYs; "CHART RECORDER ON WITH SETUP". 
f. Press START STOP P. Press ENTER. The Photovac will analyze the air in the trailer. It will print a chromatogram, some analysis information, and set up information. See example in Figure 7-3. If a peak appears on the chromatogram, obtain an analytical zero (section 7.4.3). Change the operating parameters as described in section 7.6.3.4.

g. Press CAART. Press DOWN ARROW until the LCD says; "CHART RECORDER ON WITH BASELINE".

\subsubsection{Changing status Report settings}

To correct the date or time:

a. Press USE.

b. Press 1 to select Library \#1. Press ENTER

c. Enter the day of the month (e.g. 24). Press ENTER.

d. Enter the number of the month (e.g. 04). Press ENTER.

e. Enter the year (e.g. 1989). Press ENTER.

f. Enter the current hour (e.g. 14). Press ENTER.

g. Enter the current minute (e.g. 24). Press ENTER.

h. If you mis-enter a number, press CLEAR and enter the right one.

To correct an event on or off time:

a. Press EVENT. Enter the number of the event that needs change. Press ENTER.

b. If the on rime for the event is right, press ENTER. If it is not right, enter the correct on Time and press ENTER.

c. If the off time for the event is right, press ENTER. If is is not right, enter the correct off Time shown for the event and press ENTER.

d. Repeat steps a. - c. for each event that has on or off times that do are not correct.

\subsubsection{Changing Library list settings}

a. If the library number (in the upper left hand corner) is not 1, Press USE, CLEAR, 1, and ENTER, in that order.

b. Any other differences can be modified by following the calibration procedure (section 7.4 .2 )

DEC7900:2 
7.6.3.4 Changing Analysis and set-up settings

a. Reset the Analysis Number to 1 after each day's analysis by turning the instrument off and then on.

b. Don't try to change the Internal Temperature.

c. If the Gain is not 2, then Press GAIN, CLEAR, 2, and ENTER.

d. To change User Identification (see Exhibit 7-3), Press INFO. Enter the name of the site. Press ENTER. Enter a description of the samples. Press ENTER.

e. Don't try to change the offset.

f. If the chart speed is not 1, Press CHAR' Press DOWN ARROW until the LCD says; "CHART SPEED: 1 ".

g. If slope sensitivity is not $1616 \quad 6 \mathrm{mV} / \mathrm{sec}$, press SENS. Enter 16. Press ENTER. Enter 16. Press ENTER. Enter 6. Press ENTER.

h. If Window $+/-$ is not 10 percent, Press wINDO. Enter 10 . Press ENTER.

i. If Minimum Area is not 5 mVSec, Press AREA. Enter 5. Press ENTER.

j. If Timer Delay is not 0.0 sec, Press CYCLE. If the LCD does not say: "TIMER DELAY?" at all, press CLEAR and CYCLE again.

k. When LCD says: "TIMER DELAY?", press CLEAR, 0 , and ENTER.

1. The LCD should now say "ANALYSIS TIME? 120". If it shows another analysis time, press CLEAR, $1,2,0$, and ENTER.

m. The LCD should say "CYCLE TIME? Min", press CLEAR, 0 , and ENTER.

n. Press ENTER 5 times. The LCD should say: "READY ENTER COMMAND" .

7.7 PREVENTIVE MAINTENANCE, TROUBLE-SHOOTING AND SERVICING Section 7.7.1 lists potential causes of some equipment problems and corrective actions to take. Sections 7.7 .2 to 7.7 .6 describe some of these corrective actions.

DEC7900:2 
7.7.1 Indicators of Instrument Malfunction

SYMPTOM

LCD indicated LAMP NOT

READY more than $3 \mathrm{~min}$

after switch-on.

Printer doesn't

eunction

Plotter starts, then

stops immediately.

No peaks appear.

Early peaks appear but later peaks missing.

Unwanted late peaks appear, possibiy during next analysis.

peaks appear during air run.

Valve remains ON indicated on LCD.
PROBABLE CAUSE

Source needs tuning.

printer disabled

"ANALYSIS TIME" is 0

Improper valve setting.

Leaky gas fittings.

Septum in injection port needs changing of tightening.

Valve Eailure

Backelush too early. Backelush too late.

"ANALYSIS TIME" too short

Contaminated column

ON time greater than OFF time.
CORRECTIVE ACTION

Tune source (section 7.7 .31 .

PresS FEED key

Set proper analysis time, use CYCLE key. (section 7.6.3.4)

Check event settings (Section 7.6.3.2).

Tighten ald fittings using fingers only. DO NOT over-tighten fittings.

Change of tighten (Section 7.7.4)

Photovac authorized service only.

Increase EVENT 3 OFF time (Section $7.6 .3 .2)$.

Decrease EVENT 3 OFF time (section 7.6 .3 .21 .

Increase ANALYSIS TIME to 10 times the series flow time (Section 7.6.3.4).

Perform analytical zero (Section 7.4.3).

Elush column (Section 7.7 .21

Check LIST Or EVENT status on LCD (Section 7.6 .3 .11 .

DEC7900: 2 


\section{C-18}

Sensitivity too low.

The peak appears, but it is identified as "unknown" calibrant is wrong. Leak in system.

High "Offset"

Contaminated column

Valve timing is wrong

Lamp is failing.

Peak not calibrated.
Revision: 0

Date: $11 / 6 / 90$

check cylinder label.

Finger tighten all suspect fittings.

Check column

attachment and

injection port.

DO NOT OVER-TIGHTEN

fittings.

Perform analytical

zero (section 7.4.3).

Flush column (section 7.7.2).

Reset event settings (Section 7.6.3.2).

Replace lamp (Section $7.7 .3 .2)$.

Calibrate (section 7.4.2).

Calibrate more frequently.

Check plotter and ID *s of peak (section 7.4 .21

Battery life too short. Lamp power too high.

Get status report (Section 7.6.3.1). If SOURCE POWER > 50, re-tune lamp (section 7.7 .3 .11 .

Operating on CYCLE

Set cycle time to 0 (Section 7.6 .3 .4 )

Flow rate too low.

Re-set flow rates [Section 7.3 (e)].

Flow rate too high.
Re-set flow rates [section 7.3 (e)].

DEC7900: 2 
Instrument uses air carrier too fast.
Elow rate too high.

Carrier gas leak.
Re-set flow rates (section 7.3 (e)).

Tighten all fittings. (especially on column) DO NOT OVER-TIGHTEN

VALVE FITTINGS.

\subsubsection{Flushing Contaminated Columns}

a. Turn the Red Flow valve to set the flow through the flowmeter to $10 \mathrm{ml} / \mathrm{min}$ or more.

b. Allow the columns to flush overnight.

c. If background contamination remains, take the instrument to a Photovac authorized service location for column decontamination.

\subsubsection{Source Lamp Maintenance}

\subsubsection{Source Lamp Tuning}

a. With the instrument on, swing the computer module up on its hinge to reveal the Photovac lamp housing, which is a black box marked PHOTOVAC.

b. Remove the special tuning tool, (a plastic screwdriver) from the clip on the front face of the black box. DO NOT USE A METAL TOOL for this adjustment as you will surely cause an electrical short circuit.

c. Engage the tool in the slot of the small screw beneath the hole in the box lid. Observe the LCD while you rotate the screw slowly in a clockwise direction. You may have to make several slow rotations. Stop when the the message changes to "READY ENTER COMMAND".

d. Press TEST. Enter "7853". Press ENTER. The message "LAMP POWER" followed by a number, between 20 and 50 , will appear.

e. Tune the lamp to yield a LAMP POWER level of 30 to 35 that also produces a "READY" message.

f. If the "READY" message does not appear at all, take the instrument to a photovac authorized service location for lamp replacement.

9. Turn the instrument off ("OFF" + "ENTER") and then "ON" again. Within 3 minutes, the "READY" message should return. 
h. If The "READY" does not appear on re-start, repeat the procedure.

1. Tune the lamp to the lowest LAMP POWER level that yields reliable start-ups. Reliable start-up is more important for instrument function than lamp power.

\subsubsection{Source Lamp Replacement}

a. Turn the instrument off.

b. Swing the computer module up on its hinge to reveal the Photovac lamp housing, which is a black box marked PHOTOVAC.

c. Remove the 4 securing screws from the lid of the lamp housing. Inside you will see a white Teflon cylinder screwed into the right wall of the box. This cylinder is the lamp holder and has a silver wire wound around it in a spiral.

d. Gently remove the connecting wire from its socket in the free end of the lamp holder.

e. Gently unscrew the lamp holder and withdraw it. You will see the lamp inside the holder as you pull it away from the wall. Be careful not to drop the lamp.

f. Withdraw the old lamp from the holder with a clean laboratory tissue.

9. Place the lamp $0-r i n g$ (use the O-ring from the old lamp, if necessary) on the new lamp, about $5 \mathrm{~mm} f$ rom the end face of the window. Handle the new lamp with a clean laboratory tissue. Be very careful not to touch the window end with your fingers.

h. Insert the new lamp into the holder

1. Screw the holder back into place. MARE SURE IT GOES IN STRAIGHT AND IS NOT CROSS THREADED.

j. Tighten until you begin to feel the resistance from the o-ring.

k. Replace the connecting wire into its socket.

1. Replace the lid and make sure all 4 screws are returned and are tight.

m. Press Power ON. Tune the lamp (section 7.7.3.1). 


\subsubsection{Leaking Septum}

While you will rarely inject samples through MANUAL INJECTION ports, you must change the septum if the column appears to leak. Leakage may appear as poor replication and an unstable baseline.

a. Insert a spare GC syringe needle into the MANUAL INJECTION port so that it spears the septum.

b. Leaving the needle in place, unscrew the retainer and withdraw it, with the septum impaled on the needle.

c. Discard the old septum.

d. Ensuring that the new septum is handled as little as possible between the fingers, position the new septum, Teflon face down, on the end of the retainer and spear it with needle through the injection channel to hold the septum in exactly the correct alignment.

e. Carefully screw the retainer back into position with the needle maintaining the septum in the correct position until it is seated.

f. Watch the flow through the flow-meter for the outlet port as the retainer is tightened.

9. A steady flow rate, which does not increase as the retainer is further tightened, indicates the retainer is in the correct position.

h. DO NOT OVER-TIGHTEN THE septum retainer. This can cause needle blockage.

\subsubsection{Printer/Plotter Paper Replacement}

Reep at least one spare roll of plotter paper (\#SA-303) in stock so replacement can be made as soon as the one in use is finished.

a. Remove the paper roll cover. The paper will come out with the cover.

b. Slip the paper roll spindle out of the cover and drop the paper roll.

c. Place a new roll between the plotter cover clips in the same direction as the old roll.

d. Insert the spindle through the cover clips and the paper roll.

e. Unroll approximately $12^{n}$ of paper.

DEC7900: 2 
f. While holding onto the cover and paper, feed the end of paper through the paper feed slit behind the plotter roller.

9. Feed the paper through the slit on the plotter cover.

h. Snap the plotter cover back into place.

i. Press the "FEED" key to verify that the paper roll feeds properly.

\subsubsection{Changing plotter Pens}

a. Remove the plotter cover and keep it away from the pen carriage.

b. Press "PEN" until you the pen you want to change is in position.

c. Press the white lever at the front right of the plotter cutout. The pen will pop up.

d. Remove the pen with a plastic letter opener hook.

e. Insert a pen of the corresponding color.

f. Gently push the pen into place. Make sure the tip is resting in the ring or it will not write properly.

7.8 Other Types of Service

All other types of repair may be performed only by the CDM regional equipment warehouse. Meters must return to the warehouse for a preventive maintenance check at least once a month. 
EXCERPTS FROM:

ENVIRONMENTAL COMPLIANCE BRANCH

STANDARD OPERATING PROCEDURES

AND

QUALITY ASSURANCE MANUAL

FEBRUARY 1, 1991

Section 6.0 Field Analytical Procedures

Section D. 4 Method D.4 Dissolved Oxygen

(Membrane Electrode)

v. S. Environmental Protection Agency

Region IV

Environmental Services Division

College Station Road

Athens, Georgia 30613 
Section No. 6.1 Revision No. 0 Date: $2 / 1 / 91$

Page 1 of 1

\subsection{FIELD ANALYTICAL PROCEDURES}

\subsection{GENERAL}

Field analytical equipment used by Branch personnel should be suitable for the analysis to be accomplished and properly calibrated. In addition to being accurate, field analyses must be conducted on a sample which is representarive of the source from which it was collected. Therefore, the type of sample and location of the sampling site are critical. A detailed discussion of sample type and sample site selection is given in Section 4 for the various media investigated by Branch personnel.

The objectives of this section are to:

- Iist the specific field analytical techniques that shall be used by Branch personnel;

- Iist the specific quality control procedures and calibration techniques for each piece of field analytical equipment used by Branch personnel;

- list the source of all reagents and standards used to perform field analyses and/or calibrate field analytical equipment; and

- specify the training required of Branch personnel to perform the listed field analyses.

Specific field analytical methodology for each parameter is given in Appendix D. 
Section No. 6.2

Revision No. 0

Date: $2 / 1 / 91$

Page 1 of 1

\subsection{SPECIFIC ANALYTICAI TECHNIQUES}

The specific field analytical techniques used by Branch personnel are listed below and the specific procedures for each analytical cechnique and field test are presented in Appendix D.

Analytical

Parameter

Temperature

pH

Specific

Conductance

Dissolved Oxygen (DO)
Method

Calibrated glass (mercury), dial (mechanical), or electrometric thermometer

Modified Winkler or membrane electrode

Wheatstone bridge rype or equivalent meter corrected to 25 . C

Electrometrically using a glass electrode in combination with a reference poten-
Reference

1 tial or a combination electrode

Total Chlorine Residual

TracerFluorescence

Analysis of fluorescent dyes using a fluorometer

Salinity
Back titration, lodometric with starch or amperometric end-point or DPD colorimetric
1

1

1

1

2

3

\section{Equipment}

Mercury filled glass, mecharical dial type thermometer, or thermistor with electronic readout

Portable field pH meter

Standard DO kit with fresh sodium thiosulfate, or membrane electrode and electronic readout

Self-contained conductivity meter, Wheatstone bridge type, or equivalent with automatic temperature compensation to 25 . $C$ or "dial in" temperature compensation

Iodometric backtitration kit with fresh reagents, or amperometric titrator with fresh reagents, or DPD kit with color standards

Rhodamine WT dye and Turner fluorometer

Beckman RS5-3 Portable

Salinomerer and Hydrolab Surveyor II Meter 
Section No. 6.3

Revision No, 0

Date: $2 / 1 / 91$

Page 1 of 4

\subsection{SPECIFIC QUALITY CONTROL PROCEDURES}

Quality assurance procedures for field analysis, and field analytical and test instrumentation calibration are an essential part of these standard oper. ating procedures. All field analytical procedures shall be conducted in duplicate at least 10 percent of the time. A record of these duplicate analyses shall be kept in field logbooks. A significant difference in the replicate analyses (greater than specified in the following sections) shall result in recalibration of the instruments used, re-examination of the analytical methodology being used, or re-examination of the sampling location.

All field analyses must be traceable to the specific individual performing the analyses. Time records shall be kept in local time using the military 2400 hour format and shall be recorded to the minute. This information shall be entered into the field logbooks for all field analyses performed by Branch personnel.

A specific calibration and/or standardization plan for all field analytical equipment is presented in this subsection. Included in this plan are: calibration and maintenance intervals; listing of required calibration standards and conlitions requiring recalibration.

\subsubsection{Temperature}

6.3.1.1 Initial Calibration -. All thermometers shall be initialiy calibrated against a National Bureau of Standards (NBS) certified thermometer or one traceable to NBS certification.

6.3.1.2 Inspection and Calibration -. Each glass mercury filled thermometer shall be inspected before each field trip to see that it is not cracked and has no air space in the mercury column. If a mechanical dial-type thermometer is used, it should not have a broken face cover or otherwise show damage. A cross-check with a calibrated NBS certified thermometer shall be made at least semi-annually. Thermistors and electronic readout units should be calibrated in the same manner. Recording thermometers shall be checked for recording accuracy before each use. The recorder time scale accuracy shall be checked semi-annually. Before using a thermometer in the field, a visual observation shall be made to assure that it has not been damaged. If a thermistor is used, the instrument shall be checked against a thermometer before field use. Cross-checks and duplicate field analyses should agree within $\pm 0.5^{\circ} \mathrm{C}$.

6.3.1.3 Calibration Records -- A logbook shall be maintained with each thermometer number and/or equipment property number recorded. All calibration information including individuals making the calibrations and dates of calibration shall be recorded.

$0.5^{\circ} \mathrm{C}$.

6.3.1.4 Reporting Units - Report all temperature data to the nearest

\section{$6.3 .2 \mathrm{DH}$}

6.3.2.1 Equipment -- Only electronic (portable) pH meters with automatic 
temperature compensation (ATC) should be used. Temperature resistant, combination electrodes should be employed in conjunction with the meters. pH test paper will be used only for determining $\mathrm{pH}$ ranges, for determining approximate pH values, or for concentrated hazardous waste samples which would damage the instrument.

6.3.2.2 Equipment Inspection and Calibracion - The pH meter shall be checked before each field trip for any mechanical or electrical failures, weak batterles, and cracked or fouled electrodes. The slope of the meter shall also be checked initially with three fresh standard buffer solutions (e.8., 4, 7, and 10). All pH recorders shall be checked for recording accuracy and time scale accuracy. While in the field, the meter shall be calibrated daily before use with two buffers bracketing the expected sample pH. Thereafter, the meter shall be checked against two buffers when moving to a new sample location. Fresh buffer solutions shall be used for each field trip. In case of an apparent pH violation, the electrode shall be checked with $\mathrm{pH} 7.0$ buffer and recalibrated to the closest reference buffer. Then the sample shall be retested. Duplicate tests should agree within 0.1 standard unit.

\subsubsection{Reporting Units - Report $\mathrm{pH}$ to the nearest 0.1 standard unit.}

\subsubsection{Dissolved Oxygen (DO)}

6.3.3.1 Equipment -. Modified Winkler kits and membrane electrode DO meters should be used.

6.3.3.2 Equipment Inspection and Calibration - - DO meters shall be checked before each field trip by inspecting the membrans for air bubbles and holes. If the membrane is dry, it shall be replaced and soaked in wacer before calibrating. Calibration should be made against the modified Winkler test.

DO kits shall be refilled with new standardized sodium thiosulfate before each field trip. Each solution shall be checked for clarity and volume.

Before using the DO meter each day, duplicate deionized or known clean water samples shall be collected by siphoning water from a bucket into two DO bottles. These duplicate samples shall be analyzed by the modified Winkler test for DO content. The DO meter shall be calibrated against the DO concent measured by the winkler test by placing the DO probe in the bucket containing the water used for the Winkler test.

While using the DO meter, the instrument shall be recalibrated at least twice per day or if a change in water quality is noted. If the sample temperature is $5^{\circ} \mathrm{C}$ greater than the calibration temperature, the meter shall also be recalibrated.

Duplicate analyses should agree with $\pm 0.1 \mathrm{mg} / \mathrm{l}$.

6.3.3.3 Reporting Units - Results for the DO test should be reported to the nearest $0.1 \mathrm{mg} / 1$. 
Section No. 6.3

Revision No. 0

Date: $2 / 1 / 91$

Page 3 of 4

\section{3 .4 Specific Conductance}

6.3.4.1 Equipment - A portable specific conductance meter, Wheatstone bridge type or equivalent should be used.

6.3.4.2 Inspection and Calibration -. Each conductivity meter shall be checked before each field trip. Batteries shall be checked, and conductivity cells shall be cleaned and checked against known conductivity standards (KCI).

6.3.4.3 Field calibration -. Before using in the fleld, check instrument daily with known standards. Refer to the instrument instructions for temperature conductance calculations. Duplicate field analyses should agree within \pm 10 percent.

6.3.4.4 Reportine Untts -- Results should be expressed in micromhos/centimeter (umhos $/ \mathrm{cm}$ ) corrected to $25^{\circ} \mathrm{C}$. Results should be reported to the nearest ten units for readings under 1,000 umhos $/ \mathrm{cm}$ and the nearest 100 units for readings over 1,000 umhos $/ \mathrm{cm}$.

\subsubsection{Total Chlorine Residual}

6.3.5.1 Equipment -. The iodimetric back titration method with a starchiodide end point or amperometric end point or a Hach DR 100 colorimetric (DPD) kit may be used.

6.3.5.2 Inspection and Calibration -. Each t1tration kit or meter shall be checked before each field trip by inspecting the meter for battery strength and fresh reagents. The normality of the lodate should be checked with a distilled water blank to establish a correction factor for the titrant. This will also serve to check the response of the amperometric titrator. Duplicate chlorine residual analyses should agree within $\pm 0.01 \mathrm{mg} / 1$.

If the Hach DR 100 colorimeter (DPD) kit is used, the method must agree with the requirements of Method 408E, "Standard Methods," 16th Edition, or Method 330.5 "Methods for Chemical Analysis of Water and Wastes, "and calibration scales must be calibrated on site at a minimum of three points (blank and two standards) that bracket the expected sample concentration.

6.3.5.3 Reporting Units - Results should be reported to the nearest $0.01 \mathrm{mg} / 1$ residual chlorine.

\subsubsection{Eluorescent Tracing}

6.3.6.1 Iracer -. Rhodamine WT dye is the standard tracer used by Branch personnel.

6.3.6.2 Eluorometer -. A filter fluorometer (fluorometer) is the instrument used to determine intensity of emitted light or concentration of dye in the sample.

6.3.6.3 Eluorometer Calibration and Calibration Standards - Before a fluorometer is used in the field, it shall be checked against a set of standard 
Section No. 6.3

Revision No. 0

Date: $2 / 1 / 91$

Page 4 of 4

dye solutions. All standard concentrations shall be made relative to the stated concentration of the manufacturer's solution.

All standard solutions shall be made with distilled water. Sufficient solution volumes shall be made to permit calibration checks. Calibration checks shall be conducted whenever the fluorometer has been turned off for an extended period of time.

The fluorometer and all associated equipment shall be thoroughly cleaned between uses.

6.3.6.4 Reporting Units - - Turner Design fluorometer results shall be reported as \pm 1 percent of full scale concentration.

\subsubsection{Salintey}

6.3.7.1 Equipment - A portable salinometer, electrical conductivity type shall be used.

6.3.7.2 Inspection and Calibration .. Each salinometer shall be checked before every field trip. Batteries shall be checked and the cell inspected to determine if it is free of marine growth and salt. The meter shall be checked against the resistor loop supplied with the meter.

6.3.7.3 Reportine Units - Results should be reported to the nearest 0.1 part per thousand of salinity. 


\section{C-30}

Section No. 6.4 Revision No. 0 Date: $2 / 1 / 91$

Page 1 of 1

\subsection{SEMI-ANNUAL MAINTENANCE}

All analytical and test instruments and kits shall be inspected on semi. annual basis, whether used during the intervening period or not. The purpose of the semi-annual inspection is to maintain the equipment in a ready-to-use condition. This inspection shall consist of a general examination of the electrical system (including batteries) and a calibration against standards. Any expired reagents, broken glassware, or parts shall be replaced. 


\subsection{SOURCES OF CHEMICALS AND STANDARDS}

All chemicals used in test $k 1 t s$ and with field analytical instruments as reagents and standards shall be supplied and standardized by the Analytical Support Branch (ASB). Certified pH buffer solutions shall be purchased from chemical supply houses. All reagents and solutions shall have expiration dates attached to the containers. All out-of-date reagents, buffers, and chemical solutions shall be properly disposed of at their axpiration date. All field reagent containers shall be ldentified with the chemical name, concentration, and date prepared.

Tracer-fluorescence standards will be prepared for each study using the actual tracer as outlined in Appendix 0.9. 


\section{C-32}

Section No. 6.6

Reviaion No. 0

Date: $2 / 1 / 91$

Page 1 of 1

\subsection{TRAINING}

Each member of the Branch Involved in fleld studles shall undergo an Initial review of fleld analytical and test procedures and equipment. After the Initial reviow, subsequant reviews shall take place annuslly. The Branch Quality Assurance Officer, in confunction with personnel from the ASB, shall conduct the instruction. Any now instrumentation adopted by the Branch will be introduced to Branch personnel in a training session before it will be authorized for routine use. 
Sec.ion No. 6.7 Revision No. 0 Dace: $2 / 1 / 91$

Page 1 of 1

6.7 REFERENCES

1. "Guidelines for Establishing Test Procedures for the Analysis of Pollutants," Eederal Register, Volume 49, No. 209, 40 CFR 136, October 26. 1984, and any subsequent revisions.

2. Wlison, J. F., Eluorometrtc Procedures for Dye Tracing: USGS Techniaues of Water-Resources Invertigatione, Book 3, Chapter A12, United States Department of Interior, Geological Survay, 1968.

3. Standard Methode for the Examination of Water and Wastewater, 1985, $16 \mathrm{ch}$ Edition.

4. Methods for Chemical Analysis of Water and Wastes, EPA, 600/4-79-020, and all current revisions. 
Section No. D.4 Revision No. 0 Date: $2 / 1 / 91$

Page 1 of 2

METHOD D.4 DISSOLVED OXYGEN (MEMBRANE ELECTRODE)

\section{D.4.1 Saope and Aopliageton}

The membrane electrode (ME) probe method for DO measurements 18 recommended for those samples containing materials which interfere with the modified Winkler procedure as 11sted in Section D.3.1 of Method D.3.

The ME probe method may be used as a substitute for the modifled Winkler procedure provided that the meter itself is standardized against the Winkler wethod on samples free of Interferences.

\section{D.4.2 Summary of Method}

The most common ME instruments for determination of DO in water are depen. dent upon electrochemical reactions. Under staady-state conditions, the current or potential can be correlated with DO concentration. Interfacial dynamics at the ME-sample incerface are factor in probe response and a signiflcant degree of interfacial turbulence is necessary. For precision performance, turbulence should be constant.

Refer to the manufacturer's instructions for calibrating and operating each specific DO meter.

\section{D.4.3 Interferences}

- Dissolved organic materials are not known to interfere in the output Erom DO probes.

- Dissolved inorganic salts are a factor in the performance of DO probes

- Reactive gases which pass through the ME probes may interfere. For example, chlorine will depolarize the cathode and cause a high probe output. Long-term exposures to chlorine will coat the anode with the chloride of the anode metal and eventually desensitize the probe. Hydrogen sulfide will interfere with ME probes if the applied potential is greater than the half-wave potential of the sulfide Ion.

- Dissolved oxygen ME probes are temperature sensitive, and temperature compensation is normally provided by the manufacturer.

\section{D.4.4 Apparatus}

- YSI Model 57 DO Meter

- YSI 5700 Series DO Probe

- Hydrolab Surveyor II 


\section{D.4.5 Samole Handling}

Refer to Appendix D.3.4 (Method D.3).

\section{D.4.6 Calibration}

1. Fill a clean bucket with uncontaminated or deionized water and place the ME probe into the bucket. Using the siphon method described in Section D.3.4.4 of Method D.3, Fill duplicate BOD bottles and determine the DO by the Winkler method.

2. Adjust the meter according to manufacturer's instructions. Be sure to adjust the meter to the remperature of the water in the bucket, then calibrace the DO Indicator dial to read the average DO concentration of the two samples determined by the Winkler test.

\section{D.4.7 Test Procedure}

1. When making measurements be sure that the ME stirring apparatus is working, adjust the temperature compensator, and read the DO dial to the nearest $0.1 \mathrm{mg} / 1$.

2. Keep the probe in water when not in use to prevent the membrane from drying out.

3. If the sample temperature is $5^{\circ} \mathrm{C}$ greater than the calibration temperature, the meter should be recalibrated to the temperature of the sample.

4. Recalibrate agzinst the Winkler test when the DO readings show a distinct change in DO levels, or when the probe has been in waters high in sulfide.

\section{D.4.8 Precision and Accuracy} accuracy.

Manufacturer's specification claims $0.1 \mathrm{mg} / 1$ repeatability with \pm 1 percent

\section{D.4.9 References}

Standard Methods for the Examination of Water and Wastewater, 16 th Edition p. 395, Method 421 F (1985).

Mechods for Chemical Analysis of Water and Wastes, US-EPA, 360.1 (1983).

Instruction Manual YSI Model 57. Dissolved Oxygen Merer, Science Division, Yellow Springs Instrument Company.

Surveyor II Operating Manual, Hydrolab Corporation. 
Section No, D. 5

Revision No. 0

Date: $2 / 1 / 91$

Page 1 of 2

\section{METHOD D.5 SPECIFIC CONDUCTANCE}

\section{D.5.1 Scope and Application}

This method is applicable to ground, surface, and saline waters, as well as domestic and industrial wastes.

\section{D.5.2 Summary of Method}

- The specific conductance of a sample is measured by use of a selfcontained conductivity meter. Whetstone bridge-type, or equivalent.

- Samples are preferably analyzed at $25^{\circ} \mathrm{C}$. If not, temperature corrections are made and results reported at $25^{\circ} \mathrm{C}$.

\section{D.5.3 Test Procedure}

1. Follow instructions manual for specific field conductivity meter used.

2. Check the meter with two standard solutions of approximate specific conductances of 100 and 1,000 umhos $/ \mathrm{cm}$, or standards that bracket the expected sample conductance. If the meter does not read within one percent of the standards, determine what the problem is and correct it before proceeding. Most field instruments read conductivity directly; with those instruments, follow the manufacturer's instructions. Report the results to the nearest ten units for readings under 1,000 umhos $/ \mathrm{cm}$ and the nearest 100 units for readings over 1,000 umhos $/ \mathrm{cm}$.

3. Record the actual sample temperature when the measurement is made. The meter reading should be converted to specific conductance at $25^{\circ} \mathrm{C}$ using the information in the manufacturer's instruction manual.

\subsection{Apparatus Section}

- Beckman SoluBridge๑ Model RB-5/RB-6

- YSI Model 3530 Flow Through Cell

- Hydrolab Corporation Surveyor II

\section{D.5.5 Precision and Accuracy}

The conductivity meters listed above have an accuracy of \pm 2 percent of reading. With satisfactory equipment, results within 1 percent of the true value should be obtained. 


\section{C-37}

Section No. D.5 Revision No. 0 Date: $2 / 1 / 91$

Page 2 of 2

\section{D.5.6 References}

Standard Methods for the Examination of Water and Wastewater, 16th Edition, p. 76, Method 205 (1985).

Annufil Book of ASTM Standards, Part 31, Water," Standard D1125-64, P. 120. Methods for Chemical Analysis of Water and Wastes, US-EPA, 120.1 (1983). Instruction Manual. SoluBridge RB-5/RB-6, Beckman Instruments, Inc., Rev. January 1982.

Surveyor II Operating Manual, Hydrolab Corporation, Rev. A February 1985. YSI Model 3560 Water Quality Monitoring System Instructions, July, 1988. 
C-38

This Page Intentionally Left Blank 


\section{PROTOCOLS FOR SHORT TERM TOXIOTY SCREENING OF HAZARDOUS WASTE SITES}

by

Joseph C. Greene', Cathy L. Bartels?.

William I Warren-Hicks 3 , Benjamin R. Parkhurst 4 Gregory L. Linder ${ }^{2}$, Spencer A. Peterson'. and William E. Miller'
United States Environmental Protection Agency Corvallis Environmental Research Laboratory Ecotoxicology Branch Hazardous Waste Assessment Team 200 S.W. 35th Street Corvallis, OR 97333

2Northrop Services, Incorporated Corvallis Environmental Research Laboratory Hazardous Waste and Water Section 200 S.W. 35 th Street Corvallis, OR 97333

3Kilkelly Environmental Associates Highway 70 West - The Water Garden

Raleigh, NC 27622

4Western Aquatics, Inc.

P.O. Box 546

203 Grand Avenue Laramie, WY 82070 
bands around the petri dishes to reduce evaporation loss of the medium. Fresh (liquid) stock cultures may be started at four-week intervals by transfer of cells from a single clone in a petri dish to an appropriate volume of liquid medium.

\section{A.5.5.3 Culture Medium}

The culture medium is used to maintain the stock cultures of the test organisms. Culture medium is used as a control in each test and as the diluent in each test. Steps for preparing the culture medium follow:

1. Prepare five stock nutrient solutions using reagent-grade chemicals as described in Table A-2.

2. Add $1 \mathrm{~mL}$ of each stock solution, in the order listed in Table A-2, to approximately $900 \mathrm{~mL}$ of distilled or deionized water. Mix well after the addition of each solution.

3. Dilute to $1 \mathrm{~L}$, $\mathrm{mix}$ well, and adjust the $\mathrm{pH}$ to $7.0 \pm 0.1$, using $0.1 \mathrm{~N}$ sodium hydroxide or hydrochloric acid, as appropriate. The final concentration of macronutrients and micronutrients in the culture medium is given in Table A-3.

4. Sterilize the filtration apparatus, including $0.2 \cdot \mu \mathrm{m}$ pore diameter membranes. Membranes may be constructed of Tefion, glass fiber, or cellulose triacetate. Membranes must be autoclaved to ensure an aseptic system.

5. Immediately filter the $\mathrm{pH}$-adjusted medium through a $0.2-\mu \mathrm{m}$ pore diameter membrane at a vacuum of not more than $380 \mathrm{~mm}$ ( $15 \mathrm{in}$ ) mercury, or at a pressure of not more than one-half atmosphere (8 psi).

6. Place the filtered medium immediately into sterile culture flasks. No further sterilization steps are required before the inoculation of the medium.

Unused sterile medium should stored at $4^{\circ} \mathrm{C}$ in the dark for not more than one month before use. Storage may result in substantial loss of water by evaporation.

\section{A.5.6 CULTURE METHODS FOR THE EARTHWORMS (EISENIA FOETIDA)}

\section{A.5.6.1 Introduction}

Large numbers of E. foetida of known age and size can be easily cultured. Considerable information has been accumulated concerning their growth (Neuhauser et al. 1980), reproduction (Hartenstein et al. 1979), and physical requirements (Kaplan et al. 1980). This information and the ease of culturing makes E. foetida an appropriate earthworm for testing the toxicity of solid hazardous wastes.

\section{A.5.6.2 Distribution}

E. foetida can be found worldwide in its specific habitat, which includes manure and soils with a high proportion of organic matter (Fender 1985).

\section{A.5.6.3 Life Crele}

E. foetida reaches maturity in seven to eight weeks at $22 \pm 2{ }^{\circ} \mathrm{C}$. It is very prolific; a single worm produces two to five cocoons per week, each with several worms. 


\section{A.5.6.4 Morphology and Taxonomy}

Classification of the earthworm Eisenia foetida is controversial. Some authorities recognize two subspecies, foetida and andrei (Edwards 1984), while others recognize the subspecies as distinct species (Fender, 1985). Identification with the naked eye is not $100 \%$ accurate. There are no studies which indicate a sensitivity difference between andrei and foetida; conventional toxicological literature does not differentiate between the two. For these reasons, this manual simply refer to $E$. foetida as the designated name of the species used in the test. CERL has used andrei as its test organism for the last two years. In any case, results of the tests should include an identification of the organism used.

\section{A.5.6.5 Culture Methods}

\section{A.5.6.5.1 Sources of Organisms-}

Starter cultures of E. toetıda can be obtained from Mr. Julian Stewar, Vittor \& Associates, 8100 Cottage Hill Road, Mobile, AL 36695.

\section{A.5.6.5.2 Culture Vessels-}

The earthworms can be grown in any number of suitable containers including glass, polyethylene, and wood. The size of the container affects the ability to handle and move the earthworms as required by the laboratory protocol. Excessive container weight may make moving. feeding, and harvesting procedures difficult. The containers should be covered with a glass lid containing air holes.

\section{A.5.6.5.3 Culture Media-}

The earthworms are grown in peat moss bedding. The bedding pH is adjusted between 5 and 8 by adding up to three percent by weight of $\mathrm{CaCO}_{3}$. When using peat, care must be taken to avoid ovenwatering. Peat tends to become water logged with time and anaerobic conditions develop. Indications of anaerobic conditions occur after two to three months and include (1) a change in color between the bottom bedding material and the upper one to two inches of material, and (2) development of a strong odor.

\section{A.5.6.5.4 Culture Conditions-}

E. foetida stock cultures are maintained in a growth chamber in the dark at the same temperature as used for testing. The chambers must be capable of maintaining a temperature of $22 \pm 2^{\circ} \mathrm{C}$.

\section{A.5.6.5.5 Feeding-}

A mixture of alfalfa pellets is used as the maintenance organic food substrate for the earthworms. The mixture is saturated with water and aged for two weeks in a sealed container. The aged food is sprinkled on the surface of the culture tray. Alfalta pellets can be obtained from agricultural feed and supply stores

\section{A.5.6.5.6 Culture Maintenance-}

Crowding of adult worms in the growith container must be avoided. Crowding decreases the growth rate and reproduction efficiency. Splitting the bedding material in half every three to four months with pH-adjusted peat moss will prevent overcrowding (Neuhauser et al. 1980). 
When the bedding appears dry on the surface, water should be added. However, saturation can cause the earthworms to crawl out of the rearing container. Therefore, water should be added at a rate that keeps the material wet, but avoids standing water in the bottom of the rearing pan. Water use will depend on the ambient temperature and relative humidity. Watering additions can, however, easily be adjusted to the particular conditions of the rearing room.

A pH range of 5 to 8 is best for optimum growing conditions. Earthworms subjected to moisture and $\mathrm{pH}$ conditions outside the optimum range will leave the container or die.

\section{A.5.6.5.7 Production Level-}

At least four culture containers should be maintained to ensure a sufficient number of earthworms on a continuing basis.

\section{A.5.6.6 Test Oraanisms}

Adult E. foetida (at least two months old with a clitellum) are used for the toxicity test. The earthworms should weigh 300 to $500 \mathrm{mg}$ and be from the same culture container. From 150 to 300 earthworms may be required for each test. 


\section{A.8.5 EARTHWORM SURVIVAL (EISENIA FOETIDA)}

\section{A.8.5.1 Scope and Application}

This method (modified from the methods described by Edwards (1984) and Goats and Edwards (1982)) estimates the acute toxicity of solid hazardous wastes to the earthworm (E. foetida) in a 10.d static test. The responses measured include the synergistic, antagonistic, and additive effects of all the chemical, physical, and biological components that adversely affect the physiological and biochemical functions of the test organisms. The method uses soil as the exposure medium because the exposure conditions closely resemble natural conditions. The method could also be used to test aqueous samples by using $100 \%$ artificial soil and by using the aqueous samples in place of distilled or deionized water to hydrate the test soils. This method should be performed by, or under the supervision of, professionals experienced in environmental toxicity testing.

Detection limizs of the toxicity of an hazardous waste solution or pure substance are organism dependent.

\section{A.8.5.2 Summary of Method}

Earthworms (E. foetida) are exposed in a static system for 14 days to different concentrations of solid hazardous wastes mixed with artificial soil. Test results are based on survival of the worms

\section{A.8.5.3 Definitions}

For definitions of key terms, refer to the Glossary.

\section{A.8.5.4 Interterences}

Toxic substances may be introduced by contaminants in water, glassware, sample hardware, artificial soil, and testing equipment (see Section A.4, Facilities and Equipment). Low dissolved oxygen (DO) concentrations or saturation of soils with water may mask the presence of toxic substances.

Pathogenic organisms in test materials may also affect test organism survival, and confound test results.

Improper hazardous waste sampling and handling may adversely affect test results (see Section A.7, Hazardous Waste Sampling and Handling).

\section{A.8.5.5 Safety}

For a discussion on safety, see Section A.2, Health and Safety.

\section{A.8.5.6 Apparatus and Equipment}

1. Earthworm culture units - see Section A.5.6. This test requires $150-300$ earthworms $>60$ days old weighing 300 to $500 \mathrm{mg}$. It is preferable to obtain the earthworms from an in-house culture unit.

2. Sample containers - for sample shipment and storage (see Section A.7, Hazardous Waste Sampling and Handling).

3. Environmental chamber or equivalent facility with temperature control $\left(22 \pm 2^{\circ} \mathrm{C}\right)$. 
4. Water purification system -. Millipore Milli-Q or equivalent.

5. Balance, analytical - capable of accurately weighing earthworms to $0.001 \mathrm{~g}$.

6. Balance, top-loading - capable of weighing soil samples to $1.0 \mathrm{~g}$.

7. Reference weights, Class 5 - for checking performance of balance Weights should bracket the expected weights of the weighing pans and the expected weights of the pans plus worms or soil.

8. Test chambers - standard 1-pint canning jars with serew-top lids and rings.

9. Volumetric flasks and graduated cylinders - Class A, borosilicate glass or non-toxic plastic labware, 10- to $1000-\mathrm{mL}$.

10. Volumetric pipets - Class A, 1- to $100-\mathrm{mL}$

11. Serological pipets - 1- to 10-mL, graduated

12. Pipet bulbs and fillers - Propipet ${ }^{R}$ or equivalent.

13. Bulb-thermograph or electronic-chart type thermometers--for continuously recording temperature.

14. National Bureau of Standards certified thermometer (see EPA Method 170.1, EPA 1979b).

\section{A.8.5.7 Reagents and Consumable Materials}

1. Reagent water - defined as activated-carbon-filtered, distilled or deionized water that does not contain substances toxic to the test organisms. A watef purification system may be used to generate reagent water (see number 4 above).

2. Solid hazardous waste sample - see Section A.7, Hazardous Waste Sampling and Handling.

3. Artificial soil consisting of (by weight) $10 \% 2.36-\mathrm{mm}$-screened sphagnum peat, $20 \%$ colloidal kaolinite clay, and $70 \%$ grade 70 silica sand. The artificial soil must be well mixed after it is prepared. Peat, sand, and clay can be obtained from local suppliers.

4. pH buffers 4, 7, and 10 (or as per instructions of instrument manufacturer) for standards and Calibration check (see EPA Method 150.1, EPA 1979b).

5. Laboratory quality assurance samples and standards for the above methods.

6. Reference toxicant (see Section A.3, Quality Assurance).

7. Test organisms - earthworms (E. foetida): see Section A.5.6 for culture methods for earthworms. The species taxonomy should be verified using appropriate systematic keys (Fender 1985). Adult E. foetida (at least two months old with a clitellum) used for each test should weigh 300 to $500 \mathrm{mg}$ and be from the same culture container.

\section{A.8.5.8 Sample Collection, Preservation, and Storage}

For a discussion on collecting, preserving, and storing samples, see Section A.7, Hazard Waste Sampling and Handling. 


\section{A.8.5.9 Cellibretion and Stunderdizntion}

For a discussion on calibration and standardization, see Section A.3, Quality Assurance.

\section{A.8.5.10 Qunlitycontrol}

For a discussion on quality control, see Section A.3, Quality Assurance.

\section{A.8.5.11 Procedures}

\section{A.8.5.11.1 Test Soils-}

One of two dilution factors, 0.3 or 0.5 , is commonly used. A dilution factor of approximately 0.3 allows testing between $100 \%$ and $1 \%$, using only five concentrations (100\%, 30\%, 10\%, 3\%, and 1\%). This series of dilutions minimizes the level of effort, but, because of the wide interval between test concentrations, provides poor test precision $( \pm 300 \%)$. A dilution factor of 0.5 provides greater precision $( \pm 100 \%)$, but requires several additional dilutions to span the same range of concentrations. Improvements in precision decline rapidly as the dilution factor is increased beyond 0.5 . A dilution factor of 0.5 is generally preferred.

If the hazardous waste is known or suspected to be highly toxic, a lower range of concentrations should be used (such as 10\%, 5\%, 2.5\%, 1.25\%, and $0.63 \%$ ). If a high rate of mortality is observed during the first 1 to $2 \mathrm{~h}$ of the test, additional dilutions at the lower range of concentrations should be added.

The volume of hazardous waste required for three replicates per concentration, each containing $200 \mathrm{~g}$ of test soil, is approximately $1200 \mathrm{~g}$. Prepare enough test soil at each concentration to provide sufficient soil for chemical analyses.

\section{A.8.5.11.2 Glassware Proparation-}

Drill or punch a 1/16-in. hole into the center of each canning jar lid. Clean all jars using the procedures outlined in Section A.4, Facilities and Equipment. The rinse cycle in some dishwashers is colder than the wash cycle; this creates a thermal shock, which may crack the soft glass jars. The cleaned jars should be dried at $50^{\circ} \mathrm{C}$ in a forced air oven and stored with lids (without holes) on in a dust-free environment until needed. The lids should be examined after each use because the seal may deteriorate during repeated washing. Replace the lids and screw rings as needed.

\section{A.8.5.11.3 Start of the test-}

Tests should begin as soon as possible, proferably within $24 \mathrm{~h}$ of test soil collection. If the persistence of sample toxicity is not known, the maximum holding time should not exceed $36 \mathrm{~h}$. In no case should the test be started more than $72 \mathrm{~h}$ after tert soil collection. Just prior to testing, the temperature of the test soils should be adjusted to $20 \pm 2 \mathrm{C}^{\circ}$

Homogenize the solid waste material using a blender. Mix the homogenized solid waste material with artificial soil to prepare $700 \mathrm{~g}$ each of a geometric series of test soil concentrations. e.9. 100, 50, 25, 12.5, 6.25, 3.13\% dry weightdry weight, plus controls (100\% artificial soil). To ensure even distribution of the test soil mixture, the total amount for each concentration is mixed together in a blender before dividing into replicates. 
Atter mixing, test soils need to be hydrated with deionized water to create a moist, but not saturated, testing environment. The earthworm test soils are to be hydrated to $75 \%$ of water holding capacity. Hydration water required to achieve the desired hydration is calculated as follows:

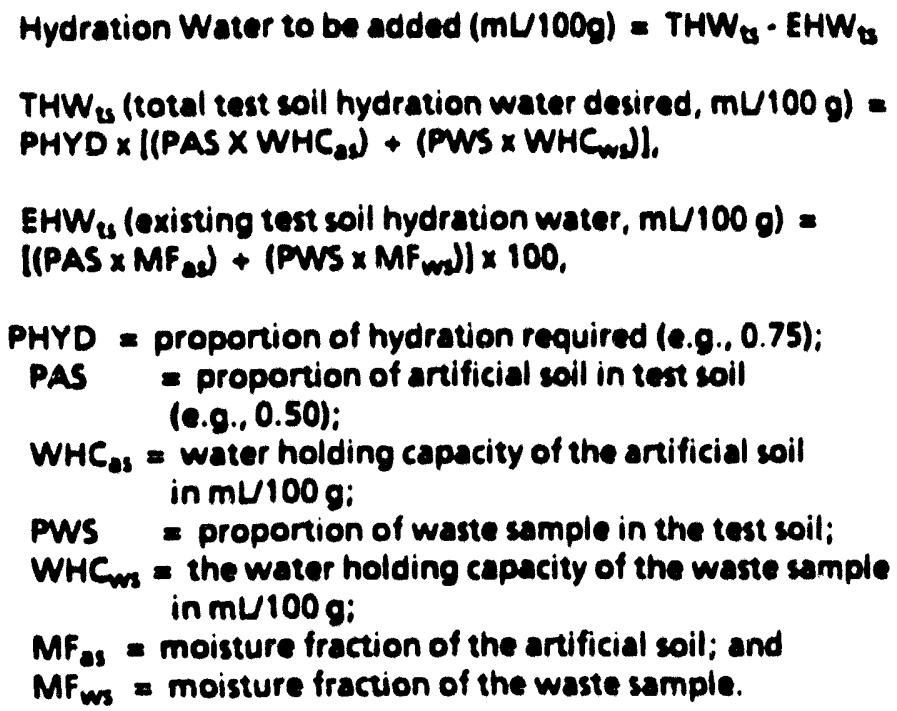

Ten earthworms are placed into each of the three replicate jars each containing $200 \mathrm{~g}$ (dry weight) of test soil. (Randomize the position of test chambers at the beginning of the test.) Adult earthworms should be handled with a spatula.

The earthworms should be placed on the surface of the test soil in a pint jar, capped, and secured. The tests are incubated to give a soil temparature of $20 \pm 2^{\circ} \mathrm{C}$ under continuous light. The test jars must not be shadad.

\section{A.8.5.11.4 Light, Photoperiod, and Temperature-}

Lighting should be at continuous ambient laboratory levels, which is approximately (540 to 1080 (ux), with no shading.

\section{A.8.5.11.5 Feeding-}

To avoid further interferences, the worms are not fed during the test.

\section{A.8.5.11.6 Routine Chemical and Physical Analyses-}

At a minimum, the following measurements are made:

- The pH of the test soils should be measured at the beginning and end of the test.

- The temperature of the environmental control chamber should be continuously monitored.

- The TOC of the test soils should be measured in one test jar at all test concenteations and in the control. 


\section{A.8.5.11.7 Observations During the Test--}

Mortality is assessed by emptying the test soil onto a tray and sorting the worms from the soil. Dead worms are discarded. (E. fontida are considered dead when they do not respond to a gentle touch to their anterior.) Live worms are placed back into their test jars and placed on the surface of the soil. The numbers of live and dead worms in each test chamber are recorded at 14 days and the dead worms are discarded.

Decay of dead worms can be rapid and, if all 10 worms per container are not found, it can be assumed that the worms decayed beyond recognition.

\section{A.8.5.11.8 Termination of the Test-}

The test is terminated after 14 days of exposure. At termination, the number of live and dead worms in each test chamber are counted.

\section{A.8.5.11.9 Acceptability of Test Results-}

For the test results to be acceptable, mean survival in the controls must be at least $90 \%$.

\section{A.8.5.11.10 Summary of Test Conditions-}

A summary of test conditions is listed in Table A-9.

\section{A.8.5.12 Calculations}

The effect measured during the toxicity tests using E. foetide is death.

See Section 2 in the main text for a description of dats analysis methods. Both 7.d and 14-d LC5Os and $95 \%$ confidence intervals should be calculated.

\section{A.8.5.13 Precision and Accuracy}

Section A.3, Quality Assurance, describes test precision; the accuracy of toxicity tests cannot be determined. 
TABLE A-9. SUMMARY OF RECOMMENDED TEST CONOINONS FOR E. EOFIIDA
SUAVUAL TEST

1. Test type:

2. Soil temparature (०O):

3. Light quality:

4. Light intensity:

5. Photoperiod:

6. Test vessel type and size:

7. Test soil mass:

8. Test soil pH*

9. Artificial soil (\% weight):

10. Test soil moisture content:

11. Renewal of test materials:

12. Age of test organisms:

13. Number of test organisms per chamber:

14. Number of replicate chambers per dilution:

15. Feeding regime:

16. Dilution factor:

17. Test duration:

18. Effect measured:
Suatic

$20 \pm 2^{\circ} \mathrm{C}$

Ambient laboratory light

540-1080 lux

Continuous illumination

1-pint glass canning jars with rings and lids $1 / 8$ inch air hole $200 \mathrm{~g}$

$\geq 4$ but $\leq 10$

$10 \% 2.36 \mathrm{~mm}$-screened sphagnum peat, $20 \%$ colloidal keslinite clay, and $70 \% \cdot$ grade 70 silica sand

75\% of water holding capacity

None

$>60$ days

10

3

Do not feed

0.5

14 days

Death - If pH is outside this range, results maiy reflect ph toxicity. Adjustments of ph to 4.0 or 10.0 may
result in altered toxicity of other constituents. See Sec 1.4. and A 7.7. 


\section{A.8.6 LETTUCE SEED GERMINATION (LACTUCA SATVA)}

\section{A.8.6.1 Scope and Application}

This method (modified from the method described by Thomas and Cline (1985)) estimates the acute toxicity of solid hazardous wastes to lettuce (L. Sativa) in a 120-h static test. The responses measured include the synergistic, antagonistic, and additive effects of all the chemical, physical, and biological components that adversely affect the physiological and biochemical functions of the test organisms. The method uses soil as the exposure medium because the exposure conditions closely resemble natural conditions. The method could also be used to test aqueous samples by using $100 \%$ artificial soil and using the aqueous samples in place of distilled or deionized water to hydrate the test soils. This method should be performed by, or under the supervision of, professionals experienced in environmental toxicity testing. dependent.

Detection limits of the toxicity of a hazardous waste solution or pure substance are organism

\section{A.8.6.2 Summary of Method}

Lettuce seeds (L. Sativa) are exposed in a static system for $120 \mathrm{~h}$ to different concentrations of solid hazardous wastes mixed with artificial soil. Test results are based on the successful germination of the seeds.

\section{A.8.6.3 Definitions}

For definitions of key terms, refer to the Glossary.

\section{A.8.6.4 Interferences}

Toxic substances may be introduced by contaminants in water, glassware, sample hardware. artificial soil, and testing equipment (see Section A.4, Facilities and Equipment).

Improper hazardous waste sampling and handling may adversely affect test results. test results.

Pathogenic organisms in test materials may affect test organism survival, and also confound

\section{A.8.6.5 Safety}

For a discussion on safety, see Section A.2, Health and Safety.

\section{A.8.6.6 Apparatus and Equipment}

1. Wire mesh screens for sizing seeds (fractions of an inch): $1 / 6 \times 1 / 28,1 / 6 \times 1 / 30,1 / 6 \times 1 / 32,1 / 6 \times$ 1/3. A.T. Ferrell and Company, Saginaw, MI 48601 or Seedburo Equipment Company, Chicago, IL 60607.

2. Forceps

3. pH meter

4. Storage bottles

5. $12^{\prime \prime} \times 12^{\prime \prime}$ polyethylene resealable bags (e.g., Ziploc $\left.R\right)$ 
6. An illuminated magnifier

7. Sample containers .. for sample shipment and storage (see Section A.7, Hazardous Waste Sampling and Handling).

8. Controlled environmental chamber capable of maintaining a uniform temperature of $24 \pm 2^{\circ} \mathrm{C}$ and $4300 \pm 430$ lux of light operating on a clock timer to control diurnal cycling.

9. Water purification system - Millipore Milli-Q or equivalent.

10. Balance, top loading - capable of woighing soil samples to $0.1 \mathrm{~g}$.

11. Reference weights, Class S - for checking performance of balance. Weights should bracket the expected weights of the weighing pans and the expected weights of the pans plus samples.

12. Test chambers - the bottom halves of plastic petri dishes, $150-\mathrm{mm}$ wide by $15-\mathrm{mm}$ high placed in $12^{\circ} \times 12^{\prime \prime}$ polyethylene resealable bags.

13. Volumetric flasks and graduated cylinders -- Class A, borosilicate glass or non-toxic plastic labware, 10- to 1000-mL.

14. Volumetric pipets - Class A, 1- to 100-mL.

15. Serological pipets - 1. 10 10-mL, graduated.

16. Pipet bulbs and fillers - PropipetR or equivalent.

17. Bulb-thermograph or electronic-chart type thermometers .- for continuously recording temperature.

18. National Bureau of Standards certified thermometer (see EPA Method 170.1, EPA 1979b).

\section{A.8.6.7 Reagents and Consumable Materials}

1. Reagent water -- defined as activated-carbon-filtered, distilled or deionized water that does not contain substances toxic to the test organisms. A water purification system may be used to generate reagent water (see number 9 above).

2. Solid hazardous waste sample

3. Artificial soil - the artificial soil used in the lettuce seed germination test is commercially available, 20-mesh, washed silica sand.

4. Cover sand - commercially available 16-mesh sand, which has been passed through a 20 mesh sieve to remove fines.

5. pH buffers 4, 7, and 10 (or as per instructions of instrument manufacturer) for standards and calibration check (see EPA Method 150.1, EPA 19796).

6. Laboratory quality assurance samples and standards for the above methods.

7. Reference toxicant (see Section A.3, Quality Assurance). 
8. Test organisms - lettuce (butter crunch variety). Lactuca sativa $L$. The seeds used in this test are available from commercial seed companies. Seed from one lot should be purchased in amounts adequate for one year's testing. Information on seed lot, year, or growing season in which they were collected and germination percentage should be provided by the seed source. Only untreated (not treated with fungicide, repellents, etc.) seeds are acceptable for use in this toxicity test.

\section{A.8.6.8 Sample Collection, Preservation, and Storage}

For a discussion on collecting, preserving, and storing samples, see Section A.7, Hazardous Waste Sampling and Handling.

\section{A.8.6.9 Calibration and Standardization}

For a discussion on calibration and standardization, see Section A.3, Quality Assurance.

\section{A.8.6.10 Qualiviv Control}

For a discussion on quality control, see Section A.3, Quality Assurance.

\section{A.8.6.11 Procedures}

\section{A.8.6.11.1 Test Soils-}

One of two dilution factors, 0.3 or 0.5 , is commonly used. A dilution factor of approximately 0.3 allows testing between $100 \%$ and $1 \%$, using only five concentrations $(100 \%, 30 \%, 10 \%, 3 \%$, and $1 \%)$. This series of dilutions minimizes the level of effort, but, because of the wide interval between test concentrations, provides poor test precision $( \pm 300 \%)$. A dilution factor of 0.5 provides greater precision $( \pm 100 \%)$, but requires several additional dilutions to span the same range of concentrations. Improvements in precision decline rapidly as the dilution factor is increased beyond 0.5 . A dilution factor of 0.5 is generally preferred.

\section{A.8.6.11.2 Glassware Preparation-}

All glassware used in preparing the soil samples must be thoroughly washed as described in Section A.4, Facilities and Equipment.

\section{A.8.6.11.3 Start of the Test-}

Sample preparation should begin as soon as possible, preferably within $24 \mathrm{~h}$ of sample collection. If the persistence of sample toxicity is not known, the maximum holding time should not exceed $36 \mathrm{~h}$. Just prior to testing, the temperature of the test soils should be adjusted to $24 \pm 2{ }^{\circ} \mathrm{C}$.

Homogenize the solid waste material using a blender. Mix the homogenized solid waste material with artificial soil to prepare $\mathbf{4 0 0} \mathrm{g}$ each of a geometric series of test soil concentrations, i.e., $100,50,25,12.5,6.25,3.13 \%$ dry weight hazardous waste/dry weight artificial soil, plus controls $(100 \%$ artificial soil). To ensure even distribution of the test soil mixture, the total amount for each concentration is mixed together in a blender before dividing into replicates.

After purchase, size grading of seeds is carried out on the entire seed lot. Small samples, 100150, are sized at a time. 

removed.

In addition, the seed lot must be inspected. Trash, empty hulls, and damaged seed are

Nest the four wire mesh sizing screens, with the one containing the largest holes on top and those with successively smaller holes in sequence below. A blank or bottom pan is used to collect the fraction that passes through all screens.

Pour the seeds onto the top screen, then shake the whole set of nested screens (by hand or with a vibrator) until all the seed remains on one screen or reaches the bottom pan. The separated fractions are set aside and retained. This procedure is repeated until all the seed in the lot is sized. The size class containing the most seed is selected and used for the duration of the tests. The seeds in each size class are divided into small lots, placed in separate envelopes or sacks, and stored in airtight, waterproof containers in a refrigerator at $4^{\circ} \mathrm{C}$.

Place $100 \mathrm{~g}$ of each concentration of air-dried control or test soil in each of three replicate 150-mm plastic petri dishes. Randomize the position of the test containers. Place $\mathbf{4 0}$ seeds in each dish. Space the seeds at least 0.5 inch from the edge of the petri dish to ensure that they will be covered with test soil. Press the seeds into the test soil with the bottom of a clean beaker. Pour $90 \mathrm{~g}$ of cover sand on top of the hydrated test soil. Level the cover sand with a ruler or small piece of cardboard. Place petri dish cover over the bottom to prevent water loss and spillage prior to incubation.

Hydrate the test soils with deionized water to create a moist, but not saturated, testing environment. The lettuce seed germination test soils are to be hydrated to $85 \%$ of water holding capacity. Hydration water required to achieve the desired hydration is calculated as follows.

$$
\begin{aligned}
& \text { Hydration Water to be added }(\mathrm{mL} / 00 \mathrm{~g})=T H W_{t s}-E H W_{t s} \\
& T H W_{t s} \text { (total test soil hydration water desired, } \mathrm{mL} / 100 \mathrm{~g} \text { ) = } \\
& \text { PHYD } \times\left[\left(\text { PAS } \times W H C_{a s}\right)+\left(\text { PWS } \times W H C_{W s}\right)\right] \text {. } \\
& \left.E H W_{t s} \text { (existing test soil hydration water, } \mathrm{mL} 100 \mathrm{~g}\right)= \\
& {\left[\left(\text { PAS } \times M_{\text {as }}\right)+\left(\text { PWS } \times \text { M F }_{\text {Ws }}\right)\right] \times 100 \text {, }}
\end{aligned}
$$

where PHYD = proportion of hydration required (e.g., 0.85):

PAS = proportion of artificial soil in test soil (e.g., 0.50):

$W H C_{a s}=$ water holding capacity of the artificial soil in mU100 g:

PWS = proportion of waste sample in the test soil:

$W H C_{w s}=$ the water holding capacity of the waste sample in $\mathrm{mL} 100 \mathrm{~g}$;

$M F_{a s}=$ moisture fraction of the artificial soil; and

$M F_{\text {ws }}=$ moisture fraction of the waste sample.

If $M F_{\text {as }}=0$, which would be the case if the artificial soils are prepared from dry ingredients, then $E H W_{t s}=P W S \times M F_{W s} \times 100$.

Place each covered petri dish into a resealable polyethylene bag, centered over the bottom of the bag. Raise the sides of the uag into a vertical position over the dish. Remove the dish cover and seal (airtight) the bag, leaving as much air space as possible. Randomly distribute the bags in an environmental chamber.

\section{A.8.6.11.4 Light, Photoperiod, and Temperature-}

Incubate at $24 \pm 2^{\circ} \mathrm{C}$ in the dark for $48 \mathrm{~h}$, followed by $16 \mathrm{~h}$ of light and $8 \mathrm{~h}$ dark until termination of the test at the end of $120 \mathrm{~h}$. Light intensity should be $4300 \pm 430$ lux. 
A.8.6.11.5 Routine Chemical and Physical Analyses-

At a minimum, the following measurements are made:

- The pH of the test soils should be measured at the beginning and end of the test (Black 1965 . 1982).

- Soil temperature is measured at the beginning of each $24-h$ exposure period in one replicate of each test concentration and in the control.

A.8.6.11.6 Observations During the Test-

No observations are made during the test.

\section{A.8.6.11.7 Termination of the Test-}

After $120 \mathrm{~h}$, the number of germinated seeds in each dish is determined by counting each seedling that protrudes above the soil surface.

A.8.6.11.8 Acceptability of Test Results-

For the test results to be acceptable, mean germination in the controls must be at least $90 \%$.

\section{A.8.6.11.9 Summary of Test Conditions-}

A summary of test conditions is listed in Table A-10.

\section{A.8.6.12 Calculations}

The effect measured during the toxicity tests using lettuce (L. a.tiva) seeds is germination.

See Section 2 in the main text for a description of data analysis methods.

Report the LC50 and its $95 \%$ confidence limits. The LC5O is an estimate of the median lethal concentration.

\section{A.8.6.13 Precision and Accuracy}

Section A.3. Quality Assurance, describes test precision; the accuracy of toxicity tests cannot be determined. 
TABLE A-10. SUMMARY OF RECOMMENDED TEST CONDITIONS FOR LETTUCE SEED (L. SATIVA) GERMINATION TEST

1. Test type:

2. Temperature $\left({ }^{\circ} \mathrm{C}\right)$ :

3. Light quality:

4. Light intensity:

5. Photoperiod:

6. Test vessel type and size:

7. Test soil mass:

8. Test soil moisture content:

9. Artificial soil:

10. Test soil pH:

11. Renewal of test materials:

12. Age of test organisms:

13. Number of test organisms per chamber:

14. Number of replicate chambers per dilution:

15. Dilution factor:

16. Test duration:

17. Effect measured:
Static

$24 \pm 2^{\circ} \mathrm{C}$

Fluorescent

$4300 \pm 430$ lux

Initial $48 \mathrm{~h}$ dark, followed by $16 \mathrm{~h}$ of light and $8 \mathrm{~h}$ of dark until termination of the test.

The bottom halves of plastic petri dishes, $150-\mathrm{mm}$ wide by $15-\mathrm{mm}$ high, placed in $12^{\prime \prime} \times 12^{\mu \prime}$ polyethylene resealable bags.

$100 \mathrm{~g}$

$85 \%$ of water holding capacity

20-mesh, washed silica sand

$\geq 4$ but $\leq 10$

None

seeds

40

3

0.5

$120 \mathrm{~h}$

Germination

- If pH is outside this range, results may reflect pH toxicity. Adjustment of pH 204.0 or 10.0 may result in altered toxicity to other constituents. See Sec 1.4 and A.7.7. 
C-55

\title{
ENVIRONMENTAL SCIENCES DIVISION
}

\section{TOXICOLOGY LABORATORY}

\section{QUALITY ASSURANCE PROGRAM}

\author{
L. A. Keros \\ A. J. Stewar \\ L. F. Whaker \\ L E Roberson
}

Prepared for the

U.S. Deparment of Enery, Omce of Defense Programs Oak Ridge Y-12 Plant, Health, Safety, Environmeat and Acosontability Division (Activity No. 72222250 1:NOR)

Prepared by the

OAK RDGE NATIONAL LABORATORY.

Oak Ridge, Tennescee 37831-6285

managed by

MARTIN MARIETTA ENERGY SYSTEMS, INC

for the

US. DEPARTMENT OF ENEROY

under conunea DE-ACOS-84OR21400 
ESD TOXICOLOGY LABORATORY

SECTION CONTENTS

PAGE

1 of 4

QUALITY ASSURANCE MANUAL

DATE

04-13-92

\section{SUBJECT: CONTENTS}

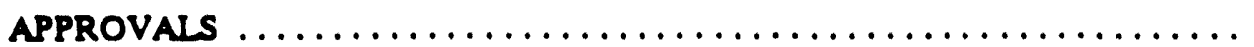

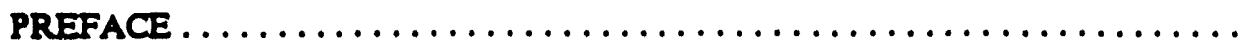

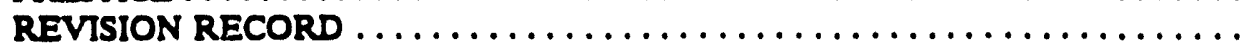

INTRODUCTION . . . . . . . . . . . . . . . . . . . . . . . . .

Table 1 Location of ORNL QA elements in the QA

pirn of the ESD Toxicology Laboratory

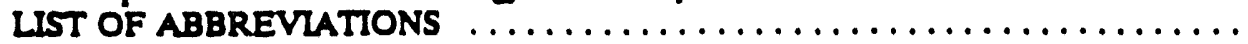

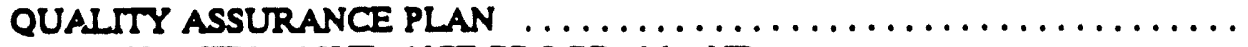

QUALTIY ASSURANCE PROGRAM AND

LABORATORY ACTIVITIES .

APPR

PREFACE

REV

Purpose of the QA Plan

QA Activities

Training

Management Ascessment

Purpose of the Laboratory

Laboratory Procedures

ORGANIZATIONAL RESPONSIBILTIES . . . . . . . . . . . . .

INTRO

Cenerd Responsibilities

Secion Hend

Group Leader

QA Administration

QA Specialist

Technical Staf and Students

Other Support and Service Perconnel

Approvals

Fig. QAP-21 Organizational structure and

lines of communication

Fis. QAP.22 Flow of information from toxicity testing

and negotiation scheme for NPDES permix

Fic. QAP.23 Pathway for reporting

resuls of racicity tests

PROCUREMENT DOCUMENT CONTROL AND CONTROL

OF PURCHASEDUSED ITEMS AND SERVICES

QAP-3

Purchaces trom Company Stores

Purchnes trom Veadors

Requisitions

Procureres ent of Services

Project-Specific Needs

Identifacion, Storage, Handling, and Control of Items

Chin of Custody

Sample Custody

Smple Custodinn

Chain-of-Custody Record

Cunin-of-Custody Form

ABBR

QAP

QAP-1

QAP-2 
ESD TOXICOLOGY LABORATORY

QUALITY ASSURANCE MANUAL
SECTION CONTENTS

\section{SUBJECT: CONTENTS}

Custody Seals and Shipping Procedures

Laboratory Custody Procedures

Dispoeal of Samples and Other Physical Evidence

Fif. QAP-3.1 Chain-of-Custody steps for

sampling, testing, and reporting

Exhibit QAP-3.1 Sample chain-of-custody form

DOCUMENT CONTROL AND

QUALTY ASSURANCE RECORDS

QAP-4

Revisions

Maintenance of Records

QA Records to Be Maintained

DNSTRUCTIONS AND PROCEDURES

QAP.5

Project Activities, Procedures, and Control of Processes

Listing of Procedures

Description of Procedures

MEASURING AND TEST EQUIPMENT

QAP-6

Callibration

Labeling

Mrintenance

Project-Specific Requirements

Equipment Requiring Calibration in Accordance with

Procedures in the Manufacturer's Manual

NONCONFORMANCE AND CORRECTIVE ACTIONS

Unplanned Deviations

Responsibilities of Project Participants

Reporting of Problems

Corrective Action

Exhibit QAP-7.1 Nonconformance report (NCR) form

Exhibit QAP.7.2 Corrective action report and sutus (CARS) form

AUDITS AND SURVEIILANCES $\ldots \ldots \ldots \ldots \ldots \ldots \ldots \ldots \ldots \ldots$ QAP-8

Audies

Surveillances

Reporting

Surveillance Activities Performed by

the Group Leader

SOFTWARE QUALTTY ASSURANCE $\ldots \ldots \ldots \ldots \ldots \ldots \ldots \ldots \ldots \ldots$ QAP.9

STANDARD OPERATING PROCEDURES $\ldots \ldots \ldots \ldots \ldots \ldots \ldots \ldots \ldots \ldots \ldots$ SOP

PREPARATION OF DILUTE MINERAL WATER ............. SOP-1

Exhibit SOP-1.1 Log Sheet for Use of Dilute Mineral Water (DMW)

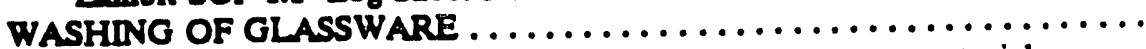

SOP-2

Exhibit SOP-21 Request for disposal of hazardous waste material

Exhibit SOP-22 Environmental Seiences Division certification

of nonradiosctive waste 
PREPARATION OF CERIODAPHNU FOOD $\ldots \ldots \ldots \ldots \ldots \ldots \ldots$

MANTENANCE OF CERIODAPHNU CULTURES $\ldots \ldots \ldots \ldots \ldots \ldots$

Exhibit SOP 4.1 Culture log sheet

Exhibit SOP-4.2 Brood Board survival and reproduction log sheet

PREPARATION OF NEWLY HATCHED BRINE SHRRMP $\ldots \ldots \ldots \ldots$

CULTURE OF FATHEAD MINNOWS $\ldots \ldots \ldots \ldots \ldots \ldots \ldots \ldots \ldots$

COLLECTION AND HANDLING OF SAMPLES $\ldots \ldots \ldots \ldots \ldots \ldots \ldots$

PREPARATION OF SAMPLES $\ldots \ldots \ldots \ldots \ldots \ldots \ldots \ldots \ldots \ldots$

SOP-6

SOP-7

FATHEAD MINNOW TOXICITY TEST . ..................

SOP-8

Exhibit SOP-9.1 Fathead minnow weight and survival

SOP.9

for Lotus program log sheet

Exhibit SOP-9.2 Fathead minnow test information log sheet

Exhibit SOP-9.3 Fathead minnow teat daily information log sheet

Exhibit SOP-9.4 Fathead minnow daily test results log sheet

CERIODAPHNL TOXICITY TEST .

SOP-10

Exhibit SOP-10.1 Ceriodaphria test information log sheet

Exhibit SOP-10.2 Ceriodaphria dally test information log sheet

Exhibit SOP-10.3 Daily survival and reproduction log sheet

PERFORMANCE OF CHEMICAI ANALYSES . . . . . . . . . . . . .

Exhibit SOP-11.1 Daily chemistry information log sheet

Exhibit SOP-11.2 Daily calibration for final D.O. log sheet

Extubit SOP-11.3 Daily chemistry data log sheet

STATISTICAL ANALYSES OF DATA FROM THE

FATTEAD MINNOW TOXICITY TEST $\ldots \ldots \ldots$

STATISTICAL ANALYSES OF DATA FROM THE

CERIODAPHNL TOXICITY TEST

SOP-12

FATHEAD MINNOW REFERENCE TEST . .................

Exhibit SOP-14.1 Datu sheet for thethead minnow reference test

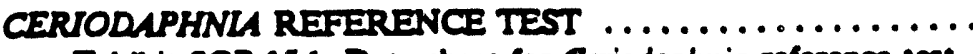

Exhibit SOP-15.1 Dat sheet for Ceriodaphnia reference teast

DATA LOGGING AND CARE OF TECHINICAL NOTEBOOKS .......

FATTHEAD MDNNOW ACUTE TOXICITY TEST ...............

Exhibit SOP-17.1 Fathead minnow acute toxicity teat log sheet

CERIODAPHNM ACCUTE TOXICITY TEST $\ldots \ldots \ldots \ldots \ldots \ldots \ldots$

Exhibit SOP-18.1 Ceriodaphria scute toxidity test log sheet

REFERENCE PROCEDURES $\ldots \ldots \ldots \ldots \ldots \ldots \ldots \ldots \ldots \ldots \ldots \ldots \ldots$

HEALTH AND SAFETY $\ldots \ldots \ldots \ldots \ldots \ldots \ldots \ldots \ldots \ldots \ldots \ldots \ldots$

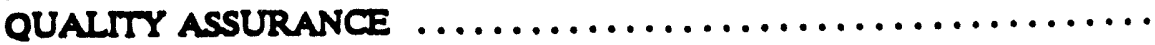

FACIITIES AND EQULPMENT $\ldots \ldots \ldots \ldots \ldots \ldots \ldots \ldots \ldots$

DILUTION WATER $\ldots \ldots \ldots \ldots \ldots \ldots \ldots \ldots \ldots \ldots \ldots \ldots$

SAMPLING OF EFFLUENTSRECEIVING WATERS

AND HANDLING OF SAMPLES $\ldots \ldots \ldots \ldots \ldots \ldots \ldots \ldots \ldots$

CRRONIC TOXICITY TEST ENDPODNSS AND

DATA ANALYSIS 
C-59

ESD TOXICOLOGY LABORATORY

SECTION CONTENTS

QUALTYY ASSURANCE MANUAL

PAOE

4 of 4

DATE

$04-13-92$

SUBJECT: CONTENTS

FATHEAD MDNNOW (PIMEPHLLES PROMELAS)

LARVAL SURVTVAL AND

GROWTH TEST METHOD 1000.0

REF.7

CERIODAPHNL SURVTVAL AND REPRODUCTION

TEST METHOD 10020

REFA

DNDEX

INDEX 


\section{ENVIRONMENTAL SCIENCES DIVISION} TOXICOLOGY LABORATORY

\section{QUALTTY ASSURANCE PROGRAM}

QAP-X-89-ES-0002

APPROVALS

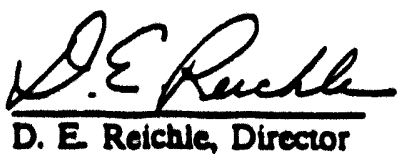

Eovironmental Sciences Division

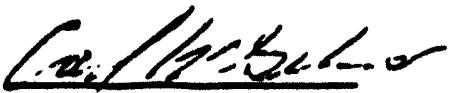

C.W. Gehn, Section Head

Environmental Toxicology

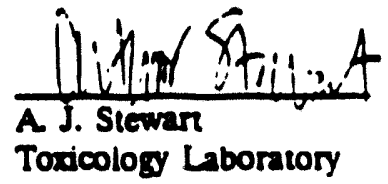

2. C. Chesum 4/10/89

I. E Roberson

Quality Deparmeat

Environmental Sciences Division

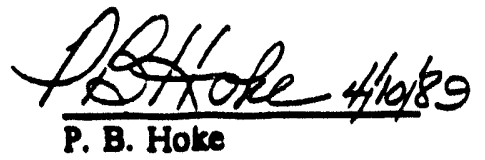




\section{SUBAECT: PREAACE}

This maual contains the quality asurance plan and the standard operating procedures used by the Environmental Sciences Division Toxicology Laboratory. The plan wis developed trom the requirements oullined in the Marin Mariana Enary Systems Qualiny Procedures Manual and the Oak Ridge Narional Laborasory Qualiny Assurance Manual.

The plan, which spels out specifc requirements mandated by sponsors and the managemeat of Oak Ridge National Laboratory, is designed to be easily read by all staff associated with the Todicolory Laboratory.

Elements of the QA plan and the standard opernting procedures of the Toxicolocy Laboratory are contrined in white-tabbed sections (hbeled QAP and SOP, respectively) of this manual. A separate white-tabbed section (REF) is devoted to the ational testing procedures upon which the standard operating procedures are based.

An index has been included at the back of the manual to facilitate access to many imporant topics. Additions to the index an be made at any time to maximize the usefulneas of the documeal. Such additions will not be regarded as plan revisions.

I would like to thank G. M. Logadon for her editorial expertise in designing and reviewing this document; ber painstaking efforts to clarify the tent brve been much appreciated. I also thank K. N. Gibson for her many useful suggestions about design and her long hours of work in adapting the document to WordPerfect 5.0. 
ESD TOXICOLOGY LABORATORY

SUBJECT: REVISION RECORD

All chnoges, additions, and deletions to the QA plan or procedures of the ESD Toxicology Laboratory are to be recorded on the following charr.

\begin{tabular}{|c|c|c|c|c|}
\hline $\begin{array}{l}\text { Revised } \\
\text { section }\end{array}$ & Nature of revision & $\begin{array}{l}\text { Revision } \\
\text { date }\end{array}$ & Siganture & $\begin{array}{l}\text { Insertion } \\
\text { date }\end{array}$ \\
\hline $\begin{array}{l}\text { iAP-6.900.14 } \\
\text { SP.15 }\end{array}$ & 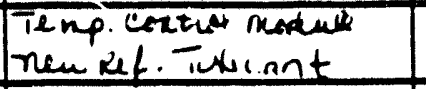 & 9120189 & Kronat Kass & $11 / 7 / 84$ \\
\hline SOP-1 & Prep. of dilutid minerd $\mathrm{H}_{2} \mathrm{O}$ & 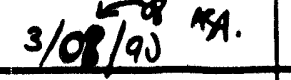 & Astansut & $5 / 22 / 90$ \\
\hline so $P-3$ & Prep \& Cevindephani fod & $3 / 08 / 90$ & As sturant & $5 / 22 / 90$ \\
\hline QAP-2 & Organizational responsiti. & $09 / 13 / 90$ & As ftewrant & $09 / 24 / 90$ \\
\hline $\begin{array}{l}\text { Pourm satro } \\
\text { Revisions Pen }\end{array}$ & Many: Not Menc 4 Gre & Mund 4 tramonde, & A freunet & Apip 16,91 \\
\hline Coinents: & Replacenumet. & $10 / 01 / 91$ & A, Sunsut & $12 / 04 / 91$ \\
\hline $\begin{array}{l}\text { contents; sop } \\
\text { antentisis sof: }\end{array}$ & Replacement, & $4 / 13 / 92$ & A. Strwant & $6 / 24 / 92$ \\
\hline & & & & \\
\hline & & & & \\
\hline & & & & \\
\hline & & & & \\
\hline & & & & \\
\hline & & & & \\
\hline & & & & \\
\hline & & & & \\
\hline & & & & \\
\hline & & & & \\
\hline & & & & \\
\hline
\end{tabular}




\section{SUBJECT: INTRODUCTION}

\section{Origin of the QA Program}

In 1979, the American Society of Mechanical Engineers (ASME), under mandate of the American National Standards Institute (ANSI), doveloped and isuved a antional standard entitled Qualiny Asaurance Progrem Requbrements for Nuclear Focilities, ocherwise known as ANSUASME NQA-1. This standurd was subequently appanded and rovised.

Martin Marietu Enery Syatems, Inc, requires that the quality asurance (QA) programs at its hallities be in acoordance with ANSUASME NOA-1. Thus, Oak Ridge National Laboratory (ORNL) has catablished a program based on the national stundurd The ESD Toxicology Laboratory OA plan incorporates laboratory-wide procedures with division procedures and program procedures related to quality. As part of ORNL, the Tordeology Laboratory in the Environmental Sedences Division (ESD) has developed a set of project-specific standard operating procedures to complement the Toxicology Laboratory QA plan.

\section{Required Elements of the QA Plan}

The ORNL version of NQA.1 wonuins 19 QA elements, each of which should be addressed by a QA program. However, 4 of the 19 elements (Deajgn Control"; "Inspection"; Test Control"; and "Impection, Tesh and Operating Status") either are not applicable to work conducted in the EDD Towicology Laboratory or overtap with QA elements addresced in other sections. These four elemeats are therefore aot included as separate items in this plan. Table 1 lists the ORNL QA elements and their location in the QA plan of the ESD Toxicology Laboratory. The rationale for the exclusion of nonupplicable elements follow.

\section{Rational for the Erelusion of Elements}

Four elements in the ORNL QA plan are considered nomapplicable to the Toricology Laboratory for the following reasons.

1. NQA-1 Element 4-Desizm Control":

The design of the ESD Todicology Laboratory is controlled thro ugh applicable documeatation procodures as specified in "Instructions and Procedures" (Sect. QAP-S) and in the standard operating procedures (Sect. SOP). Reports generated by the operation of the laboratory will not be subject to extermal review processes before being submitted to the customer for appraisal.

2 NQA-1 Elemeat 10-"Inspection":

Proceses and product inspections, as normally defined for manufectured items, are not applicable for work done in the laboratory. 


\section{SUBSECT: INTRODUCTION}

3. NQA-1 Element 11-Test Coatrol":

Tests performed by the Toxicology Laboratory are of a clinical mature and are not designed to confirm the scoeptability of manufactured iteme. The control of procedures is spectifed in "Instructions and Procedures" (Soct. QAP.5), and the control of equipment is described in "Measuring and Teat Equipment" (Sect. QAP-6).

4. NQA-1 Elemeat 14-'Inspection, Tesh and Operating Status":

Calibration and control equipmeat is specified in "Measuring and Test Equipment" (Sect. QAP. 6) and in the individual stundard operating procedures (Sect. SOP). 
ESD TOXICOLOGY LABORATORY

QUALTTY ASSURANCE MANUAL
SECTION

PAGE

DATE
INTRO

3 of 4

01-23-91

\section{SUBECT: INTRODUCTION}

Table 1. Location of ORNL QA elements in the QA plan of the ESD Taricology Laboratory

\begin{tabular}{|c|c|c|c|c|}
\hline $\begin{array}{l}\text { NQA-1 } \\
\text { BASIC } \\
\text { EI ENENT }\end{array}$ & $\begin{array}{l}\text { TO BE } \\
\text { APPLIAD } \\
\text { (YN) }\end{array}$ & $\begin{array}{c}\text { APPLCABLE } \\
\text { ORNL QA } \\
\text { PROCEDURE(S) }\end{array}$ & $\begin{array}{l}\text { DIVISION } \\
\text { SPECIFIC } \\
\text { PROCEDURES }\end{array}$ & $\begin{array}{l}\text { ADDIMONS } \\
\text { CARIFICATIONS }\end{array}$ \\
\hline 1. Orgnimesion & $\mathbf{Y}$ & QA-L-1-100 & QAP-2 & \\
\hline 2 Q & $\mathbf{Y}$ & $\begin{array}{l}\text { QA-L-2-100 } \\
\text { QA-L2-101 } \\
\text { QA-L-2-102 } \\
\text { QA-L-2-103 } \\
\text { QA-L-2-104 } \\
\text { QA-L-2-105 } \\
\text { QA-L2-106 }\end{array}$ & QAP-1 & \\
\hline 3. Danin & $\mathbf{N}$ & $\begin{array}{l}\text { QA-L-3-100 } \\
\text { QA-L3-101 } \\
\text { QA-L3-102 }\end{array}$ & & See Rationale \\
\hline 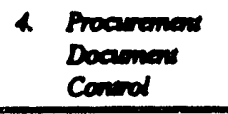 & $\mathbf{Y}$ & $\begin{array}{l}\text { QA-L+100 } \\
\text { QA-LA-101 }\end{array}$ & QAP-3 & \\
\hline 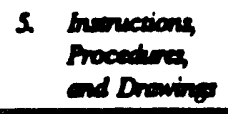 & $\mathbf{Y}$ & QA-L5-100 & QAP-5 & \\
\hline a Doanners & $\mathbf{Y}$ & QA-L-6-100 & QAP-4 & \\
\hline 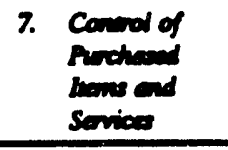 & $\mathbf{Y}$ & $\begin{array}{l}\text { QA-L-7-100 } \\
\text { QA-L-7-101 } \\
\text { QA-L-7-102 }\end{array}$ & QAP-3 & \\
\hline 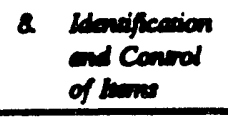 & $\mathbf{Y}$ & QA-L\&-100 & QAP-3 & \\
\hline $\begin{array}{l}\text { 9. Convol of } \\
\text { Procenese }\end{array}$ & $\mathbf{Y}$ & QA-L-100 & QAP-5 & \\
\hline 1a. Inpocition & $\mathbf{N}$ & QA-L-10-100 & & See Rationale \\
\hline 11. TE Coniol & $\mathbf{N}$ & QA-L-11-100 & & See Rationale \\
\hline
\end{tabular}


ESD TOXICOLOGY LABORATORY

SECTION INTRO

QUALTY ASSURANCE MANUAL

PAGE

DATE

$01-23-91$

SUBECT: INTRODUCTION

\begin{tabular}{|c|c|c|c|c|}
\hline $\begin{array}{l}\text { NQA-1 } \\
\text { BASIC } \\
\text { EIEMENT }\end{array}$ & $\begin{array}{l}\text { TO BE } \\
\text { APPLIED } \\
\text { (YN) }\end{array}$ & $\begin{array}{c}\text { APPUCABLE } \\
\text { ORNL QA } \\
\text { PROCEDURE(S) }\end{array}$ & $\begin{array}{c}\text { DIVISION } \\
\text { SPECIFIC } \\
\text { PROCEDURES }\end{array}$ & $\begin{array}{c}\text { ADDIMONS } \\
\text { CARIFICATIONS }\end{array}$ \\
\hline 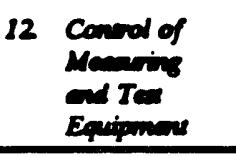 & $\mathbf{Y}$ & QA-L-12-100 & QAP-6 & \\
\hline $\begin{array}{l}\text { 13. Hovaling } \\
\text { sconsen and } \\
\text { Shipping }\end{array}$ & $\mathbf{Y}$ & QA-L $13-100$ & QAP-3 & \\
\hline 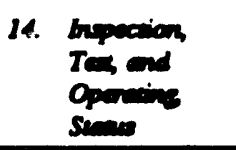 & $\mathbf{N}$ & $\begin{array}{l}\text { QA-L-14-100 } \\
\text { QA-L-14-101 }\end{array}$ & & See Rationale \\
\hline $\begin{array}{l}\text { 15. Convol of } \\
\text { Nanconformid } \\
\text { nom }\end{array}$ & $\mathbf{Y}$ & QA-L-15-100 & QAP-7 & \\
\hline $\begin{array}{l}\text { 16. Compation } \\
\text { Nation }\end{array}$ & $\mathbf{Y}$ & $\begin{array}{l}\text { QA-L-16-100 } \\
\text { QA-L-16-101 } \\
\text { QA-L-16-102 } \\
\text { QA-L-16-103 }\end{array}$ & QAP-7 & \\
\hline 17. Qualiy & $\mathbf{Y}$ & QA-L-17-100 & QAP 4 & \\
\hline 12. Aution and & $\mathbf{Y}$ & $\begin{array}{l}\text { QA-L-18-100 } \\
\text { QA-L-18-101 } \\
\text { QA-L-18-102 }\end{array}$ & QAP-8 & \\
\hline 19. Soptumere & $\mathbf{Y}$ & QA-L-19-100 & QAP-9 & \\
\hline
\end{tabular}




\section{SUBJECT: QUAITY ASSURANCE PROGRAM AND LABORATORY ACTIVITIES}

\section{Purpoce of the QA Plan}

If consistently implemented, a properly designed quality assurance/quality control (QAVC) plan provides both the means to produce data of prescribed quality and the documentation necessary to demonstrate that quality. Because QAQC lapses can result trom uncertainties about responsible partiea, a project QAOC plan should detail not onty the technical procedures that are used to obtain data but atso the types of administrative controls that are in place to ensure that the technical procedures are used property and consistently.

This plan is developed to conform to requirements specified by sponsors and by Martin Marietta Energy Systems, Inc, in Policy Procedure GP-5, "Quality Assurance Program." GP-5 requires that QA. plans be prepared, organized, and implemented in accordance with ANSUASME NQA-1.

This plan is designed to ensure that all reportable data generated by the ESD Toxicology Laboratory are valid, traceable, and in accordance with the laboratory's requirements. Such conformity is to be achieved through use of the QA plan, standand operating procedures, laboratory notebooks, and reports.

\section{QA Activitien}

The following QA satvities will be reported to the ESD QAS.

1. changes in the scope of this plan;

2 changes in surveillance plans;

3. results of surveillance activities; and

4. cocurrence reports, reports of significant corrective actions, and surveillance findings.

\section{Training}

Training of personnel to ensure adequate levels of competence in performing laboratory tasks will be documented Technical expertise and personnel compliance with QA requirements will be monitored by periodic blind tests and surveillance to ensure that suitable proficiency is achieved and maintained.

\section{Management Acseasment}

The effectiveness and adequacy of the plan will be periodically and independently assessed by the Group Leader and the section head through discussions, staff meetinga, and investigation of any potential problem areas. 
ESD TOXICOLOGY LABORATORY

QUALTY ASSURANCE MANUAL
SECTION

PAGE

DATE
QAP-1

2 of 2

$01-23-91$

\section{SUBECT: QUALTY ASSURANCE PROGRAM AND LABORATORY ACTIVITIES}

\section{Purpose of the Laboratory}

The ESD Toricology Laboratory conducts chronic and acute tests with Ceriodaphria dubia and fathead minnow larve to estimate toricity of ambient water and effluent sampies from wastewater treatment operations at ORNL, the Oak Ridge Gaseous Diffusion Plant (ORGDP), and the Oak Ridge Y.12 Plant. Towicity lests are required by the Torictity Control and Monitoring Plan (TCMP) and the Biological Monitoring Plan and Abatement Program (BMPAP) of the National Pollutant Discharge and Elimination System (NPDES) permit for each U.S. Department of Energy (DOE) facility. DOE ultimately reports test results to the Tennessee Department of Health and Environment (TDHE).

The results of the TCMP tests are reported on a test-by-test basis, whereas the results of the BMPAP tests are reported separately in annual reports drafted for each facillty. Tests to identify toxicants and to evaluate changes in westewater treatment operations are initiated on a case-by-case basis under the

guidelines established in the TCMP section of the facility's NPDES permit.

\section{Laboratory Procedures}

The standard operating procedures presented in this plan were dertived from two documents published by the U.S. Environmental Protection Agency (EPA): EPA600/485/013, Methods for Mearuring the Acute Taciciry of Effuents to Freshwater and Marine Organisms, and EPAV600/4-85/014, Short Term Methods for Estimating the Chronic Toricity of Eftuents and Receiving Waters to Freshwater Organisms. These two documents, together with this QA plan, provide specific guidance in the fulfillmeat of NPDES permit requirements and the QA requirements of Martin Marietta Energy Systems, Inc. 


\section{SUBSECT: INSTRUCTIONS AND PROCEDURES}

\section{Project Activities, Procedures, and Control of Processes}

Activities in the Toxicology Laboratory are to be performed in acoordance with requirements set by sponsors and with divisional QAVC requirements. Standard operating procedures specified by the sponsor, as well as the control of processes for testing and maintaining test organisms, are described in a separate section (Sect. SOP).

\section{Listing of Procedures}

The sampling procedures described it Sect. SOP are used for collecting samples. Procedures for testing and analysis are selected in this order. (1) EPA procedures; (2) analytical procedures prescribed by Marin Marietta Energy Systems, Inc; (3) procedures prescribed by the ORNL Analytical Chemistry Division; and (4) project-specific procedures developed for the particular needs of the Toxicology Laboratory.

\section{Description of Procedures}

Descriptions of all technical procedures relevant to the Toxicology Laboratory are contained in the standard operating procedures of this manual (Sect. SOP).

EPA procedures upon which the standard operating procedures are based can be found in a separate section entitled "Reference Procedures" (Sect. REF).

Procedure development and control responsibilities are defined in the ESD Quality Assurance Mnnull, procedure QA-ES-5-101. 
This Page Intentionally Left Blank 
ESD TOXICOLOGY LABORATORY

\section{SUBSECT: ABBREVIATIONS AND CODES}

$\begin{array}{ll}\text { ANSI } & \text { American National Standards Institute } \\ \text { ANOVA } & \text { annlysis of variance } \\ \text { ASME } & \text { American Society of Mechanical Engineers } \\ \text { BMPAP } & \text { Biological Monitoring Plan and Abatement Program } \\ \text { CONC } & \text { Test concentration } \\ \text { CONT } & \text { control } \\ \text { D.F. } & \text { degrees of treedom } \\ \text { D.O. } & \text { dissolved oxygen } \\ \text { DOE } & \text { U.S. Department of Energy } \\ \text { EPA } & \text { U.S. Environmental Protection Agency } \\ \text { ESD } & \text { Environmental Sciences Division } \\ \text { ESQIS } & \text { Energy Systems Quality Information System } \\ \text { FC } & \text { free chlorine } \\ \text { FHM } & \text { fathead minnow } \\ \text { GLM } & \text { general linear models } \\ \text { ICP } & \text { Inductively Coupled Plasma Spectrophotometry } \\ \text { LSD } & \text { least significant difference } \\ \text { MSE } & \text { mean square error } \\ \text { NCR } & \text { nonconformance report } \\ \text { NEIC } & \text { National Enforcement Investigation Center } \\ \text { NPDES } & \text { National Pollutant Discharge and Elimination System } \\ \text { NQA-1 } & \text { National Quality Assurance Standard 1 } \\ \end{array}$


ESD TOXICOLOGY LABORATORY

\section{SUBJECT: ABBREVIATIONS AND CODES}

\begin{tabular}{ll} 
ORNL & Oak Ridge National Laboratory \\
ORGDP & Oak Ridge Gaseous Diffusion Plant \\
QA & quality assurance \\
QAP & quality assurance plan \\
QC & quality control \\
QER & quality event repor \\
QTR & quality investigation report \\
REF & reference procedure \\
REP & replicate \\
REV & revision sheet \\
SAS & Statistical Analysis System, registered trademark of the SAS Institute, Inc. \\
& Cary, North Carolina \\
SOP & standard operating procedure \\
SOR & siphoned out and returned \\
TCA & trout chow and Cerophyl misture supplemented with algae \\
TCMP & Toxicity Control and Monitoring Plan \\
TCO & trout chow and Cerophyl mixture \\
TDHE & Tenneasee Department of Health and Environment \\
TRC & total residual chlorine \\
$S$ & standard deviation \\
\hline
\end{tabular}


ESD TOXICOLOGY LABORATORY QUALITY ASSURANCE PROGRAM

SUBJECT: QUALTTY ASSURANCE PLAN-CONTENTS

QAP-1: QUALITY ASSURANCE PROGRAM AND LABORATORY ACTIVITIES

QAP-2: ORGANIZATIONAL RESPONSIBILTIES

QAP-3: PROCUREMENT DOCUMENT CONTROL AND CONTROL OF PURCHASED/USED ITEMS AND SERVICES

QAP-4: DOCUMENT CONTROL AND QUALTYY ASSURANCE RECORDS

QAP-5: INSTRUCTIONS AND PROCEDURES

QAP-6: MEASURING AND TEST EQUIPMENT

QAP-7: NONCONFORMANCE AND CORRECTTVE ACTIONS

QAP-8: AUDITS AND SURVEILLANCES

QAP-9: SOFTWARE QUALITY ASSURANCE 


\section{C- 74}

This Page Intentionally Left Blank 


\section{SUBEECT: QUALITY ASSURANCE PROORAM AND LABORATORY ACTIVITES}

\section{Purpose of the QA Plan}

If consistently implemented, a properly designed quality assurance/quality control (QAOC) plan provides both the means to produce data of prescribed quality and the documentation necessary to demonstrate that quality. Because QAVC lapses can result trom uncerainties about responsible parties, a project QAVC plan should detail aot only the technical procedures that are used to obtain data but also the types of administrative controls that are in place to ensure that the technical procedures are used properly and consistently.

This plan is developed to conform to requirements speciffed by sponsors and by Martin Marietta Energy Systems, Inc, in Policy Procedure OP.5, "Quality Assurance Program." GP.5 requires that QA plans be prepared, organized, and implemented in accordance with ANSUASME NQA-1.

This plan is designed to ensure that all reportable data generated by the ESD Toxicology Laboratory are valid, traceable, and in accordance with the laboratory's requirements. Such conformity is to be achieved through use of the QA plan, standard operating procedures, laboratory notebooks, and reports.

\section{QA Activities}

A quarterly summary of QA activities will be included in the Toxicology Laboratory's status reports. The summary will conform to ORNL QA Procedure QA-L-2-103 and include the following:

1. changes in the scope of this plan;

2. changes in organizational assignments;

3. changes in surveillance plans;

4. results of surveillance activities; and

5. quality incident reports, unusual occurrence reports, reports of significant corrective actions, and surveillance findings about corrective actions.

\section{Training}

Training of personnel to ensure adequate levels of competence in performing laboratory tasks will be documented. Technical expertise and personnel compliance with QA requirements will be monitored by periodic blind tests and surveillance to ensure that suitable proficiency is achieved and maintained. 


\section{SUBSECT: QUALTY ASSURANCE PROORAM AND LABORATORY ACTTVITES}

\section{Management Asceasment}

The effectiveneas and adequacy of the plan will be periodically and indepeadently ascessed by the Group Leader and the section bead through discussions, staff meetings, and investigation of any potential problem areas.

\section{Purpose of the Laboratory}

The ESD Todicology Laboratory conducts chronic and a. "the tests with Ceriodaphnia dubia and the thead minnow lavae to estimate toxicity of ambient water and ealuent samples from wastewater treatment operations at ORNL, the Oak Ridge Gaseous Diffusion Plant (ORGDP), and the Oak Ridge Y-12 Phne. Toxicity teass are required by the Toxicity Control and Monitoring Phan (TCMP) and the Biologial Monitoring Plan and Abatement Program (BMPAP) of the National Pollutant Discharge and Elimination System (NPDES) permit for each U.S. Department of Energy (DOE) Ecility. DOE ultimately repors test results to the Tennescee Department of Health and Environment (TDHE).

The results of the TCMP tests are reporied on a test-by-test basis, whereas the results of the BMPAP tests are reported separately in annual reports drafted for each tacility. Tests to identify towicants and to evaluate changes in wastewater treatment operations are initiated on a case-bycase basis under the guidelines established in the TCMP section of the facility's NPDES permit.

\section{Laboratory Procedures}

The standard operating procedures presented in this plan were derived from two documents published by the U.S. Environmental Protection Agency (EPA): EPA600/4-85/013, Methods for Mearuring che Acure Toxicisy of Effluents to Freshwater and Marine Organisms, and EPA/600/4-85/014, Shor Term Methods for Estimacing the Chronic Toriciny of Effucents and Receiving Waters to Freshwater Organisms. These two documents, together with this QA plan, provide specific guidance in the fulfillmeat of NPDES permit requirements and the QA requirements of Martin Marietta Energy Systems, LnC. 
C.77

ESD TOXICOLOGY LABORATORY

SECTION

QAP-2

QUALTIY ASSURANCE MANUAL

\section{SUBECT: OROANIZATIONAL RESPONSIBMITIES}

This section applies to all projects and experiments of the ESD Tcaicology Laboratory. It identifes and describes the administrative and technical organization used to ensure project quality.

\section{General Responsibilities}

Figure QAP-21 shom the organizational structure and the lines of communiation between the ORNL administration (-) and the QA administration (-) aspects of the Toxicology Laboratory. Figure QAP-22 show the scheme of NPDES permit negotiations between state and federal governmeat organizations and Marin Marietla Energy Systems, inc., in relationship to testing requirements fulfilled by the Toxicology Laboratory. Figure OAP.23 shows the pathways by which toricity test results are reported (the dashed line indicates that EPA is aot reporied to on a regular basis but may be called in for consultation).

\section{Section Head}

The rection head is responsible for overall QA policy and the developmeat of a QA program for the Toricolosy Laboratory. He will asceas the adequacy of the laboratory QA plan every rwo years. So that any neceasary reviajons will be incorponted at the two year deadline, the Section Head will meet with the Group Leader to areess the adequacy of the plan and make the appropriate changes to the plan 6 monthe prior to the two year deadlise In addition, the section head will participace in the investigntion of problems or poteatial problems regarding laboratory management or the sdministration of quality assurance.

\section{Group Leader}

The Oroup Leader is responsible for the quality and technical adequacy of projects in the Toricology Laboratory and will oversee operations in the Laboratory. The Group Leader's responsibilities include

1. anigning duties to the haboratory stafr and orienting the staff to the needs and requirements of the laboratory,

2 reviewing laboralory-specific sponsor-related procedures and internally prepared plans and reports;

3. ensuring that all sctivities related to the technical and quality aspects of the laboratory are in compliance with sponsor requirements;

4. serving as a linison between the laboratory and other organizations, such as laboratories, the Qunlity Deparment and the Health and Safety Division;

5. determining the effect of nonconformances, the appropriateness of reporting nonconformances to mangement, and the provisions for documenting such reporting. 
SUBECT: ORGANIZATIONAL REYPONSEIITIES

6. notifying QA personnel of nonconformances and their effects upon the work of the luboratory;

7. reviewing and coordinnting corrective action roports;

8. reviewing and beorponting applicable policy and regulation requirements that affect the Inboratory;

9. Utring the lead in planning ascesments of the laboratory's technical activities as tas as they may affeca quality and providing control over such activities to an exteat consisteat with sponsor and divisional requirements;

10. ensuring the implemeatation of all surveillances, audits, and quality-related corrective actions;

11. ensuring the adequate implementation of sponsor requirements and laboratory task requirements through the use of standurd operating procodurea;

12 asouring and documenting the training of personnel performing activities that affect quality,

13. emouring that protection and control of all log books and deaignated QA records are consinieat with sponeor requirements and ORNL requiremeati; and

14. ensuring the traceability of all samples and data within the conones of the laboratory.

\section{QA Administration}

The manager of the ORNL QA program is ultimateby responsible for the administration and coordination of the ESD QA program. The ESD QA Specialist hes the specific responsibility of administering the QA program of the Toricolory Laboratory. The QA Specinlist is independeat from cout and echedule considerations and has acoes 20 all wort areas The QA organizition has the authority, acceth, and orgnnizational treedom as designaled in QA-L-100, paragraph 100.4. The work covered by this plan is subject to audits and surveillances.

\section{QA Specialist}

The QA Speciallat will

1. Lead efforts to establish QA programs that are responsive both to requirements set by the ORNL QA program and 20 sponeor requiremeats,

2 periodically comine and documeat compliance with QA requirements, 


\section{SUBIECT: ORGANIZATIONAL RESPONSIBILTIES}

3. conduct periodic surveillance and audits of laboratory activities that affect quality, and

4. provide verification of all corrective actions that may be required.

\section{Technical Staff and Students}

Quality in the Toxicology Laboratory depends on the conscientiousneas of individuals in adhering to well-defined procedures. The cooperation and abilities of the technical staff in maintaining high QA and their assistance in reporting any lapses in QA are paramount to the overall objective of the Laboratory QA plan.

The technical staff are responsible for conducting laboratory activities in a manner that will ensure the higheat possible quality of the test date In this regard, it is the responsibility of each technical staff member or student to conduct the toricity tests and their associated procedures acoording to the standard operating procedures described in this manual.

\section{Other Support and Service Personnel}

The Group Leader ensures that support and services provided by other personel and facilitica most the requirements specified in this plan. In the case of samples provided by others, the Group Leader ensures that the appropriate quality control measures and the steps in the chain of custody are property documented.

\section{Approvals}

This QA plan must first meet the approval of ESD management and the management of the Torioology Laboratory. The plan must then be approved by the manager of the ORNL QA program. 
ESD TOXICOLOGY LABORATORY

QUALITY ASSURANCE MANUAL
SECTION

PAGE

DATE
QAP-2

4 of 6

$02-13-90$

SUBECT: ORGANIEATIONAL REYPONSIBITITIES

ORNL-DWG 88M-9567A

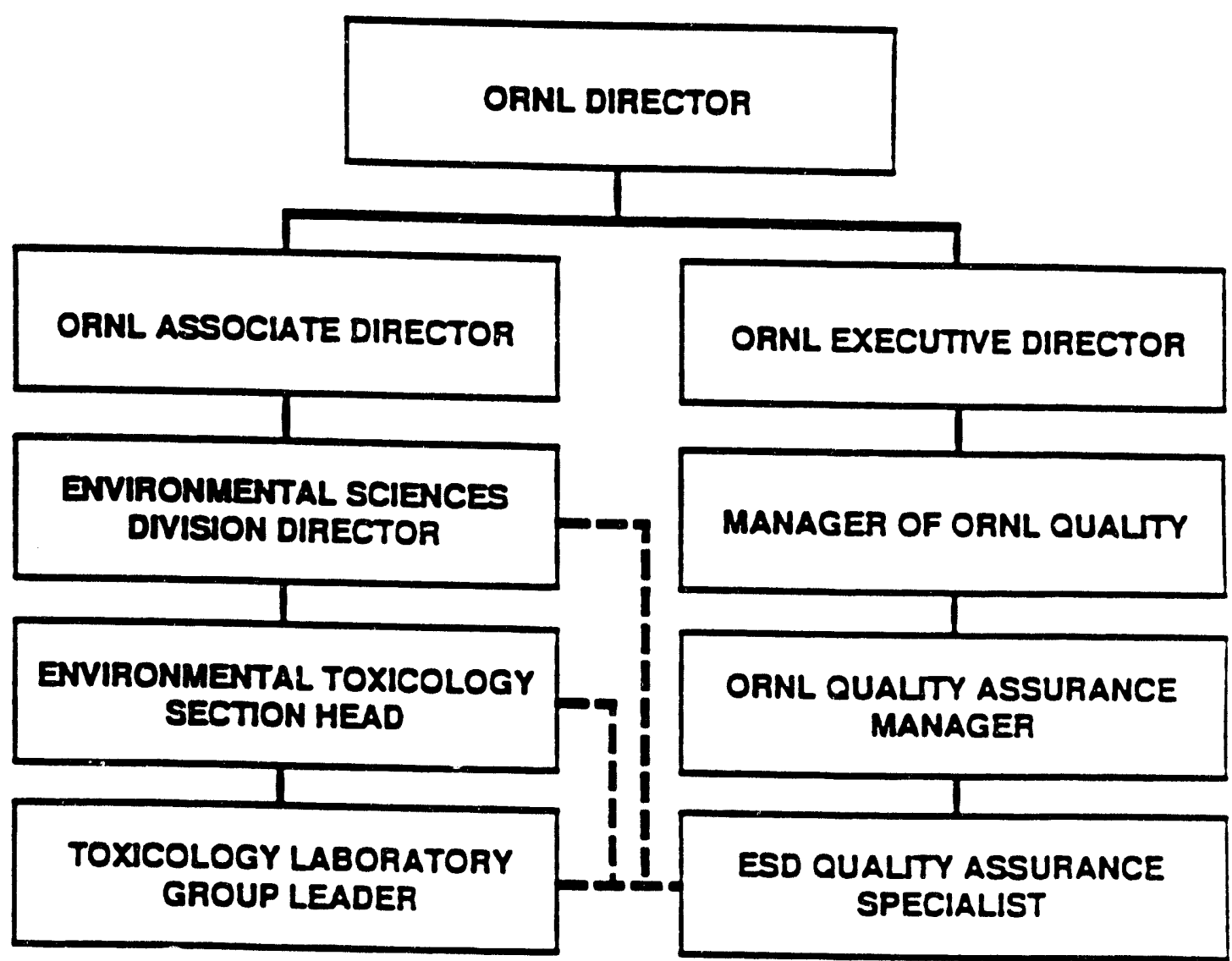

Fis QAP-21 Orgnimtional structure and lines of communiction. 
ESD TOXICOLOGY LABORATORY QUALITY ASSURANCE MANUAL

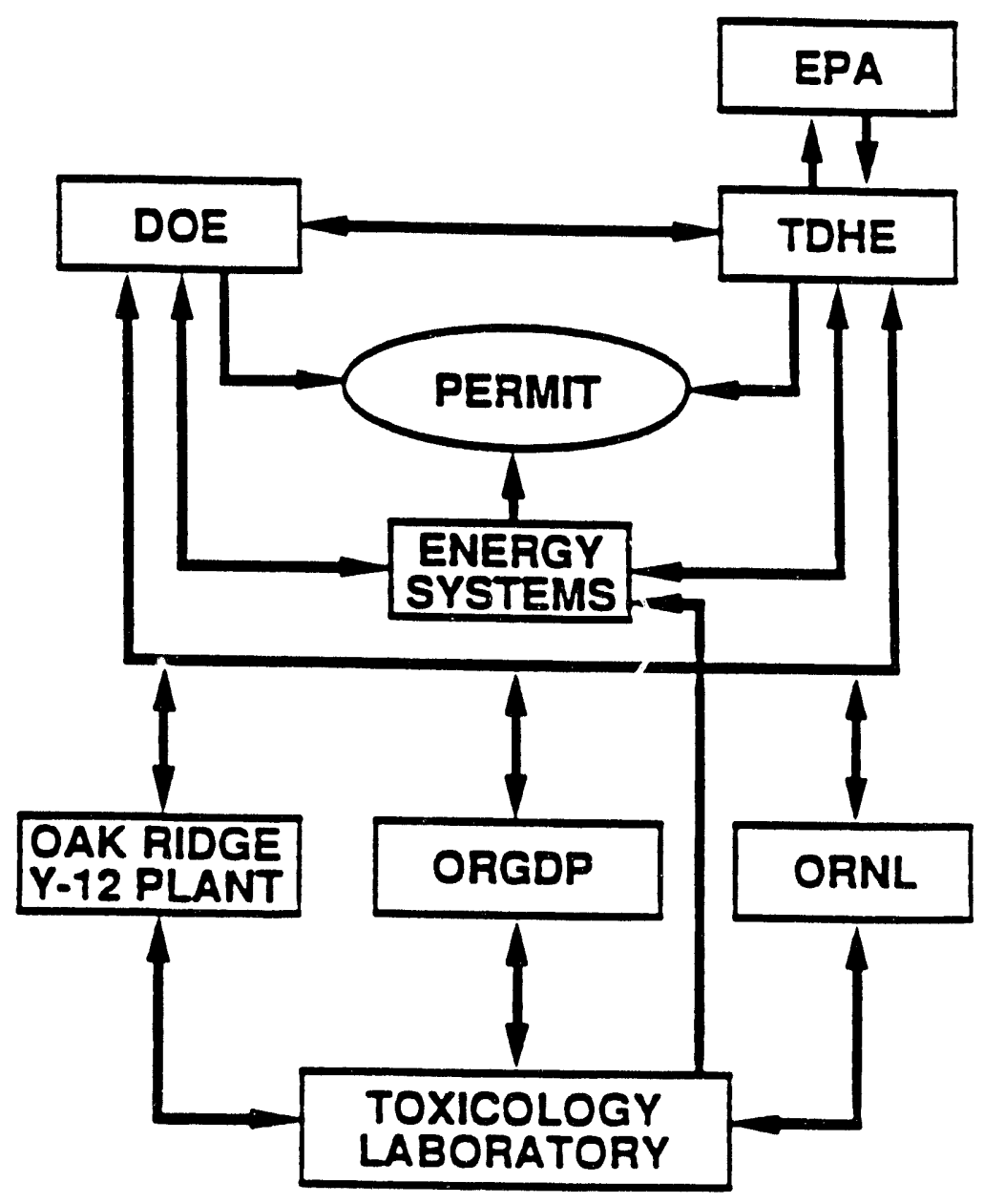

Fig. QAP-22 Fow of information from toxicity testing and negotiation scheme for NPDES permits. 


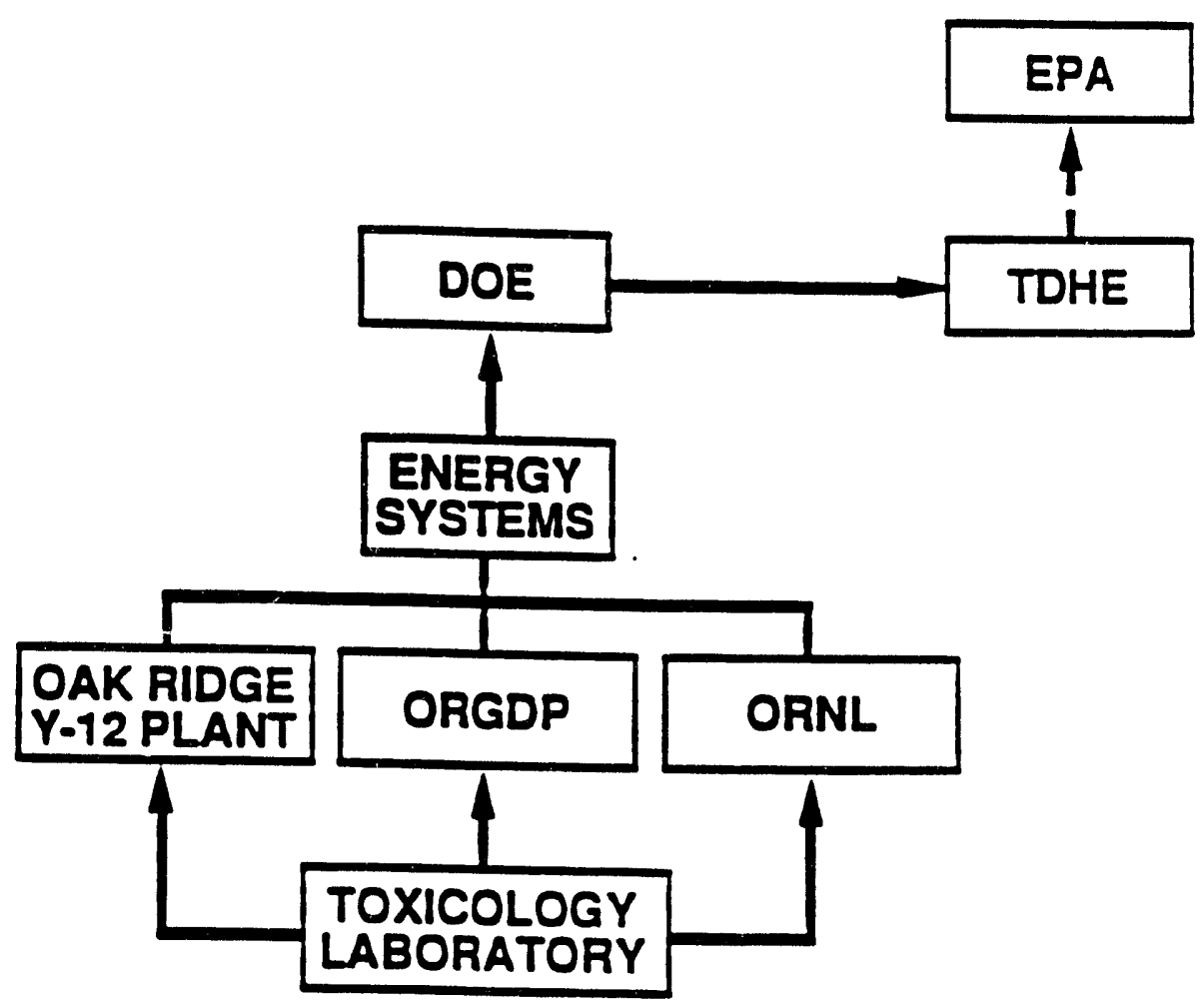

Fig QAP-23 Pathways for reporting results of toxicity tests. 


\section{SUBSECT: PROCUREMENT DOCUMENT CONTROL AND CONTROL OF PURCHASED/USED ITEMS AND SERVICES}

This section describes the procedures used to ensure that the correct items and services are purchased or used and that items and services conform to specified requirements.

\section{Purchases from Company Stores}

When items stocked by Energy Systems Stores are necessary for work in the Toxicology Laboratory and fulfill quality requirements, they are to be purchased from Stores rather than from an outside vendor.

\section{Purchases from Vendors}

When Stores cannot supply finished items that are necessary in generating data in the Toxicology Laboratory, such items may be purchased from outside vendors. Purchases will consist of standard catalog items and standard models of off-the-shelf items.

\section{Requisitions}

Purchase requisitions are routinely available and are to be used to obtain necessary items. The purchase orders should contain specific identification of the manufacturer's catalog/model number, as applicable. Purchase requisitions are to be prepared and reviewed for conformance to the required technical and quality specifications. All purchase requisitions must be approved by the section head before being transmitted to the Procurement Division. Changes to purchase requisitions are to be reviewed and approved by those persons who approved the original purchase requisition.

\section{Procurement of Services}

The procurement of services (such as sample analyses) must be requested by the Group Leader or his designee. The Group Leader is to specify the scope of the analysis, as well as the QA and technical requirements of the anatysis.

\section{Project-Specific Needs}

The principal service purchased by the Toxicology Laboratory consists of water analyses, performed by the ORNL Analytial Chemistry Division. The Group Leader will ensure that the submission of samples and the documentation of their test results are consistent with criteria set for quality in the laboratory.

If any special items or services are identified as requiring more exrensive QA documentation or control, this QA plan will be revised by the Group Leader and by the appropriate QA Specialist for those items and services. 


\section{SUBECT: PROCUREMENT DOCUMENT CONTROL AND CONTROL OF PURCHASED/USED ITEMS AND SERVICES}

\section{Identification, Storage, Handling, and Control of Items}

Only correct and accepted items that are traceable to their source may be used. If stock materials and laboratory equipment are adequately labeled by the supplier and if they are stored in such a manner that their identity and status are maintained, they do not require additional identification, controks, or markings.

Equipment used in the laboratory procedures is described in the individual standard operating procedures (Sect. SOP). The person performing a procedure is responsible for ensuring that only equipment identified in the laboratory test procedures is used.

The Group Leader or the Sample Custodian (or alternate) will witness and initial the identification of each new sample or sample lot upon its arrival at the laboratory. Individuals performing tests are responsible for ensuring the correct use of each sample as identified. Unused portions of samples containing hazardous waste at toxic concentrations will be returned to the point of origin for disposal.

\section{Chain of Custody}

Figure QAP-3.1 shows the steps in the chain-of-custody scheme that are to be followed for sampling and testing (the dashed line indicates that samples are sent to the Analytical Chemistry Division only when necessary). Exhibit QAP-3.1 shows a sample chain-of-custody form that is to be used to document each step of the sample-handling process. The Sample Custodian will check the completeness of the entries on the chain-of-custody form. Then the form will be copied, and the copy will be placed in the notebook of chain-of-custody.

\section{Sample Custody}

To establish the integrity of samples, it may be necessary to demonstrate to a court that the samples were maintained under custody from the time they were collected in the field to the time they were analyzed in the laboratory. The field sampler is personally responsible for the care and custody of the collected samples until they are transferred or dispatched property.

The National Enforcement Investigation Center (NEIC) defines custody in the following way:

A sample is under custody if:

1. It is in your possession, or

2. It is in your view, after being in your possession, or

3. It was in your possession and you locked it up, or

4. It is in a desigmated secure area. 


\section{SUBJECT: PROCUREMENT DOCUMENT CONTROL AND CONTROL OF PURCHASED/NSED ITEMS AND SERVICES}

\section{Sample Custodian}

The ESD Toxicology Laboratory requires chain-of-custody procedures and thus should appoint a Sample Custodian and alternate(s). The Sample Custodian is responsible for the following:

1. receiving and logging in samples to the laboratory from the site of collection so that neither the identity nor the integrity of samples is in doubh

2 notifying the analysis personnel of sample arrival, and

3. coordinating intralaboratory delivery of samples with appropriate custody records.

\section{Chain-of-Custody Record}

The chain-of-custody record is used to document the transfer of the possession and custody of samples. The record attests that, between sample collection and laboratory analysis, the sample was constantly under custody.

\section{Chain-of-Custody Form}

Serialized chain-of-custody forms should contain the following information.

1. Survey site name: Record the site at which the sampling was conducted.

2 Samplers' signatures: Record the signatures of all the individuals who physically collected the sample and initiated the chain-of-custody record.

3. Date of collection: Using a six-digit number, indicate the year, month, and day of collection.

4. Time of collection: Using a four-digit number, indicate military time of collection.

5. Sample L.D. number(s).

6. Number of containers: Indicate the number of containers used for the respective sample LD. number(s).

7. Analysis (optiona): Indicate the analysis that will be performed on the respective sample.

8. Remarks: Make comments about the individual sample(s) (i.e., "sample container was broken and disposed of?).

9. Relinquished by and received by: Indicate the individual who relinquishes possession and custody of the sample and the individual who accepts the possession and custody of the sample. Also include the date and time of the transfer. Note that the first person to relinquish the sample must be one of the individuals that collected the sample. 
ESD TOXICOLOGY LABORATORY

SECTION

QAP-3

QUALTY ASSURANCE PROGRAM

\section{SUBJECT: PROCUREMENT DOCUMENT CONTROL AND CONTROL OF PURCHASEDNUSED ITEMS AND SERVICES}

10. Sample recetved with custody seals intact: The laboratory Sample Custodian will indicate the condition of the custody seals and check the integrity of the contents.

11. Sample labels, sample tag, and chain of custody: The laboratory Sample Custodian will check whether all the contents of the package are in order.

12. Remark: Comments should be made about all the samples imventoried on the chainof-custody record. Include method of shipment and courier name(s).

The identification number of the chain-of-custody form and the sample identification number should accompany the sample and resulting data from the point of sample collection to the point of sample disposal, and they should be included in the final report.

\section{Custody Seals and Shipping Procedures}

Occasionally, samples to be tested are seat to the laboratory by outside vendors. In such cases shipping containers will be padlocked or sealed for shipment. While being shipped to the laboratory, samples sometimes may be handled by postal clerks, couriers, or others. However, the samples are effectively in a secured area: the NEIC procedure requires that a custody seal be afiixed to the shipping container in such a way that, if the shipping container is property secured and arrives at the laboratory with the custody seak intact and with adequate documentation, the integrity of the samples can be demonstrated. Therefore, signatures from these intermediary clerks and couriers are not required.

The method of shipment, courier name(s), and other pertinent information are entered in the "Remarks" box on the chain-of-custody record. All shipments will be acompanied by the chainof-custody record identifying its contents. The original record will acompany the shipment, and a copy will be retained by the Group Leader. If sent by mail, the paclage will be registered with return receipt requested. If seat by common carrier, a government bill of lading will be used. Air freight shipments are shipped collect The Toxicology Laboratory will retain freight bills, post office receipts, and bills of lading as part of the sample's permaneat documentation.

\section{Laboratory Custody Procedures}

For the purposes of the Toxicology Laboratory, Building 1504 is considered a secure area: the outside doors are locked after work hours, and only authorized (badged) personnel are permitted in the building. The laboratory areas in Building 1504 shall be maintained as secured areas and shall be restricted to authorized personnel.

Samples should be handled by the minimum possible number of persons. 


\section{SUBEECT: PROCUREMENT DOCUN ENT CONTROL AND CONTROL OP PURCHASED/USED ITEMS AND SERVICES}

Incoming samples shall be received only by the Sample Custodian or alternate(s), who will indicate receipt by signing the chain-of-custody record sheet accompanying the samples and retain the sheet as a permanent record. Couries picking up samples at the airport or post office shall sign jointly with the Sample Custodian or alternate.

Laboratory personnel are responsible for the care and custody of a sample and should be prepared to testify that the sample was in their possession and in view or secured in the laboratory at all times from the moment it was received from the Sample Custodian (or alternate) to the time the tests were run.

\section{Disposal of Samples and Other Physical Evidence}

Once the anatyses of the samples are completed, the unused portions of the samples, together with identifying labels and other documentation, must be returned to the Sample Custodian or alternate. 
ESD TOXICOLOGY LABORATORY

SUBJECT: PROCUREMENT DOCUMENT CONTROL AND CONTROL OF PURCHASED/USED ITEMS AND SERVICES

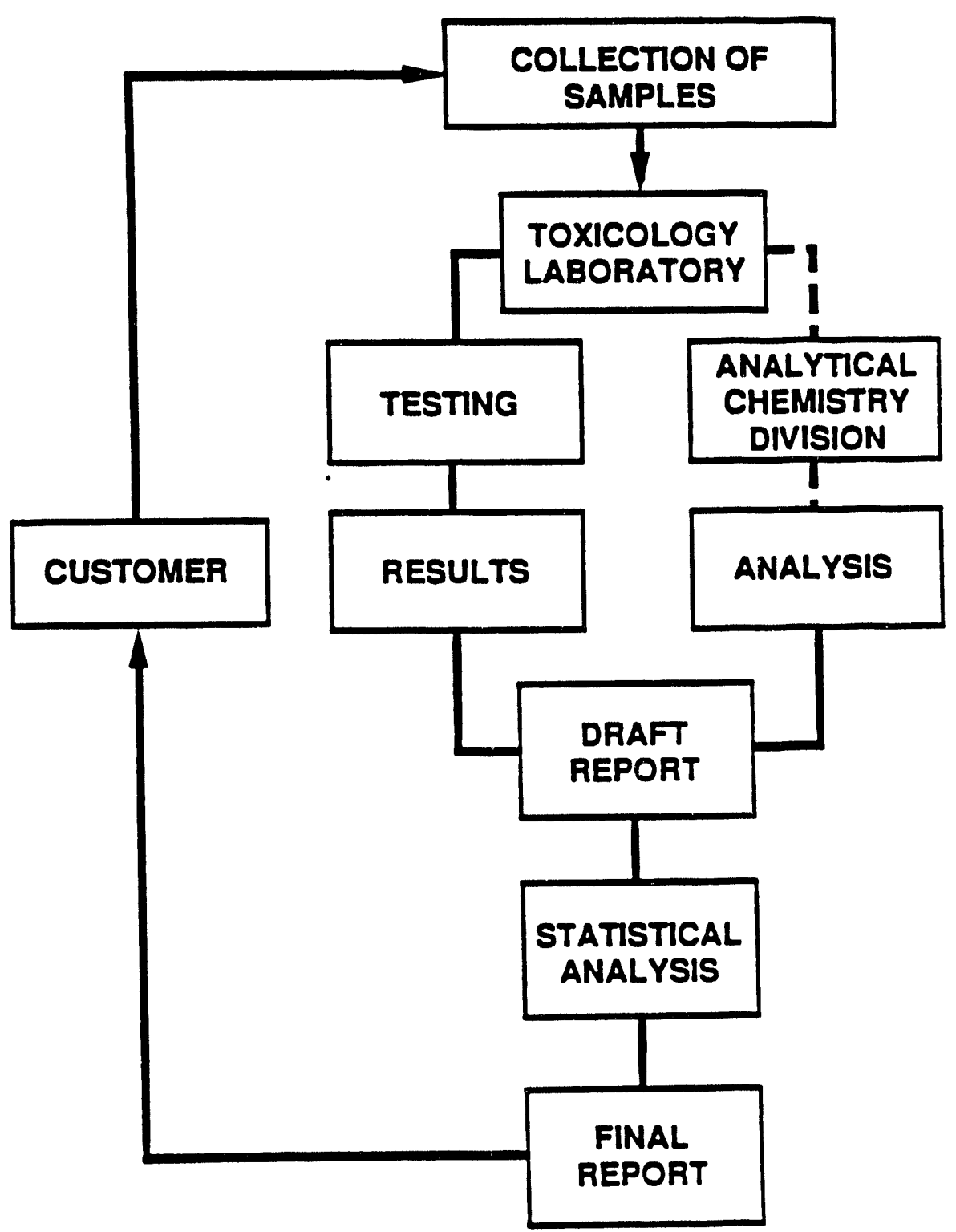

Fig. QAP-3.1 Chain-of-custody steps for sampling, testing, and reporting. 
ESD TOXICOLOGY LABORATORY

SECTION

QAP-3

\section{QUALITY ASSURANCE PROGRAM}

PAGE

7 of 7

DATE

$03-01-89$

\section{SUBSECT: PROCUREMENT DOCUMENT CONTROL AND CONTROL OF PURCHASED/USED ITEMS AND SERVICES}

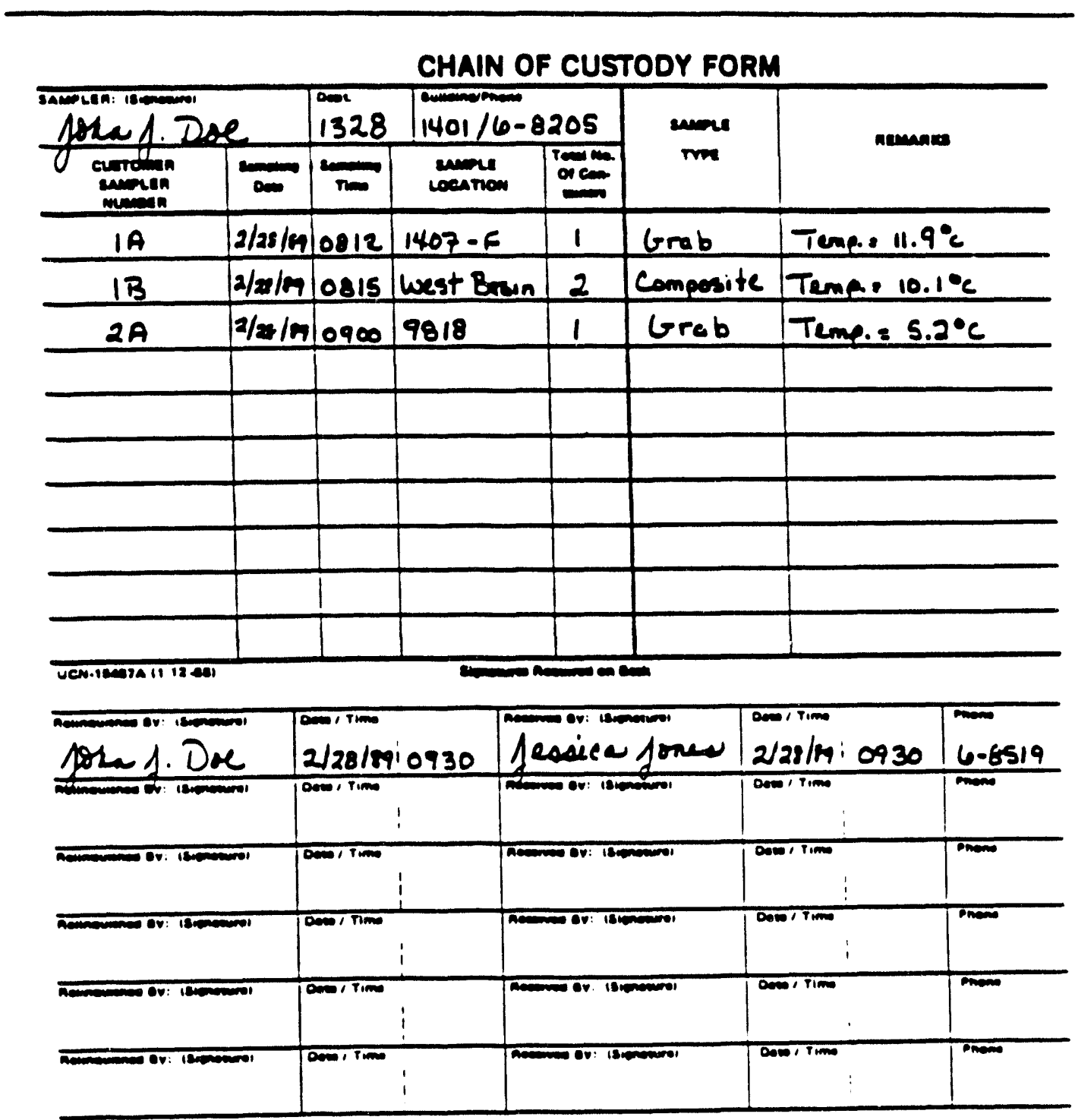

nemanks

netunn ro icenom

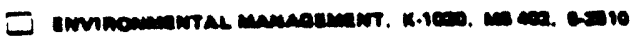

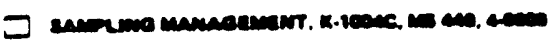

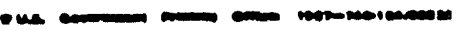

Exhibit QAP-3.1 Sample chain-of-custody form. 
C-90

This Page Intentionally Left Blank 
C-91

ESD TOXICOLOGY LABORATORY

SECTION

QAP4

QUALITY ASSURANCE PROGRAM

SUBECT: DOCUMENT CONTROL AND QUALTY ASSURANCE RECORDS

\section{Revisions}

Copies of the most recent revisions of this QA plan and the standard operating procedures are to be maintained and controlled by the Group Leader and the ESD OA Specialist. The Group Leader has the responsibility of ensuring the distribution and implementation of all revisions.

Obsolete portions of these documents should be removed when revised portions are inserted. A revision sheet (Sect. REV) is to be maintained by the person to whom the manual is assigned.

\section{Maintenance of Records}

Table QAP 4.1 lists those documents that are designated as QA records. All QA records generated by the Toxicology Laboratory will be retained for at least 5 years. 
ESD TOXICOLOGY LABORATORY

\section{SUBJECT: DOCUMENT CONTROL AND QUALTTY ASSURANCE RECORDS}

Table QAP-4.1. QA records to be maintained

Technical notebooks

Sponsor requirements

Instructions

Procedures

QA requirements

QA plan

QRs, NCRs, and QERs'

Surveillance reports

Software programs

Documentation of software validation review

Risk asseasment

Training tecords

Chain-of-custody documentation

Documentation of instrument calibration

$++$

Documenution of anatyses

Audit reports

The symbol * signifies that both the Group Leader and the ESD QA Specialist will keep a copy in locations that are secure, protected, separate, and accessible. The symbol ++ signifies that the Group Leader or his designee will keep the original document in a location that is secure, protected, and accessible.

'QRR = quality investigation report; NCR = nonconformance report; and QER = quality event repor. 


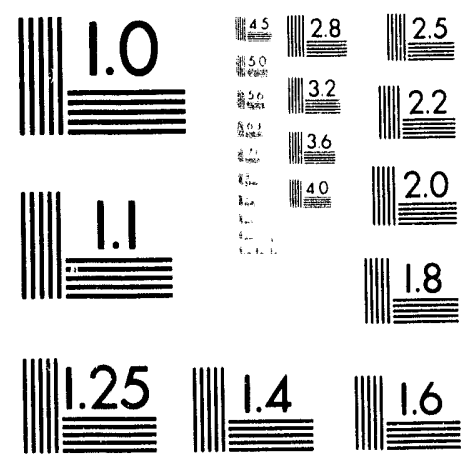



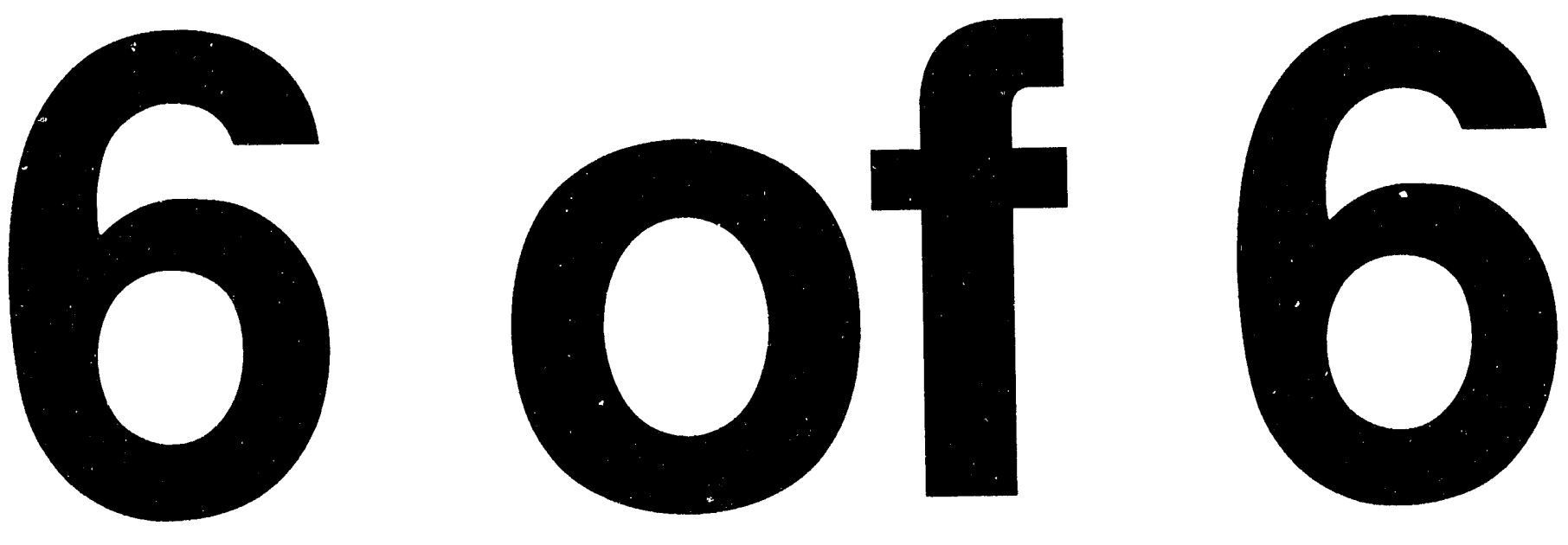
C-93

ESD TOXICOLOGY LABORATORY

SECTION

QAP-5

QUALITY ASSURANCE PROGRAM

PAGE

DATE

03-01-89

\section{SUBSECT: INSTRUCTIONS AND PROCEDURES}

\section{Project Activities, Procedures, and Control of Processes}

Activities in the Toxicology Laboratory are to be performed in accordance with requirements set by sponsors and with divisional QAVC requirements. Standard operating procedures specified by the sponsor, as well as the control of processes for testing and maintaining teat organisms, are described in a separate section (Sect. SOP).

\section{Listing of Procedures}

The sampling procedures described in Sect. SOP are used for collecting samples. Procedures for testing and analysis are selected in this order. (1) EPA procedures; (2) anatytical procedures prescribed by Martin Marietta Energy Systems, Inc:; (3) procedures prescribed by the ORNL Analyrical Chemistry Division; and (4) project-specific procedures developed for the particular needs of the Toxicology Laboratory.

\section{Description of Procedures}

Descriptions of all technical procedures relevant to the Toxicology Laboratory are contained in the standard operating procedures of this manual (Sect. SOP).

EPA procedures upon which the standard operating procedures are based an be found in a separate section entitled "Reference Procedures" (Sect REF). 
C-94

This Page Intentionally Left Blank 
ESD TOXICOLOGY LABORATORY

SF.CTION

\section{SUBJECT: MEASURING AND TEST EQUIPMENT}

This section describes the policies ensuring that instruments and other measuring and test equipment used for activities affecting the quality of data are calibrated and adjusted at specified intervals so that they maintain the required degree of accuracy.

\section{Calibration}

Measuring and test equipmeat used to obtain reportable data must be calibrated in accordance with sponsor requirements and the manufacturer's instructions. The frequency of calibration will be determined by sponsor requiremeats and/or the best professional judgment of the Group Leader.

Measuring eind test equipmeat that has been calibrated by the manufacturer may be used. Standards are to be used to verify that measuring and test equipment will yield acceptable data. The descriptions of the applicable procedures will state the standards to be used, the trequency of standardization, and the acceptable criteria (mnximum and minimum range), along with the directions for evaluating the standard. Results of the analysea of standards must be recorded in the registered log boois specified in the individual standard operating procedures (Sect. SOP). The appropriate laboratory personnel will initial and date each analysis of a standard to signify that the measuring and test equipmeat has been calibrated and that it will yield results meeting acceptable criteris

\section{Labeling}

Whenever possible measuring and test equipment should be labeled to indicate their calibration status. When direct labeling is not practical, the calibration status of an item should be noted in the regiatered log books specified in the individual standard operating procedures (Sece. SOP).

\section{Suppect Equipment}

When measuring or test equipmeat is suspect, it should be removid immediately from service and repaired andfor recalibrated. If it is found to be out of calibration, an immediate investigation is to be initiated (if applicable) to determine the validity of measurements aken since the last acceptable stundardization. Reportable data obtained with the suspect equipment during this interval will be noted in appropriate laboratory notebooks and in a quality investigation report, if deemed necesenry by the Group Leader (see "Nonconformance and Corrective Actions," Sect. QAP.7).

\section{Maintenance}

Preventattve maintenance of field and laboratory instruments should be conducted in accordance with schedules recommended by the appropriate vendors or manufacturers. 
ESD TOXICOLOGY LABORATORY

SECTION

QAP-6

QUALITY ASSURANCE PROGRAM

\section{SUBJECT: MEASURNG AND TEST EQUIPMENT}

The Anatytical Chemistry Division is responsible for the calibration and maintenarce of all equipment that is required to perform anatyses of samples for the Toxicology Laboratory.

\section{Project-Specific Requirements}

Table QAP-6.1 lists equipment requiring calibration for use in the Toxicology Laboratory.

Table QAP-61. Equipment requiring calibration in accordance with procedures in the manufacturer's manual

\begin{tabular}{|c|c|c|}
\hline Ilem & $\begin{array}{l}\text { Frequency of } \\
\text { alibration or } \\
\text { calibration check }\end{array}$ & Calibrator \\
\hline pH meter & Before each use & Individual user \\
\hline Conductivity meter & Weekly & Designated user \\
\hline Discolved oxygen meter & Before each use & Individual user \\
\hline $\begin{array}{l}\text { Thermometer } \\
\text { (digital) }\end{array}$ & Quarterty & Designated user \\
\hline Cahn microbalance & Every 6 months & I\&C \\
\hline Mettler balance & Every 6 months & I\&C \\
\hline $\begin{array}{l}\text { Temperature control } \\
\text { (module) }\end{array}$ & Yearty & I\&C \\
\hline Automatic pipettes & Weekly & Designated user \\
\hline
\end{tabular}

T\&C = Instrumentation and Controls Division. 
ESD TOXICOLOGY LABORATORY

SECTION

QAP-7

QUALITY ASSURANCE MANUAL

\section{SUBSECT: NONCONFORMANCE AND CORRECTIVE ACTIONS}

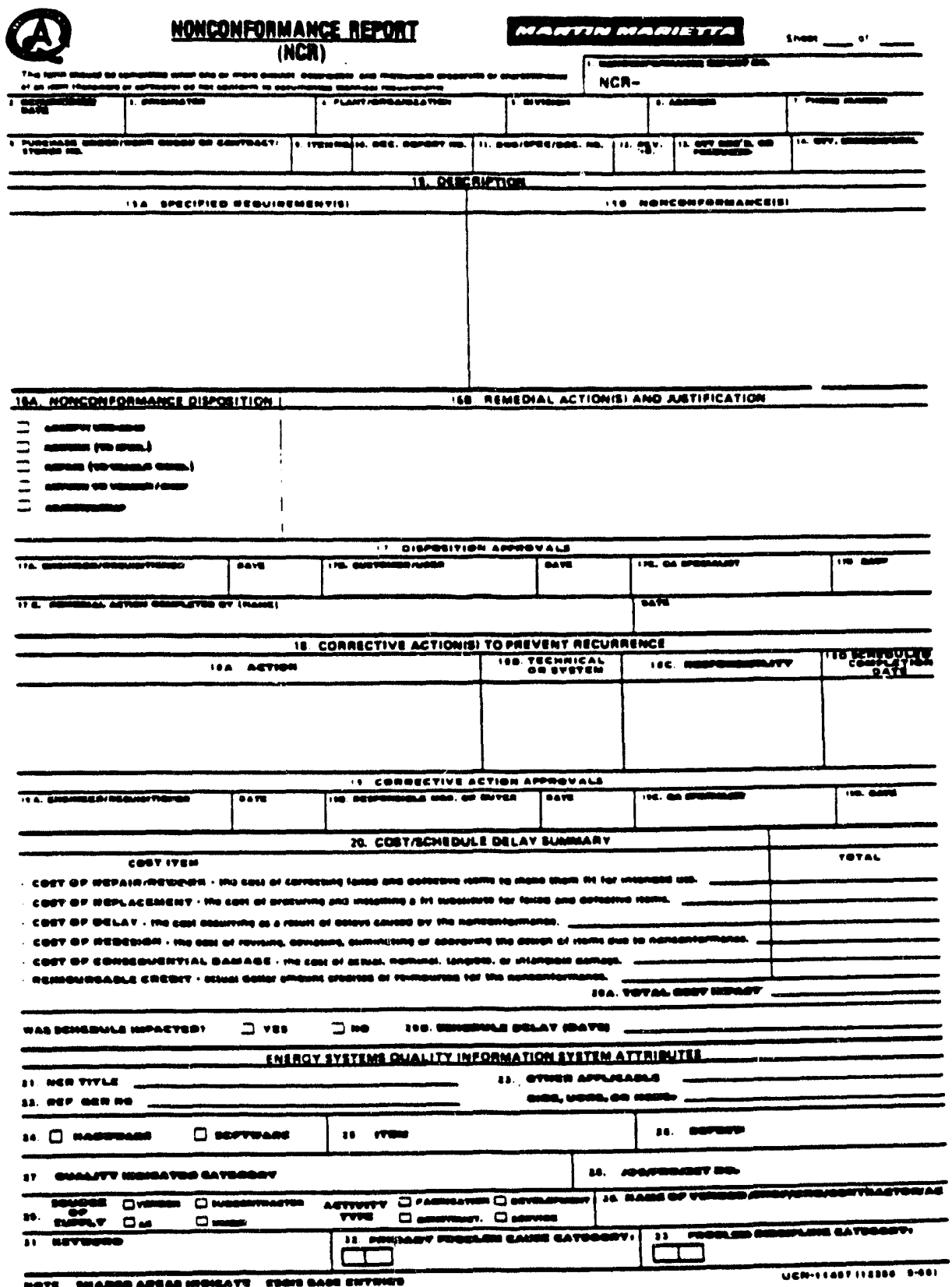

Exhibit QAP-7.1. Nosconformance report (NCR) form. 


\section{C-98}

$\therefore$

ESD TOXICOLOGY LABORATORY

QUALITY ASSURANCE MANUAL

SECTION

QAP-7

PAGE

4 of 4

DATE

01-23-91

SUBECT: NONCONFORMANCE AND CORRECTIVE ACTIONS

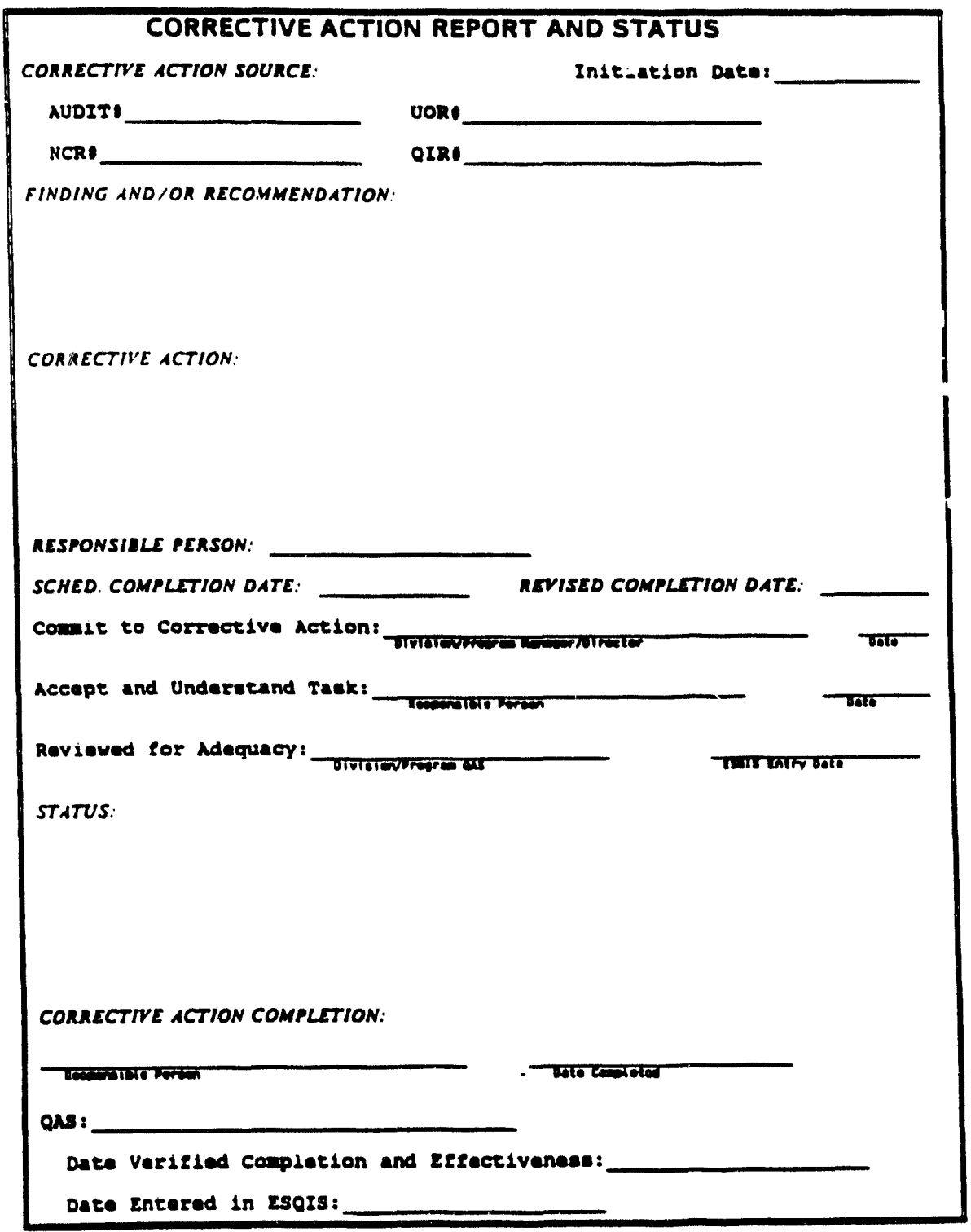

Exhibit QAP-72 Corrective action repont and status (CARS) form. 


\section{SUBSECT: NONCONFORMANCE AND CORRECTIVE ACTIONS}

This section identifies methods and policies for the documentation, evaluation, coirective action, and close-out activities that are necessary when an unplanned deviation from the standard operating procedures is detected or when errors are noted in reportable data. Further, it identifies the requirements for the documentation and implementation of corrective actions.

\section{Unplanned Deviations}

All unplanned deviations will be evaluated with respect to their possible impact on reportable data. All deviations from standard operating procedures, equipment calibrations, or any aspect of the $Q A$ plan will be evaluated and documented Nonconforming items will be controlled to prevent their inadvertent use.

\section{Responsibilities of Project Participants}

Persons paricipating in the work of the Toxicology Laboratory will ensure the prompt identification. control, and disposition of nonconforming items. Each laboratory participant will submit records of all nonconformances to the Group Leader and/or the Division OA Specialist within a reasonable period of time following the initial identification and documentation of the nonconformance. The nonconformance will then be evaluated by the Group Leader. The evaluation will determine if the nonconformance has adversely affected the results of the data.

\section{Reporting of Problems}

The Group Leader and the QA Specialist or an appropriate member of division management will determine if the event justifes the issuance of a nonconformance report. The appropriate report will document the event, the findings of the evaluation, and the required corrective actions. Exhibits QAP-7.1 and QAP-7.2 show the various forms used for documenting deficiencies in quality.

All occurrences related to this project will be identified, categorized, reported, corrected, and documented in accordance with the ORNL QA Manual, procedure QA-L-16-100, Occurrence Reporting.

\section{Corrective Action}

The Group Leader will prepare the corrective action plan and assign responsibility for implementing corrective actions. The corrective actions will be documented on a standard corrective action repon and status (CARS) form, available from the ORNL Quality Deparment. All CARS forms must be attached to the appropriate deficiency form. Exhibit QAP-7.2 shows the form used for documenting corrective actions. The QA Specialist will monitor the action plan to ensure that the corrective action(s) are implemented and completed. 
ESD TOXICOLOGY LABORATORY

\section{SUBECT: NONCONFORMANCE AND CORRBCTIVE ACTIONS}

The status of corrective actions will be periodically evaluated by the ESD QAS. Corrective actions that are incomplete after their scheduled completion date are to be cacalated to the next higher level of management.

Additional information regarding nonconformances and corrective actions may be found in Sects. 15 and 16 of the ORNL Quality Assurance Manual. 
ESD TOXICOLOGY LABORATORY

\section{SUBJECT: AUDTIS AND SURVEIL_ANCES}

This section identifies the requirements for planning performing and reporting audits and surveillances to verify compliance with all aspects of the QA program of the ESD Toxicology Laboratory and to determine the program's effectiveneas.

\section{Audits}

The Toxicology Laboratory is subject to audits by sponsors, TDHE, EPA, ORNL, and the ESD QA Specialist.

\section{Surveillances}

In compliance with requirements specified in the ORNL Quality Aesurance Manual, Laboratory activities will be under surveillance by the ESD QA Specialist and the laboratory's Group Leader (or his designee). Surveillance activities are listed in Table QAP-8.1. The frequency of surveillance and the sctivities 10 be enmined will be determined by the Group Leader and/or the ESD QA Specialist.

\section{Reporting}

Surveillance activities conducted by the Oroup Leader (or his designee) and the ESD QA Specialist will be documented and copies sent to the manager of the ORNL QA program. 
ESD TOXICOLOGY LABORATORY

SECTION

QAP-8

PAGE

2 of 2

QUALITY ASSURANCE MANUAL

DATE

01-23-91

\section{SUBJECT: AUDITS AND SURVEILLANCES}

Table QAP-81. Surveillance activitiea performed by the Group Leader or designee

\begin{tabular}{|c|c|}
\hline Activity & Frequency \\
\hline Spol-checking tecthical notebools & Twice Montbly \\
\hline $\begin{array}{l}\text { Tracking water samples through sampling } \\
\text { teating, water chemistry, and report } \\
\text { preparation phases of a toxicity test }\end{array}$ & Quarterty \\
\hline Validating ambient sampling sites & $\begin{array}{l}\text { Same as sampling } \\
\text { frequency }\end{array}$ \\
\hline $\begin{array}{l}\text { Submitting blind samples for toxicity Testing } \\
\text { and/or water quality measurements }\end{array}$ & Twice yearty \\
\hline $\begin{array}{l}\text { Paricipating in laboratory meetings and } \\
\text { diecussions }\end{array}$ & Moathly \\
\hline $\begin{array}{l}\text { Verifying Ceriodaphria fecundity } \\
\text { by repeat counts }\end{array}$ & Twice yearly \\
\hline $\begin{array}{l}\text { Verifying statistical computations } \\
\text { on final reports (Le, means } \\
\text { and standard deviations) }\end{array}$ & Monthly \\
\hline
\end{tabular}




\section{SUBJECT: SOFTWARE QUALTTY ASSURANCE}

The software used in the analysis of data obtained in the Toxicology Laboratory is classified as Category 5 defined in ORNL QA Procedure QA-L-19-100.

Caregory 5 includes software developed by scientists and engineers in the course of their research and development activities. This software consists of procedures, programs, and analysis techniques that are designed and developed as a part of theoretical or experimental research in the physical, biological, mathematical, and engineering sciences. The documentation of such software, including design standards, developmental methodology, program verification, and instructions for use, is carried out in the manner usual for scientific and engineering research and development. Such documentation may include entry of appropriate material in research noteboola and/or the publication of material in refereed literature. 
C-104

This Page Intentionally Left Blank 


\section{DISTRIBUTION}

1. D. T. Bell

2. V. J. Brumback

3. E. T. Collins

4. M. F. P. DeLoeier

5. J. D. Gass

6. C. D. Goins

7. J. T. Grumsti

8. A. Halouma

9. P. J. Halsey

10. J. A. Hodgins

11. J. B. Hunt

12 W. K. Jago

13. C. Kimbrough

14-15. A. K. Lee/DOE-OSTI

16. J. M. Loar

17-21. D. M. Matteo

22. M. McKinney

23. L. W. McMahon

24. G. K. Moore

25. T. I. Nakamoto

26. H. C. Newsom/D. C. White

27. M. J. Norris

28. B. Nourse

29-30. P. T. Owen

31. T. J. Pierce

32 G. E. Rymer

33. C. M. Smith

34. G. W. Suter

35. T. S. Tison

36. R. R. Turner

37. T. Voskuil

38. C. S. Walker

39. D. R. Watkins

40. R. W. Weigel

41. R. K. White

42. Y-12 Technical Library

43-47. ER Document Management Center

48. Y-12 ER Document Center

49. Y-12 Central Files

50. D. W. Swindle, Radian Corporation, 120 South Jefferson Circle, Oak Ridge, TN 37830

51-52 R. L Nace, Branch Chief, Nonenrichment Facilities, Oak Ridge Program Division, Office of Eastern Area Programs, Office of Environmental Restoration, EM-423, Trevion 2, U.S. Department of Energy, Washington, DC 20585

53. R. C. Sleeman, DOE Oak Ridge Operations Office, P.O. Box 2001, Oak Ridge, TN 37831-8541

54-55. H. M. Thron, Chief, Enrichment Facilities, Oak Ridge Program Division, Office of Eastern Area Programs, Office of Environmental Restoration, EM-423, Trevion 2, U.S. Department of Energy, Washington, DC 20585

56-65. S. L. Lankford, DOE Oak Ridge Operations Office, P.O. Box 2001, Oak Ridge, TN 37831-8541

66. R. L Cartson, Radian Corporation, 120 South Jefferson Circle, Oak Ridge, TN 37830 

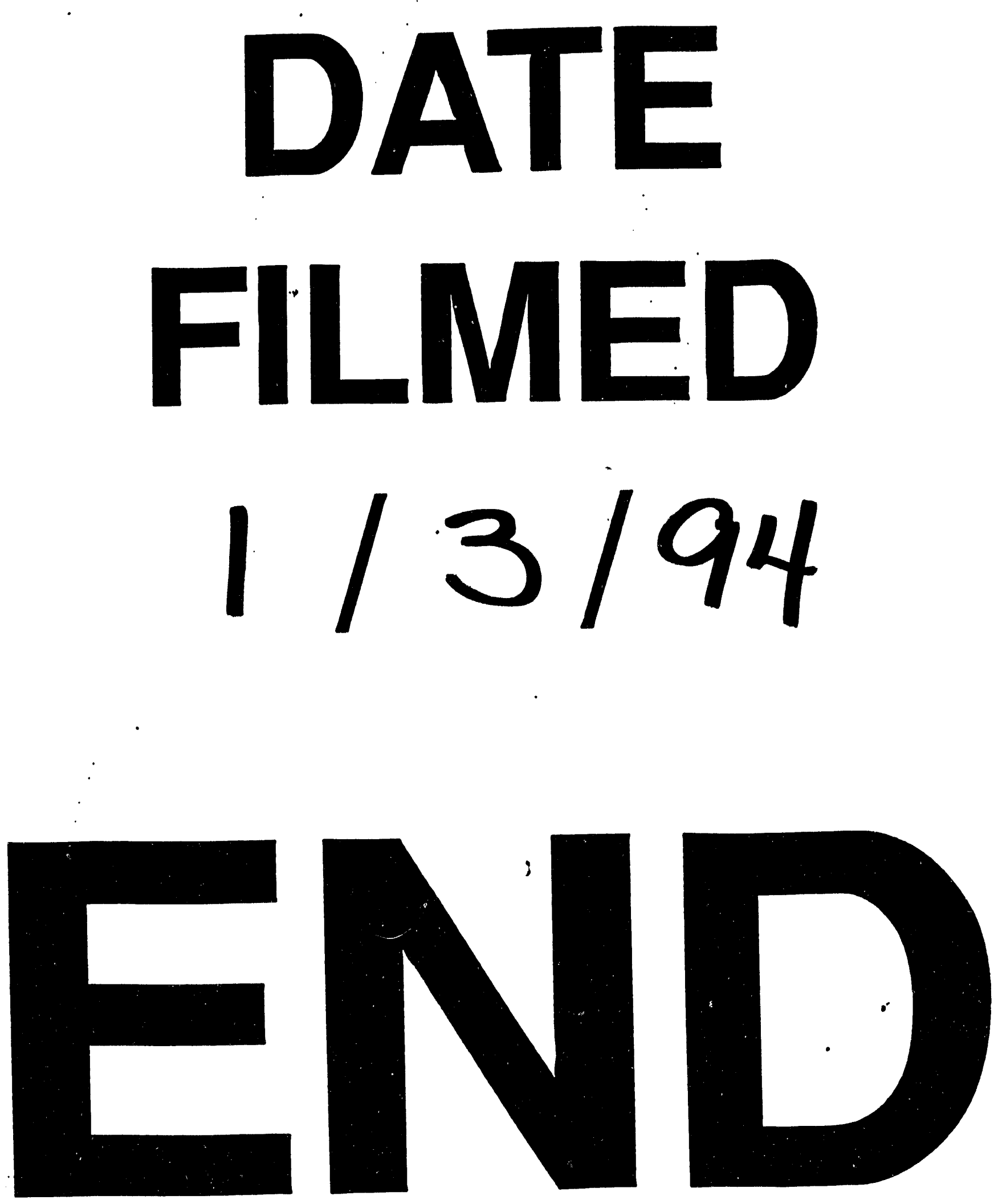


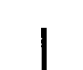

